\title{
Constraining Lateglacial and early Holocene environmental changes in Wales and Germany using tephrochronology.
}

\author{
Jones, Gwydion
}

How to cite:

Jones, Gwydion (2018) Constraining Lateglacial and early Holocene environmental changes in Wales and Germany using tephrochronology.. Doctoral thesis, Swansea University.

http://cronfa.swan.ac.uk/Record/cronfa39863

Use policy:

This item is brought to you by Swansea University. Any person downloading material is agreeing to abide by the terms of the repository licence: copies of full text items may be used or reproduced in any format or medium, without prior permission for personal research or study, educational or non-commercial purposes only. The copyright for any work remains with the original author unless otherwise specified. The full-text must not be sold in any format or medium without the formal permission of the copyright holder. Permission for multiple reproductions should be obtained from the original author.

Authors are personally responsible for adhering to copyright and publisher restrictions when uploading content to the repository.

Please link to the metadata record in the Swansea University repository, Cronfa (link given in the citation reference above.)

http://www.swansea.ac.uk/library/researchsupport/ris-support/ 


\section{Constraining Lateglacial and early}

Holocene environmental changes in

Wales and Germany using

tephrochronology

\section{Gwydion Jones}

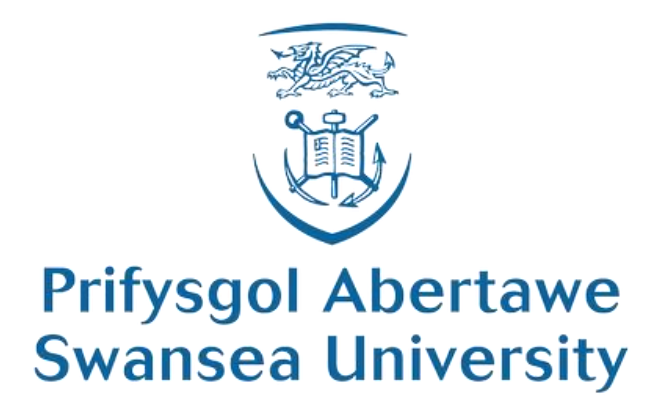

Thesis submitted to Swansea University in fulfilment of the requirements for the degree of Doctor of Philosophy

Department of Geography, College of Science

Swansea University 


\section{Abstract}

Evidence for the abrupt Lateglacial climatic changes is observed in many palaeorecords, however the mechanisms and triggers behind these changes are still unknown. The preferred hypothesis is thought to be linked with the disruption in the North Atlantic Ocean circulation, therefore palaeoclimatic records from maritime regions are needed to investigate the impact of these abrupt changes. The Greenland ice-core records provide high-resolution evidence of these changes, in addition to many marine and terrestrial records throughout the North Atlantic. However, there is a lack of studies on sites in the south western coastal regions of the British Isles that are well-constrained by robust chronologies. The latter, in particular, hampers our understanding of the mechanisms driving the rapid climate changes of the Lateglacial due to the difficulties of integrating and comparing the climatic response in diverse proxy records. In an attempt to resolve these challenges tephrochronology was employed as a precise correlation technique to investigate three Lateglacial sequences from Wales (Llyn Llech Owain, Cors Carmel and Panty-Llyn). An additional site from north Germany (Lake Hämelsee) was also included in this study and chosen due to its potential to preserve tephra from more than one volcanic region and develop a European tephra framework or stratotype for the Lateglacial.

Twenty-one tephra deposits were identified across the network of sites. Twelve deposits have been correlated to known eruptions and in most cases have extended the geographical distribution of their respective ash dispersal. Icelandic tephra deposits of Lateglacial age such as the Askja-S Tephra have been discovered in Welsh sites for the first time highlighting the potential of employing tephrochronology more widely in areas such as Wales, south England and perhaps France. Furthermore, three non-Icelandic deposits, that originate from the Cascade region, Alaska and Italy, have been discovered in the Llyn Llech Owain record, allowing the synchronisation of records across a trans-continental scale. The Askja-S Tephra, Ulmener Maar Tephra and Vedde Ash are added to the tephrostartigraphy of the Hämelsee record highlighting its importance as a key site within the European tephra lattice. Nine of the discovered tephra deposits in Llyn Llech Owain and Lake Hämelsee have not been correlated and may represent new eruptions and potentially new tephra isochrons for future studies. Tephra results are supplemented by multi-proxy palaeoenvironmental reconstructions including lithostratigraphic data, sediment geochemistry, palaeoecology and radiocarbon dating where possible.

In addition to providing fix-points for potential age-models, the discovered tephra deposits allow the study sites to be independently synchronised with other tephra bearing sites. This allows investigations to be made between sites to constrain any leads or lags in the environmental response to climate change and in turn help determine the mechanisms that cause these abrupt climate changes. 


\section{DECLARATION}

This work has not previously been accepted in substance for any degree and is not being concurrently submitted in candidature for any degree.

Signed (candidate)

Date

\section{STATEMENT 1}

This thesis is the result of my own investigations, except where otherwise stated. Where correction services have been used, the extent and nature of the correction is clearly marked in a footnote(s).

Other sources are acknowledged by footnotes giving explicit references. A bibliography is appended.

Signed (candidate)

Date

\section{STATEMENT 2}

I hereby give consent for my thesis, if accepted, to be available for photocopying and for inter-library loan, and for the title and summary to be made available to outside organisations.

Signed (candidate)

Date 


\section{Acknowledgements}

Firstly, I would like to thank Professor Siwan Davies for her constant support and encouragement. Diolch yn fawr am fod yn oruchwylwraig grêt! I would also like to thank my second supervisor Professor Neil Loader for his support during the $\mathrm{PhD}$ and for his assistance during the bulk sediment chemistry analysis. Thanks also to Dr Sarah Davies from Aberystwyth University for her support during the XRF scanning and diatom analysis part of the project. Thank you to Professor Mike Walker from Aberystwyth University for his support during the $\mathrm{PhD}$, assistance during field work and allowing me to study Llyn Llech Owain and Cors Carmel.

Thank you to members of the Swansea tephra group (past and present) including Peter Abbott, Anna Bourne, Paul Albert, Eliza Cook, Adam Griggs and Gareth James for laboratory/field assistance and advice. Thank you to Chris Hayward for his assistance with the use of the electron microprobe at the Tephrochronology Analytical Unit, University of Edinburgh. Thank you to Hollie Wynne and Dr Patrick Robson from Aberystwyth University for assistance during the diatom analysis work. Thank you to Dr Richard Staff form Oxford University for invaluable assistance during the radiocarbon dating and age modelling work. Thanks also to Tom Brain, Dai Brain and Idris Birch for field work assistance.

This study was funded by the Coleg Cymraeg Cenedlaethol. The radiocarbon dates for this study were facilitated by NERC Radiocarbon Dating Facility (NRCF) funding (Radiocarbon Analysis Allocation Number 1882.0415).

Finally, I thank my family for their support and Emlyn for his friendly greetings in the evenings after work. Most of all I thank my better half Hannah for always being there for me and keeping a smile on my face - Diolch yn fawr! 


\section{Publications arising from this study}

The following papers have been published as a direct result of this study. Some sections of chapters are quoted verbatim from Jones et al., (2017a) and Jones et al., (2017b):

Jones, G., Davies, S. M., Farr, G. J. \& Bevan, J. 2017a. Identification of the Askja-S Tephra in a rare turlough record from Pant-y-Llyn, south Wales. Proceedings of the Geologists' Association. 128, 523-530.

Jones, G., Lane, C. S., Brauer, A., Davies, S. M., Bruijn, R., Engels, S., Haliuc, A., Hoek, W. Z., Merkt, J. \& Sachse, D. 2017b. The Lateglacial to early Holocene tephrochronological record from Lake Hämelsee, Germany: a key site within the European tephra framework. Boreas.

doi:http://dx.doi.org/10.1111/bor.12250. 


\section{Table of contents}

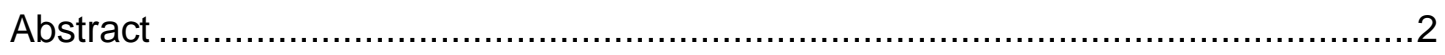

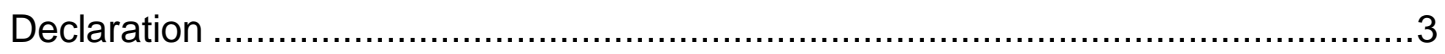

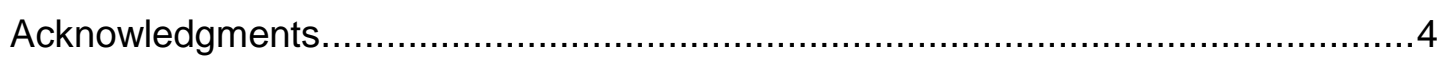

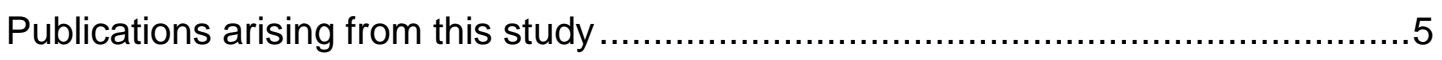

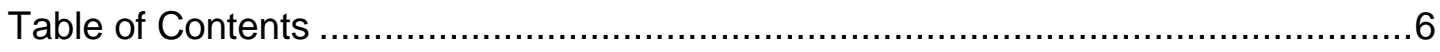

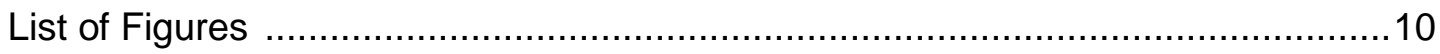

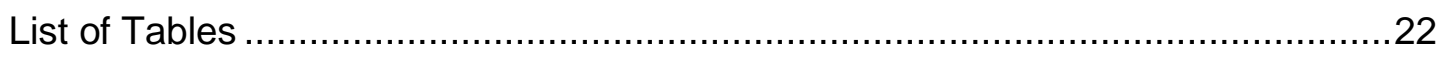

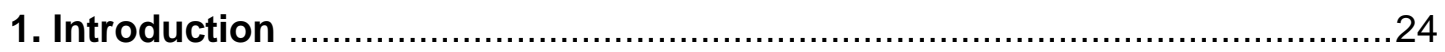

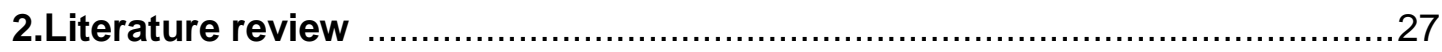

2.1 The Lateglacial period ( 14.7 -11.7 ka cal BP): definition and terminology ...27

2.1.1 Climatic and Environmental changes during the Lateglacial .............31

2.1.2 Proposed causes of Lateglacial changes ........................................37

2.2 Principles of Tephrochronology and Tephrostratigraphy ............................39

2.2.1 Stratigraphy of key tephra deposits for the Lateglacial and early Holocene in Europe .................................................................... 41

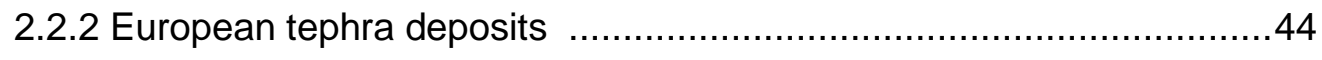

2.2.3 Far-travelled tephra deposits ................................................... 44

2.2.4 Key Icelandic Tephra deposits .................................................46

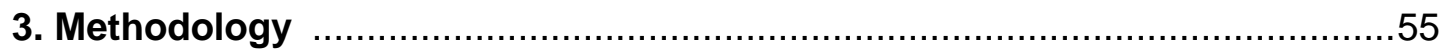

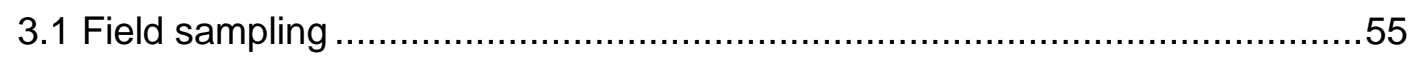

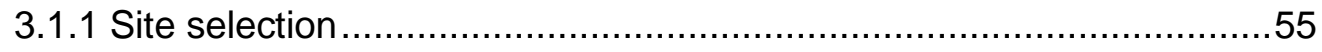

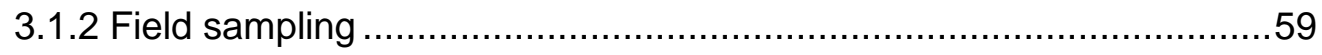

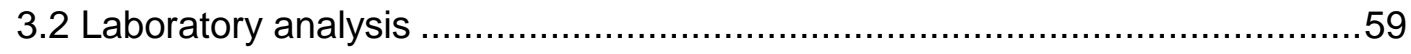

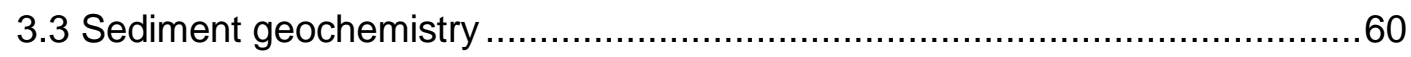

3.3.1 XRF (X-ray Fluorescence) ITRAX Core Scanning ..........................60

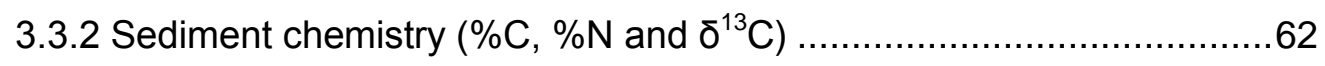

3.3.3 Loss on Ignition (LOI) .................................................................6 


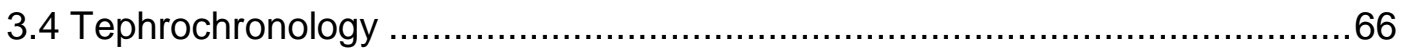

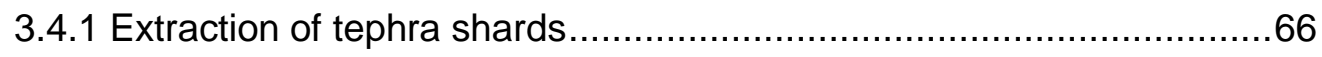

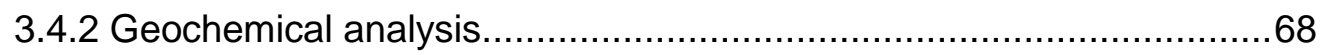

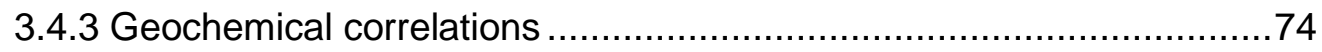

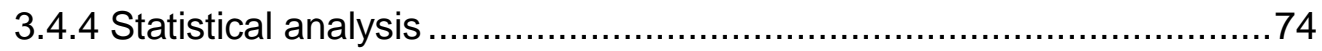

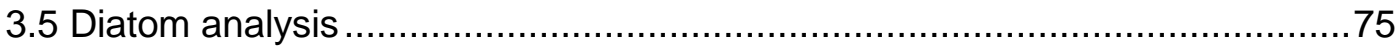

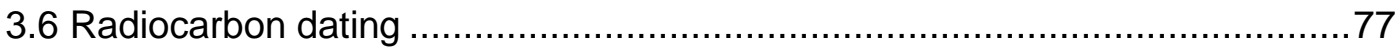

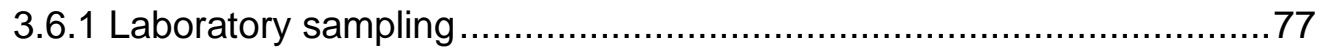

3.6.2 Calibration and age-modelling ………............................................79

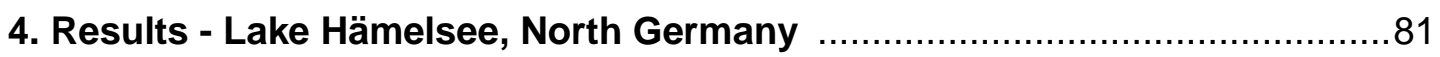

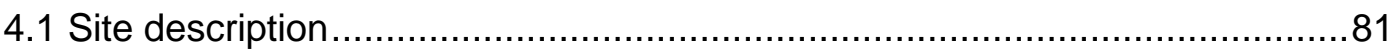

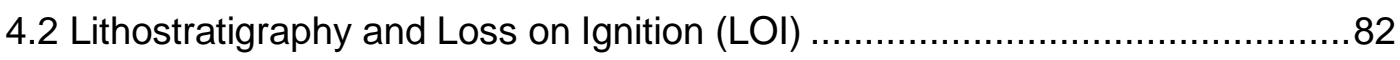

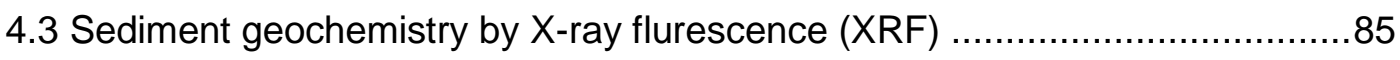

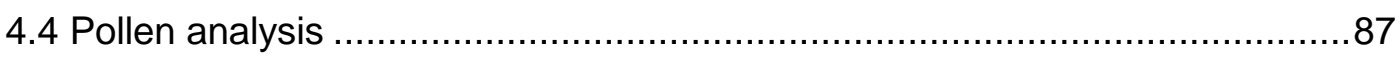

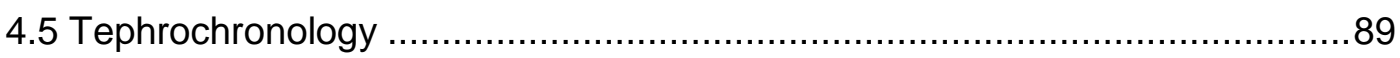

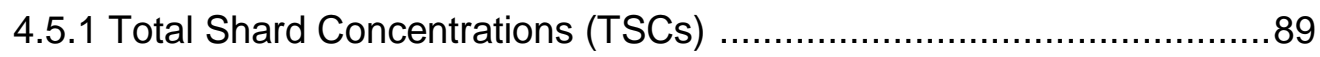

4.5.2 Geochemical analysis, morphological characteristics and tephra

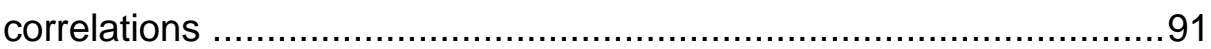

5. Results - Llyn Llech Owain, Carmarthenshire ........................................108

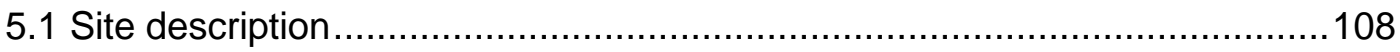

5.1.1 Previous work at Llyn Llech Owain .............................................112

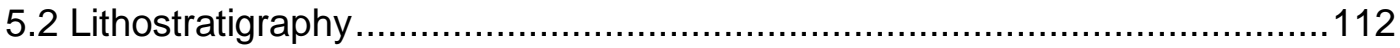

5.3 Bulk Sediment Chemistry (\%C, \%N and $\delta 13 \mathrm{C})$.......................................114

5.4 Sediment geochemistry by X-ray fluorescence (XRF)..............................122

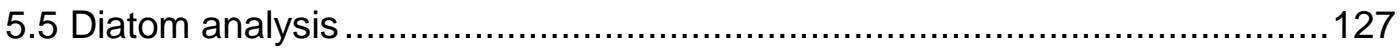

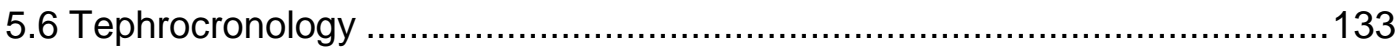

5.6.1 Total shard concentrations (TSCs) ...............................................133

5.6.2 Geochemical analysis, morphological characteristics and tephra

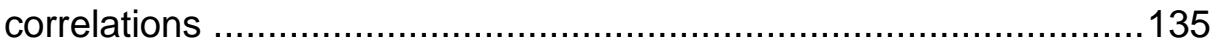

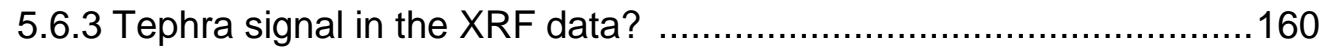

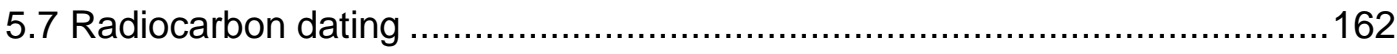

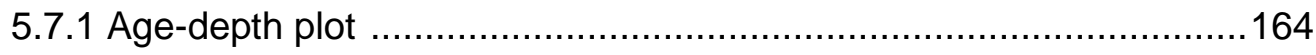


5.7.2 Age model A 169

5.7.3 Age model B 169

5.7.4 Age model C 172

5.7.5 Age model D 175

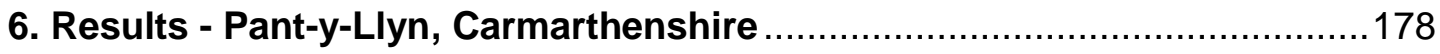

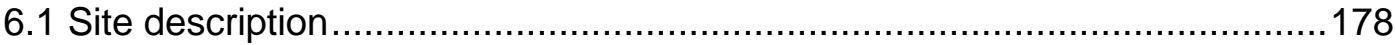

6.2 Lithostratigraphy and Loss on Ignition (LOI) ........................................181

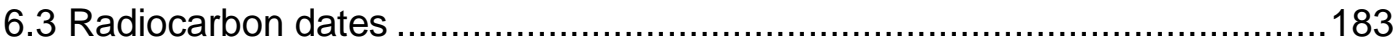

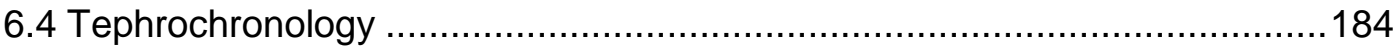

6.4.1 Total Shard Concentrations (TSCs) and morphological

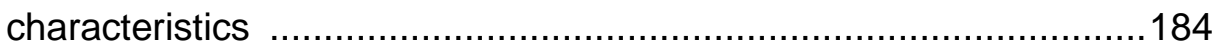

6.4.2 Geochemical analysis and tephra correlations .............................184

7. Results - Cors Carmel, Carmarthenshire ….......................................... 187

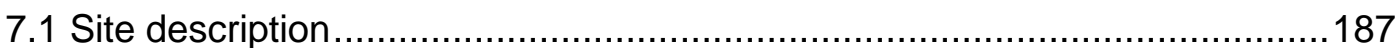

7.1.1 Previous work at Cors Carmel .................................................... 187

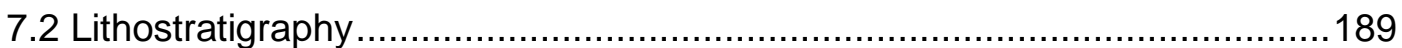

7.3 Bulk Sediment Chemistry (\%C, \%N and $\delta 13 C)$.................................... 192

7.4 Sediment geochemistry by X-ray fluorescence (XRF)............................. 193

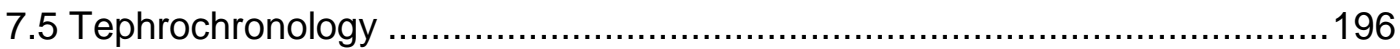

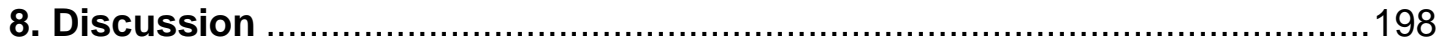

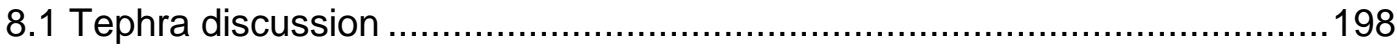

8.1.1 Borrobol-type tephra deposits (LLO_804, LLO_782, LLO_778, HÄM_1616) ................................................................. 198

8.1.2 Glacier Peak G (LLO_766) ......................................................204

8.1.3 Laacher See Tephra (HÄM_T1558) ........................................207

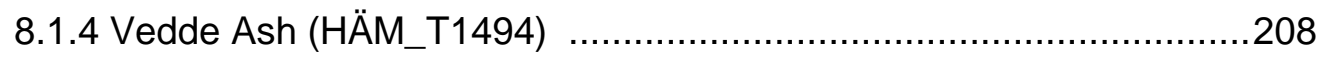

8.1.5 Ulmener Maar Tephra (HÄM_T1451) .........................................209

8.1.6 Askja-S (HÄM_T1445-1444 and PLL_500) ................................209

8.1.7 Saksunarvatn Ash (HÄM_T1401.5) .......................................216

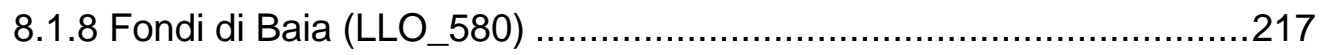

8.1.9 Lairg A (LLO09_516) ............................................................219

8.1.10 Aniakchak (LLO09_297) ...........................................................222 
8.1.11 Unknown tephra deposits - new eruptions?

8.1.12 Within site and inter-site differences: tephra deposition and

taphonomic processes 229

8.1.13 Conclusion 232

8.2 Using correlated tephra deposits to constrain past environmental changes 235

8.2.1 Borrobol and Penifiler Tephras (LLO_782 and LLO_778) 235

8.2.2 Glacier Peak G (LLO_766) ...................................................238

8.2.3 Laacher See Tephra (HÄM_T1558) ...........................................239

8.2.4 Vedde Ash (HÄM_T1494) .....................................................242

8.2.5 Ulmener Maar Tephra (HÄM_T1451) ..........................................245

8.2.6 Askja-S (HÄM_T1445-1444 and PLL_500) ................................247

8.2.7 Saksunarvatn Ash (HÄM_T1401.5) ..........................................249

8.2.8 Fondi di Baia (LLO_580) .......................................................251

8.2.9 Lairg A (LLO09_516) ..............................................................251

8.2.10 Aniakchak (LLO09_297) .....................................................253

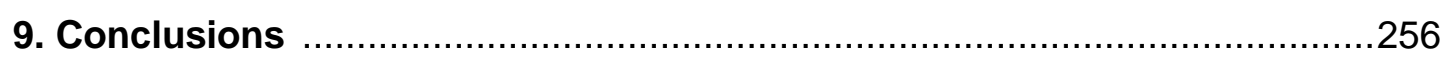

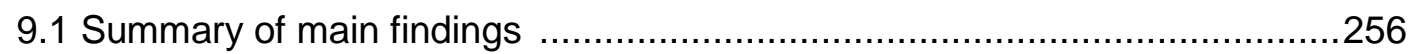

9.2 Recommendations for future work .......................................................259

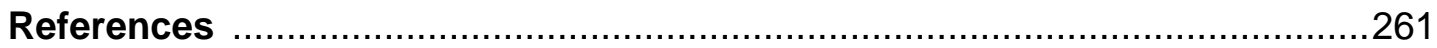

Appendix 1. Tephra major element data and secondary standards data for Llyn Llech Owain, Pant-y-Llyn and Lake Hämelsee.

Appendix 2. Diatom data for Llyn Llech Owain.

Appendix 3. Bulk sediment geochemistry data for Llyn Llech Owain and Cors Carmel.

Appendix 4. ITRAX XRF data for Llyn Llech Owain and Cors Carmel.

Appendix 5. Loss on Ignition data for Pant-y-Llyn.

All available as electronic copies placed at the back of thesis. 


\section{List of Figures}

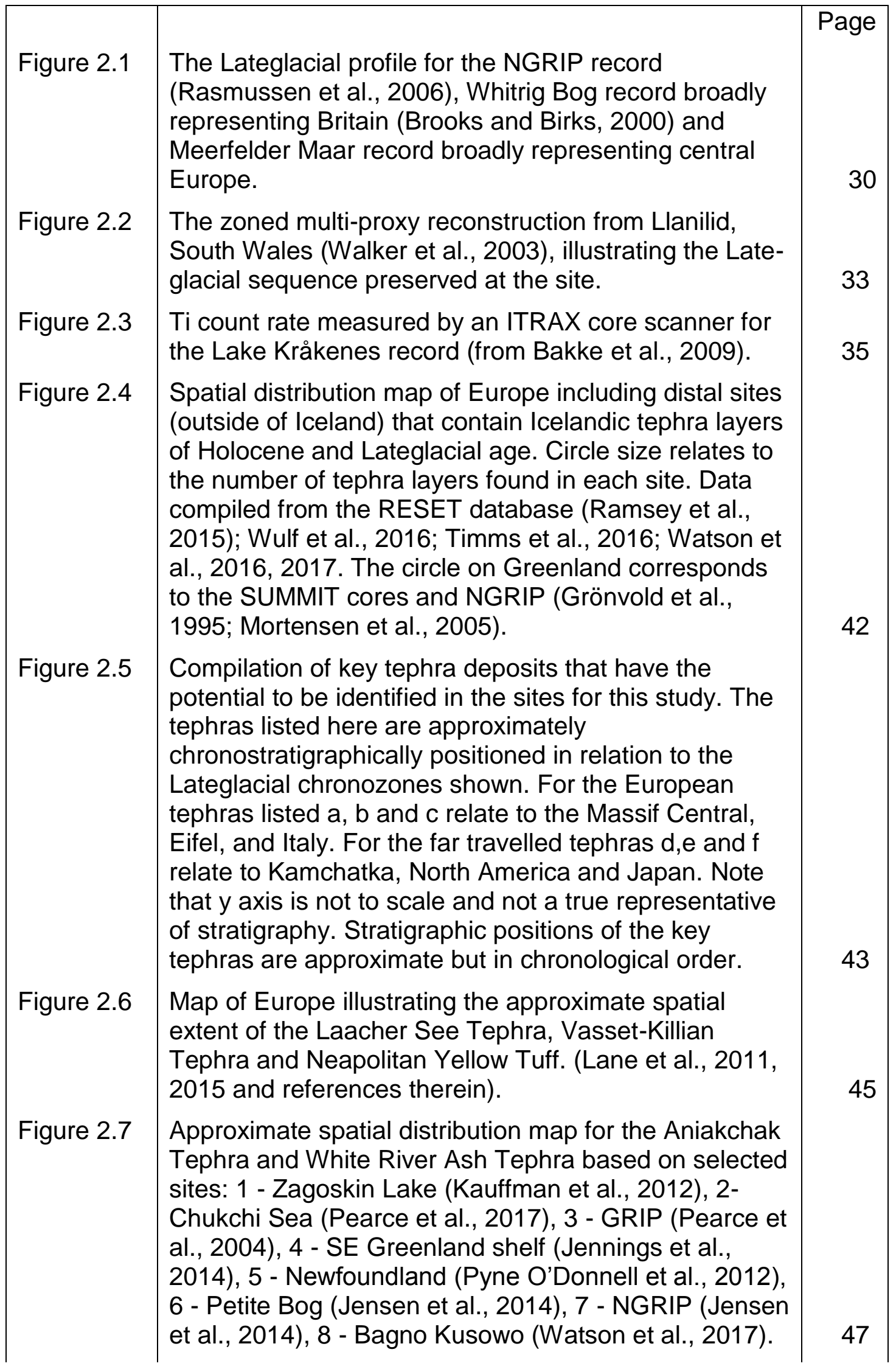


\begin{tabular}{|l|l} 
Figure 2.8 & Map showing the approximate spatial distribution of the
\end{tabular} Vedde Ash (modified from Lane et al., 2012 and reference within).

Figure 2.9 Map showing the approximate spatial distribution of the Askja-S Tephra (modified from Wulf et al., 2016).

Figure 2.10 Six selected Scottish sites that contain the Borrobol Tephra (BT), Penifiler Tephra (PT) or both. Loch Etteridge (Albert, 2007; Lowe et al., 2008; MacLeod et al., 2015), Loch an t'Suidhe, Tynaspirit West, Borrobol (Pyne O'Donnell, 2007), Abernethy Forest (Matthews et al., 2011), Whitrig Bog (Turney et al., 1997; Brooks and Birks, 2000). Sites included show the different forms of tephra peaks, based on total shard concentrations (note the variable $\mathrm{x}$-axis) and their respective positions in relation to the LOI or Chironomid-inferred temperature record. The oscillations marked 'a' and 'b' possibly correspond to Gl-1d and GI-1b and the dashed line represents the Lateglacial Interstadial onset and Loch Lomond Stadial onset based on either LOI or Chironomid-inferred temperature record (as interpreted by the authors).

Figure 3.1 Summary of techniques used for each site.

Figure 3.2

Figure 3.3

A. Map of North West Europe showing the locations of the sites studied in this PhD. B. Sataelite image from Google maps showing the locatio of Llyn Llech Owain $\left(51^{\circ} 48\right.$ ' $\left.55^{\prime \prime} \mathrm{N}, 4^{\circ} 4^{\prime} 44^{\prime \prime} \mathrm{W}\right)$, Cors Carmel $\left(51^{\circ} 49^{\prime} 20^{\prime \prime} \mathrm{N}\right.$, $\left.4^{\circ} 2^{\prime} 22^{\prime \prime} \mathrm{W}\right)$ and Pant-y-Llyn ( $51^{\circ} 49^{\prime} 51^{\prime \prime} \mathrm{N}, 4^{\circ} 1^{\prime}$ $26^{\prime \prime} \mathrm{W}$ ). C. Satelite image (from Google maps) showing the location of Lake Hämelsee $\left(52^{\circ} 45^{\prime} 34^{\prime \prime} \mathrm{N}, 9^{\circ} 18^{\prime}\right.$ 40" E).

Schematic diagram of the sub-sampling strategy for the Llyn Llech Owain cores.

Figure 3.4 Photographs of the ITRAX core scanner at Aberystwyth University.

Figure 3.5 Images of the set-up for manually picking shards using a gas chromatography syringe mounted on a micromanipulator.

Figure 3.6 Lipari and BCR2g secondary standard values for each analytical session/group whilst operating the EPMA for tephra geochemical analysis. Recommended values (dashed lines) are based on Wilson, (1997) and Sparks, (1990). Raw secondary standard data is available in appendix 1 . 
\begin{tabular}{|l|l} 
Figure 4.1 & A) Location map showing Lake Hämelsee, in Germany,
\end{tabular} volcanic centres, and other sites mentioned in the text.

B) Coring location and the surrounding catchment.

Figure 4.2

Lithostratigraphy (as compiled by Aritina Haulic and Achim Brauer), biostratigraphy (as compiled by Falko Turner and colleagues) and Loss on Ignition (LOI) (as compiled by Wim Hoek and Renee de Bruijn) for the Lake Hämelsee record.

Figure 4.3 Sediment geochemistry profiles for the Lake Hämelsee sequence between $1300-1700$. Lithostratigraphy is plotted against depth along with the LOI profile and $\mathrm{K}$, $\mathrm{Ti}$ and Fe profiles analysed by an ITRAX XRF core scanner. Lithostratigraphy and XRF data was compiled by Aritina Haulic and Achim Brauer. LOI data was compiled by Wim Hoek and Renee de Bruijn.

Figure 4.4 A) Pollen diagram (produced by Faulko Turner and colleagues) for the Lake Hämelsee sequence between $1400-1760 \mathrm{~cm}$. B) Summary pollen diagram showing the tree and herb percentage between 1380-1675 cm.

Figure 4.5 Lithostratigraphy, loss on ignition, approximate depths for chronostratigraphic units and tephra shard concentrations (TSC) (10 and $1 \mathrm{~cm}$ resolution) from core $\mathrm{H} 1$ and $\mathrm{H} 2$ for Lake Hämelsee. Both profiles are plotted on the composite depth scale.

Figure 4.6 Major element results for the tephra deposits identified in the Hämelsee record between 1700 and $1300 \mathrm{~cm}$ (composite depth). A) Total alkali silica classification follows that of Le Bas et al (1986). B) Inset of the rhyolitic deposits.

Figure 4.7 Bivariate plot showing the correlation of HÄM_T1616 to the indistinguishable Borrobol and Penifiler tephras (data from Lind et al., 2016 and Timms et al., 2016).

Bivariate plot showing the correlation of the phonolitic shards of HÄM_T1558 to the Laacher See Tephra (data from Riede et al., 2011; Lane et al., 2012).

Figure 4.9 Bivariate plot showing the correlation of HÄM_T1494 and HÄM_T1470 to the Vedde Ash (data from Lane et al., 2012a; Lane et al., 2012c; MacLeod et al., 2014).

Figure 4.8

Figure 4.10

Bivariate plot showing comparisons of HÄM_T14561455 and HÄM_T1451 to the Vedde Ash and Askja-S tephra. The correlation of HÄM_T1445-1444 to the Askja-S tephra (data from Wastegård, 2002; Pyne O'Donnell, 2007; Lilja et al., 2013; Lane et al., 2012; Wulf et al., 2016; Timms et al., 2016). 
Figure 4.11 Bivariate plot showing the correlation of the basaltic shards of HÄM_T1401.5 to the Saksunarvatn Ash (data from Lind et al., 2011; Davies et al., 2012; Bramham-Law et al., 2013).

Figure 4.12 Lake Hämelsee tephrostratigraphy between 1300-1700 $\mathrm{cm}$ composite depth plotted against lithostratigraphy. Tephra deposits are labelled according to the main text, along with the tephra correlation, and geochemical symbol as referred to in Figure 4.5-4.10.

Figure $5.1 \quad$ A) Location of Llyn Llech Owain, bedrock geology and coring location. B) Aerial photograph of Llyn Llech Owain. Contains British Geological Survey Bedrock Geological Map and Ordnance Survey data (C) Crown Copyright and database rights 2017.

Figure 5.2 Pollen diagram for the Lateglacial and Holocene at Llyn Llech Owain (Walker \& Jones, 2006). Radiocarbon dates are shown on the left.

Figure 5.3 Low resolution pollen diagram spanning the Lateglacial to early Holocene (modified from Walker \& Jones, 2006).

Figure 5.4 A) Photographs of the cores (taken in the field), plotted against depth. B) Photograph of core 2013 (630-730 $\mathrm{cm}$ ) containing the Interstadial, Loch Lomond Stadial and early Holocene sediments.

Figure 5.5 Analyses performed on acid-treated and untreated samples to determine whether acid treatment was necessary to eliminate the presence of carbonate. Standard deviation of the acetanilide standards measured during isotopic and elemental analysis also inserted.

Figure 5.6 Bulk chemistry records (\%C, \%N, C:N and $\left.\delta^{13} \mathrm{C}\right)$ plotted against depth. Carbon and Nitrogen content and $\delta^{13} \mathrm{C}$ values were measured online using a PDZEuropa ANCA GSL Elemental Analyser interfaced to a 20/20 isotope ratio mass spectrometer (see section 3.3.2). Five zones have been assigned (ChZ1-5) based on visual changes in the data profiles. Symbols relate to the zones assigned and showed in Figure 5.7.

Figure 5.7

Meyers $\left(\delta^{13} \mathrm{C}\right.$ vs C:N) bi-plots (Meyers, 1994). Plot $A$ illustrates the whole data set. Approximate terrestrial and aquatic signature envelopes are inserted (modified from Meyers, 1994, Meyers and Lallier-Vergès, 1999 and Mackie et al., 2005). Plot B is zoomed in on the aquatic vegetation types. Measurements on modern macrophyte vegetation (Marestail and Water Lily) were 
Figure 5.8

Figure 5.9

Figure 5.10

Figure 5.11

Figure 5.12

Figure 5.13

Figure 5.14

Figure 5.15

Figure 5.16

Figure 5.17

Figure 5.18 sampled and analysed by N. Loader. Symbols relate to the zone (ChZ1-5) based on the visual changes in the data profiles in Figure 5.6.

Selected XRF profiles, analysed by an ITRAX core scanner.

A) \%C and Inc/Coh ratio (XRF) plotted against depth.

B) scatter plot showing a $R 2=0.8918$ positive relationship between the \%C and Inc/Coh data.

Llyn Llech Owain diatom assemblage of species with an abundance greater than $2 \%$.

Llyn Llech Owain diatom assemblages. Some species have been grouped for a simplified representation (Fragilaria types, Navicula types and Eunotia types).

Llyn Llech Owain diatom assemblages. Only the high resolution $(2-\mathrm{cm})$ samples spanning the major tranistions (Glacial-Interstadial- Stadial- Holocene) are shown.

Total shard concentrations for Llyn Llech Owain core 2009 (A) and core 2013 (B). Tephra deposits that have been geochemically analysed are labelled with a symbol, which relates to figures 5.14-5.24. Tephra deposits that have not been geochemically analysed are labelled '?'. \%C profile is also plotted for reference.

The full data set from the analysed tephra layers in Llyn Llech Owain plotted using the Total Alkali Silica classification of LeBas et al., (1986). Geochemical data are normalized.

Selected bivariate plots showing tephra glass shard major element compositions for LLO_804, LLO_782 and LLO_778. (Reference envelopes are based on data from Lind et al., 2016, Cook, 2015 and Koren et al., 2008).

Selected bivariate plots showing tephra glass shard major element compositions for LLO_778, LLO_767 and LLO_766. (Reference envelopes are based on data from Pyne O'Donnell et al., 2016; Lind et al., 2016).

Selected bivariate plots showing tephra glass shard major element compositions for LLO_767. (Reference envelopes are based on data from Turney et al., 2006; Koren et al., 2008; Lane et al., 2015; Lind et al., 2016).

Selected bivariate plots showing tephra glass shard major element compositions for LLO_580 (population 1) and envelopes for similarly aged Italian Tephras. (Reference envelopes are based on data from Smith et

123

126

128 129 


\begin{tabular}{|c|c|}
\hline & al., 2011). \\
\hline Figure 5.19 & $\begin{array}{l}\text { Selected bivariate plots showing tephra glass shard } \\
\text { major element compositions for LLO_580 (population } \\
2 \text { 2,3 and outlier) and envelopes for similarly aged } \\
\text { Icelandic Tephras. (Reference envelopes are based on } \\
\text { data from Wastegård, 2002; Ranner et al., 2005; Pyne- } \\
\text { O'Donnell, 2007; Lind and Wastegård, 2011; Matthews } \\
\text { et al., 2011; Lane et al., 2011, 2012a; Lind et al., 2013; } \\
\text { Lilja et al., 2013; Wulf et al., 2016; Timms et al., 2016; } \\
\text { Jones et al., 2017). }\end{array}$ \\
\hline Figure 5.20 & $\begin{array}{l}\text { Selected bivariate plots showing tephra glass shard } \\
\text { major element compositions for LLO_483, LLO_468 } \\
\text { and LLO09_505. (Reference envelopes are based on } \\
\text { data from Coulter et al., 2012). }\end{array}$ \\
\hline Figure 5.21 & $\begin{array}{l}\text { Selected bivariate plots showing tephra glass shard } \\
\text { major element compositions for LLO09_516. } \\
\text { (Reference envelopes are based on data from Watson } \\
\text { et al., 2016). }\end{array}$ \\
\hline Figure 5.22 & $\begin{array}{l}\text { Selected bivariate plots showing tephra glass shard } \\
\text { major element compositions for LLO09_345. } \\
\text { (Reference envelopes are based on data from Watson } \\
\text { et al., 2016; Dugmore, 1995; Plunkett et al., 2004; } \\
\text { Lawson et al., 2007; Roland et al., 2014; Bergman et } \\
\text { al., 2004; Jones et al., 2017). }\end{array}$ \\
\hline Figure 5.23 & $\begin{array}{l}\text { Selected bivariate plots showing tephra glass shard } \\
\text { major element compositions for LLO09_297. } \\
\text { (Reference envelopes are based on data from } \\
\text { Kauffman et al., } 2012 \text { and Pyne O'Donnell et al., } \\
\text { 2012). }\end{array}$ \\
\hline Figure 5.24 & $\begin{array}{l}\text { FeO vs CaO bivariate plot showing the compositions of } \\
\text { glass shard analyses from all tephra deposits from Llyn } \\
\text { Llech Owain in relation to the Icelandic volcanic field } \\
\text { (comprised of glass analyses of dacitic and rhyolitic } \\
\text { tephra deposits from Iceland stored in the RESET } \\
\text { database - Bronk Ramsey et al., 2015) (modified from } \\
\text { Bourne et al., 2016). }\end{array}$ \\
\hline Figure 5.25 & $\begin{array}{l}\text { Stratigraphy and XRF profile ( } \mathrm{Si}, \mathrm{K}, \mathrm{Fe}, \mathrm{Ti}, \mathrm{Ca}) \text {. } \\
\text { Elemental data are normalized against the incoherent } \\
\text { and coherent values and smoothed (10 point moving } \\
\text { average). Red line denotes the position of tephra layer } \\
\text { LLO_804 and LLO_782. }\end{array}$ \\
\hline Figure 5.26 & $\begin{array}{l}\text { Age vs depth plot including all radiocarbon samples } \\
\text { (cal BP and un-modelled). Lithostratigraphy, \%C, } \\
\text { approximate depths for chronostratigraphical units from } \\
\text { Llyn Llech Owain and approximate ages for the } \\
\text { Lateglacial plotted on the ' } x \text { ' axis. Tephra layers found } \\
\text { in the Llyn Llech Owain record are also plotted: }\end{array}$ \\
\hline
\end{tabular}


Figure 5.27

Figure 5.28

Figure 5.29

Figure 6.1

Figure 6.2

Figure 6.3 Lithostratigraphy, radiocarbon dates, loss on ignition, $\mathrm{CaCO}_{3}$ content and total shard concentrations for the

Age model B. P_Sequence deposition model constructed using OxCal v.4.3 (Bronk Ramsey, 2009, 2017). Model includes all radiocarbon dates analysed onsets from the NGRIP record (Rasmussen et al., 2014) as added constraints.

Age model C. P_Sequence deposition model constructed using OxCal v.4.3 (Bronk Ramsey, 2009, 2017). Model includes all radiocarbon dates analysed Penifiler Tephra (13,807-14,071 cal BP - Bronk Ramsey et al., 2015), LLO_766 Glacier Peak Tephra (13,450-13,740 cal BP - Pyne O'Donnell et al., 2016), LLO_580 Fondi di Baia (9,525-9,695 - Smith et al., 2011).

Age model D. P_Sequence deposition model constructed using OxCal v.4.3 (Bronk Ramsey, 2009, tephra layers LLO 782 Borrobol Tephra $(14,004-$ Penifiler Tephra (13,807-14,071 cal BP - Bronk Ramsey et al., 2015), LLO_766 Glacier Peak Tephra (13,450-13,740 cal BP - Pyne O'Donnell et al., 2016), LLO_580 Fondi di Baia (9,525-9,695 - Smith et al., 2011) and the Holocene and GS-1 onset climatic 2014). Long: $-4^{0} 1^{\prime} 26$ "), coring location and local bedrock geology. Contains British Geological Survey Bedrock Geological Map and Ordnance Survey data (C Crown Copyright and database rights 2017.

Photographs of Pant-y-Llyn turlough illustrating the ephemeral nature of the turlough. Photographs taken by Gareth Farr (British Geological Survey) from the same location relative to the turlough looking down from the northern side.
LLO_782 Borrobol Tephra (14,004-14,192 cal BP Bronk Ramsey et al., 2015), LLO_778 Penifiler Tephra (13,807-14,071 cal BP - Bronk Ramsey et al., 2015), LLO_766 Glacier Peak Tephra (13,450-13,740 cal BP Pyne O'Donnell et al., 2016), LLO_580 Fondi di Baia (9,525-9,695 - Smith et al., 2011). and the Holocene and GS-1 (Loch Lomond equivalent) and tephra layers: LLO_782 Borrobol Tephra (14,00414,192 cal BP - Bronk Ramsey et al., 2015), LLO_778 2017). Model includes all radiocarbon dates analysed, 14,192 cal BP - Bronk Ramsey et al., 2015), LLO_778 constraints from the NGRIP record (Rasmussen et al.,

Location map of Pant-y-Llyn turlough (Lat: $51^{\circ} 49^{\prime} 51^{\prime \prime}$, 
Figure 6.4

Figure 7.1

Figure 7.2

Figure 7.3

Figure 7.4

Figure 7.5

Figure 8.1
Pant-y-Llyn core (BGS Borehole reference SN61NW12). Radiocarbon dates are derived from bulk sediment samples. Calibrated age ranges are shown here and outlined in Table 1. Askja-S Tephra age estimates are from Bronk Ramsey et al., 2015 (a) and Ott et al., 2016 (b).

Selected bivariate plots showing tephra PLL_500 glass shard major element composition correlating to the Askja-S Tephra. Hässeldalen, L-274 , Høvdarhagi, Skopun, Fosen, Suðuroy, An Druim, Breakish, Hovsdalur, Ashik and Abernethy Tephra data also shown for discrimination. Data have been normalised. Data from: (Wastegård, 2002; Ranner et al., 2005; Pyne O'Donnell, 2007; Lind \& Wastegård, 2011; Matthews et al., 2011; Lane et al., 2011, 2012a; Lind et al., 2013; Lilja et al., 2013; Wulf et al., 2016; Timms et al., 2016 and Jones et al., 2017).

A) Location of Cors Carmel, bedrock geology and coring location. B) Arial photograph of Cors Carmel. Contains British Geological Survey Bedrock Geological Map and Ordnance Survey data (C) Crown Copyright and database rights 2017.

Percentage pollen diagram from Cors Carmel, spanning $480-0 \mathrm{~cm}$ which is thought to represent the Holocene. Radiocarbon dates and lithostratigraphy is also plotted against depth (from Walker and James, 1992).

Bulk chemistry records $\left(\% \mathrm{C}, \% \mathrm{~N}, \mathrm{C}: \mathrm{N}\right.$ and $\left.\delta^{13} \mathrm{C}\right)$ plotted against depth. Carbon and Nitrogen content and $\delta^{13} \mathrm{C}$ values were measured online using a PDZEuropa ANCA GSL Elemental Analyser interfaced to a 20/20 isotope ratio mass spectrometer (see section 3.3.2). Four zones have been assigned (ChZ1-4) based on visual changes in the data profiles.

191

Selected XRF profiles, analysed by an ITRAX core scanner (see section 3.3.1). $\mathrm{K}$ and Ti data is shown as a 10 point moving average. Four zones have been assigned (XZ 1-4) based on visual changes in the data profiles.

Total shard concentrations for Cors Carmel core 2014.

A synthesis of tephra identified in this thesis shown alongside the key tephras from Iceland, the Mediterranean and Pacific Arc. The stratigraphic positions of each tephra are shown as approximations 
against the Lateglacial chronozones. For the European tephras listed a, b and c relate to the Massif Central, Eifel, and Italy. For the far travelled tephras $d$, e and $f$ relate to Kamchatka, North America and Japan. Note that the ' $y$ ' axis is not to scale and not a true representative of stratigraphy. Stratigraphic positions of the key tephras are approximate based on best age estimates published in the literature (Blockley et al., 2014 and references within; Lane et al., 2017and references within; Lawson et al., 2012 and references within). The core stratigraphy represented for the Llyn Llech Owain record is a combination of core 2013 and 2009 even though a sound core correlation was not possible.

Schematic tephrostratigraphy diagram for the Borroboltype tephra deposits noted in the text. Depths and chronostratigraphic units are approximate given the information in their respective publications (Timms et al., 2016; Cook, 2015; Eiríksson et al., 2000; Pyne O'Donnell, 2007; Matthews et al., 2011; Albert, 2007). NGRIP Borobol type and KOL GS-2 are chronologically positioned based on ages published within their applicable studies (Cook, 2015; Eiríksson et al., 2000). BT at Loch an t'Suidhe is positioned in the glacial unit based on LOI values in Pyne O'Donnell, (2007). LET-1a is positioned on the transition bewteen the glacial unit and Lateglacial Inetrstadial based on LOI values in Albert, (2007) and MacLeod et al., (2015). The Borrobol Tephra is positioned in the early Interstadial based on findings from Borrobol and Whitrig Bog (Turney et al., 1997). The Penifiler Tephra is positioned in the mid Interstadial based on findings from Tynaspirit West and Borrobol (Pyne O'Donnell, 2007) and Abernethy Forrest (Matthews et al., 2011). QM1 213 and 218 are tephra deposits found from Quoyloo Meadow (Timms et al., 2016), positioned during the late Interstadial. Some of the deposits listed may represent the same eruption.

Figure 8.3 $\mathrm{SiO}_{2} \vee \mathrm{Na}_{2} \mathrm{O}+\mathrm{K}_{2} \mathrm{O}$ and $\mathrm{CaO} \vee \mathrm{TiO}_{2}$ bivariate plots showing tephra glass shard major element compositions for LLO_804, LLO_782, LLO_778, HÄM_T1616 and envelopes for other Borrobol-type tephras noted in the text. (Reference data and envelopes are based on data from Albert, 2007 (LET1a and LET-1b); Matthews et al., 2011 (AF638 adn AF672); Cook, 2015 (NGRIP GS-2); Lind et al., 2016 (BO 521, BO486 and HP 303); Timms et al., 2016 (QM1 213 and QM1 218)). 
\begin{tabular}{|l|l} 
Figure 8.4 & Compilation of sites that contain tephra deposits with a
\end{tabular} Borrobol-type signature (modified form Lind et al., 2016). 1 - NGRIP (Cook, 2015), 2 - North Icelandic Shelf (Eiríksson et al., 2000), 3 - Dimna Bog (Koren et al., 2008), 4 - Hässeldala port (Davies et al., 2003), 5 Skallahult (Davies et al., 2003), 6 -Quoyloo Meadow (Timms et al., 2016) note that the tephras identified here are positioned in the late Interstadial, 7 - Loch An Druim (Ranner et al., 2005), 8 - Tanera Mor (Roberts et al., 1998), 9 - Borrobol (Turney et al., 1997), 10 Druim Loch (Pyne O'Donnell, 2007), 11 - Loch Ashik (Pyne O'Donnell, 2007), 12 - Loch an t'Suidhe (Pyne O'Donnell, 2007), 13 - Abernethy Forest (Matthews et al., 2011), 14 - Loch Etteridge (Albert, 2007), 15 Tynaspirit West (Turney et al., 1997), 16 - Whitirg Bog (Turney et al., 1997), 17 - Llyn Llech Owain (this study), 18 - Lake Hämelsee (this study).

Figure 8.5

Proposed spatial distribution map for the Aniakchak Tephra and Glacier Peak G Tephra. 1 - Zagoskin Lake (Kauffman et al., 2012), 2- Chukchi Sea (Pearce et al., 2017), 3 - GRIP (Pearce et al., 2004), 4 - SE

Greenland shelf (Jennings et al., 2014), 5 -

Newfoundland (Pyne O'Donnell et al., 2012), 6 - Veinot Lake, 7 - Thin-Ice Pond, 8 - Crocker Pond (Pyne O'Donnell et al., 2016).

Figure 8.6 $\mathrm{SiO}_{2} \vee \mathrm{Na}_{2} \mathrm{O}+\mathrm{K}_{2} \mathrm{O}$ bivariate plot showing tephra glass shard major element compositions for HÄM_T14451444 and PLL_500 and envelopes for similarly aged Icelandic Tephras. (Reference envelopes are based on data from Wastegård, 2002; Ranner et al., 2005; PyneO'Donnell, 2007; Lind and Wastegård, 2011; Matthews et al., 2011; Lane et al., 2011, 2012; Lind et al., 2013; Lilja et al., 2013; Wulf et al., 2016; Timms et al., 2016; Jones et al., 2017).

Figure 8.7 Location map showing some of the key European sites to which Lake Hämelsee and Pant-y-Llyn can be correlated through the Askja-S Tephra.

Figure 8.8 Spatial distribution maps for the Askja-S Tephra. a) Sites where the Askja-S Tephra is present. b) Current spatial distribution envelope for the Askja-S Tephra (modified from Wulf et al., 2016). c) Suggested plume trajectory, given the location of sites where the Askja-S is present and absent. Site numbers and details are provided in full in Table 8.1.

Figure 8.9 Location map showing some of the key European sites to which Lake Hämelsee can be correlated through one or more tephra deposits. 
Figure 8.10 Location maps showing some of the key sites to which Llyn Llech Owain can be correlated. Map A - through the Fondi di Baia, Glacier Peak $G$ and Aniakchak Tephras. Map B - through the Lairg A, Penifiler and Borrobol Tephras.

Figure 8.11 Spatial distribution map of sites including the Lairg A tephra. (Modified from Lawson et al., 2012 and Watson et al., 2016). 1 - Sellevoll (Vorren et al., 2007), 2 Borge (Pilcher et al., 2005), 3 - Klocka Bog (Bergman et al., 2004), 4 - Degerö Stormyr (Watson et al., 2016), 5 - Jardelunde (van den Bogaard and Schminckle, 2002), 6 - Grambow (van den Bogaard and

Schminckle, 2002), 7 - Lairg (Dugmore et al., 1995), 8 Temple Hill Moss (Langdon et al., 2003), 9 - Malham Moss (Watson et al., 2016), 10 - Garry Bog (Hall et al., 1994), 11 - Fallahogy (Barber et al., 2000), 12 -

Ballynahone (Pilcher et al., 1996), 13 - Sluggan (Hall et al., 1994), 14 - Claraghmore (Watson et al., 2016), 15 An Loch Mór (Chambers et al., 2004), 16 - Moyreen (Plunkett, 1999, 2006). Red dot represents the Llyn Llech Owain location.

Figure 8.12 Bivariate plot of $\mathrm{SiO}_{2} \vee \mathrm{K}_{2} \mathrm{O}$ concentrations in tephras derived from the main European ash provinces.

Adapted from Davies et al., (2002) and Mortensen et al., (2005).

Figure 8.13 Map showing the spatial extent of the tephra deposits found at Llyn Llech Owain.

Figure 8.14 Compilation of selected Borrobol (and) Penifiler Tephra bearing sites illustrating the potential for investigating differences in environmental response during the Lateglacial Interstadial onset.

Figure 8.15 Compilation of selected Glacier Peak G Tephra bearing sites illustrating the potential for investigating differences in environmental response during the Lateglacial Interstadial.

Figure 8.16 Compilation of selected Laacher See Tephra (LST) bearing sites illustrating the potential for investigating differences in environmental response during the Lateglacial Interstadial.

Figure 8.17 Compilation of selected Vedde Ash bearing sites illustrating the potential for investigating differences in environmental response during the Younger Dryas.

Figure 8.18 Compilation of selected Ulmener Maar Tephra (UMT) bearing sites illustrating the potential for investigating differences in environmental response during the early Holocene. 
Figure 8.19 Compilation of selected Askja-S Tephra bearing sites illustrating the potential for investigating differences in environmental response during early Holocene.

Figure 8.20 Compilation of selected Saksunarvatn Ash bearing sites illustrating the potential for investigating differences in environmental response during the early Holocene.

Figure 8.21 Compilation of selected Lairg A Tephra bearing sites illustrating the potential for investigating differences in environmental response during the Holocene.

Figure 8.22 Compilation of selected Aniakchak Tephra bearing sites illustrating the potential for investigating differences in environmental response during the Holocene. 


\section{List of Tables}

\begin{tabular}{|c|c|c|}
\hline Table 2.1 & $\begin{array}{l}\text { Summary of the chronostratigraphic names for the } \\
\text { events during the Lateglacial period and their } \\
\text { approximate age estimates (Mangerud et al., 1974; } \\
\text { Lowe and Gray, 1980; Litt et al., 2001; Lowe et al., } \\
\text { 2001; Rasmussen et al., 2014). }\end{array}$ & Page \\
\hline Table 3.1 & $\begin{array}{l}\text { Summary of the acetanilide standards analysed during } \\
\text { the analysis of Carbon, Nitrogen and } \delta^{13} \mathrm{C} \text { using a PDZ- } \\
\text { Europa ANCA GSL Elemental Analyser. }\end{array}$ & 6 \\
\hline Table 3.2 & $\begin{array}{l}\text { Summary of the Lipari and BCR2g secondary standards } \\
\text { analysed. The recommended values for Lipari and } \\
\text { BCR2g are noted at the top of the table. Groups (a-h) } \\
\text { represent the different operating sessions. }\end{array}$ & 7 \\
\hline Table 4.1 & $\begin{array}{l}\text { Summary of glass shard major element compositions, } \\
\text { presented as means and standard deviation }(2 \sigma) \text { values } \\
\text { for each tephra deposit in the Lake Hämelsee record. }\end{array}$ & 92 \\
\hline Table 4.2 & $\begin{array}{l}\text { Tephra correlations and published age estimates for the } \\
\text { correlated tephra deposits found within the Lake } \\
\text { Hämelsee sequence. }\end{array}$ & 106 \\
\hline Table 5.1 & $\begin{array}{l}\text { Bulk sediment chemistry results }\left(\% \mathrm{C}, \% \mathrm{~N} \text { and } \delta^{13} \mathrm{C}\right) \text { on } \\
\text { acid treated and untreated samples (see section } 3.3 .2) \text {. }\end{array}$ & 115 \\
\hline Table 5.2 & $\begin{array}{l}\text { Summary of glass shard major element compositions, } \\
\text { measured by electron microprobe (see section } 3.4 .2) \\
\text { and presented as means and standard deviation }(2 \sigma) \\
\text { values for each tephra deposit in the Llyn Llech Owain } \\
\text { record. Dataset has been normalized with original totals } \\
\text { noted. Operating conditions are noted in the methods } \\
\text { section 3.4.2. }\end{array}$ & 136 \\
\hline Table 5.3 & $\begin{array}{l}\text { Total Shard Concentrations (TSCs), number of shards } \\
\text { geochemically analysed, degree of homogeneity, } \\
\text { proposed correlation and age estimate for each } \\
\text { geochemically analysed tephra deposit found within the } \\
\text { Llyn Llech Owain record. }\end{array}$ & 159 \\
\hline Table 5.4 & $\begin{array}{l}\text { Radiocarbon determinations and un-modelled calibrated } \\
\text { age ranges for Llyn Llech Owain. T - terrestrial plant } \\
\text { macrofossils; a - unidentified aerial wood fragments; } b \text { - } \\
\text { betula leaf fragments. A - aquatic plant macrofossils; a } \\
\text { - potamogeton seeds; b - ceratophyllum seeds; c- } \\
\text { chara oospores; } d \text { - epidermal tissue. B - bulk sediment }\end{array}$ & 163 \\
\hline
\end{tabular}


(humin fraction). Age estimates are calibrated against the IntCal13 calibration curve (Reimer et al., 2013).

Table 5.5 Comparison of the best age estimates for the Tephras found in the Llyn Llech Owain sequence against the output age estimates from age model B.

Table 6.1 Four radiocarbon dates measured from bulk sediment at 14CHRONO Centre at Queens University Belfast. Ages were calibrated using OxCal and the IntCal13 calibration set (Bronk Ramsey, 2009; Reimer et al., 2013). AcidAlkali-Acid (AAA) pre-treatment was undertaken on samples. Dates supplied by the British Geological Survey.

Table 6.2 Summary geochemical data displayed as major oxide concentrations (average and standard deviation) for the tephra layer 499-500 cm (PLL_500). A complete list of analyses and full microprobe operating conditions can be found in the appendix.

Table 7.1 Radiocarbon dates from Cors Carmel as noted in Walker and James, (1992).

Table 8.1 A compilation of positive and negative findings of the Askja-S Tephra (ordered by publication date). Absences are noted according to the sampling interval, age models and the stratigraphic position of other tephras in the original studies.

Table 9.1 Summary of the tephra deposits found in Llyn Llech Owain, Pant-y-Llyn and Lake Hämelsee, their homogeneity status and proposed correlations. 


\section{Introduction}

The period marking the termination of the last glaciation was characterised by abrupt and rapid climatic changes (e.g. Walker, 1995; Björck et al., 1998). The observed climatic changes are referred to as the Lateglacial period and approximately dates from 14.7 to $11.7 \mathrm{ka}$ cal BP (Hoek, 2008). Evidence of these changes is well preserved in the Greenland ice-core records where variations in the $\delta^{18} \mathrm{O}$ values reflect changes in palaeo-temperature (Johnsen et al., 1997). Terrestrial records also preserve evidence of Lateglacial climate changes such as the chironomid-based temperature record from Whitrig Bog, Scotland (Brooks et al., 2000). The abrupt changes associated with the Lateglacial include a warmer interstadial phase following the termination of the last glacial period, followed by a return to cold stadial conditions and in turn back to the warmer present interglacial period known as the Holocene. Evidence from the ice-core records indicate the changes occurred on decadal timescales (Steffensen et al., 2008) with temperature changes in the range of $\sim 12{ }^{\circ} \mathrm{C}$ (Kindler et al., 2014).

The causes or triggers for these abrupt changes are thought to reside from changes in the ocean circulation and/or changes in atmospheric dynamics (Broecker, 2003; Barker et al., 2015). Palaeo-climatic records from maritime regions are fundamental to investigate the impact of these changes. The lack of records from south west Britain highlights the importance of investigating sites from south Wales. Lake Hämelsee is also investigated to bridge the east-west transect of palaeo-climatic records between Central Europe, the North Atlantic and Greenland. A key challenge for climate scientists is to pinpoint the mechanisms of these rapid climatic changes. However, to fully understand the triggers and mechanisms, regional proxy records need to be precisely dated and synchronized in order to investigate the relative responses to the climatic changes. Many terrestrial proxy records, however, are plagued with chronological limitations, largely based on radiocarbon dating issues (Muscheler et al., 2008). One of the very few Lateglacial studies in Wales (Walker et al., 2003) is based on radiocarbon dating which 
may inhibit reliable synchronisation with other records in order to investigate possible leads or lags in environmental responses to the Lateglacial climate changes. One approach to overcome these issues is to employ tephra horizons that are instantaneously deposited as precise and independent time-markers for synchronising records (Lowe, 2011; Davies, 2015).

Tephrochronology is a correlation technique that employs instantaneously deposited and geochemically unique volcanic ash (tephra) deposits as precise age-markers, or isochrons, when preserved in sedimentary archives (Thórarinsson, 1944; Lowe, 2011). In the last few decades, cryptotephra discoveries (tephra deposits invisible to the naked eye) have revolutionised the technique and has led to its application in new geographical areas that were not traditionally associated with tephra work (e.g. Dugmore, 1989; Davies et al., 2003; Davies, 2015). Traces of cryptotephra deposits have been discovered in Wales before, however they have not been characterised by their geochemical composition, with the exception of Watson et al., (2017). Identification of tephra deposits correlated to known eruptions will allow the sites to be independently synchronised with other tephra-bearing sites to investigate the environmental response to the Lateglacial climatic changes. In addition, the tephra deposits could be utilised as precise age constraints and implemented into future age-models.

Lake Hämelsee, north Germany, is also included in this study as an additional site. It was chosen due to its locality and potential to preserve tephra deposits from more than one volcanic region which in turn could improve the European tephra framework or stratotype for the Lateglacial. Lake Hämelsee is also in a key geographical position to link varved records from northern central Poland and Western Germany.

The project aims are as follows:

1) To assess the tephra content within Llyn Llech Owain, Cors Carmel and Pant-y-Llyn in Wales and Lake Hämelsee in north Germany. 
2) To geochemically fingerprint each tephra deposit and correlate them to known eruptions to provide tephrostratigraphic and tephrochronological constraints for the records.

3) To develop proxy reconstructions, where possible, including lithostratigraphic constraints, sediment geochemistry and diatom analysis.

4) To utilise the tephra deposits as tie-points between the study sites and those published elsewhere in order to assess any differences in environmental response to the Lateglacial climate changes. 


\section{Literature Review}

\subsection{The Lateglacial period ( 14.7 $-11.7 \mathrm{ka}$ cal BP): definition and terminology}

The Lateglacial period (also referred to as the Late Glacial, Late glacial, Lateglacial or last glacial-interglacial transition (LGIT)) is known as the transitional period between the last cold stage (Pleistocene epoch) and the present interglacial (Holocene). In the North Atlantic area the Lateglacial period spans approximately between 14.7-11.7 cal years BP, and was marked by rapid climatic events. This period is probably the most intensively studied time interval of the Quaternary period and has been referred to as a 'virtual laboratory' in which complex forcing mechanisms that drive climatic changes can be investigated (Hoek, 2008). High resolution investigations of the Lateglacial period are also possible due to the accessibility and preservation of sequences. A wealth of palaeoarchives such as ice cores, marine sediment and terrestrial deposits preserve a detailed record of climatic changes during this relatively recent period of the Quaternary. Insights into the abrupt climatic changes during the Lateglacial are used to validate climate models, which in turn lead to better predictions of future climate change (e.g. Renssen et al., 2007; Roche et al., 2014).

Lateglacial climate changes have long been recognised in Europe (Jessen, 1935; Iversen, 1942). Jessen, (1935) initially defined the Lateglacial sequence based on palynology by recognising three successive pollen zones. 'Pollen zone I' was referred as the Early Dryas, 'pollen zone II' was referred as the warmer Allerød stage, and 'pollen zone III' was referred as the Late Dryas. Iversen, (1942) added a further subdivision to the interstadial phase prior to the Allerød which was based on evidence from the site Bølling in Denmark. In turn, biostratigraphy became less important and 
chronostratigraphy was used more frequently with the development of radiocarbon dating. Mangerud et al., (1974) was the first to establish the chronological subdivision for the Lateglacial based on radiocarbon dated biostratigraphic zones from Scandinavian sites. They define the Bølling and Allerød as the period between 13,000 and $11,000{ }^{14} \mathrm{C}$ years BP and the period between 11,000 and $10,000{ }^{14} \mathrm{C}$ years BP defining the Younger Dryas chronozone. A growing body of evidence, however, illustrates that Lateglacial climate changes are indeed time-transgressive (e.g. Lane et al., 2013) and highlights the need for a strict protocol for the use of chronostratigraphic terms in different regions as recommended by the INTIMATE community (Björck et al., 1998; Lowe et al., 2001; Lowe et al., 2008). INTIMATE recommends that local terminology should initially be used to discuss local/regional climatic or environmental events, independently of the ice-core record. Subsequent synchronisation to the ice-core stratotype should then be made with secure age models in addition to independent age constraints such as tephra deposits (Lowe et al., 2008). The events during the Lateglacial period for different localities are summarised in Table 2.1.

In Britain, the lacustrine Lateglacial sedimentary succession is characterised by a tripartite sequence with the basal clay unit representing glacial conditions of the Last Cold Stage (Dimlington Stadial), overlain by organic lake muds deposited during the warmer conditions of the Lateglacial Interstadial (Windermere), and then succeeded by a clay unit representing a return to colder conditions during the Loch Lomond Stadial. The climatic warming at the start of the Holocene is typically preserved as organic lake muds. Evidence for Lateglacial changes is also preserved in the Greenland ice-core record which is clearly shown by electrical conductivity measurements (ECM) (Taylor et al., 1993). Measurements for $\delta^{18} \mathrm{O}$ values also illustrates the Lateglacial climate changes in the Greenland ice-cores where lower $\delta^{18} \mathrm{O}$ values observed during Greenland Stadial 2 (GS-2) and Greenland Stadial 1 (GS-1) indicate colder temperatures compared with the higher $\delta^{18} \mathrm{O}$ values during Greenland Interstadial $1(\mathrm{Gl}-1)$ and Holocene 
Table 2.1 - Summary of the chronostratigraphic names for the events during the Lateglacial period and their approximate age estimates (Mangerud et al., 1974; Lowe and Gray, 1980; Litt et al., 2001; Lowe et al., 2001; Rasmussen et al., 2014).

\section{Approximately equivalent chronozones}

\begin{tabular}{|c|c|c|c|}
\hline NW Europe & Britain & Greenland & onset \\
\hline Holocene & Holocene & Holocene & $\sim 11.7 \mathrm{ka} \mathrm{BP}$ \\
\hline Younger Dryas & Loch Lomond Stadial & GS-1 & $\sim 12.9 \mathrm{ka} \mathrm{BP}$ \\
\hline & & Gl-1a & \\
Allerød & & Gl-1b & \\
& Windermere Interstadial & Gl-1c & \\
Older Dryas & & Gl-1d & \\
Bølling & & Gl-1e & $\sim 14.7 \mathrm{ka} \mathrm{BP}$ \\
\hline Pleniglacial & Dimlington Stadial & GS-2 & \\
\hline
\end{tabular}



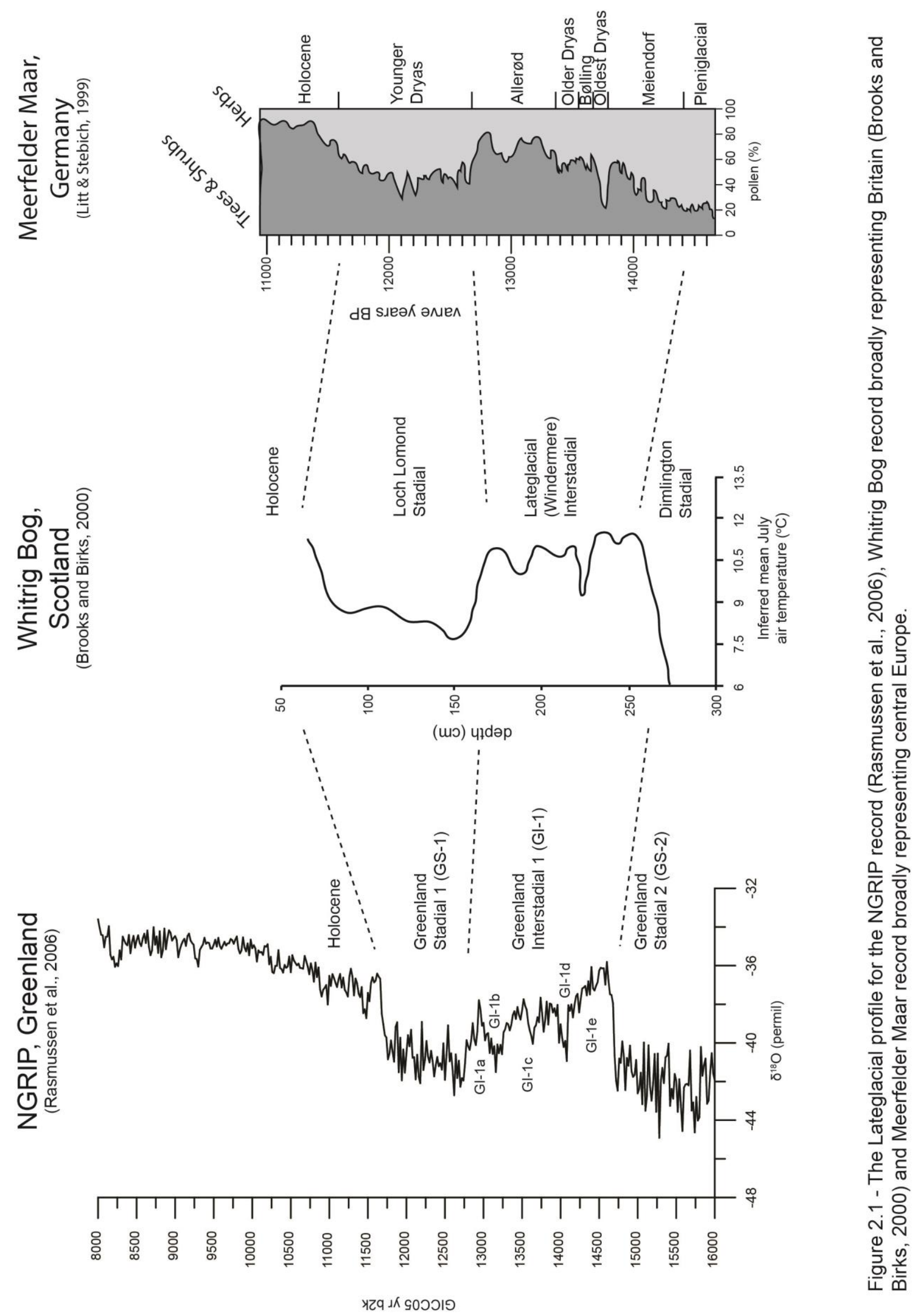
which indicate warmer temperatures (Figure 2.1). The Greenland ice-core records provide a considerable amount of detail, compared to terrestrial and marine sedimentary records, where the Lateglacial Interstadial is sub-divided into 5 parts (locally named Gl-1e - Gl-1a) with Gl-1b and d representing cold oscillations (Rasmussen et al., 2014). The Greenland ice-core records also provide a precise chronology which is constructed using a multi-parameter approach based on annually resolved ice-core layers (Rasmussen et al., 2006). The precise chronological constraints in the ice-core records has allowed investigations to the abruptness of the climatic changes observed and show that the transition from the Stadial to Interstadial took place within a decade (Steffensen et al., 2008).

Abrupt changes are also captured in terrestrial records including the chironomid-based record from Whitrig Bog, Scotland (Brooks et al., 2000) (Figure 2.1). Low inferred temperatures are observed during the Last Cold Stage and Loch Lomond Stadial with higher inferred temperatures during the interstadial and Holocene. Short-lived cold fluctuations are also seen during the interstadial at Whitrig Bog however it is unclear due to dating uncertainties whether they represent synchronous events to $\mathrm{Gl}-1 \mathrm{~d}$ and $\mathrm{Gl}-1 \mathrm{~b}$ in the ice-core record.

\subsubsection{Climatic and Environmental changes during the Lateglacial}

Several studies have focused on reconstructing climatic and environmental changes during the Lateglacial period in Britain, especially in Scotland (e.g. Matthews et al., 2011, Brooks and Birks, 2000: Brooks et al., 2012) and Ireland (e.g. Van Asch et al., 2012; Walker et al., 2012), but very few studies have been reported in Wales. Furthermore, only a handful of sites have been investigated in high-resolution. Such studies are important due to their geographical maritime locality and their sensitivity to changes or disruption in the North Atlantic Ocean circulation which is thought to be the main cause of 
the abrupt Lateglacial climatic changes (Broecker, 2003). Such studies are also important to provide a fuller framework covering Wales, as highlighted by the INTIMATE project (INTegrating Ice core, MArine, and TErrestrial records), to synchronise records from the ice, marine and terrestrial environments (Lowe et al., 2008; Blockley et al., 2012). INTIMATE note that further studies and investigations on Lateglacial sequences is necessary to help fully understand the climatic complexities of that time period and thus provide fuller insights and knowledge to power climate models of past and future environments. Two of the limited numbers of Welsh sites that have observed Lateglacial climatic changes within their sedimentary records include Llyn Gwernan (Lowe, 1981; Lowe et al., 1988; Lowe and Lowe, 1989) and Glanllynnau (Coope and Brophy, 1972; Simpkins, 1974). These relatively early studies used pollen and coleopteran analysis to reconstruct the classic tripartite Lateglacial changes. The most recent investigation of a Welsh Lateglacial sequence was undertaken by Walker et al., (2003) and focused on a sedimentary deposit preserved within an opencast coal mine in Llanilid, south Wales. A comprehensive multi-proxy approach, which included pollen, plant macrofossils, coleopteran, geochemical properties and stable-isotope analysis, revealed the Lateglacial tripartite succession (Figure 2.2). The coleopteran data reveal two cold fluctuations during the Lateglacial Interstadial with mean July temperatures dropping by more than $5^{\circ} \mathrm{C}$. Evidence of the cold fluctuations was also observed in the pollen data with decreasing Juniperus during the first temperature drop and a decline in Betula during the second cold phase. Pollen assemblages showed the establishment of scrub tundra during the Loch Lomond Stadial at Llanilid and the coleopteran-based temperature record revealed mean July temperatures in the range of $10-11{ }^{\circ} \mathrm{C}$ during this cold period. The Holocene onset is marked by a sudden increase in temperatures of around $9{ }^{\circ} \mathrm{C}$, the expansion of Betula woodland as inferred by the pollen assemblages and an abrupt increase in bulk organic carbon values. Applying a multi-proxy approach provides a wealth of information and a comprehensive reconstruction from a sedimentary archive (e.g. Brooks et al., 1997; Walker et al., 2003; Walker et al., 2012; Lotter et al., 2012), where some insights may be lost if only a single proxy technique is used. 


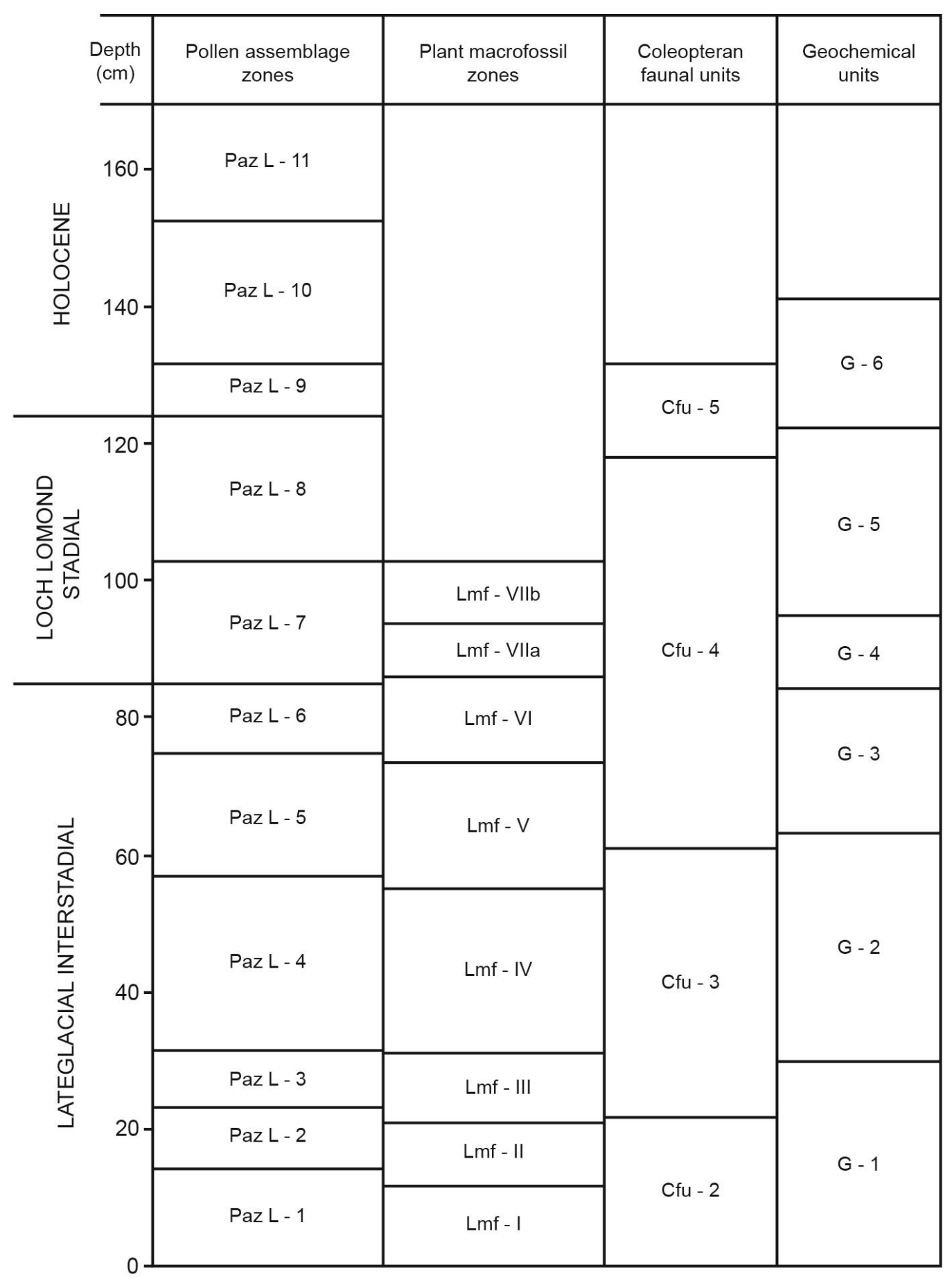

Figure 2.2 - The zoned multi-proxy reconstruction from Llanilid, South Wales (Walker et al., 2003), illustrating the Late-glacial sequence preserved at the site. 
A range of different proxy techniques have been applied to Lateglacial records and range from lithostratigraphic and geochemical methods to palaeoecological methods such as pollen, diatoms and chironomid analysis. Geochemical analysis of lake sediments provides insights in to changes within the lake environment and also geomorphological activity around the catchment area. A crude proxy for palaeoenvironmental changes that can be observed in sedimentary archives is organic content which can be derived by using the Loss on Ignition (LOI) technique (Heiri et al., 2001). The general LOI curve that is expected in Lateglacial sequences would start with an increase in values after deglaciation, inconsistent high values during the interstadial, followed by a sharp decline during the stadial period and then increased values where more organic material is produced during the Holocene (e.g. Walker et al., 2012).

A relatively newer technique is the use of high-resolution X-ray fluorescence core scanning techniques to obtain sediment geochemistry data (e.g. Bakke et al., 2009; Neugebauer et al., 2012; Wulf et al., 2013). The ITRAX XRF core scanner method provides a high-resolution, continuous, non-destructive, multi-elemental data set for sedimentary sequences (Davies et al., 2015). XRF core scanning data however, only provides relative changes in elemental compositions of sediments and does not obtain absolute geochemical compositional data. Developments in the technologies of XRF scanning has enabled measurements of sedimentary sequences of up to sub-millimetre scales, which has allowed even the smallest events to be recorded (Croudace et al., 2006; Francus et al., 2009). Several studies have utilised the XRF scanning technique in order to investigate Lateglacial environmental changes (e.g. Balascio et al., 2011; Neugebauer et al., 2012). Most studies use the data retrieved by ITRAX core scanners in order to investigate changes in detrital material in-puts as inferred by elevated minerogenic elements such as Ti and K (e.g. Bakke et al., 2009; MartinPuertas et al., 2012) (Figure 2.3). The Loch Lomond Stadial ( Younger Dryas) can be effectively observed through elevated values of minerogenic elements which can be interpreted as an increase in in-wash, thus suggesting a colder climate. Another application for the use of XRF scanning 


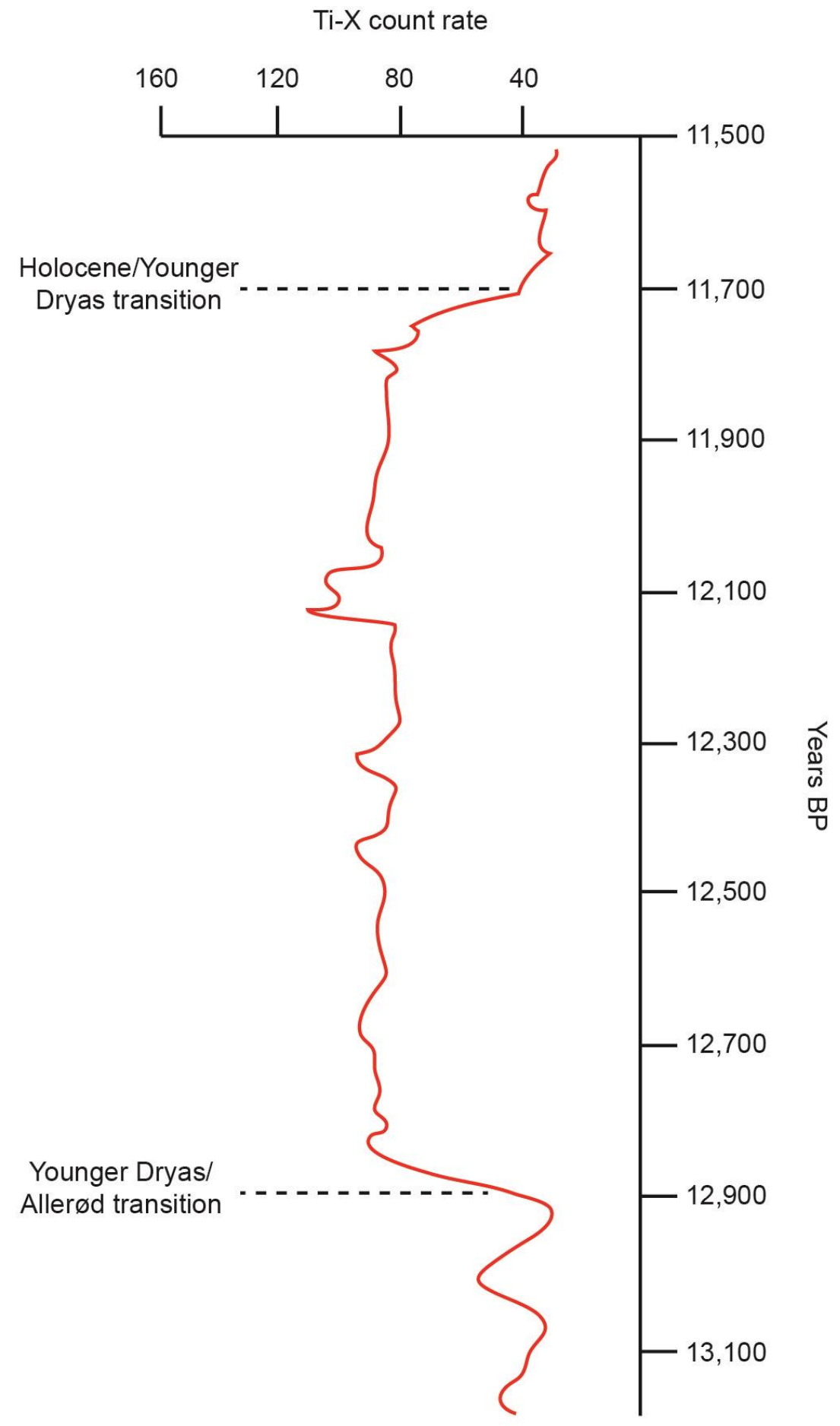

Figure 2.3 - Ti count rate measured by an ITRAX core scanner fo rthe Lake Kråkenes record (from Bakke et al., 2009). 
is to identify events in the sedimentary sequence, such as tephra deposits (e.g. Kylander et al., 2012; Wulf et al., 2013). One of the most commonly applied palaeoecoogical techniques is pollen analysis. For terrestrial sequences in Germany such as Meerfelder Maar, the Lateglacial stratigraphic sub-division has been characterised mainly by palynology (Litt et al., 2001) and is shown in Figure 2.1. The Last Cold Stage is referred to as the Pleniglacial in Germany and is characterised by an open, treeless landscape with sedges and herbs dominating the vegetation assemblage. This period is followed by the Meiendorf biozone which is thought to represent the onset of the Lateglacial Interstadial. This period features an increase in tree and shrub pollen such as Betula. The Oldest Dryas biozone follows, where pronounced and abrupt climate deterioration occurred resulting in a decrease in shrub and tree pollen and replaced by an increase in herb pollen. The Oldest Dryas biozone is thought to be linked with the GI$1 \mathrm{~d}$ event and is also thought to be present in the Whitrig Bog record. This biozone is followed by the Bølling biozone which is characterised by a sudden increase in Betula pollen. However, the Older Dryas biozone follows in close succession where a slight decrease in tree pollen is observed and is considered as a less pronounced climatic period. The Older Dryas biozone is followed by the Allerød which is characterised by a sustained high assemblage of tree pollen and is thought to have a duration of around 670 years (Litt and Stebich, 1999). The Younger Dryas biozone follows, which is marked by a substantial change to an open habitat with the pollen assemblages showing an abundance of herb pollen and a decrease in tree pollen. The Younger Dryas biozone is thought to be associated with the Loch Lomond Stadial where colder conditions prevailed. The Preboreal biozone follows, where tree pollen assemblages increase considerably suggesting a dense woodland habitat and climatic amelioration.

Several studies have also used diatom assemblages in Britain including Wales as a proxy for reconstructing lake responses to Lateglacial climate changes (e.g. Pennington, 1943; Round, 1957; Evans, 1970; Haworth, 1976; Robinson, 2004, Crabtree, 1969; Evans and Walker, 1977). Diatom assemblages are very useful tools in Quaternary studies as indicators of local 
habitat changes within the lake under investigation. They have short lifecycles, and due to their restricted ecological tolerances within lacustrine environments they respond rapidly and directly to environmental change (Battarbee, 1986). Diatoms are classified as algae and are members of the Bacillariophyta division. They are unicellular, eukaryotic organisms distinguished by their siliceous cell walls. Every diatom is made up of two identical thecae, where the valve face of the thecae is complexly patterned, allowing most to be identified at species level (Birks et al., 1990). Freshwater diatoms, are mainly controlled by the trophic status, $\mathrm{pH}$, and salinity of the lake. Changes in these parameters can affect the diatom community, thus applying diatom analysis on lake sediment records can provide evidence of changes in these parameters through time.

In general, Lateglacial investigations in Britain report that diatoms are absent in the sediments representing the Dimlington Stadial, where unfavourable diatom preservation conditions prevailed, with diatoms first appearing during the interstadial onset. Fragilaria species tends to be the first diatom species to appear, which are considered to be a pioneer species that has a large ecological tolerance. Diatoms are typically absent during the Loch Lomond Stadial in most sites but succeeded by a more diverse assemblage during the early Holocene development.

\subsubsection{Proposed causes of Lateglacial changes}

The Lateglacial climatic oscillations are generally considered to have occurred in the North Atlantic, with evidence preserved in several archives from terrestrial studies within NW Europe, North Atlantic marine records and the Greenland ice cores. However, the climatic oscillations of the Lateglacial period, especially the Younger Dryas, have also been detected in areas outside NW Europe. Pollen studies from Turkey and Greece in the eastern Mediterranean show evidence of the Younger Dryas and also indicate that conditions were more arid than any time during the last glacial period 
(Rossignol-Strick, 1995). Evidence found in deposits from around the globe suggests that the Lateglacial climatic oscillations were a worldwide phenomenon, including records from the north Pacific coast of America (Mathewes, 1993), pollen records from the Andes of South America (Moreno et al., 2001), the southern Alps of New Zealand (Lowell et al., 1995), and even marine cores from as far away as the western Pacific (Kudrass et al., 1991). However, in the Antarctica records the climatic oscillations are of opposite signal to the Greenland records (Blunier et al., 1998). The increasing temperature during the Lateglacial Interstadial in Greenland is seen as a decrease in temperatures in Antarctica, and the cold phase of GS1 coincides with relatively warm temperatures in Antarctica.

Such complex climatic signals means that understanding the causes or mechanisms behind these climatic changes are still unknown (Blockley et al., 2012). The preferred hypothesis for causing abrupt climate change is the disruption in the North Atlantic deep-water ocean circulation, which results from a burst of freshwater input (Broecker, 2003). However, Barker et al., (2015) suggest that freshwater input does not trigger abrupt climatic changes but provides a positive feedback for enhancing and/or extending stadial conditions.

The favoured hypothesis for the cause of the Younger Dryas Stadial is the rapid in-flux of meltwater into the North Atlantic from proglacial Lake Agassiz which is believed to have had the capacity to interrupt the ocean circulation (Broecker et al., 1989; Clement and Peterson, 2008). An alternative but contentious hypothesis for the Younger Dryas cooling is suggested to be contributed by an extra-terrestrial impact, which destabilized the Laurentide ice sheet contributing to a sudden outburst of freshwater (Firestone et al., 2007).

To test the dominant climate-driving mechanisms in the North Atlantic questions need to be answered on whether the rapid climatic events, and the environmental reaction to them, happened at the same time over the North Atlantic and Europe or whether there were any leads or lags between them. 
This critical requirement is hampered by limitations and uncertainties associated with the dating techniques.

\subsection{Principles of Tephrochronology and}

\section{Tephrostratigraphy}

Tephrochronology is a unique method for linking, dating and synchronizing palaeoenvironmental sequences and events (Lowe, 2011). The great potential of tephra deposits was first recognised by Thórarinsson, (1981), where he utilised visible tephra deposits for providing dated horizons for pollen investigations in Iceland. Tephra is a term proposed by Thórarinsson,

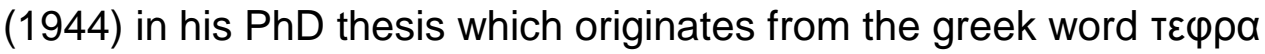
meaning 'ashes'. After a volcanic eruption, tephra can be transported by the wind over thousands of kilometres from the source volcano and can be preserved in palaeoenvironmental archives such as lake sediments, peat bogs, marine sediments, and ice cores (e.g. Davies et al., 2007, Abbott and Davies, 2012, Griggs et al., 2014). Tephra deposition is assumed to occur instantaneously (within days to weeks), and their unique geochemical signatures facilitate their employment as unique and commonly widespread isochronous markers which can be used for correlating between sites.

For this method to be used correctly, correlation of the tephra horizons needs to be accurate and precise. Early studies depended on physical and visual properties of the tephra shards for correlating. For example, the Laacher See Tephra, erupted from the Eifel region in Germany, has a very vesicular morphology (Bogaard and Schmincke, 1985) and also the Vedde Ash, of Icelandic origin, consists of 'butterfly' shaped shards (Mangerud et al., 1984). However such features are not reliable enough to clarify the same eruption because similar characteristics can be produced by eruptions of the same volcanic centres (Turney et al., 2004). Geochemical properties must be 
obtained from tephra glass shards for a more reliable correlation. The geochemical properties of glass shards depend on the bulk geochemical properties of the magma at the time of the eruption and also the character of the volcanic eruption itself (Barker, 1983). As a result, most eruptions produce its own unique geochemical fingerprint, even the eruptions from the same volcanic centres. The most widely used method to determine the geochemical fingerprint of a tephra horizon is electron microprobe analysis, where detailed geochemistry can be obtained from individual glass shards (Hunt and Hill, 1993). The electron microprobe uses Wavelength Dispersive Spectrometry to calculate the assemblage of major elements (expressed as oxides) within the separate shards (Hayward, 2012). Although in some instances the geochemical properties of two eruptions can be very similar. In such circumstances, the use of laser ablation inductively-coupled mass spectrometry (LA-ICP-MS) may be applied to provide data for minor and trace elements (Pearce et al., 2007) and aid correlations that were not possible when only comparing major element compositions (e.g. Davies et al., 2012; Meara, 2013; Bramham-Law et al., 2013).

If tephra deposits are to be used to provide fix-points in age models (tephrochronology), then each event needs to be independently dated, before their use as age estimates within chronological models. There are numerous methods used to do this such as radiocarbon dating, where organic material is present (Birks et al., 1996), radiometric techniques such as argon isotope (Van den Bogaard, 1995) and fission-track dating for older tephra deposits (Bigazzi et al., 2005). Direct dates can also be achieved by detecting tephra layers in ice cores where ice-layer counting is used (Grönvold et al., 1995), and also in varved lake sediments (Zillen et al., 2002; Wulf et al., 2008; Lane et al., 2015). If tephras are to be used solely for correlation between sites (tephrostratigraphy) then precise age estimates are not essential.

Stratigraphic information, however is always an important consideration when establishing tephra correlations.

Cryptotephra is the term used to describe tephra horizons invisible to the naked eye. Until the late 1990s, the application of tephrochronology for Late- 
glacial sequences was largely based on the occurrence of visible horizons. Discrete cryptotephra horizons were identified in distal peat bog deposits as early as the 1960s, where stratigraphic information was employed to suggest the preservation of the Hekla 3, Hekla 4, Askja 1875 and Öraefajökull 1362 cryptotephras in Swedish, Norwegian and Faroes peat bogs (Persson, 1966, 1971). It was the discovery of cryptotephra in Scottish peat (Dugmore, 1989), however, that instigated the recent advances in the search for ash deposits far removed from volcanic centres. Extensive employment of extraction techniques such as ashing (for organic rich deposits; Dugmore, 1989) and density separation (for minerogenic sediments; Turney, 1998) together with robust chemical characterisation of glass shards (Hayward, 2012) have given rise to an abundant European network of cryptotephra discoveries and led to its application in new geographical areas that were not traditionally associated with tephra work. There are very few reported findings, however, of distal ash deposits south of $53^{\circ}$ latitude and east of $6^{\circ}$ longitude and noticeable gaps in Wales, southern England and large parts of France are evident on spatial distribution maps (Figure 2.4). Tephra findings in Welsh sedimentary deposits are rare, but the dispersal of the 2010 Eyjafjallajökull eruption shows, Icelandic ash-fall over south Wales is a distinct possibility (Davies et al., 2010). There have been some traces of tephra in Wales, such as a mid-Holocene horizon found in deposits from the Cambrian Mountains (Buckley and Walker, 2002) and a Lateglacial tephra in deposits from Traeth Mawr in the Brecon Beacons (Williams, 2001). As yet, these discoveries have not been supported by geochemical analysis, with the exception of a recent study by Watson et al., (2017).

\subsubsection{Stratigraphy of key tephra deposits for the Lateglacial and early Holocene in Europe}

The key tephra horizons that could potentially be identified in the sites for this study are shown in Figure 2.5. The listed tephras provide a compilation of 


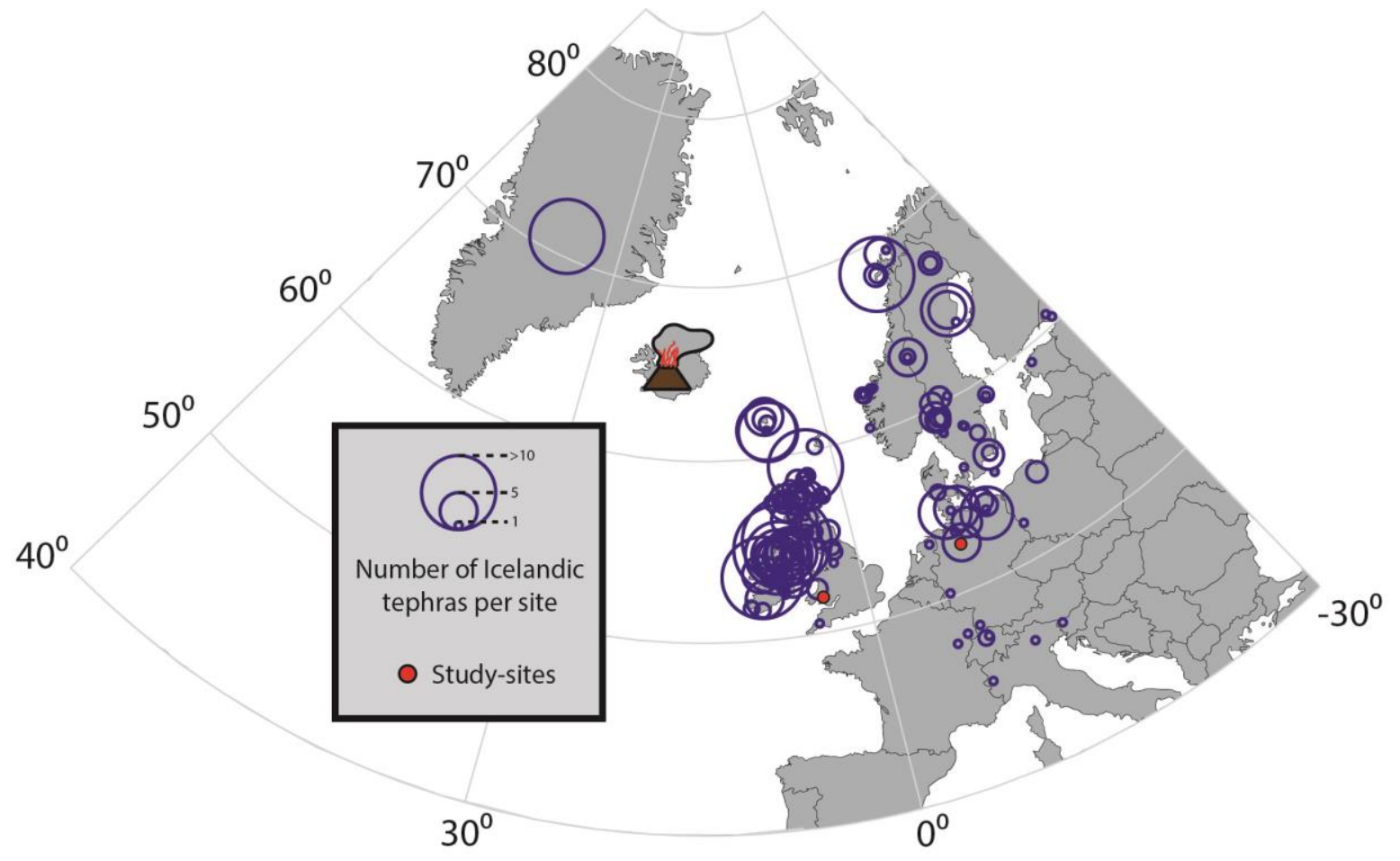

Figure 2.4 - Spatial distribution map of Europe including distal sites (outside of Iceland) that contain Icelandic tephra layers of Holocene and Lateglacial age. Circle size relates to the number of tephra layers found in each site. Data compiled from the RESET database - Bronk Ramsey et al., (2015); Wulf et al., (2016); Timms et al., (2016); Watson et al., (2016, 2017). The circle on Greenland corresponds to the SUMMIT cores and NGRIP (Grönvold et al., 1995; Mortensen et al., 2005). 


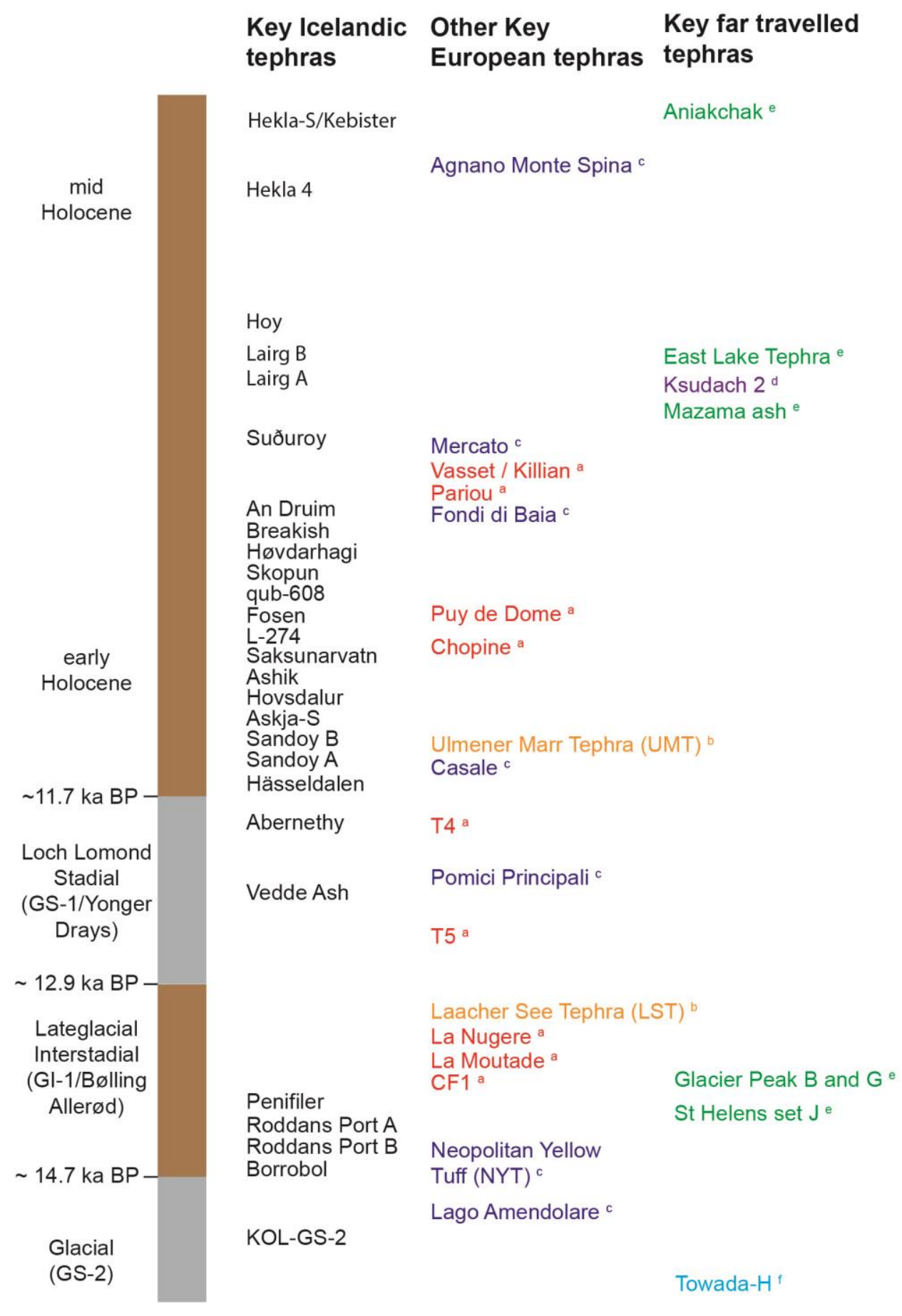

Figure 2.5 - Compilation of key tephra deposits that have the potential to be identified in the sites for this study. The tephras listed here are approximately chronostratigraphically positioned in relation to the Lateglacial chronozones shown. For the European tephras listed $a, b$ and $c$ relate to the Massif Central, Eifel, and Italy. For the far travelled tephras d,e and $f$ relate to Kamchatka, North America and Japan. Note that y axis is not to scale and not a true representative of stratigraphy. Stratigraphic positions of the key tephras are approximate based on best age estimates published in the literature (Blockley et al., 2014 and references within; Lane et al., 2017and references within; Lawson et al., 2012 and references within). 
deposits spanning the Lateglacial time interval that are widespread and lead to the increased potential for inter-site correlations. The tephra layers that is most likely to be present in the sites for this study would be from Iceland due to the prevailing wind direction and based on previous tephra studies.

Several tephra deposits are listed in Figure 2.5, however, some are more widespread than others. For example, the Pariou, Chopine, T4, T5, CF1 and La Moutade tephras from the Massif Central and Eifel volcanic regions have only been found in a few sites, in comparison with the Vedde Ash, which has been identified in several sites across Europe (Lane et al., 2012) and is also present in the Greenland ice-core records (Mortensen et al., 2005).

\subsubsection{European tephra deposits}

The most widespread tephra deposits of Lateglacial age from the Massif Central, Eifel and Italy are thought to be the Laacher See Tephra $(\sim 12.9 \mathrm{ka}$ BP), Vasset-Killian Tephra ( 9.4 ka BP) and Neapolitan Yellow Tuff ( 14.1 ka BP) (Figure 2.6). As yet, none of these tephra deposits have been discovered as far as Britain, probably due to the dispersal directions. These tephras are unlikely to be present in Welsh sites, however a previous study by Matthews, (2008) has reported the discovery of un-named Italian tephras in a site in Exmoor. A recent study by Lane et al., (2015) has also demonstrated the potential of discovering Italian tephra deposits with the discovery of the Neopolitan Yellow Tuff (NYT) in Meerfelder Maar, Germany. The widely dispersed Laacher See Tephra has already been identified as a visible deposit in Lake Hämelsee (Merkt et al., 1993). Cryptotephra investigations may reveal other tephra deposits that have originated from continental Europe such as the Neopolitan Yellow Tuff or the Vasset-Killian Tephra.

2.2.3 Far-travelled tephra deposits 

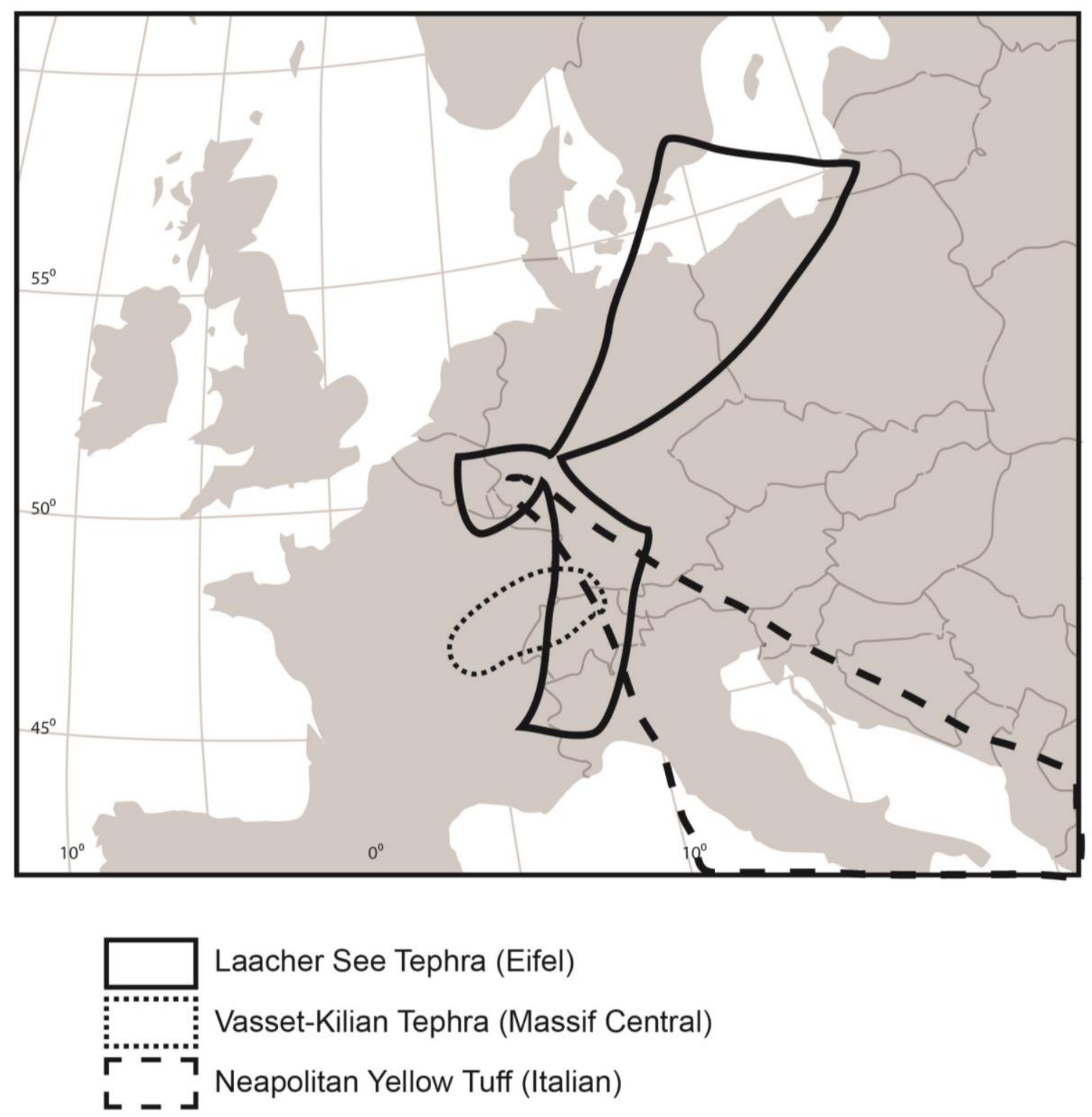

Figure 2.6 - Map of Europe illustrating the approximate spatial extent of the Laacher See Tephra, Vasset-Killian Tephra and Neapolitan Yellow Tuff. (Lane et al., 2011, 2015 and references therein). 
Recent studies have also demonstrated the potential for inter-continental tephra deposits (e.g. Jensen et al., 2014; Bourne et al., 2016; van der Bilt et al., 2017), therefore key far-travelled tephras from large volcanic eruptions with an ash dispersal axis towards Wales are also included in Figure 2.5. Perhaps the most relevant far-travelled tephra, with regards to the sites investigated in this study, is the White River Ash which was sourced from the Bona-Churchill volcano in the Wrangell volcanic field of south eastern Alaska. This deposit has a dispersal extent that spans across most of north America and Canada, the Greenland ice sheet and north west Europe with the most easterly discovery at Bagno Kusowo peatland in northern Poland (Watson et al., 2017) (Figure 2.7). Another far-travelled tephra deposit that demonstrates the potential of discovering far-travelled tephras in this study includes the Aniakchak Tephra. The Aniakchak Tephra originates from the Aleutian Range, southwest Alaska and its wide dispersal extent spans across north America and is also present in the Greenland ice cores (Pearce et al. 2004; Pyne-O'Donnell et al., 2012; Jennings et al., 2014; Zdanowicz et al., 2014; Pearce et al., 2017) (Figure 2.7). These far-travelled tephra discoveries have enabled inter-continental synchronization of palaeoclimate records which allows potential investigations to constrain lead-lag relationships between the tephra-bearing sites.

\subsubsection{Key Icelandic Tephra deposits}

The most widely dispersed Icelandic tephra deposits of Lateglacial age is the Vedde Ash which erupted from the Katla volcano in Iceland (Lane et al., 2012). The Vedde Ash is stratigraphically positioned during the mid Loch Lomond Stadial (Younger Dryas or GS-1) and has been dated to 12,121 \pm 114 b2k in the Greenland ice-cores (Mortensen et al., 2005; Rasmussen et al., 2006), to $12140 \pm 43$ varve years BP in Meerfelder Maar (Lane et al., 2015) and to $12023 \pm 43$ cal. a BP by Bronk Ramsey et al., (2015). Its wide spatial distribution spans most of north west Europe and the north Atlantic 


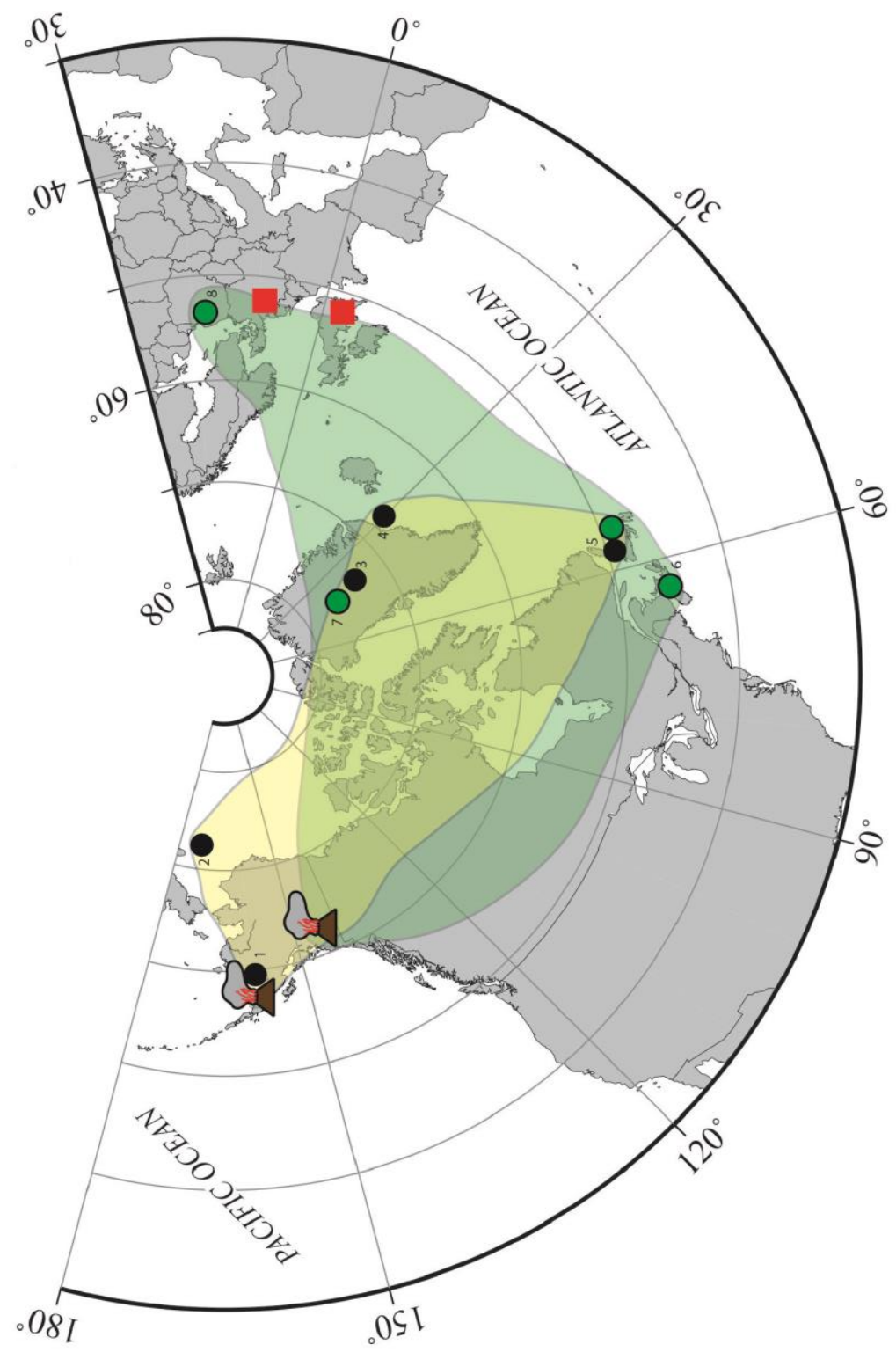

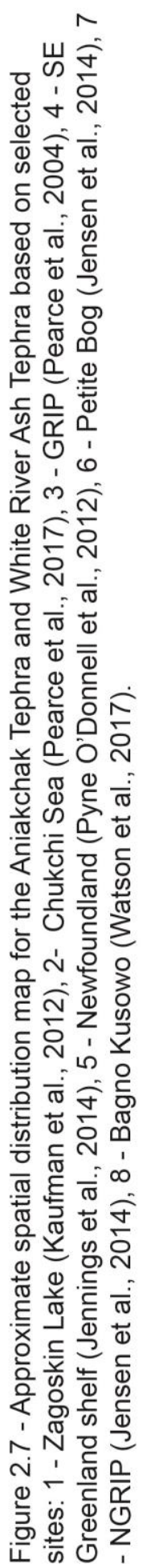




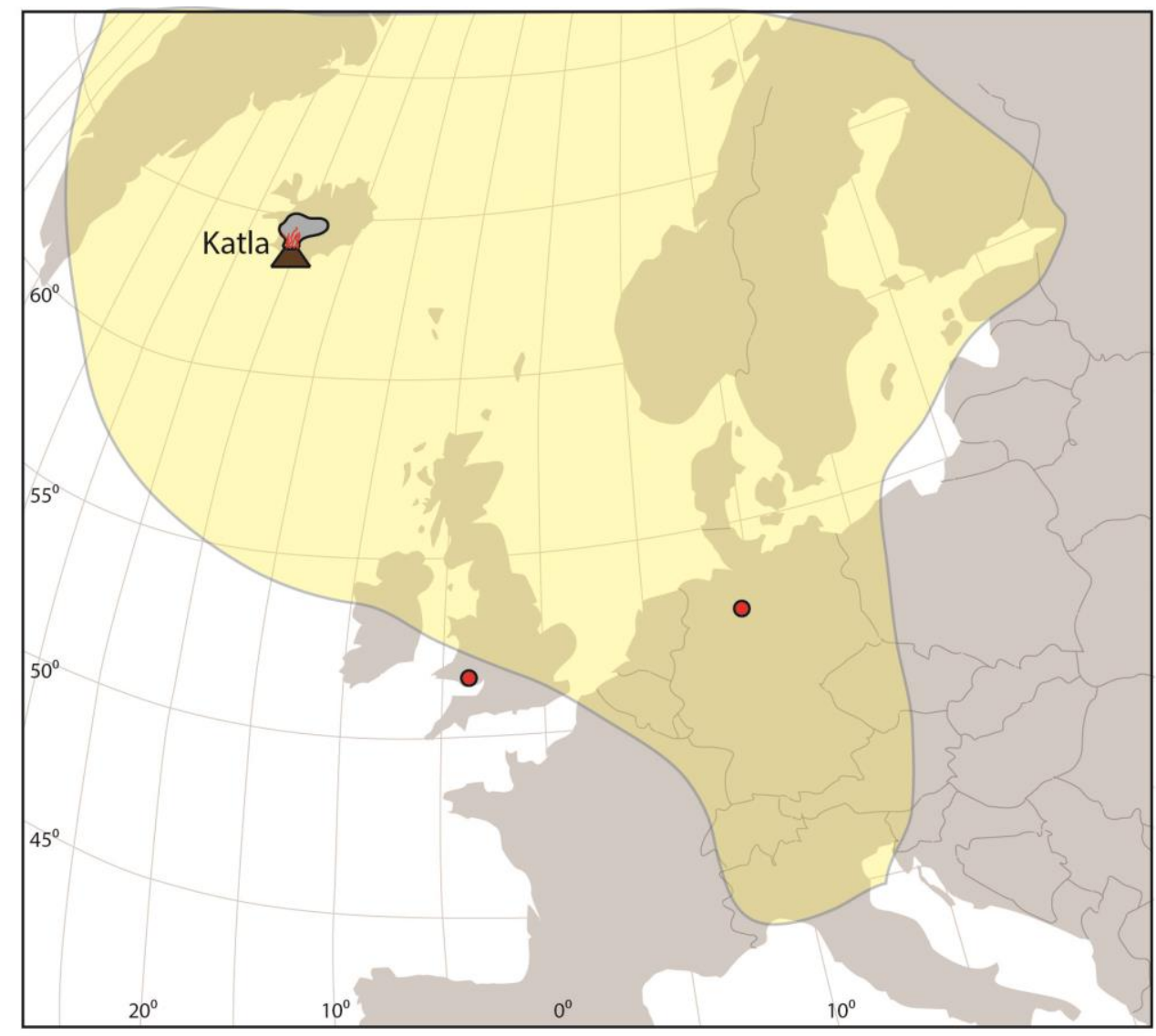

Approximate Vedde Ash

spatial distribution

Study sites: Llyn Llech Owain, Cors Carmeland

Pant-y-llyn (Wales) and Lake Hämelsee (Germnay)

Figure 2.8 - Map showing the approximate spatial distribution of the Vedde Ash (modified from Lane et al., 2012 and reference within). 
with its furthest findings in western Russia (Wastegård et al., 2000), Slovenia (Lane et al., 2011) and northern Norway (Vorren et al., 2007) (Figure 2.8). The discovery of the Vedde Ash in the Greenland ice-cores (Mortensen et al., 2005) makes the deposit an important tephra marker allowing independent correlations to be made with the widely used INTIMATE event stratigraphy (Rasmussen et al., 2014).

Another wide spread Icelandic tephra deposit is the early Holocene Askja-S Tephra which erupted from the Dyngjufjöll volcanic system. The Askja-S Tephra is dated to $10830 \pm 57$ cal BP (Bronk Ramsey et al., 2015) and has been discovered in sites from Arctic Norway (Pilcher et al., 2005) to Switzerland (Lane et al., 2011) and from northern Ireland (Turney et al., 2006) to north Poland (Wulf et al., 2016) (Figure 2.9).

The Borrobol Tephra is another tephra deposit that has the potential to be identified in the study sites. The Borrobol Tephra (BT) was first detected at the type-site Borrobol in north-east Scotland (Turney et al., 1997). This tephra layer is thought to represent an important isochronous age marker for the Lateglacial Interstadial onset as it's positioned just after the initial rise in the LOI curve. Its estimated age at the Borrobol site was ca 14,400 cal BP (Lowe et al., 1999) however a refined and updated age of $14,098 \pm 47$ cal BP is now in place for the BT which was derived by age-modelling a range of radiocarbon dates (Bronk Ramsey et al., 2015). Following the initial discovery of the BT, subsequent studies found other tephra layers of similar geochemistry but positioned later in the interstadial based on LOI curve or younger radiocarbon ages (Davies et al., 2004). These discoveries led to the discussion that there might have been more than one eruption during the interstadial from the volcano that sourced the BT. A succeeding study by Pyne O'Donnell, (2007) confirmed the speculation of another Borrobol-type tephra during the interstadial with the discovery of a mid-Interstadial tephra found in a number of Scottish sites, where the BT was also present, which was named the Penifiler Tephra (PT). The PT geochemistry is indistinguishable to the BT, however, basaltic shards with Katla geochemistry 


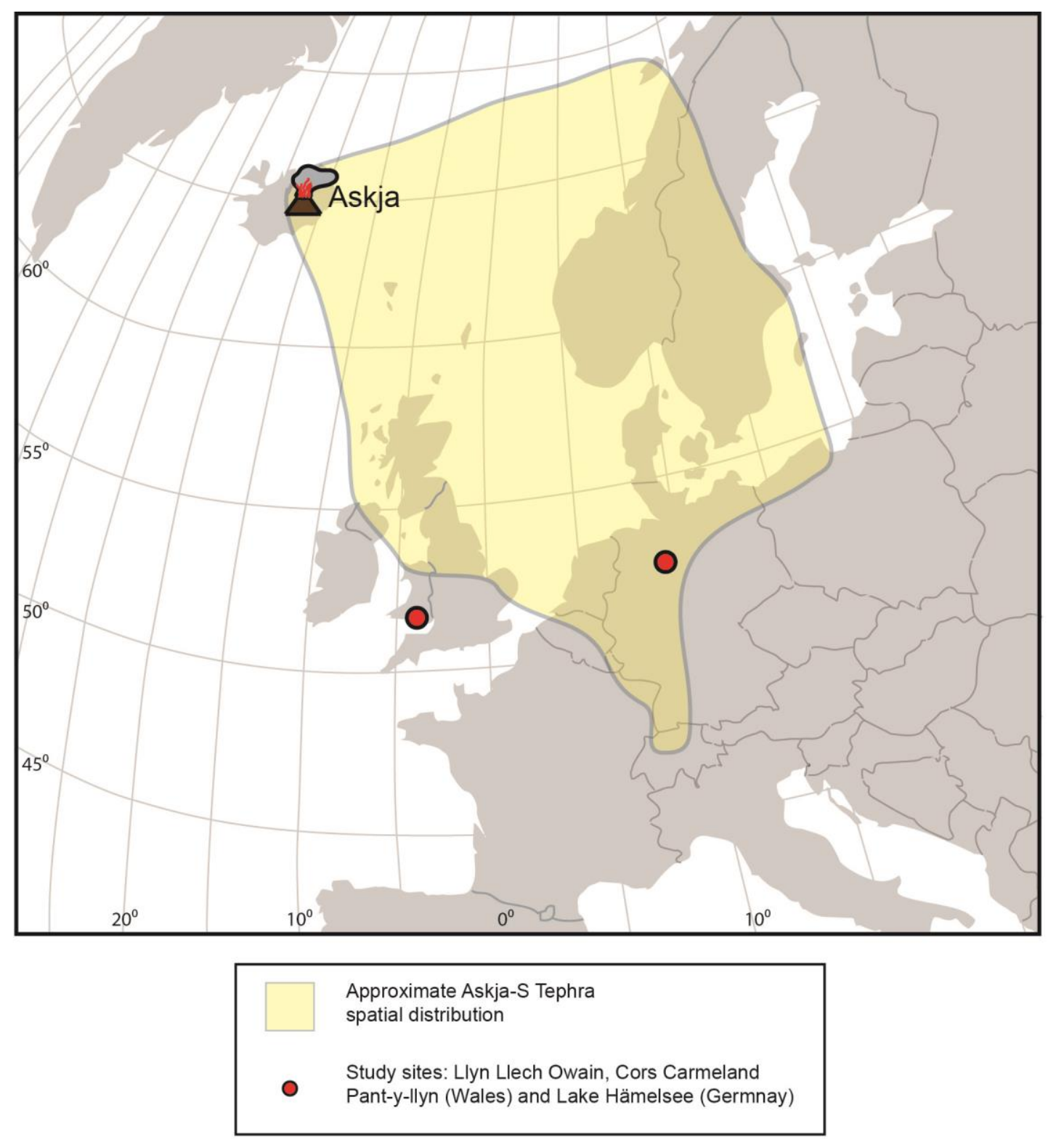

Figure 2.9 - Map showing the approximate spatial distribution of the Askja-S Tephra (modified from Wulf et al., 2016). 
are also found in some of the PT deposits within some Scottish sites (Pyne O'Donnell et al., 2008). The PT is associated stratigraphically with the midInterstadial or GI-1C and its current best age estimate is 13,939 \pm 66 cal BP (Bronk Ramsey et al., 2015). In addition to Scottish sites, the BT has also been discovered in two Swedish sites from Hässeldala port and Skallahult (Davies et al., 2003). In both sites only one tephra layer is present and due to the BT and PT having indistinguishable geochemistry, correlation to either is reliant on a secure stratigraphic correlation to the early part of the Lateglacial Interstadial (BT) or to the mid-interstadial (PT). More recently Timms et al., (2016) identified two more cryptotephra deposits, of the same composition as the BT and PT deposits, within a sediment record from Orkney (Scotland), which lie in the latter part of the interstadial. When only one tephra deposit of BT chemistry is identified in the Interstadial part of a record, the two deposits identified by Timms et al., (2016) offer additional possible correlations. If a secure stratigraphic framework is not in place then a correlation to any of the BT-type tephras would be difficult to achieve.

A feature of the BT in some sites is the wide stratigraphical spread of shards up and down the core profile, occupying a sizable portion of the early interstadial, instead of a distinct peak. This makes pinpointing the first ash deposition or isochron position misleading. Some sites also contain, more than one peak within the BT diffuse distribution which may suggest more than one eruption spaced closely in time. The diffuse distribution of the BT is best shown in Loch an t'Suidhe and Borrobol with the PT also showing similar features in Abernethy Forest (Figure 2.10). The indication of two closely spaced peaks in shards is also exhibited in the Loch an t'Suidhe and Loch Etteridge record (Albert, 2007). Three peaks are evident in the Tynaspirit West record (Figure 2.10), however only the BT and PT, albeit with their diffuse distribution, are suggested to be present by Pyne O'Donnell, (2007). A suggested reason proposed by Pyne O'Donnell et al., (2008) for the diffused BT shard distribution is the harsh climatic regime during the termination of the Glacial period and the following ice retreat causing poor vegetation cover and unstable catchment slopes with loose material available for reworking to take place. Another alternative hypothesis is that the BT may 

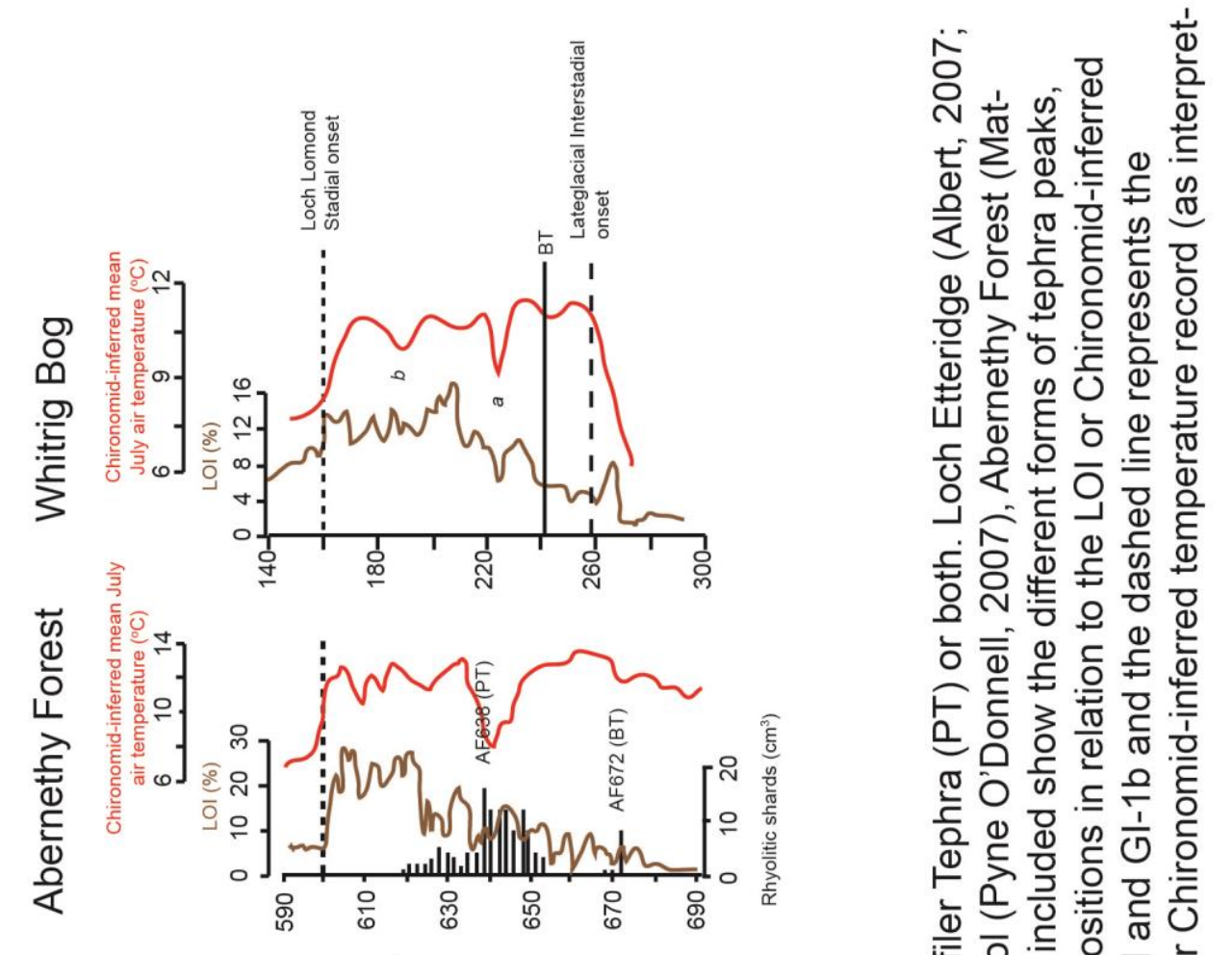

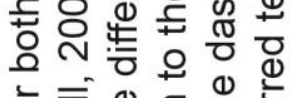

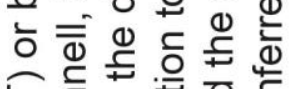

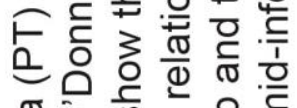

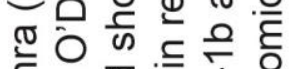

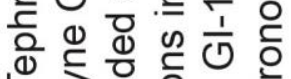

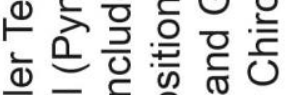
䢣

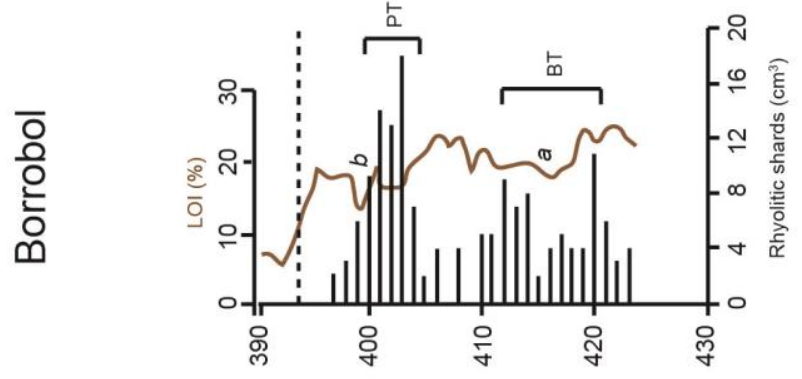

্ֻয
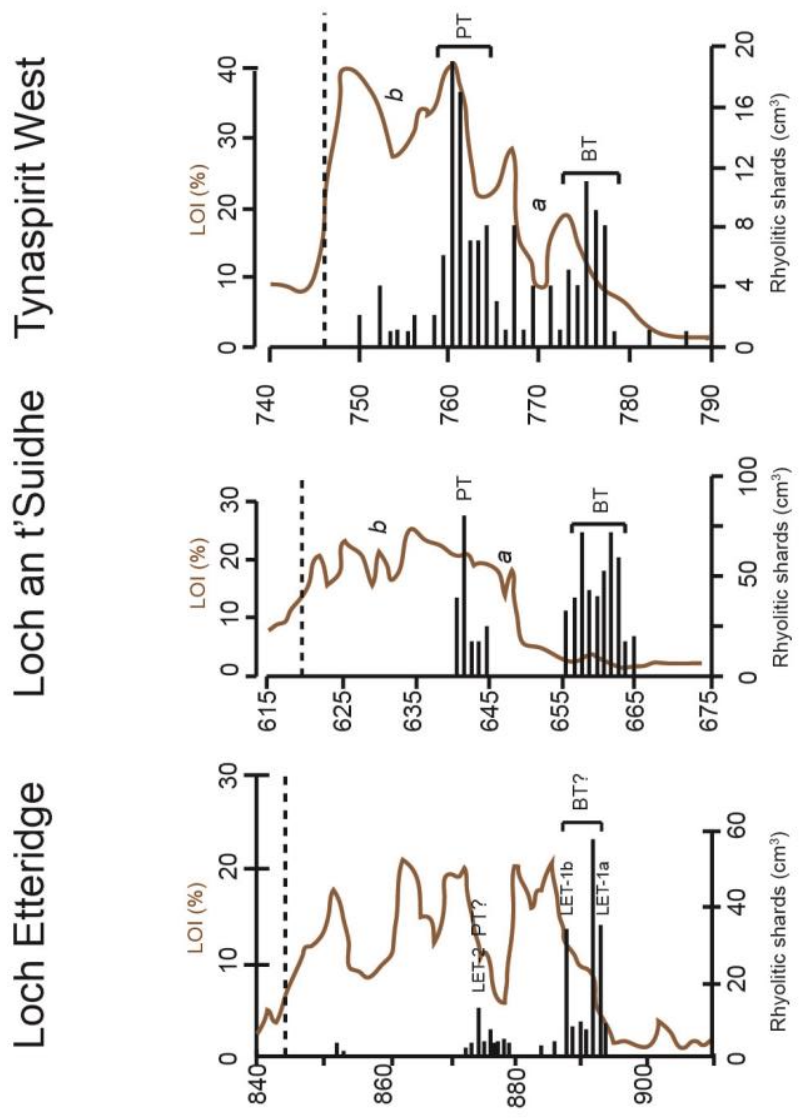

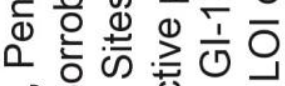

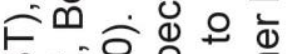

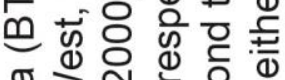
진

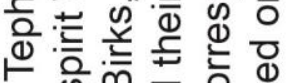

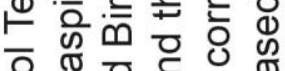

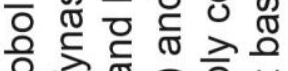

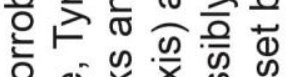
๑ ๗. 을 음 든 गั

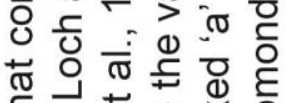
F 凹 क유는

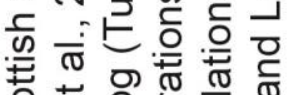
苞苗 ऽ व

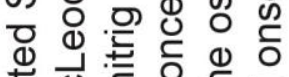

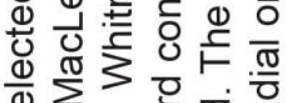

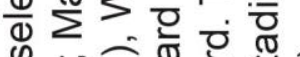
क क유유 ๙

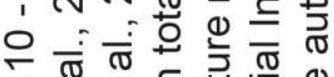

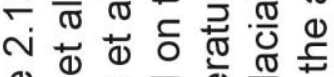

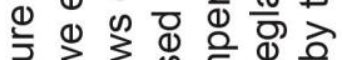

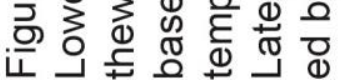


be a product of two eruptions, which is especially evident in the Loch Etteridge and lake Borrobol records (Pyne O'Donnell et al., 2008).

The assigned BT at Loch an t'Suidhe is noticeably positioned stratigraphically before the rise in LOI values (Pyne O'Donnell, 2007), with the first occurrence of tephra shards positioned at $663 \mathrm{~cm}$ and the rise in LOI values at $649 \mathrm{~cm}$. Based on LOI, this position is thought to represent the Glacial period and not the early Lateglacial Interstadial where the BT is typically found in other sites. However, Pyne O'Donnell, (2007) note that the stratigraphic position of the BT at Loch an t'Suidhe does not reflect another or previously unrecorded tephra. They suggest that the LOI stratigraphy is inconsistent with other sequences and that organic matter accumulation at Loch an t'Suidhe lagged behind other sites. Additionally, Walker and Lowe, (in press) discuss that underpinning the Lateglacial Interstadial onset or the onset of lake sedimentation is problematic due to the sediments being mostly devoid of climatic proxies such as pollen, diatoms or chironomids. Therefore, establishing the stratigraphical position for the Lateglacial Interstadial temperature rise is difficult based on LOI data alone. With the possible reasons noted above in mind however, the discovery of a tephra layer of similar geochemistry to the BT in the stratigraphical unit prior to the LOI rise in Loch an t'Suidhe, does suggest the possibility of an older tephra layer that erupted before the BT. Another tephra layer with a BT-type chemistry has been reported in a marine core on the North Icelandic shelf stratigraphically positioned in the Glacial period and named the KOL-GS-2 tephra (Eiríksson et al., 2000). An age estimate of $16.49-16.65 \mathrm{cal}$ ka BP is assigned to the KOL-GS-2 tephra which could potentially be linked with the BT found in Loch an t'Suidhe. A further BT-type deposit is also present in the Greenland icecores stratigraphically positioned during GS-2 and dated to $17,326 \pm 319$ b2k (Cook, 2015).

Although these tephra layers of BT signature are established to have originated from Iceland based on trace element data (Lind et al., 2016), the volcanic provenance is still unclear, where previous studies have suggested Snæfellsjökull (Davies et al., 2003), Öræfajökull (Lind et al., 2013), Torfajökull (Davies et al., 2004) and also Hekla (Lind et al., 2013). Holocene 
tephras of BT signatures have also been discovered in NW European sites (e.g. Pilcher et al., 2005; Lind \& Wastegård 2011). 


\section{Methodology}

Four sites are investigated in this study. The field and laboratory methods employed for each site are outlined in Figure 3.1.

\subsection{Field sampling}

\subsubsection{Site selection}

\section{Lake Hämelsee}

Lake Hämelsee in northern Germany was selected for this study due to its potential to develop a tephra framework for the Lateglacial period (Figure 3.2). Visible tephra deposits have previously been identified in this record, including the 10.3 ka BP Icelandic Saksunarvatn Ash and the 12.9 ka BP Laacher See Tephra, from the Eifel region of Germany (Merkt et al., 1993; Merkt \& Müller, 1999). This partially-varved sequence, however, has never been explored in terms of its cryptotephra record and its location in central Europe is ideal as a repository for tephras originating from multiple volcanic centres. This potential is highlighted by discoveries of tephras originating from Italian, Icelandic and Eifel volcanic sources in the Meerfelder Maar sediments, $350 \mathrm{~km}$ to the southwest of Hämelsee (Lane et al., 2015). Access to samples from this site was secured via my participation at the INTIMATE Example research training school. Cores were retrieved from Lake Hämelsee during the training school with the aim of constructing a detailed Lateglacial palaeoclimate record, using both traditional and state-ofthe-art dating methods and proxy techniques. My contribution to this multiproxy investigation was a detailed investigation of the cryptotephra deposits preserved within this record. 


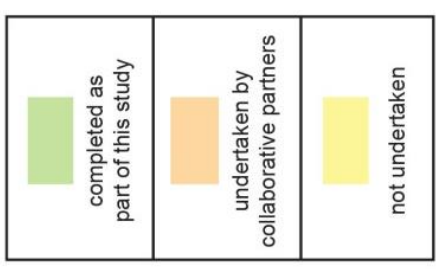

\begin{tabular}{|c|c|c|c|c|c|c|c|}
\hline 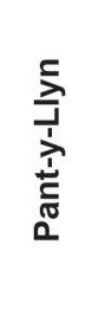 & 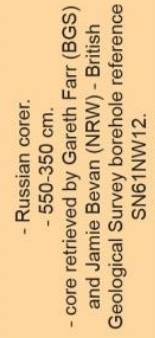 & 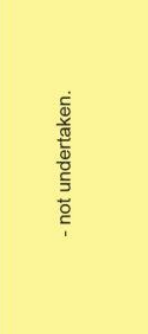 & 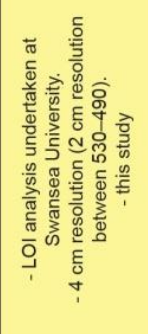 & 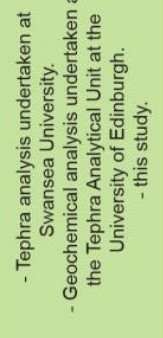 & 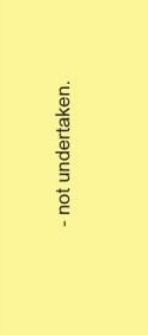 & 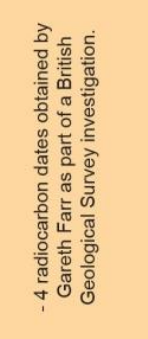 & 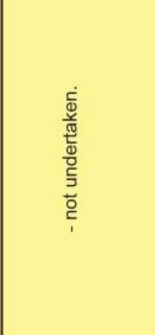 \\
\hline 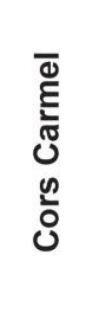 & 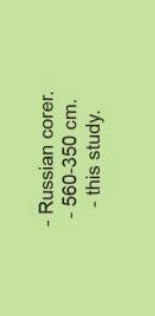 & 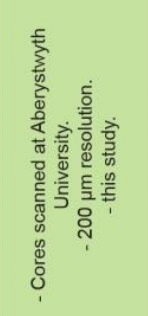 & 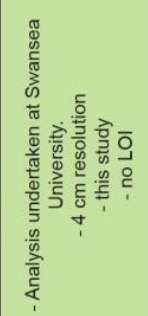 & 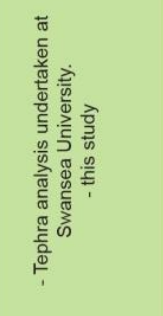 & 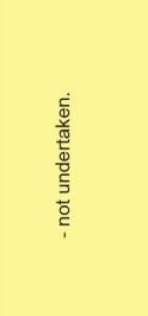 & 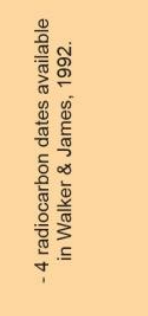 & 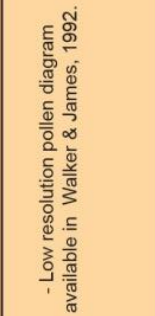 \\
\hline 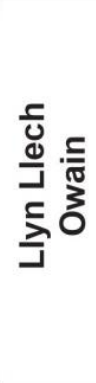 & 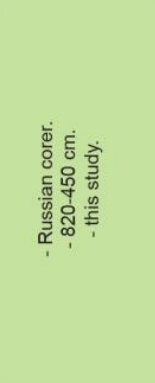 & 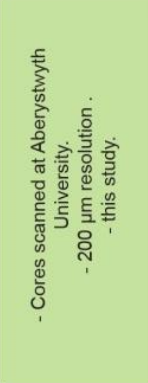 & 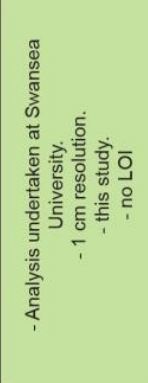 & 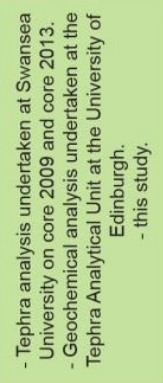 & 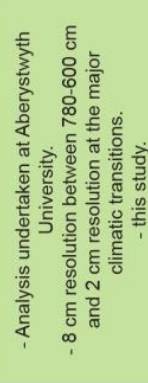 & 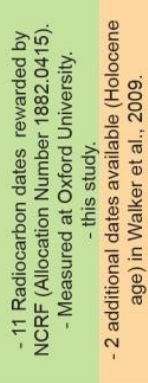 & 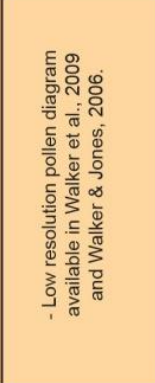 \\
\hline & 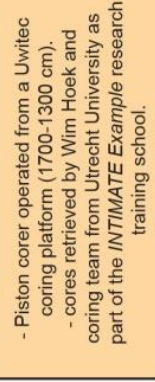 & 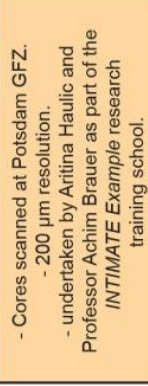 & 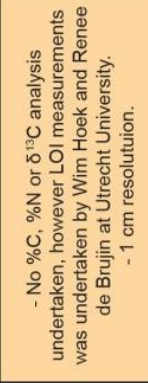 & 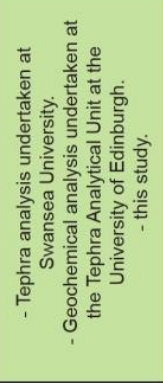 & 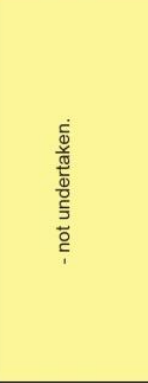 & 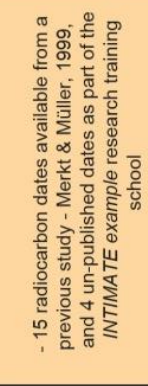 & 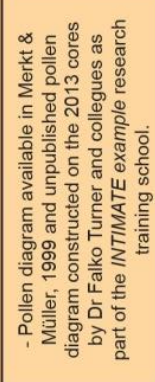 \\
\hline & 흥 $\frac{\text { 은 }}{\frac{5}{2}}$ & 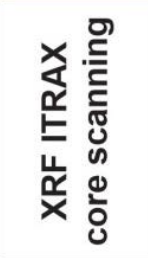 & 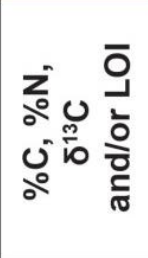 & $\frac{\pi}{\frac{\pi}{2}}$ & $\frac{\varepsilon}{\frac{n}{\omega}}$ & 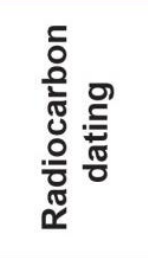 & $\frac{\text { ळ }}{\overline{\bar{O}}}$ \\
\hline
\end{tabular}

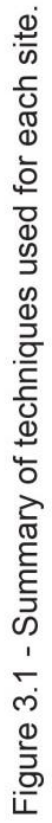




\section{$\underline{\text { Sites in Wales }}$}

Three sites in Wales were selected as part of this investigation, Llyn Llech Owain, Cors Carmel and Pant-y-Llyn (Figure 3.2). Very few Lateglacial sequences are preserved and studied in Wales, and even fewer have showed or attempted to show the presence of tephra shards within its sediments. These three sites were selected for their partial-full record of Lateglacial changes and their geographic proximity to the Atlantic Ocean where climatic changes associated with changes in ocean circulation are potentially recorded in the sedimentary records (Nesje et al., 2004). With the exception of a recent study by Watson et al., (2017), there have been traces of potential cryptotephra deposits identified in sites in the Brecon Beacons and mid-Wales but these findings have not been supported by geochemical characterisation of the shards (Williams, 2001; Williams et al., 2007; Buckley and Walker, 2002). Exploring the potential of employing cryptotephras in Wales during the Lateglacial is a key focus of this thesis. Preliminary investigations by Mike Walker and colleagues (Walker and James, 1992; Walker and Jones, 2006; Walker et al., 2009) have demonstrated that the sequences from Llyn Llech Owain and Cors Carmel span the full Lateglacial period. The investigations of these sites, however, largely focused on the Holocene and included low-resolution pollen analysis and a small number of radiocarbon dates. These discoveries highlight the potential value of the sites as two of the few Lateglacial sequences preserved in the west of the British Isles.

Pant-y-Llyn is a turlough, and is the only known turlough in Britain (Campbell et al., 1992), although they are common in the Republic of Ireland (Naughton et al., 2012). Turloughs are ephemeral water bodies associated with topographic depressions in karst and are periodically inundated mainly by groundwater, but also runoff, during the course of a year. Turloughs do not have a true inflow or outflow stream, and both fill and empty either diffusely across their base or via estavelles, a type of sink hole (Tynan et al., 2007). Sediments from turloughs are rich in calcium carbonate (Coxon and Coxon, 1994) and an investigation of their infill can provide insight into the development and formation of these rare features. Cores were retrieved from 

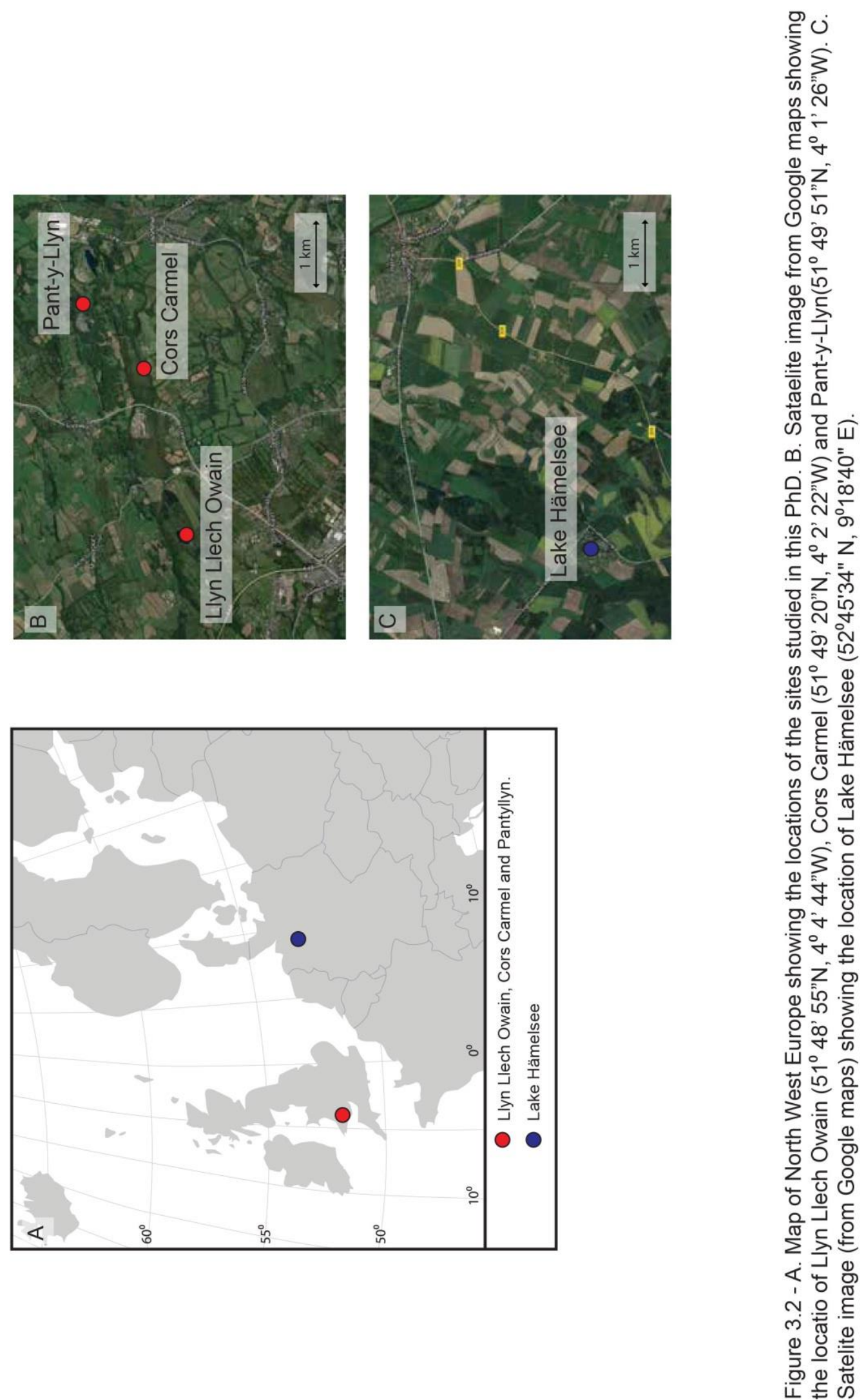
Pant-y-Llyn by Gareth Farr (BGS) and Jamie Bevan (NRW) as part of a palaeohydrology investigation of the site. Four radiocarbon dates were obtained from the sequence. Although a full Lateglacial sequence was not obtained at Pant-y-Llyn, the basal clay unit is thought to represent the Loch Lomond Stadial (Jones et al., 2017). Pant-y-Llyn is also geographically located close to Llyn Llech Owain and Cors Carmel providing an opportunity to investigate differences in the tephra deposition between each site.

\subsubsection{Field sampling}

A Russian corer ( $1 \mathrm{~m}$ long and $5 \mathrm{~cm}$ diameter) was used to recover the cores from Llyn Llech Owain, Cors Carmel and Pant-y-Llyn. Two adjacent holes were used to retrieve $10 \mathrm{~cm}$ overlapping sections for each sequence. Core positions were closely spaced (within $50 \mathrm{~cm}$ ) where the surface elevation was constant. No overlaps were retrieved for the Pant-y-Llyn sequence (coring undertaken by Gareth Farr and Jamie Bevan from the British Geological Survey (BGS) and Natural Resources Wales (NRW) - borehole reference SN61NW12). A piston corer mounted onto an Uwitec coring platform was used to retrieve cores from Lake Hämelsee which was operated by Wim Hoek and the coring team from Utrecht University as part of the INTIMATE example research training school.

To avoid any contamination, the coring equipment at each site was cleaned with water and blue roll paper after retrieving each core. The retrieved cores were transferred into plastic drain pipes, labelled with the site identifying code, depths and arrow for the direction to top of core. Each core was wrapped in plastic film and sealed with duck-tape. All cores were then stored horizontally in a cold room at $<4^{0} \mathrm{C}$. 


\subsection{Laboratory analysis}

Brief descriptions of the cores were undertaken in the field but cores were examined in more detail in the laboratory. Descriptions included sediment type, colour, humification and whether biological components were present. The sub-sampling strategy varied by site however a schematic diagram for the Llyn Llech Owain cores is summarized in Figure 3.3. A sampling strategy for the Cors Carmel cores was not necessary because of less proxies being implemented for that site. For the Pant-y-Llyn and Lake Hämelsee records, the sediment cores were stored elsewhere (BGS and Utrecht University), therefore sample requests were made to the sampling coordinators.

Discussions took place for each site with regards to how much sediment was needed for the tephra work to ensure sample availability. A summary for the techniques implemented for all sites is outlined in Figure 3.1.

\subsection{Sediment geochemistry}

\subsubsection{XRF (X-ray Fluorescence) ITRAX Core Scanning}

Cores from Llyn Llech Owain and Cors Carmel were scanned using the ITRAX core scanning facility at Aberystwyth University in January 2014 and November 2015 respectively. Lake Hämelsee cores were scanned using the same ITRAX system at Potsdam GFZ by Aritina Haulic and Achim Brauer as part of the INTIMATE example research training school project.

The ITRAX core scanner produces a fast, non-destructive, micro-XRF analysis of elemental geo-chemistry ranging from Aluminium to Uranium. The core scanner at Aberystwyth has a Si-drift detector, 3kW X-ray generator with a $3 \mathrm{~kW}$ molybdenum target tube, where the $\mathrm{X}$-rays are emitted through the tube turret focused by a proprietary flat-beam optical device. The ITRAX 


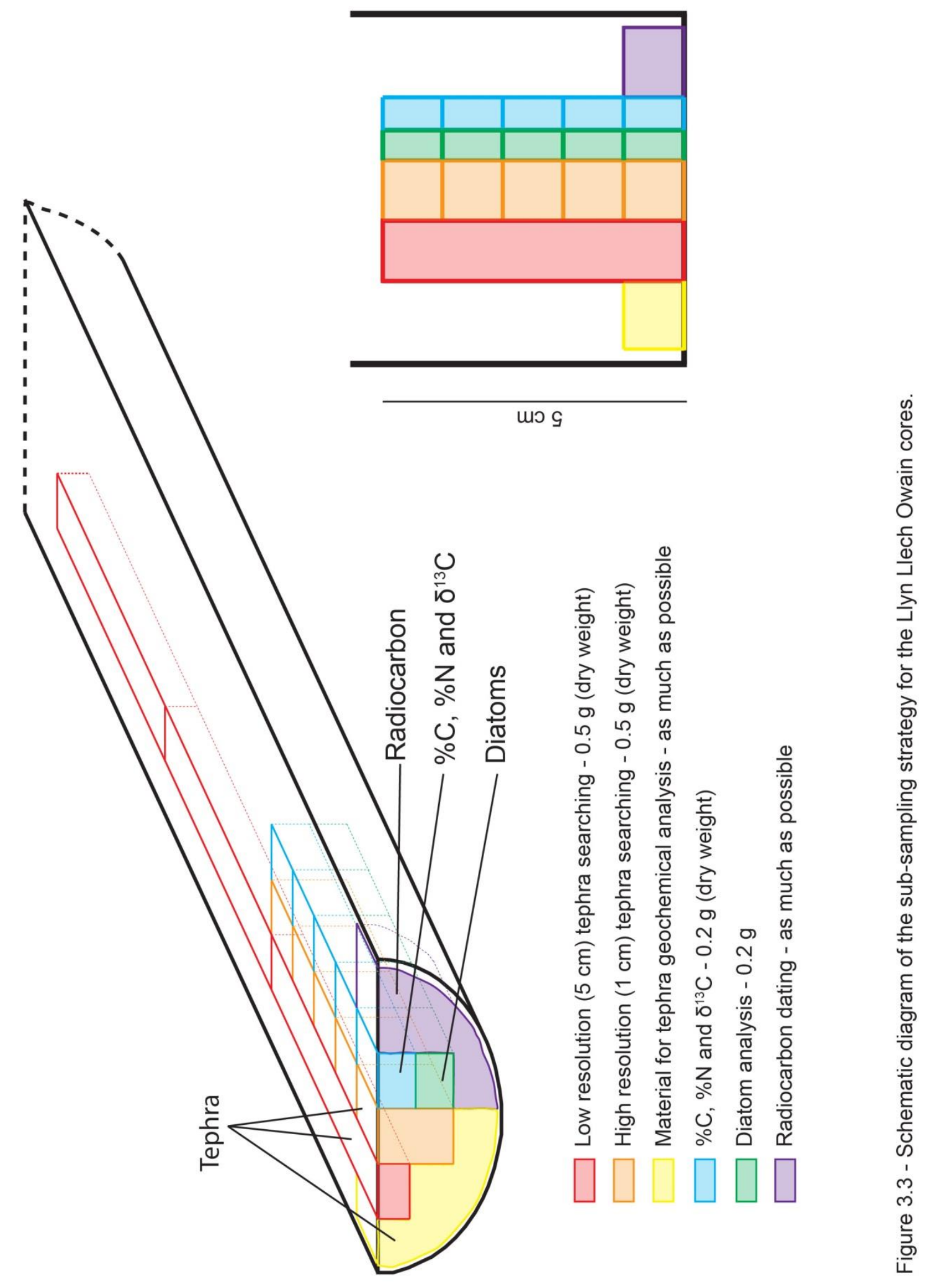


system was operated following the standard protocol methodology outlined in Croudace et al., (2006). Advanced technical information on the ITRAX system can also be found in Croudace et al., (2006). Prior to analysis, the cores were cleaned perpendicular to the core length to expose a fresh surface, free of any contamination. The prepared cores were placed on the core holder with the core top positioned on the right hand side of the instrument, being measured first (Figure 3.4). The core position coordinates were inserted into the Core Scanner Navigator program in addition to the excitation voltage and X-ray tube current. An initial scan was undertaken of the core surface to confirm no physical contact between the detector and the core. Using the Q-Spec program, elements were chosen for detection and by analysis of a representative part of the core sediment, the element peak area fitting parameters were attuned and improved. The X-ray voltage was set to $60 \mathrm{kv}$, with a current of $50 \mathrm{ma}$ and an exposure time of 100 milliseconds. The XRF voltage was set to $30 \mathrm{kv}$, with a current of $50 \mathrm{ma}$ and an exposure time of 10 seconds. A sampling resolution of $200 \mu \mathrm{m}$ was achieved for all cores. After scanning the cores, an assessment of the Argon and kcps (kilocounts per second) values were made along the sequence to assess any problems with the core surfaces. Argon (from irradiation of air) and kcps should be relatively constant throughout the sequence if the scanning analysis was good with no undulations in the core. Any distinct variations reflect surface disturbances which need to be accounted for prior to interpreting the data. The cores were retrieved using the two hole overlapping method thus allowing XRF data from the top and bottom $5 \mathrm{~cm}$ of each core to be discarded accounting for the noise at the core ends.

\subsubsection{Sediment chemistry $\left(\% \mathrm{C}, \% \mathrm{~N}\right.$ and $\left.\delta^{13} \mathrm{C}\right)$}

Sub-samples of approximately $0.3 \mathrm{~g}$ of bulk wet sediment were retrieved from the cores at $1 \mathrm{~cm}$ resolution for the Llyn Llech Owain record and $4 \mathrm{~cm}$ for the Cors Carmel record and subsequently freeze dried at $-48^{\circ} \mathrm{C}$ for 48 hours. Samples were lightly crushed and homogenised by shaking the sample tube 

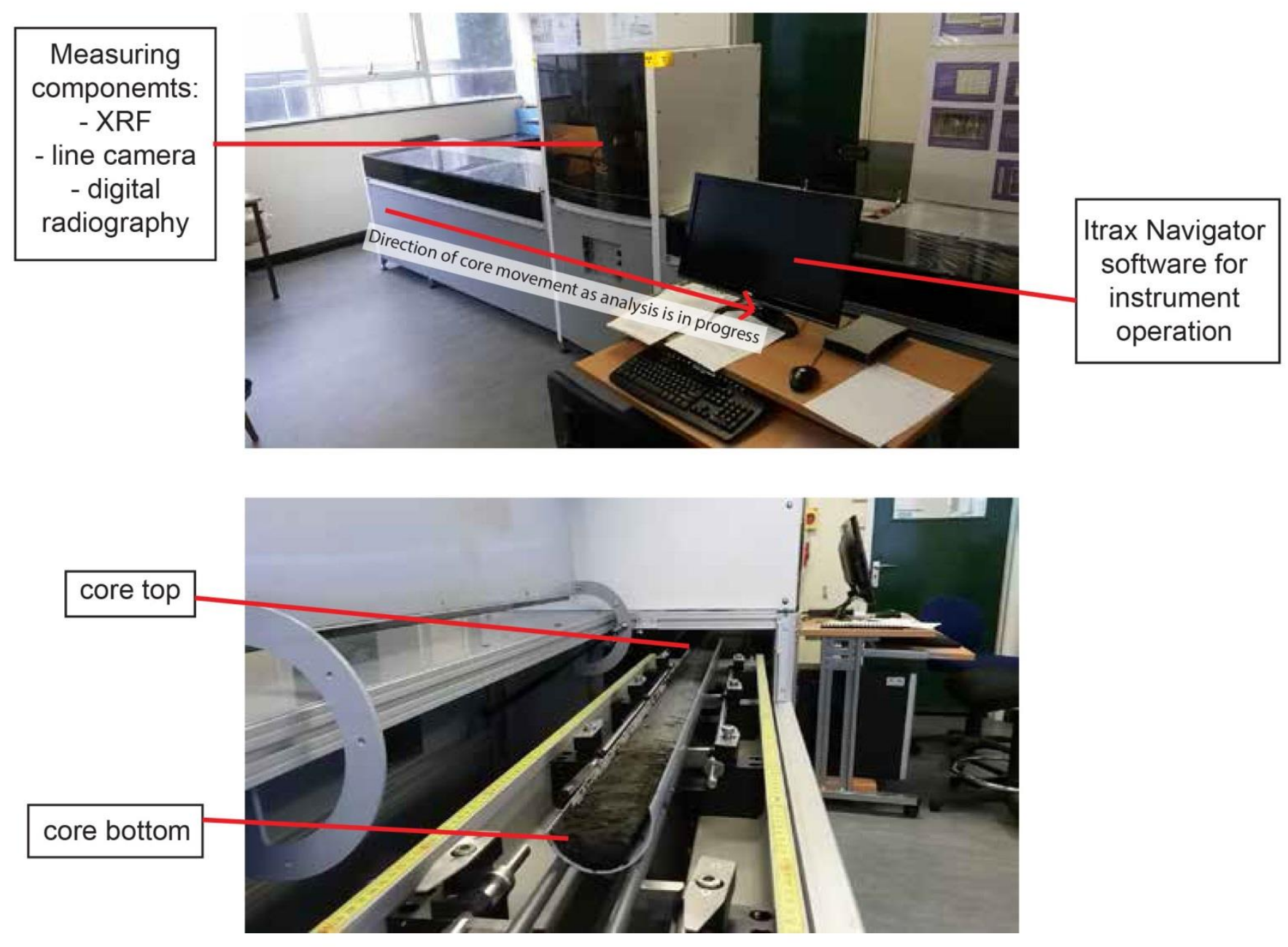

Figure 3.4 - Photographs of the ITRAX core scanner at Aberystwyth University. 
prior to weighing. Samples were weighed within a range of $0.30-0.35 \mathrm{mg}$ for the organic peat samples and $5.00-6.00 \mathrm{mg}$ for the clay-rich samples. These weights enabled a more consistent beam area during combustion of the samples. By maintaining the beam area for $\mathrm{CO}_{2}$ between c. $2 \mathrm{E}-7 \mathrm{~mA}$ and $4 \mathrm{E}-$ $7 \mathrm{~mA}$, equivalent to between 100 and 200 micrograms of carbon, the resulting carbon isotope value could be determined with reduced sample-size effects. Some samples were repeated for isotopic analysis with amended weights to achieve the required beam area. Samples were weighed into tin (Sn) capsules, crimped closed, prior to elemental and isotopic analysis.

Acid treatment was not necessary for Llyn Llech Owain and Cors Carmel due to the absence of carbonates throughout the sediment sequences. The local bedrock for Llyn Llech Owain and Cors Carmel is 'Twrch Sandstone formation' that typically have minimal or no carbonate content. Furthermore, no chemical reaction was ever observed after adding $\mathrm{HCl}(10 \%)$ to the samples being investigated for tephra, indicating the absence of carbonate in the sediment. However, test analyses were undertaken on samples representing all sediment types along the Llyn Llech Owain core sequence (i.e. peat, early Holocene muds, YD clay, interstadial mud and glacial clay) to quantifiably evaluate whether carbonates were present (see section 5.3).

Carbon and Nitrogen content and $\delta^{13} \mathrm{C}$ values were measured online using a PDZ-Europa ANCA GSL Elemental Analyser interfaced to a 20/20 isotope ratio mass spectrometer. Sample names and weights were initially entered into the computer system and samples were then placed in order in a carousel for measurement by the elemental analyser. Analysis was automated with samples dropped into a furnace through a constant flow of helium, which promotes an abrupt and full combustion. The oxygen and water leftover, following combustion at $1000^{\circ} \mathrm{C}$, was removed through passing a copper filter, allowing the remaining $\mathrm{CO}_{2}$ and $\mathrm{N}_{2}$ to pass through the system. The computer software captures the measurement from the sample and assesses the information, producing the \%C and \% $\mathrm{N}$ data. The $\mathrm{CO}_{2}$ and $\mathrm{N}_{2}$ are then carried to the mass spectrometer for the $\delta^{13} \mathrm{C}$ isotope values to be measured. 
Acetanilide standards were measured to examine the accuracy of the instrument and precision of the analysed samples (Table 3.1). In addition, 'blank' samples (i.e. empty tin capsules) were analysed during each run to assess the instrument performance. Drift correction was applied through the computer software if standards were offset to the reference acetanilide samples.

Table 3.1 - Summary of the acetanilide standards analysed during the analysis of Carbon, Nitrogen and $\delta^{13} \mathrm{C}$ using a PDZ-Europa ANCA GSL Elemental Analyser.

\begin{tabular}{|c|c|c|c|}
\hline & $\% \mathrm{~N}$ & $\% \mathrm{C}$ & $\delta^{13} \mathrm{C} \%$ \\
\hline Recommended values & 10.36 & 71.09 & -30.42 \\
\hline average $(n=98)$ & 10.39 & 71.21 & -30.43 \\
\hline stdev & 0.27 & 0.95 & 0.12 \\
\hline
\end{tabular}




\subsubsection{Loss on Ignition (LOI)}

Loss on Ignition was employed for the Pant-y-Llyn samples only, at a 4-cm resolution between $550-530 \mathrm{~cm}$ and $490-300 \mathrm{~cm}$ and at a $2-\mathrm{cm}$ resolution between $530-490 \mathrm{~cm}$ spanning the transition from the basal unit of reddish silty clay and organic lake mud unit. The standard protocol of Heiri et al., (2001) was followed with freeze dried $1 \mathrm{~cm}^{3}$ samples initially weighed and then placed in a furnace at $550^{\circ} \mathrm{C}$ for $2 \mathrm{~h}$ to determine the organic matter loss by weight percent. This was followed by a further $2 \mathrm{~h}$ at $1000^{\circ} \mathrm{C}$ to determine the calcium carbonate $\left(\mathrm{CaCO}_{3}\right)$ loss by weight percent. Organic matter is oxidized to carbon dioxide and ash at temperatures between $200-550^{\circ} \mathrm{C}$ and a further evolution of carbon dioxide from carbonate minerals at temperatures between $700-1000^{\circ} \mathrm{C}$ allowing the estimated loss by weight percent to be calculated.

\subsection{Tephrochronology}

\subsubsection{Extraction of tephra shards}

Tephra analysis was initially undertaken at a low-resolution. Sediment cores were sampled contiguously in $5-\mathrm{cm}$ segments (Figure 3.3). Samples were freeze-dried and homogenised by shaking the sample bag rigorously. A starting weight of $0.5 \mathrm{~g} \mathrm{dw}$ (dry weight) was used for each low-resolution sample. Each sample was ashed in the furnace at $550^{\circ} \mathrm{C}$ for at least 2 hours to remove any organic material. The sample residues were then treated with $6 \mathrm{ml}$ of $10 \% \mathrm{HCl}$ (Hydrochloric acid) to eliminate any carbonates. Even though no carbonates were present in the Llyn Llech Owain and Cors Carmel sediments, this procedure was a quick and easy step that also acted to soften and disperse the samples prior to sieving. Carbonates were present in the Pant-y-Llyn and Lake Hämelsee sediments, thus HCL treatment was 
essential. Samples were left in $\mathrm{HCl}$ for at least 2 hours or until any chemical reaction had ceased. For the clay-rich samples, $6 \mathrm{ml}$ of $10 \% \mathrm{NaOH}$ (Sodium Hydroxide) solution was added as a dispersant to disintegrate the clay sediment for easier sieving. The $\mathrm{NaOH}$ solution was added to the sample at room temperature for less than one hour. Each sample was centrifuged using deionised water to clean the samples before and after the $\mathrm{NaOH}$ treatment.

The samples were then wet sieved at 80 and $25 \mu \mathrm{m}$ and a density separation was employed following the methodology outlined by Turney, (1998) and Blockley et al., (2005). A density float of $2.3 \mathrm{~g} \mathrm{~cm}^{3}$ was used initially to remove less dense material such as diatoms. The second float of $2.5 \mathrm{~g} \mathrm{~cm}^{3}$ was used to isolate the rhyolitic shards as they typically have a density of 2.3-2.5 $\mathrm{g} \mathrm{cm}^{3}$. If present, basaltic tephra shards would be found within the heavier density fraction $\left(>2.5 \mathrm{~g} \mathrm{~cm}^{3}\right)$ together with the heavy minerogenic particles. A magnetic separation technique was employed to isolate basaltic tephra particles from heavy minerals in the $>2.5 \mathrm{~g} \mathrm{~cm}^{3}$ density fraction (Mackie et al., 2002). A Frantz IsoDynamic Magnetic separator was used with the following settings: current of $0.85 \mathrm{nA}$, tilt of $-15^{\circ}$ and a slope of $22.5^{\circ}$ (Griggs, 2016). The $>2.5 \mathrm{~g} \mathrm{~cm}^{3}$ density fraction was only searched if brown shards were encountered in the $2.3-2.5 \mathrm{~g} \mathrm{~cm}^{3}$ fraction. The $2.3-2.5 \mathrm{~g} \mathrm{~cm}^{3}$ and the selected ferromagnetic $>2.5 \mathrm{~g} \mathrm{~cm}^{3}$ density fractions was then mounted onto microscope slides using Canada Balsam.

Where distinct peaks in shard concentrations were revealed (i.e. higher concentrations compared to the background), $1 \mathrm{~cm}$ sub-samples were resampled from the core to determine the position of the tephra deposit to the nearest $1 \mathrm{~cm}$, following the same methodology outlined above.

A light-powered, polarizing, microscope (Olympus CX41) was used to identify and count the tephra shard concentrations and quantify the number of shards per $0.5 \mathrm{~g} \mathrm{dw}$ of sediment. Isotropism, particle morphology and Becke line characteristics were the main criteria used to identify tephra shards. 


\subsubsection{Geochemical analysis}

Sediment samples that revealed peaks in shard concentration were reprepared for geochemical analysis. With the exception of the ashing step, samples were processed following the same methodology as outlined above. High heat is known to alter the chemical composition of the tephras through alkali mobilisation (Dugmore and Newton, 1992). Instead, the organic material was removed by sieving and density separation. Any coarse macrofossils were typically isolated by the $80 \mu \mathrm{m}$ sieve and the finer organic material would be floating in the $<2.3 \mathrm{~g} \mathrm{~cm}^{-3}$ fraction. For samples that contained a high organic content, it was necessary to undertake the density separation step more than once.

If the shard concentrations were low (e.g. $<50$ shards per $\mathrm{g} \mathrm{dw}$ ), the starting sediment volume was increased to as much as possible, whilst keeping in line with the sampling strategy, to optimise the extraction and isolation of sufficient tephra shards. For these samples, a gas-chromatography syringe mounted on a micro-manipulator was used to manually pick out individual tephra shards (Lane et al., 2014) (Figure 3.5). The processed samples were suspended in de-ionised water and a pipette was used to place an aliquot into a welled slide placed on the stand of an optical microscope. Particle shape and isotropism were the main features used to identify the tephra shards. The pink tint, which is a distinguished characteristic of rhyolitic shards mounted in Canada balsam, or epoxy resin, is less obvious when shards are suspended in water. The gas chromatography syringe was then used to manipulate the shards onto a frosted microscope slide $(28 \times 48 \mathrm{~mm})$, placed adjacent to the welled slide (Figure 3.5). Picking shards in this way is a time-intensive and meticulous process, but this ensures a pure tephra 


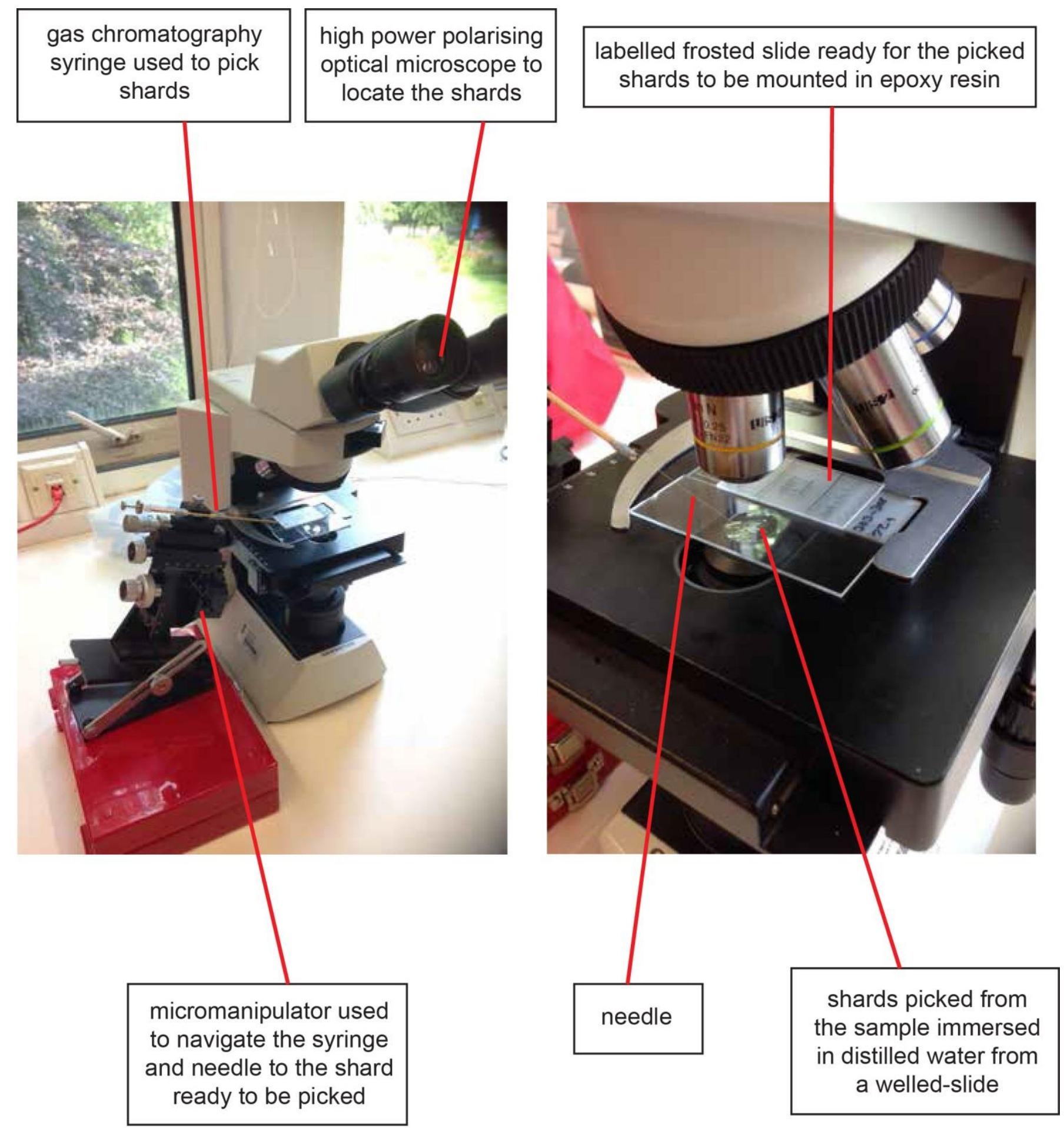

Figure 3.5 - Images of the set-up for manually picking shards using a gas chromatography syringe mounted on a micromanipulator. 
sample is obtained which increases the efficiency of the Electron-Probe Micro Analysis (EPMA) work. A map of each slide, with coordinates of shard locations, was recorded to aid in the relocation of tephra shards during geochemical analysis.

Slides were sectioned for geochemical analysis using decreasing grades of silicon carbide paper until an exposed horizontal shard surface was exposed. Care was taken to ensure an even surface topography for each slide. An uneven surface can cause problems during geochemical analysis e.g. scattering of $X$-rays which do not reach the detector, and limited electron absorption onto the tephra shard (Hall and Hayward, 2014). Sectioned slides were polished using an automated polisher using 9, 6 and $1 \mu \mathrm{m}$ diamond suspension and manually with a $0.3 \mu \mathrm{m}$ micro-polish.

Geochemical analysis was undertaken at the Tephra Analytical Unit at the University of Edinburgh using a Cameca SX100 Wavelength Dispersive Spectrometer Electron-Probe Micro Analysis (WDS EPMA), fitted with five vertical WD spectrometers. Ten major and minor elements were analysed: $\mathrm{Si}, \mathrm{Al}, \mathrm{Ti}, \mathrm{Fe}, \mathrm{Mn}, \mathrm{Mg}, \mathrm{Ca}, \mathrm{Na}, \mathrm{K}$ and $\mathrm{P}$ which are expressed as oxide percentages. As the $\mathrm{x}$-ray energy produced is distinct to each element and the intensity proportional to the concentration of the element present, the geochemical composition can be determined (Hunt and Hill, 1993). Slides were carbon coated prior to geochemical analysis. EPMA operating conditions are adapted from Hayward (2012) and vary by beam size and are as follows: $5 \mu \mathrm{m}$ beam diameter - Accelerating voltage: $15 \mathrm{kV}$ Beam Current: $2 \mathrm{nA}$ for $\mathrm{Na}, \mathrm{K}, \mathrm{Si}, \mathrm{Al}, \mathrm{Mg}, \mathrm{Fe}, \mathrm{Ca}$ and $80 \mathrm{nA}$ for Mn, Ti, P. $3 \mu \mathrm{m}$ beam diameter - Accelerating voltage: $15 \mathrm{kV}$ Beam Current: $0.5 \mathrm{nA}$ for $\mathrm{Na}, \mathrm{Al}, 2 \mathrm{nA}$ for K, Si, Mg, Fe, Ca and 60 nA for Mn, Ti, P. For further operating conditions see Hayward (2012). Internal calibration is undertaken daily using pure metals, simple silicate minerals and synthetic oxides, including andradite. Lipari and BCR $2 g$ secondary standards were analysed before, during and at the end of analytical sessions to examine the accuracy and precision of the instrument, precision of the tephra analyses and to allow comparison between the data from each analytical period (following Kuehn et al., 2011). Secondary standards are shown in Figure 3.6 and Table 3.2, in addition to 


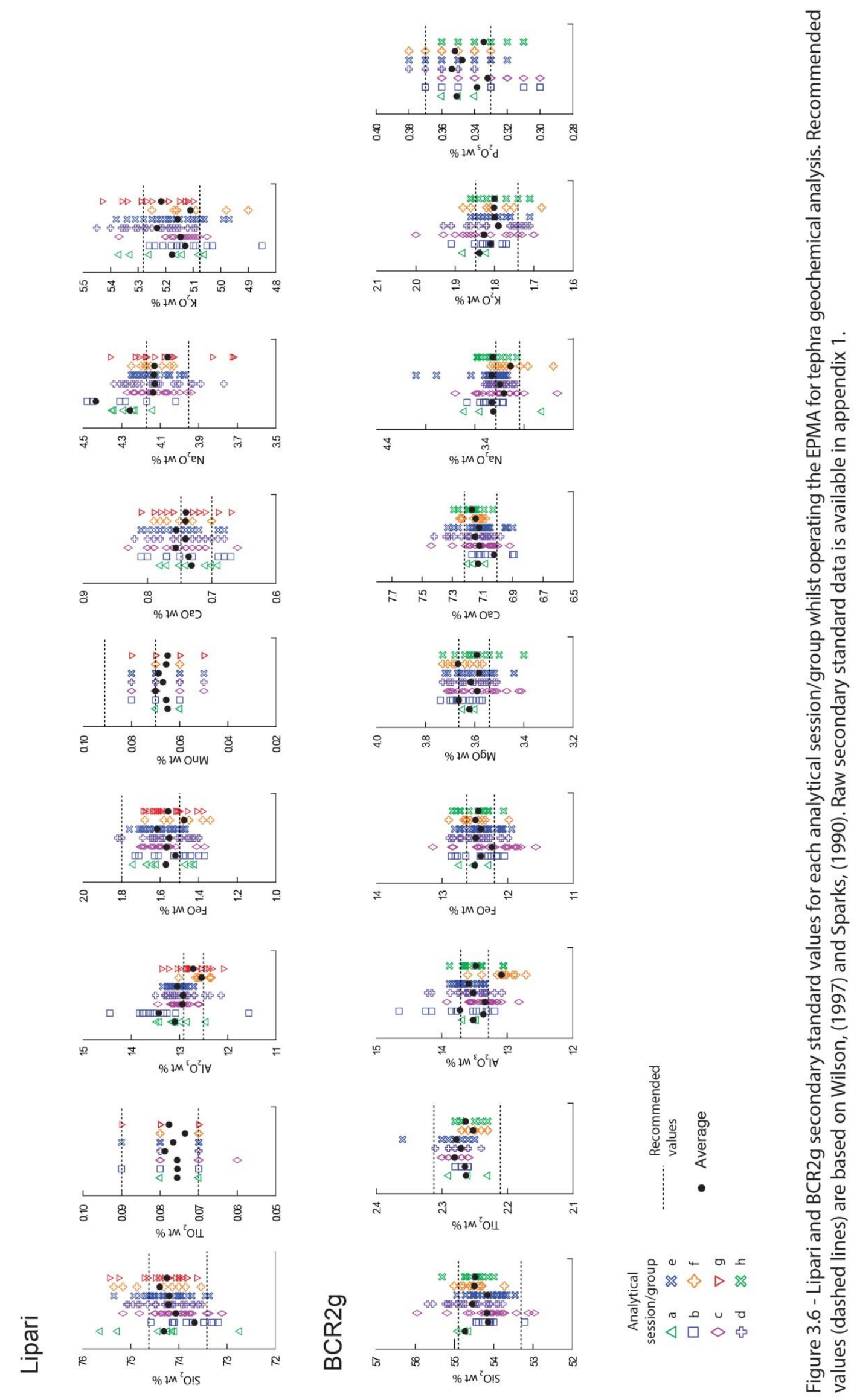




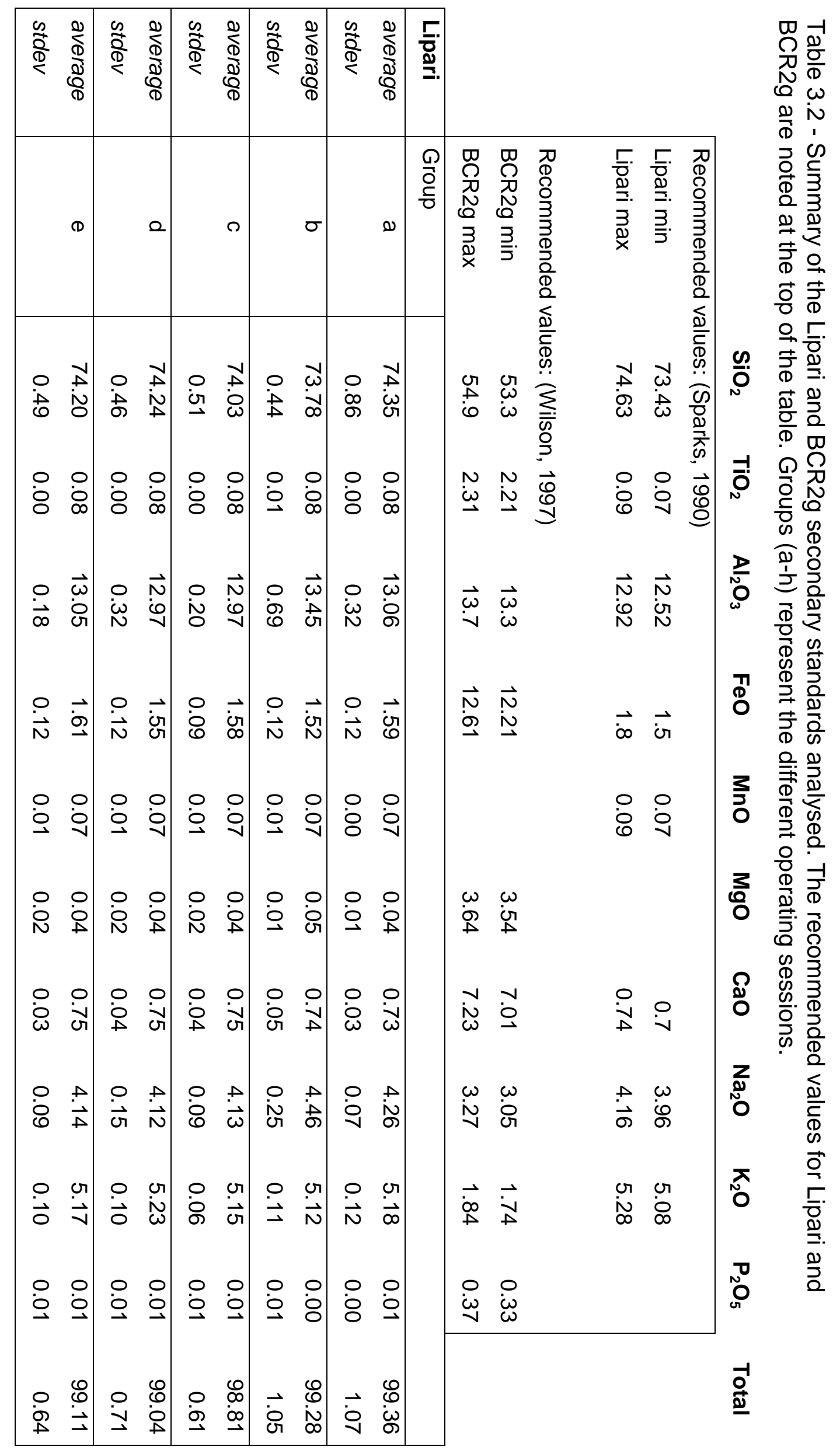




\begin{tabular}{|c|c|c|c|c|c|c|c|c|c|c|c|c|c|c|c|c|c|c|}
\hline$\frac{\stackrel{c}{d}}{\frac{D}{D}}$ & 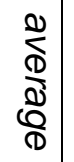 & $\underset{⿱}{\stackrel{D}{D}}$ & 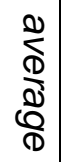 & $\underset{⿱}{\stackrel{\infty}{D}}$ & 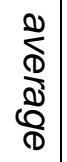 & $\frac{\frac{D}{d}}{\stackrel{D}{Q}}$ & 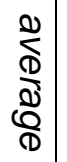 & 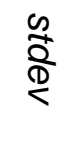 & 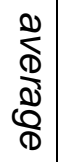 & 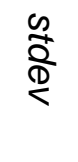 & 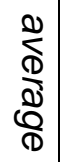 & $\frac{\mathscr{C}}{\frac{D}{\mathbb{Q}}}$ & 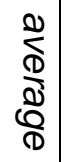 & $\mid \begin{array}{l}\boldsymbol{D} \\
\mathbf{\Omega} \\
\mathbf{N} \\
\mathbb{0}\end{array}$ & $\underset{\frac{c}{d}}{\frac{0}{d}}$ & 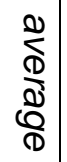 & $\frac{c}{\frac{c}{2}}$ & 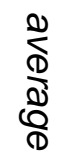 \\
\hline & $\tau$ & & $\rightarrow$ & & (D) & & e & & 0 & & $\sigma$ & & טم & $\mid \begin{array}{l}\Omega \\
\frac{\rho}{0} \\
\frac{\tau}{0}\end{array}$ & & 0 & & $\rightarrow$ \\
\hline $\begin{array}{l}\stackrel{\circ}{\omega} \\
+\infty\end{array}$ & 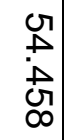 & $\stackrel{\circ}{\mathscr{\omega}_{\mathcal{G}}}$ & 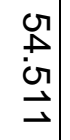 & $\begin{array}{l}\stackrel{0}{\text { N }} \\
\text { N }\end{array}$ & $\begin{array}{l}U \\
\stackrel{T}{\vec{A}} \\
\vec{A}\end{array}$ & 어 & $\begin{array}{l}0 \\
+ \\
9 \\
\text { a }\end{array}$ & $\begin{array}{l}\text { 영 } \\
\text { ه̀ }\end{array}$ & $\begin{array}{l}0 \\
\stackrel{\vec{\omega}}{\omega} \\
\vec{\omega}\end{array}$ & 임 & $\begin{array}{l}0 \\
\stackrel{+}{\vec{N}} \\
\vec{N}\end{array}$ & $\stackrel{\circ}{\vec{G}}$ & $\begin{array}{l}\text { ज. } \\
\stackrel{\text { on }}{\text { on }}\end{array}$ & & $\begin{array}{l}\circ \\
\stackrel{0}{*}\end{array}$ & 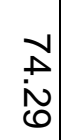 & $\begin{array}{l}\text { O } \\
\text { O }\end{array}$ & $\begin{array}{l}\stackrel{V}{+} \\
\dot{0}\end{array}$ \\
\hline $\begin{array}{l}\circ \\
\text { 움 } \\
\text { a }\end{array}$ & $\begin{array}{l}N \\
\tilde{N} \\
\mathbb{D}\end{array}$ & $\begin{array}{l}\circ \\
\stackrel{0}{0}\end{array}$ & $\begin{array}{l}N \\
N \\
\tilde{\omega}\end{array}$ & $\begin{array}{l}\text { O } \\
\text { ○े }\end{array}$ & $\begin{array}{l}N \\
N \\
\infty\end{array}$ & $\begin{array}{l}\circ \\
\text { 옴 }\end{array}$ & $\begin{array}{l}N \\
N \\
\infty\end{array}$ & 웅 & $\begin{array}{l}N \\
\mathbf{N} \\
\infty\end{array}$ & 웅 & $\begin{array}{l}N \\
\tilde{N}\end{array}$ & $\begin{array}{l}\text { ㅇ } \\
\text { ○े }\end{array}$ & $\begin{array}{l}N \\
\tilde{N}\end{array}$ & & $\begin{array}{l}\circ \\
ㅇ\end{array}$ & $\begin{array}{l}\circ \\
\dot{0} \\
\stackrel{0}{0}\end{array}$ & $\begin{array}{l}\circ \\
8\end{array}$ & 웅 \\
\hline $\begin{array}{l}\stackrel{0}{\text { N }} \\
\stackrel{+}{v}\end{array}$ & $\begin{array}{l}\vec{\omega} \\
\overrightarrow{0} \\
N\end{array}$ & $\begin{array}{l}0 \\
\text { UN } \\
\perp\end{array}$ & $\begin{array}{l}\vec{\omega} \\
\dot{0} \\
\vec{v}\end{array}$ & $\stackrel{\circ}{\stackrel{\circ}{\infty}}$ & $\begin{array}{l}\bar{\omega} \\
\dot{\phi}\end{array}$ & $\begin{array}{l}\text { O } \\
\text { N }\end{array}$ & $\begin{array}{l}\bar{\omega} \\
\dot{c} \\
\phi\end{array}$ & $\stackrel{\circ}{\stackrel{\circ}{A}}$ & $\begin{array}{l}\vec{\omega} \\
\dot{\omega} \\
\omega\end{array}$ & $\begin{array}{l}\stackrel{\circ}{+\infty} \\
\stackrel{\infty}{\infty}\end{array}$ & $\begin{array}{l}\vec{\omega} \\
\dot{v}\end{array}$ & $\stackrel{\circ}{\stackrel{0}{二}}$ & $\begin{array}{l}\bar{\omega} \\
\text { ज্ }\end{array}$ & & $\stackrel{0}{\dot{\omega}}$ & $\vec{N}$ & i & $\vec{N}$ \\
\hline $\begin{array}{l}\circ \\
\stackrel{\text { N్ర్ }}{\mathcal{G}}\end{array}$ & $\begin{array}{l}\vec{N} \\
\overrightarrow{0} \\
\vec{A}\end{array}$ & $\begin{array}{l}\stackrel{0}{1} \\
\text { N } \\
\infty\end{array}$ & $\begin{array}{l}\vec{N} \\
\vec{G} \\
\overrightarrow{0}\end{array}$ & $\stackrel{\circ}{\text { N }}$ & $\begin{array}{l}\vec{N} \\
\stackrel{\Delta}{ \pm}\end{array}$ & $\begin{array}{l}\text { ㅇ } \\
\text { N }\end{array}$ & $\begin{array}{l}\vec{N} \\
\vec{G}\end{array}$ & 업 & $\begin{array}{l}\vec{N} \\
\stackrel{N}{\omega}\end{array}$ & 잉 & $\begin{array}{l}\vec{N} \\
\stackrel{\vec{D}}{+}\end{array}$ & $\begin{array}{l}\circ \\
\stackrel{\text { N }}{\text { Un }}\end{array}$ & $\begin{array}{l}\vec{N} \\
\stackrel{N}{N}\end{array}$ & & $\begin{array}{l}0 \\
\dot{0}\end{array}$ & $\overrightarrow{\text { ğ }}$ & $\begin{array}{l}\stackrel{0}{\vec{二}} \\
\end{array}$ & $\overrightarrow{\vec{\theta}}$ \\
\hline 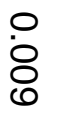 & $\begin{array}{l}\stackrel{.}{\vec{\omega}} \\
\dot{\omega}\end{array}$ & $\begin{array}{l}\circ \\
\stackrel{\circ}{\circ} \\
\infty\end{array}$ & 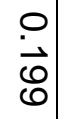 & $\begin{array}{l}\circ \\
\stackrel{\circ}{\longrightarrow}\end{array}$ & $\begin{array}{l}\text { ㅇ } \\
\text { Nิ }\end{array}$ & 응 & $\begin{array}{l}\text { ㅇ } \\
\text { Nิ }\end{array}$ & $\stackrel{\circ}{\circ}$ & $\begin{array}{l}\text { ㅇ } \\
\text { Nิ }\end{array}$ & 웅 & $\begin{array}{l}\text { 잉 } \\
\text { No }\end{array}$ & $\stackrel{\circ}{\circ}$ & $\begin{array}{l}0 \\
\text { Ñ }\end{array}$ & & $\begin{array}{l}\circ \\
\stackrel{0}{0}\end{array}$ & $\begin{array}{l}\text { 임 } \\
\text { 인 }\end{array}$ & 웅 & $\stackrel{\circ}{\circ}$ \\
\hline 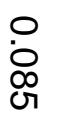 & $\begin{array}{l}\omega \\
u \\
0 \\
\not\end{array}$ & $\begin{array}{l}0 \\
\text { 엉 }\end{array}$ & $\begin{array}{l}\omega \\
0 \\
心 \\
\infty\end{array}$ & $\stackrel{0}{\circ}$ & $\begin{array}{l}\omega \\
\text { ⿹ु }\end{array}$ & 웅 & $\begin{array}{l}\omega \\
\text { న } \\
\end{array}$ & $\begin{array}{l}0 \\
8 \\
8\end{array}$ & $\begin{array}{l}\omega \\
\text { g్ }\end{array}$ & 웅 & $\begin{array}{l}\omega \\
\stackrel{\omega}{\sigma}\end{array}$ & $\begin{array}{l}\circ \\
\dot{\omega}\end{array}$ & $\begin{array}{l}\omega \\
\text { న }\end{array}$ & & $\begin{array}{l}\text { O } \\
\text { ○े }\end{array}$ & $\begin{array}{l}\text { Oे } \\
\dot{\omega}\end{array}$ & $\begin{array}{l}\text { O } \\
\text { O̊ }\end{array}$ & 움 \\
\hline $\begin{array}{l}\circ \\
\text { 워 } \\
\text { w }\end{array}$ & $\begin{array}{l}v \\
\vec{v}\end{array}$ & $\begin{array}{l}\circ \\
\text { 영 }\end{array}$ & $\begin{array}{l}V \\
\vec{v} \\
\mathrm{v}\end{array}$ & $\begin{array}{l}\stackrel{0}{\vec{\Xi}} \\
\end{array}$ & $\stackrel{v}{\vec{Z}}$ & $\begin{array}{l}\stackrel{\circ}{\vec{Z}} \\
\end{array}$ & $\vec{v}$ & $\stackrel{\circ}{\vec{N}}$ & $\stackrel{v}{\vec{N}}$ & $\stackrel{\circ}{\overrightarrow{0}}$ & $\begin{array}{l}v \\
\grave{v}\end{array}$ & 웅 & $\stackrel{\vec{v}}{\vec{v}}$ & & $\begin{array}{l}\circ \\
\stackrel{0}{\perp}\end{array}$ & $\stackrel{O}{\underset{D}{D}}$ & $\begin{array}{l}0 \\
\dot{\omega}\end{array}$ & जै \\
\hline$\stackrel{\circ}{\stackrel{0}{N}}$ & $\begin{array}{l}\omega \\
\omega \\
\omega \\
\omega\end{array}$ & $\stackrel{\stackrel{0}{\overrightarrow{0}}}{\stackrel{p}{\perp}}$ & $\begin{array}{l}\omega \\
\vec{\omega} \\
\omega\end{array}$ & $\begin{array}{l}\text { O } \\
\text { N }\end{array}$ & $\begin{array}{l}\omega \\
\omega \\
\omega\end{array}$ & $\begin{array}{l}0 \\
8 \\
8\end{array}$ & $\begin{array}{l}\omega \\
\dot{N} \\
\sigma\end{array}$ & $\begin{array}{l}\text { O } \\
\text { ơ }\end{array}$ & $\begin{array}{l}\omega \\
\vec{v}\end{array}$ & $\stackrel{\circ}{\vec{\Xi}}$ & $\stackrel{\omega}{\omega} \underset{v}{\omega}$ & $\begin{array}{l}\circ \\
\stackrel{+}{N}\end{array}$ & $\begin{array}{l}\omega \\
\tilde{\tilde{U}}\end{array}$ & & $\stackrel{\circ}{\text { N }}$ & $\begin{array}{l}+ \\
\dot{0} \\
+\end{array}$ & $\begin{array}{l}\circ \\
\circ \\
\infty\end{array}$ & 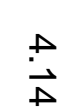 \\
\hline 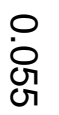 & $\begin{array}{l}\vec{\perp} \\
\underset{\emptyset}{\infty}\end{array}$ & $\begin{array}{l}\text { ○ } \\
\text { 잉 }\end{array}$ & $\begin{array}{l}\dot{\infty} \\
\dot{0}\end{array}$ & 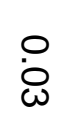 & $\overrightarrow{\dot{o}}$ & 웅 & $\vec{\mho}$ & $\begin{array}{l}\text { O } \\
\text { வे }\end{array}$ & $\begin{array}{r}\vec{\infty} \\
\dot{\omega}\end{array}$ & $\begin{array}{l}\circ \\
\dot{1}\end{array}$ & $\begin{array}{l}\overrightarrow{\dot{\infty}} \\
\mathrm{N}\end{array}$ & $\begin{array}{l}\stackrel{\circ}{0} \\
\dot{\omega}\end{array}$ & $\begin{array}{l}\vec{\phi} \\
\dot{c}\end{array}$ & & $\stackrel{\circ}{\overrightarrow{0}}$ & 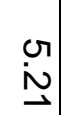 & $\stackrel{\circ}{\vec{\Xi}}$ & $\stackrel{G}{\vec{J}}$ \\
\hline $\begin{array}{l}\circ \\
\stackrel{\circ}{ } \\
\text { ㄱ }\end{array}$ & $\begin{array}{l}\text { ㅇ } \\
\dot{\omega} \\
\text { W }\end{array}$ & $\begin{array}{l}\stackrel{0}{\circ} \\
\stackrel{\vec{U}}{v}\end{array}$ & $\begin{array}{l}\text { 어 } \\
\text { U్ } \\
\end{array}$ & $\begin{array}{l}\text { O } \\
\text { Oे }\end{array}$ & $\begin{array}{l}\text { O } \\
\dot{\omega} \\
\text { जu }\end{array}$ & $\begin{array}{l}\stackrel{\circ}{\circ} \\
\text { 옴 }\end{array}$ & $\begin{array}{l}\text { ㅇ } \\
\dot{\omega}\end{array}$ & $\begin{array}{l}\text { O } \\
\text { 우 }\end{array}$ & $\stackrel{\text { 이 }}{\dot{\omega}}$ & $\begin{array}{l}\text { O } \\
\text { రे }\end{array}$ & $\begin{array}{l}\text { 이 } \\
\dot{\phi} \\
\perp\end{array}$ & 웅 & $\begin{array}{l}0 \\
\dot{\omega} \\
\omega\end{array}$ & & $\begin{array}{l}\circ \\
\stackrel{0}{0}\end{array}$ & 잉 & $\begin{array}{l}0 \\
0\end{array}$ & 요 \\
\hline $\begin{array}{l}\text { 이 } \\
\text { Uू }\end{array}$ & $\begin{array}{l}0 \\
\stackrel{0}{N} \\
\vec{N}\end{array}$ & $\begin{array}{l}0 \\
\text { ํㅓ }\end{array}$ & 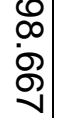 & $\begin{array}{l}\text { ㅇ } \\
\text { मे }\end{array}$ & $\begin{array}{l}\infty \\
0 \\
\infty \\
\omega\end{array}$ & $\begin{array}{l}\text { O } \\
\dot{\infty}\end{array}$ & 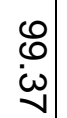 & $\begin{array}{l}\circ \\
\infty \\
0\end{array}$ & $\begin{array}{l}\infty \\
\stackrel{0}{ } \\
\text { N }\end{array}$ & $\stackrel{\circ}{\not}$ & $\begin{array}{l}0 \\
0 \\
0 \\
0\end{array}$ & $\stackrel{\circ}{\stackrel{\omega}{\omega}}$ & $\begin{array}{l}0 \\
\text { Gु } \\
\text { ज़ }\end{array}$ & & 엄 & $\begin{array}{l}\infty \\
\stackrel{D}{ } \\
\forall\end{array}$ & $\begin{array}{l}\text { ○ } \\
\infty \\
\infty\end{array}$ & $\begin{array}{l}0 \\
\$ \\
\$ \\
\phi\end{array}$ \\
\hline
\end{tabular}


the recommended value ranges (Wilson, 1997 and Sparks, 1990). Some of the analysed secondary standards lie outside the recommended value range, reflecting heterogeneity of the standard blocks, however the averages are all within the recommended range.

\subsubsection{Geochemical correlations}

Graphical bivariate plots are used to assess potential correlations with other tephras. Bivariate plots are among the most useful and most widely used method for presenting and testing geochemical correlations. Major and minor element compositions from single-glass shard analyses were compared to available published datasets in order to find the best correlation for each tephra deposit. The most likely sources for tephra in Wales and Germany are Icelandic, Eifel, Massif Central and Italian volcanoes, therefore European databases were used such as Tephrabase (Newton et al., 2007) and RESET (Bronk Ramsey et al., 2015). However, cryptotephra from as far away as Alaska has also been identified in Northern Germany and Ireland (Jensen et al., 2014), therefore large eruptions from further afield were also considered.

\subsubsection{Statistical analysis}

In addition to bivariate plots, statistical methods can provide a more objective way of testing tephra correlations and quantify the certainty or uncertainty in the proposed correlations (Pollard et al., 2006; Pearce et al., 2008; Bourne et al., 2010; Lowe et al., 2017). In this study a comparison of tephra correlations were made through the use of similarity coefficient analysis (e.g. Tryon et al., 2009; Placzek et al., 2009; Brendryen et al., 2010), calculated using the equation below (Borchardt et al., 1972):

$$
d_{(1,2)}=\frac{\sum_{k=1}^{n} R_{k}}{n}
$$


Where $d_{(1,2)}=d_{(2,1)}$ is the similarity coefficient for the comparison between samples one and two, $\mathrm{k}$ is the element number, $\mathrm{n}$ is the number of elements, $R_{k}=X_{k 1} / X_{k 2}$ if $X_{k 2} \geq X_{k 1}$ or $X_{k 2} / X_{k 1}$ if $X_{k 1}>X_{k 2}, X_{k 1}$ is the concentration of element $k$ in sample 1 and $X_{k 2}$ is the concentration of element $k$ in sample 2 (Borchardt et al., 1972). Similarity coefficients were calculated using mean values from the major elements analysed, excluding concentrations with $<1 \%$ following recommendations from Hunt et al., (1995). Similarity coefficient are expressed in values between 0.6 - 1.0, with 1.0 suggesting an exact geochemical correlation. Values over 0.95 mostly represent good geochemical correlation however values below 0.9 suggests no geochemical correlation (Begét et al., 1992).

A number of different statistical techniques have been applied in tephra correlations such as principal components analysis (PCA) and discriminant function analysis (DFA) (Pollard et al., 2006; Pearce et al., 2008; Bourne et al., 2010; van der Bilt et al., 2017). Each has their own merits and pitfalls for examining different data-sets and tephra compositions. Statistical techniques are used to supplement other methods such as visual examination of the geochemical data on bivariate plots as well as stratigraphic information. Neither criteria can be used in isolation and often more advanced statistical techniques are reserved for problematic scenarios in tephra correlations (Lowe et al., 2017). We employ the similarity coefficient to support our suggested correlations.

\subsection{Diatom analysis}

Diatom analysis was only undertaken at Llyn Llech Owain as this represented the main multi-proxy record for this investigation. Diatom frustules were extracted from the sediments following the methodology 
outlined by Battarbee (1986). Treatment with $\mathrm{HCl}$ was omitted as no carbonate was present in the samples (see section 3.3.2). Each sample was air-dried and $0.2 \mathrm{~g}$ was treated overnight at room temperature with $20 \mathrm{ml}$ of $30 \%$ hydrogen peroxide $\left(\mathrm{H}_{2} \mathrm{O}_{2}\right)$ to oxidise any organic material. The following morning, the samples were gradually warmed up in a water bath to $90^{\circ} \mathrm{C}$. Additional fresh $\mathrm{H}_{2} \mathrm{O}_{2}$ was added to the samples until the chemical reaction ceased. Typically, the samples were left in $\mathrm{H}_{2} \mathrm{O}_{2}$ for around 5 days, with samples containing a higher organic content immersed for 7 days. The samples were then subsequently washed using de-ionised water and centrifuged 4 times to remove any traces of $\mathrm{H}_{2} \mathrm{O}_{2}$. After decanting the last centrifuged wash, each sample was transferred to a volumetric flask containing $30 \mathrm{ml}$ of de-ionised water. After gently mixing the $30 \mathrm{ml}$ homogenised sample, $500 \mu \mathrm{l}$ was pipetted onto a $19 \mathrm{~mm}$ diameter coverslip and left to evaporate overnight. A drop of ammonia solution was added to the sample before pipetting to disperse the sample to aid an even distribution of sample on the cover slip. The dry samples were then mounted in naphrax onto labelled microscope slides placed on a hot plate at $\sim 150{ }^{\circ} \mathrm{C}$ and examined under a Nikon Labophot-2 phase-contrast light microscope using immersion oil at $\times 1000$ magnification. Dilutions were necessary for most samples due to the high ratio of clay material to diatom frustules or due to diatom concentrations being too high for identification and counting to be possible.

Diatoms have distinct morphologies and shapes which allow individual diatoms to be identified to species level. The sensitivity of diatoms to various environmental parameters can thus be used to reconstruct past environmental changes. Counting started at a mid-point at the top of the coverslip until a total of 400 diatom frustules were counted and identified following identification books by Krammer and Lange-Bertalot (1986, $1988,1991 a, b)$. Only diatom frustules that contained more than half of the body were recorded. 
If 400 diatoms were counted before finishing the transect, diatoms were still counted (but not identified) until the end of the transect was encountered to allow estimated diatom abundance to be calculated. The cover slip diameter of $19 \mathrm{~mm}$ gave a surface area (S) of $283.5 \mathrm{~mm}^{2}$ and the width of the field of view was $220 \mu \mathrm{m}$ giving a total area of $4.18 \mathrm{~mm}^{2}$ for one transect (s). To obtain an estimate of the number of diatoms on the whole coverslip the following equation was used where $n$ is equal to the amount of diatoms in 1 transect:

$$
\mathrm{n} \times(\mathrm{S} / \mathrm{s})=\mathrm{N}
$$

If more than one transect was counted to obtain 400 diatoms, the area of the field of view of one transect (s) needs to be multiplied by the number of transects before calculating the total number of diatoms on the coverslip $(N)$. The total initial volume of the sample (V) is $30 \mathrm{ml}$, should then be divided by the dilution ratio used for each sample (e.g. $30 \mathrm{ml}(\mathrm{V}) / 1 / 20$ (dilution ratio) $=$ 600 ). The total initial volume of sample (after taking dilution into consideration) (V) should then be divided by the volume pipetted onto the coverslip (v) which was $0.5 \mathrm{ml}$.

$$
(\mathrm{V} / \mathrm{V}) \times \mathrm{N}
$$

This should then give an estimate of the number of diatoms frustules per 0.2 $g \mathrm{dw}$. This equation for determining an estimate for the diatom frustule abundance for each sample was adapted from Davies, (2010).

\subsection{Radiocarbon dating}

\subsubsection{Laboratory sampling}

Above ground terrestrial plant macrofossils were initially extracted for radiocarbon dating as they are considered the most suitable material for dating of lake sediments (Olsson, 2009). Samples were digested in $10 \%$ 
$\mathrm{NaOH}$ (Sodium hydroxide) in a water bath at $\sim 70^{\circ} \mathrm{C}$ for $\sim 45$ minutes and then centrifuged to neutral $\mathrm{pH}$ with de-ionized water. The samples were then sieved at $300 \mu \mathrm{m}$ and $80 \mu \mathrm{m}$ and the macrofossils were identified and picked under a light-powered microscope. Macrofossils were then transferred into glass vials filled with weak acid and kept in a dark cold store at $<4^{\circ} \mathrm{C}$.

Even though aquatic macrofossils or bulk sediment samples are not entirely suitable for radiocarbon dating (Marty and Myrbo, 2014), they were picked in this investigation as terrestrial macrofossils were absent in most samples. Several search attempts were made to retrieve terrestrial macrofossils, however only aquatic macrofossils were found in the gyttja parts of the sequence $(780-710 \mathrm{~cm}$ and $670-580 \mathrm{~cm}$ ). Where no macrofossils (aquatic or terrestrial) were present, bulk sediment was necessarily employed for dating. Eleven new radiocarbon dates were obtained from the 2013 Llyn Llech Owain core (summarized in Table 5.3). The samples consisted of the following: terrestrial macrofossils from the upper peat part of the sequence (2 samples), aquatic macrofossils (4 samples) and bulk sediment samples ( 5 samples) (Table 5.3).

The radiocarbon dates for this study were facilitated by NERC Radiocarbon Dating Facility (NRCF) funding (Radiocarbon Analysis Allocation Number 1882.0415). The samples were pre-treated at the Oxford Radiocarbon Accelerator Unit (ORAU) prior to measurements on the Accelerator Mass Spectrometry (AMS), following the methodology outlined by Brock et al., (2010). An acid-base-acid (or acid-alkali-acid) chemical pre-treatment was used on the samples to eliminate any contamination. Firstly the samples were soaked in $1 \mathrm{M} \mathrm{HCl}$ at $80^{\circ} \mathrm{C}$ for 20 minutes to remove any sedimentary and carbonate contaminants, and then rinsed ( $\geq 3$ times) to neutral pH using ultrapure milliQ ${ }^{\mathrm{TM}}$ de-ionised water. The samples were subsequently immersed in $0.2 \mathrm{M} \mathrm{NaOH}$ at $80^{\circ} \mathrm{C}$ for 20 mins to remove the organic acid contaminants (principally the humic and fulvic fractions), and rinsed again to neutral $\mathrm{pH}$ using ultrapure milliQ ${ }^{\mathrm{TM}}$ de-ionised water. Then, a final acid wash was undertaken using $1 \mathrm{M} \mathrm{HCl}$ at $80^{\circ} \mathrm{C}$ for 1 hour to remove any dissolved atmospheric $\mathrm{CO}_{2}$ that might have been absorbed during the preceding base 


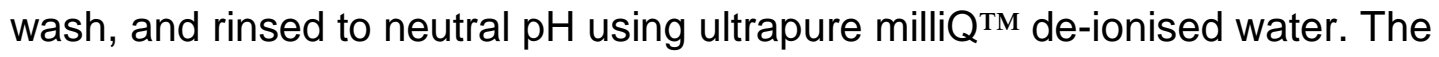
residual material represents the dateable component of the sample and was freeze dried prior to measurement. Once the material is purified, the samples were weighed into tin capsules, combusted, analysed for their stable isotope ratios followed by graphitization ready for the AMS (Dee and Bronk Ramsey, 2000).

Two dendrochronologically dated tree-ring standards were chemistry pretreated alongside the samples. Four oxalic acid standards and two background age anthracite standards were used on the AMS in conjunction with the dendrochronologically dated tree-ring standards to provide a measure of precision.

\subsubsection{Calibration and age-modelling}

Radiocarbon dates for each sample were calibrated using the IntCal 13 calibration dataset (Reimer et al., 2013) and Bayesian age models were built using OxCal v.4.3 (Bronk Ramsey, 2008; Bronk Ramsey and Lee, 2013; Bronk Ramsey, 2017). Dr Richard Staff provided invaluable assistance with the age measurements and age modelling work. A Bayesian age-modelling approach was employed, which allows a combination of prior and likelihood information to be made in a formal way (Bronk Ramsey, 2008). Bayesian analysis allows a representative set of possible ages, in the form of probability distribution functions, to be mathematically calculated for each depth point in a sedimentary sequence where the order of deposition and depth is considered. Several studies have used this approach for climate reconstruction records (e.g. Walker et al., 2003; Blockley et al., 2004).

Four deposition models are available in OxCal and each has their own purpose and suitability for a given situation (Bronk Ramsey, 2008). A D_Sequence model is used when the age gaps between samples are precisely known, which is theoretically the case in ice core, tree ring and varved lake records. If the age gaps between samples are known 
approximately with normally distributed uncertainty, a $\mathrm{V} \_$Sequence model is used. U_Sequence model is applied when the accumulation rate is unknown but assumed to be totally uniform. A P_Sequence model is used if the deposition process conforms to a Poisson-process. P_Sequence (i.e. Poisson process) deposition models were applied for the Llyn Llech Owain age models. P_Sequence models take into consideration that the deposition rate can vary through time, rather than assuming a constant deposition throughout the record (Bronk Ramsey, 2008). Deposition rates are known to vary in lake sediments of Lateglacial age where different rates are seen between the Interstadial, Loch Lomond Stadial and early Holocene. The P_Sequence model allows for the variability within each of these periods to be incorporated in OxCal through the use of boundaries, in addition to the added constraint of a parameter ' $k$ '. A low $k$ value allows increased flexibility away from a uniform deposition rate, whereas a high $\mathrm{k}$ value restricts the deposition rate to be more linear (Bronk Ramsey and Lee, 2013). Outlier analysis was also used for the models which detect and down-weight any outlier dates in an objective manner (Bronk Ramsey, 2009; Bronk Ramsey et al.,2010).

Four P_Sequence models were constructed (with the assistance of $\mathrm{Dr}$ Richard Staff) for the Llyn Llech Owain sequence. Model A used only the eleven radiocarbon dates analysed. Model $B$ implemented age constraints on the major climatic transitions from the Greenland ice core record to hypothesis test the tephra correlations. Model $\mathrm{C}$ incorporated the geochemically constrained tephra horizons as added age constraints. Model $D$ included added age constraints on the major climatic transitions from the Greenland ice core records (see section 5.7). 


\section{Results - Lake Hämelsee, North Germany}

\subsection{Site description}

Lake Hämelsee, North Germany, (Lat: $52^{\circ} 45^{\prime} 34^{\prime \prime} \mathrm{N}$, Long: 9 18' 40" E, 19.5 $\mathrm{m}$ a.s.I) is located in the Weichselian fluvial sand plain of the Weser-Aller river system. The lake is almost circular (Figure 4.1), with a diameter of $\sim 400$ $\mathrm{m}$ and the maximum water depth of the lake currently is $4.9 \mathrm{~m}$. It is a closed lake system, solely fed by precipitation and groundwater, making it a desirable site for a palaeoenvironmental study. The sedimentary sequence studied by Merkt and Müller (1999) showed that sedimentation within the basin began during the Pleniglacial-Lateglacial transition and continued throughout the Holocene. The Lateglacial sediments are partially varved adding further value to the sequence.

A new sediment sequence (HÄM13) was cored from Lake Hämelsee during the first INTIMATE Example research training school in July 2013 (www.intimate.nb.ku.dk/), with the aim of constructing a detailed palaeoclimate record for the Lateglacial, using both traditional and state-ofthe-art dating and proxy techniques.

Using a piston corer operated from a Uwitec coring platform, two parallel overlapping core successions $(\mathrm{H} 1$ and $\mathrm{H} 2)$ were retrieved from the middle part of the lake at $3.3 \mathrm{~m}$ water depth (within $10 \mathrm{~m}$ of each other), to allow sufficient material for a multiproxy study. Cores $(60 \mathrm{~mm}$ diameter) were retrieved in $3 \mathrm{~m}$ long sections and cut into $1 \mathrm{~m}$ long segments for transport in the field. The base of the lake fill and transition into underlying sandy fluvial sediments was reached at approximately $17 \mathrm{~m}$ sediment depth. The two cores have been split in two halves, photographed, and described and the half core segments are stored at $4{ }^{\circ} \mathrm{C}$ in Utrecht and Potsdam for further research. Consequently all sample depths, have been correlated onto a composite-core depth scale using identifiable marker deposits and horizons 


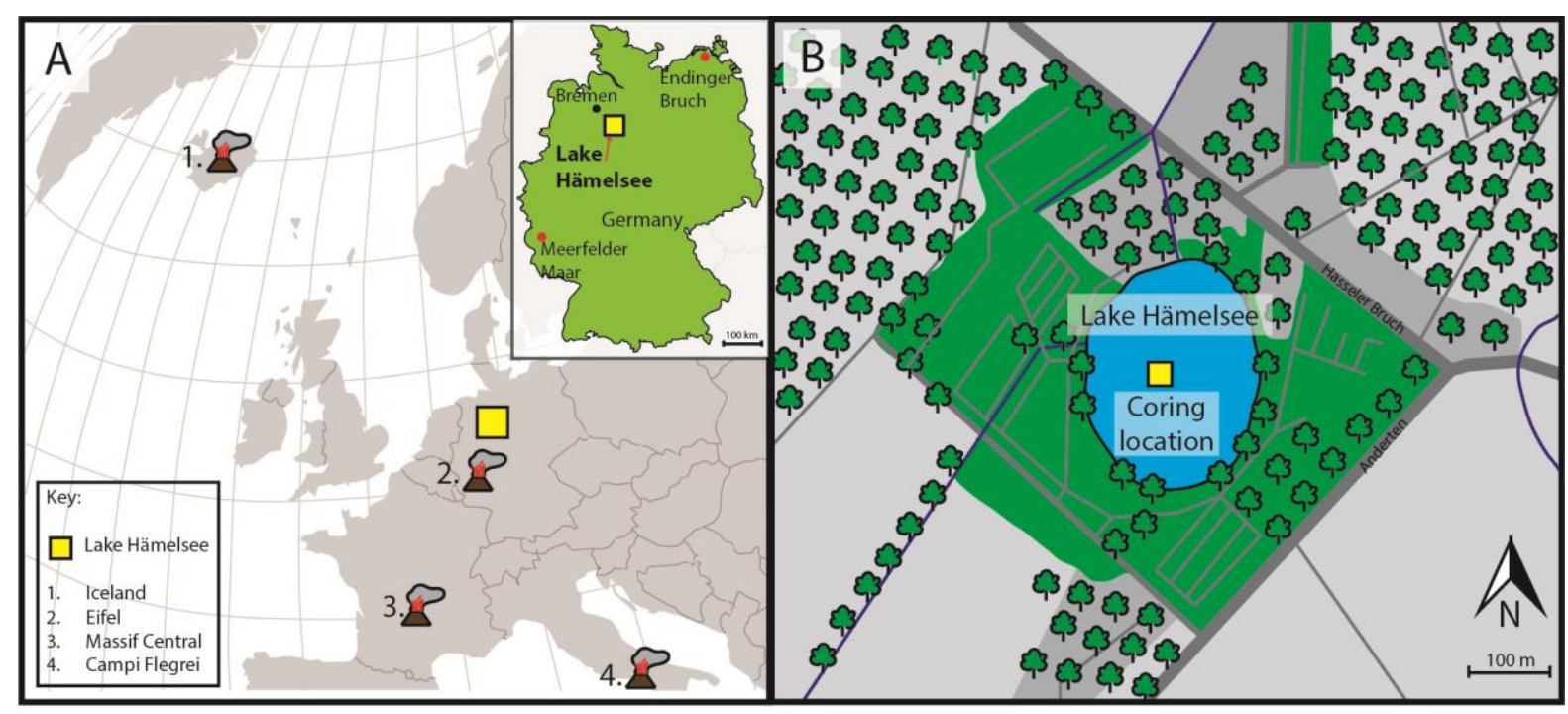

Figure 4.1 - A) Location map showing Lake Hämelsee, in Germany, volcanic centres, and other sites mentioned in the text. B) Coring location and the surrounding catchment.

observed through magnetic susceptibility, ITRAX XRF scans, loss on ignition (LOI) data and tephra deposits (core correlations undertaken by Aritina Haliuc and Achim Brauer). Based on the core descriptions, five lithozones have been distinguished (Figure 4.2).

\subsection{Lithostratigraphy and Loss on Ignition (LOI)}

The core examined in this study spans between 1700 and $1300 \mathrm{~cm}$ (Figure 4.2). Wim Hoek, Renee de Bruijn, Aritina Haluic and Achim Brauer were responsible for the LOI and lithostratigraphy work as part of the INTIMATE example research training school. The sedimentary sequence is sub-divided 


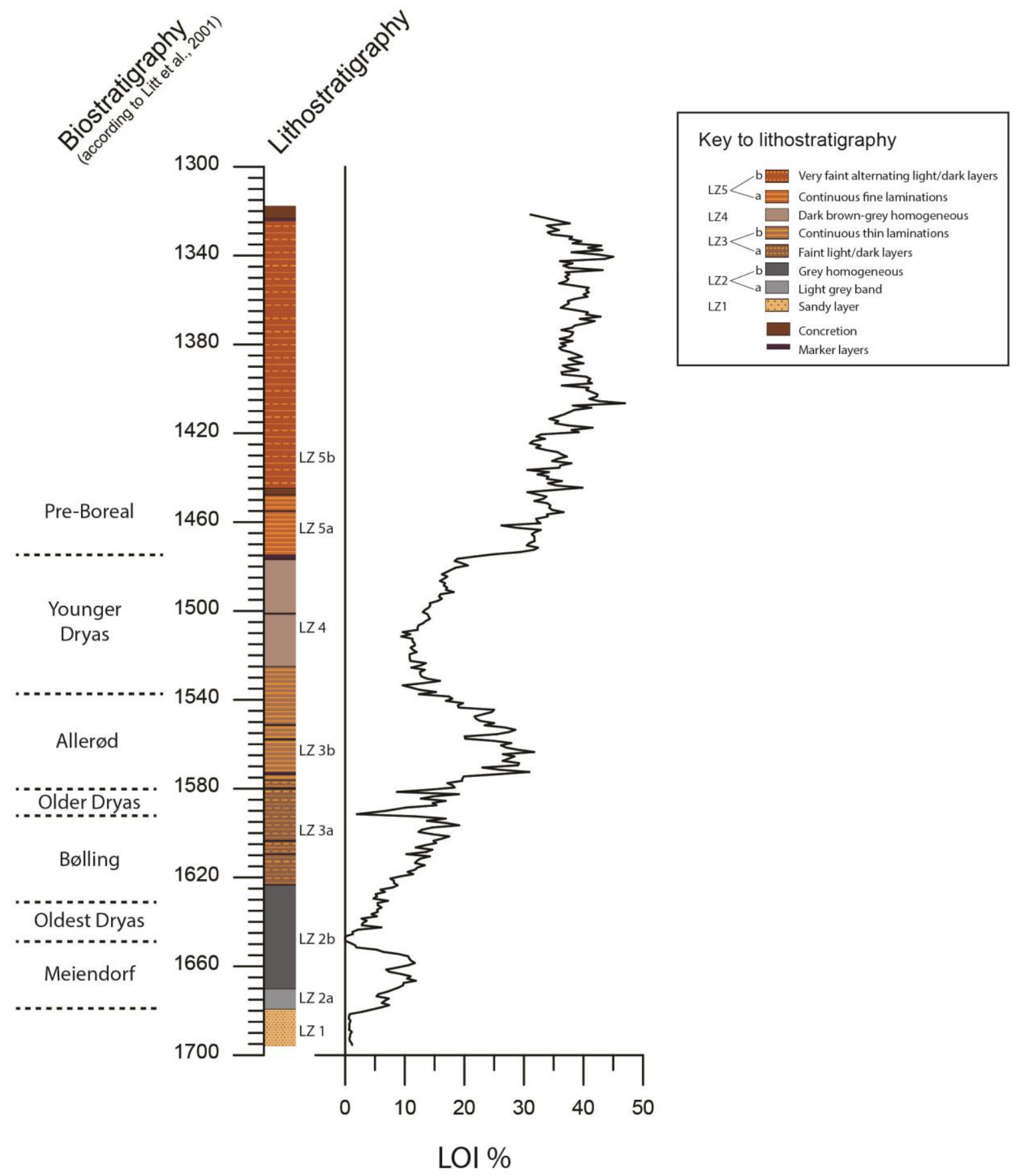

Figure 4.2 - Lithostratigraphy (as compiled by Aritina Haulic and Achim Brauer), biostratigraphy (as compiled by Falko Turner and colleagues) and Loss on Ignition (LOI) (as compiled by Wim Hoek and Renee de Bruijn) for the Lake Hämelsee record. 
into five lithozones (LZ) based on sediment composition, structure, colour and the presence and structure of varves (Figure 4.2). Glacio-fluvial sands are present at the base of the sequence from $1700-1680 \mathrm{~cm}$ (LZ 1) with very low LOI values, which is followed by an unit of grey homogenous clay sediments from 1680-1624 cm (LZ 2a and b). The LOI values suddenly increases at $1680 \mathrm{~cm}$ (LZ 2a) to values between 7-11\%, followed by a sudden decrease in LOI values at $1652 \mathrm{~cm}$. A gradual increase is seen in the $L O I$ values from $1652 \mathrm{~cm}$ to the end of LZ 2b. This zone is overlain by a section composed of sediments of alternating brown organic and light grey clay layers from 1624-1575 cm (LZ 3a), where LOI values continue to increase to $\sim 15 \%$ at $1602 \mathrm{~cm}$. The rest of LZ 3a is characterised by fluctuating LOI values with sudden peaks and troughs between 1602-1575 $\mathrm{cm}$. LZ 3b $(1575-1525 \mathrm{~cm})$ consists of sediments with continuous thin varved laminations, containing mainly siderite, calcite and organic layers. A sudden increase in LOI values to $\sim 30 \%$ is seen at $1575 \mathrm{~cm}$, followed by a gradual decrease to $\sim 13 \%$ at $1530 \mathrm{~cm}$. Zones $L Z 1$ to $3 \mathrm{~b}$ are assumed to represent the Lateglacial Interstadial which include the Meiendorf, Older Dryas, Bølling, Oldest Dryas and Allerød periods, based on the pollen record and in accordance with Litt et al., (2001). LZ 3b is overlain by dark brown-grey clastic homogenous sediments from 1525-1478 cm (LZ 4), with low LOI values $(\sim 13 \%)$ which is assumed to represent the Younger Dryas Stadial. LOI values remain at $\sim 13 \%$ until a sudden increase to $32 \%$ is seen at 1478 $\mathrm{cm}$. At $1478 \mathrm{~cm}$ the lithostratigraphy changes to more organic sediments consisting of fine alternating light and dark laminas (LZ 5a), however, the poor preservation of the laminas during this zone has not allowed varve counting. The sharp increase in LOI values to $32 \%$ at the LZ 5a onset (1478 $\mathrm{cm}$ ) is thought to represent the Holocene onset. The overlying unit LZ $5 \mathrm{~b}$ (1448-1300 cm), consists of dark-organic material, interrupted by faint light carbonate and dark organic layers. A small shift is also seen in the LOI values at $1412 \mathrm{~cm}$ and elevated values of between $36-45 \%$ characterise the top of the sequence. 


\subsection{Sediment geochemistry by X-ray fluorescence (XRF)}

Selected XRF elemental profiles are shown in Figure 4.3. Aritina Haulic and Achim Brauer analysed the cores at Potsdam GFZ as part of the INTIMATE example research training school (see section 3.3.1 and Figure 3.1).

High $\mathrm{K}$ and Ti are observed within the basal unit $(1680-1620 \mathrm{~cm})$ of the Hämelsee record, with values ranging from $1300-1800$ and 800-1100 cps respectively. A short lived decrease is seen within LZ2b, however, between $1650-1645 \mathrm{~cm}$ with values reducing to 500 and $80 \mathrm{cps}$. This episode is also reflected in the Fe and LOI record with values reducing to near zero, which is thought to represent the Oldest Dryas period, as inferred from the pollen record (see below and Figure 4.3).

Between 1618-1576 cm (LZ3a), a reduction in the $K$ and Ti values is observed with values of $750-1200$ and $470-640 \mathrm{cps}$. A further reduction is observed in $\mathrm{K}$ and Ti values from 1100 and 600 at $1580 \mathrm{~cm}$ to 250 and 150 cps at $1575 \mathrm{~cm}$ respectively. The LOI record also shows a change at this point with values increasing to $27 \%$ in addition to elevated Fe values. LZ3b $(1575-1545 \mathrm{~cm})$ is thought to represent the Allerød period where thin laminations are observed in the core. $\mathrm{K}$ and Ti values increase in overlying sediment with values increasing from 500 and 250 at $1545 \mathrm{~cm}$ to 2000 and 1100 at $1532 \mathrm{~cm}$ suggesting an increase in minerogenic in-wash into the lake. High Ti values of $\sim 1050 \mathrm{cps}$ are observed between $1532-1480 \mathrm{~cm}$, in addition to low $\mathrm{Fe}(\sim 5000 \mathrm{cps})$, which is thought to represent the Younger Dryas Stadial. The $\mathrm{K}$ record however, shows a two part profile during this unit with lower values (1250 cps) seen during the latter part of $L Z 4$ between $1520-1480 \mathrm{~cm}$. A rapid decrease is seen in the $K$ and Ti values at $1478 \mathrm{~cm}$ with values reducing from 800 and $600 \mathrm{cps}$ to 50 and $80 \mathrm{cps}$ at $1475 \mathrm{~cm}$. This rapid change is also seen in the Fe record with values increasing from 4000 to $22000 \mathrm{cps}$ from $1478 \mathrm{~cm}$ to $1475 \mathrm{~cm}$. LZ5a is thought to represent the Pre-Boreal or early Holocene warming. Low $\mathrm{K}$ and Ti values persist to the top of the record at $1370 \mathrm{~cm}$ with the exception of a small short-lived increase in the Ti profile at $1400 \mathrm{~cm}$. 


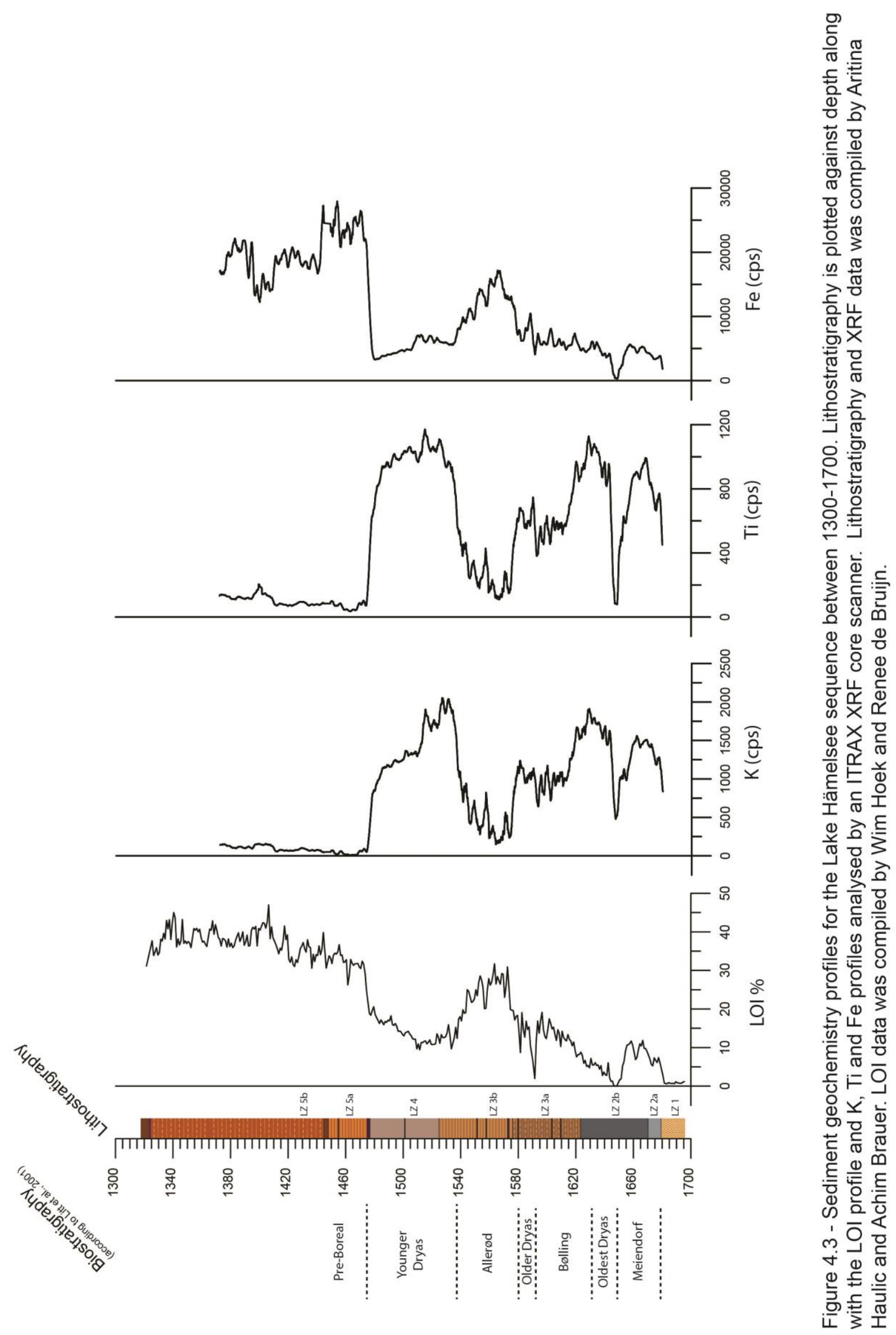




\subsection{Pollen analysis}

A pollen diagram and a summary (tree and herbs) pollen diagram for the Lake Hämelsee sequence is shown in Figure 4.4. Falko Turner and colleagues were responsible for all pollen work as part of the INTIMATE example research training school. The biostratigraphic boundaries for the sequence, as shown in Figure 4.2 and 4.3, are based on major changes in the plant taxa composition in accordance with the regional pollen stratigraphy (Litt et al., 2001).

Herbaceous pollen dominates the lowermost part of the sequence between 1670 and $1636 \mathrm{~cm}$ with values in the range of 60-70\%. Salix, Juniperus and other taxa such as Artemisia and Helianthemum characterise this period. A short-lived increase in tree pollen (Betula and Pinus) is seen between 1636 and $1625 \mathrm{~cm}$ with values of $50-60 \%$. This is followed by a short-lived period of decreased tree pollen with values of $30 \%$ between 1625 - and $1614 \mathrm{~cm}$, which is thought to represent the Oldest Dryas period. This period also sees the short-lived appearance of Empetrum with relatively stable levels of herb pollen e.g. Artemisia. A gradual increase in tree pollen values is seen from $40 \%$ at 1614 to $>80 \%$ at $1581 \mathrm{~cm}$ and coincides with Betula expansion. The high tree pollen assemblages continues at $>80 \%$ up to $1537 \mathrm{~cm}$, which is thought to represent the Bølling and Allerød period. This period is followed by a gradual decrease in tree pollen from $80 \%$ at 1537 to $55 \%$ at $1520 \mathrm{~cm}$. Higher values of herbs ( $45 \%)$ is seen during this period with increases in Empetrum between 1520 and $1474 \mathrm{~cm}$ suggesting a gradual opening of the dominating birch(-pine) forest indicative of the Younger Dryas. An abrupt transition is seen at $1474 \mathrm{~cm}$ with low tree pollen (55\%) increasing to $80 \%$ within a few centimetres. This change is thought to represent the early Holocene onset with a stabilizing landscape and the spread of tree birch. The initial increase in tree pollen at $1474 \mathrm{~cm}$ is followed by a period of decreased tree pollen values (55-65\%) between 1461 and $1440 \mathrm{~cm}$ and an increase in herbs and grasses, notably Poaceae, indicative of the "Rammelbeek-Phase" which is also seen in a number of pollen records in northwest Europe (e.g. 


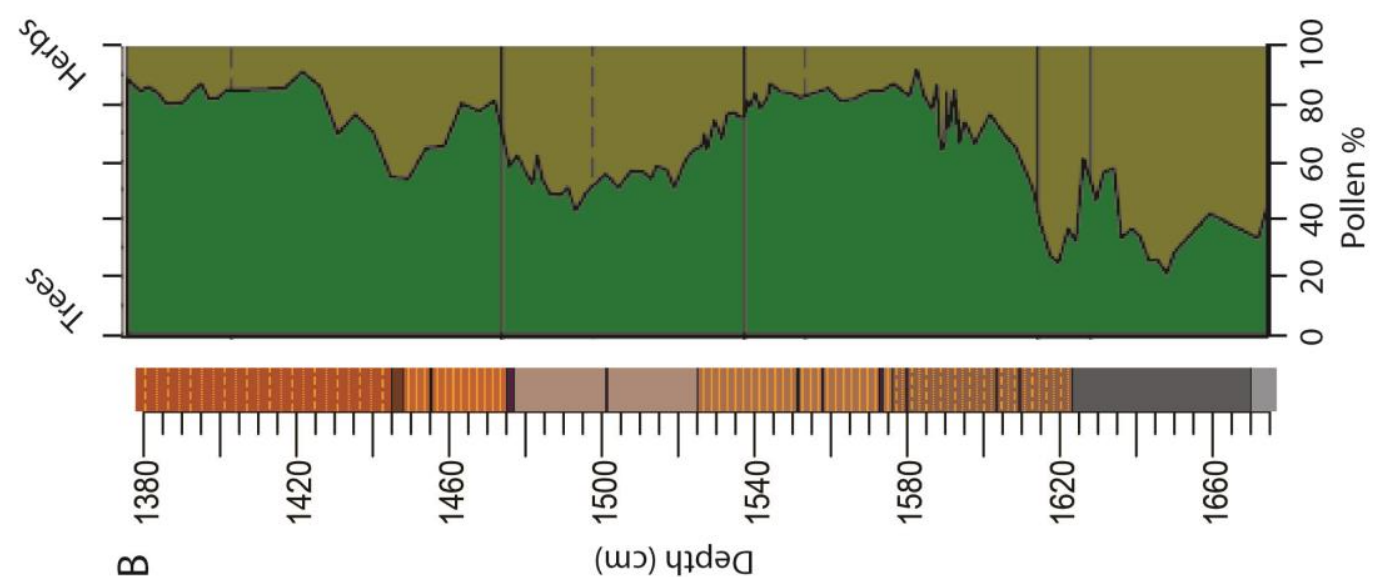

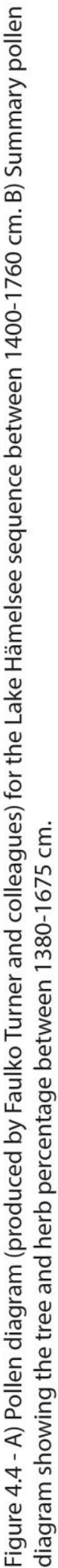

$\varangle$ 
Van Geel et al., 1980; Bohncke and Hoek, 2007). The "Rammelbeek-Phase" is followed by a gradual increase in tree pollen to $90 \%$ at $1425 \mathrm{~cm}$ which is sustained to the top of the record until $1380 \mathrm{~cm}$.

\subsection{Tephrochronology}

Eight tephra deposits are identified in this sequence (Figure 4.5). Shard concentrations range for each deposit with the largest deposit being visible, occurring as a 500 $\mu \mathrm{m}$ thick layer, and the smallest consisting of only 12 shards. Most deposits are comprised of a distinct peak (e.g. HÄM_T1401.5 and HÄM_T1616) but some (e.g. 1470 and 1456) are not as clearly defined. Morphological characteristics of the glass shards for the deposits found in the record include fluted, cuspate, platy, vesicular and highly crystallised (Figure 4.5). The geochemical results confirm the presence of the Saksunarvatn Ash and the Laacher See Tephra within the Hämelsee sequence, as first reported by Merkt et al., (1993). Six additional cryptotephra horizons have been located and three of these are correlated to known eruptions. All tephra deposits are named here after their depth in the composite core. Where a deposit has been identified in both $\mathrm{H} 1$ and $\mathrm{H} 2$, any differences in their occurrence are described. Here we present the TSC, shard morphology, geochemical composition (Figure 4.5 and Table 4.1), and correlation to known eruptions for each tephra deposit, starting with the oldest. The geochemical data discussed in the text and shown in the bi-plots and Table 4.1 are normalized. Raw data-sets are available in the appendix.

\subsubsection{Total Shard Concentrations (TSCs)}

Tephra shard analysis was initially undertaken at $10 \mathrm{~cm}$ resolution between $1700-1300 \mathrm{~cm}$ in core $\mathrm{H} 1$ and between 1620-1300 in core H2 (Figure 4.5). Samples that contained $>10$ shards per $0.5 \mathrm{~g} \mathrm{dw},(1620-1610 \mathrm{~cm}, 1560-1550$ $\mathrm{cm}, 1500-1480 \mathrm{~cm}, 1450-1440 \mathrm{~cm}, 1400-1390 \mathrm{~cm}$ in core $\mathrm{H} 1$ and 1560-1550 $\mathrm{cm}, 1500-1480 \mathrm{~cm}$ in core $\mathrm{H} 2$ ), were sampled at higher resolution to isolate 


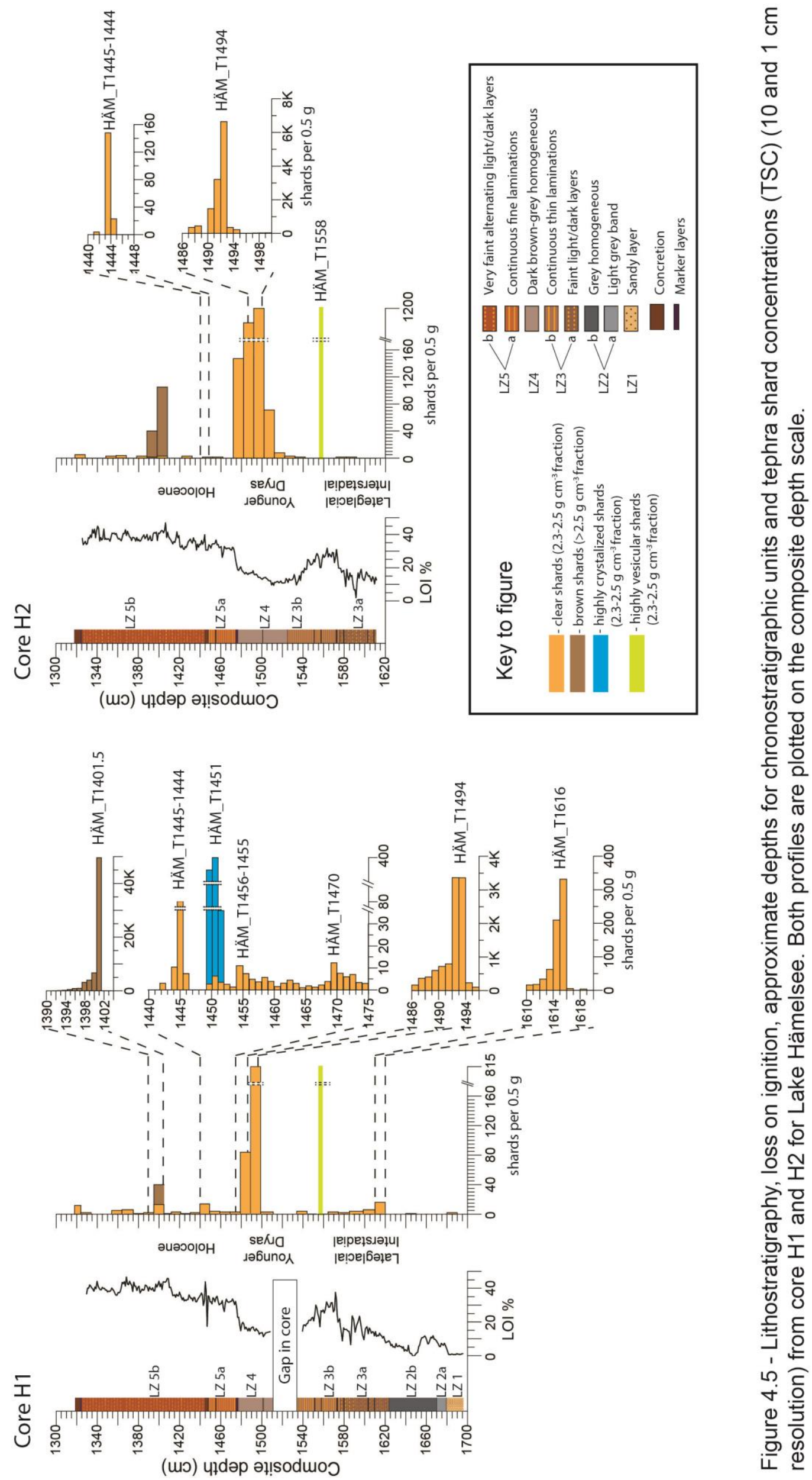


the position of the tephra layers to the nearest $1 \mathrm{~cm}$. Peak shard concentrations were identified at $1616-1615 \mathrm{~cm}$ (331 shards per $0.5 \mathrm{~g} \mathrm{dw}$ ), $1494-1493 \mathrm{~cm}$ (3360 shards per $0.5 \mathrm{~g} \mathrm{dw}$ ), $1445-1444 \mathrm{~cm}$ (73 shards per 0.5 $\mathrm{g} \mathrm{dw}) 1401-1400 \mathrm{~cm}(49,554$ shards per $0.5 \mathrm{~g} \mathrm{dw})$ in core $\mathrm{H} 1$ and at $1494-$ $1493 \mathrm{~cm}$ (6640 shards per $0.5 \mathrm{~g} \mathrm{dw}$ ) in core $\mathrm{H} 2$.

\subsubsection{Geochemical analysis, morphological characteristics and tephra correlations}

\section{$\underline{\text { HÄM T1616 (uncorrelated) }}$}

The oldest tephra deposit, occurring between $1616-1615 \mathrm{~cm}$ with a TSC of 331 shards per $0.5 \mathrm{~g}$, was found only in core $\mathrm{H} 1$ (Figure 4.5), which reached deeper than H2. Shards are clear, with a fluted morphology. The shard concentration profile reveals a distinct basal peak, where the isochron is placed, with a declining tail of shards above the peak up to $1610 \mathrm{~cm}$ (Figure 4.5). Based on the comparison of $\mathrm{H} 1$ lithostratigraphy and LOI to Merkt and Müller (1999), this part of the sequence is believed to correlate to the latter part of the Lateglacial Interstadial. Geochemical analysis revealed HÄM_T1616 to be a rhyolitic tephra (Figure 4.6), with 76.55-77.51 wt\% $\mathrm{SiO}_{2}$, 1.25-1.65 wt\% FeO, 0.66-0.81 wt\% $\mathrm{CaO}$ and 3.83-4.16 wt\% $\mathrm{K}_{2} \mathrm{O}$. HÄM_T1616 has a similar compositional signature to the Icelandic Borrobol (BT) and Penifiler (PT) tephra deposits (Figure 4.7). These tephra deposits are known to be compositionally indistinguishable, with similarity coefficients values $>0.95$, and have both been found in a number of sites across northern Europe (Davies et al., 2003; Matthews et al., 2011; Lind et al., 2016). Correlation to one or the other of these deposits is therefore reliant upon secure stratigraphic correlation to either the early part of the Lateglacial Interstadial (BT) or to the cold conditions of the Older Dryas that punctuate the Interstadial in many records (PT). More recently, Timms et al., (2016) identified two more cryptotephra deposits, of the same composition as the 


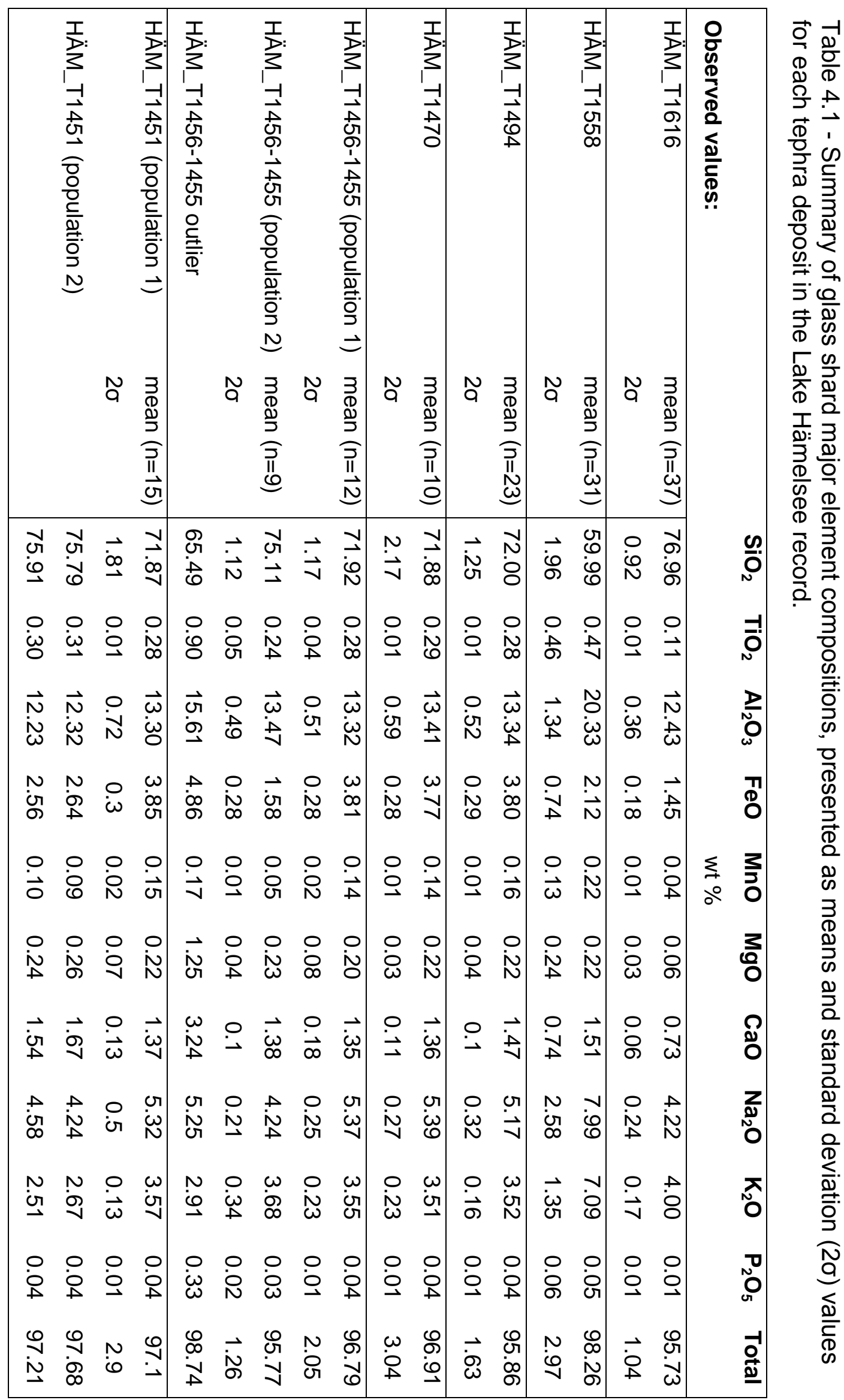




\begin{tabular}{|c|c|c|c|c|}
\hline & 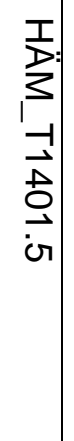 & 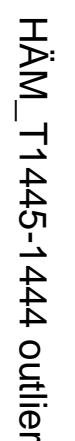 & & 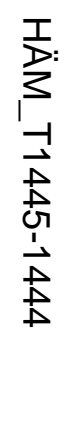 \\
\hline$\tilde{a}$ & $\begin{array}{l}3 \\
\mathbb{D} \\
\stackrel{D}{J} \\
د \\
\vec{J} \\
\| \\
\pm \\
\pm\end{array}$ & & N & 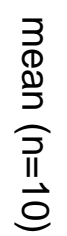 \\
\hline$\stackrel{\circ}{0}$ & $\begin{array}{l}\overrightarrow{0} \\
0 \\
0\end{array}$ & $\frac{N}{\stackrel{N}{0}}$ & $\overrightarrow{\dot{\phi}}$ & హె \\
\hline$\stackrel{\circ}{\underset{A}{N}}$ & $\begin{array}{l}\omega \\
\stackrel{\omega}{N}\end{array}$ & $\stackrel{0}{\text { iv }}$ & ○ & $\stackrel{\circ}{\dot{\omega}}$ \\
\hline$\stackrel{\ominus}{\vee}$ & $\begin{array}{l}\vec{\omega} \\
\vec{\omega}\end{array}$ & $\begin{array}{l}\vec{N} \\
\stackrel{\infty}{\infty}\end{array}$ & 옅 & $\begin{array}{l}\vec{N} \\
\stackrel{N}{N}\end{array}$ \\
\hline $\begin{array}{l}\stackrel{0}{0} \\
\dot{\infty} \\
\end{array}$ & $\begin{array}{l}\vec{A} \\
\text { Ut } \\
A\end{array}$ & $\begin{array}{l}\omega \\
\stackrel{\omega}{\sigma}\end{array}$ & $\stackrel{\circ}{\vec{G}}$ & $\begin{array}{l}0 \\
\dot{8}\end{array}$ \\
\hline 읏 & $\begin{array}{l}0 \\
\hat{\omega} \\
\dot{\omega}\end{array}$ & $\stackrel{\circ}{\vec{v}}$ & 잉 & $\begin{array}{l}\circ \\
\dot{\circ}\end{array}$ \\
\hline 이 & $\begin{array}{l}G \\
u \\
\infty\end{array}$ & $\stackrel{\circ}{\overrightarrow{0}}$ & $\begin{array}{l}\circ \\
\text { 우 }\end{array}$ & $\stackrel{O}{N}$ \\
\hline$\stackrel{\circ}{\stackrel{\circ}{\perp}}$ & $\begin{array}{l}0 \\
0 \\
\infty\end{array}$ & $\overrightarrow{\vec{\sigma}}$ & $\stackrel{0}{\stackrel{0}{N}}$ & $\vec{\sigma}$ \\
\hline 어N & $\begin{array}{l}N \\
Y\end{array}$ & $\frac{G}{\overrightarrow{0}}$ & 이 & $\stackrel{\vec{t}}{\overrightarrow{0}}$ \\
\hline 욱 & $\begin{array}{l}\circ \\
\pm \\
\pm\end{array}$ & $\stackrel{\omega}{\underline{v}}$ & $\begin{array}{l}\stackrel{0}{N} \\
\end{array}$ & 명 \\
\hline 움 & $\begin{array}{l}0 \\
\dot{\omega} \\
\vec{u}\end{array}$ & $\begin{array}{l}\text { O } \\
\text { மे }\end{array}$ & $\begin{array}{l}\text { O } \\
\text { O }\end{array}$ & 임 \\
\hline $\overrightarrow{\vec{B}}$ & $\begin{array}{l}0 \\
0 \\
-1 \\
\infty\end{array}$ & $\begin{array}{l}0 \\
\stackrel{y}{y}\end{array}$ & $\stackrel{\sim}{\stackrel{n}{9}}$ & $\begin{array}{l}0 \\
\text { vo } \\
\dot{v}\end{array}$ \\
\hline
\end{tabular}



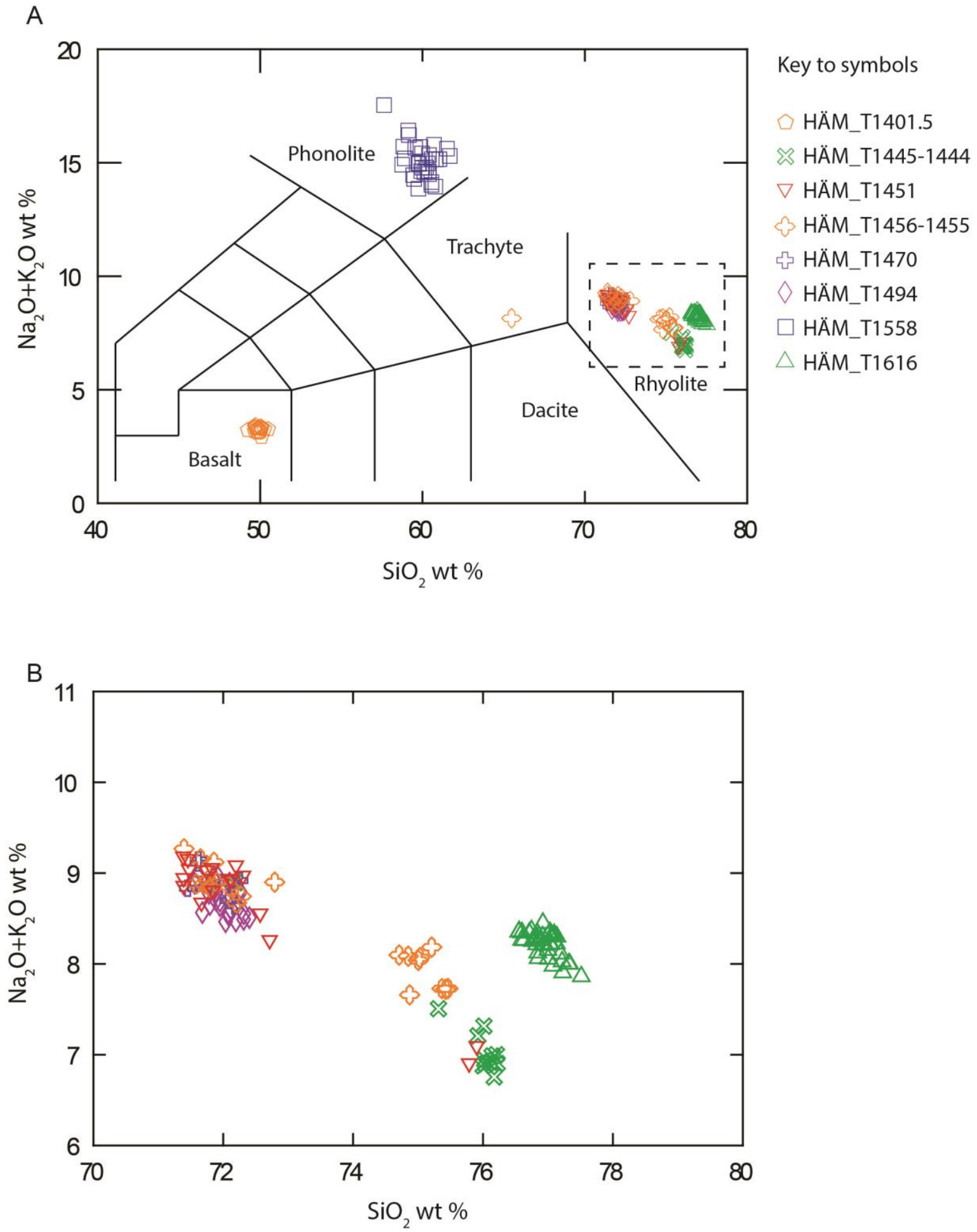

Figure 4.6 - Major element results for the tephra deposits identified in the Hämelsee record between 1700 and $1300 \mathrm{~cm}$ (composite depth). A) Total alkali silica classifcation follows that of Le Bas et al (1986). B) Inset of the rhyolitic deposits. 


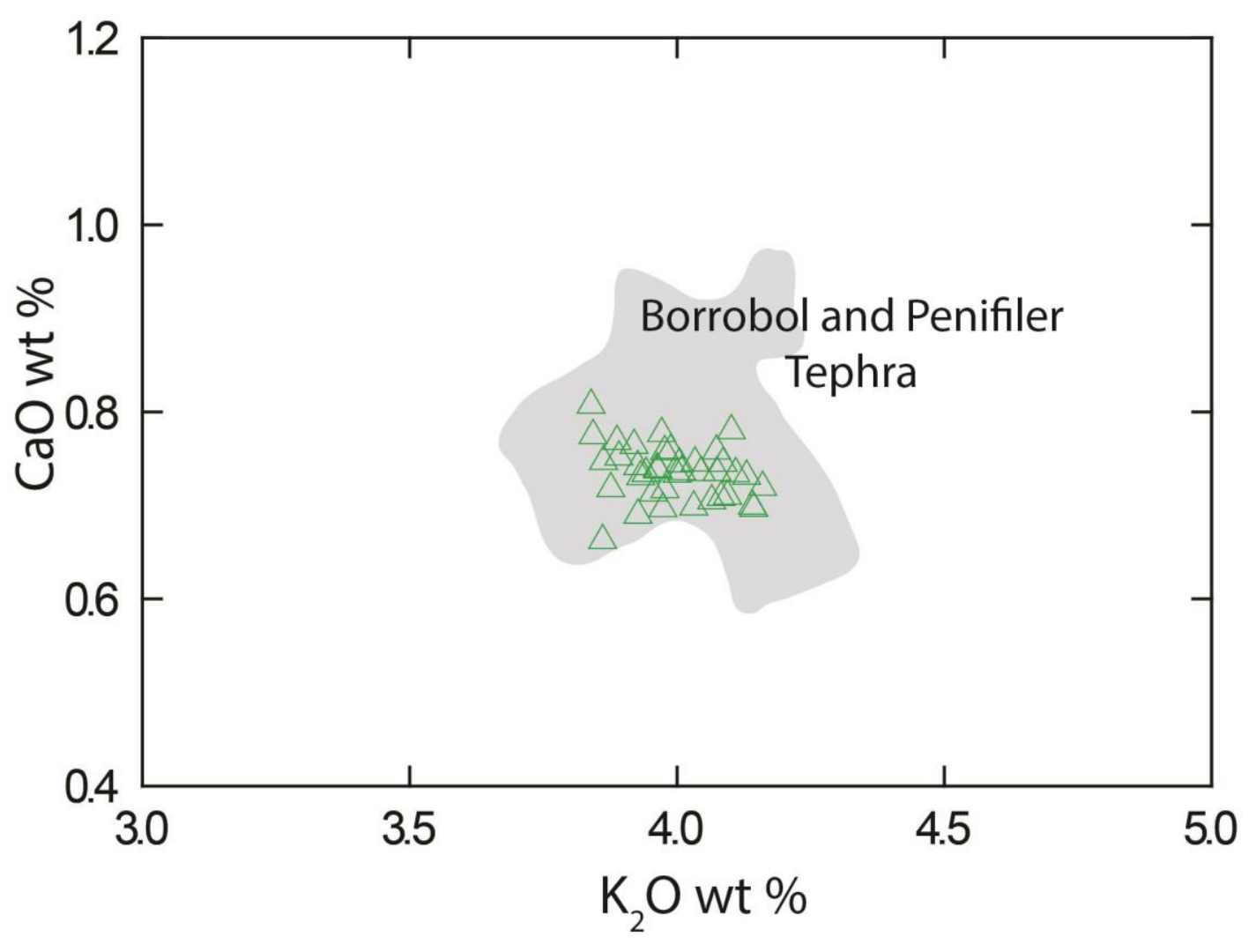

Figure 4.7 - Bivariate plot showing the correlation of HÄM_T1616 to the indistinguishable Borrobol and Penifiler tephras (data from Lind et al., 2016 and Timms et al., 2016). 
BT and PT deposits, within a sediment record from Orkney (Scotland), which also lie in the latter part of the Interstadial. These deposits offer two additional possible matches for HÄM_T1616. The difficulties of distinguishing between these Borrobol-like tephra deposits and the consequences for the Hämelsee sequence are explored further in section 8.1.1.

\section{$\underline{\text { HÄM T1558 (Laacher See Tephra) }}$}

Tephra deposit HÄM_T1558 is the only visible tephra deposit in the Hämelsee succession, occurring as a $\sim 500 \mu \mathrm{m}$ thick, light grey layer within the varved portion of the Allerød sediments (Figure 4.5) within both cores $\mathrm{H} 1$ and $\mathrm{H} 2$; slightly thicker than the $\sim 200 \mu \mathrm{m}$ layer observed in the same position previously by Merkt \& Müller (1999). Colourless, highly vesicular and cuspate glass shards are confined almost entirely within two adjacent $1 \mathrm{~cm}$ samples (1559-1557 cm). In thin section the tephra layer is seen to occur above the winter-Chrysophyceae layer and below the next summer siderite layer, indicating an eruption that occurred between spring and early summer (Merkt \& Müller 1999). HÄM_T1558 has a phonolitic composition, with 57.64$61.68 w t \% \mathrm{SiO}_{2}, 0.12-0.88 w t \% \mathrm{TiO}_{2}, 19.12-21.89 \mathrm{wt} \% \mathrm{Al}_{2} \mathrm{O}_{3}$ and 6.37-8.15 $w t \% \mathrm{~K}_{2} \mathrm{O}$, which correlates to the Laacher See Tephra (LST) (Figure 4.6 and 4.8), confirming the results of Merkt \& Müller, (1999). The LST originated from the Eifel region of Germany and is widely found within Central European archives, occurring consistently within the latest part of the interstadial (van den Bogaard \& Schmincke, 1985). The Laacher See Tephra has been dated to $12,880 \pm 40$ varve years (Brauer et al., 1999) in Lake Meerfelder Maar and to $12937 \pm 23$ cal. a BP in a multi-site Bayesian-based radiocarbon age model by Bronk Ramsey et al., (2015). HÄM_T1558 shows a predominant correlation to the upper phase of the LST, which is previously thought to have been dispersed in a southerly direction rather than northwards. Upper phase LST shards are also present in Wegliny, southwest Poland (Housley et al., 2013) further contradicting the previously thought dispersal axis of the upper phase LST. Some shards also show 


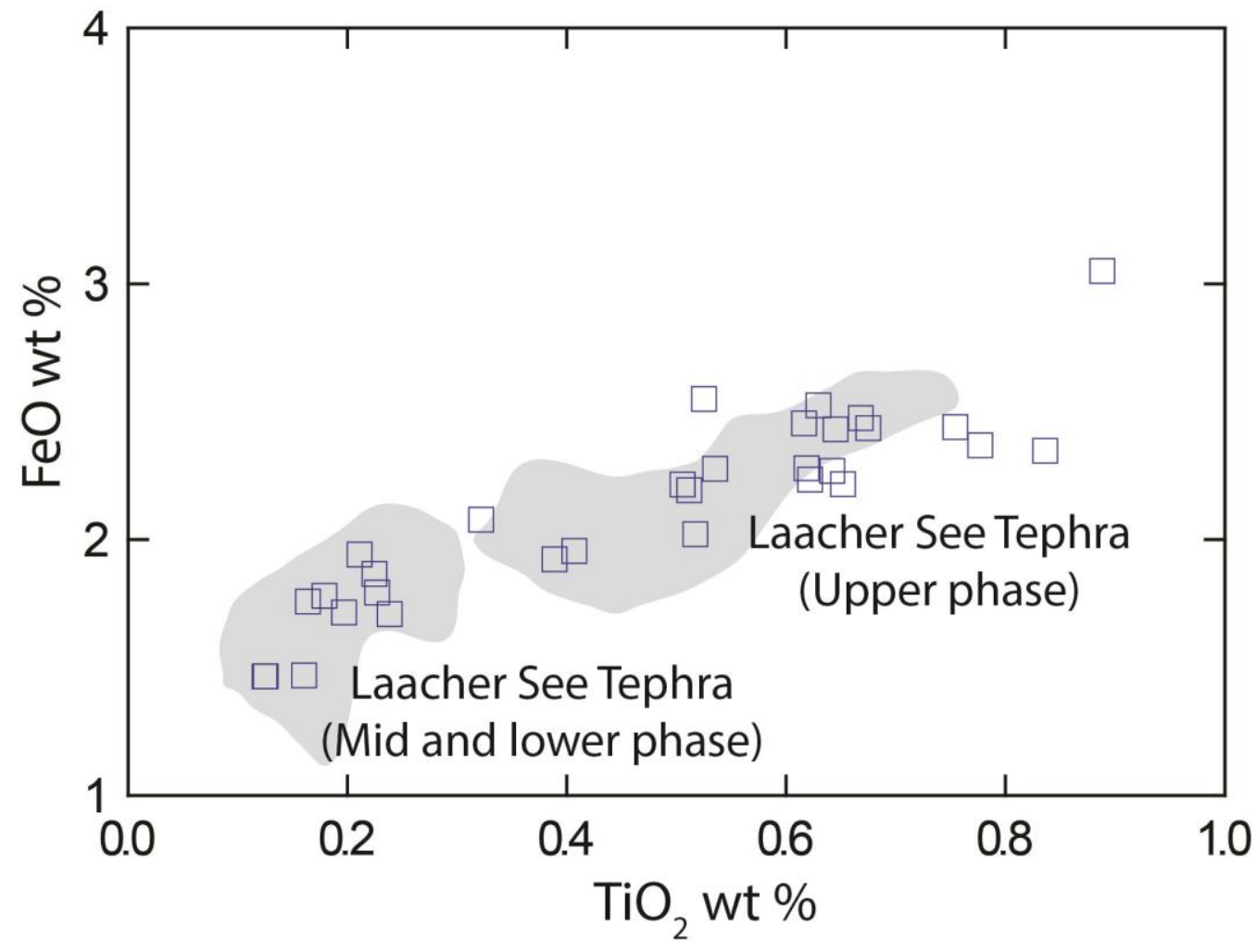

Figure 4.8 - Bivariate plot showing the correlation of the phonolitic shards of HÄM_T1558 to the Laacher See Tephra (data from Riede et al., 2011; Lane et al., 2012). 
affinity to the mid and lower phase of the LST, as indicated by the $\mathrm{FeO}, \mathrm{TiO}_{2}$ and $\mathrm{MgO}$ values (Figure 4.8), suggesting that the dispersal of the phases may have been more widespread than previously thought.

\section{HÄM T1494 (Vedde Ash)}

HÄM_T1494 is found within both cores approximately midway through sediments correlated to the Younger Dryas Stadial. TSC of 3360 shards per $0.5 \mathrm{~g}$ occurs in core $\mathrm{H} 1$ and 6640 shards per $0.5 \mathrm{~g}$ in core $\mathrm{H} 2$. The shard concentration profile has a sharp basal peak, with only a small number of shards penetrating to $2 \mathrm{~cm}$ below. The peak in glass shard concentrations is largely constrained within $2 \mathrm{~cm}$ depth in both cores, with a gradually declining tail of shards observed above the peak. In core $\mathrm{H} 1$, glass shard concentrations do not drop below 10 shards per $0.5 \mathrm{~g}$ until $1476 \mathrm{~cm}$, in line with the lithozone $4-5 a$ transition (Figure 4.5). Glass shards are platy and many have bubble junction features. HÄM_T1494 is rhyolitic, with 71.5672.40 wt\% $\mathrm{SiO}_{2}$, 3.35-4.02 wt\% FeO, 1.33-1.55 wt\% $\mathrm{CaO}$ and 3.27-3.72 wt\% $\mathrm{K}_{2} \mathrm{O}$ (Figure 4.6 and 4.9). Based on its composition and stratigraphic position midway through the Younger Dryas, HÄM_T1494 is correlated to the Vedde Ash, erupted from the Katla volcano in Iceland. A similarity coefficient value of 0.98 occurs between HÄM_T1494 and the Vedde Ash. The Vedde Ash has been dated to $12,121 \pm 114 \mathrm{~b} 2 \mathrm{k}$ in the Greenland ice cores (Mortensen et al., 2005; Rasmussen et al., 2006), to 12,140 \pm 43 varve year BP in Meerfelder Maar (Lane et al., 2015) and to 12,023 \pm 43 cal BP by Bronk Ramsey et al., (2015a).

\section{Tephra occurrences between $1475-1449 \mathrm{~cm}$}

In lithozone 5a, tephra glass shards are present in variable concentrations of less than 12 shards per $0.5 \mathrm{~g}$ up until the next distinct deposit, HÄM_ T14451444 (described below)(Figure 4.5). Lithozone 5a is correlated to the early Holocene at Hämelsee (Figure 4.2). Whilst these concentrations are low, the demonstrated occurrence of tephra horizons in other sites across Europe 


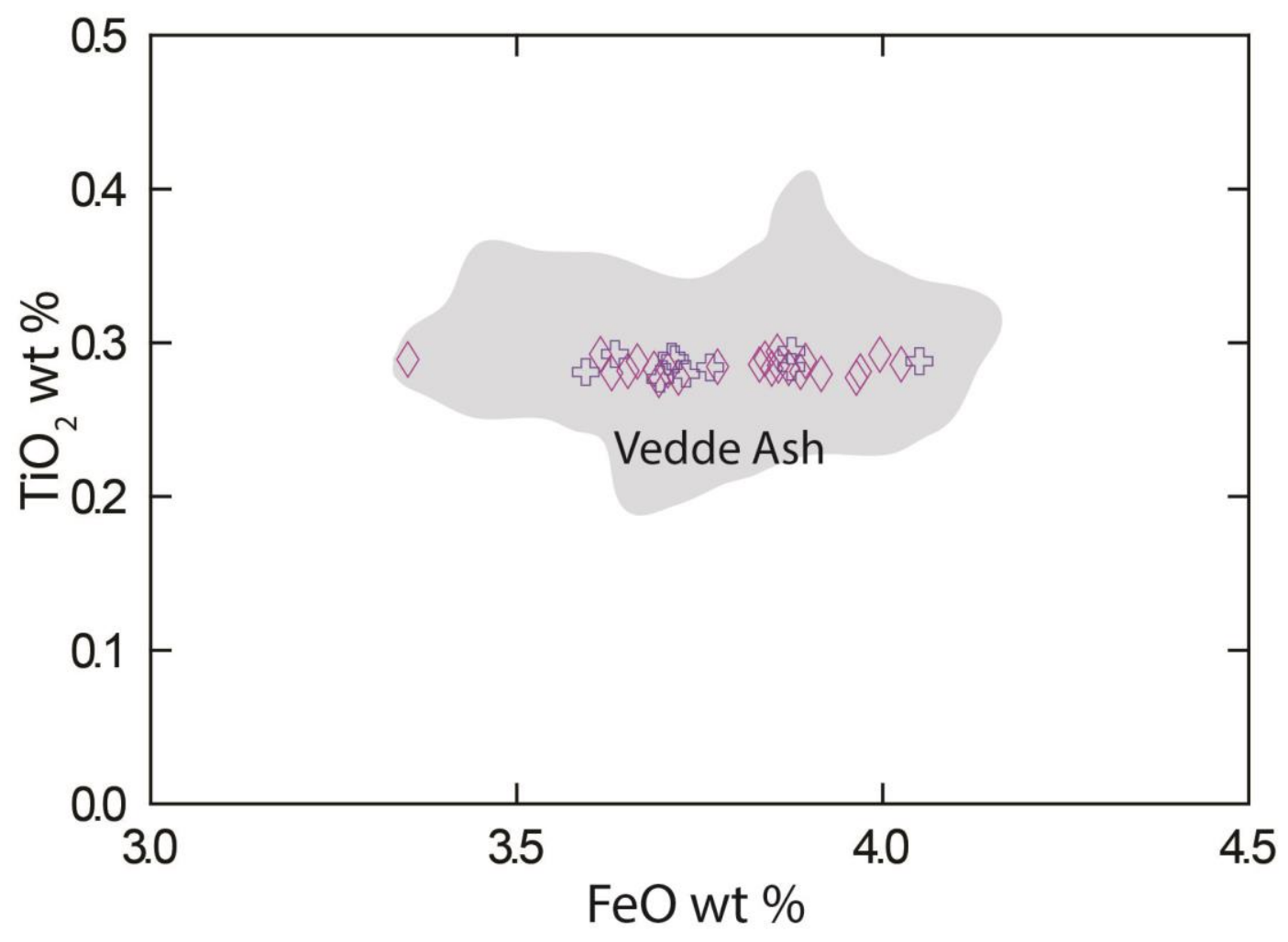

Figure 4.9 - Bivariate plot showing the correlation of HÄM_T1494 and HÄM_T1470 to the Vedde Ash (data from Lane et al., 2012a; Lane et al., 2012c; MacLeod et al., 2014). 
during this time (e.g. the Hässeldalen and Askja-S tephra deposits; Lane et al., 2012; Wulf et al., 2016) justified investigation of this interval at $1 \mathrm{~cm}$ resolution.

Three small peaks, which stood out above the background, were selected between 1449 and $1475 \mathrm{~cm}$ for geochemical analysis. These were HÄM_T1470, HÄM_T1456-1455 and HÄM_T1451. Adjacent samples HÄM_T1456 and HÄM_T1455 were processed separately, but are treated below as a single sample.

\section{i. $\quad$ HÄM T1470 (uncorrelated)}

This small peak has a TSC of 12 shards per $0.5 \mathrm{~g}$, lies $23 \mathrm{~cm}$ above the Vedde Ash horizon (HÄM_T1494) and is located in the early Holocene sediments. Glass shards are clear, with platy morphologies. Their rhyolitic composition is indistinguishable to that of HÄM_T1494 (correlated to the Vedde Ash) (Figure 4.9). A number of tephra deposits have been found in other European Lateglacial sequences that have glass shard compositions that are indistinguishable from the Vedde Ash (Lane et al., 2012). Most notable is the Abernethy Tephra, which has been identified lying close to the transition between the Younger Dryas and early Holocene (Matthews et al., 2011; MacLeod et al., 2015) and dated to $11462 \pm 122$ cal BP (Bronk Ramsey et al., 2015). The correlation of HÄM_T1470 to Abernethy Tephra, however, remains tentative and questionable, due to the continued appearance of shards of Vedde Ash composition right up until the start of the early Holocene in the Hämelsee record.

ii. $\quad$ HÄM T1456-1455 (uncorrelated)

A TSC of eleven shards per $0.5 \mathrm{~g}$ was counted between $1556-1555 \mathrm{~cm}$ depth, with seven shards per $0.5 \mathrm{~g}$ in the overlying sample (Figure 4.5). Glass shards are clear and have a platy morphology. Both samples were picked and analysed and both contain mixed populations of tephra. Across the two centimetre interval three compositional populations were observed. 
Population 1 contains 12 shards which are indistinguishable from HÄM_T1494 (correlated to the Vedde Ash). Population 2 contains nine shards which have a rhyolitic composition with 74.70-75.46 wt\% $\mathrm{SiO}_{2}, 13.18$ $13.88 \mathrm{wt} \% \mathrm{Al}_{2} \mathrm{O}_{3}, 1.29-1.75 \mathrm{wt} \% \mathrm{FeO}$. Comparisons were made with similarly aged tephras, including the Hässeldalen, Hovsdalur, Fosen, L-274, Suðuroy, An Druim, Breakish, Høvdarhagi, Abernethy, Skopun and Ashik, however no correlations were made suggesting that population 2 of HÄM_T1456-1455 may represent a previously unknown eruption (Figure 4.10). This population could be an additional isochronous marker for the early Holocene. One shard was analysed with a distinct trachytic composition, with $65.48 \mathrm{wt} \% \mathrm{SiO}_{2}, 0.91$ $\mathrm{wt} \% \mathrm{TiO}_{2}, 15.60 \mathrm{wt} \% \mathrm{Al}_{2} \mathrm{O}_{3}$ and $1.25 \mathrm{wt} \% \mathrm{MgO}$. A trachytic tephra is most likely from a non-Icelandic volcanic origin, however no matching tephra composition has yet been found and this shard remains uncorrelated (Figure 4.6).

iii. $\quad$ HÄM T1451 (Ulmener Maar?)

Tephra deposit HÄM_T1451 consists of shards with two types of morphology. A TSC of six clear, platy shards per $0.5 \mathrm{~g}$ and 389 highly crystallised particles per $0.5 \mathrm{~g}$ was observed (Figure 4.5). WDS-EPMA was only undertaken on the clear platy shards, of which 17 were analysed, revealing two populations with distinct chemical compositions. Population 1 contains 15 shards that are indistinguishable from HÄM_T1494 (correlated to the Vedde Ash) and population 2 contains two shards which are indistinguishable from HÄM_T1445-1444 (described below) (Figure 4.10). The highly crystallised particles are largely isotropic but the shape tends to be more rounded/sub-angular indicating formation from a crystal-rich melt (Lane et al., 2015). Whilst WDS-EPMA was not possible on these particles, they appear highly similar to tephra particles from the $\sim 11 \mathrm{ka}$ BP Ulmener Maar Tephra (UMT) observed in Meerfelder Maar and at other sites in western Germany (Zolitschka et al., 1995; Brauer et al., 1999; Lane et al., 2015). Based upon the morphological similarity and corresponding stratigraphic position at the onset of the Holocene, HÄM_T1451 could be associated with the UMT. However, the UMT is a product of quite a weak 

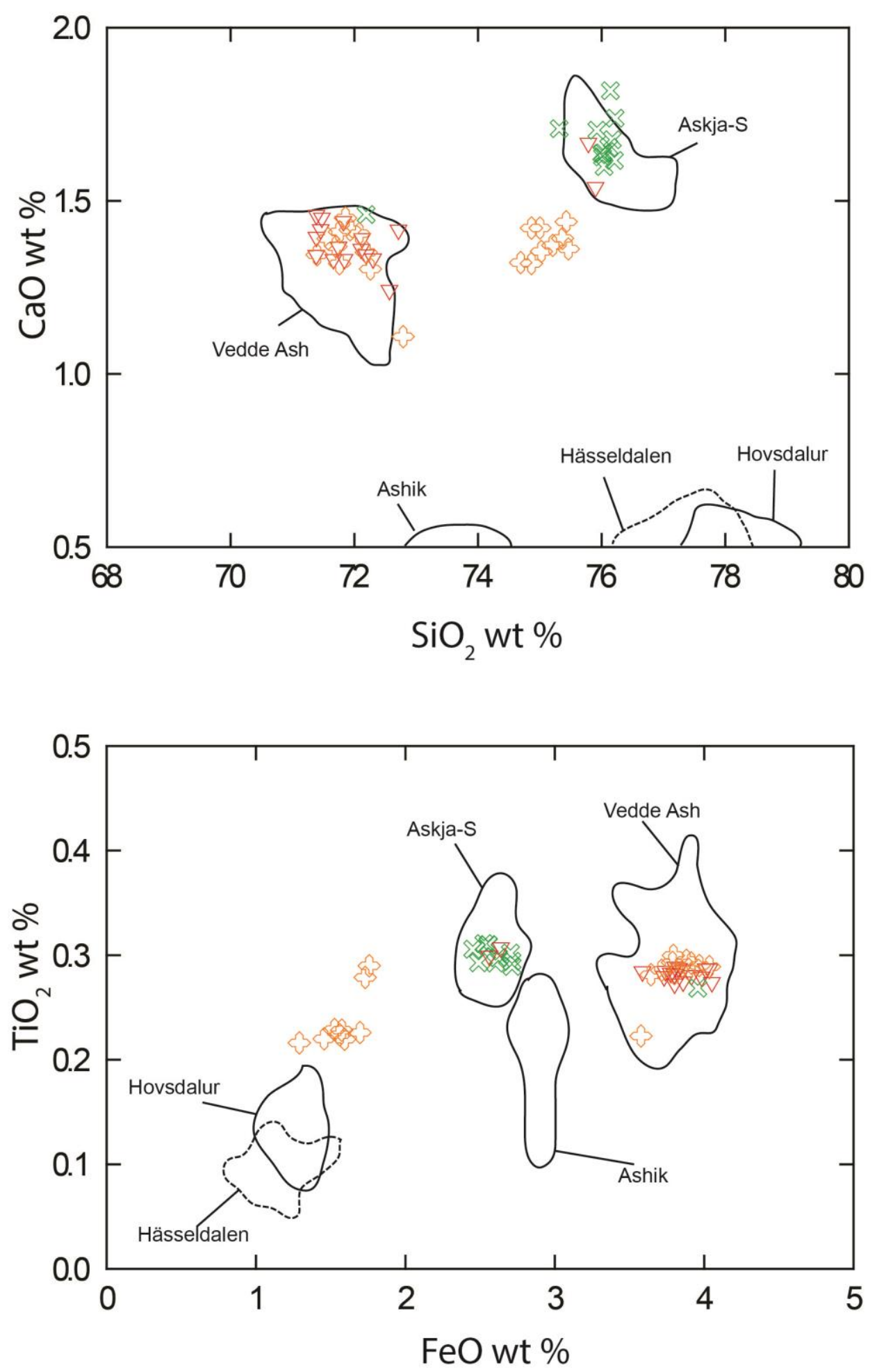

Figure 4.10 - Bivariate plot showing comparisons of HÄM_T1456-1455 and HÄM_T1451 to the Vedde Ash and Askja-S tephra. The correlation of HÄM_T1445-1444 to the Askja-S tephra (data from Wastegård, 2002; Pyne O'Donnell, 2007; Lilja et al., 2013; Lane et al., 2012; Wulf et al., 2016; Timms et al., 2016). 
phreatic eruption within the Eifel Volcanic Field, located $\sim 350 \mathrm{~km}$ south of Lake Hämelsee (Sabine Wulf, pers comm; Zolitschka et al., 1995; Brauer et al., 1999). In addition, the spatial distribution is restricted to local sites (Meerfelder Maar and Holzmaar) and only discovered in proximal to medial sites as a very thin layer. The lack of UMT discoveries, however, may be due to particles of such morphological features being ignored or missed within cryptotephra studies where glass shards of more typical morphology (platy, fluted, vesicular etc.) are the main focus. Due to the lack geochemical data and the restricted dispersal of the UMT reported in the literature, HÄM_T1451 is only tentatively correlated to the UMT and remain speculative that the crystalised particels are a product of the UMT eruption.

\section{HÄM T1445-1444 (Askja-S)}

This tephra deposit was found in both cores, with a concentration of 73 shards per $0.5 \mathrm{~g}$ in core $\mathrm{H} 1$ and 148 shards per $0.5 \mathrm{~g}$ in core $\mathrm{H} 2$ (Figure 4.5). Glass shards are clear and have platy and fluted morphologies. The shard concentration profile shows a sharp peak at $1445-1444 \mathrm{~cm}$ depth with a small amount of shards $1 \mathrm{~cm}$ below and above. Geochemical analysis was only undertaken on the tephra deposit in core $\mathrm{H} 1$ and has revealed a rhyolitic tephra with 75.31-76.21 wt\% $\mathrm{SiO}_{2}$, 2.45-2.71 wt\% $\mathrm{FeO}, 1.60-1.82 \mathrm{wt} \% \mathrm{CaO}$, 2.51-2.73 wt\% $\mathrm{K}_{2} \mathrm{O}$ (Figure 4.6 and 4.10), correlating to the Askja-S tephra. A similarity coefficient value of 0.98 between HÄM_T1445-1444 and the Askja-S supports this correlation. The age of the Askja-S Tephra has been modelled by Bronk Ramsey et al., (2015) to 10,830 \pm 57 cal BP, however, based on a varve-interval from the Hässeldalen tephra in Lake Czechowskie, Poland, Ott et al., (2016) provide an older age of 11,228 \pm 26 cal BP. Our results confirm that the Askja-S tephra is younger than the Ulmener Maar tephra, suggesting that the Ott et al., (2016) age estimate may be marginally too old. However, due to the centennial-scale uncertainties on individual ages for the Hässeldalen and Ulmener Maar tephra, in addition to the fact the UMT is only tentatively correlated to HÄM_T1451, a more precise age of the Askja-S tephra cannot be proposed. 


\section{$\underline{\text { HÄM T1401.5 (Saksunarvatn Ash) }}$}

The uppermost tephra deposit, visible in thin section analysis, has a very high TSC of 49,554 shards per $0.5 \mathrm{~g}$. Glass shards are brown and have blocky morphologies. The shard concentration profile has a sharp basal peak with no glass shards below (Figure 4.5). Gradually decreasing shard concentrations are observed up to $1394 \mathrm{~cm}$. Consistent with the findings of Merkt et al., (1993), geochemical analyses reveal a basaltic composition, with 48.68-51.46 wt\% $\mathrm{SiO}_{2}$, 2.72-3.18 wt\% $\mathrm{TiO}_{2}, 13.36-15.21 \mathrm{wt} \% \mathrm{FeO}$, 9.66-10.43 wt\% $\mathrm{CaO}$ (Figure 4.6), correlating to published data from the Saksunarvatn Ash (Figure 4.11). A similarity coefficient value of 0.98 occurs between HÄM_T1401.5 and the Saksunarvatn Ash. The Saksunarvatn Ash has been found in several terrestrial sites in Europe (Timms et al., 2016), and in marine core LINK 14:185 in the North Atlantic (Rasmussen et al., 2011; Davies et al., 2012). A tephra deposit of the same major element composition has also been identified in the GRIP ice core (Grönvold et al., 1995; Davies et al., 2012) with an age of 10,297 \pm 45 b2k (Rasmussen et al., 2006). However, Davies et al., (2012) demonstrate a compositional difference between the tephra in GRIP and LINK 14:185 based on trace element data which may suggest two separate eruptions occurred closely spaced in time, with two ash plumes directed in opposite directions to one another. Consequently, HÄM_T1401.5 is correlated to the eruption that dispersed ash in a south easterly direction, as initially recognised by Mangerud et al., (1984). The Saksunarvatn Ash has been dated at Kråkenes to $10,210 \pm 35$ cal BP (Lohne et al., 2014).

Table 4.2 and Figure 4.12 summarises the tephra deposits found in the Lake Hämelsee sequence, their proposed correlatives and reference age estimates. 


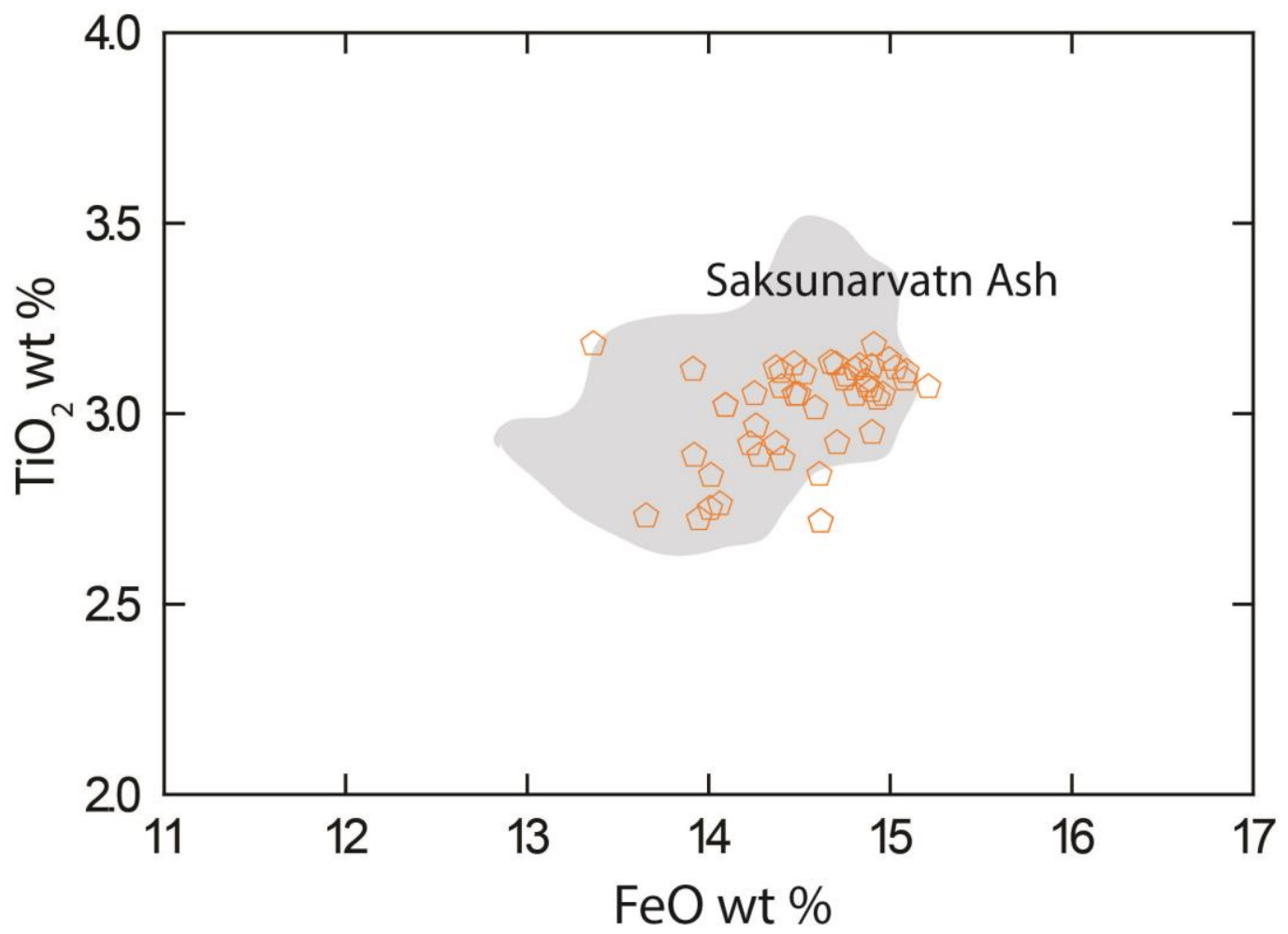

Figure 4.11 - Bivariate plot showing the correlation of the basaltic shards of HÄM_T1401.5 to the Saksunarvatn Ash (data from Lind et al., 2011; Davies et al., 2012; Bramham-Law et al., 2013). 


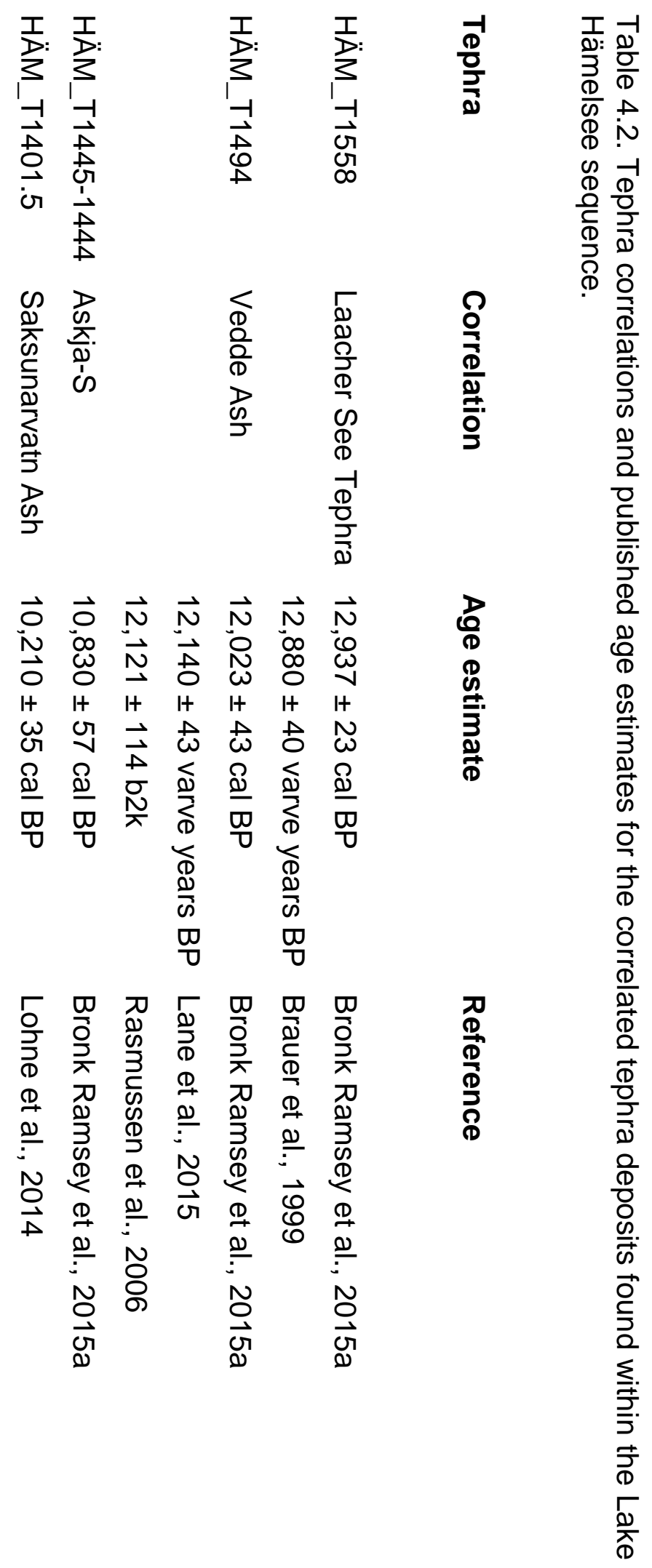




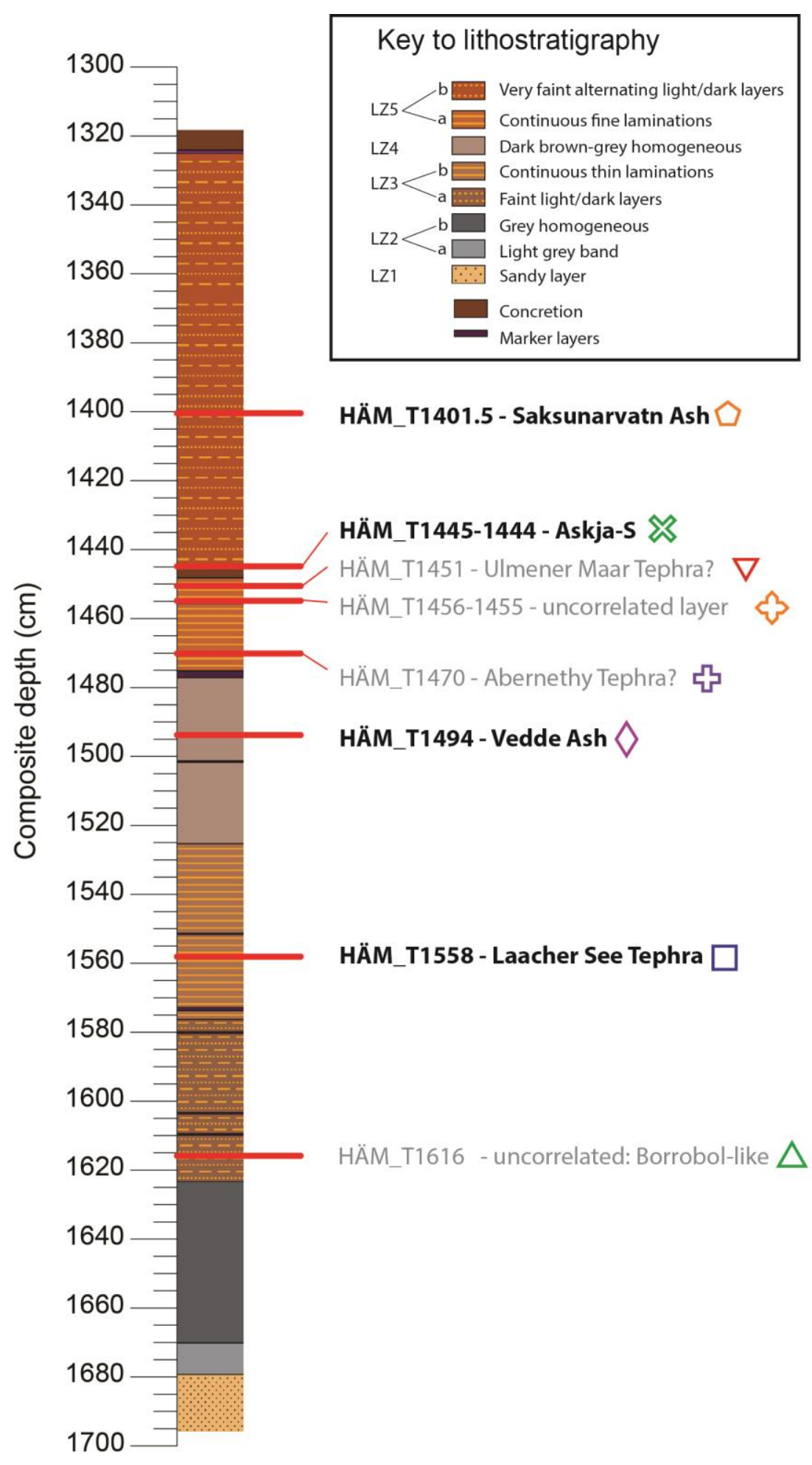

Figure 4.12 - Lake Hämelsee tephrostratigraphy between $1300-1700 \mathrm{~cm}$ composite depth plotted against lithostratigraphy. Tephra deposits are labelled according to the main text, along with the tephra correlation, and geochemical symbol as referred to in Figure 4.5-4.10. 


\section{Results - Llyn Llech Owain, Carmarthenshire}

This chapter presents the Llyn Llech Owain results including geochemistry, diatom analysis, tephra analysis and radiocarbon dating. Pollen results from previous studies by Walker \& Jones, (2006) and Walker et al., (2009) are also presented.

\subsection{Site description}

Llyn Llech Owain ( $51^{\circ} 48^{\prime} 55^{\prime \prime} \mathrm{N}, 4^{\circ} 4^{\prime} 44^{\prime \prime} \mathrm{W}$ ) is a small lake, approximately $250 \mathrm{~m}$ long and $200 \mathrm{~m}$ wide, located $4 \mathrm{~km}$ north of Cross Hands (Figure 5.1). The lake is situated approximately $260 \mathrm{~m}$ above sea level and lies within the Twrch Sandstone Formation. Along the east, south and western fringes of the lake, boggy mire surfaces have developed. A full Lateglacial sediment sequence was retrieved by Walker et al., (2009) from the western fringing area of the lake, close to an outflowing stream. New core sequences were retrieved from the same area in October 2013, using a Russian sampler (5 $\mathrm{cm}$ diameter), during which the Lateglacial tripartite sedimentary sequence was successfully retrieved. In this study, sediment geochemistry, diatom analysis, tephra and radiocarbon dating was undertaken on the 2013 core sequence, whilst only tephra analysis was undertaken on the Holocene part of the 2009 core sequence. A pollen diagram and two radiocarbon dates for the 2009 core sequence are presented in Walker \& Jones, (2006) and Walker et al., (2009) (Figure 5.2 and 5.3). 


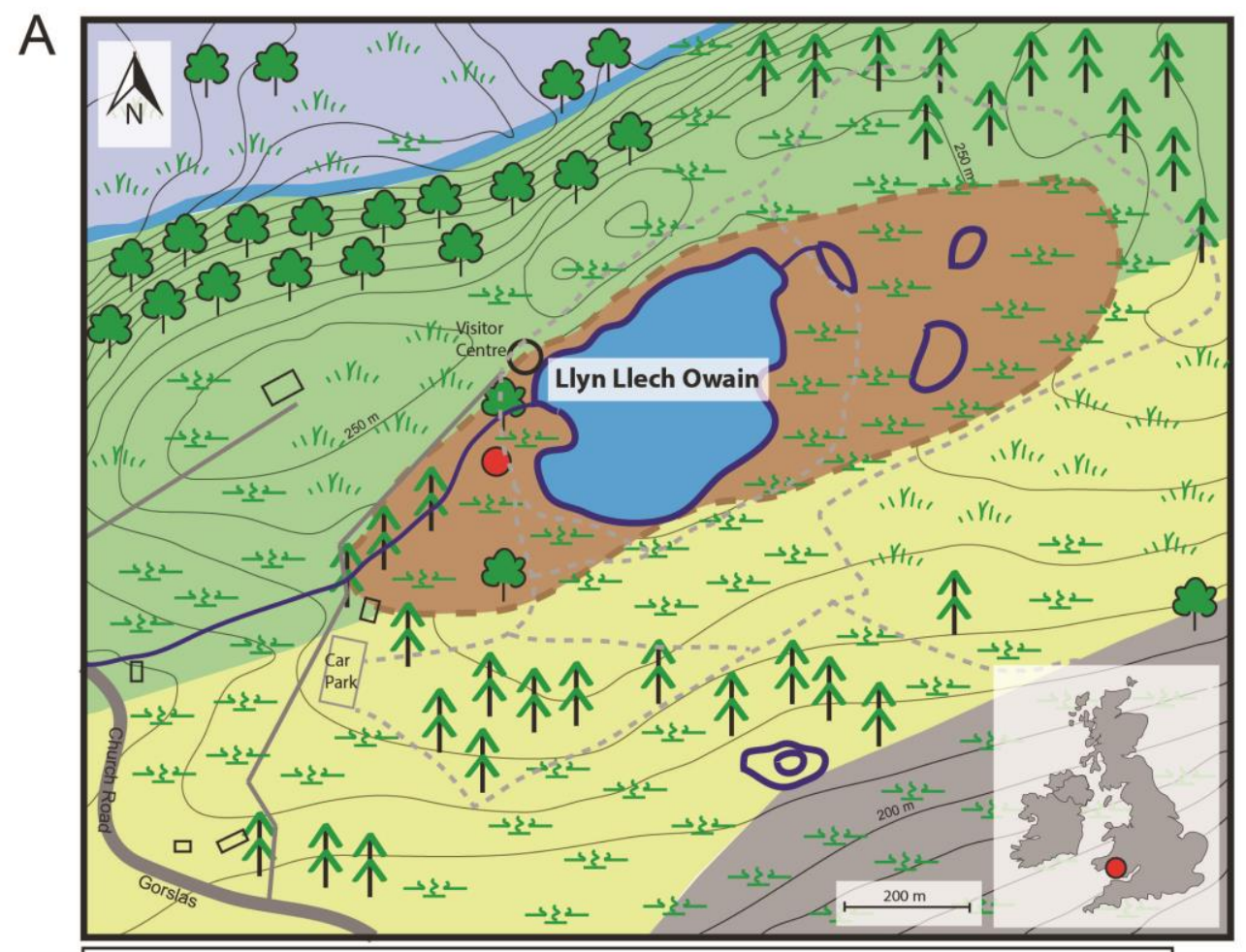

\begin{tabular}{|c|c|c|c|c|}
\hline Core location & Non-coniferous trees & $\rightarrow \geq-$ Marsh & Penderyn Oolite Member & Bishopston Mudstone Formation \\
\hline $\begin{array}{l}\text { Road } \\
\text { Contour lines }\end{array}$ & Coniferous trees & $\therefore W_{t}$, Grass & $\begin{array}{l}\text { Oxwich Head Limestone } \\
\text { Formation }\end{array}$ & $\begin{array}{l}\text { South Wales Lower Coal } \\
\text { Measures Formation }\end{array}$ \\
\hline N... Footpath & Ponds / Streams & & Twrch Sandstone Formation & Peat deposits \\
\hline
\end{tabular}

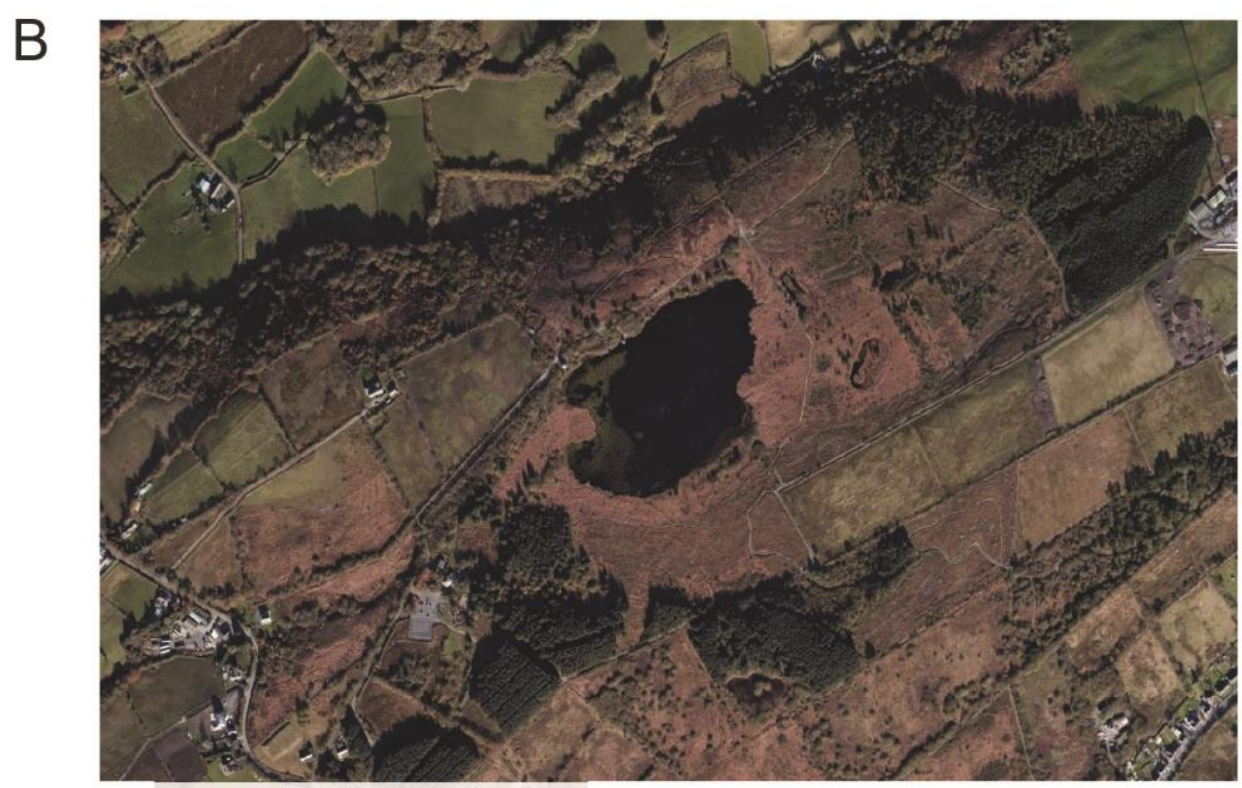

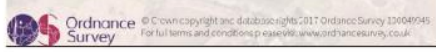

Figure 5.1 - A) Location of Llyn Llech Owain, bedrock geology and coring location. B) Aerial photograph of Llyn Llech Owain. Contains British Geological Survey Bedrock Geological Map and Ordnance Survey data () Crown Copyright and database rights 2017. 


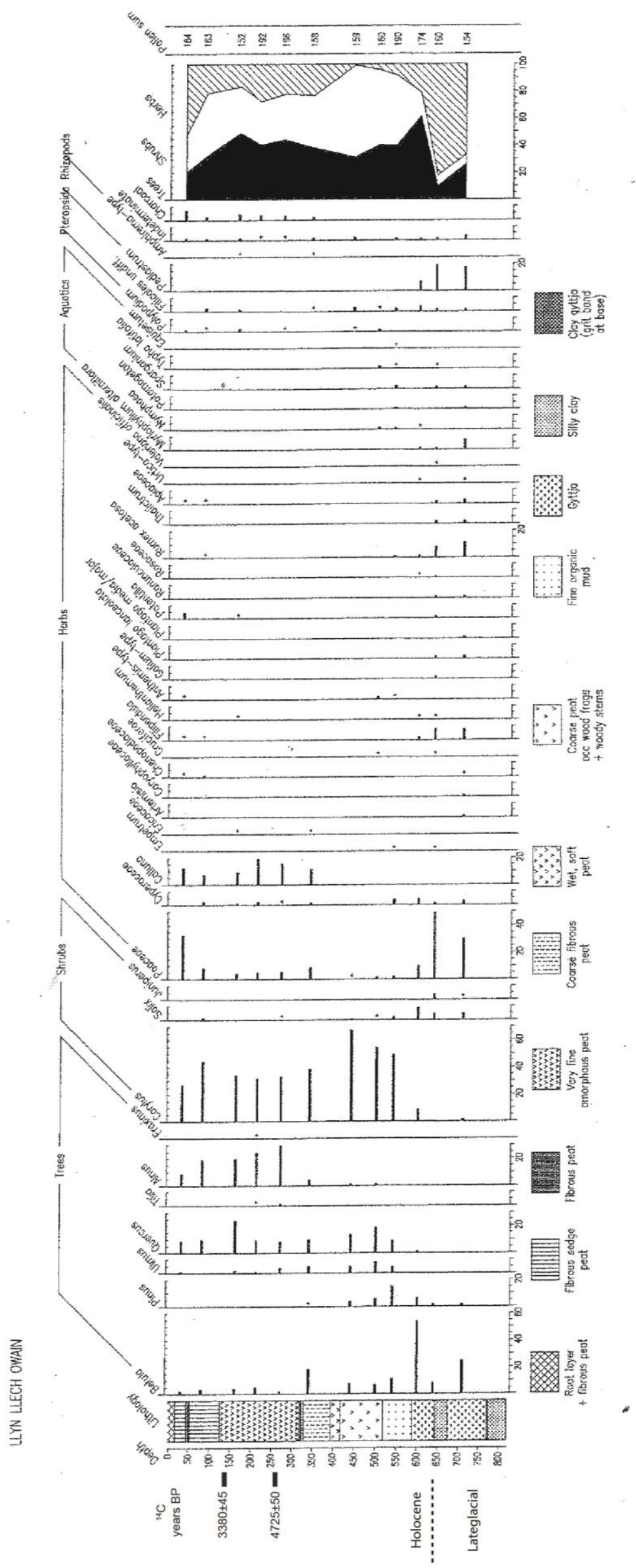

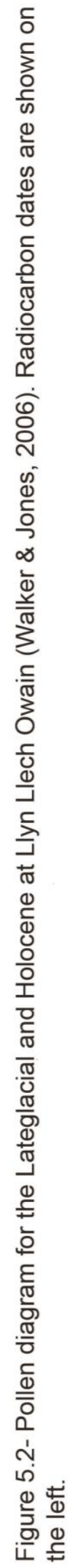




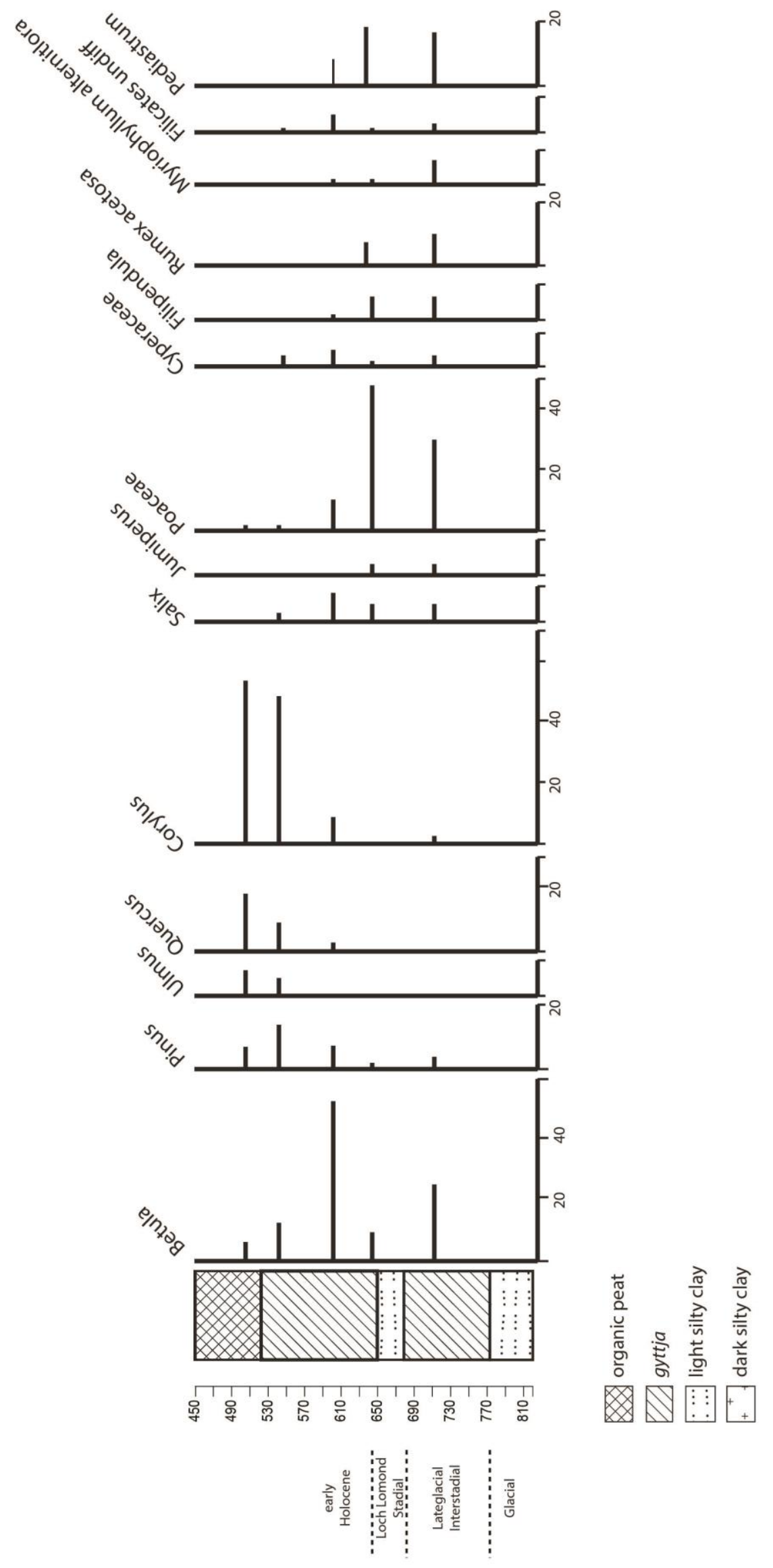

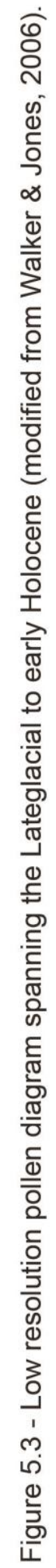




\subsubsection{Previous work at Llyn Llech Owain}

The classic Lateglacial tripartite sediment sequence, showing the typical shifts from gyttja to silty clay and followed by early Holocene gyttja, was first established at Llyn Llech Owain by Mike Walker and colleagues. A lowresolution pollen diagram was established by Walker \& Jones, (2006) and Walker et al., (2009) showing the vegetation changes through the Lateglacial and Holocene (Figure 5.2). The results show the typical vegetation changes akin to other Lateglacial sites in Wales (e.g. Walker et al., 2003). Only five samples were analysed for pollen during the Lateglacial; one in the Lateglacial Interstadial, another one spanning the Loch Lomond Stadial early Holocene transition and three during the early Holocene (Figure 5.3). The pollen assemblages indicate the presence of birch woodland during the Lateglacial Interstadial, followed by a shift to a tundra landscape, with Poaceae dominating, during the Loch Lomond Stadial. At the Holocene onset the plant succession changed significantly from open shrub tundra at $650 \mathrm{~cm}$ to birch/hazel woodland at $600 \mathrm{~cm}$ (Figure 5.3). Two radiocarbon dates were obtained at $141 \mathrm{~cm}$ and $259 \mathrm{~cm}$ (Figure 5.2) which provided age constraints for the mid-Holocene part of the sequence.

\subsection{Lithostratigraphy}

A lithostratigraphic description and core images of the new core sequence (retrieved in 2013) are presented in Figure 5.4. An $8.2 \mathrm{~m}$ sequence was retrieved from the site but bedrock was not reached. A basal grey clay unit forms the lowermost unit $(820-781 \mathrm{~cm})$ and the corer could not penetrate through this deposit. This unit is believed to represent sediments of Glacial (or GS-2) age. A gradual transition (over $\sim 7 \mathrm{~cm}$ ) is observed between this basal unit and the overlying organic lake mud (gyttja) deposit between 781$710 \mathrm{~cm}$. At $710 \mathrm{~cm}$ a sharp transition to a light grey silty clay unit is 


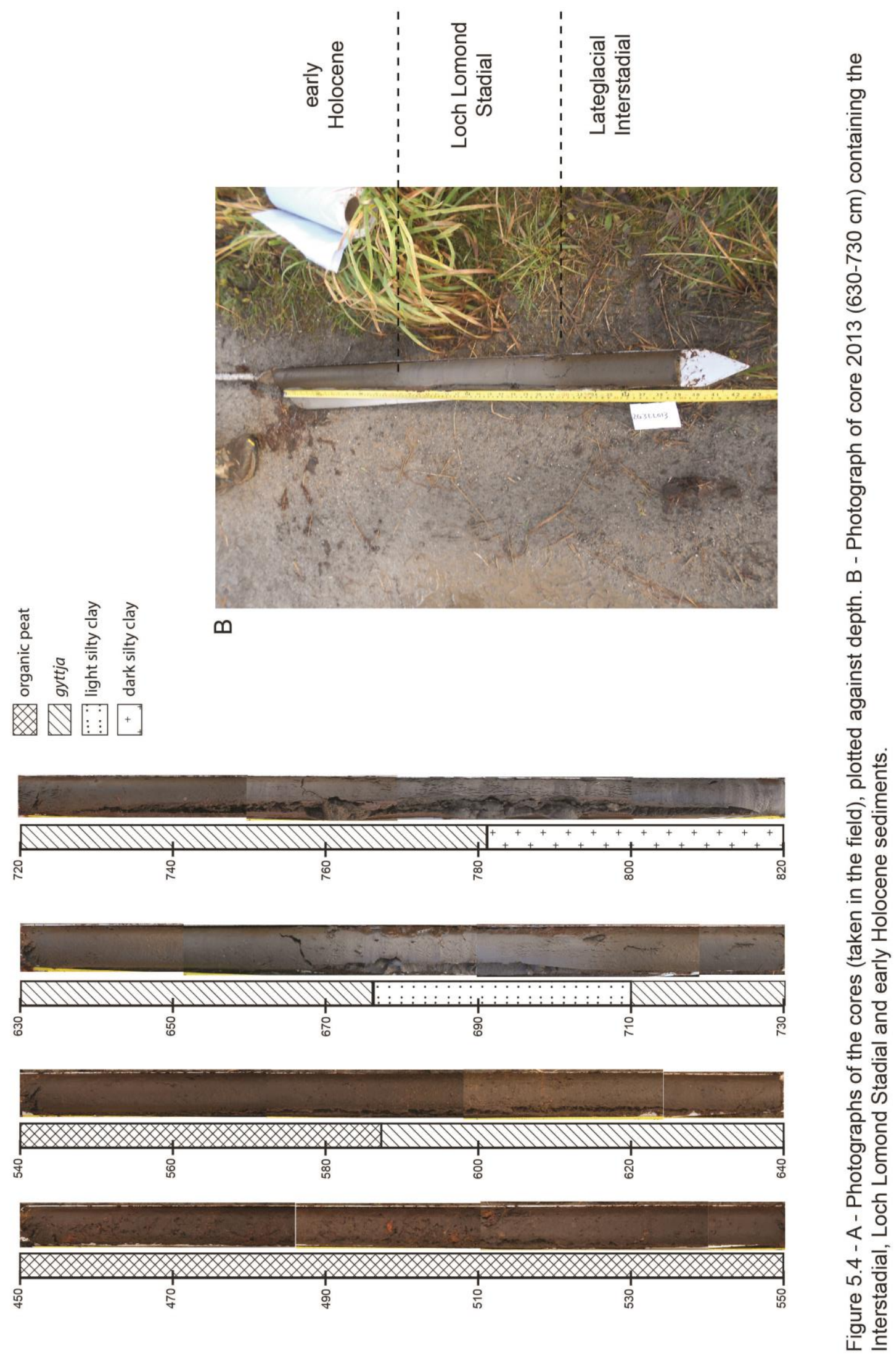


observed, distinctive of the Loch Lomond Stadial $(710-675 \mathrm{~cm})$. This clay unit is $35 \mathrm{~cm}$ thick and at $675 \mathrm{~cm}$ a gradual transitional change occurs (over $\sim 10$ $\mathrm{cm}$ ) into brown lake muds (gyttja) representing increased organic accumulation following the onset of the Holocene. A further lithostratigraphic change occurs at $587 \mathrm{~cm}$ where the sediments change to dark organic peat. This lithostratigraphic tripartite sequence is characteristic of the Lateglacial found at numerous other sites across the UK (e.g. Walker et al., 2003; Walker et al., 2012; Pyne O’Donnell et al., 2008).

The 2009 core sequence spans from $520-270 \mathrm{~cm}$ and represents the early Holocene to $\mathrm{mid} / \mathrm{late}$ Holocene. Coarse dark brown peat represents the lowermost unit, between $520-418 \mathrm{~cm}$, with the occasional wood fragments and woody stems present. This unit is followed by a smaller unit of very wet fine soft peat between $418-395 \mathrm{~cm}$. Coarse fibrous peat represents the next unit between $395-330 \mathrm{~cm}$ followed by very fine dark brown amorphous peat between $330-270 \mathrm{~cm}$.

\subsection{Bulk Sediment Chemistry (\%C, \%N and $\left.\delta^{13} \mathrm{C}\right)$}

Samples were analysed at $1 \mathrm{~cm}$ resolution throughout the whole 2013 core sequence from $820-450 \mathrm{~cm}$. As noted in section 3.3.2, analyses were performed on acid-treated and untreated samples to determine whether acid treatment was necessary to eliminate the presence of carbonate. These analyses were undertaken on 16 samples, 4 samples each from the main lithostratigraphic units (Table 5.1 and Figure 5.5).

The $\% \mathrm{C}, \% \mathrm{~N}$ and $\delta^{13} \mathrm{C}$ values are very similar for both untreated and acid treated samples (Figure 5.5). For the minerogenic samples very little difference is observed between the untreated and treated samples (Figure 5.5) but some offsets are seen in the more organic samples especially in the $\% \mathrm{C}$ profile. For the latter, the treated samples contain slightly higher \%C values, although only 2 samples are outside the standard deviation of the acetanilide standards measured during isotopic and elemental analysis. 
Higher $\% \mathrm{C}$ values are normally expected in the untreated samples. These slight offsets probably reflect the natural variability/heterogeneity nature of the samples where slightly differing values would be expected.

Table 5.1 - Bulk sediment chemistry results $\left(\% \mathrm{C}, \% \mathrm{~N}\right.$ and $\left.\delta^{13} \mathrm{C}\right)$ on acid treated and untreated samples (see section 3.3.2).

\begin{tabular}{|c|c|c|c|c|c|c|}
\hline \multirow{2}{*}{ Sample } & \multicolumn{3}{|c|}{ Untreated } & \multicolumn{3}{c|}{$\begin{array}{c}\text { 10\% HCl } \\
\text { treated }\end{array}$} \\
\cline { 2 - 7 } depth (cm) & $\%$ N & $\%$ C & VPDB & $\%$ N & $\%$ C & VPDB \\
\hline $640-641$ & 2.70 & 29.75 & -24.81 & 2.87 & 32.76 & -24.57 \\
$650-651$ & 2.94 & 28.27 & -24.34 & 3.10 & 31.24 & -24.12 \\
$660-661$ & 2.55 & 27.21 & -19.86 & 2.75 & 30.90 & -19.41 \\
$670-671$ & 1.34 & 13.32 & -19.16 & 1.48 & 15.11 & -19.66 \\
$680-681$ & 0.23 & 2.06 & -22.27 & 0.16 & 1.87 & -22.22 \\
$690-691$ & 0.23 & 2.01 & -22.62 & 0.17 & 1.87 & -22.50 \\
$695-696$ & 0.29 & 2.83 & -23.26 & 0.24 & 2.76 & -23.20 \\
$700-701$ & 0.36 & 3.76 & -22.81 & 0.32 & 3.66 & -22.62 \\
$710-711$ & 1.80 & 18.23 & -22.03 & 1.99 & 20.79 & -21.92 \\
$720-721$ & 1.34 & 17.77 & -21.89 & 1.47 & 19.58 & -21.71 \\
$740-741$ & 1.47 & 17.92 & -22.09 & 1.61 & 19.58 & -22.45 \\
$760-761$ & 2.44 & 27.58 & -23.29 & 2.68 & 30.92 & -22.83 \\
$780-781$ & 0.61 & 6.53 & -22.47 & 0.54 & 6.54 & -22.45 \\
$790-791$ & 0.60 & 6.78 & -22.87 & 0.55 & 6.51 & -23.06 \\
$800-801$ & 0.50 & 5.73 & -22.37 & 0.47 & 5.63 & -22.54 \\
$810-811$ & 0.39 & 3.93 & -22.55 & 0.32 & 3.73 & -22.48 \\
\hline
\end{tabular}

A Wilcoxon matched pairs signed ranks test was undertaken on the $\% \mathrm{C}$ data which revealed a $T$ value of 35 . Given $n=16$, the two tail critical value for $p=$ 0.05 and 0.01 are 29 and 19 , thus the difference is not statistically significant. Despite these small offset, the results confirm that no carbonates are present in the sediments at Llyn Llech Owain. As such, the acid pre-treatment step was omitted for subsequent samples analysed in this way. 


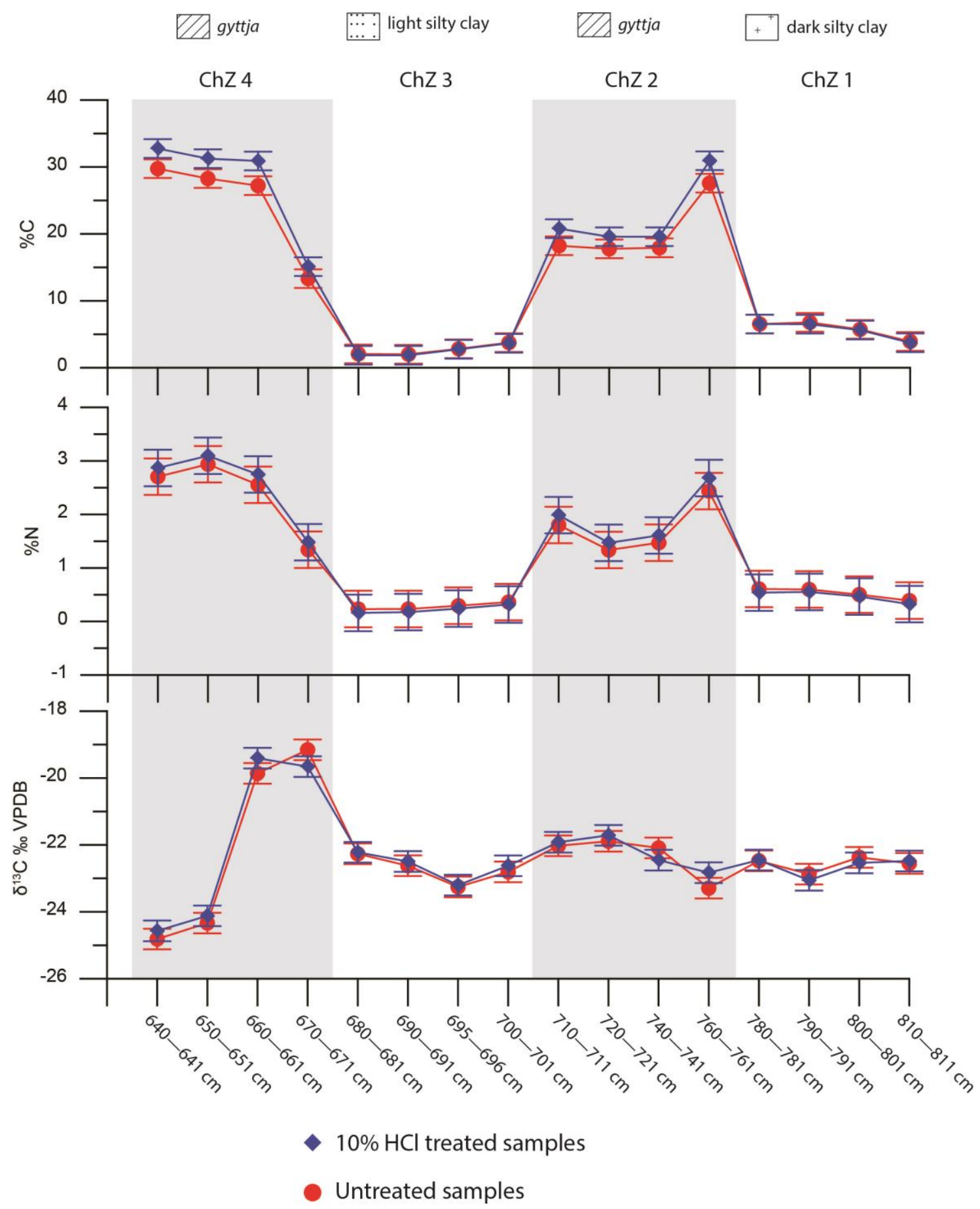

Figure 5.5 - Analyses performed on acid-treated and untreated samples to determine whether acid treatment was necessary to eliminate the presence of carbonate. Standard deviation of the acetanilide standards measured during isotopic and elemental analysis also inserted. 
The complete bulk sediment chemistry profiles are plotted alongside the lithostratigraphy in Figure 5.6. In general, the bulk sediment chemistry profiles reflect the major changes in the lithostratigraphic units. Five zones have been assigned to this sequence; Chemistry Zones (ChZ) 1 - 5, based on visual changes in the \% $\%$, record and lithostratigraphy. The $\mathrm{C}: \mathrm{N}$ and $\delta^{13} \mathrm{C}$ values within each zone are plotted on a Meyers plot, which distinguishes the different sources of organic matter (aquatic/algal or terrestrial) (Meyers, 1994) (Figure 5.7).

Low \%C values $(0-8 \%)$ and $\% \mathrm{~N}$ values $(<0.6 \%)$ characterise the basal clay unit ChZ1 indicative of a cold (glacial) environment. With the exception of one sample at $815 \mathrm{~cm}, \mathrm{C}: \mathrm{N}$ ratio values are largely constant at $\sim 10$ in this zone. A short-lived peak of 14 in $\mathrm{C}: \mathrm{N}$ ratios at $815 \mathrm{~cm}$, is accompanied by a peak of $14 \%$ in the $\delta^{13} \mathrm{C}$ data, which is more characteristic of marine sediments. This sample was re-analysed and revealed similar values. This increase is only represented by a single sample and with no indication of any lithostratigraphical change this is interpreted as an anomalous result. With the exception of $815 \mathrm{~cm}, \delta^{13} \mathrm{C}$ values are relatively stable in this zone with values ranging from -21 to $-24 \%$. The low $\% \mathrm{C}$ values during this zone reflect low productivity within the lake with the $\delta^{13} \mathrm{C}$ and $\mathrm{C}: \mathrm{N}$ values indicating that the small amount of organic matter present during this period is aquatic algal matter. $\delta^{13} \mathrm{C}$ values of -21 to $-24 \%$ and $\mathrm{C}: \mathrm{N}$ values of $9-11$ are typical of algal/aquatic sources (Meyers and Lallier-Vergès, 1999) (Figure 5.7).

A substantial change is observed in the $\% \mathrm{C}$ and $\% \mathrm{~N}$ profiles for the overlying ChZ 2 zone which corresponds with the gyttja unit between 779 and $710 \mathrm{~cm}$. Two distinct phases are seen here, $\mathrm{ChZ} 2 \mathrm{a}$ and $2 \mathrm{~b}$ separated at $748 \mathrm{~cm}$. A marked increase is evident from low \%C values $(6 \%)$ and $\% \mathrm{~N}$ values $(0.6 \%)$ at $779 \mathrm{~cm}$ to $23 \%$ and $2 \%$ at $772 \mathrm{~cm}$, respectively. These increases may indicate climatic warming and an increase in organic productivity within the lake, a shift that typically characterises the Lateglacial Interstadial. Lower \%C and $\% \mathrm{~N}$ values characterise the overlying $\mathrm{ChZ} 2 \mathrm{~b}$ subzone indicating internal variability during the Interstadial. Bulk organic carbon results fluctuate between 19 and $29 \%$ between 772 and $748 \mathrm{~cm}$ within ChZ 2a whereas ChZ 


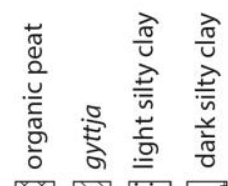 \\ $\otimes \mathbb{1}: \vdots+$}

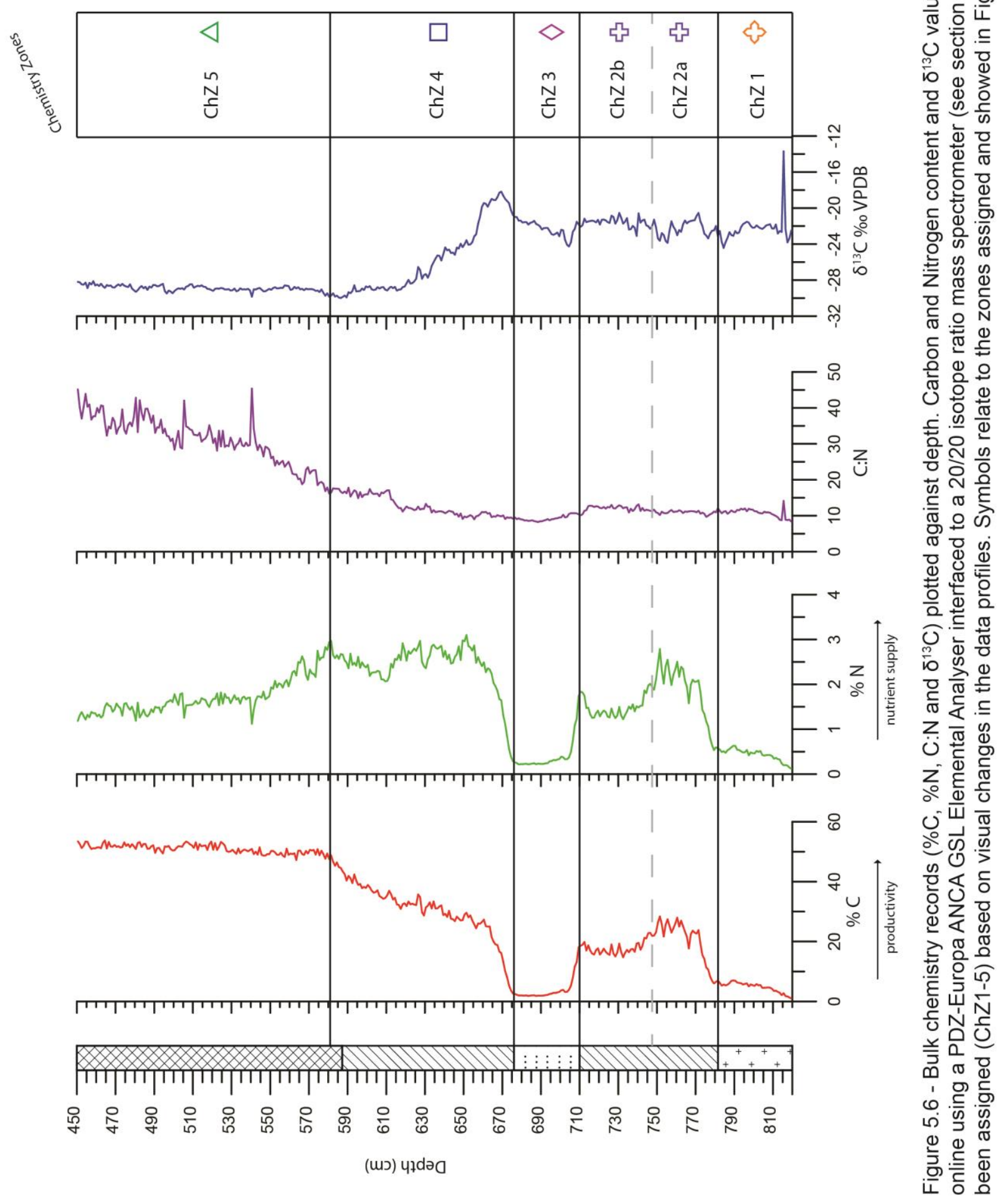




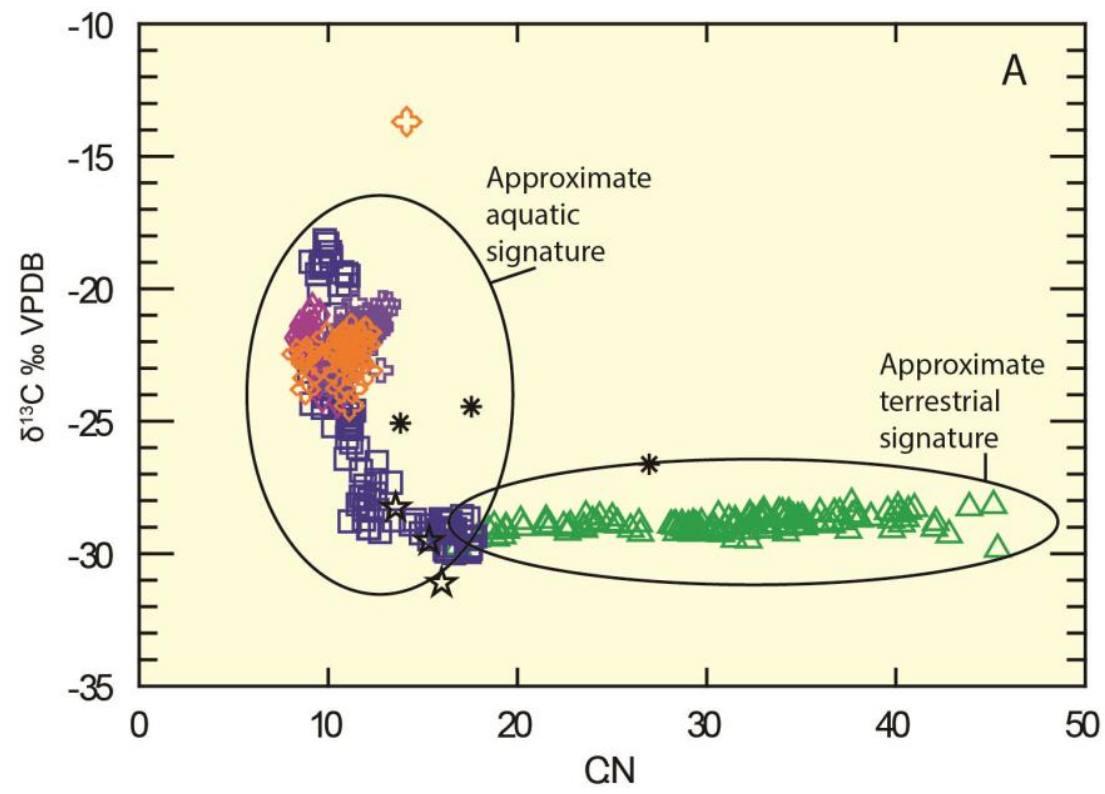

ChZ5 $\triangle$

ChZ 4

ChZ3

ChZ2 ほ

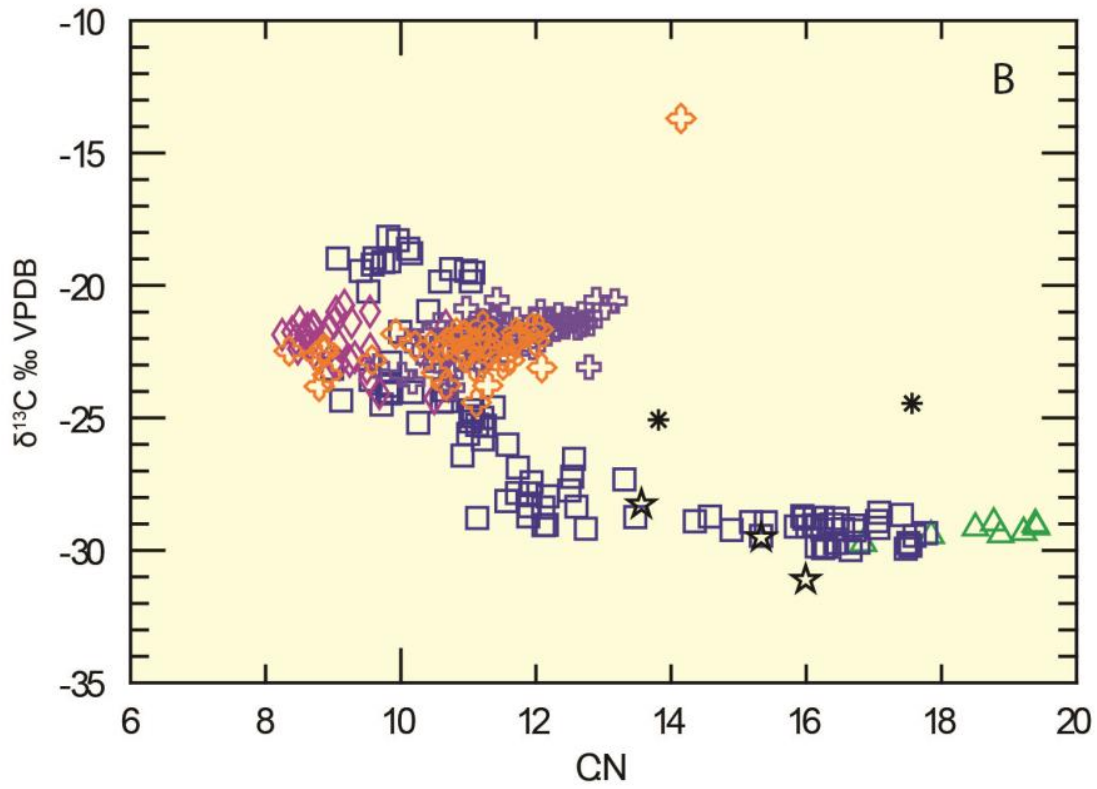

ChZ 1

Modern

Marestail *

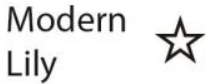

Modern
Lily

Figure 5.7 - Meyers $\left(\delta^{13} \mathrm{C}\right.$ vs $\left.\mathrm{C}: \mathrm{N}\right)$ bi-plots (Meyers, 1994). Plot A illustrates the whole data set. Approximate terrestrial and aquatic signature envelopes are inserted (modified from Meyers,1994, Meyers Lallier-Vergès, 1999 and Mackie et al., 2005). Plot B is zoomed in on the aquatic vegetation types. Measurements on modern macrophyte vegetation (Marestail and Water Lily) were sampled and analysed by N. Loader. Symbols relate to the zone (ChZ1-5) based on the visual changes in the data profiles in Figure 5.6. 
2b $(748-710 \mathrm{~cm})$ is characterised by slightly lower ( $18 \%)$ and more stable $\% \mathrm{C}$ values. Similar, but more pronounced, trends are also seen in the \%N profile. These values in ChZ $2 a$ indicate higher vegetation productivity and nutrient supply which may suggest a warmer or more favourable climatic condition for vegetation growth compared with $\mathrm{ChZ} 2 \mathrm{~b}$. C:N ratios remain fairly constant at around 11 throughout $\mathrm{ChZ} 2$. The $\delta^{13} \mathrm{C}$ profile also remains relatively stable throughout ChZ 2 with values ranging from -24 to $-20.5 \%$ indicating the likely vegetation type contribution to the sediments throughout the Lateglacial Interstadial to be largely aquatic algal matter.

ChZ 3 consists of very low and constant \%C ( 3\%) and \%N ( 0.3\%) values from 705 to $675 \mathrm{~cm}$ indicative of a return to cold conditions and low productivity within the lake itself, typical of the Loch Lomond Stadial. The transition from ChZ 2 to ChZ 3 occurs over $5 \mathrm{~cm}$ indicating a rapid lake response to the sudden climatic change at the Loch Lomond onset. A short lived peak in \%N occurs at $711 \mathrm{~cm}$ prior to the transition into $\mathrm{ChZ} 3$ possibly indicating a sudden in-flux of nutrients into the lake. C:N ratios decrease slightly to 9 in ChZ 3 but remain stable throughout this zone. A short lived decrease in $\delta^{13} \mathrm{C}$ values to $-24 \%$ occurs at $705 \mathrm{~cm}$ and is followed by a gradual increase to $-21 \%$ at $675 \mathrm{~cm}$. Low \%C values suggest that the relative amount of vegetation in the surrounding catchment is reduced and the $\delta^{13} \mathrm{C}$ values indicate that aquatic algal matter is the likely dominant source.

ChZ 4 is characterized by another sudden change with an increase in \%C and $\% N$. An increase in $\% \mathrm{C}$ values is observed from $2 \%$ at $675 \mathrm{~cm}$ to $25 \%$ at $664 \mathrm{~cm}$ indicating a significant increase in lake productivity during this period. A similar trend is also seen in the \%N profile for the same depths. This shift in lithostratigraphy from light silty clay to more organic gyttja sediments and bulk sediment chemistry is indicative of the early Holocene warming. Bulk carbon values then show a gradual increase over $84 \mathrm{~cm}$ to $48 \%$ at $580 \mathrm{~cm}$. Nitrogen values are relatively stable during this period, however some fluctuations are evident at $645 \mathrm{~cm}, 630 \mathrm{~cm}$, and $610 \mathrm{~cm}$ possibly indicating short-lived episodes of depleted nutrient supply into the lake. 
Significant changes are observed in the $\delta^{13} \mathrm{C}$ record at $\mathrm{ChZ} 4$ reflecting changes in the vegetation composition. A short-lived increase in $\delta^{13} \mathrm{C}$ values is observed at the onset of ChZ 4 where values increase to around $-19 \%$ and persist for $13 \mathrm{~cm}$ between $673-660 \mathrm{~cm}$. The more positive values at these depths may indicate a change in vegetation type from algal matter within an open/deep lake environment, which persisted throughout the Lateglacial Interstadial and Loch Lomond Stadial, to perhaps a more aquatic macrophyte type vegetation. This change may indicate a lowering lake level and/or infilling of the lake during this period. This fluctuation is followed by a decrease in $\delta^{13} \mathrm{C}$ values from $-19 \%$ at $660 \mathrm{~cm}$ to $-29 \%$ at $617 \mathrm{~cm}$. The $\delta^{13} \mathrm{C}$ values remain stable at around $-29 \%$ for the rest of $\mathrm{ChZ} 4$ and throughout ChZ 5 indicating a more terrestrial plant composition dominating the lake catchment where the core was retrieved.

The core was retrieved from the rim of the current lake (Figure 5.1) and the $\delta^{13} \mathrm{C}$ record provides an insight into the infilling and development of a mire environment at the fringes. During the Lateglacial Interstadial and Loch Lomond Stadial, the lake is likely to have been larger and deeper where the coring location may have been located in open water. This is indicated by the $\delta^{13} \mathrm{C}$ values indicating an algal vegetation composition. The changes in $\delta^{13} \mathrm{C}$ values within $\mathrm{ChZ} 4$, however indicate a more macrophyte type vegetation which may reflect shifts in lake-level or the start of infill. Measurements on modern macrophyte vegetation (Marestail and Water Lily) (sampled opportunistically and analysed by Prof Neil Loader) shown in and 5.7 yielded values similar to the bulk samples in ChZ 4, supporting the interpretation for this part of the sequence. Further changes in the $\delta^{13} \mathrm{C}$ record within $\mathrm{ChZ} 4$ where more negative values occur at $652 \mathrm{~cm}$, may indicate further infill of the lake where the coring location may have developed to a mire environment as seen today.

ChZ 5 is characterised by relatively constant \%C values (47-54\%) between $580 \mathrm{~cm}$ and $450 \mathrm{~cm}$ indicating minimal minerogenic in-wash from the catchment and the encroachment/lake infill as seen today. A gradual decrease in $\% \mathrm{~N}$ values is observed from $3 \%$ at $580 \mathrm{~cm}$ to $1.5 \%$ at the top of the sequence. The $\mathrm{C}: \mathrm{N}$ profile gradually increases and is characterised by 
distinct fluctuations, from values around 17 at $580 \mathrm{~cm}$ to around 40 at the top of the sequence indicating a more bog/terrestrial environment with terrestrial vegetation dominating the core location. The terrestrial vegetation signature is also distinct in the Meyers plot (Figure 5.7).

\subsection{Sediment geochemistry by X-ray fluorescence (XRF)}

Selected XRF elemental profiles are shown in Figure 5.8 and the full dataset, retrieved by an ITRAX XRF core scanner is available in the appendix. The $\mathrm{Ti}$ and $\mathrm{K}$ data have been normalized by the sum of the incoherent and coherent values and plotted as a 10 point moving average. The $\mathrm{Ti}$ and $\mathrm{K}$ record has also been sub-divided into zones (XZ 1-5) based on visual changes in the profile. The $\mathrm{Zr} / \mathrm{Rb}$ and Inc/Coh profiles are plotted as ratios and also shown as a 10 point moving average. $\mathrm{Zr} / \mathrm{Rb}$ ratios have been used as a proxy for increased grain size, where peaks in the data could be interpreted as increased energy for sediment transport and intensified erosion episodes (Davies et al., 2015; Kylander et al., 2011).

The $\mathrm{Ti}$ and $\mathrm{K}$ profiles are very similar and reflect the amount of detrital minerogenic in-wash into the catchment (Balascio et al., 2011; MartinPuertas et al., 2012; Davies et al., 2015). The minerogenic elements, including $\mathrm{Fe}, \mathrm{Rb}, \mathrm{Sr}, \mathrm{Ba}$ and $\mathrm{Si}$, show very similar profiles and $\mathrm{Ti}$ and $\mathrm{K}$ are shown here as representative elements for the amount of detrital minerogenic in-wash. High values ( 0.018-0.03) are observed in the lowermost mineral-rich unit between 820-777 cm within XZ 1, indicating a period of intensified erosion in the catchment and high levels of in-wash into the lake. Low $\mathrm{Zr} / \mathrm{Rb}$ values are observed within this unit reflecting the sediment composition to be fine material typical of silt and clays.

A sudden change is observed at the onset of $X Z 2 a(777 \mathrm{~cm})$ where values decrease from 0.02 to near zero at $765 \mathrm{~cm}$. This substantial change indicates a major decrease in the minerogenic in-wash into the lake and may suggest a stabilization of the surrounding catchment with vegetation development 

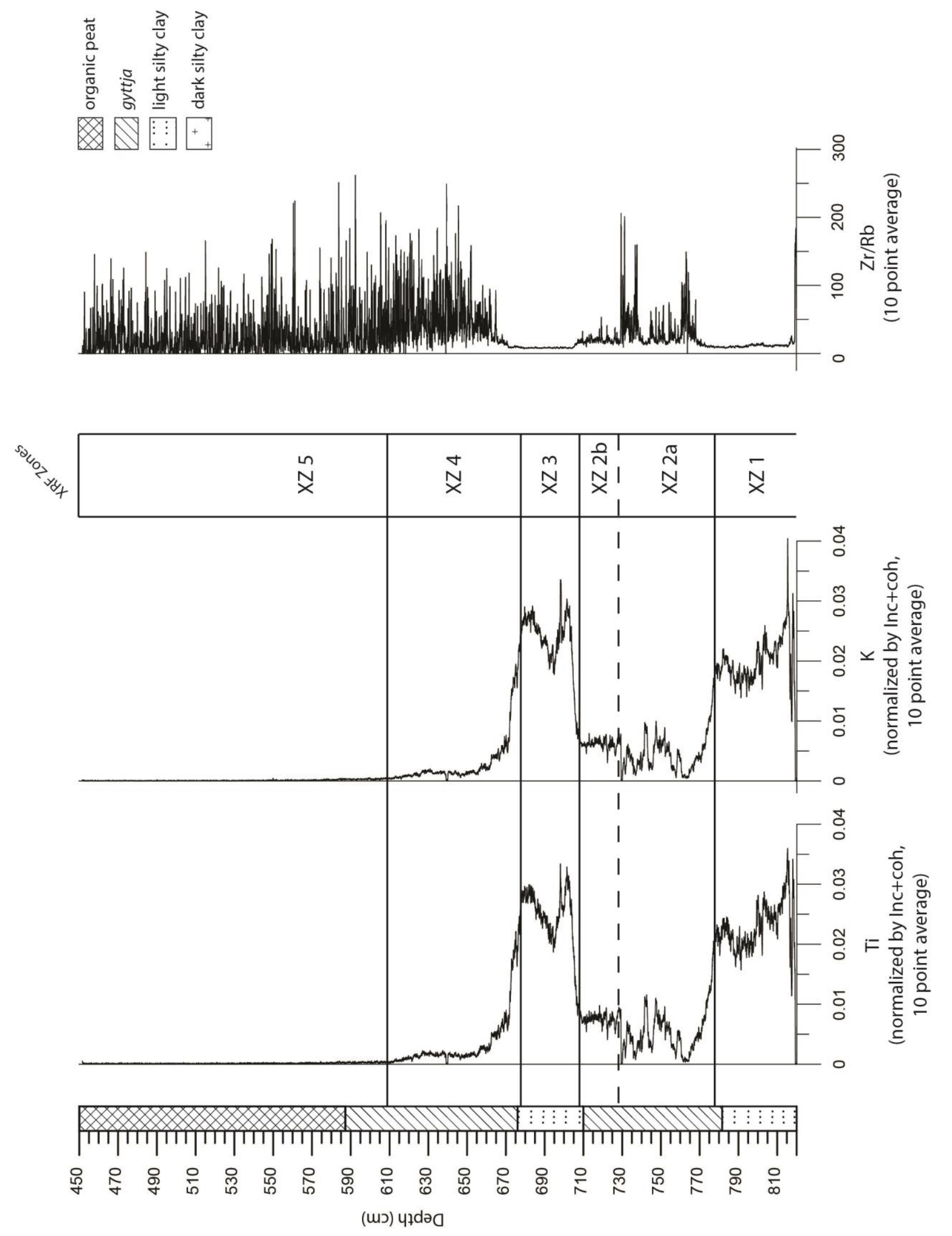

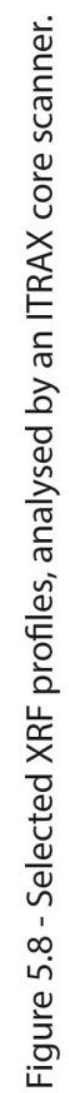


limiting erosion. This suggests a period of climatic warming indicative of the Lateglacial Interstadial. Even though the Interstadial part of the sequence is characterized by low $\mathrm{Ti}$ and $\mathrm{K}$ values, fluctuating values are observed in $\mathrm{XZ}$ $2 a$ between $765-730 \mathrm{~cm}$. Rapid increases in $\mathrm{Ti}$ and $\mathrm{K}$ values are observed at $759 \mathrm{~cm}, 755-748 \mathrm{~cm}, 742 \mathrm{~cm}$ and $734 \mathrm{~cm}$ possibly indicating small levels of minerogenic in-wash. These values, however are still considerably lower than observed during $X Z 1$ and $X Z 3$. During the latter part of the Interstadial in $X Z$ $2 \mathrm{~b}$, between $730-709 \mathrm{~cm}, \mathrm{Ti}$ and $\mathrm{K}$ values are more stable. Ti and $\mathrm{K}$ values of $\sim 0.0075$ are observed during this period ( $X Z 2 b$ ), indicating that erosion and minerogenic in-wash was possibly still occurring, although not to the same extent as the glacial period. The stable values however most likely indicate development of catchment vegetation throughout this latter part of the Interstadial. Short-lived peaks are observed in the Interstadial part of the $\mathrm{Zr} / \mathrm{Rb}$ profile indicating coarser grained sediments preserved at $762 \mathrm{~cm}, 737$ $\mathrm{cm}$ and $730 \mathrm{~cm}$. These peaks may represent layers of coarser grained sediments and suggests periods of intensified erosion or an increase in energy for sediment transport. These peaks in $\mathrm{Zr} / \mathrm{Rb}$ also coincide with troughs in the $\mathrm{Ti}$ and $\mathrm{K}$ profiles during the interstadial. High $\mathrm{Ti}$ and $\mathrm{K}$ values are associated with detrital in-wash as well as representing fine-grained sediments like silts and clay (Davies et al., 2015), supporting the signal of increased grain sizes at $762 \mathrm{~cm}, 737 \mathrm{~cm}$ and $730 \mathrm{~cm}$ through the $\mathrm{Zr} / \mathrm{Rb}$ record.

A rapid increase is observed at $705 \mathrm{~cm}(\mathrm{XZ} 3)$ with both $\mathrm{Ti}$ and $\mathrm{K}$ values increasing to $\sim 0.03$, indicating a sudden increase in erosion and minerogenic in-wash. This corresponds to a lithostratigraphic shift to the silty clay unit and lower \%C values (Figure 5.5) characteristic of the Loch Lomond Stadial. High $\mathrm{Ti}$ and $\mathrm{K}$ values persist throughout the Stadial between $705-676 \mathrm{~cm}$, however a short lived episode is observed at $\sim 694 \mathrm{~cm}$ where values decrease to $\sim 0.02$ indicating a period of decreased erosion and minerogenic in-wash. This period is followed by a return to higher $\mathrm{Ti}$ and $\mathrm{K}$ values $(0.03)$ between $685-677 \mathrm{~cm}$.

An abrupt decrease in $T i$ and $K$ values is observed at the onset of $X Z 4$ at $676 \mathrm{~cm}$ with values falling from $\sim 0.03$ to 0.0025 at $660 \mathrm{~cm}$. This reduction 
indicates a substantial decrease in the amount of erosion and minerogenic in-wash and coincides with a transition to organic sedimentation within this part of the sequence. This change in the XRF data together with the lithostratigraphic change and an increase in $\% \mathrm{C}$ and $\% \mathrm{~N}$ suggests a rapid period of climatic warming and a reduction in mineral in-wash. Ti and $\mathrm{K}$ values remain stable at $\sim 0.0025$ from $660-615 \mathrm{~cm}$ indicating limited erosion and minerogenic in-wash was possibly still happening during this period, however the values are very small compared with the Loch Lomond Stadial. $\mathrm{Ti}$ and $\mathrm{K}$ values decrease to near zero at $615 \mathrm{~cm}(\mathrm{XZ}$ 5), and remain low to the end of the sequence at $450 \mathrm{~cm}$, suggesting minimal erosion and minerogenic in-wash.

Some studies, including Roberts et al., (2016), use the incoherence/coherence (Inc/Coh) ratio retrieved by the ITRAX core scanner as a proxy for organic matter. An increase in the Inc/Coh ratio indicates a larger concentration of organic matter due to organic carbon having a lower atomic mass than carbonates, silica or alumniosilicates (Jenkins, 1999; Burnett et al., 2011). In this study, \%C measurements on bulk sediment have also been measured (see Figure 5.5), which allows a comparison to be made between both profiles. Therefore a determination can be made to see if the Inc/Coh ratio can be used reliably as a proxy for organic matter (Figure 5.9). Even though the profiles do not overlap perfectly the general Lateglacial tripartite pattern is clearly observed in both profiles. The transition depths (i.e. Interstadial onset, Stadial onset and Holocene onset) are the same, however some differences are observed. As mentioned in the section 5.3, the Interstadial is separated into two sections with higher values in the first section (ChZ 2a: $772-748 \mathrm{~cm}$ ) and lower values in the second section (ChZ 2b: $748-710 \mathrm{~cm}$ ). A similar pattern is seen in the $\mathrm{Inc} /$ Coh record, however a short period of higher values is seen between $738-730 \mathrm{~cm}$ indicating a slightly different signal to the $\% \mathrm{C}$ record during this part of the sequence. Another difference observed between the two profiles is seen during the early Holocene part of the sequence. The onset occurs at the same depth, however in the \%C profile a gradual increase to stable values is seen from the onset to $580 \mathrm{~cm}$ where values stabilize much quicker in the $\mathrm{Inc} / \mathrm{Coh}$ 

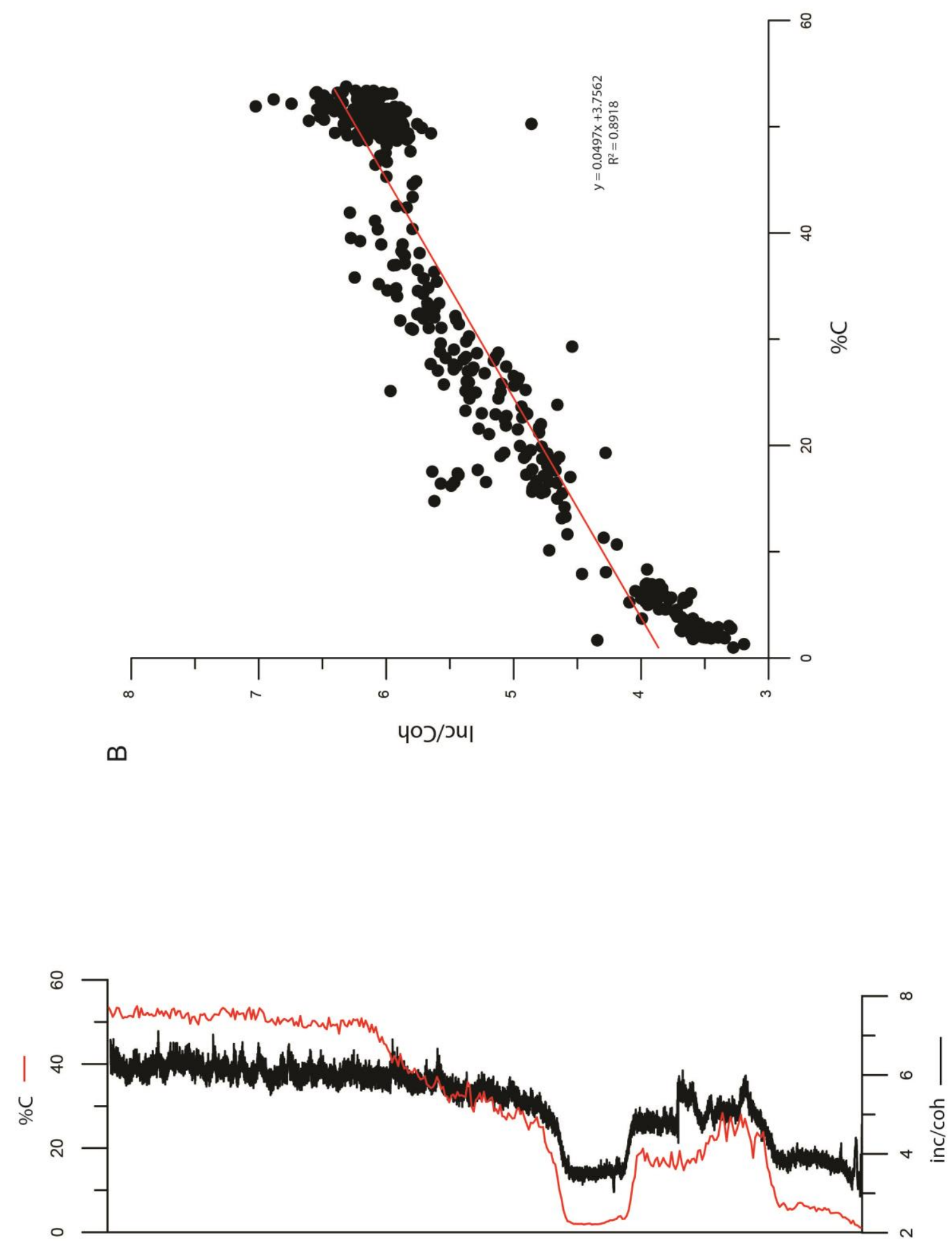

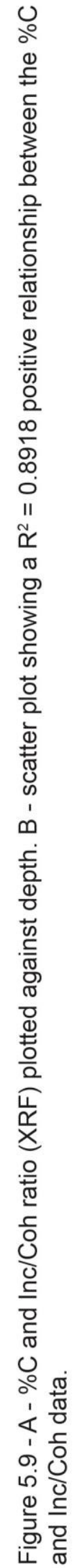


profile. Generally the pattern is very similar and holds a strong $R^{2}$ value of 0.8918 (Figure 5.9); this indicates the Inc/Coh ratio retrieved from the ITRAX core scanner can be a valuable proxy for organic matter.

\subsection{Diatom analysis}

Initially, subsamples were investigated throughout the core to determine the presence and preservation of diatoms. Diatom preservation was poor or absent in the basal clay unit between 820-777 cm and none were found in the upper part of the sequence in the peat deposit above $590 \mathrm{~cm}$. Diatom analysis was therefore, undertaken at $8 \mathrm{~cm}$ resolution between $777-602 \mathrm{~cm}$ spanning the Lateglacial Interstadial, Loch Lomond Stadial and early Holocene sediments and high-resolution sampling $(2 \mathrm{~cm})$ was undertaken over the major transitions between $777-770 \mathrm{~cm}$ (Glacial to Lateglacial Interstadial), $713-702 \mathrm{~cm}$ (Lateglacial Interstadial to Loch Lomond Stadial) and $677-658 \mathrm{~cm}$ (Loch Lomond Stadial to early Holocene). Diatoms with a representation of $>2 \%$ are illustrated in Figure 5.10. A simplified figure has also been constructed (Figure 5.11) where the diatom assemblages have been grouped to total Fragilaria types, Navicula types and Eunotia types. A further figure has been constructed (Figure 5.12) concentrating on the higher resolution results of the Glacial-Interstadial-Stadial-Holocene transitions. Zones (DZ 1-5) have been defined based on visual observations of changes in the assemblages. The estimated diatom abundance profile is plotted on Figures 5.50, 5.51 and 5.52 which gives an indication of the diatom productivity but also reflects diatom preservation in the sediment record.

The first occurrence of diatoms occur at $780.5 \mathrm{~cm}$ at the start of diatom zone 1 (DZ 1), however, they are in very low concentrations (only 20 damaged frustules found in the whole coverslip). No diatoms were found in the basal clay unit indicating an unfavourable environment for diatom growth. The minerogenic-rich sediment in the basal unit, as indicated by the Ti profile, 


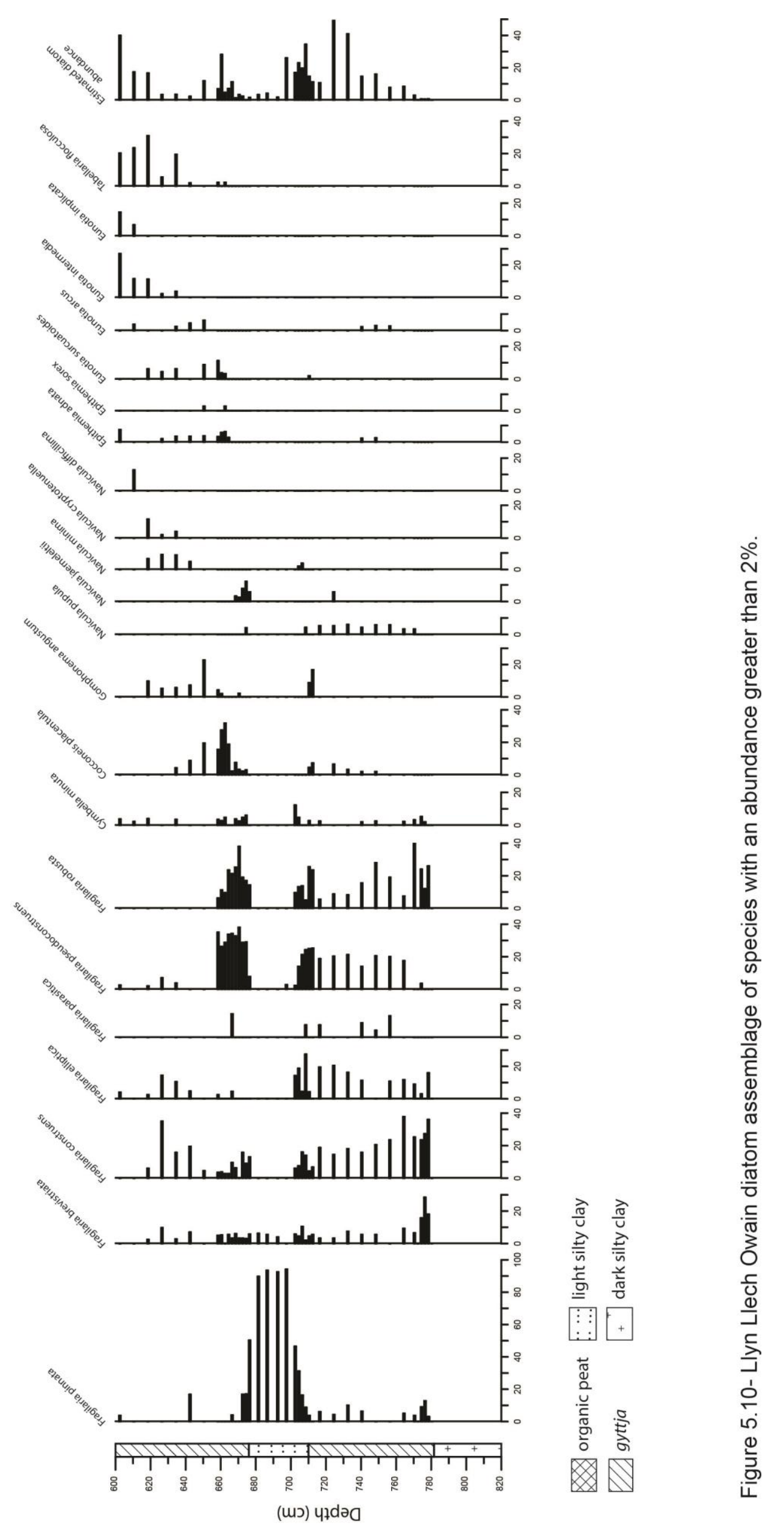




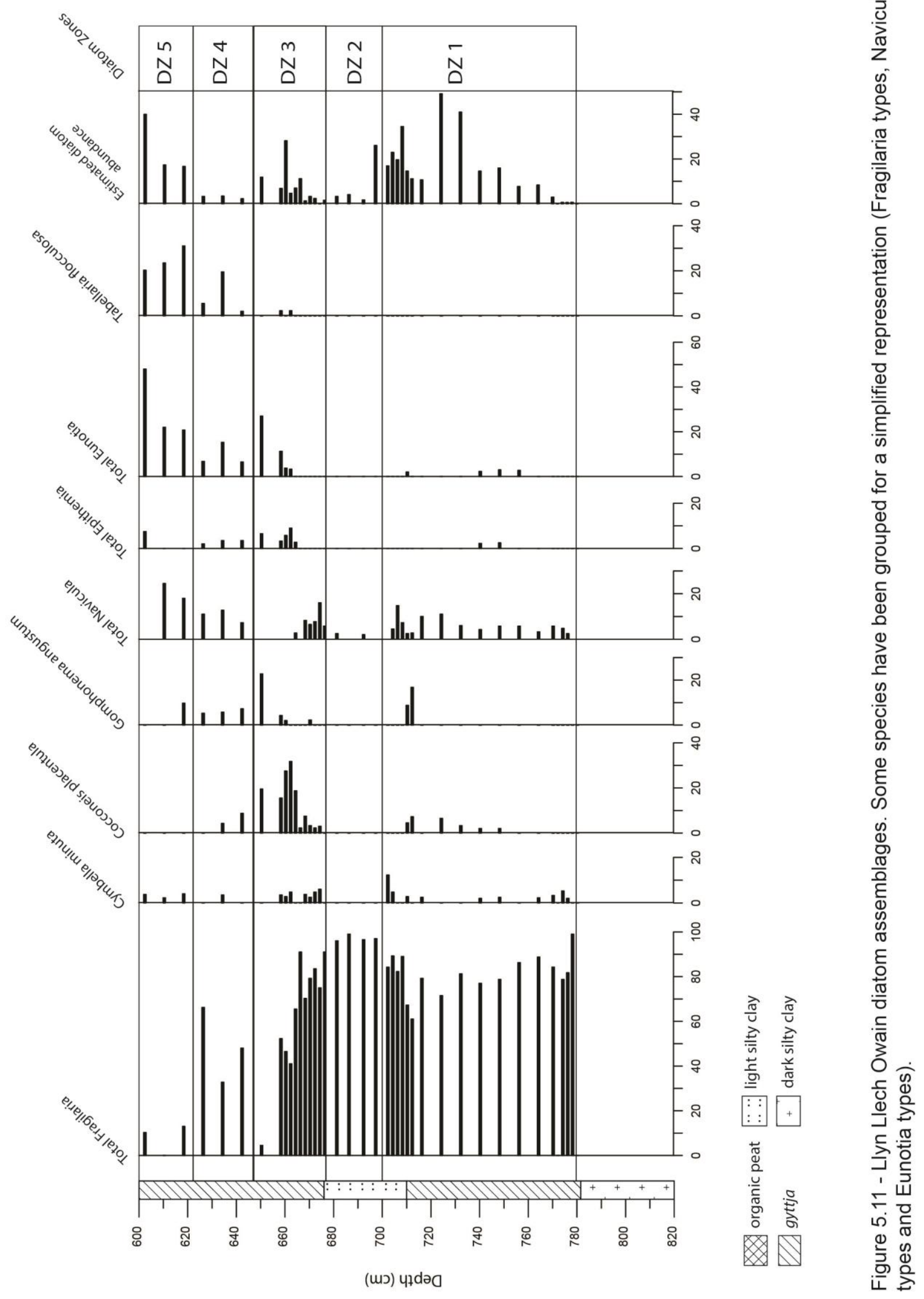




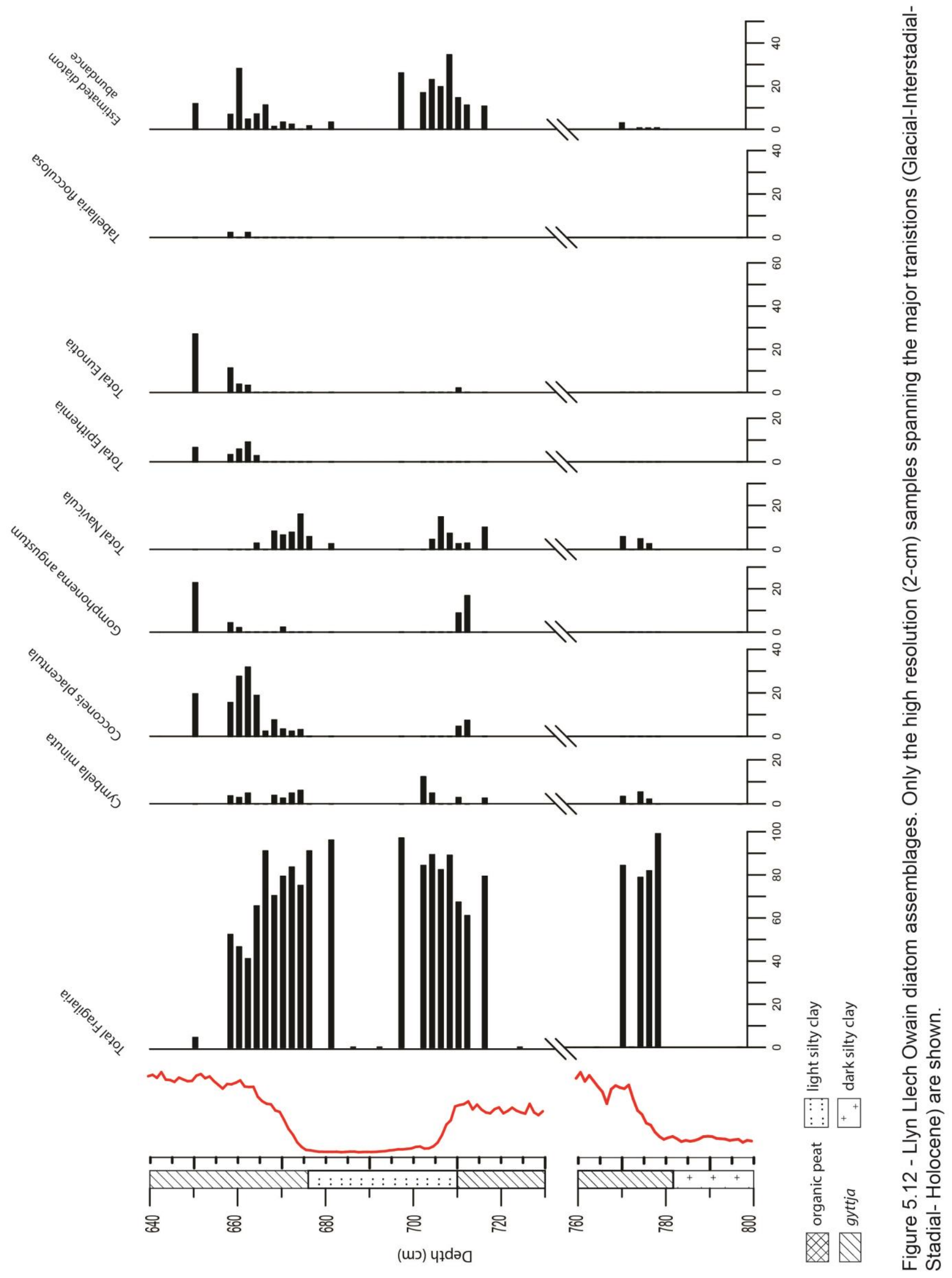


may also indicate turbid lake waters which would preclude adequate light for diatom productivity. Diatoms are also often mechanically damaged prior to burial in mineral-rich sediments which may also account for the absence of diatoms in the basal unit. The first sample containing $>400$ diatoms is at $776.5 \mathrm{~cm}$, which lies immediately after the termination of the glacial period as indicated by the increasing \%C profile (ChZ 2a) and decreasing Ti profile (DZ 1). Fragilaria species dominate the assemblage from the first occurrence of diatoms at $776.5 \mathrm{~cm}$ and throughout the Interstadial part of the sequence (DZ 1). These are considered as pioneer species and are often the first diatoms to colonise recently de-glaciated lakes (Haworth, 1976). The estimated diatom abundance data show very low concentrations at the termination of the glacial clay unit at $776.5 \mathrm{~cm}$ followed by an increase in abundance through the interstadial unit during DZ 1. Despite the dominance of Fragilaria species, small numbers of Cymbella minuta, Cocconeis placentula, Navicula pupula, Epithemia adnata and Eunotia arcus are also observed in DZ 1. Epithemia and Cocconeis species are epiphytic species, and along with the $\mathrm{C}: \mathrm{N}$ and $\delta^{13} \mathrm{C}$ values during this period (see section 5.3), suggests an increasing availability of habitat with more aquatic vegetation present.

The maximum diatom abundance occurs at $724.5 \mathrm{~cm}$, during the Interstadial and remains relatively high until $697.5 \mathrm{~cm}$ at the start of DZ 2 which is located $\sim 10 \mathrm{~cm}$ above the Loch Lomond Stadial onset based on stratigraphy. The high values during the beginning of the Loch Lomond Stadial may reflect high nutrient inputs during catchment instability as reflected by the high $\mathrm{Ti}$ values at this point in the record. Low \% values are observed during this part of the sequence, however, with the exception of a short-lived small peak at $711 \mathrm{~cm}$ (see Figure 5.6) which may be responsible for the high abundance of diatoms during this part of the sequence.

The Loch Lomond Stadial is mostly dominated by Fragilaria pinnata together with low concentrations of Fragilaria brevistriata (DZ 2). The diatom abundance suddenly decreases to very low values at $692.5 \mathrm{~cm}$ during the remainder of DZ 2 and the start of DZ 3 at $668.5 \mathrm{~cm}$ as was expected for the Loch Lomond Stadial. Diatom preservation is known to be sparse in the Loch 
Lomond Stadial sediments in other British sites (Round, 1957; Haworth, 1969; Haworth, 1976), however successful counts were made from samples in Llyn Llech Owain (DZ 2). Fragilaria species are considered as pioneer species that have a wide environmental tolerance to which they can live (Haworth, 1969). The dominance of the Fragilaria pinnata species during this period, indicate a relatively unfavourable environment for diatom productivity and along with the \%C and XRF data suggests a cold environment with high levels of erosion characteristic of the Loch Lomond Stadial.

The diatom assemblage suddenly changes at $674.5 \mathrm{~cm}$ from Fragilaria pinnata to Fragilaria pseudoconstuens and Fragilaria robusta, which is stratigraphically located on the early Holocene onset (DZ 3). A short-lived dominance of Navicula jaerneleltii is observed at $676.5 \mathrm{~cm}$ at the start of DZ 3 , although in low concentration. At $664.5 \mathrm{~cm}$, midway through DZ 3, a sudden appearance of Cocconeis placentula is observed, along with Fragilaria pseudoconstuens and Fragilaria robusta making up most of the assemblage, however, low abundances of Epithemia adnata and Eunotia subrcuatoides are also observed at these depths indicating a more diverse diatom assemblage during the early Holocene. The increasing number of epiphytic species also suggests a more developed aquatic ecosystem during DZ3. A significant decrease in Fragilaria species is observed at $650.5 \mathrm{~cm}$ which is replaced by Cocconeis placentula, Gomphonema angustum and Eunotia arcus, however Fragilaria brevistriata, construens and elliptica return to dominate the assemblage between $642.5-618.5 \mathrm{~cm}$ during DZ 4. During DZ 5 the Fragilaria species mostly disappear from the assemblage at 618.5 $\mathrm{cm}$ and is replaced with Eunotia species and Tabellaria flocculosa. This increase in more acidophilus species suggests a more oligotrophic environment indicative of natural lake acidification as seen in a number of other sites during the early Holocene (e.g. Round, 1957, 1961; Evans, 1970; Evans \& Walker, 1977; Walker, 1978). More recently however, post-glacial lake acidification is suggested to be related to soil mineral depletion (Boyle, 2007; Boyle et al., 2013). The diatom abundance significantly increases also at this depth suggesting a period of high diatom productivity during this period associated with the natural acidification of the lake system. 


\subsection{Tephrochronology}

\subsubsection{Total Shard Concentrations (TSCs)}

Tephra shard analysis was initially undertaken at $5 \mathrm{~cm}$ resolution between $820-450 \mathrm{~cm}$ in core 2013 (Figure 5.13). Tephra shards were found, albeit in small concentrations, throughout most of the sequence, but these were not all confirmed by geochemical analysis. Samples that contained $>10$ shards per $0.5 \mathrm{~g} \mathrm{dw},(805-795 \mathrm{~cm}, 785-765 \mathrm{~cm}, 735-730 \mathrm{~cm}, 670-665 \mathrm{~cm}, 595-590$ $\mathrm{cm}, 580-570 \mathrm{~cm}, 485-480 \mathrm{~cm}, 470-460 \mathrm{~cm}$ and $455-450 \mathrm{~cm}$ ), were sampled at higher resolution to isolate the position of the tephra layers to the nearest $1 \mathrm{~cm}$. Despite the low shard concentrations, samples from the middle of the Loch Lomond Stadial; 700-695 cm and 690-685 cm, were also sampled at high resolution, in an attempt to isolate the Vedde Ash (Lane et al., 2012).

Peak shard concentrations were identified at $804-03 \mathrm{~cm}$ (154 clear shards per $0.5 \mathrm{~g} \mathrm{dw}$ ), $782-81 \mathrm{~cm}$ (55 clear shards per $0.5 \mathrm{~g} \mathrm{dw}$ ), 778-777 cm (9 clear shards per $0.5 \mathrm{~g} \mathrm{dw}$ ), $767-766 \mathrm{~cm}$ (9 clear shards per $0.5 \mathrm{~g} \mathrm{dw}$ ), $689-688 \mathrm{~cm}$ ( 5 clear shards per $0.5 \mathrm{~g} \mathrm{dw}$ ), $686-685 \mathrm{~cm}$ (4 clear shards per $0.5 \mathrm{~g} \mathrm{dw}$ ), 595 $594 \mathrm{~cm}$ (9 clear shards per $0.5 \mathrm{~g} \mathrm{dw}$ ), 580-579 cm (19 clear shards per $0.5 \mathrm{~g}$ $\mathrm{dw}$ ), $575-574 \mathrm{~cm}$ ( 15 clear shards per $0.5 \mathrm{~g} \mathrm{dw}$ ), $483-482 \mathrm{~cm}$ ( 45 clear shards per $0.5 \mathrm{~g} \mathrm{dw}$ ), $468-467 \mathrm{~cm}$ (46 clear shards per $0.5 \mathrm{~g} \mathrm{dw}$ ), 452-451 $\mathrm{cm}$ (11 clear shards per $0.5 \mathrm{~g} \mathrm{dw}$ ) (Figure 5.13).

No distinct peak in shard concentrations was observed after high resolution sampling over depths $735-730 \mathrm{~cm}, 700-695 \mathrm{~cm}$ and $670-675 \mathrm{~cm}$. Sampling was repeated twice for these depths and failed to reveal a distinct peak in shard concentrations.

In addition to the 2013 core, another core was retrieved in 2009 by Mike Walker and colleagues which spanned the Holocene part of the Llyn Llech Owain record. This was used in this study solely to explore the tephra 


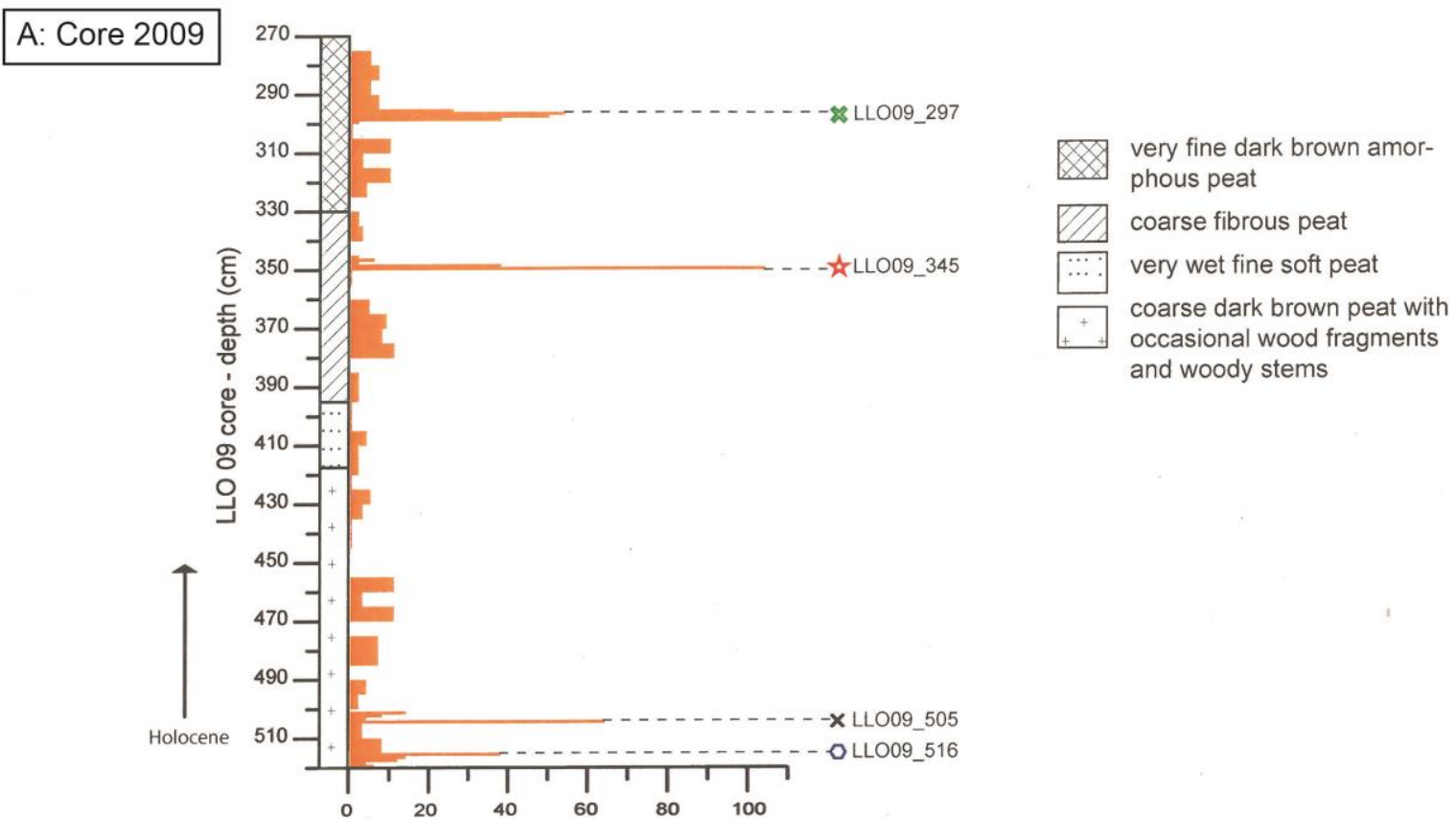

Core 2013 is not cross-correlated to core 2009 due to the lack of tie points. It is assumed that the 2009 core represents the mid-late Holocene.
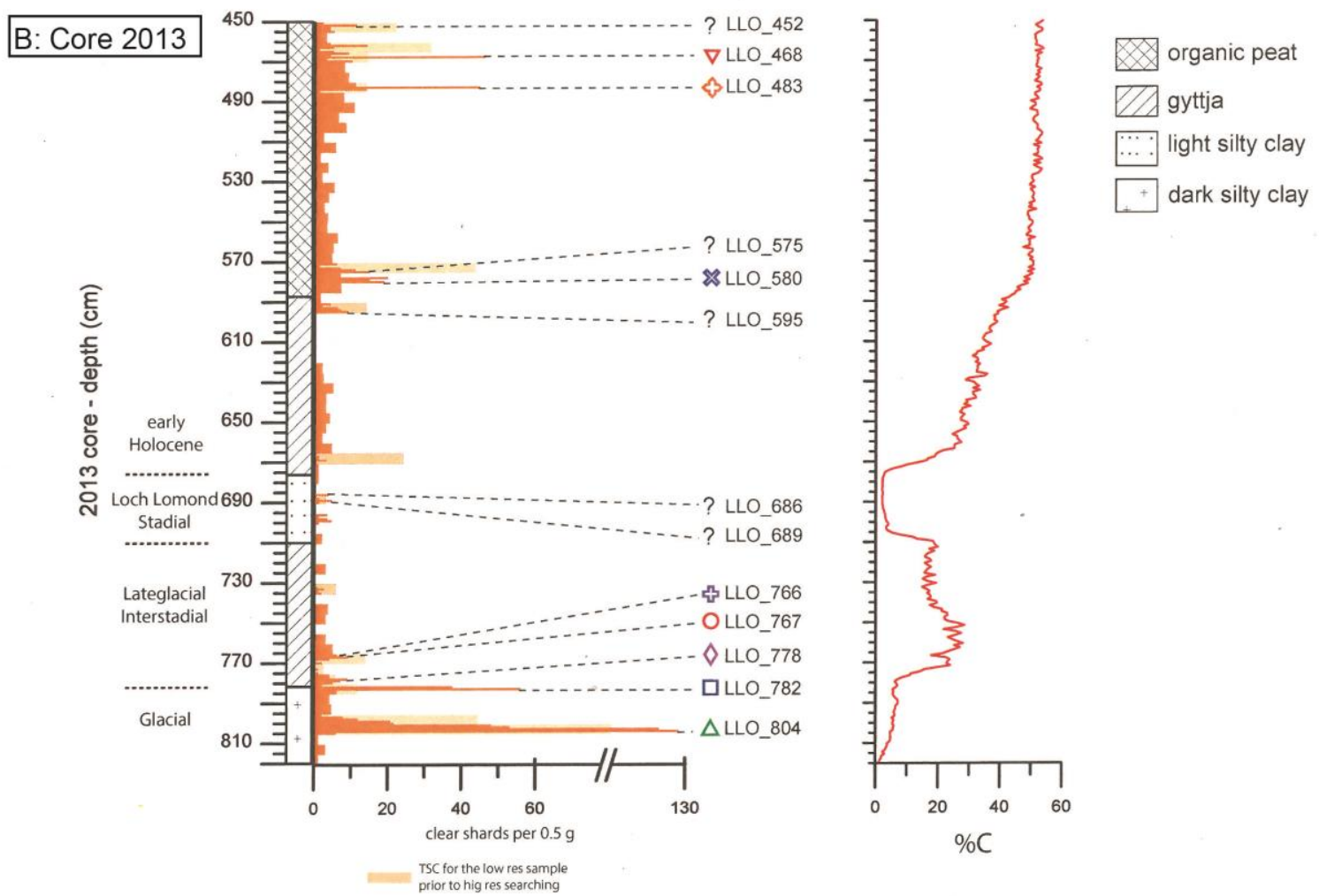

Figure 5.13 - Total shard concentrations for Llyn Llech Owain core 2009 (A) and core 2013 (B). Tephra deposits that have been geochemically analysed are labelled with a symbol, which relates to figures 5.14-5.24. Tephra deposits that have not been geochemically analysed are labelled '?'. \%C profile is also plotted for reference. 
content. Low resolution counts revealed $>20$ shards per $0.5 \mathrm{~g}$ dw at $520-515$ $\mathrm{cm}, 505-500 \mathrm{~cm}, 350-345 \mathrm{~cm}$ and $295-290 \mathrm{~cm}$. Following tephra analysis at $1 \mathrm{~cm}$ resolution, four peaks were revealed at $516-515 \mathrm{~cm}$ (38 clear shards per $0.5 \mathrm{~g} \mathrm{dw}$ ), $505-504 \mathrm{~cm}$ (64 clear shards per $0.5 \mathrm{~g} \mathrm{dw}$ ), 345-344 cm (104 clear shards per $0.5 \mathrm{~g} \mathrm{dw}$ ) and $297-296 \mathrm{~cm}$ ( 53 clear shards per $0.5 \mathrm{~g} \mathrm{dw}$ ) (Figure 5.13).

5.6.2 Geochemical analysis, morphological characteristics and tephra correlations

Tephra glass shards were successfully extracted from tephra layers 804-803 cm (LLO_804), 782-781 cm (LLO_782), 778-777 cm (LLO_778), 767-766 cm (LLO_767), 766-765 cm (LLO_766), 580-579 cm (LLO_580), 483-482 (LLO_483) and 468-467 cm (LLO_468) in the 2013 core, as well as $516-515$ cm (LLO09_516), 505-504cm (LLO09_505), 345-344 cm (LLO09_345) and 297-296 cm (LLO09_297) in the 2009 core, which allowed geochemical analysis to be undertaken (Table 5.2 and Figure 5.14). Glass shards were too sparse or not encountered at all during attempted extraction for the remaining tephra layers $(689-688 \mathrm{~cm}, 686-685 \mathrm{~cm}, 595-594 \mathrm{~cm}, 575-574 \mathrm{~cm}$ and $452-451 \mathrm{~cm}$ ) and therefore, no geochemical data were obtained. All tephra deposits are named here after their bottom depth in the sequence and the core sequence found (e.g. LLO_804 for the 2013 'master' core and LLO09_345 for the 2009 core).

Where possible 20 shards were analysed for each deposit, however shards were sparse in most tephra deposits making extracting for geochemical analysis difficult. All tephra deposits from Llyn Llech Owain have a rhyolitic composition, with the exception of one sample (LLO_580) which has a trachytic composition (Figure 5.14). The geochemical data discussed in the 


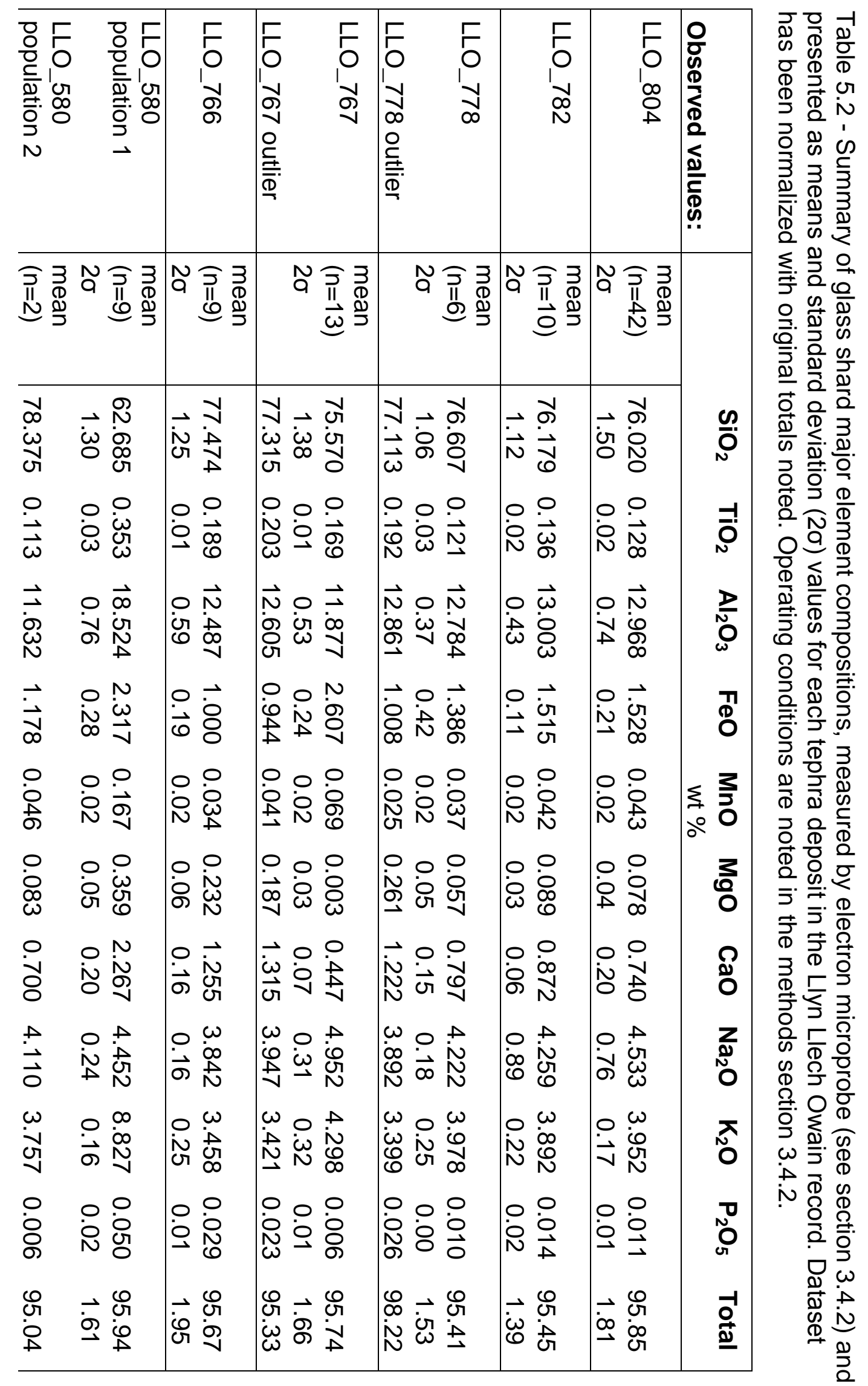




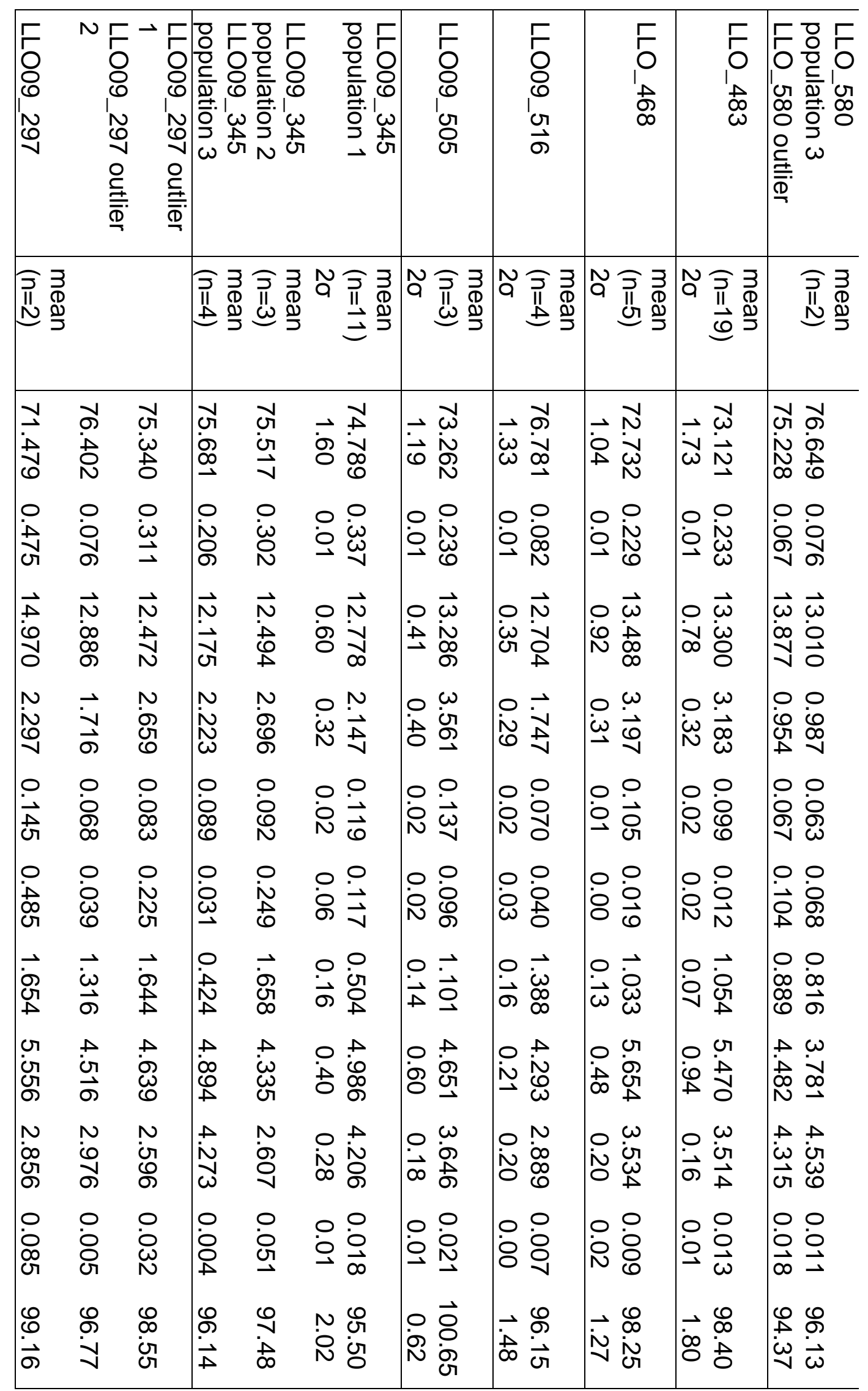



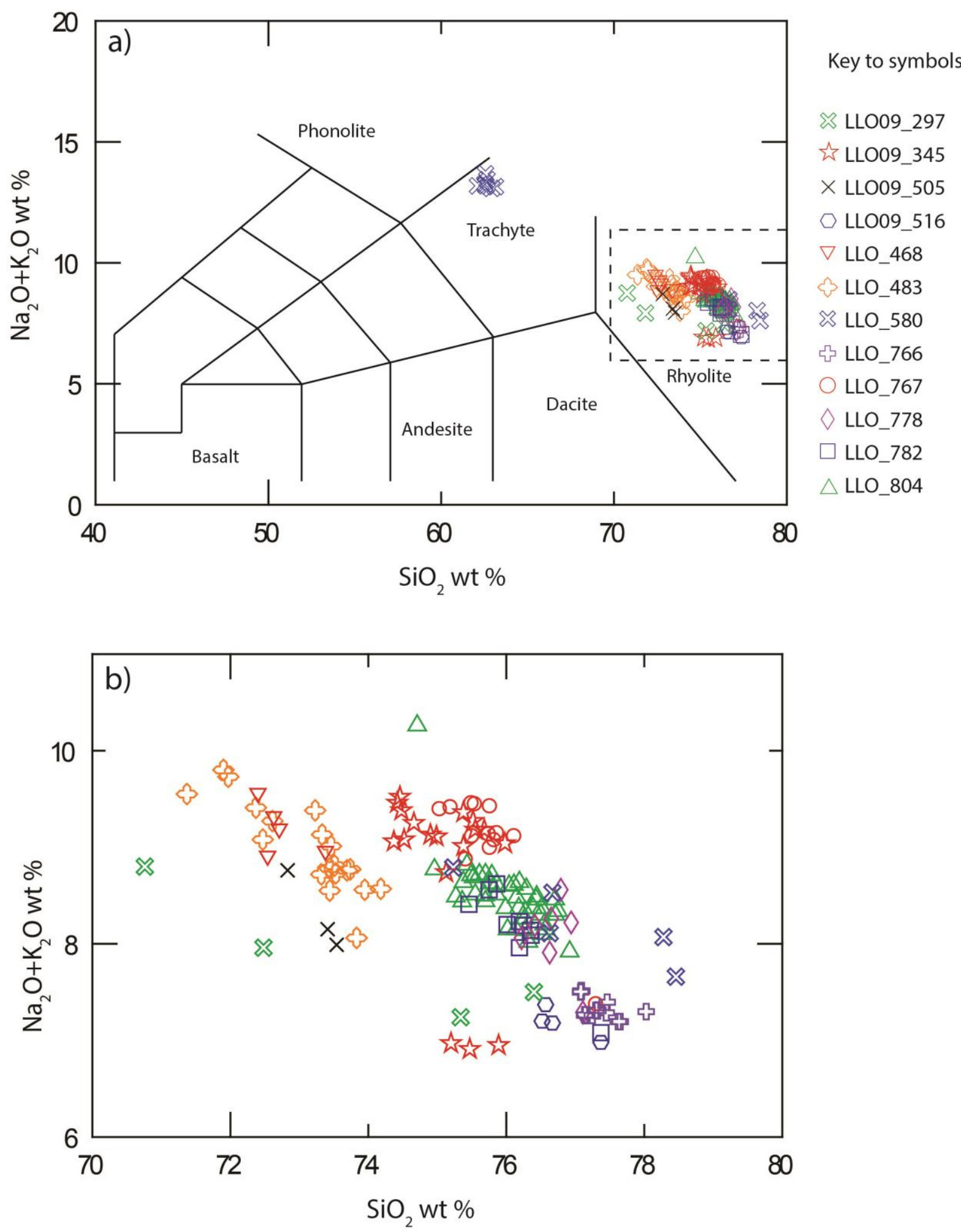

Figure 5.14 - The full data set from the analysed tephra layers in Llyn Llech Owain plotted using the Total Alkali Silica classification of LeBas et al., (1986). Geochemical data are normalized. 
text and showed in the bivariate plots and Table 5.2 are normalized. Raw data are available in the appendix.

There have only been hints of potential cryptotephra deposits in sites in Wales published in the literature. Sites in the Brecon Beacons and Mid Wales have recorded the presence of tephra shards within their sedimentary records but these findings have not been supported by geochemical analyses of the shards themselves (Williams, 2001; Buckley and Walker, 2002). Cryptotephra deposits are very sparse in sites south of $53^{\circ}$ latitude and west of $6^{\circ}$ longitude (Figure 2.4), however the findings within this study, and recent publication by Watson et al., 2017, have demonstrated that tephra deposits are found further south of $53^{\circ}$ latitude and west of $6^{0}$ longitude.

\section{LLO_804}

Tephra layer LLO_804 is the oldest tephra layer identified in the Llyn Llech Owain sequence with a TSC of 125 clear shards per $0.5 \mathrm{~g} \mathrm{dw}$.

Stratigraphically, LLO_804 lies in the glacial sediments in the basal clay unit (ChZ 1 and $X Z 1$ ). Forty-two shards have been geochemically analysed revealing a rhyolitic composition (Figure 5.14 and 5.15) with 74.7-76.93 wt\% $\mathrm{SiO}_{2}, 1.3-1.7 \mathrm{wt} \% \mathrm{FeO}$ and 0.54-0.88 wt\% CaO. LLO_804 has a similar compositional signature to the Borrobol (BT) and Penifiler (PT) tephra layers (Figure 5.15). The BT and PT are chemically indistinguishable (PyneO'Donnell et al., 2008; Matthews et al., 2011; Lind et al., 2016) (see section 2.2.4). Based on stratigraphic position and chemical composition, LLO_804 was initially thought to be correlated with either the ice core GS-2 tephra or/and the KOL-GS-2 tephra. Geochemical analyses reveal most chemical elements to be indistinguishable, however there is an offset seen in the $\mathrm{CaO}$ wt \% data which rejects the proposed correlation (Figure 5.15). Tephra layer LLO_804 may therefore represent a new eruption and adds to the already complex BT tephrostratigraphy. Another possible tephra correlation for LLO_804 is the Dimna Ash which was also deposited during the Glacial period (Koren et al., 2008), however, the correlation can be rejected based 


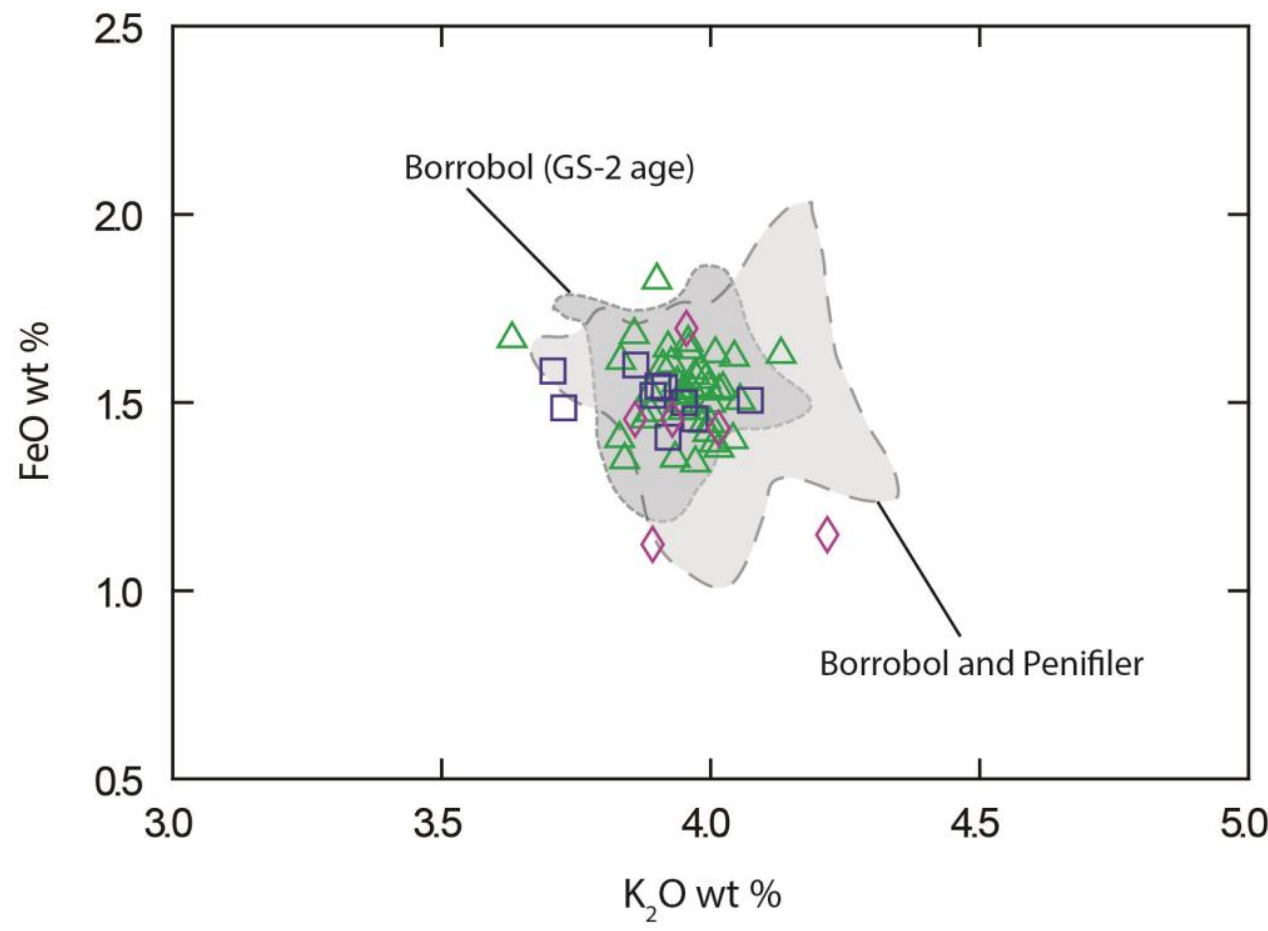

Key to symbols

$\diamond$ LLO_778

LLO_782

$\triangle$ LLO_804

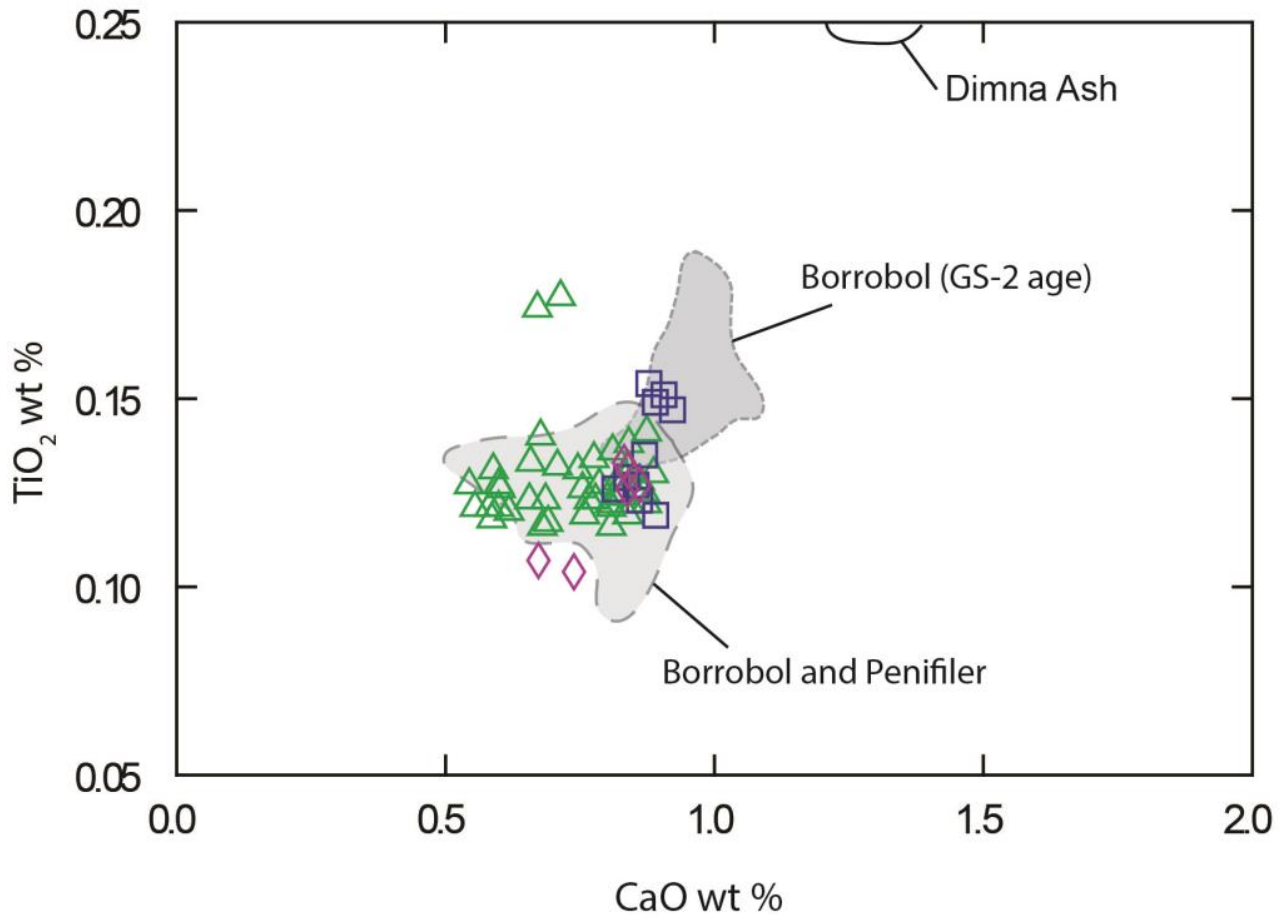

Figure 5.15 - Selected bivariate plots showing tephra glass shard major element compositions for LLO_804, LLO_782 and LLO_778. (Reference envelopes are based on data from Lind et al., 2016, Cook, 2015 and Koren et al., 2008). 
on geochemical composition with the Dimna Ash having lower $\mathrm{SiO}_{2}$ content and higher $\mathrm{CaO}$ and $\mathrm{FeO}$ values.

\section{LLO_782}

This tephra layer has a TSC of 55 clear shards per $0.5 \mathrm{~g} \mathrm{dw}$ and lies stratigraphically very close to the transition between the lowermost silty clay unit (ChZ1) and the organic mud of the Lateglacial Interstadial (ChZ2). Ten single-shards were analysed by electron microprobe revealing a rhyolitic tephra (Figure 5.14 and 5.15) with 75.4-77.36 wt\% $\mathrm{SiO}_{2}$, 1.4-1.6 wt\% $\mathrm{FeO}$ and $0.81-0.92 \mathrm{wt} \% \mathrm{CaO}$. LLO_782 is geochemically indistinguishable to LLO_804, although the LLO_782 data lies on the higher limit of the LLO_804 $\mathrm{CaO}$ envelope. Again, LLO_782 has a similar compositional signature to the Borrobol (BT) and Penifiler (PT) tephra layers (Figure 5.15).

Underpinning the Lateglacial Interstadial onset or the onset of lake sedimentation is problematic due to the sediments being mostly devoid of climatic proxies such as pollen, diatoms or chironomids. Therefore, establishing the Lateglacial Interstadial temperature rise is difficult based on the evidence currently available. This is also seen in Scottish sites as discussed by Walker and Lowe (in press), with the exception of Whitrig Bog in the Scottish Borders where a chironomid based reconstruction shows the rise in temperature at the beginning of the Lateglacial Interstadial (Brooks et al., 1997; Brooks \& Birks, 2000). The Borrobol Tephra is present in the Whitrig Bog record and is clearly located above the transition from low temperatures of the Glacial period and the climatic warming of the Lateglacial Interstadial as constrained by a chironomid-based temperature record (Turney et al., 1997; Brooks \& Birks, 2000).

The sediment geochemistry data for the Llyn Llech Owain record suggests LLO_782 cannot be correlated to the Borrobol Tephra. Further constraints are required e.g. chironomid-based temperature record to define the interstadial onset at Llyn Llech Owain. One possibility is that LLO_782 is correlated to the LET-1a tephra from the Loch Etteridge record based on the 
stratigraphic (LOI/\%C) position. However, as noted above and discussed by Walker \& Lowe, (in press), pinpointing the Lateglacial Interstadial onset is problematic unless the record has a temperature reconstruction from a chironomid or other temperature-based proxy. For this reason, LLO_782 is tentatively correlated to the Borrobol Tephra, which is dated to $14,098 \pm 47 \mathrm{cal}$ BP (Bronk Ramsey et al., 2015).

\section{LLO_778}

Only 9 shards per $0.5 \mathrm{~g} \mathrm{dw}$ were identified within deposit LLO_778. It lies stratigraphically in the early Lateglacial Interstadial sediments. Seven shards have been geochemically analysed and revealed six rhyolitic shards with 76.22-77.11 wt\% $\mathrm{SiO}_{2}, 1.12-1.69 \mathrm{wt} \% \mathrm{FeO}$ and $0.67-0.86 \mathrm{wt} \% \mathrm{CaO}$. This population overlaps with the high $\mathrm{SiO}_{2}$ end of the LLO_804 population (Figure 5.15), which has a similar compositional signature to the Borrobol (BT) and Penifiler (PT) tephra layers (Figure 5.15). If tephra deposit LLO_782 is tentatively correlated to the Borrobol Tephra, as noted above, then it is possible to tentatively correlate LLO_778 to the Penifiler Tephra $(13,939 \pm 66$ cal BP; Bronk Ramsey et al., 2015), which is known to have been deposited after the Borrobol Tephra. Only $4 \mathrm{~cm}$ separate LLO_782 and LLO_778 which would equate to $\sim 40$ years per $\mathrm{cm}$ sedimentation rate which may support the tentative correlation. However, in other Borrobol and Penifiler Tephra bearing sites the gap between both tephra deposits are larger (13 cm in Loch Etteridge; $15 \mathrm{~cm}$ in Tynaspirit West; $35 \mathrm{~cm}$ in Abernethy Forest), and the Penifiler Tephra is mostly seen at a higher stratigraphic position in the Interstadial deposits (Albert, 2007; Pyne O'Donnell, 2007; Matthews et al., 2011) This deposit may, therefore, represent re-worked product of the LLO_782 Borrobol Tephra deposit, however as part of this study, LLO_778 is tentatively correlated to the Penifiler Tephra.

The outlying shard also has a rhyolitic composition with $77.11 \mathrm{wt} \% \mathrm{SiO}_{2}$, $1.01 \mathrm{wt} \% \mathrm{FeO}, 1.22 \mathrm{wt} \% \mathrm{CaO}$ and $0.26 \mathrm{wt} \% \mathrm{MgO}$. This shard reveals a high $\mathrm{CaO}$ relative to $\mathrm{FeO}$ geochemical composition, which discriminates it from 
Icelandic eruptions of dacitic and rhyolitic composition (Figure 5.24), thus searches were made for correlations from further afield. A number of recent studies have also identified far-travelled tephras (e.g. Jensen et al., 2014; Bourne et al., 2016; van der Bilt et al., 2017; Watson et al., 2017). Based on stratigraphy and geochemical signatures a correlation to the Glacier Peak G Tephra is suggested (Figure 5.16). This tephra is sourced from the Cascade range, western North America and dated to 13.74-13.45 cal ka BP (Pyne O'Donnell et al., 2016). Other tephra deposits of similar ages were also considered: St Helens J and S Tephras, however these could be discriminated due to lower $\mathrm{K}_{2} \mathrm{O}$ values (Figure 5.16). Comparisons were also made with other large North American eruptions that have a dispersal axis towards Wales, including the Mazama and East Lake Tephras but these are ruled out based on the geochemical composition and stratigraphy. Only one shard form deposit LLO_778, however, has a geochemical signature similar to the Glacier Peak Tephra and the significance of this shard is discussed further below in relation to LLO_766.

\section{LLO_767}

This small tephra deposit has a TSC of 9 colourless shards per $0.5 \mathrm{~g} \mathrm{dw}$. It stratigraphically lies in the early Lateglacial Interstadial sediments. Fourteen shards have been geochemically analysed and revealed 13 rhyolitic shards with 75.04-76.12 wt\% $\mathrm{SiO}_{2}, 11.46-12.21$ wt $\% \mathrm{Al}_{2} \mathrm{O}_{3}, 2.43-2.84$ wt $\% \mathrm{FeO}$ and 0.38-0.52 wt\% $\mathrm{CaO}$ and an outlying shard with $77.31 \mathrm{wt} \% \mathrm{SiO}_{2}, 0.94 \mathrm{wt} \%$ $\mathrm{FeO}, 1.32 \mathrm{wt} \% \mathrm{CaO}$ and $0.19 \mathrm{wt} \% \mathrm{MgO}$ (Figure 5.14). The main population differs to the geochemical signature of the $\mathrm{BT}$ and also differs to other known Lateglacial Interstadial aged tephras including Roddans Port A and B, Dimna Ash, Laacher See Tephra and the Neopolitan Yellow Tuff (Figure 5.17). This population therefore has not been correlated to any known eruption in the literature and may represent a previously unknown or new eruption. The outlying shard has an indistinguishable composition to the outlier in LLO_778 which is correlated to the Glacier Peak G tephra (Figure 5.16). 


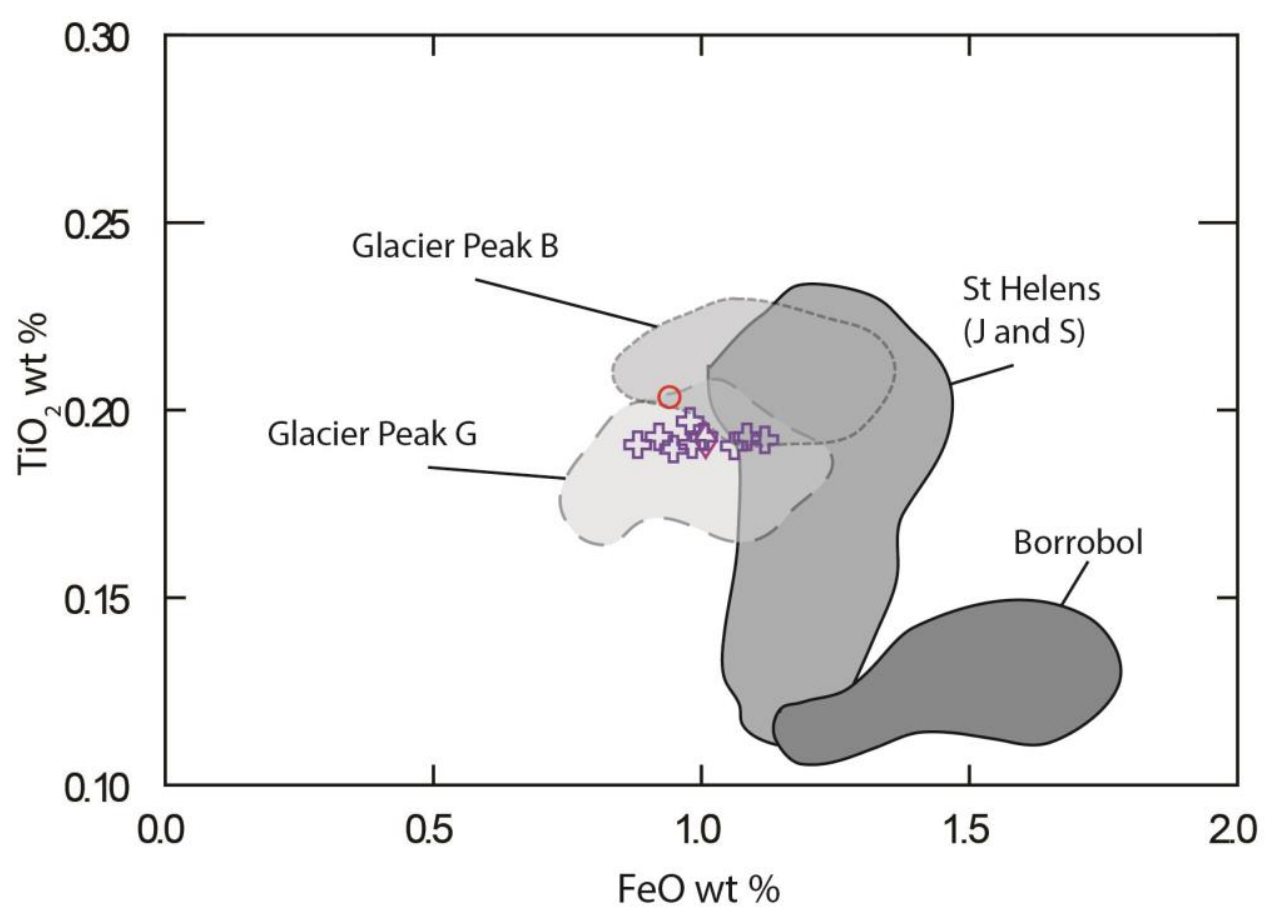

Key to symbols

ß LLO_766

O LLO_767

$\diamond$ LLO_778

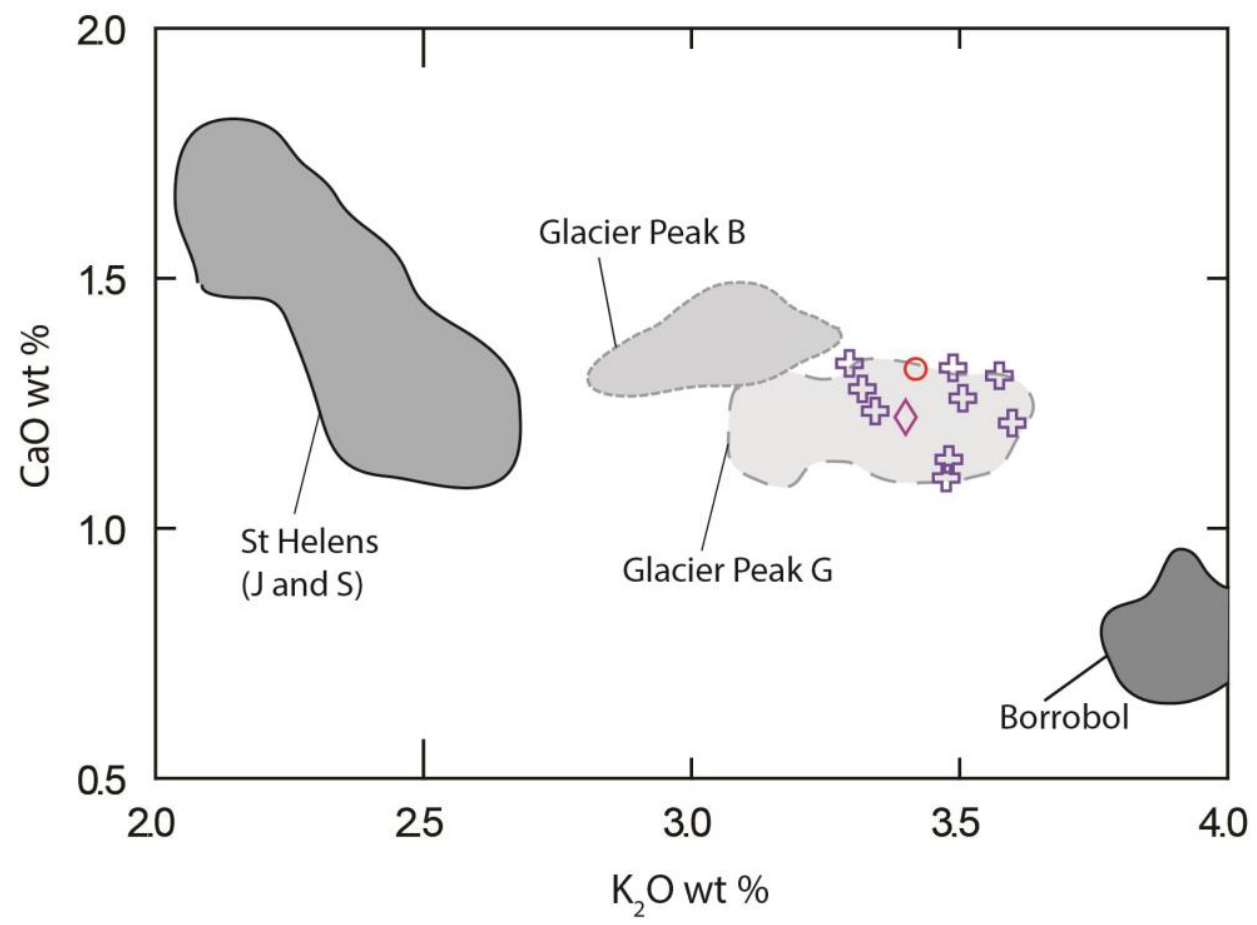

Figure 5.16 - Selected bivariate plots showing tephra glass shard major element compositions for LLO_778, LLO_767 and LLO_766. (Reference envelopes are based on data from Pyne O'Donnell et al., 2016; Lind et al., 2016). 

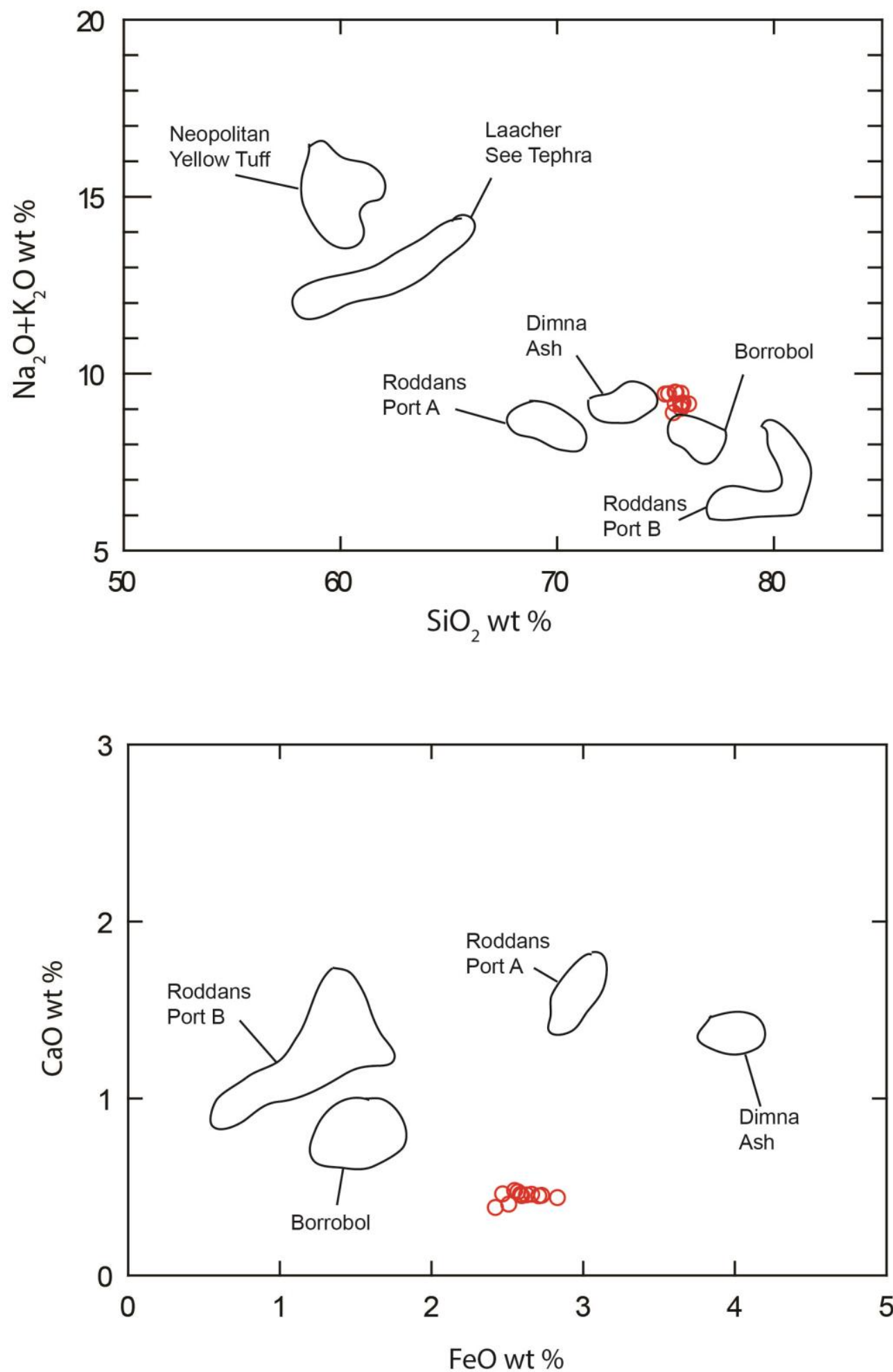

Figure 5.17 - Selected bivariate plots showing tephra glass shard major element compositions for LLO_767. (Reference envelopes are based on data from Turney et al., 2006; Koren et al., 2008; Lane et al., 2015; Lind et al., 2016). 
This tephra layer lies $1 \mathrm{~cm}$ above LLO_767 and has a TSC of 6 clear shards per $0.5 \mathrm{~g} \mathrm{dw}$. Nine shards have been geochemically analysed and revealed a homogenous rhyolitic composition with 77.09-78.10 wt\% $\mathrm{SiO}_{2}, 0.85-1.25$ wt\% $\mathrm{FeO}, 1.14-1.36 \mathrm{wt} \% \mathrm{CaO}$ and $0.19-0.30 \mathrm{wt} \% \mathrm{MgO}$, which is similar to the outlying shards in LLO_778 and LLO_767 and correlates with the Glacier Peak G Tephra (Figure 5.16). These shards can be chemically distinguished from other similarly aged tephras including the Borrobol Tephra and the St Helens $\mathrm{J}$ and $\mathrm{S}$ Tephras (Figure 5.16). A similarity coefficient value of 0.98 is derived between this deposit and the Glacier Peak G Tephra. Given the higher shard concentrations and the compositional homogeneity in this sample, deposit LLO_766 is thought to represent the isochron position providing an age estimate of 13.74-13.45 cal ka BP (Pyne O'Donnell et al., 2016). This depth is also consistent with the sedimentary succession and the tentative correlations to the Borrobol and Penifiler Tephras located below. The outlier shards in deposits LLO_778 and LLO_767 may indicate postdepositional reworking.

\section{LLO_580}

This tephra deposit has a TSC of 19 clear shards per $0.5 \mathrm{~g} \mathrm{dw}$ and lies stratigraphically in the early Holocene part of the sequence. Fourteen shards were geochemically analysed and revealed a heterogeneous sample with three separate populations and one outlier. Population 1 consists of 9 trachytic shards with 62.11-63.14 wt\% $\mathrm{SiO}_{2}, 17.89-18.99 \mathrm{wt} \% \mathrm{Al}_{2} \mathrm{O}_{3}$, 2.07$2.43 \mathrm{wt} \% \mathrm{CaO}$ and 8.71-9.06 wt\% $\mathrm{K}_{2} \mathrm{O}$ (Figure 5.14 and 5.18). This population reveals a high $\mathrm{CaO}$ relative to $\mathrm{FeO}$ geochemical composition, which discriminates it from Icelandic eruptions of dacitic and rhyolitic composition (Figure 5.24), thus searches were made for correlations from further afield. Volcanic sources from Jan Mayen, Azores, Massif Central, Laacher See and the Cascades were compared however, based on the high alkali and $\mathrm{Al}_{2} \mathrm{O}_{3}$ content the most probable volcanic source was Campi Flegrei (Italy). The stratigraphic position of LLO_580 indicates an 

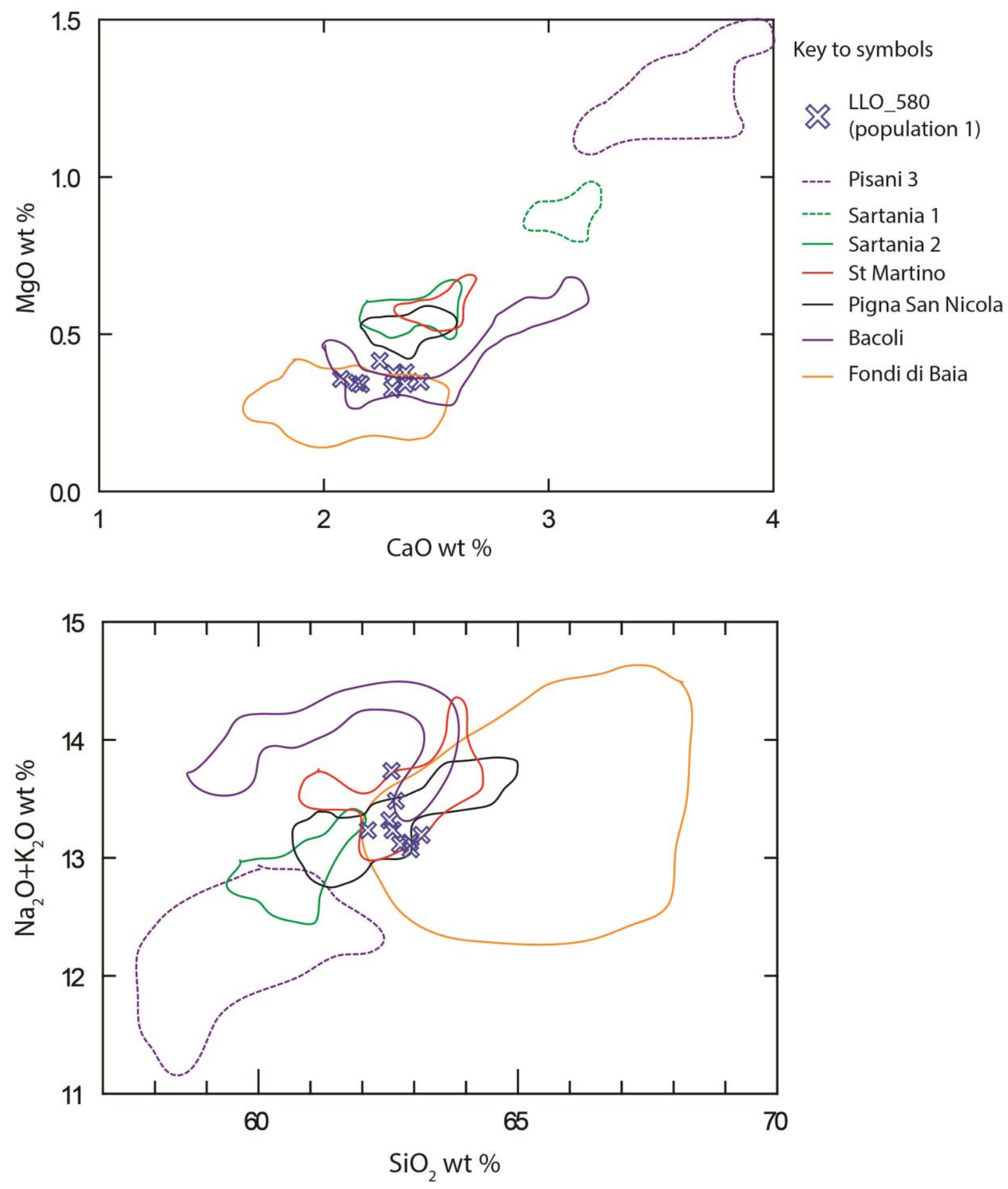

Figure 5.18 - Selected bivariate plots showing tephra glass shard major element compositions for LLO_580 (population 1) and envelopes for similarly aged Italian Tephras. (Reference envelopes are based on data from Smith et al., 2011). 
approximate early Holocene age and comparisons were made against Campi Flegrei tephras of similar ages including the Fondi di Baia, Bacoli, Pigna San Nicol, St Martino, Sartania 1 and 2, and Pisani 3 tephras (Smith et al., 2011) (Figure 5.18). Based on the geochemical data, notably the $\mathrm{MgO}$ content, the most probable candidates are the Fondi di Baia and Bacoli, however a slightly better overlap is made with the Fondi di Baia envelope, especially seen in the TAS plot (Figure 5.18). Even so, LLO_580 does differ slightly to the $\mathrm{K}_{2} \mathrm{O}$ and $\mathrm{Na}_{2} \mathrm{O}$ composition for the Fondi di Baia Tephra making it only a tentative correlation. A radiocarbon date was obtained (LLO14C_576.5), albeit based on aquatic macrofossils, from a sample $4 \mathrm{~cm}$ above LLO_580 which yielded an age estimate of 9279-9020 cal BP (unmodelled). The Fondi di Baia Tephra has an age estimate of 9695-9525 cal BP (Smith et al., 2011), which supports the tentative correlation to an extent.

Population 2 consists of two rhyolitic shards with 78.28-78.46 wt\% $\mathrm{SiO}_{2}$, 1.13-1.22 wt\% $\mathrm{FeO}$ and 3.62-3.89 wt\% $\mathrm{K}_{2} \mathrm{O}$. Population 3 consists of 3 rhyolitic shards with 75.08-76.66 wt\% $\mathrm{SiO}_{2}, 0.07 \mathrm{wt} \% \mathrm{TiO}_{2}$ and 4.46-4.62 $w t \% \mathrm{~K}_{2} \mathrm{O}$ (Figure 5.19). The geochemical signature for these shards are within the Icelandic envelope (Figure 5.24) so comparisons were made with Icelandic tephras of similar age, including the Abernethy, Askja-S, Hovsdalur, Fosen, An Druim, Suðuroy, Hässeldalen, L-274, Høvdarhagi, Skopun, Breakish and Ashik Tephras (Figure 5.19). The TAS plot and $\mathrm{FeO}$ vs $\mathrm{TiO}_{2}$ plot shows a degree of similarity between population 2 and the Hovsdalur and Hässeldalen, whereas population 3 shows affinity to the Hässeldalen tephra. However, the $\mathrm{CaO}$ values distinguish both correlations suggesting population 2 and 3 to be unknown tephras and may represent new eruptions.

\section{LLO_483}

This tephra deposit has a TSC of 45 clear shards per $0.5 \mathrm{~g} \mathrm{dw}$ and stratigraphically lies in the early-mid Holocene part of the Llyn Llech Owain sequence. Nineteen shards have been geochemically analysed and revealed a homogenous rhyolitic composition with 71.36-74.18 wt\% $\mathrm{SiO}_{2}, 0.23-0.24$ wt $\% \mathrm{TiO}_{2}, 1.00-1.12 \mathrm{wt} \% \mathrm{CaO}, 3.38-3.68 \mathrm{wt} \% \mathrm{~K}_{2} \mathrm{O}$ and $12.78-14.18 \mathrm{wt} \%$ 

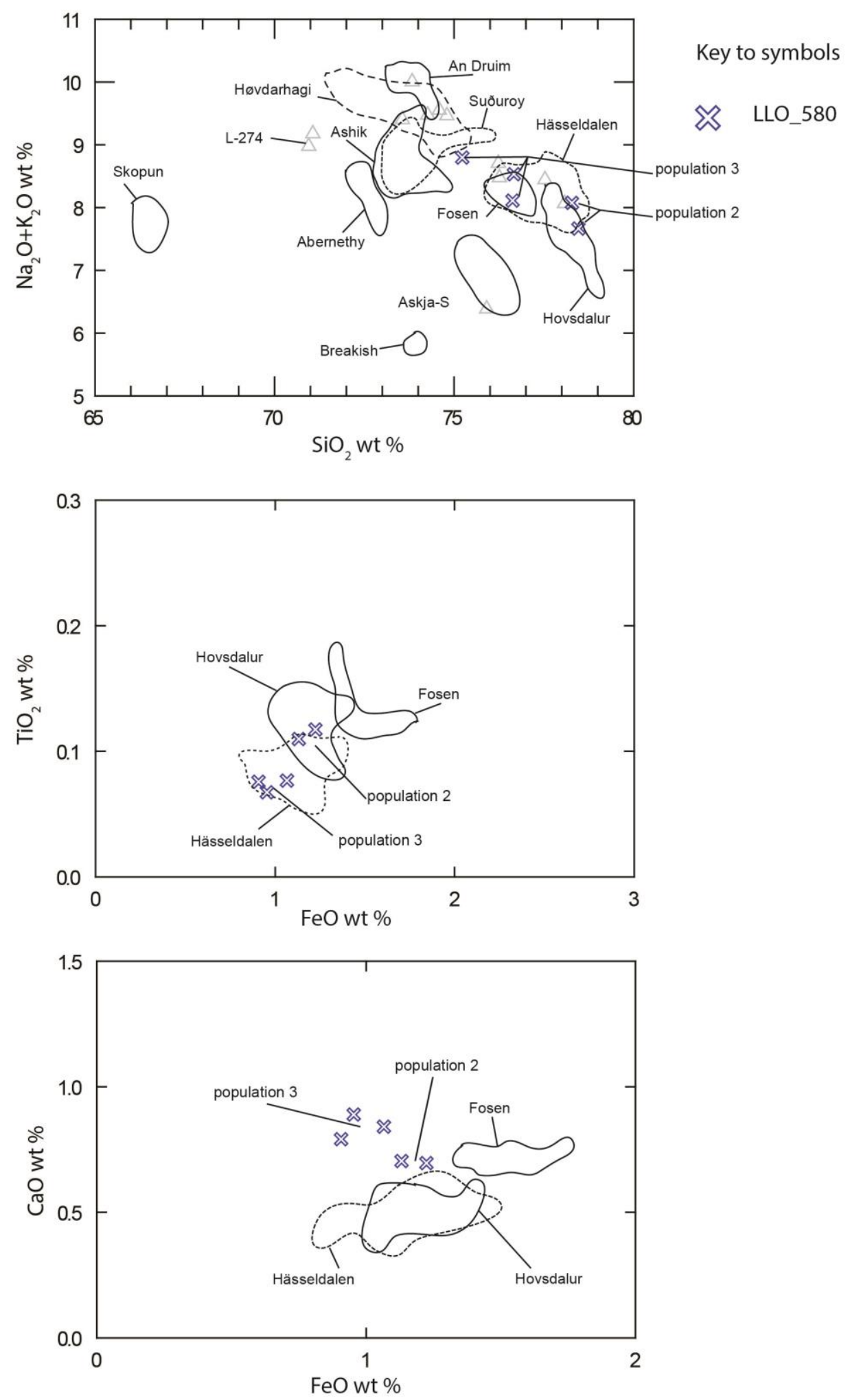

Figure 5.19 - Selected bivariate plots showing tephra glass shard major element compositions for LLO_580 (population 2,3 and outlier) and envelopes for similarly aged Icelandic Tephras. (Reference envelopes are based on data from Wastegård, 2002; Ranner et al., 2005; Pyne-O'Donnell, 2007; Lind and Wastegård, 2011; Matthews et al., 2011; Lane et al., 2011, 2012a; Lind et al., 2013; Lilja et al., 2013; Wulf et al., 2016; Timms et al., 2016; Jones et al., 2017). 
$\mathrm{Al}_{2} \mathrm{O}_{3}$. Comparisons were made against similar aged tephras including Abernethy, Askja-S, Hovsdalur, Fosen, An Druim, Suðuroy, Hässeldalen, L274, Høvdarhagi, Skopun, Breakish, Ashik and Lairg A and B Tephras. Based on geochemical composition, notably the $\mathrm{CaO}, \mathrm{TiO}_{2}$ and $\mathrm{Al}_{2} \mathrm{O}_{3}$ values, the LLO_483 deposit shows affinity to the Öræfajökull volcanic system (Figure 5.20). LLO_483 is consistent with the composition of the Öræfajökull 1362 eruption (Coulter et al., 2012) but this correlation is not supported by the stratigraphic position. There is no evidence for older Öræfajökull eruptions of early-mid Holocene age recorded in the literature, which suggests that LLO_483 is a newly identified eruption.

\section{LLO_468}

This tephra layer has a TSC of 46 clear shards per $0.5 \mathrm{~g} \mathrm{dw}$ and is stratigraphically placed $15 \mathrm{~cm}$ above LLO_483. Five shards have been geochemically analysed and revealed a homogenous rhyolitic composition which is indistinguishable to LLO_483, with 72.40-73.38 wt\% $\mathrm{SiO}_{2}, 0.23-0.24$ $w t \% \mathrm{TiO}_{2}, 0.97-1.11 \mathrm{wt} \% \mathrm{CaO}, 3.42-3.63 \mathrm{wt} \% \mathrm{~K}_{2} \mathrm{O}$ (Figure 5.20). Again this composition shows affinity to the Öræfajökull 1362 eruption. As noted above there is no evidence for older Öræfajökull eruptions of early-mid Holocene age recorded in the literature, indicating LLO_483 also to be a new or previously unknown eruption. Only $15 \mathrm{~cm}$ separate LLO_483 and LLO_468 which could potentially indicate that they originate from the same eruption and that post depositional re-working may have deposited LLO_468. However, the high resolution TSC does imply two distinct peaks and a clear gap between both tephra layers (Figure 5.13), suggesting two separate eruptions.

\section{LLO09_516}

This tephra layer has a TSC of 38 clear shards per $0.5 \mathrm{~g} \mathrm{dw}$. Four shards were geochemically analysed which revealed a homogenous rhyolitic composition with 76.52-77.37 wt\% $\mathrm{SiO}_{2}, 0.07-0.08$ wt $\% \mathrm{TiO}_{2}, 12.47-12.85$ 


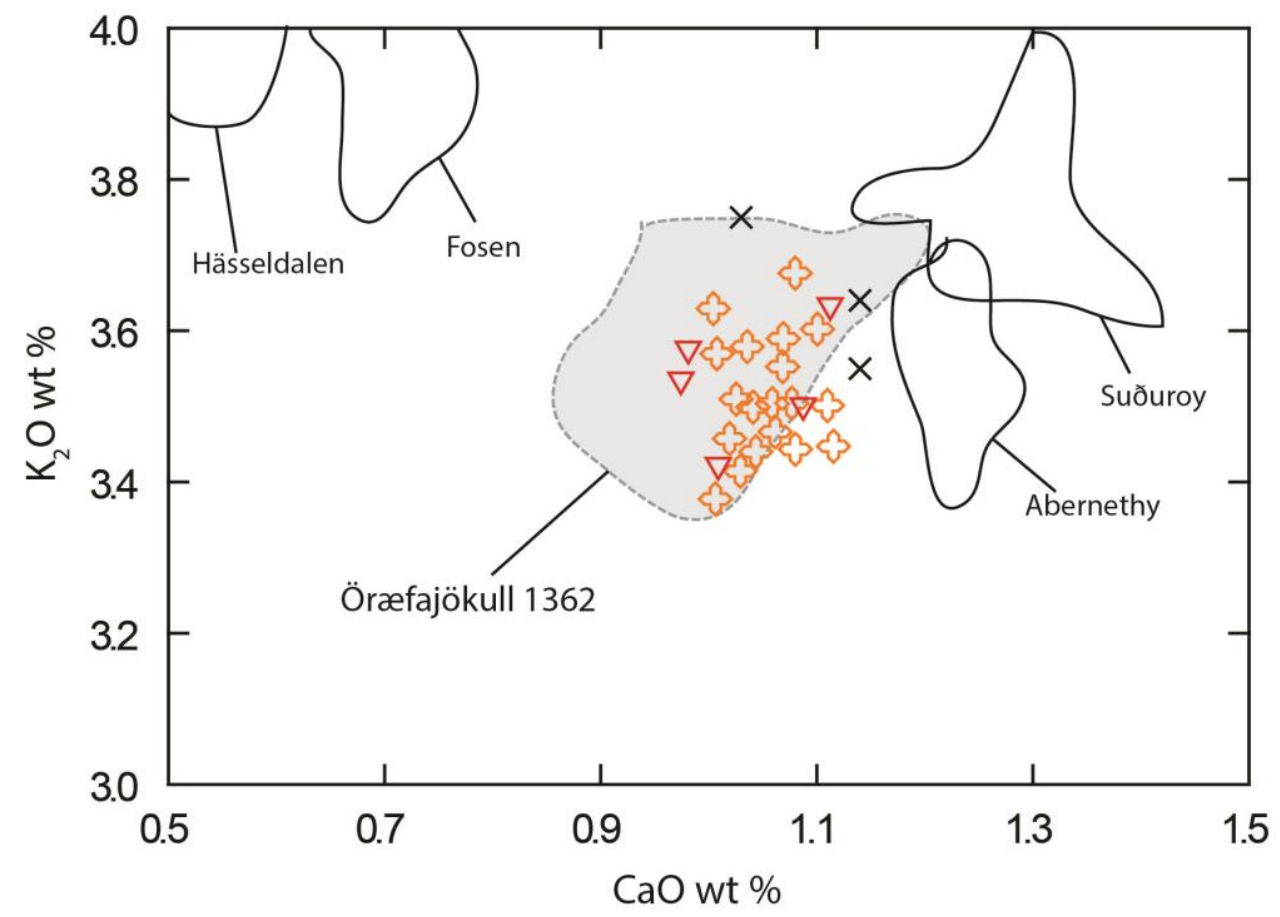

Key to symbols

$\times$ LLO09_505

$\nabla$ LLO_468

LLO_483

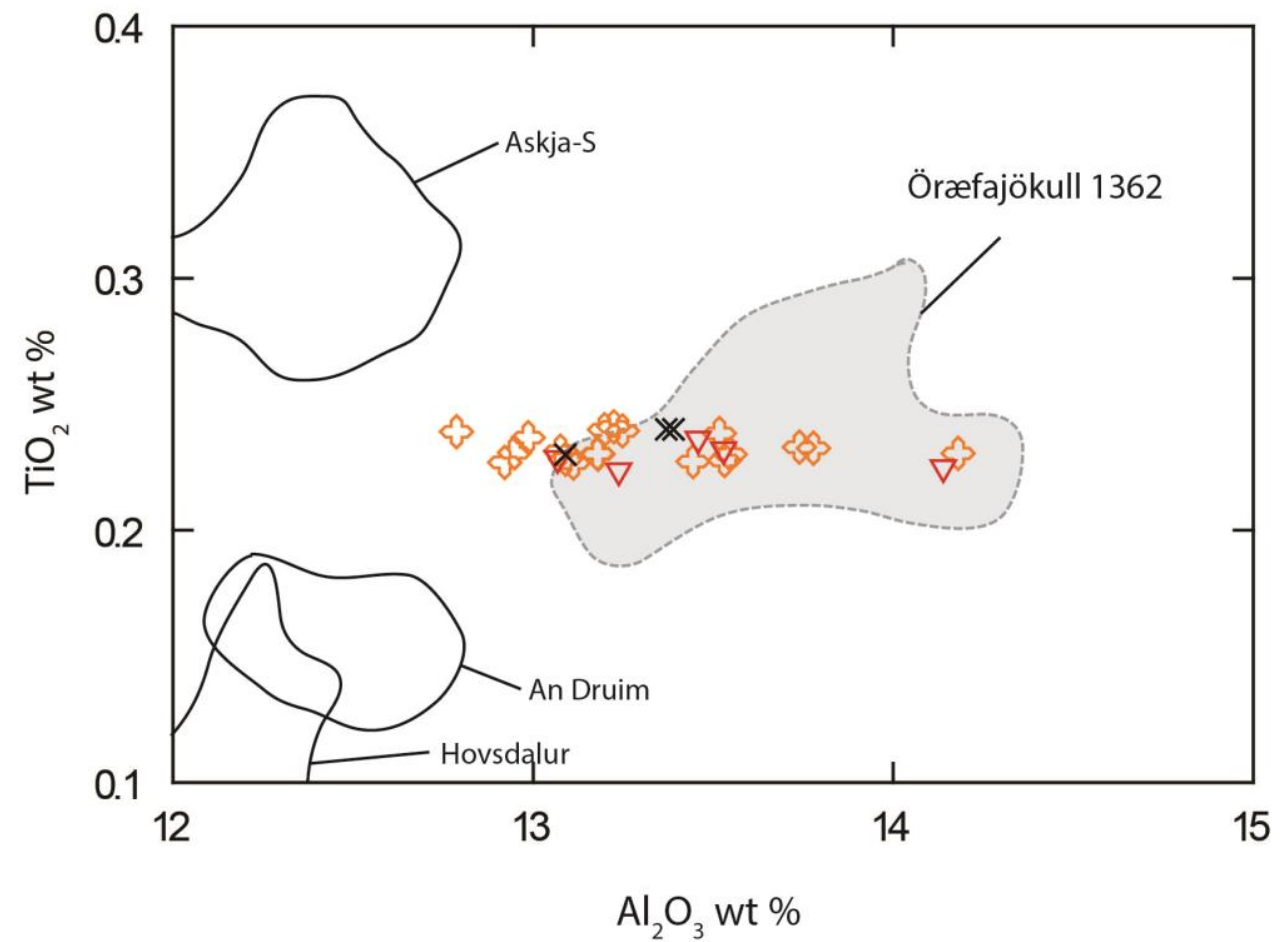

Figure 5.20- Selected bivariate plots showing tephra glass shard major element compositions for LLO_483, LLO_468 and LLO09_505. (Reference envelopes are based on data from Coulter et al., 2012). 
$\mathrm{wt} \% \mathrm{Al}_{2} \mathrm{O}_{3}$, and 2.82-3.05 wt $\% \mathrm{~K}_{2} \mathrm{O}$. This deposit is located in the early-mid Holocene part of the 2009 core sequence so comparisons were made with similarly aged tephras including Abernethy, Askja-S, Hovsdalur, Fosen, An Druim, Suðuroy, Hässeldalen, L-274, Høvdarhagi, Skopun, Breakish, Ashik, Hoy, Lairg A and B, Hekla 5,4,3 and Kebister tephras. Based on geochemical data, notably $\mathrm{SiO}_{2}, \mathrm{FeO}$ and $\mathrm{MgO}$ values, a correlation is made with the Lairg A tephra (Dugmore et al., 1995) (Figure 5.21). Only four analyses, however, were obtained for this deposit making the correlation tentative, further analyses would strengthen the correlation. The Lairg $A$ Tephra has an age estimate of 6947-6852 cal yr BP and is sourced from the Hekla volcano (Pilcher et al., 1996).

\section{LLO09_505}

This tephra deposit has a TSC of 64 clear shards per $0.5 \mathrm{~g}$. Only three shards were geochemically analysed which revealed a homogenous rhyolitic composition with $72.83-73.55 \mathrm{wt} \% \mathrm{SiO}_{2}, 3.42-3.81 \mathrm{wt} \% \mathrm{FeO}, 1.03-1.14 \mathrm{wt} \%$ $\mathrm{CaO}$ and $3.55-3.75 \mathrm{wt} \% \mathrm{~K}_{2} \mathrm{O}$. This deposit is chemically similar to LLO_483 and LLO_468 and shows affinity to the Öræfajökull 1362 eruption (Figure 5.20). As noted above, there is no evidence for older Öræfajökull eruptions of early-mid Holocene age recorded in the literature, indicating LLO09_505 also to be a new or previously unknown eruption. This deposit was identified in core sequence 2009 and potentially correlates to either LLO_483 or LLO_468 found in the 2013 core sequence. However, due to only one deposit of Öræfajökull 1362 chemistry identified in the 2009 core sequence it is not possible to correlate with either deposit from the 2013 core.

\section{LLO09_345}

This tephra deposit has a TSC of 104 colourless shards per $0.5 \mathrm{~g} \mathrm{dw}$. Eighteen shards were geochemically analysed which revealed a heterogeneous sample with 3 separate rhyolitic populations (Figure 5.14 and 5.22). Population 1 consists of 11 rhyolitic shards with $74.37-75.38 \mathrm{wt} \%$ 

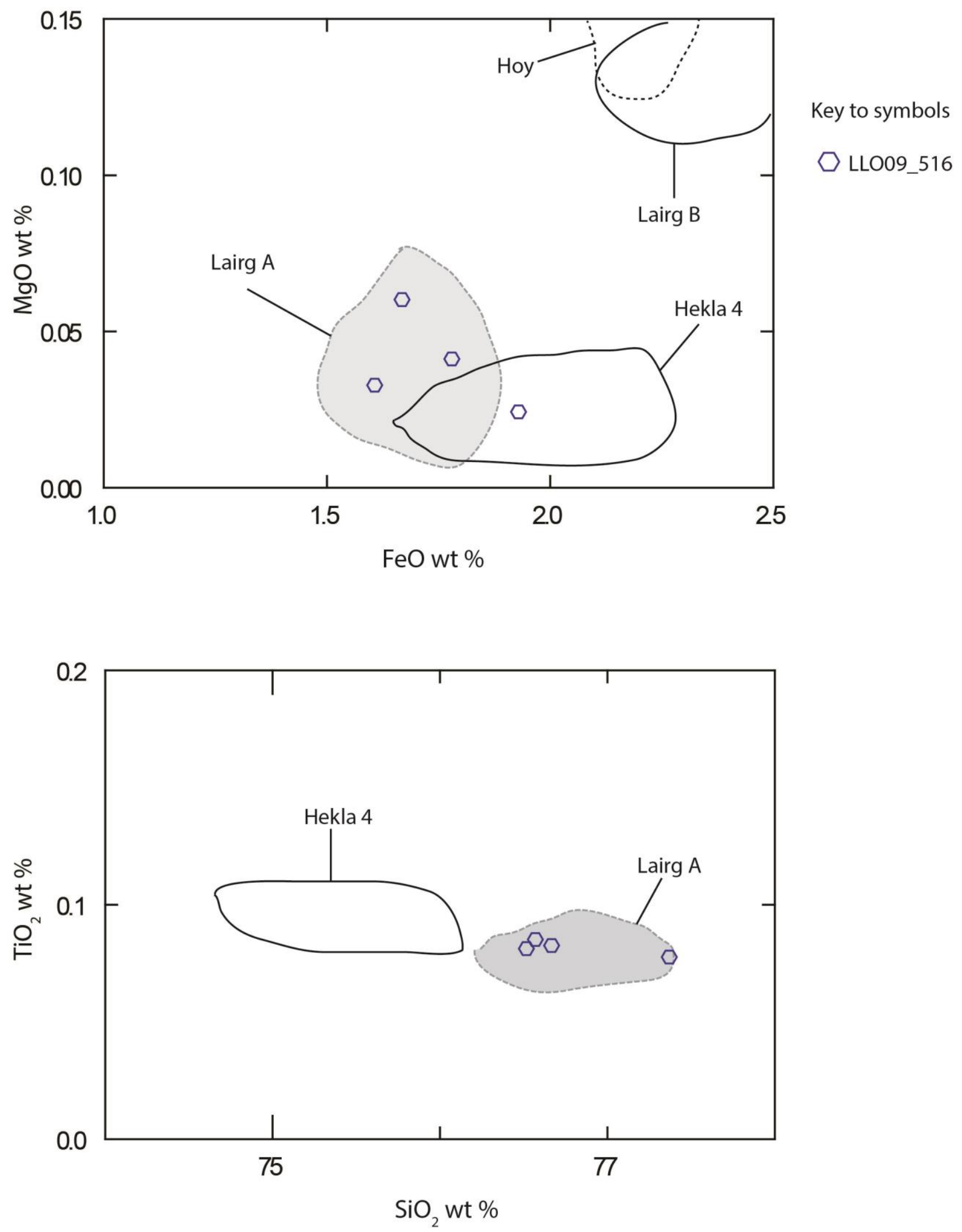

Figure 5.21 - Selected bivariate plots showing tephra glass shard major element compositions for LLO09_516. (Reference envelopes are based on data from Watson et al., 2016). 


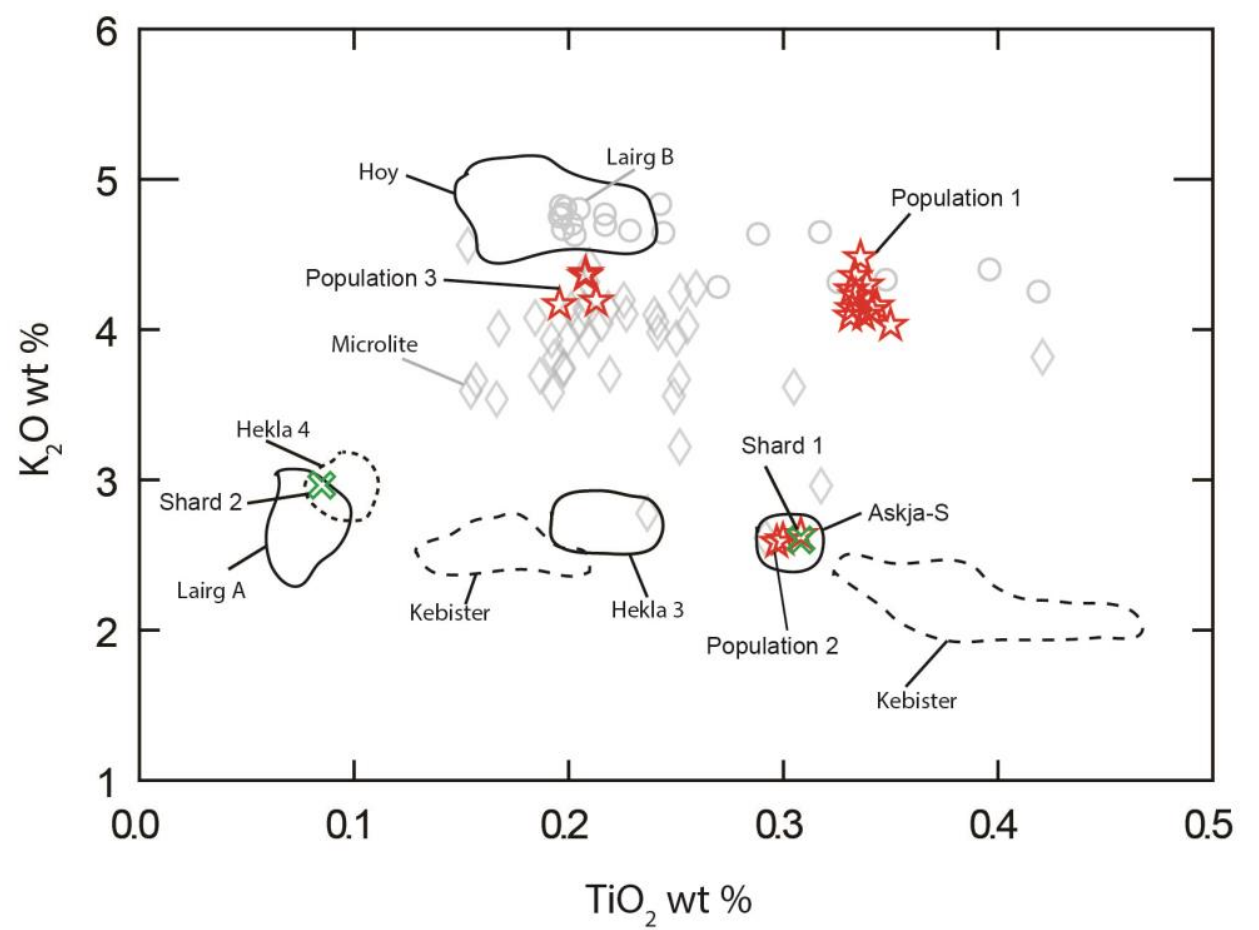

Key to symbols

为 LLO09_345

« LLO09_297

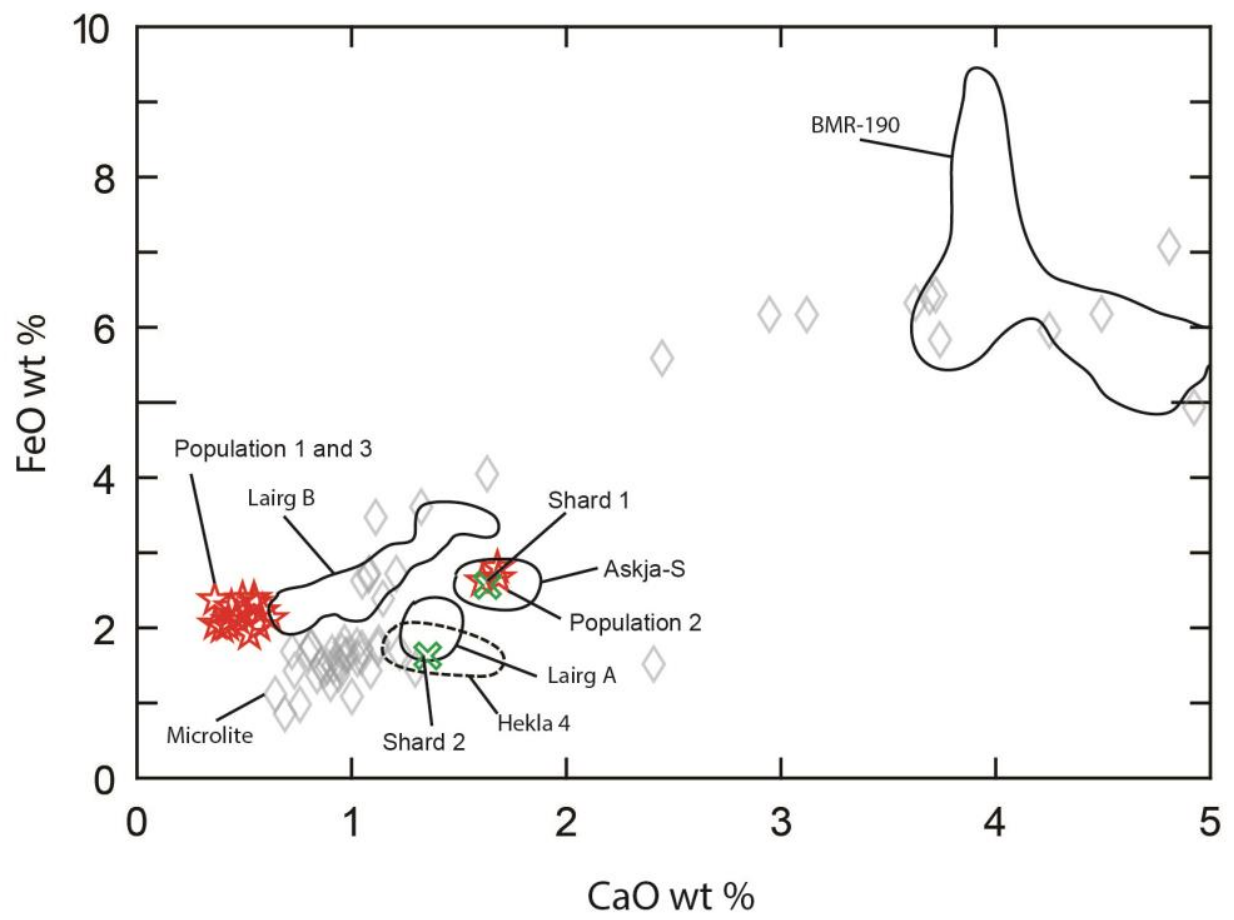

Figure 5.22 - Selected bivariate plots showing tephra glass shard major element compositions for LLO09_345. (Reference envelopes are based on data from Watson et al., 2016; Dugmore, 1995; Plunkett et al., 2004; Lawson et al., 2007; Roland et al., 2014; Bergmanet al., 2004; Jones et al., 2017). 
$\mathrm{SiO}_{2}, 0.33-0.35 \mathrm{wt} \% \mathrm{TiO}_{2}, 1.91-2.39 \mathrm{wt} \% \mathrm{FeO}$ and 0.37-0.62 wt\% $\mathrm{CaO}$.

Population 2 consists of three rhyolitic shards with 75.20-75.89 wt\% $\mathrm{SiO}_{2}$, 2.62-2.80 wt\% $\mathrm{FeO}, 1.61-1.68$ wt\% $\mathrm{CaO}$ and 2.58-2.64 wt\% $\mathrm{K}_{2} \mathrm{O}$. Population 3 consists of four rhyolitic shards with $75.52-75.98 \mathrm{wt} \% \mathrm{SiO}_{2}, 0.19-0.21 \mathrm{wt} \%$ $\mathrm{TiO}_{2}$, 4.16-4.38 wt\% $\mathrm{K}_{2} \mathrm{O}$. All three chemical populations are located within the Icelandic geochemical envelope (Figure 5.24), so comparisons were made with Icelandic tephras of similar approximate ages, including the Lairg A and B, Hoy, Microlite, Hekla 3,4,5, BMR-190 and Kebister tephras. Population 2 correlates with the early Holocene Askja-S tephra, however, LLO09_345 is stratigraphically located in the mid Holocene part of the Llyn Llech Owain sequence which does not support a correlation with the Askja-S tephra (Figure 5.22). Until recently, there have been no reported findings of other younger Askja-S type tephras, however Guð̌mundsdóttir et al., (2016) have reported a younger tephra - the Askja L- dated to approximately 9400 cal BP (Striberger et al., 2012). The Askja-L tephra has an identical chemical composition to Askja-S, however the age estimate differs to the approximate stratigraphic position of LLO09_345 which lies more towards the mid Holocene ( 5,000 years BP). This discovery may indicate the Askja volcano to be more active during this period and that population 2 of tephra layer LLO09_345 may represent a new or previously unknown eruption.

Population 3 does show some similarity with the microlite tephra based on $\mathrm{TiO}_{2}$ and $\mathrm{K}_{2} \mathrm{O}$ values, however $\mathrm{CaO}$ and $\mathrm{FeO}$ values differ. Population 1 also stands alone on the geochemical bivariate plots suggesting population 1 and 3 may represent a new or previously unknown eruption.

\section{LLO09_297}

This tephra deposit has a TSC of 54 clear shards per $0.5 \mathrm{~g} \mathrm{dw}$. Only four shards were geochemically analysed which revealed a heterogeneous sample. Shard 1 has a rhyolitic composition with $75.34 \mathrm{wt} \% \mathrm{SiO}_{2}, 0.31 \mathrm{wt} \%$ $\mathrm{TiO}_{2}$ and $2.66 \mathrm{wt} \% \mathrm{FeO}$. Shard 2 has a rhyolitic composition with $76.40 \mathrm{wt} \%$ $\mathrm{SiO}_{2}, 0.07 \mathrm{wt} \% \mathrm{TiO}_{2}$ and $1.72 \mathrm{wt} \% \mathrm{FeO}$. Shard 3 and 4 also have a rhyolitic composition with 70.76-72.21 wt\% $\mathrm{SiO}_{2}, 0.47 \mathrm{wt} \% \mathrm{TiO}_{2}, 14.74-15.19$ wt\% 
$\mathrm{Al}_{2} \mathrm{O}_{3}$, and $0.47-0.50 \mathrm{wt} \% \mathrm{MgO}$ (Figure 5.14). Geochemical comparisons were made with mid-Holocene aged tephras which is thought to represent the time period where LLO09_297 was deposited. These tephras include Lairg A and B, Hoy, Microlite, Hekla 3,4,5, BMR-190 and Kebister tephras. Shard 1 is chemically similar to population 2 in tephra deposit LLO09_345, which shows affinity to the early Holocene Askja-S eruption (Figure 5.22). As noted above, however, LLO09_345 and LLO09_297 are thought to have been deposited during the mid-Holocene, therefore rejecting a correlation with the Askja-S Tephra. Shard 2 shows geochemical affinity to the Lairg A and the Hekla 4 tephra, however based on stratigraphy a correlation is unlikely (Figure 5.22). Shards 3 and 4 were also compared to Icelandic midHolocene tephras, however, a correlation was not established. A consideration of sources further afield suggests a correlation to the Aniakchak Tephra (Pearce et al., 2004; Pyne O'Donnell et al., 2012), based on stratigraphy and geochemical signatures (Figure 5.23). This tephra was sourced from the Aleutian Range, southwest Alaska and dated to $3572 \pm 4$ cal BP (Pearce et al., 2017). Comparisons were also made against the White River Ash, Newberry Pumice and Mount Augustine Unit G however the MgO vs $\mathrm{TiO}_{2}$ bivariate plot strongly suggests a correlation to the Aniakchak Tephra (Figure 5.23).

Table 5.3 summarises the tephra deposits found in the Llyn Llech Owain sequence and their proposed correlations and reference age estimates. 


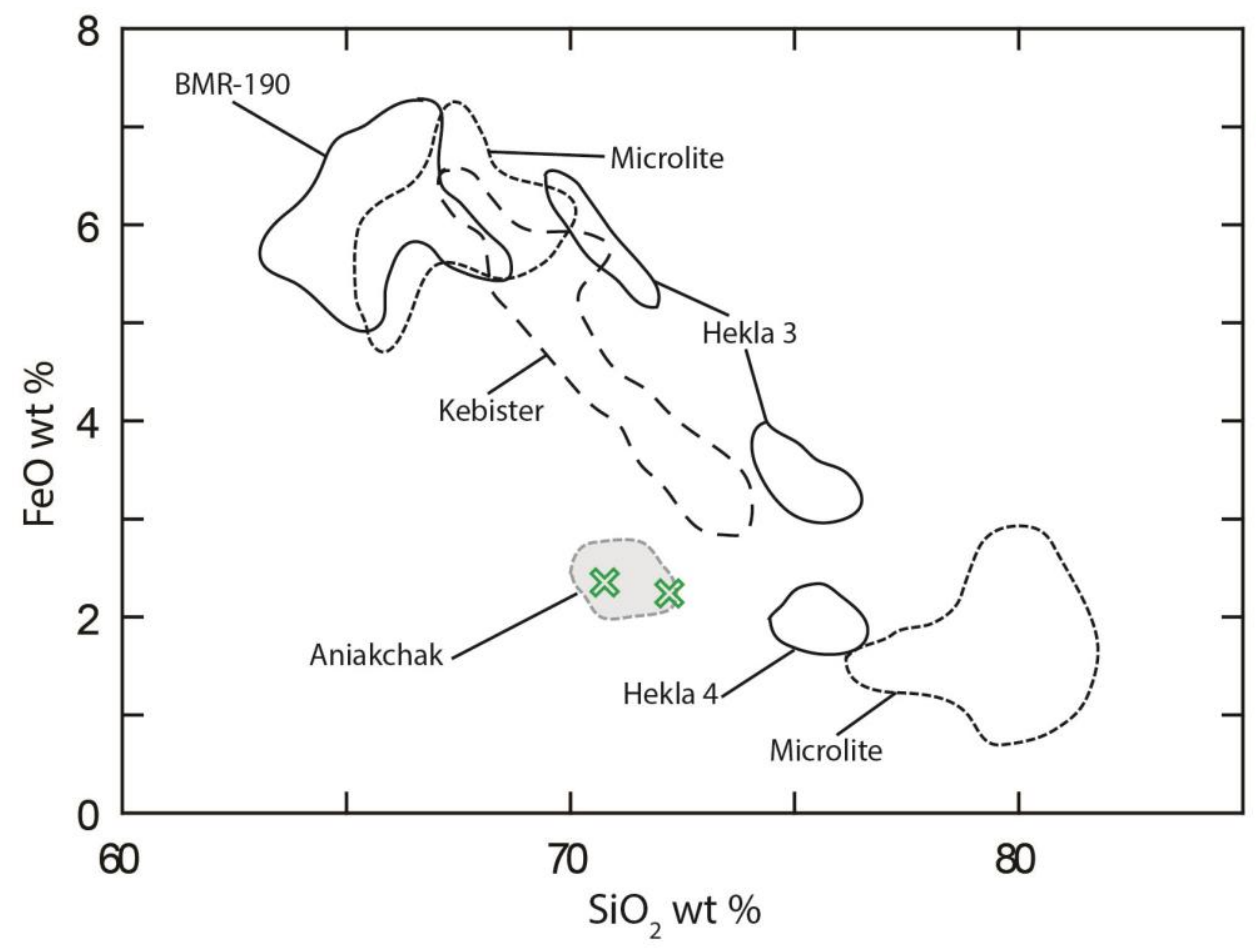

Key to symbols

\LLO09_297

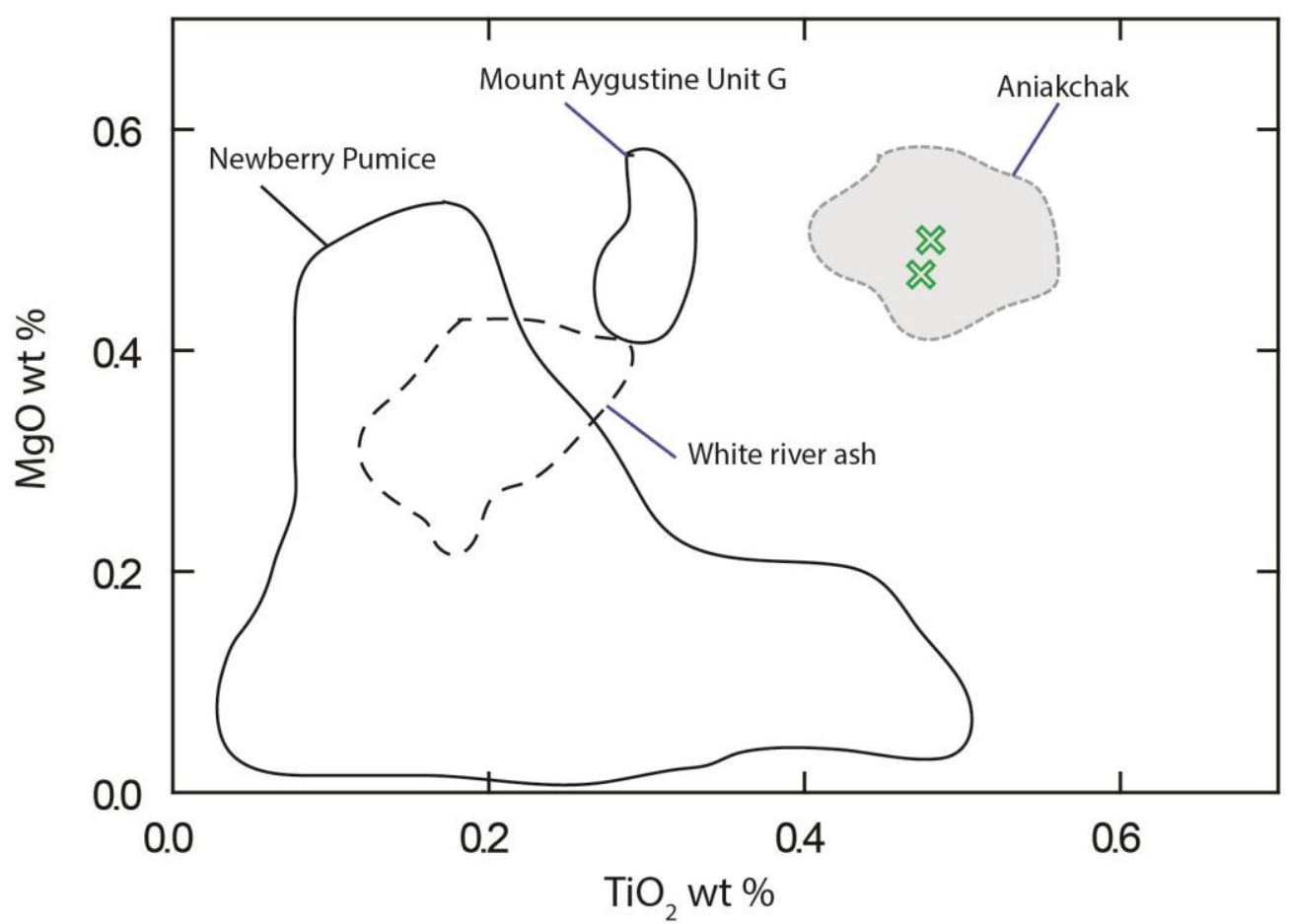

Figure 5.23 - Selected bivariate plots showing tephra glass shard major element compositions for LLO09_297. (Reference envelopes are based on data from Kauffman et al., 2012 and Pyne O'Donnell et al., 2012). 


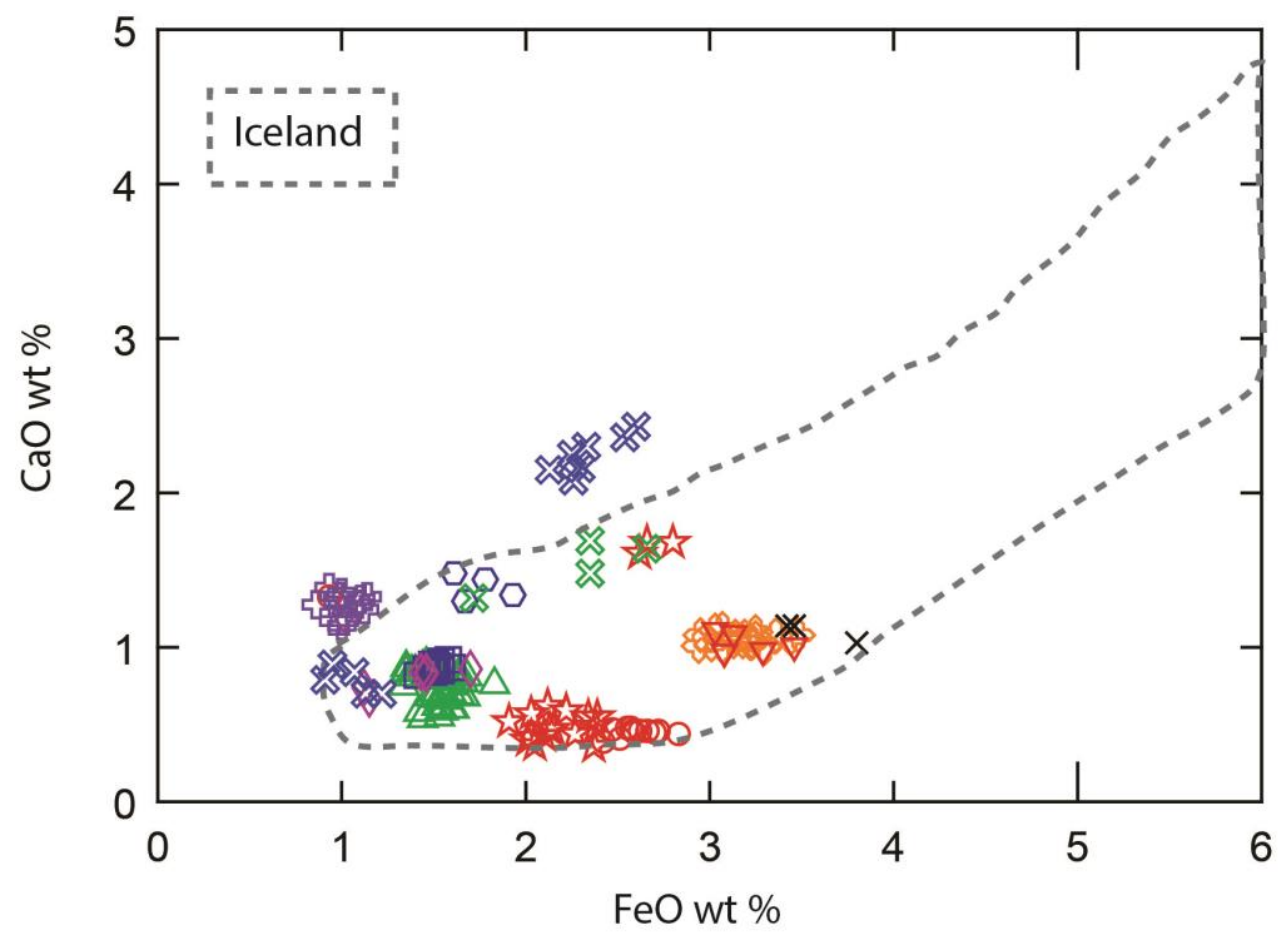

Key to symbols

¿LO009_297

放LLO09_345

$\times$ LLO09_505

○ LLO09_516

$\nabla$ LLO_468

LLO_483

¿ 2 LLO_580

↔ LLO_766

O LLO_767

$\diamond$ LLO_778

$\square$ LLO_782

$\triangle$ LLO_804

Figure 5.24 - $\mathrm{FeO}$ vs $\mathrm{CaO}$ bivariate plot showing the compositions of glass shard analyses from all tephra deposits from Llyn Llech Owain in relation to the Icelandic volcanic field (comprised of glass analyses of dacitic and rhyolitic tephra deposits from Iceland stored in the RESET database - Bronk Ramsey et al., 2015) (modified from Bourne et al., 2016). 


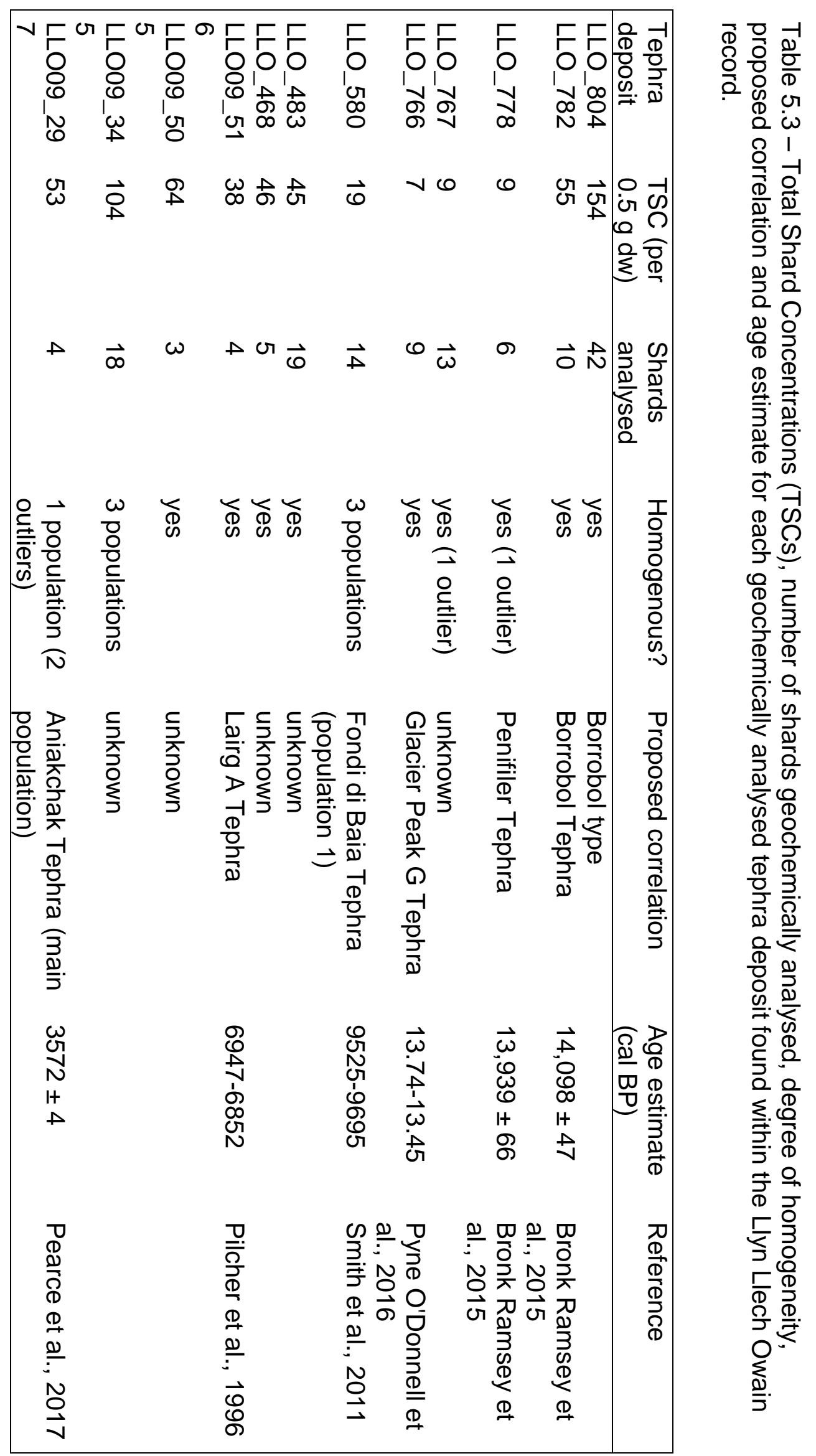




\subsubsection{Tephra signal in the XRF data?}

The main purpose of using the ITRAX core scanner on the sediment cores was to use the data retrieved as a proxy to reconstruct past environmental changes. However, XRF data have also been utilised to locate the position of cryptotephra deposits (e.g. Kylander et al., 2012; Wulf et al., 2013). This relationship was explored to determine whether an XRF signal coincided with the cryptotephra deposits. No distinct peak or signal was observed in the XRF data for the deposit that contained the highest number of shards (LLO_804 and LLO_782) (Figure 5.25). Shard concentration and the host sediment composition may be limiting factors in this study. Only visible tephra layers or high shard concentration cryptotephra deposit have been identified to date using a XRF core scanner according to Kylander et al., (2012). They discuss that visible (or $>1000$ shards $/ \mathrm{cm}^{3}$ ) tephra deposits, of basaltic composition were able to be detected with increases in $\mathrm{K}, \mathrm{Mn}, \mathrm{Fe} \mathrm{Ca}$ and Ti elemental counts. Tephra layers of rhyolitic compositions, however, are thought to be harder to detect. Wastegård et al., (2013) reported a marginal increase in $\mathrm{Ti}$ and $\mathrm{K}$ values that coincided with a visible rhyolitic tephra deposit from a sediment record in Laguna Potrok Aike. Wulf et al., (2013) however, demonstrate that detecting cryptotephra deposits that contain glass shards $(60-80 \mu \mathrm{m})$ with concentrations as low as $<10$ shards $/ \mathrm{cm}^{3}$ is possible through higher resolution XRF scans than the previously mentioned studies (at least $200 \mu \mathrm{m}$ step size and $10 \mathrm{~s}$ exposure time). 


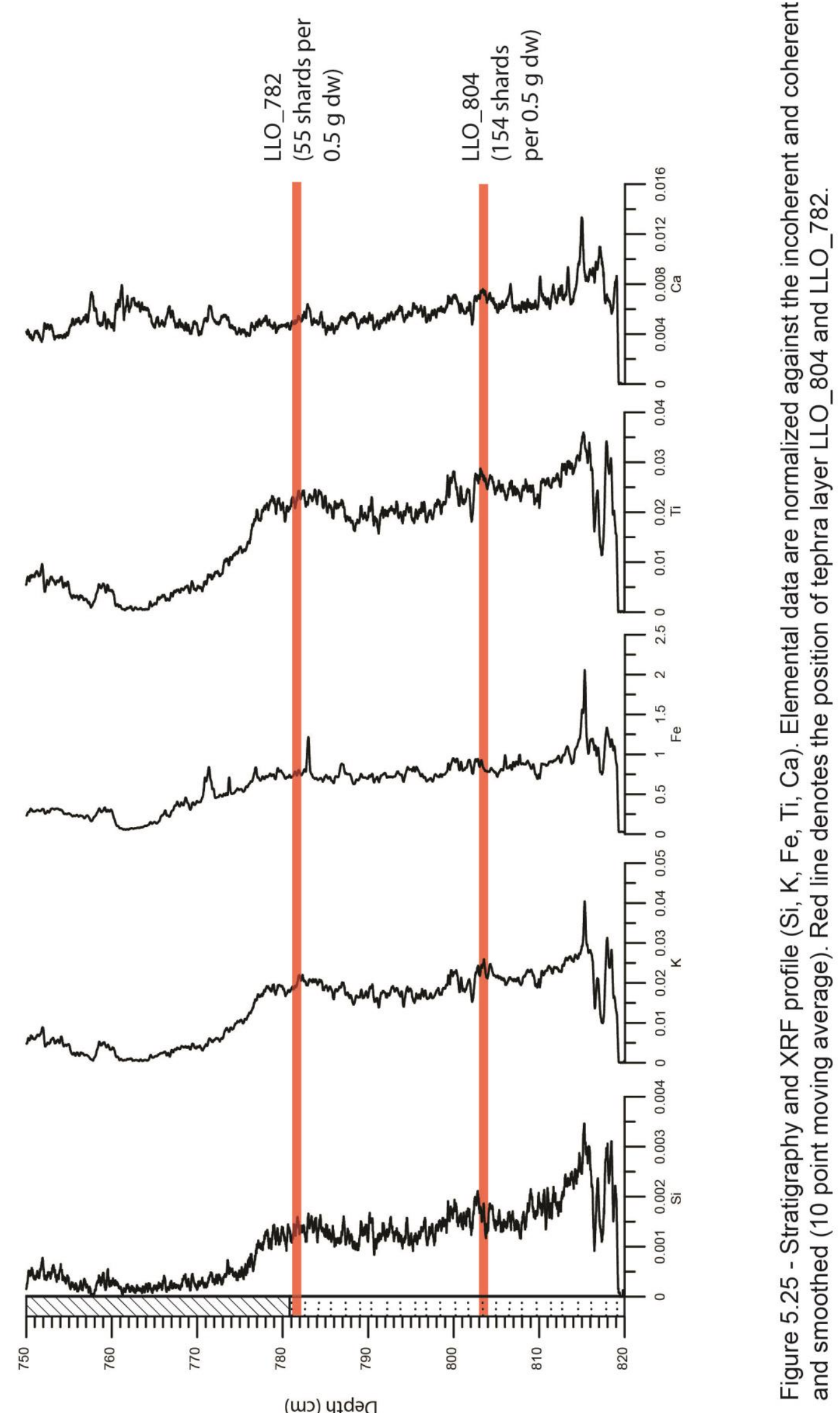




\subsection{Radiocarbon dating}

Eleven radiocarbon dates were obtained from the 2013 core and these are summarised in Table 5.3. Radiocarbon dated samples will be referred to and labelled by their depth for the following discussion (e.g. LLO ${ }^{14}$ C_802.5).

Terrestrial macrofossils were initially searched for by microscopy following sediment digestion in dilute sodium hydroxide. However, very few terrestrial macrofossils were recovered and as such, aquatic macrofossils or bulk sediment were selected for radiocarbon analysis. Sample depths were chosen based on the inferred climatic transitions, the Lateglacial Interstadial, Loch Lomond Stadial and early Holocene onsets based on the \%C profile (LLO ${ }^{14} \mathrm{C} \_771.5$, LLO ${ }^{14} \mathrm{C} \_711.5$, LLO ${ }^{14} \mathrm{C} \_700.5$, LLO ${ }^{14} \mathrm{C} \_679.5$ and LLO ${ }^{14} \mathrm{C} \_661.5$ ) and the position of the tephra deposits (LLO ${ }^{14} \mathrm{C} \_802.5$, LLO ${ }^{14} \mathrm{C} \_784.5, \mathrm{LLO}^{14} \mathrm{C} \_576.5, \mathrm{LLO}^{14} \mathrm{C} \_482.5$ and LLO $\left.{ }^{14} \mathrm{C} \_467.5\right)$. All samples were analysed at the NERC radiocarbon facility at the University of Oxford.

All dates are calibrated, against the IntCal13 calibration curve (Reimer et al., 2013) and un-modelled radiocarbon age estimates, outlined in Table 5.3 are plotted against depth in Figure 5.26. Four tephra layers identified in the Llyn Llech Owain record, which are tentatively correlated to known eruptions, are also included. These tephra layers include the Borrobol tephra at $781.5 \mathrm{~cm}$ (14004-14192 cal BP; Bronk Ramsey et al., 2015), Penifiler tephra at 777.5 cm (13807-14071 cal BP; Bronk Ramsey et al., 2015), Glacier Peak tephra at $766.5 \mathrm{~cm}$ (13450-13740 cal BP; Pyne O'Donnell et al., 2016) and the Fondi di Baia tephra at $579.5 \mathrm{~cm}$ (9525-9695 cal BP; Smith et al., 2011). Their correlation status is discussed in section 5.6.

Radiocarbon age estimates and tephra age estimates are plotted against depth in Figure 5.26. All age estimates discussed here are given at $95.4 \%$ probability ranges. This simplistic plot reveals several age reversals, together 
E E E E E E E E E

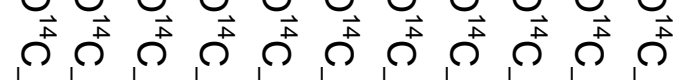

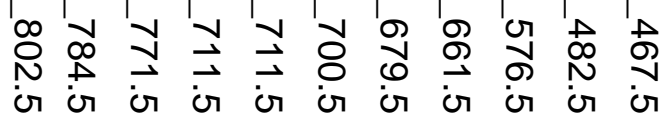

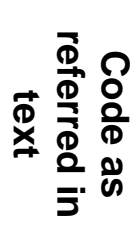

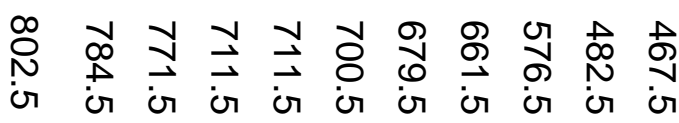

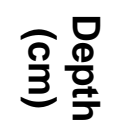

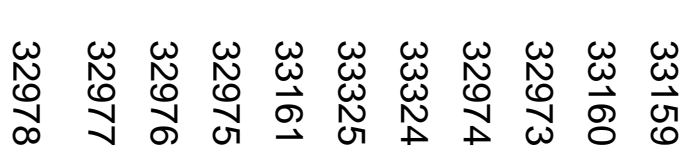

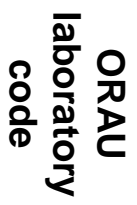

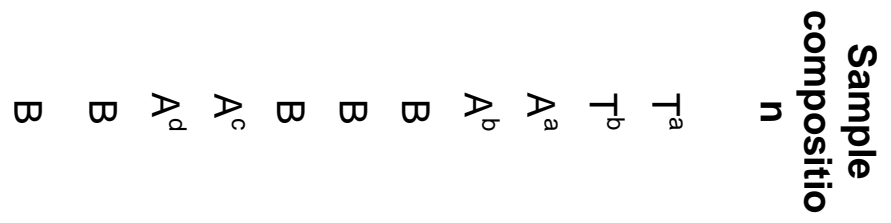

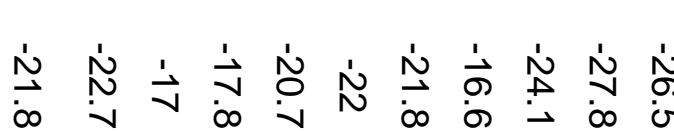

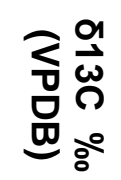

穴旅

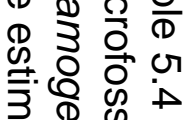
Ф) ๗ ค 을. ฏ 흠 응 讨

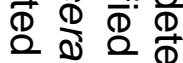

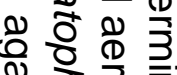

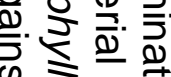

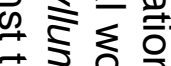
공ㅇำ

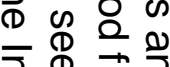

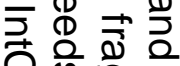
에 윽 $\bar{\omega} 1$ 更

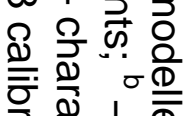
ఖ일 흥 용 응 응 舟市 ( ) गิ ${ }^{\circ} \overrightarrow{0}$

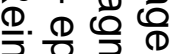

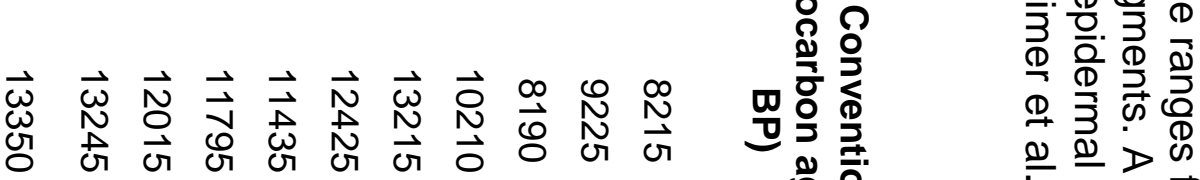

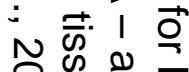
فำ め 言

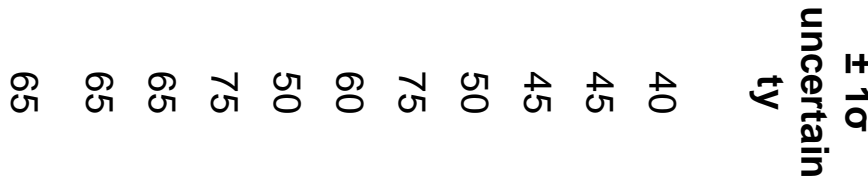
응ํํㅇ ㅇํㄱ

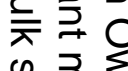
放 을 옹 ?

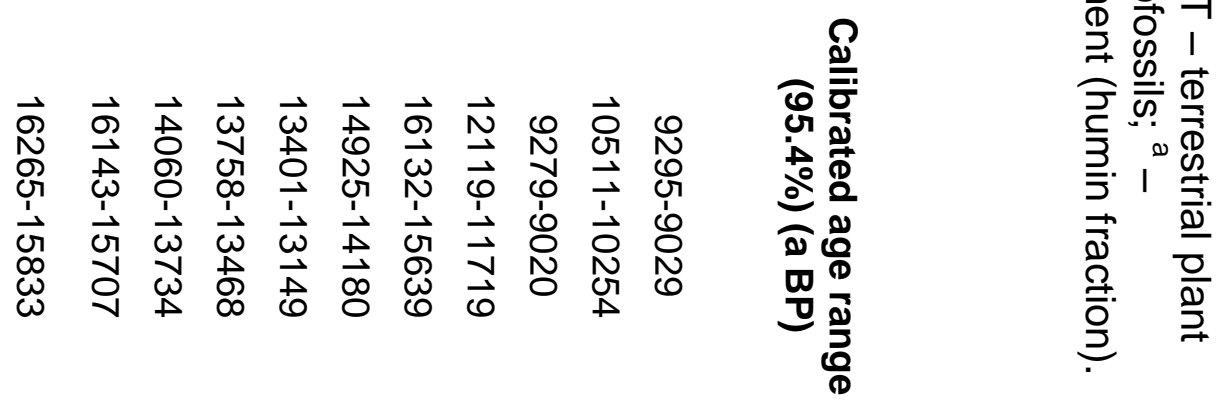


with implausible shifts in sedimentation rates. The most problematic dates in this record are found in the Loch Lomond Stadial where age estimates are erroneously old and comparable to those obtained for the Glacial period. The top three dates are also problematic as an age reversal is observed and an unrealistic sedimentation rate is seen between the top two dates. Llyn Llech Owain is not associated with limestone bedrock and no carbonates were visually observed in the sediments after the acid treatment performed for radiocarbon analysis, tephra and bulk chemistry work. Thus, hard water errors should not be an issue for this record. Due to the limited preservation of terrestrial macrofossils, all analysed samples, except for the upper two samples, consisted of either bulk sediment or aquatic macrofossils which are known to be problematic for radiocarbon dating (Walker, 2005). Terrestrial macrofossils are generally accepted to be the most suitable materials for yielding accurate radiocarbon dates in lake sediments (Björck and Wohlfarth, 2002; Olsson, 2009), however when in limited supply such as in this instance, aquatic macrofossils or bulk sediment samples are used. In such situations, one needs to take into consideration the probable uncertainties that will accompany dating such materials. These include the 'reservoir effect' where aquatic plants may have depleted ${ }^{14} \mathrm{C}$ values as they use dissolved inorganic carbon, which incorporates carbon from other sources, instead of atmospheric $\mathrm{CO}_{2}$ (Marty and Myrbo, 2014). Dating bulk sediments also pose problems as they typically yield significantly older ages, due to the secondary amalgamation of ${ }^{14} \mathrm{C}$ depleted carbon from other sources (Rothacker et al., 2013).

\subsubsection{Age-depth plot}

The age-depth relationships observed in Figure 5.26 are discussed here in relation to the NGRIP record from Greenland. NGRIP provides a representative stratotype record for the North Atlantic (Rasmussen et al., 


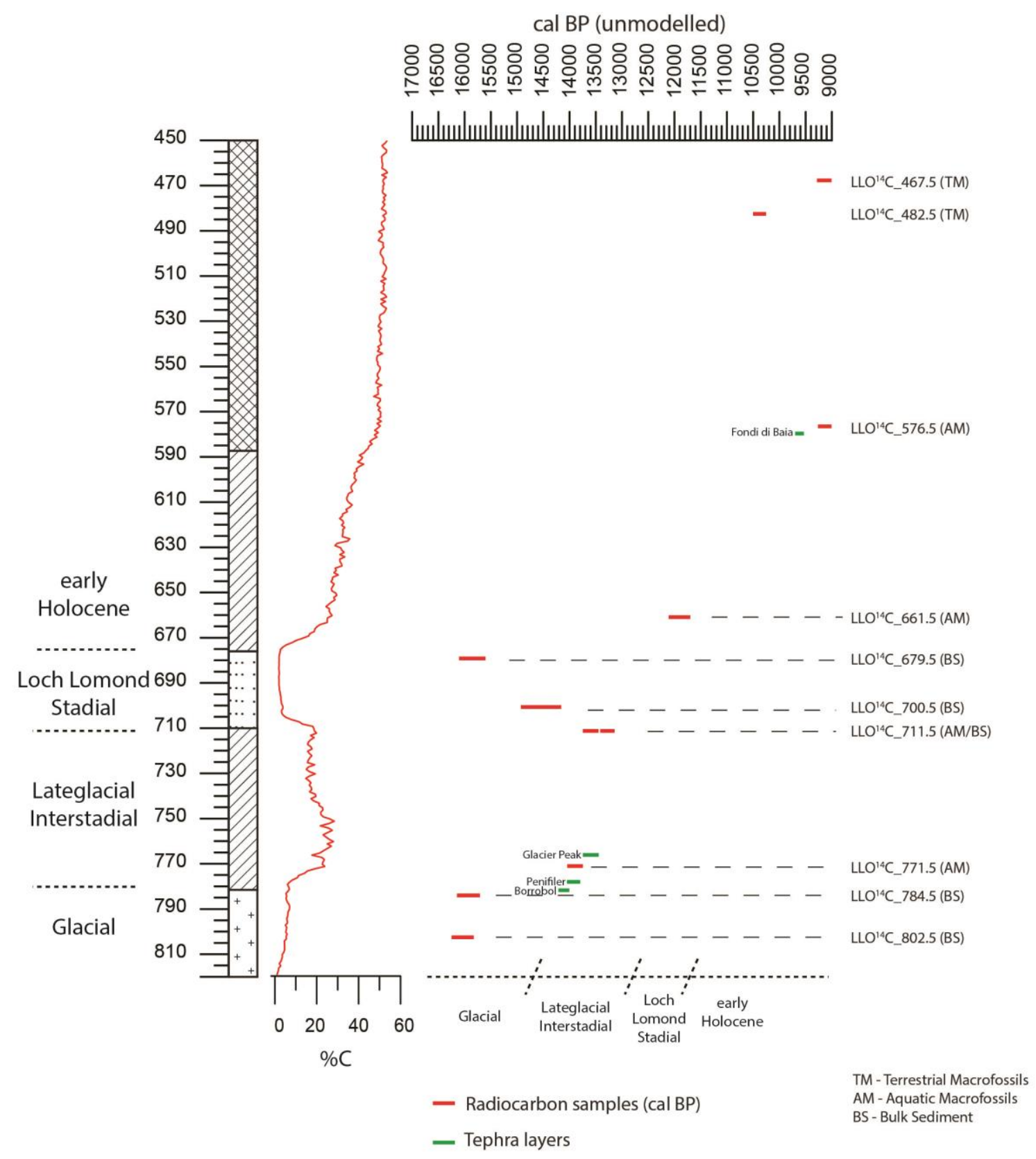

Figure 5.26 - Age vs depth plot including all radiocarbon samples (cal BP and un-modelled). Lithostratigraphy, \%C, approximate depths for chronostratigraphical units from Llyn Llech Owain and approximate ages for the Lateglacial plotted on the ' $x$ ' axis. Tephra layers found in the Llyn Llech Owain record are also plotted: LLO_782 Borrobol Tephra (14,004-14,192 cal BP - Bronk Ramsey et al., 2015), LLO_778 Penifiler Tephra (13,807-14,071 cal BP - Bronk Ramsey et al., 2015), LLO_766 Glacier Peak Tephra (13,450-13,740 cal BP - Pyne O'Donnell et al., 2016), LLO_580 Fondi di Baia (9,525-9,695 Smith et al., 2011). 
2014) and is compared here to assess the timing of key transitions, however, it is not assumed that the Lateglacial climatic changes occurred synchronously between Greenland and Wales. For a site, where age reversals are significant, the Greenland record provides well-constrained reference ages for the transitions. This is especially important for this record whereby radiocarbon age estimate deviate significantly from typical timings of transitions.

Samples LLO ${ }^{14} \mathrm{C} \_802.5$ and LLO ${ }^{14} \mathrm{C} \_784.5$ are located stratigraphically in the Glacial sediments and were chosen based on the tephra deposits found in this part of the record (LLO_804 and LLO_782). They yield radiocarbon estimates that are of Glacial age, (16265-15833 cal BP and 16143-15707 cal $\mathrm{BP}$ respectively). However, these age estimates seem too old when considering the Lateglacial Interstadial onset (dated to 14,692 \pm 138 b2k in the NGRIP record; Rasmussen et al., 2014) at Llyn Llech Owain is only 6 $\mathrm{cm}$ above LLO ${ }^{14} \mathrm{C} \_784.5$ (based on the initial increase in \%C and decrease in Ti values at $778 \mathrm{~cm}$ ). However, as mentioned previously, assigning the Interstadial onset for sites without a temperature record is difficult (Walker \& Lowe, in press). The overlying sample, LLO ${ }^{14} C_{-} \quad 771.5$, is located within the organic muds, assumed to be the Lateglacial Interstadial in the Llyn Llech Owain record, and yielded an age estimate of 14060-13734 cal BP. This age estimate does seem plausible as it is younger than the Lateglacial Interstadial onset age of $14735-14549$ cal BP from the NGRIP record (Rasmussen et al., 2014). However, these ages suggest a significant sedimentation rate of 156 years per $\mathrm{cm}$ between sample LLO ${ }^{14} \mathrm{C} \_784.5$ and $\mathrm{LLO}^{14} \mathrm{C} \_$771.5. A shift in sedimentation rate agrees with lithostratigraphic changes and a higher sedimentation rate would be expected for the lowermost mineral-rich unit relative to the organic rich unit. These significant changes in sedimentation rate may indicate a possible hiatus during this part of the sequence however, there is no indication in the proxy data or stratigraphy to support this, suggesting sample LLO ${ }^{14} C_{-} 784.5$ and LLO ${ }^{14} \mathrm{C} \_802.5$ to be erroneous. The proposed tephra layers, and their respective age estimates, found at these depths (Borrobol tephra $-782 \mathrm{~cm}$, 
Penifiler tephra - $778 \mathrm{~cm}$, Glacier Peak tephra - $766 \mathrm{~cm}$ ) support the age estimate of sample LLO ${ }^{14} \mathrm{C} \_771.5$.

At $711.5 \mathrm{~cm}$ in the Llyn Llech Owain sequence, two samples were analysed from the same depth which are located stratigraphically before the Loch Lomond onset. One sample consisted of bulk sediment (humin fraction) and yielded an age estimate of 13401-13149 cal BP and the other sample consisted of aquatic macrofossils (chara oospores) which yielded an age estimate of 13758-13468 cal BP. Even though both samples were retrieved from the same depth, an offset is revealed between both samples probably due to the differing sample types. The age estimates are also considerably offset by ca. 760 years from the aquatic macrofossil sample and $\sim 430$ years from the bulk sediment sample relative to the GS-1 onset recorded in Greenland.

A significant age reversal is also seen during the Loch Lomond Stadial with both LLO ${ }^{14} \mathrm{C} \_700.5$ and $L L O{ }^{14} \mathrm{C} \_679.5$ revealing age estimates that are erroneously older than expected, (14925-14180 cal BP and 16132-15639 cal $\mathrm{BP}$, respectively). These age estimates are significantly older than the entire GS-1 period recorded in Greenland. However, sample LLO ${ }^{14} \mathrm{C} \_661.5$, which is stratigraphically located $10 \mathrm{~cm}$ above the Holocene onset based on the proxy data, has yielded an age estimate of $12119-11719$ cal BP. This age is in better agreement with the Holocene onset as recorded in NGRIP although it is still slightly older.

The next radiocarbon sample, $\mathrm{LLO}^{14} \mathrm{C} \_576.5$, is stratigraphically located at the onset of stable \%C values and the transition from lake muds to organic peat. The sample yielded an age estimate of 9279-9020 cal BP, which was based on aquatic macrofossils (potamogeton seeds). Tephra layer, LLO_580, located $3 \mathrm{~cm}$ below LLO ${ }^{14} \mathrm{C} \_576.5$ is tentatively correlated to the Fondi di Baia tephra which has an age of 9709-9535 cal BP (Bronk Ramsey et al., 2015). This discovery indicates an offset of $\sim 480$ years and $\sim 160$ years per cm sedimentation rate between tephra layer LLO_580 and LLO ${ }^{14} \mathrm{C} \_576.5$. Based on sedimentation rates from other sites in Britain of similar stratigraphic age ( 20 years per cm: Kelly et al., 2016; Timms et al., 
2016; Watson et al., 2016) the sedimentation rate here either suggests the tephra correlation to be incorrect or the radiocarbon sample to erroneous.

The upper two radiocarbon samples, LLO ${ }^{14} C_{-} 482.5$ and LLO ${ }^{14} \mathrm{C} \_467.5$, are based on terrestrial macrofossils which should provide the most reliable age estimates. However, a minimum offset of 959 years is seen between both samples, which are only $15 \mathrm{~cm}$ apart, indicating an unrealistic sedimentation rate of $\sim 80$ years per $\mathrm{cm}$ suggesting that one, or both, samples are erroneous. A considerable age reversal is also observed between LLO ${ }^{14} \mathrm{C} \_576.5$ and $L L O{ }^{14} \mathrm{C} \_482.5$ with samples yielding age estimates of 9279-9020 cal BP and 10511-10254 cal BP respectively. If an assumption is made that $L L O{ }^{14} \mathrm{C} \_576.5$ yielded a relatively true age, then we can determine with a degree of certainty that sample LLO ${ }^{14} \mathrm{C} \_482.5$ is erroneous. Additionally, sample LLO ${ }^{14} \mathrm{C} \_467.5$ yielded an age estimate of $9295-9029 \mathrm{cal}$ BP which is slightly older than sample LLO ${ }^{14} \mathrm{C} \_576.5$ which is $109 \mathrm{~cm}$ below.

In summary, the radiocarbon age estimates obtained from Llyn Llech Owain reveal a number of puzzling observations. It is widely known and recognised that bulk sediment and aquatic macrofossils are problematic material for dating but there is no clear pattern in the results and the terrestrial macrofossil samples also appear to be unreliable. As such, it is difficult to determine, with any certainty, which ages are erroneous and which should be discarded for establishing an age model. However, four Bayesian statistical age models were constructed to test whether an age-model could be formed. Freely available software OxCal v 4.3 (Bronk Ramsey, 2008; Bronk Ramsey and Lee, 2013; Bronk Ramsey, 2017) was used for this purpose. Different models were run based upon different assumptions and constraints and P_Sequence (i.e. Poisson process) deposition models have been applied for Model B and C. P_Sequence models take consideration of the fact that the deposition rate of the sediment sequence can vary through time, rather than a constant deposition throughout the record based upon a Poisson process sedimentation (Bronk Ramsey, 2008) (see section 3.6.2). 
Age model $\mathrm{A}$ attempts to incorporate only the analysed ${ }^{14} \mathrm{C}$ dates. Age model $\mathrm{B}$ consists of all the ${ }^{14} \mathrm{C}$ dates in addition to added age estimates for the Loch Lomond Stadial (GS-1) onset and Holocene onset from the NGRIP record. Model $B$ was constructed to test the proposed tephra correlations. Age model $\mathrm{C}$ includes all the ${ }^{14} \mathrm{C}$ dates and the tephra deposits that have been tentatively correlated to known eruptions. Age model $D$ is a replicate of age model C, however added age estimates for the Loch Lomond Stadial (GS-1) onset and Holocene onset from the NGRIP record are included giving the model additional constraints to strengthen and reduce the uncertainty of the model.

\subsubsection{Age model A}

Despite attempting to construct an age model consisting of only the radiocarbon dated samples to provide a completely independent age model for the Llyn Llech Owain sequence, OxCal was unable to complete a model run due to the limited number of robust constraints. This reflects the numerous age reversals and unrealistic sedimentation rates in the sequence, as discussed above.

\subsubsection{Age model B}

Age model $B$ consists of all radiocarbon dates analysed for the sequence in addition to added chronological constraints from the NGRIP record (Rasmussen et al., 2014), including the Holocene onset and GS-1onset (Loch Lomond equivalent) (Figure 5.27). It is emphasised that the Holocene and GS-1 onsets are not synchronous between Greenland and Wales. The reason for including the precise age constraints from the NGRIP record is to test the proposed tephra correlations and to provide added constraints in what is otherwise a problematic sequence. By implementing the NGRIP ages 


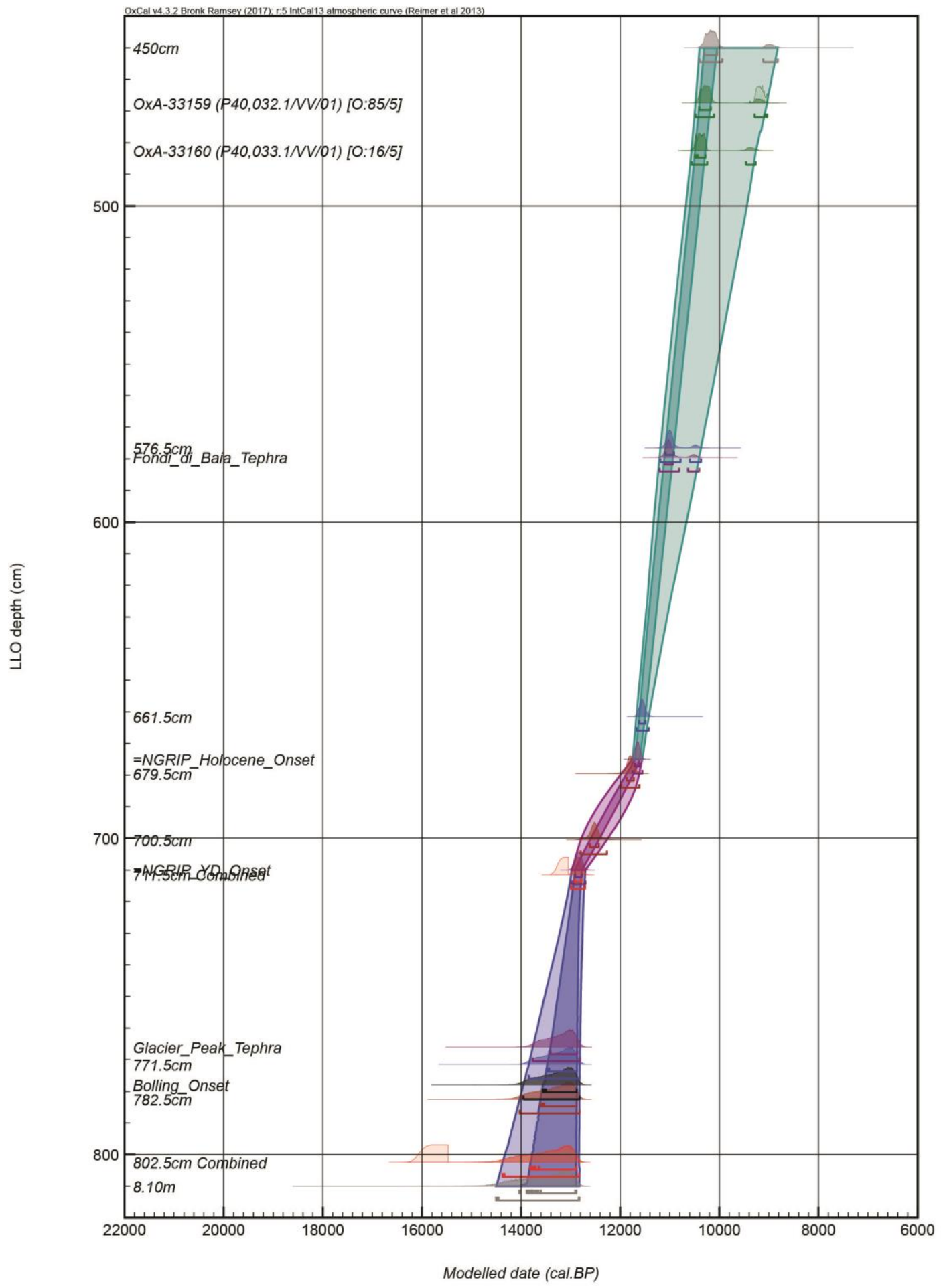

Figure 5.27-Age model B. P_Sequence deposition model constructed using OxCal v.4.3 (Bronk Ramsey, 2009, 2017). Model includes all radiocarbon dates analysed and the Holocene and GS-1 (Loch Lomond equivalent) onsets from the NGRIP record (Rasmussen et al., 2014) as added constraints. 
the model incorporates dates from another record where the model cannot be deemed independent.

Initial observations reveal large ranges in the top and bottom part of the sequence. As expected, however, with the added NGRIP constraints, the middle part of the age model is much more precise and tightly constrained. Table 5.5 shows the age estimates output from for the tephra deposits found in the Llyn Llech Owain sequence against the reported best age estimates for the proposed tephra correlations. The modelled age estimate for tephra deposit LLO_782 has a large range of 1200 years, which is due to the lack of precise constraints during this part of the sequence. The maximum age range does overlap with the minimum age range for the Borrobol tephra, however only by 16 years. The modelled age estimate for tephra deposit LLO_778 also has a large age range (1133 years), but it does overlap with the best age estimate for Penifiler with the maximum age range overlapping with the minimum range of the Penifiler age by 144 years. An age range of 953 years was given to tephra deposit LLO_766 from the age model B output. Even though the range is large the age overlap with the best age estimate for the Glacier Peak Tephra is good. However, the age estimate for tephra deposit LLO_580 which is tentatively correlated to the Fondi di Baia Tephra based on geochemical composition is offset quite considerably. The minimum age range is 713 years older than the maximum age range of the Smith et al., (2011) age estimate. This offset suggest a miss-correlation, however one could argue that age model $B$ is not robust enough during this part of the sequence to test the tephra correlations especially with the imprecision at the top of the sequence. For the following age models, LLO_580 will be considered a tentative correlation with the Fondi di Baia, however, based on the age estimate output from this model the correlation must be taken with caution. 
Table 5.5 - Comparison of the best age estimates for the Tephras found in the Llyn Llech Owain sequence against the output age estimates from age model B.

$\begin{array}{lllll}\begin{array}{l}\text { Depth } \\ \text { (cm) }\end{array} & \begin{array}{l}\text { Tephra } \\ \text { correlation? }\end{array} & \text { Reference } & \begin{array}{l}\text { Tephra age } \\ \text { (cal BP) }\end{array} & \begin{array}{l}\text { Age model B } \\ \text { (cal BP) } \\ \text { (95.4\%) }\end{array} \\ 782 & \text { Borrobol } & \begin{array}{l}\text { Bronk Ramsey } \\ \text { et al., 2015 }\end{array} & 14,004-14192 & 12820-14020 \\ 778 & \text { Penifiler } & \begin{array}{l}\text { Bronk Ramsey } \\ \text { et al., 2015 }\end{array} & 13807-14071 & 12818-13951 \\ 766 & \text { Glacier Peak } & \begin{array}{l}\text { Pyne O'Donnell } \\ \text { et al., 2016 }\end{array} & 13450-13740 & 12809-13762 \\ 580 & \text { Fondi di Baia } & \begin{array}{l}\text { Smith et al., } \\ \text { 2011 }\end{array} & 9525-9695 & 10408-11206 \\ & & & & \end{array}$

\subsubsection{Age model C}

For Model $\mathrm{C}$ the age estimates of the tephra deposits (including tentative correlations) were added (discussed in section 5.6). These tephra correlations have also been tested in model B with LLO_782, LLO_778 and LLO_766 showing good agreement but LLO_580 showing a poorer agreement. If tephra layers can be confidently correlated to known eruptions they can provide precise age constraints for sedimentary sequences and be used to produce independent age models (e.g. Lane et al., 2012; Timms et al., 2016). These tephra layers include the Borrobol Tephra $(14,098 \pm 47 \mathrm{cal}$ BP; Bronk Ramsey et al., 2015) at $781.5 \mathrm{~cm}$, Penifiler tephra $(13,939 \pm 66 \mathrm{cal}$ BP; Bronk Ramsey et al., 2015) at $777.5 \mathrm{~cm}$, Glacier Peak tephra (13,595 \pm 72.5 cal BP; Pyne O'Donnell et al., 2016) and Fondi di Baia tephra (9,622 \pm 87 cal BP; Smith et al., 2011) at $579.5 \mathrm{~cm}$. With the added age constraints, provided by the four tephra layers, a P_Sequence model was constructed, 
shown in Figure 5.28. Although this model does represent an independent age model, some issues have arisen.

Firstly, the precision is lacking with very large age ranges, especially for the late interstadial and throughout the Loch Lomond Stadial. According to this model, the Loch Lomond onset (based on \%C and Ti values $-708 \mathrm{~cm}$ ) has an age estimate of $12757-10520$ cal BP (95\%). This age estimate has a considerable range (2237 years), however only $\sim 20$ years difference is seen between the oldest age range in Llyn Llech Owain and the youngest age range for the onset of GS-1 in the Greenland ice cores.

Based on \%C and Ti values, the Holocene onset lies at $672 \mathrm{~cm}$ in the Llyn Llech Owain sequence and according to this model, has a reasonably constrained age estimate of 10347-9611 cal BP (95\%) with an error range of 736 years. However this age estimate is considerably offset to the Holocene onset recorded in the Greenland ice cores where an offset of $~ 1250$ years is seen between the oldest age range for the Holocene onset at Llyn Llech Owain and the youngest age range in the NGRIP record. The Holocene onset part of the Llyn Llech Owain sequence in model $\mathrm{C}$ is mostly based on the radiocarbon samples analysed (i.e. no tephra constraints) which is probably responsible for the imprecision during this part of the sequence.

Despite the large error ranges during the late interstadial and Loch Lomond Stadial and some uncertain age estimates, especially during the Holocene onset, age model $\mathrm{C}$ is completely independent. Therefore, it could be used to provide crude approximate age estimates for the unknown tephra discoveries identified and the environmental changes observed in the record. However, the lack of precise age constraints in model $\mathrm{C}$ gives rise to large age estimate ranges for parts of the record means that this model is of limited use. 


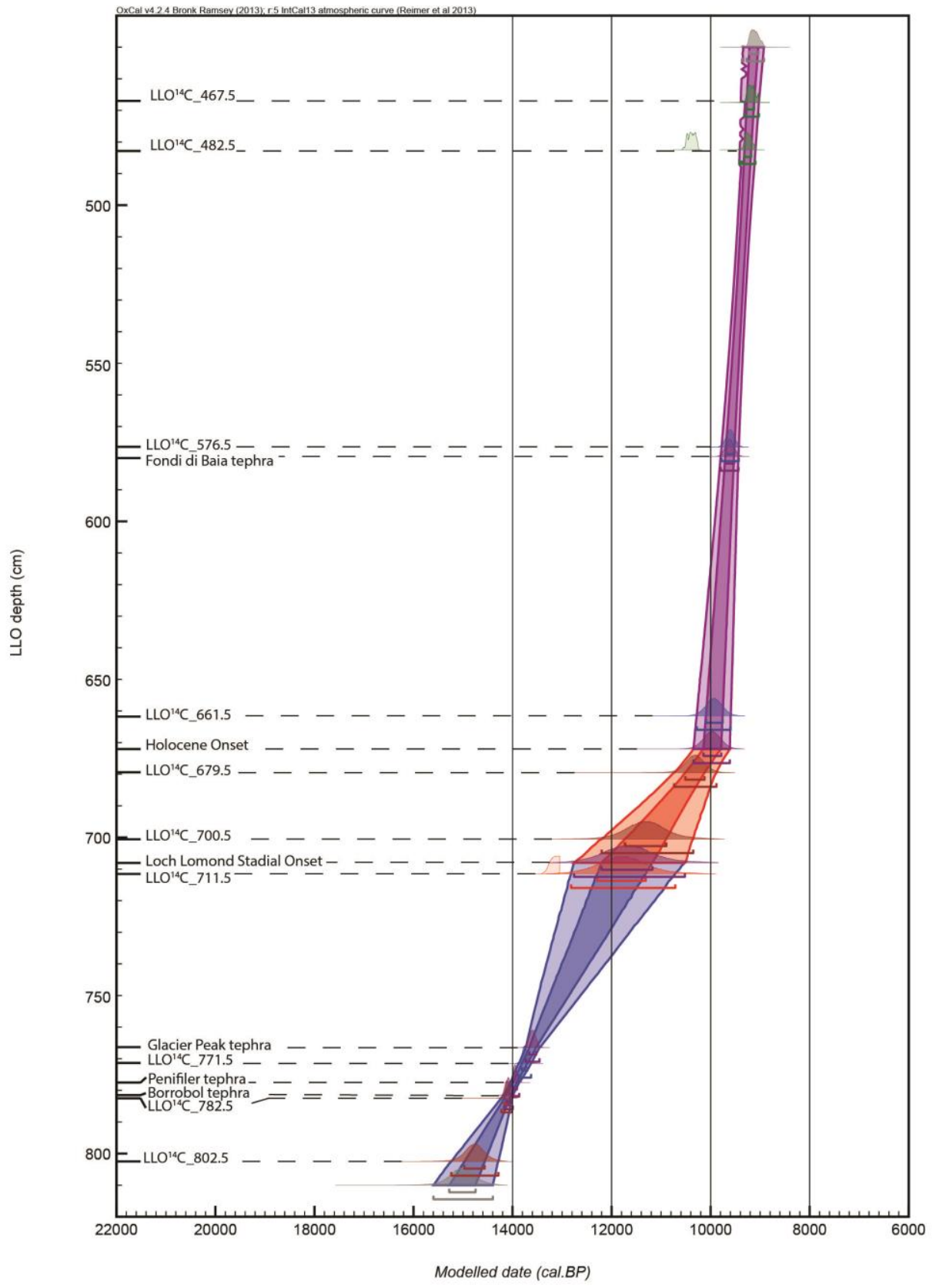

Figure 5.28- Age model C. P_Sequence deposition model constructed using OxCal v.4.3 (Bronk Ramsey, 2009, 2017). Model includes all radiocarbon dates analysed and tephra layers: LLO_782 Borrobol Tephra (14,004-14,192 cal BP - Bronk Ramsey et al., 2015), LLO_778 Pénifiler Tephra (13,807-14,071 cal BP - Bronk Ramsey et al., 2015), LLO_766 Glacier Peak Tephra (13,450-13,740 cal BP - Pyne O'Donnell et al., 2016), LLO_580 Fondi di Baia $(9,525-9,695$ - Smith et al., 2011). 


\subsubsection{Age model D}

Due to the problematic nature of age model $\mathrm{C}$, further age constraints were added in an attempt to establish a more robust model for the Llyn Llech Owain record (Figure 5.29). Age constraints for the major climatic transitions (Loch Lomond Stadial and early Holocene onsets) derived from a nearby record such as Llanilid is one possibility (Walker et al., 2003). Llanilid is a site $\sim 50 \mathrm{~km}$ from Llyn Llech Owain that contains a Lateglacial sedimentary sequence and has been studied extensively where numerous proxy techniques are constrained by $>40$ radiocarbon dates (Walker et al., 2003). However, determining the ages for the climatic transitions in the Llanilid sequence proved problematic, with a possible hiatus, obscuring the Holocene onset (Richard Staff, pers comm). As such, instead of using the Llanilid record, precise age constraints from the NGRIP record have been implemented into age model $\mathrm{D}$. This step means that age model $\mathrm{D}$ cannot be an independent model because an assumption is made that the Loch Lomond Stadial (or GS-1) and Holocene onsets occurred simultaneously between Greenland and Wales. This assumption of climate synchronicity between sites has previously been proved incorrect (e.g. Lane et al., 2013) but this was the only way to produce a precise age-model. The Loch Lomond Stadial and Holocene onset (constrained by \%C and Ti data) are the only transitions used in this model due to the difficulties of establishing the temperature rise at the Lateglacial onset.

Model $\mathrm{D}$ provides the best precision due to the added age constraints from the NGRIP ice-core record, however as this model incorporates dates from another record the model cannot be deemed independent. The uppermost part of the sequence, affected by radiocarbon samples LLO ${ }^{14} C_{-} 482.5$ and LLO ${ }^{14} C_{-} \_467.5$, yields considerable error ranges in excess of 1000 years. However, the error ranges for the interstadial and Loch Lomond Stadial have vastly improved compared with model C. 


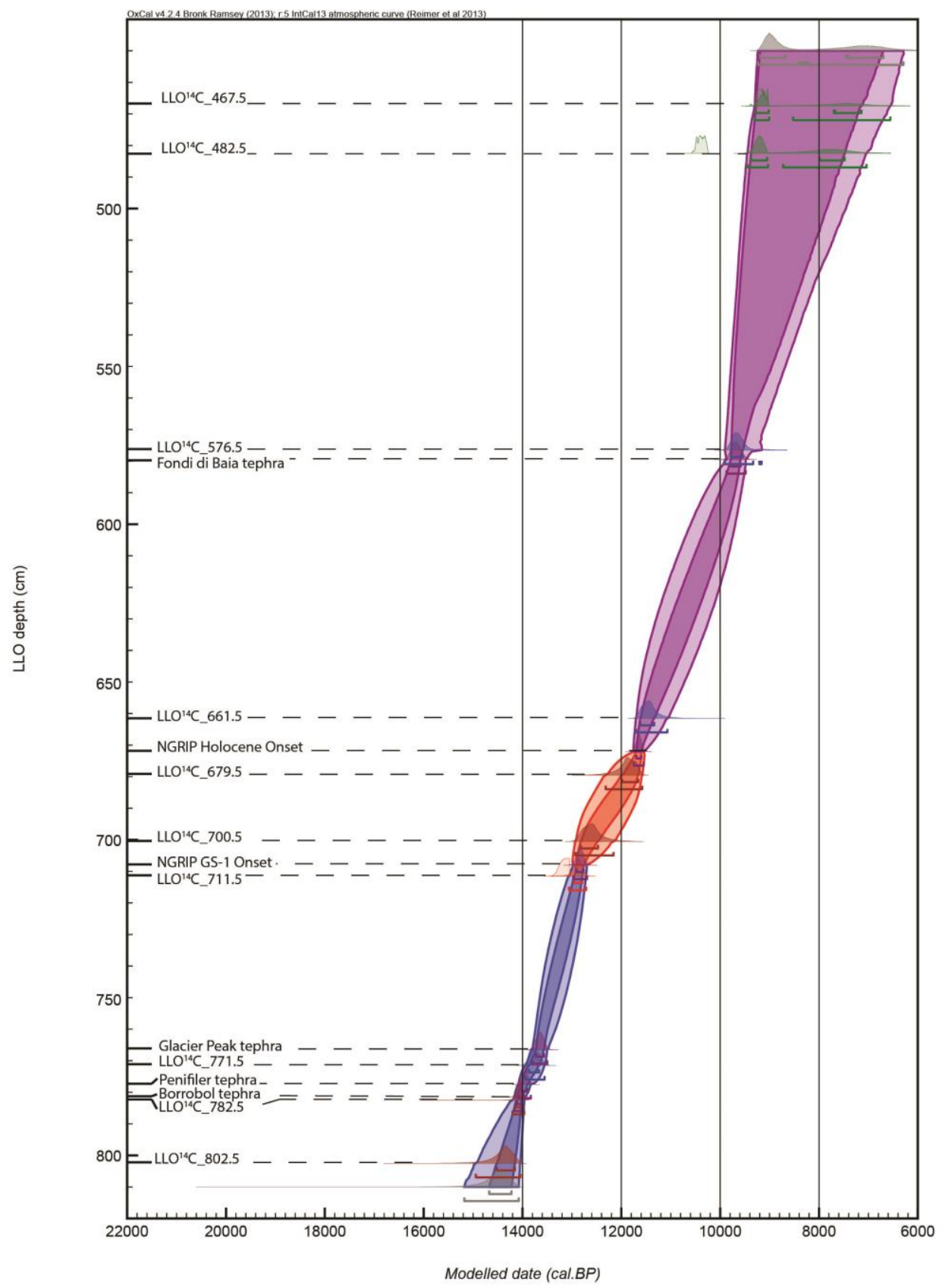

Figure 5.29 - Age model D. P_Sequence deposition model constructed using OxCal v.4.3 (Bronk Ramsey, 2009, 2017). Model includes all radiocarbon dates analysed, tephra layers LLO_782 Borrobol Tephra (14,004-14,192 cal BP - Bronk Ramsey et al., 2015), LLO_778 Penifiler Tephra (13,807-14,071 cal BP - Bronk Ramsey et al., 2015), LLO_766 Glacier Peak Tephra (13,450-13,740 cal BP - Pyne O'Donnell et al., 2016), LLO_580 Fondi di Baia (9,525-9,695 - Smith et al., 2011) and the Holocene and GS-1 onset climatic constraints from the NGRIP record (Rasmussen et al., 2014). 
Establishing a chronology for Llyn Llech Owain has been problematic with age reversals and significant deviations evident in the key transitions. None of the models are without limitations, but the Bayesian statistical approach to constructing a chronology is a step toward producing a meaningful age model from a problematic data-set. To conclude, due to the limited number of robust constraints in the Llyn Llech Owain record none of age models are recommended for use. Model D, however, provides the best precision, but should be employed with caution due to the incorporation of ages from another record. Model $D$ provides an approximate age framework for constraining the proxy evidence and the environmental responses seen within the Llyn Llech Owain record. 


\section{Results - Pant-y-Llyn, Carmarthenshire}

\subsection{Site description}

Pant-y-Llyn (Lat: $51^{\circ} 49^{\prime} 51^{\prime \prime} \mathrm{N}$, Long: $4^{0} 1^{\prime} 26^{\prime \prime} \mathrm{W}$ ) is a small turlough, approximately $160 \mathrm{~m}$ long and $60 \mathrm{~m}$ wide, and has an elongated shape orientated North to South. The turlough is located approximately $9 \mathrm{~km}$ north east from Cross Hands (Figure 6.1), situated $150 \mathrm{~m}$ OD and lies in a depression formed in the underlying Carboniferous Dowlais Limestone Formation. Turloughs are ephemeral water bodies associated with topographic depressions in karst and are periodically inundated mainly by groundwater, but also runoff, during the course of a year. Turloughs are common in the Republic of Ireland (Skeffington et al., 2006; Naughton et al., 2012) however this is the only known turlough in Britain (Campbell et al., 1992; Hardwick and Gunn, 1995) and as such is a designated Annex I priority habitat under the EU Habitats Directive 92/43/EC (McLeod et al., 2005). Turloughs do not have a true inflow or outflow stream, and both fill and empty either diffusely across their base or via estavelles, a type of sink hole (Tynan et al., 2007). Sediments from turloughs are rich in calcium carbonate (Coxon and Coxon, 1994) and an investigation of their infill can provide insight into the development and formation of these rare features.

Sediment cores were obtained on 28th August 2013 by the British Geological Survey when water levels were sufficiently low to allow access into the turlough basin (Figure 6.2). A basin survey was conducted using a peat probe and hand auger at 10 locations to determine the area with the thickest sequence of soft sediment. Using a Russian corer $(5 \mathrm{~cm}$ diameter, $0.5 \mathrm{~m}$ length) a $5.5 \mathrm{~m}$ core was obtained from the eastern part of the turlough basin, which is thought to have obtained most of the Holocene, but bedrock was not reached. The core (British Geological Survey borehole reference SN61NW12) is comprised of a sequence of unconsolidated lake muds, silts 


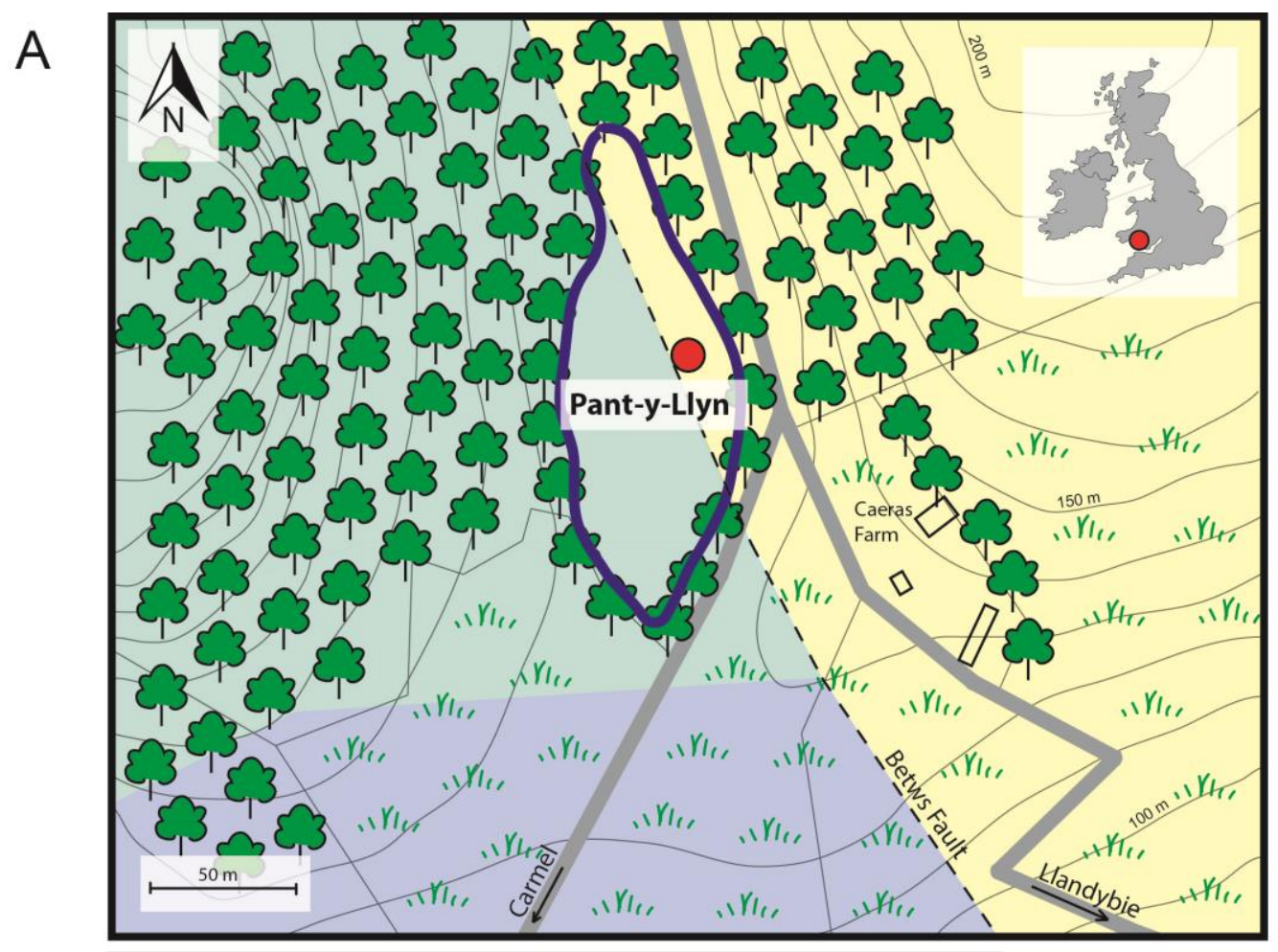

\begin{tabular}{|lll|}
\hline $\begin{array}{l}\text { Core location } \\
\text { Road }\end{array}$ & Non-coniferous trees & $\begin{array}{l}\text { Dowlais Limestone } \\
\text { Formation } \\
\text { Oxwich Head Limestone } \\
\text { Formation }\end{array}$ \\
\hline Contour lines & $\cdots Y_{t}$, Grass & Brownstones Formation \\
\hline
\end{tabular}

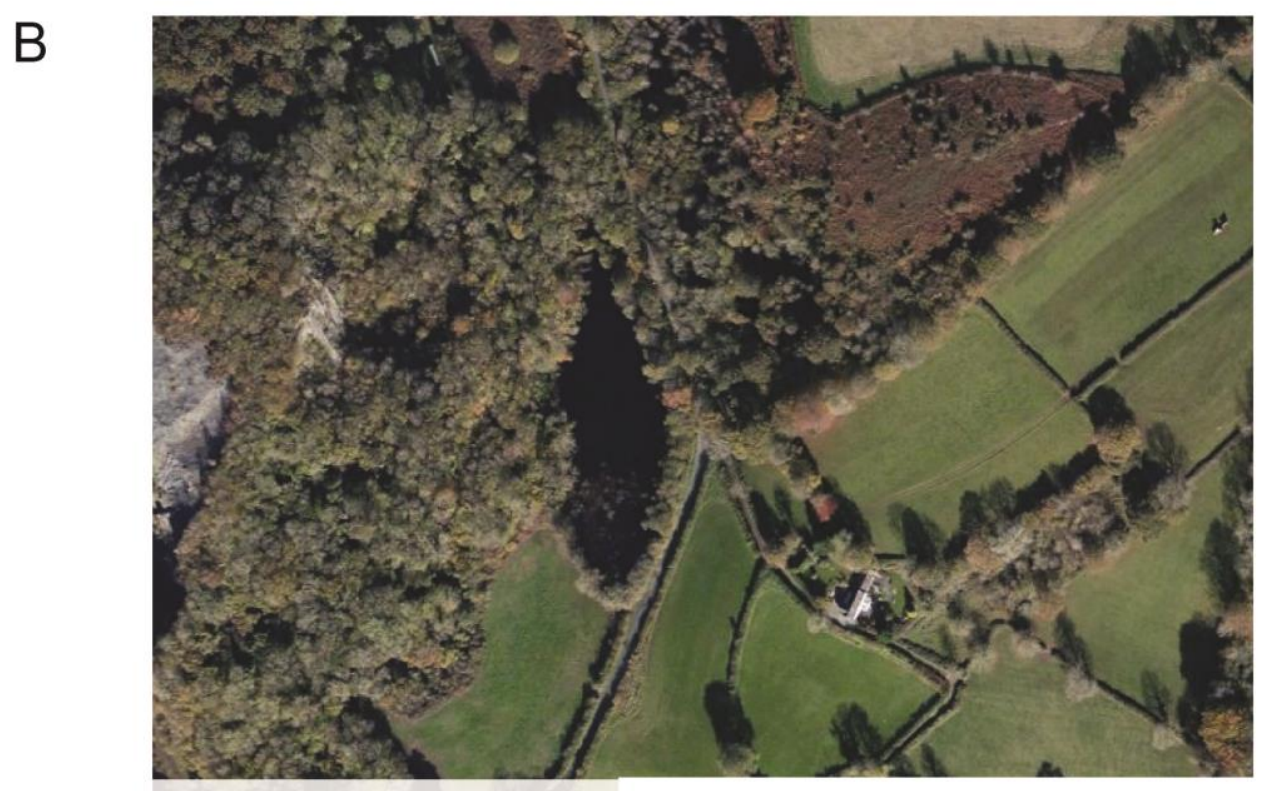

196 Ordnonce

Figure 6.1 - Location map of Pant-y-Llyn turlough (Lat: $51^{\circ} 49^{\prime} 51^{\prime \prime}$, Long: $\left.-4^{0} 1^{\prime} 26^{\prime \prime}\right)$, coring location and local bedrock geology. Contains British Geological Survey Bedrock Geological Map and Ordnance Survey data (C) Crown Copyright and database rights 2017. 

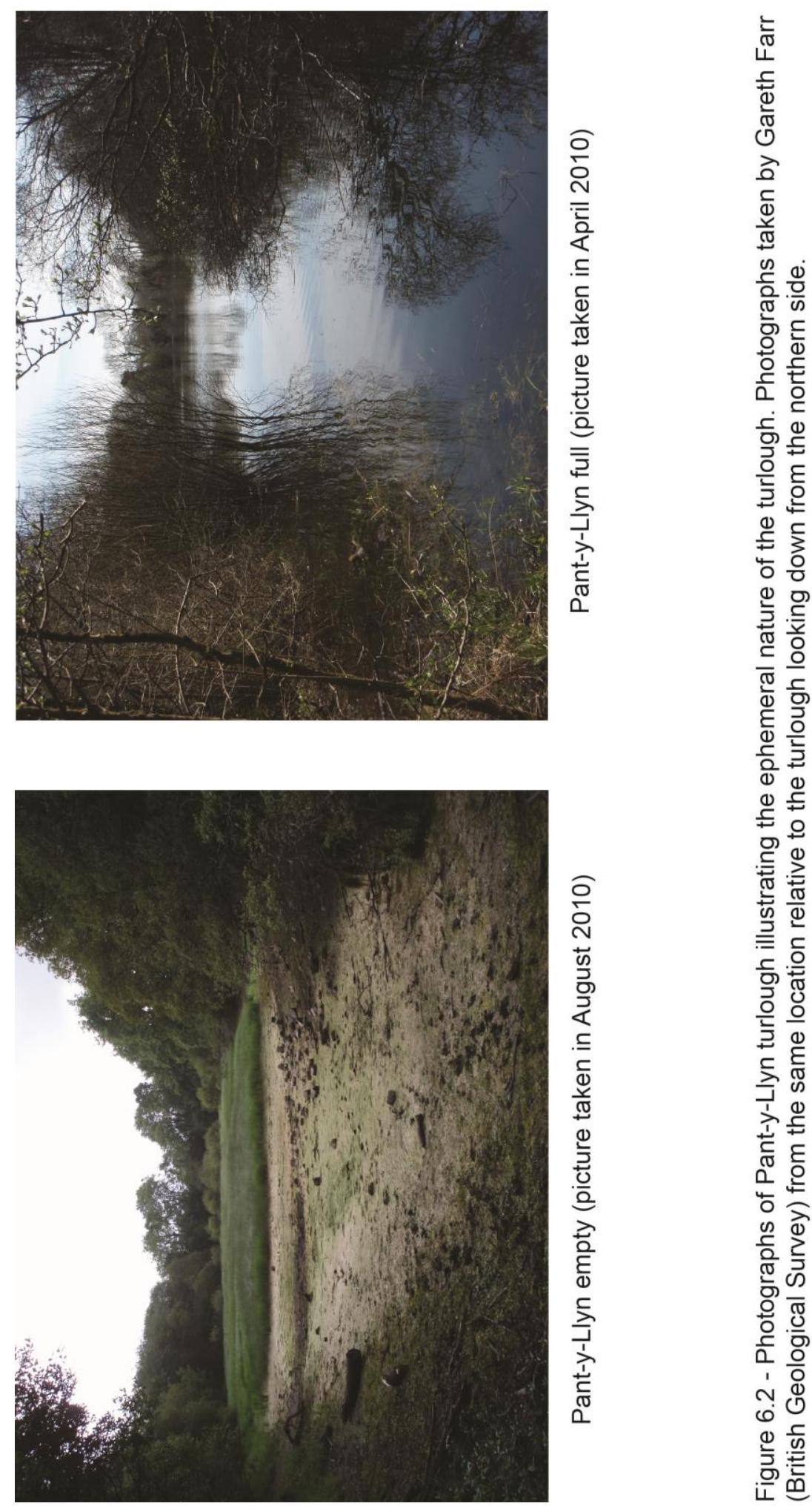
and peat. Cores were wrapped in cling film and stored in a cold room at $<4$ ${ }^{0} \mathrm{C}$ until sub-sampling was undertaken.

\subsection{Lithostratigraphy and Loss on Ignition (LOI)}

Although a $5.5 \mathrm{~m}$ core was retrieved, only the bottom $2.5 \mathrm{~m}$ (3-5.5 m), which is thought to represent the early Holocene and part of the Loch Lomond Stadial, was studied to focus on the time-interval under investigation in this study. The lithostratigraphy and LOI profiles are shown in Figure 6.3. The basal unit consists of reddish silty clay $(550-522 \mathrm{~cm})$ overlain by grey silty clay $(522-511 \mathrm{~cm})$. An organic lake mud unit is present between 511 and 450 $\mathrm{cm}$ and is overlain by brown, carbonate-rich mud that shows some evidence of fine laminations $(450-362 \mathrm{~cm})$. These are not thought to be annually resolved. Organic fen peat is found in the uppermost part of the sequence $(362-0 \mathrm{~cm})$. LOI values are low $(12 \%)$ within the basal clay unit indicating a high minerogenic input which we suggest has been deposited during the Loch Lomond Stadial. Calcium carbonate values also remain low (5\%) within this unit. A sudden increase in LOI values is observed at $511 \mathrm{~cm}$, reaching values of $50 \%$ by $508 \mathrm{~cm}$. This most likely represents the early Holocene transition. The highest LOI values (55-70\%) are observed between 500 and $466 \mathrm{~cm}$ with a shift towards slightly lower values of around $50 \%$ between 466 and $430 \mathrm{~cm}$. Calcium carbonate values begin to increase at around 480 $\mathrm{cm}$ but show marked fluctuations between 10 and $40 \%$ between 480 and $430 \mathrm{~cm}$. A short-lived peak of $70 \%$ in calcium carbonate content is observed at $422 \mathrm{~cm}$ and is accompanied by a dip in LOI at the same depth. Between 410 and $360 \mathrm{~cm}$, low LOI values (10-25\%) are accompanied by higher calcium carbonate values (60-76\%). The increase in LOI values and corresponding decrease in calcium carbonate values observed at $360 \mathrm{~cm}(47$ $\%$ and $10 \%$ respectively) coincides with a shift from lake mud to fen peat. In the uppermost part of the record, LOI increases to $60 \%$ at $335 \mathrm{~cm}$ and calcium carbonate content falls to $10 \%$ (Figure 6.3). The overall calcium 


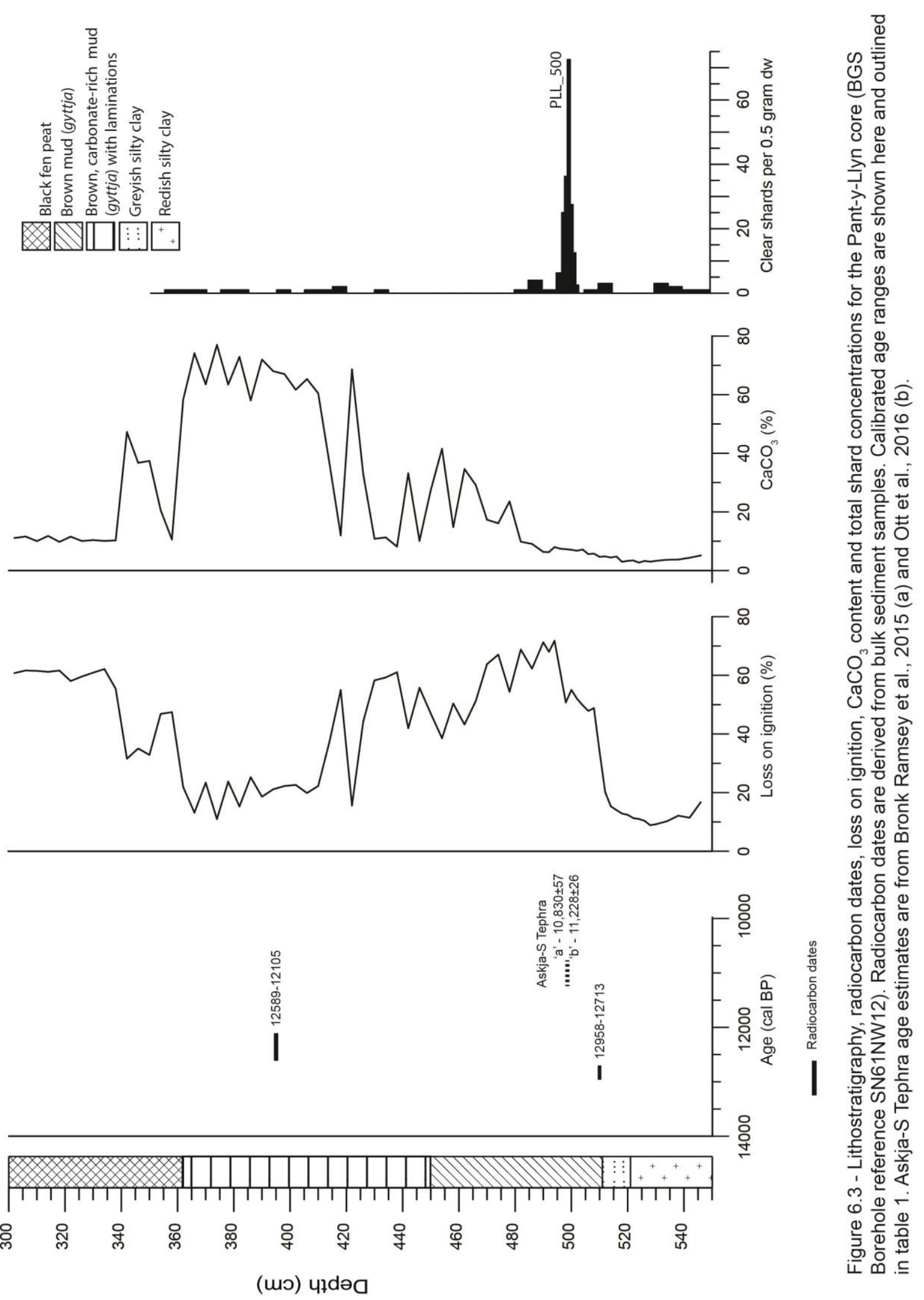


carbonate variations in this sequence may reflect periods of stronger groundwater influence in this turlough.

\subsection{Radiocarbon dates}

Radiocarbon ages obtained by Gareth Farr (BGS) from four bulk samples are summarised in Table 6.1. The lowermost radiocarbon date lies stratigraphically at the base of the lake mud unit, which is assumed to represent the early Holocene (Figure 6.3). However, the radiocarbon age estimate reveals a much older age of 12958-12713 cal BP which is closer to the onset of the Loch Lomond Stadial. Similarly, an age range of 12589$12105 \mathrm{cal}$ BP is obtained for the sample at $395 \mathrm{~cm}$, which lies $115 \mathrm{~cm}$ above the lowermost radiocarbon age, implying a relatively high sedimentation rate (7 years/cm) compared with other similar sediment deposits of this age (e.g. Quoyloo Meadow - 46 years/cm: Timms et al., 2016). The uppermost ages at 200 and $245 \mathrm{~cm}$ are also close in age ( 8.7 cal BP and $\sim 8.6 \mathrm{cal} \mathrm{BP}$, respectively) and indicate a slight inversion with the former yielding an older age than the latter (Table. 6.1).

Table 6.1 - Four radiocarbon dates measured from bulk sediment at 14CHRONO Centre at Queens University Belfast. Ages were calibrated using OxCal and the IntCal13 calibration set (Bronk Ramsey, 2009; Reimer et al., 2013). Acid-Alkali-Acid (AAA) pre-treatment was undertaken on samples. Dates supplied by the British Geological Survey.

\begin{tabular}{|c|c|c|c|}
\hline $\begin{array}{c}\text { Laboratory ID } \\
\text { code }\end{array}$ & $\begin{array}{c}\text { Depth } \\
(\mathrm{cm})\end{array}$ & $\begin{array}{c}\text { Calibrated age } \\
\text { years BP }\end{array}$ & $\begin{array}{c}\text { range (cal yr BP) } \\
(95.4 \%)\end{array}$ \\
\hline UBA-26393 & 200 & $7857 \pm 41$ & $8932-8545$ \\
UBA-26392 & 245 & $7833 \pm 37$ & $8748-8541$ \\
UBA-26394 & 395 & $10479 \pm 65$ & $12589-12105$ \\
UBA-26391 & 510 & $10953 \pm 47$ & $12958-12713$ \\
\hline
\end{tabular}




\subsection{Tephrochronology}

\subsubsection{Total Shard Concentrations (TSCs) and morphological characteristics}

Low-resolution investigation of the tephra content revealed the presence of one distinct peak in shard concentration at $495-500 \mathrm{~cm}$ whilst the rest of the sequence revealed a low background of 2-3 glass shards per 0.5 gram dry weight ( $g d w)$ at intermittent intervals (Figure 6.3). Due to the low shard concentrations, no geochemical results were attempted and without this information, the significance of the apparent background in glass shards is uncertain. The distinct peak in shard concentration between 495-500 cm was refined to $1 \mathrm{~cm}$ where a concentration of 72 shards per $0.5 \mathrm{~g} \mathrm{dw}$ was established at $499-500 \mathrm{~cm}$ (labelled PLL_500 in Figure 6.3 and 6.4). The shards were colourless and typically platy and fluted in morphology.

\subsubsection{Geochemical analysis and tephra correlations}

Microprobe analyses confirm a homogenous rhyolitic composition for PLL_500 with $\mathrm{SiO}_{2}$ values ranging between $72.24-76.4 \mathrm{wt} \%, \mathrm{~K}_{2} \mathrm{O}$ values of $2.39-2.65 \mathrm{wt} \%$ and $\mathrm{CaO}$ values of $1.5-1.75 \mathrm{wt} \%$ (Table 6.2). Major oxide bivariate plots reveal a strong correlation with the Askja-S Tephra (Figure 6.4) which can easily be distinguished from other early Holocene aged tephras such as the Hässeldalen Tephra on the basis of higher FeO and $\mathrm{CaO}$ values (Figure 6.4). The tephra at Pant-y-Llyn is also geochemically distinct relative to other early Holocene tephras including the Suðuroy, An Druim, Breakish, Hovsdalur, Høvdarhagi, L274, Skopun, Fosen, Ashik and Abernethy tephra (Figure 6.4) (Wastegård, 2002; Ranner et al., 2005; Pyne O'Donnell, 2007; Lind and Wastegård, 2011; Matthews et al., 2011; Lind et al., 2013). The Askja-S geochemical signature can also be discriminated 
from older widespread tephras such as the Vedde Ash based on higher $\mathrm{SiO}_{2}$ and $\mathrm{CaO}$ values.

Whilst chemical similarity is shown between the Askja-S Tephra and the 499$500 \mathrm{~cm}$ deposit, the radiocarbon dates would suggest an older age than presently suggested for the Askja-S Tephra. It is possible that PLL_500 could be a previously unknown tephra originating from the Dyngjufjöll volcanic system, given the closely timed tephra deposits of similar chemical signatures derived from Icelandic provenances, such as Katla (Lane et al., 2012b) or the numerous Borrobol-type deposits discovered (Lind et al., 2016; Jones et al., 2017). As yet, however, there are no reported findings of older Askja-S-type tephras in the literature. As noted previously, Guomundsdóttir et al., (2016) have reported a younger tephra - the Askja L- dated to approximately 9400 cal BP (Striberger et al., 2012) and the Askja $\mathrm{H}$ tephra dated to 8850 years old has been identified by Jóhannsdóttir, (2007). The former tephra reveals an identical chemical composition to Askja-S but the $\mathrm{Al}_{2} \mathrm{O}_{3}$ and $\mathrm{FeO}$ content for the latter differs from the Askja-S (Guðrmundsdóttir et al., 2016). The Askja $L$ and $H$, however, have never been discovered outside of Iceland making the Askja-S correlation most likely in Pant-y-Llyn. The lithostratigraphic information also supports this correlation to the early Holocene Askja-S Tephra in line with other studies (e.g. Davies et al., 2003; Wulf et al., 2016; Timms et al., 2016).

Table 6.2 - Summary geochemical data displayed as major oxide concentrations (average and standard deviation) for the tephra layer 499-500 cm (PLL_500). A complete list of analyses and full microprobe operating conditions can be found in the appendix.

\begin{tabular}{|c|c|c|c|c|c|c|c|c|c|c|c|}
\hline & \multirow[t]{2}{*}{$\mathrm{SiO}_{2}$} & \multirow[t]{2}{*}{$\mathrm{TiO}_{2}$} & \multirow[t]{2}{*}{$\mathrm{Al}_{2} \mathrm{O}_{3}$} & \multirow[t]{2}{*}{$\mathrm{FeO}$} & \multirow[t]{2}{*}{ MnO } & \multirow{2}{*}{$\begin{array}{l}\mathrm{MgO} \\
\text { wt } \%\end{array}$} & \multirow[t]{2}{*}{$\mathrm{CaO}$} & \multirow[t]{2}{*}{$\mathrm{Na}_{2} \mathrm{O}$} & \multirow[t]{2}{*}{$\mathrm{K}_{2} \mathrm{O}$} & \multirow[t]{2}{*}{$\mathrm{P}_{2} \mathrm{O}_{5}$} & \multirow[t]{2}{*}{ Total } \\
\hline $499-500 \mathrm{~cm}$ & & & & & & & & & & & \\
\hline average $(n=33)$ & 73.86 & 0.30 & 11.81 & 2.50 & 0.09 & 0.24 & 1.63 & 4.28 & 2.51 & 0.04 & 97.25 \\
\hline st dev & 0.79 & 0.01 & 0.30 & 0.09 & 0.01 & 0.03 & 0.06 & 0.17 & 0.06 & 0.01 & 1.02 \\
\hline
\end{tabular}



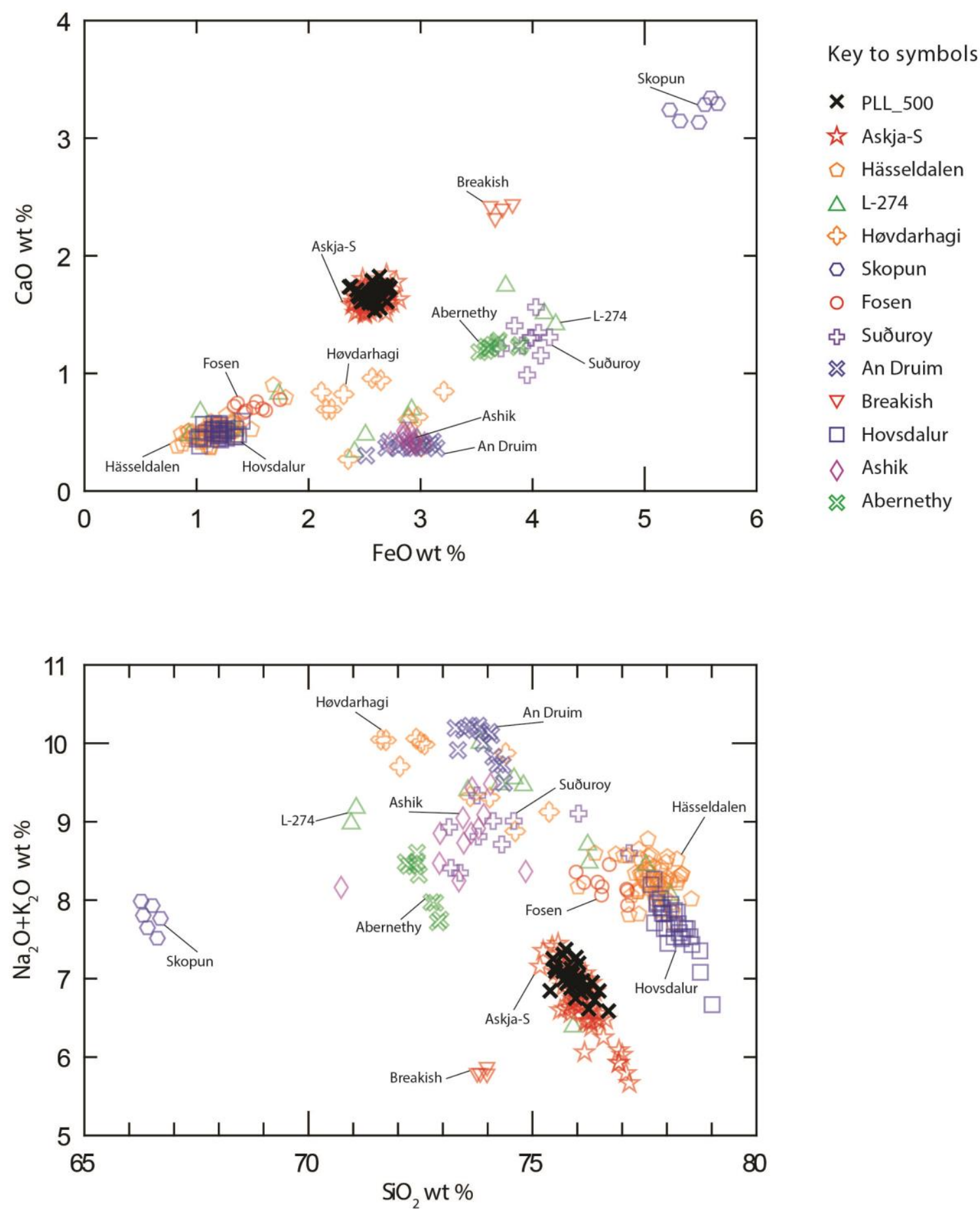

Figure 6.4 - Selected bi-plots showing tephra PLL_500 glass shard major element composition correlating to the Askja-S Tephra. Hässeldalen, L-274, Høvdarhagi, Skopun, Fosen, Suðuroy, An Druim, Breakish, Hovsdalur, Ashik and Abernethy Tephra data also shown for discrimination. Data have been normalised. Data from: (Wastegård, 2002; Ranner et al., 2005; Pyne O'Donnell, 2007; Lind \& Wastegård, 2011; Matthews et al., 2011; Lane et al., 2011, 2012a; Lind et al., 2013; Lilja et al., 2013; Wulf et al., 2016; Timms et al., 2016 and Jones et al., 2017). 


\section{Results - Cors Carmel, Carmarthenshire}

\subsection{Site description}

Cors Carmel (Lat: $51^{\circ} 49^{\prime} 20$ " N, Long: $4^{0} 2^{\prime} 23^{\prime \prime} \mathrm{W}$ ) is a topogenous mire, approximately $280 \mathrm{~m}$ long and $90 \mathrm{~m}$ wide, situated $210 \mathrm{~m}$ above sea level. The mire is located $8 \mathrm{~km}$ north-east of Cross Hands, and lies in an infilled bedrock basin within the Twrch Sandstone Formation (Figure 7.1). The site has an elongated shape orientated ENE-WSW, in a region of gently undulating terrain with higher ground $(\sim 40 \mathrm{~m})$ north of the mire and a lowering slope south east of the mire. There are no inflows but two small outflows are present, one on the east side of the mire flowing in a ENE direction and another originates towards the middle of the mire and flows in a WSW direction along the southern rim of the mire (Figure 7.1). A palaeoecological investigation was carried out by Walker and James, (1992) where a Holocene pollen reconstruction was reported (Figure 7.2). New core sequences were retrieved in October 2014 using a Russian sampler $(5 \mathrm{~cm}$ diameter), which successfully retrieved the Lateglacial tripartite sedimentary sequence.

\subsubsection{Previous work at Cors Carmel}

The classic Lateglacial tripartite sedimentary sequence was first established at Cors Carmel by Walker and James, (1992). They note that 3-4 m of peat is present in the narrowest part of the mire in the west, however they also note that over $7 \mathrm{~m}$ of sediment was retrieved, including a full Lateglacial sequence, in the eastern end of the mire where the basin widens into a more circular shape. Four radiocarbon dates were obtained for the Holocene sequence in the original study and are summarised in Table 7.1. These dates constrain a full Holocene pollen diagram from $480-0 \mathrm{~cm}$ (Figure 7.2). A 

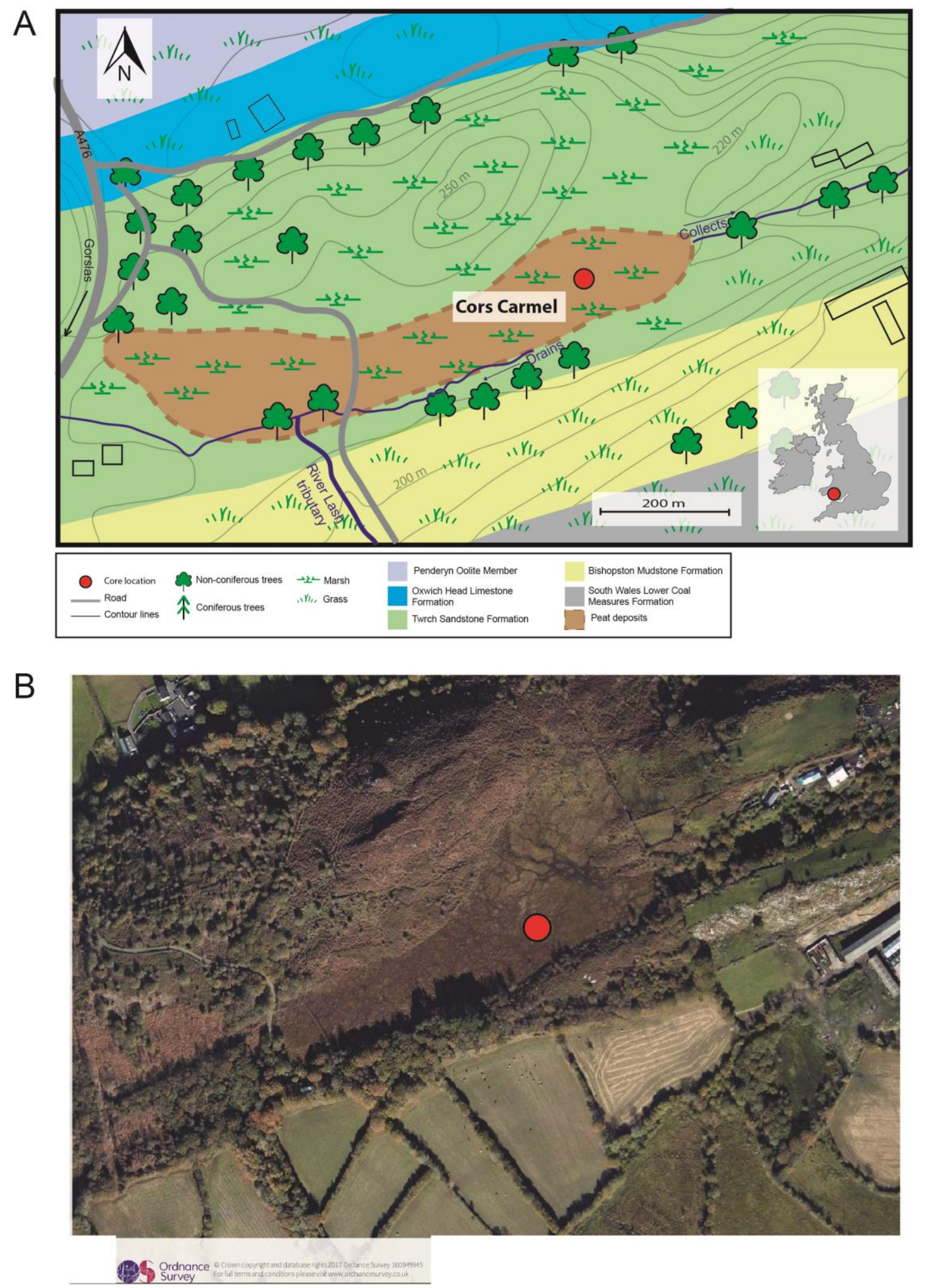

Figure 7.1 - A) Location of Cors Carmel, bedrock geology and coring location. B) Arial photograph of Cors Carmel. Contains British Geological Survey Bedrock Geological Map and Ordnance Survey data $\odot$ Crown Copyright and database rights 2017. 
Table 7.1 - Radiocarbon dates from Cors Carmel as noted in Walker and James, (1992).

\begin{tabular}{|ccccc|}
\hline Lab Ref No. & Depth $(\mathrm{cm})$ & Material & $\delta^{13} \mathrm{C} \%$ & Date BP \\
\hline OxA-3828 & 90 & Ericaceae stems & -25.8 & $3790 \pm 60$ \\
OxA-3829 & 255 & Betula wood & -25.7 & $4740 \pm 65$ \\
OxA-3830 & 370 & Alnus wood & -26.3 & $5135 \pm 70$ \\
OxA-3831 & 402 & Betula wood & -23.9 & $9285 \pm 95$ \\
\hline
\end{tabular}

treeless landscape is observed at the base of the sequence and characterised by open-habitat and herbaceous taxa, which is thought to represent the transition from the Loch Lomond Stadial to the Holocene. This period is followed by a successional ecological change over the first ca. 1000 years of the Holocene. Heathland is replaced by juniper and willow scrub, and then succeeded by birch and hazel woodland. This stage was followed by a gradual hydroseral change where infilling of the former lake led to mire development (Walker and James, 1992). Further woodland development is seen after this period with the establishment of pine and oak, followed by elm and ash and eventually alder at $375 \mathrm{~cm}$. This mid-Holocene woodland development period is followed by more open conditions at $250 \mathrm{~cm}$ with an increase in grasses and heathland pollen which is thought to reflect an increase in anthropogenic impact on the landscape through forest clearance.

\subsection{Lithostratigraphy}

The lithostratigraphy of the sequence examined in this study is shown in Figure 7.3. Bedrock was not reached during coring and the retrieved sedimentary sequence starts with a basal grey clay unit at $560 \mathrm{~cm}$ below the surface. This grey clay deposit between $560-496 \mathrm{~cm}$ is thought to represent sediment from the glacial period. This basal unit is overlain by $34 \mathrm{~cm}$ of 


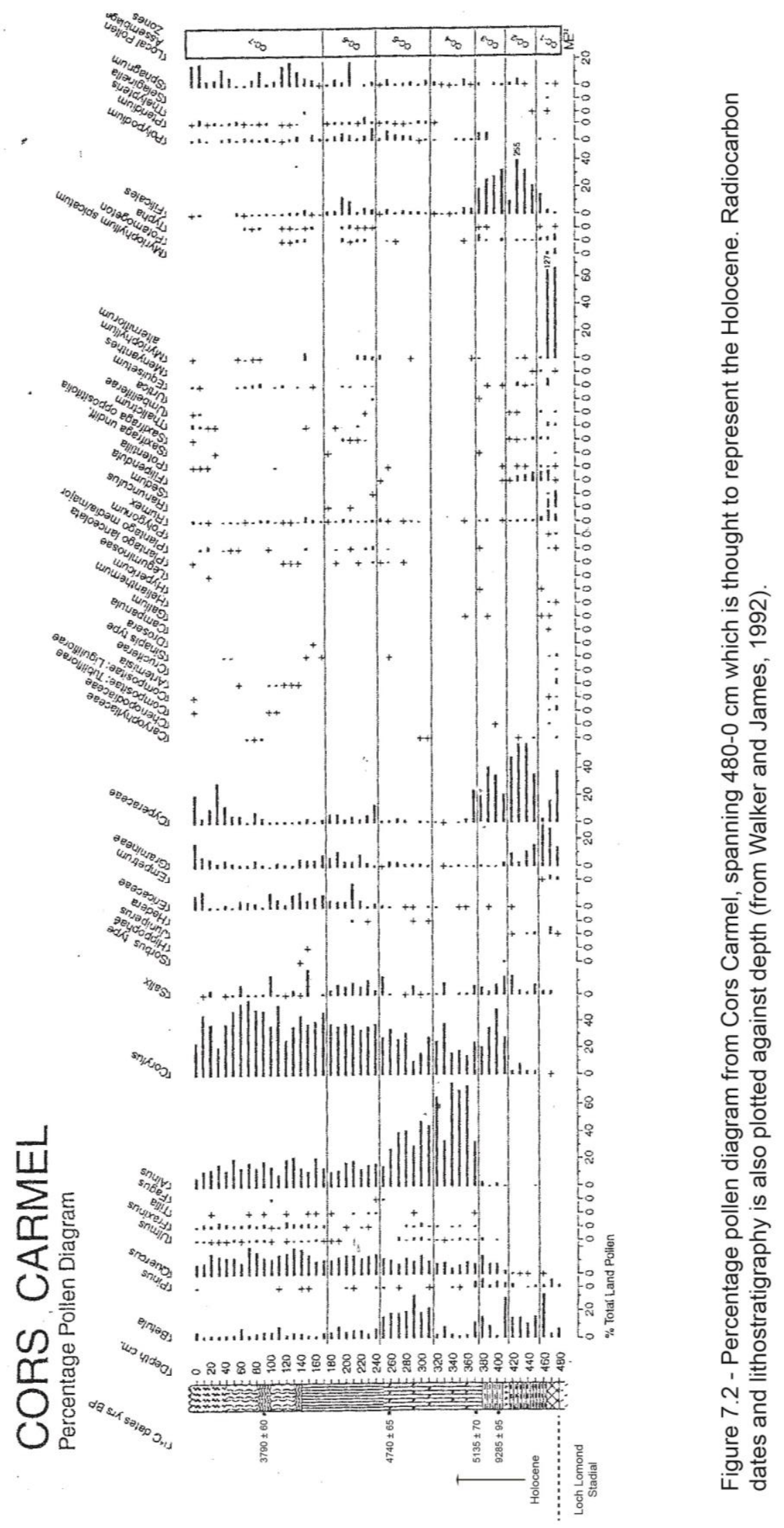




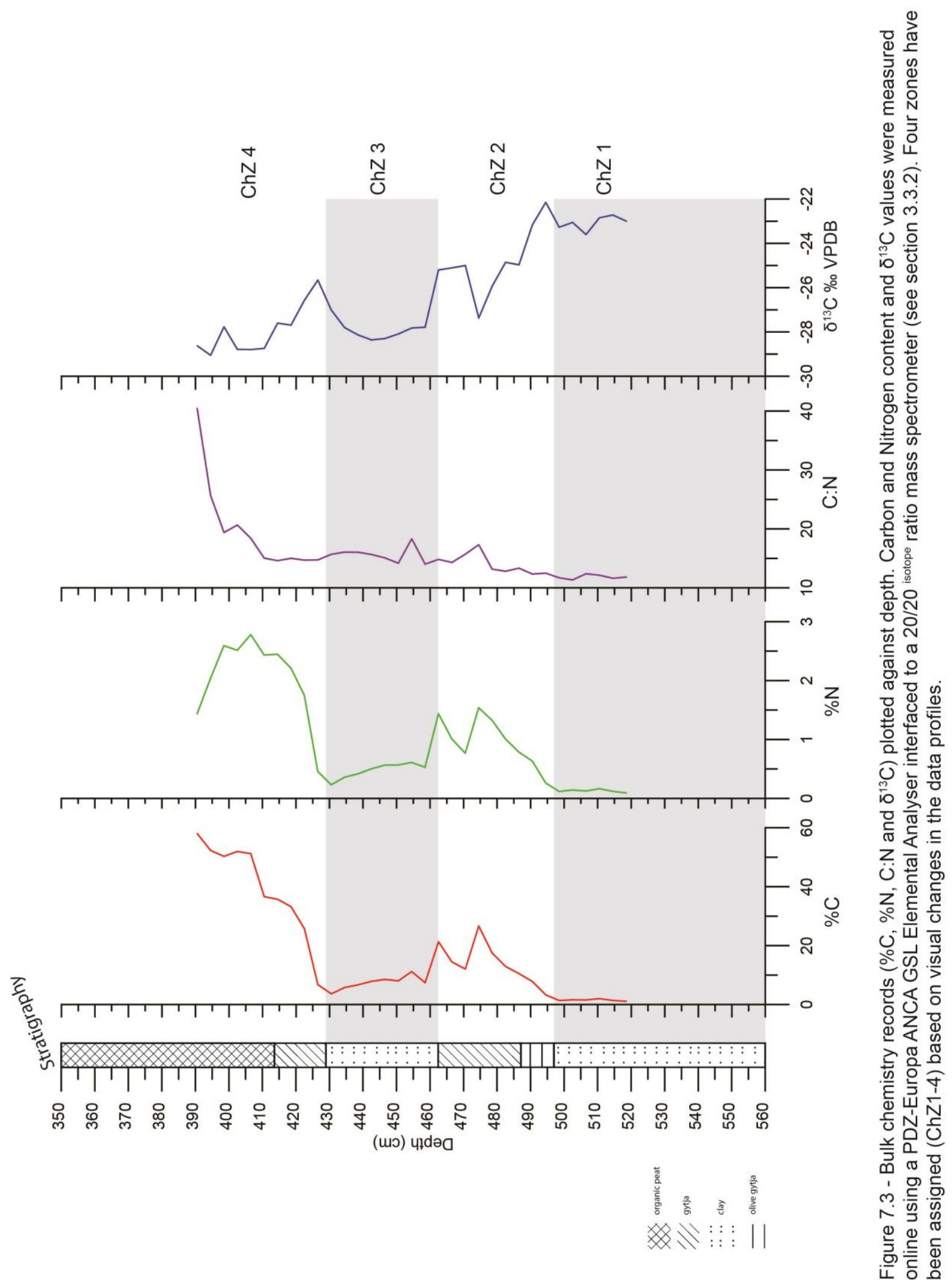


brown organic lake muds (gyttja) which started accumulating at $496 \mathrm{~cm}$ (496$462 \mathrm{~cm}$ ). At $462 \mathrm{~cm}$ a reasonably gradual transition from organic mud to light grey silty clay deposit $(462-429 \mathrm{~cm})$ is observed, distinctive of the Loch Lomond Stadial. A gradual lithostratigraphic change is observed at $429 \mathrm{~cm}$ typical of the shift to the early Holocene followed by dark organic peat at 414 $\mathrm{cm}$. This lithostratigraphic tripartite sequence is akin to that reported by Walker and James (1992) and characteristic of the Lateglacial found at numerous other sites across the UK (e.g. Walker et al., 2003).

\subsection{Bulk Sediment Chemistry (\%C, \%N and $\left.\delta^{13} \mathrm{C}\right)$}

Bulk sediment chemistry profiles are shown in Figure 7.3, where 4 zones have been defined, based on the lithostratigraphic changes and chemical data. A $4 \mathrm{~cm}$ sampling resolution was adopted between 390 and $520 \mathrm{~cm}$. Due to the lower number of samples compared to 400 samples for the Llyn Llech Owain record, $10 \% \mathrm{HCl}$ acid pre-treatment was undertaken.

In the lowermost zone, ChZ1, low \%C values ( $<2 \%)$ and \%N values $(<0.2 \%)$ characterise the basal clays between 520-497 cm. Minerogenic sediment with low organic content is indicative of deposition within a still water environment, with low productivity and thus a cold climate. Stable C:N ratio values of around 12 occur in this zone in addition to stable $\delta^{13} \mathrm{C}$ values of around $-23 \%$ indicating that the small amount of organic matter present during this period is aquatic algal matter. $\delta^{13} \mathrm{C}$ values of -21 to $-24 \%$ and C:N values of 9-11 are typical of algal/aquatic sources (Meyers and LallierVergès, 1999). A gradual increase in $\% \mathrm{C}$ and $\% \mathrm{~N}$ values is observed in zone ChZ2 with values peaking at $475 \mathrm{~cm}$ with values of $26 \%$ and $1.5 \%$, respectively. These higher values indicate increased productivity in the lake environment suggesting climatic warming and probably vegetation development in the catchment. Such changes are indicative of the Lateglacial Interstadial. A short lived decrease in \%C and \%N occurs between 470-465 $\mathrm{cm}$ with values dropping to around $12 \%$ and $0.9 \%$, respectively, followed by 
a return to higher values at $462 \mathrm{~cm}$ at the transition to $\mathrm{ChZ} 3$. The $\mathrm{C}: \mathrm{N}$ ratio values show a gradual increase from 12 to 15 throughout ChZ 2 with a small peak of 17 at $475 \mathrm{~cm}$. A decrease in $\delta^{13} \mathrm{C}$ values is seen from $-22.5 \%$ o to -25 $\%$ at the end of ChZ 2. A pronounced decrease spike (-27.2\%) is seen at $475 \mathrm{~cm}$ coinciding with the small peak in the C:N profile which may indicate a short lived period with increased terrestrial vegetation present.

ChZ 3 is characterized by prolonged low $\% \mathrm{C}$ and $\% \mathrm{~N}$ values of around $7 \%$ and $0.5 \%$, respectively, indicating a return to cold conditions with deposition in a low-productivity lake environment. The $\mathrm{C}: \mathrm{N}$ ratio profile remains relatively stable throughout ChZ 3 with values fluctuating around 15, however, a small spike of 18 is observed at $455 \mathrm{~cm}$. A sudden decrease in the $\delta^{13} \mathrm{C}$ profile is observed at the onset of ChZ 3 with values reaching around $-28 \%$ at 458 $\mathrm{cm}$, which remains stable until $435 \mathrm{~cm}$. The $\delta^{13} \mathrm{C}$ profile gradually increases towards the termination of zone ChZ 3 and reaches a peak of $-25.6 \%$ at the onset of ChZ 4 at $426 \mathrm{~cm}$. The $\delta^{13} \mathrm{C}$ profile decreases from the onset of $\mathrm{ChZ}$ 4 to around $-28.7 \%$ at $410 \mathrm{~cm}$, followed by relatively stable values to the end of $\mathrm{ChZ} 4$ at $390 \mathrm{~cm}$. The $\% \mathrm{C}$ and \%N profiles experience an abrupt increase at the onset of ChZ 4 with values increasing to around $35 \%$ and $2.5 \%$ at $414 \mathrm{~cm}$, which marks the onset of peat accumulation based on the lithostratigraphy. This shows an abrupt increase in organic matter being accumulated in the lake suggesting the development of vegetation around the catchment. The $\% \mathrm{C}$ values continue to increase to $55 \%$ at $390 \mathrm{~cm}$ whereas $\% \mathrm{~N}$ values appear to slightly stabilize for $16 \mathrm{~cm}$ until a sudden decrease to $1.4 \%$ at $390 \mathrm{~cm}$. This decrease in $\% \mathrm{~N}$ at $398 \mathrm{~cm}$ has subsequently affected the C:N profile with values increasing suddenly to 40 at $390 \mathrm{~cm}$.

\subsection{Sediment geochemistry by X-ray fluorescence (XRF)}

Selected XRF elemental profiles are shown in Figure 7.4 and the full data set is available in the appendix. The $\mathrm{Ti}$ and $\mathrm{K}$ have been normalized by the sum 


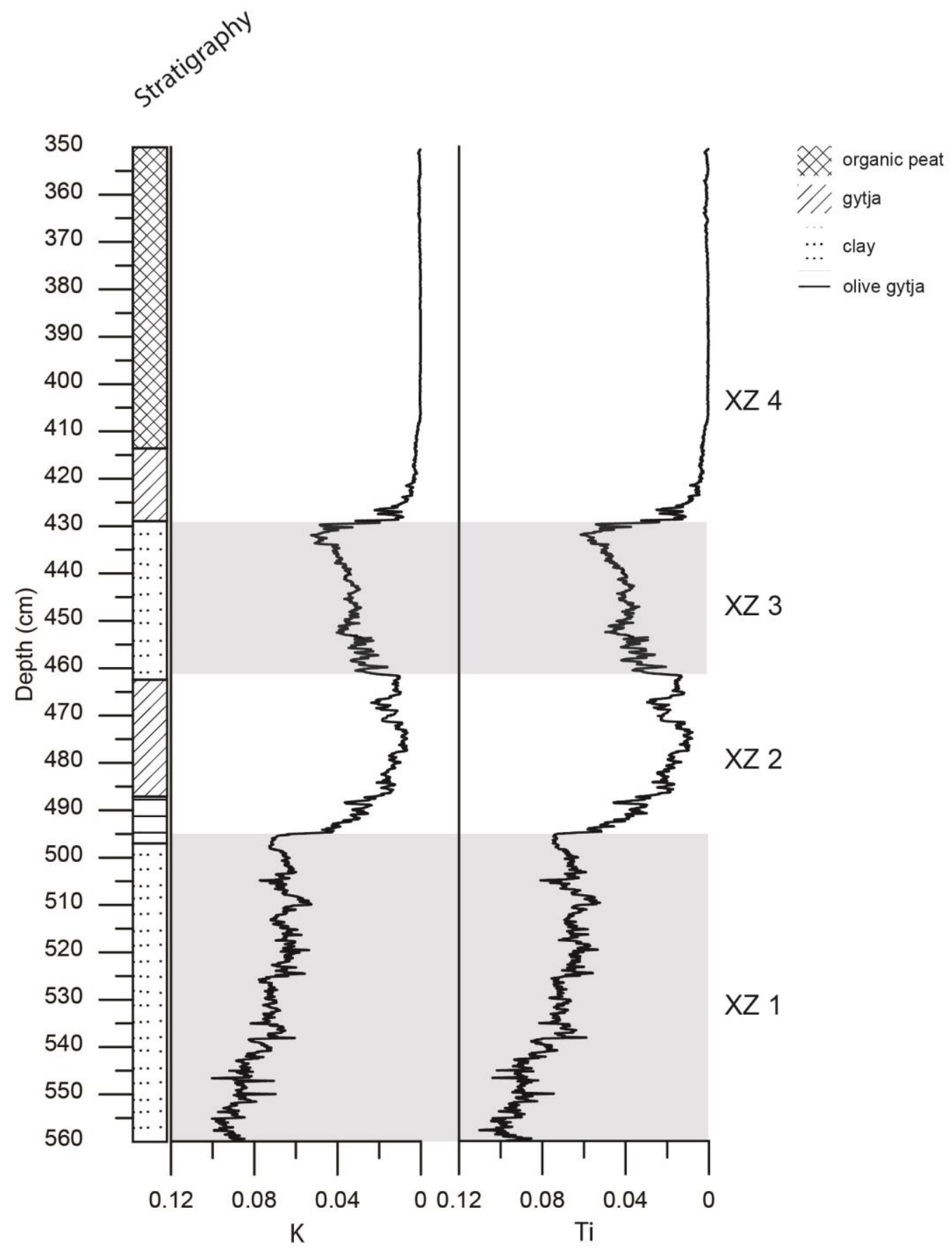

Figure 7.4 - Selected XRF profiles, analysed by an ITRAX core scanner (see section 3.3.1). K and $\mathrm{Ti}$ data is shown as a 10 point moving average. Four zones have been assigned (XZ 1-4) based on visual changes in the data profiles. 
of the incoherent and coherent values and plotted as a 10 point moving average. The Ti and $\mathrm{K}$ record has also been sub-divided into zones (XZ 1-4) based on distinct changes in the profile. These two elements provide an indication of the amount of detrital minerogenic in-wash into the basin (Davies et al., 2015). Other minerogenic elements including $\mathrm{Fe}, \mathrm{Rb}, \mathrm{Sr}, \mathrm{Ba}$ and $\mathrm{Si}$, show very similar profiles to $\mathrm{Ti}$ and $\mathrm{K}$, therefore only the $\mathrm{Ti}$ and $\mathrm{K}$ are shown here as representative elements for catchment in-wash.

High $\mathrm{K}$ and $\mathrm{Ti}$ values are seen within the basal unit $(X Z 1)$ at $560 \mathrm{~cm}$ with values of 0.09 and 0.10 . A small gradual decrease in values is seen within $X Z 1(560-495 \mathrm{~cm})$ with values reaching 0.07 and 0.075 at $495 \mathrm{~cm}$. These high values indicate a sustained period of mineral in-wash into the basin, typical of the glacial period. An abrupt shift in values is observed at the onset of $X Z 2$ with values decreasing rapidly over $1 \mathrm{~cm}$ from 0.07 and 0.075 at 495 $\mathrm{cm}$ to 0.045 and 0.055 at $494 \mathrm{~cm}$. A gradual decrease in $\mathrm{K}$ and Ti values is seen between 495 and $477 \mathrm{~cm}$ with values decreasing from 0.045 and 0.055 to 0.01 for both elements. The lower values seen in XZ2, points towards a reduction in mineral in-wash, and thus slope stabilisation during the Lateglacial Interstadial. Stable K and Ti values are seen for the remainder of $X Z 2$ up to $462 \mathrm{~cm}$, with the exception of a punctuated episode of higher values of 0.02 and 0.025 between 472 and $466 \mathrm{~cm}$. An abrupt increase is observed at the onset of $X Z 3$ with values increasing from 0.02 and 0.025 at $462 \mathrm{~cm}$ to 0.03 and 0.035 at $460 \mathrm{~cm}$. A gradual increasing trend is observed throughout $X Z 3$ with values increasing from 0.03 and 0.035 at $460 \mathrm{~cm}$ to 0.05 and 0.055 at $429 \mathrm{~cm}$. This unit is thought to represent the Loch Lomond Stadial due to the increased rate of mineral in-wash and the low \% $\mathrm{C}$ values as mentioned in section 7.3. The onset of XZ 4 marks an abrupt decrease in $K$ and Ti values from 0.05 and 0.055 at $429 \mathrm{~cm}$ to 0.01 at $428 \mathrm{~cm}$. This rapid decrease in minerogenic in-wash is thought to represent the early Holocene onset, which supports the bulk sediment geochemistry evidence where high $\% \mathrm{C}$ is evident. A further decrease in $\mathrm{Ti}$ and $\mathrm{K}$ values to near zero is observed at $407 \mathrm{~cm}$ which is sustained to the top of the sequence at $350 \mathrm{~cm}$. 


\subsection{Tephrochronology}

Tephra analysis was initially undertaken at a low resolution between 350-560 $\mathrm{cm}$. Tephra shards were found throughout the sequence albeit in very low concentrations with an average TSC of $\sim 5$ shards per $0.5 \mathrm{~g} \mathrm{dw}$ (Figure 7.5). The shards observed were all clear in colour and tended to have a platy and fluted morphology. No distinct peaks were observed above this low background. However, high-resolution analyses were undertaken from $5-\mathrm{cm}$ samples where $>6$ shards per $0.5 \mathrm{~g} \mathrm{dw}$ were found to identify and isolate the horizon to the nearest $1 \mathrm{~cm}$. These were $520-525 \mathrm{~cm}, 510-515 \mathrm{~cm}, 500-505$ $\mathrm{cm}, 485-490 \mathrm{~cm}, 475-480 \mathrm{~cm}, 420-425 \mathrm{~cm}, 390-395 \mathrm{~cm}, 375-380 \mathrm{~cm}, 355-$ $365 \mathrm{~cm}$ and are shown by grey bars in Figure 7.2. Two samples with $<6$ shards per $0.5 \mathrm{~g} \mathrm{dw}$ were also processed at high resolution in an attempt to isolate the widely dispersed Vedde Ash (440-445 cm within the Loch Lomond Stadial) and Askja-S Tephra (420-425 cm within the early Holocene sediments). Very few shards were identified in the high-resolution samples with only a maximum of 2 shards per $0.5 \mathrm{~g} \mathrm{dw}$ found at 500-501, 487-489, 478-479, 475-476, 420-421, 377-378 and 356-357 cm. However, no tephra shards were extracted from any of the samples after several attempts. 


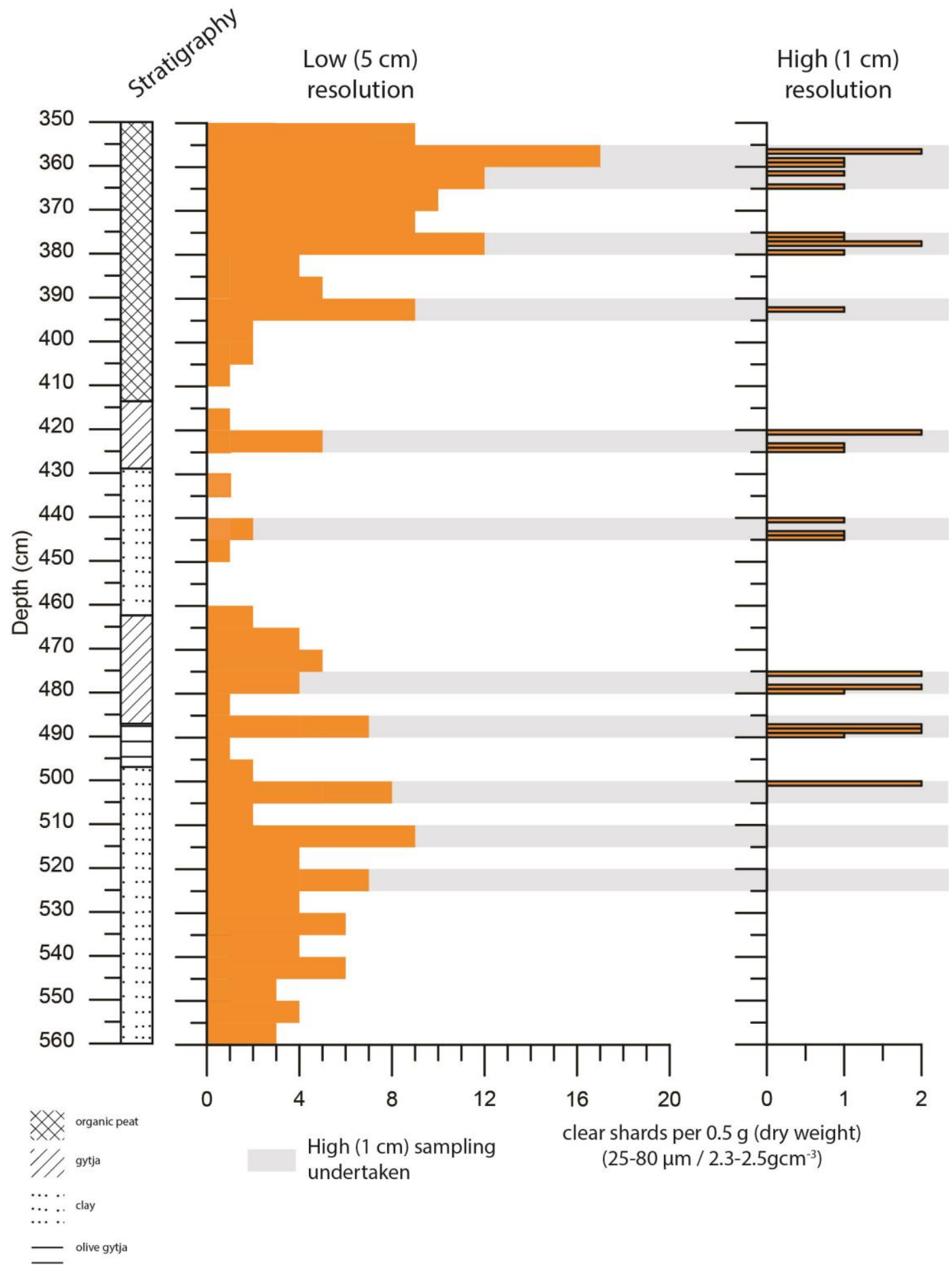

Figure 7.5 - Total shard concentrations for Cors Carmel core 2014. 


\section{Discussion}

\subsection{Tephra discussion}

Twenty-one individual tephra deposits have been identified in this study, however, only 12 have been correlated, or tentatively correlated, to known eruptions (Figure 8.1). All tephras are cryptotephra in form, with the exception of HÄM_1558, and at least eight tephras extend their geographical distributions. Thirteen tephra deposits have been found in Wales, with the majority identified at Llyn Llech Owain with one tephra identified at Pant-yLlyn. Very few tephra deposits have been identified in Wales and these findings highlight the potential of applying tephrochronology to more proxy records. Eight tephra deposits are identified in Lake Hämelsee, Germany, two of which have been previously described in Merkt et al., (1993). Most originate from Iceland and central Europe, however, there are suggestions that two deposits in Llyn Llech Owain may have originated from far-travelled sources. A synthesis of all tephra findings are shown in Figure 8.1 alongside the key tephra deposits found in Iceland, central Europe and the Pacific Arc. No tephra deposits at all were identified at Cors Carmel despite its close proximity to Llyn Llech Owain. Several tephra deposits have not been correlated to known eruptions and are considered to represent previously undocumented events. There are significant inter and intra-site differences observed in the tephra findings providing insights on tephra deposition and taphonomic processes.

The following sections provide a synthesis of the main tephra discoveries in chronological order and their implications.

8.1.1 Borrobol-type tephra deposits (LLO_804, LLO_782, LLO_778, HÄM_1616) 


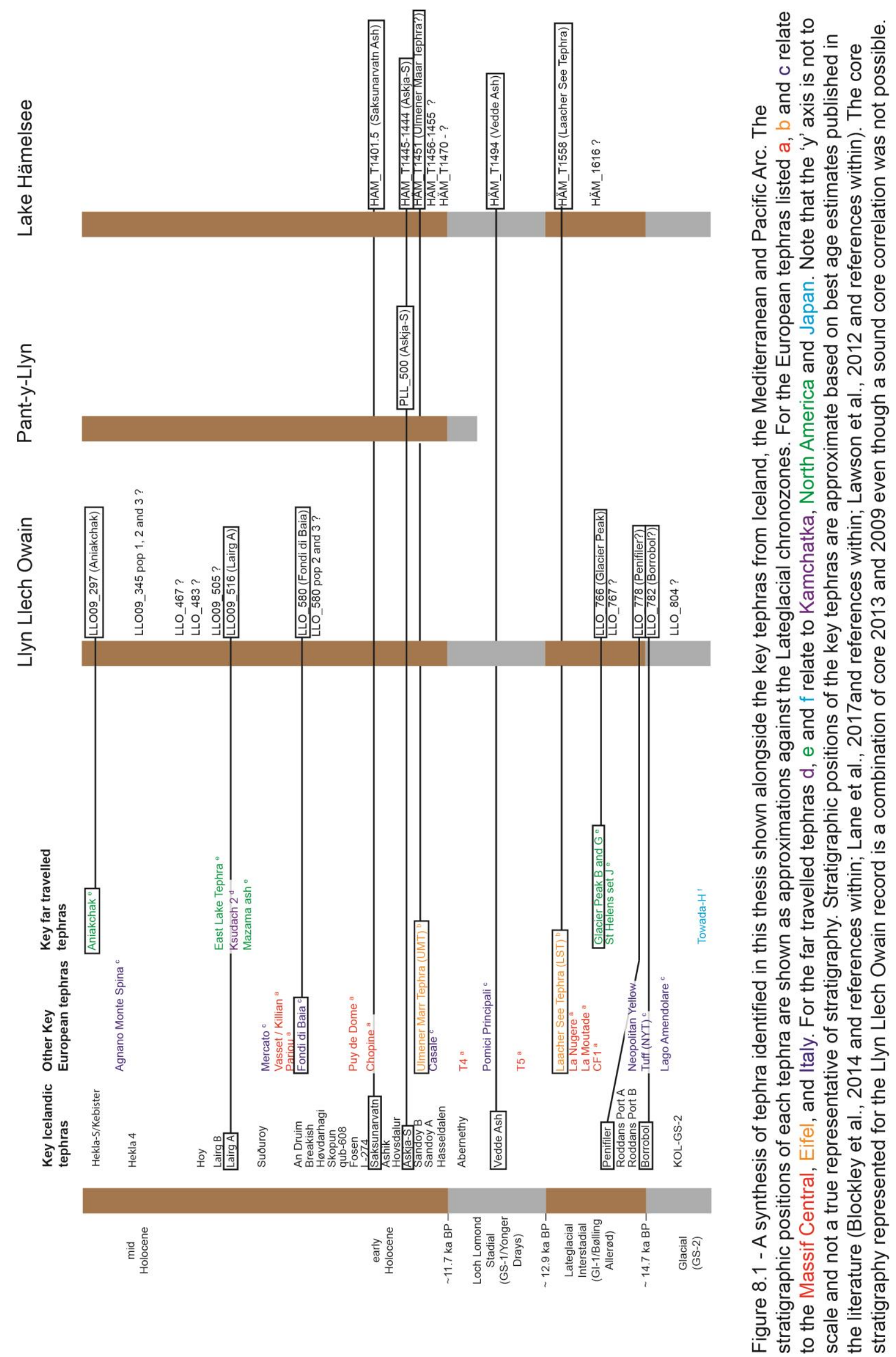


Llyn Llech Owain and Lake Hämelsee preserve tephra deposits with a chemical signature similar to the much studied Borrobol (BT) and Penifiler Tephra (PT) deposits which have been described from distal sites in Scotland. These two tephra deposits are known to be chemically indistinguishable (Pyne-O'Donnell et al., 2008; Matthews et al., 2011; Lind et al., 2016) and may only be differentiated based upon secure stratigraphic correlation. Both tephras are found within the Lateglacial Interstadial, with the BT pre-dating the PT in the early interstadial. More recently there has been evidence of further Lateglacial-age cryptotephra deposits with the same glass shard composition resulting in a very complex tephrostratigraphy (Figure 8.2). Some Scottish sites have revealed such tephras in the glacial sediments prior to the interstadial (Albert, 2007; MacLeod et al., 2015), whereas Timms et al., (2016) have discovered another two tephra deposits (QM1 213 and 218) with the same composition in the late Interstadial at Quoyloo Meadow, in the Orkneys, Scotland (Figure 8.2). Another two tephra layers with BT-type chemistry have been reported within the glacial period or GS-2 age - one in a marine core on the North Icelandic shelf, dated to 16.4916.65 cal ka BP and named the KOL-GS-2 tephra (Eiríksson et al., 2000), and the other identified in the NGRIP ice core which has an age of $17320 \pm$ 171 b2k (Cook, 2015) (Figure 8.2 and 8.3). It is unclear, however, whether they represent the same eruption.

Although all these tephra layers are thought to have originated from Iceland based on trace element data (Lind et al., 2016), the volcanic provenance is still unclear, whereas previous studies have suggested Snæfellsjökull (Davies et al., 2003), Öræfajökull (Lind et al., 2013), Torfajökull (Davies et al., 2004) and also Hekla (Lind et al., 2013). Holocene tephras with the same composition have also been discovered in NW European sites (e.g. Pilcher et al., 2005; Lind \& Wastegård 2011).

For this study, the difficulties of establishing correlations are evident when a number of tephras with similar compositions are found within Lateglacial 


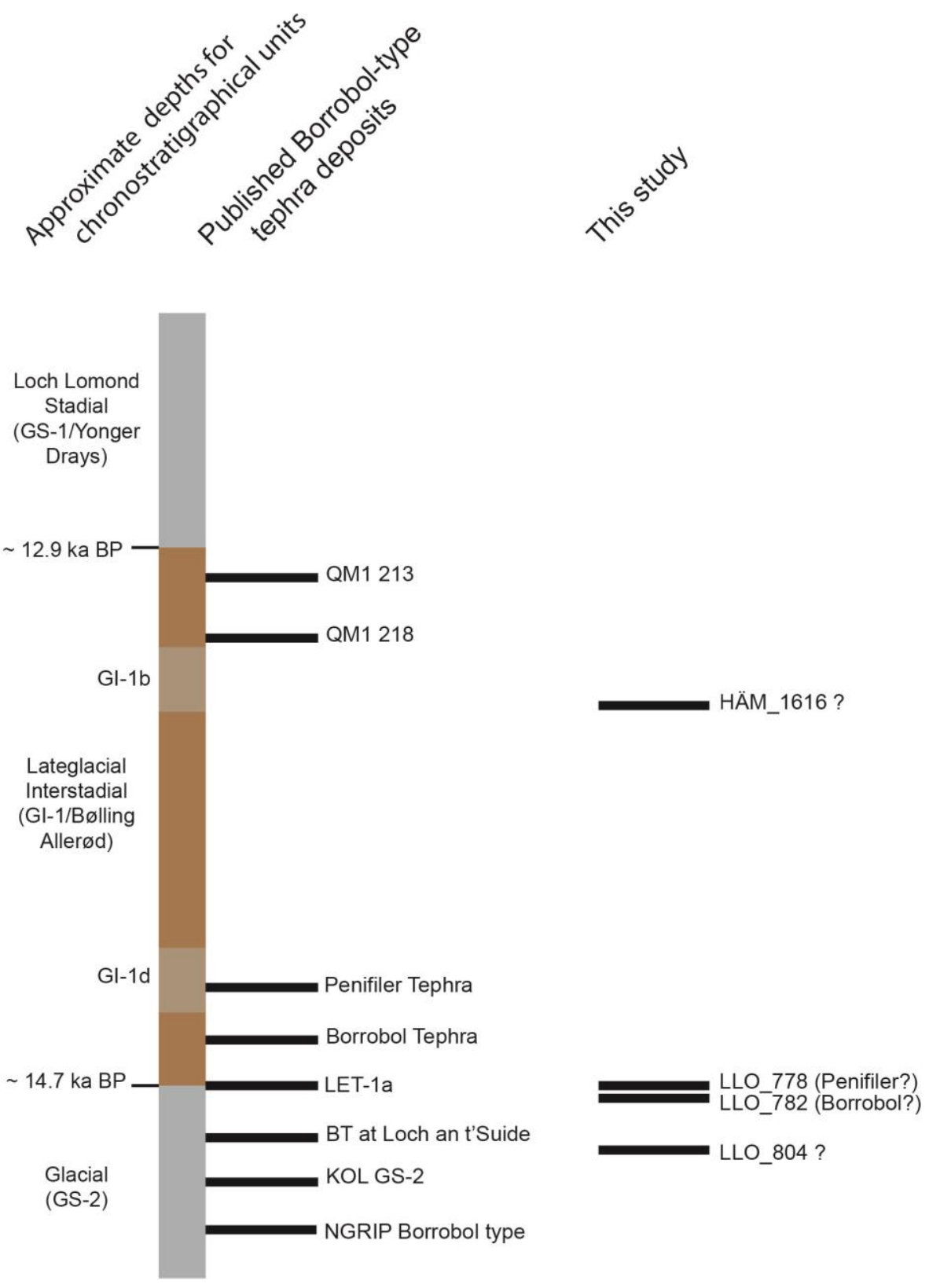

Figure 8.2 - Schematic tephrostratigraphy diagram for the Borrobol-type tephra deposits noted in the text. Depths and chronostratigraphic units are approximate given the information in their respective publications (Timms et al., 2016; Cook, 2015; Eiríksson et al., 2000; Pyne O'Donnell, 2007; Matthews et al., 2011; Albert, 2007). NGRIP Borobol type and KOL GS-2 are chronologically positioned based on ages published within their applicable studies (Cook, 2015; Eiríksson et al., 2000). BT at Loch an t'Suidhe is positioned in the glacial unit based on LOI values in Pyne O'Donnell, (2007). LET-1a is positioned on the transition bewteen the glacial unit and Lateglacial Inetrstadial based on LOI values in Albert, (2007) and MacLeod et al., (2015). The Borrobol Tephra is positioned in the early Interstadial based on findings from Borrobol and Whitrig Bog (Turney et al., 1997). The Penifiler Tephra is positioned in the mid Interstadial based on findings from Tynaspirit West and Borrobol (Pyne O'Donnell, 2007) and Abernethy Forrest (Matthews et al., 2011). QM1 213 and 218 are tephra deposits found from Quoyloo Meadow (Timms et al., 2016), positioned during the late Interstadial. Some of the deposits listed may represent the same eruption. 

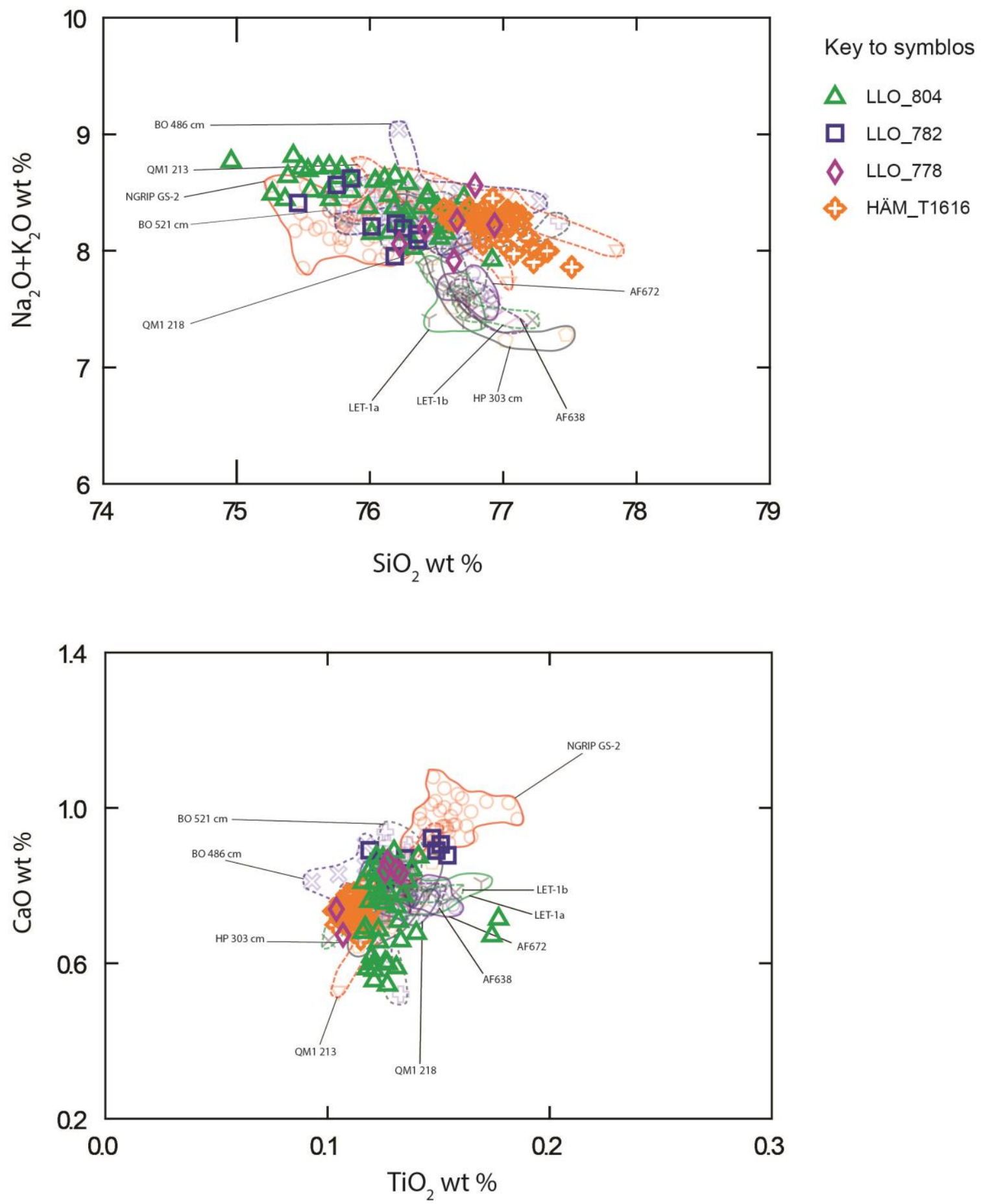

Figure $8.3-\mathrm{SiO}_{2} \vee \mathrm{Na}_{2} \mathrm{O}+\mathrm{K}_{2} \mathrm{O}$ and $\mathrm{CaO} \vee \mathrm{TiO}_{2}$ bivariate plots showing tephra glass shard major element compositions for LLO_804, LLO_782, LLO_778, HÄM_T1616 and envelopes for other Borrobol-type tephras noted in the text. (Reference data and envelopes are based on data from Albert, 2007 (LET-1a and LET-1b); Matthews et al., 2011 (AF638 adn AF672); Cook, 2015 (NGRIP GS-2); Lind et al., 2016 (BO 521, BO486 and HP 303); Timms et al., 2016 (QM1 213 and QM1 218)). 
Interstadial and preceding glacial period. According to lithostratigraphical constraints, the HÄM_T1616 deposit in Hämelsee, which has BT-type chemistry (Figure 8.3), is approximately positioned stratigraphically in the latter part of the Lateglacial Interstadial (Figure 4.5 and 8.2), suggesting the most likely correlation is to either QM1 213 or QM1 218 found in the Orkneys (Timms et al., 2016). However, without a more precise chronostratigraphy for the Hämelsee sequence yet in place, correlation to any of the many Borrobollike cryptotephra deposits has to remain uncertain.

In the Llyn Llech Owain record, three tephra deposits have been identified with a chemical signature similar to the Borrobol (LLO_804, LLO_782 and LLO_778). Based on the \%C curve and lithostratigraphy the LLO_804 was deposited during the glacial period and thus may be correlated with either the ice core GS-2 tephra and/or the KOL-GS-2 tephra (Figure 8.2). Geochemical analyses reveal most chemical elements are indistinguishable, however, there is an offset seen in the $\mathrm{TiO}_{2}$ and $\mathrm{CaO}$ wt \% data which rejects the proposed correlation (Figure 5.15 and 8.3). Another possible correlation for the LLO_804 deposit is the tephra discovered stratigraphically before the rise in LOI values in the Loch an t'Suidhe record (Pyne O'Donnell, 2007) (Figure 8.2). Pyne O'Donnell, (2007) notes that the stratigraphic position of the BT at Loch an t'Suidhe, however, does not reflect another previously unrecorded tephra and suggests that the LOI stratigraphy is inconsistent with other sequences where organic matter accumulation at Loch an t'Suidhe lagged behind other sites. Additionally, Walker and Lowe, (in press) discuss that underpinning the Lateglacial Interstadial onset or the onset of lake sedimentation is problematic due to the sediments being mostly devoid of climatic proxies such as pollen, diatoms or chironomids. Therefore, establishing the stratigraphical position for the Lateglacial Interstadial temperature rise is difficult based on LOI data alone. However, at Loch an t'Suidhe, there is a significant interval of $14 \mathrm{~cm}$ between the first occurrence of tephra shards positioned at $663 \mathrm{~cm}$ and the rise in LOI values at $649 \mathrm{~cm}$. Although there are no radiocarbon constraints for this transition for the core from Pyne O'Donnell, (2007), this seems too significant to represent a sitespecific lag in organic matter accumulation. In that case, this tephra in Loch 
an t'Suidhe may represent a BT-type eruption that occurred during the end of the glacial period. A depth of $25 \mathrm{~cm}$ is also present between tephra deposit LLO_804 and the initial rise in \%C, suggesting a stratigraphical position within the glacial period, despite the record not having a temperature palaeorecord. Therefore, LLO_804 may also be a product of the same eruption identified at Loch an t'Suidhe (Figure 8.2).

Tephra deposits LLO_782 and LLO_778 have been tentatively correlated to the BT and PT respectively (see section 5.6). If an assumption was made that the correlations are robust, the discoveries would expand the known spatial distribution of the BT and PT further south (Figure 8.4) and demonstrate the possibility of finding the BT and PT at other sites in northwest Europe. The apparent absence of the BT or PT within Irish sites may indicate that south Wales lay very close to the spatial distribution limit of the ash cloud.

\subsubsection{Glacier Peak G (LLO_766)}

Tephra deposit LLO_766 has been correlated to the Glacier Peak G Tephra sourced from the Cascade range in western North America. This deposit also shows chemical affinity to the early Interstadial aged Roddans Port B tephra identified in Northern Ireland (Turney et al., 2006). This may suggest both LLO_766 and Roddans Port B to be a product of the Glacier Peak eruption, however, the five geochemical analyses for the Roddans Port B deposit is relatively diffuse and only identified at one site. More analyses and further discoveries at other sites would confirm a robust correlation. Prior to this study, the furthest discovery of the Glacier Peak G tephra was in the east of North America in Maine and Nova Scotia (Pyne O'Donnell et al., 2016) (Figure 8.5). This tephra is positioned stratigraphically in the early Lateglacial Interstadial with an age estimate of 13.74-13.45 cal ka BP (Pyne O'Donnell et al., 2016). This is the first transatlantic discovery of the Glacier Peak G Tephra, resulting in a significant increase in its spatial distribution. 


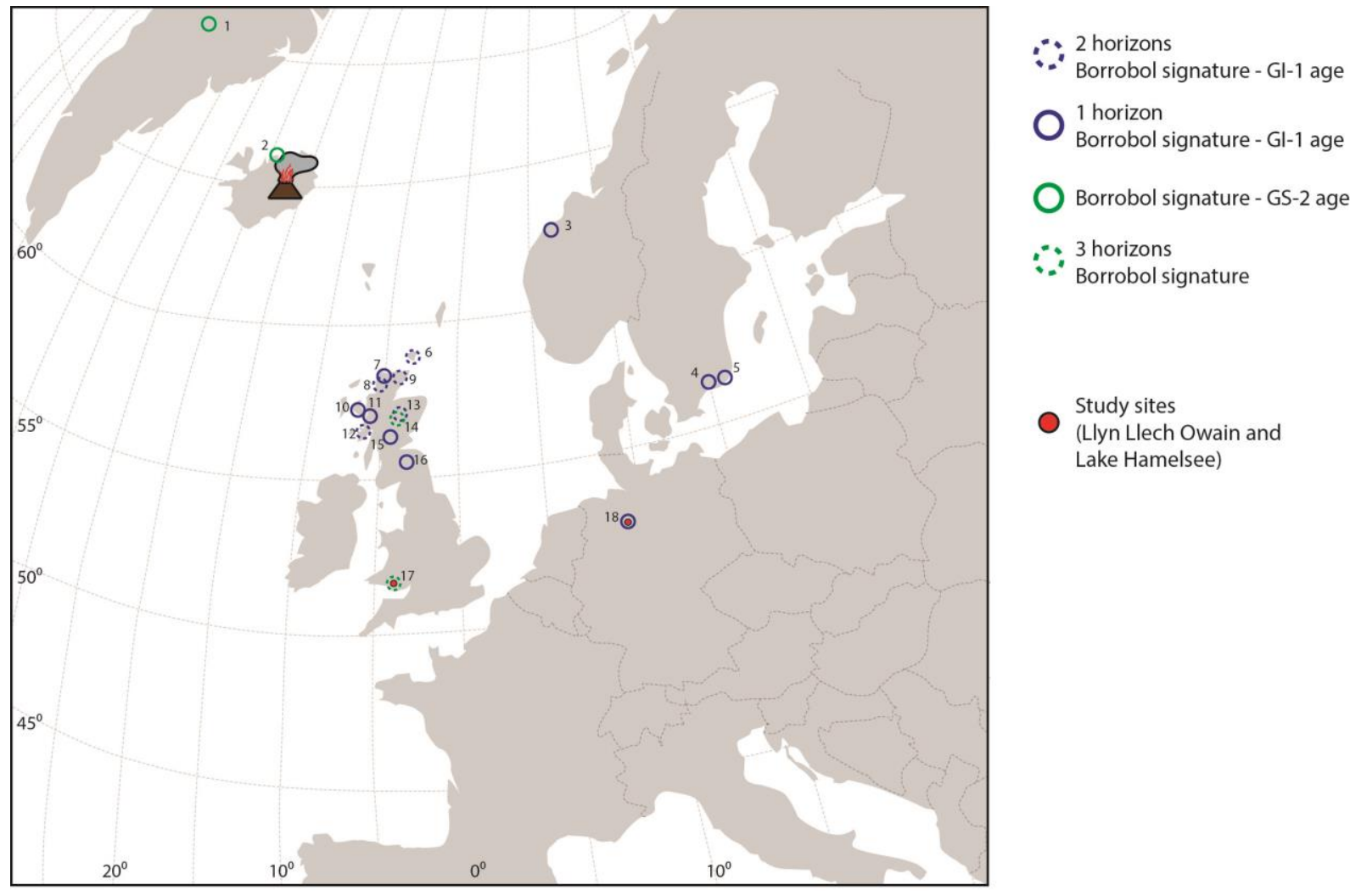

Figure 8.4 - Compilation of sites that contain tephra deposits with a Borrobol-type signature (modified form Lind et al., 2016). 1 - NGRIP (Cook, 2015), 2 - North Icelandic Shelf (Eiríksson et al., 2000), 3 Dimna Bog (Koren et al., 2008), 4 - Hässeldala port (Davies et al., 2003), 5 - Skallahult (Davies et al., 2003), 6 -Quoyloo Meadow (Timms et al., 2016) note that the tephras identified here are positioned in the late Interstadial, 7 - Loch An Druim (Ranner et al., 2005), 8 - Tanera Mor (Roberts et al., 1998), 9 - Borrobol (Turney et al., 1997), 10 - Druim Loch (Pyne O'Donnell, 2007), 11 - Loch Ashik (Pyne O'Donnell, 2007), 12 - Loch an t'Suidhe (Pyne O'Donnell, 2007), 13 - Abernethy Forest (Matthews et al., 2011), 14 - Loch Etteridge (Albert, 2007), 15 - Tynaspirit West (Turney et al., 1997), 16 - Whitirg Bog (Turney et al., 1997), 17 - Llyn Llech Owain (this study), 18 - Lake Hämelsee (this study). 


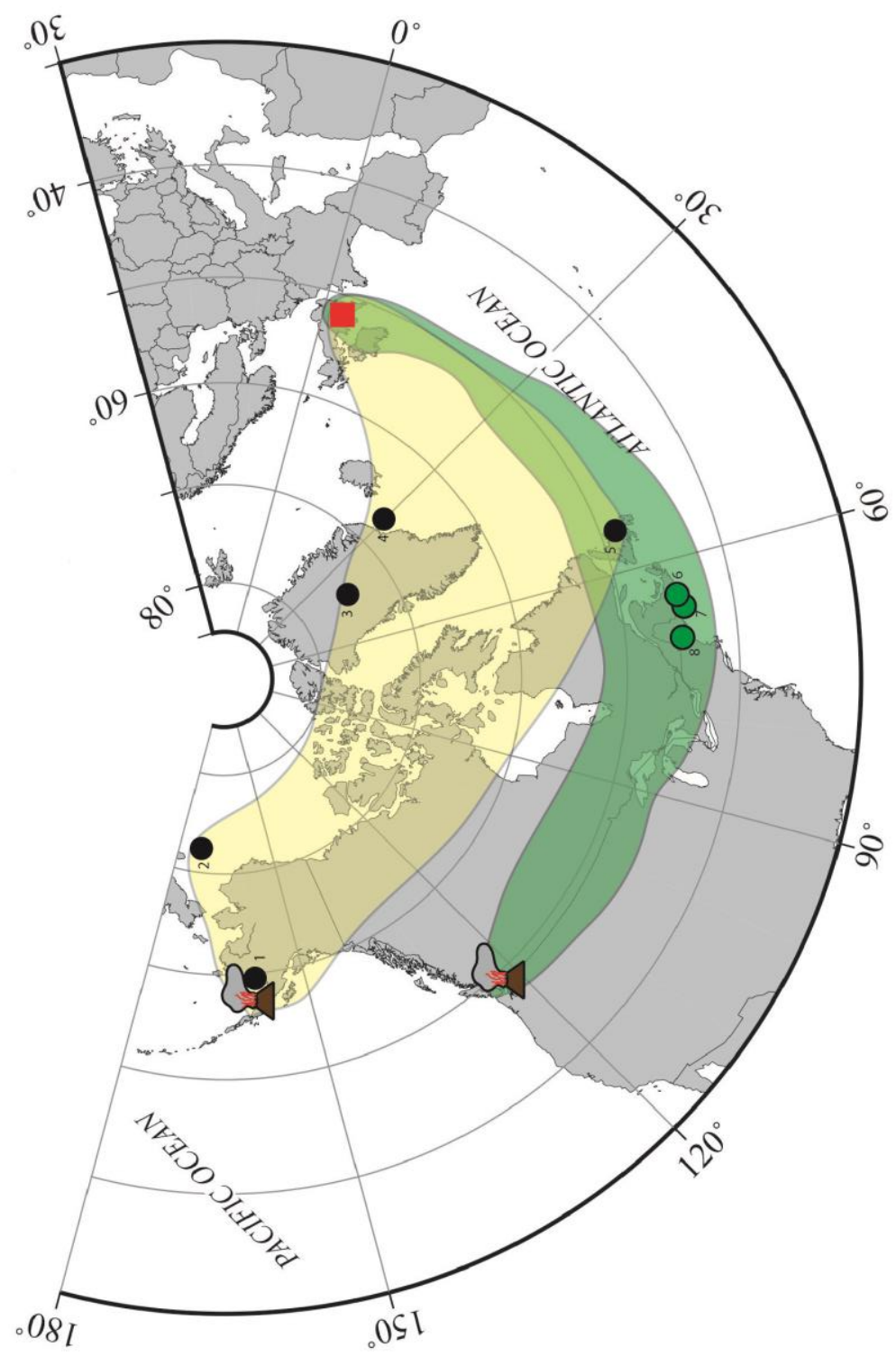

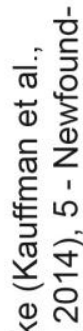

峁 $\frac{0}{\pi}$

떵

के क्ष

雨

잉

ญ்่

玄 的

웅

(1) 즌

范

잉

흥 䒛

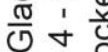

든

ส

흥ㅎํ

范口

든

需

닥

这

인

닌

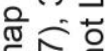

등

닥

苧

ํำ

음

뜽

뜸무

के

D

क क

응등

은 홍

เค

o

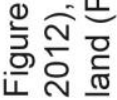


Along with providing an age estimate and transatlantic isochronous markers for the Llyn Llech Owain sequence, this finding has provided insights to the travel distances of ash clouds from such volcanic eruptions across the Atlantic Ocean and further into Europe, as previously revealed by recent studies including Jensen et al., (2014) and Watson et al., (2017) with the discovery the Alaskan White River Ash found in Britain, Poland and Germany. With the understanding of the potential distances covered by these large eruptions, assessments can be made to mitigate potential hazards posed by future volcanic eruptions to airspace disruption. A classic example of such airspace disruption is the 2010 Eyjafjallajökull event where a medium-sized eruption (VEI 4) produced an ash plume that caused the closure of airspace over Europe, cancelling over 100,000 flights, affecting 10 million passengers and costing the European aviation industry $\sim$ 3.3 billion (Mazzocchi et al., 2010). Other eruptions of similar magnitude, or greater, are known to have occurred previously. These are preserved in the sedimentary record as cryptotephras and suggest that previous eruptions would have had a similar if not more extensive, effect as the 2010 Eyjafjallajökull event (Swindles et al., 2011). It seems likely that eruptions similar to those that produced the Glacier Peak G Tephra, discovered from this study, could potentially pose an even greater impact due to the ash plume extending over North America and the Atlantic Ocean into Europe. Other recent studies have also shown the vast ash plume distances that can be achieved by explosive volcanoes, including Bourne et al., (2016) and van der Blit et al., (2017).

\subsubsection{Laacher See Tephra (HÄM_T1558)}

Tephra deposit HÄM_T1558 has been correlated to the widely dispersed Laacher See Tephra (LST), as previously identified in Lake Hämelsee by Merkt et al., (1993). Although glass shards of late Interstadial age were identified in very low concentrations in Llyn Llech Owain (Figure 5.13), geochemical analyses were not achieved to test a correlation to the LST. The 
LST originated from the Eifel region of Germany and is widely found within Central European archives, occurring consistently within the latest part of the interstadial (van den Bogaard \& Schmincke, 1985). The Laacher See Tephra has been dated to $12,880 \pm 40$ varve years (Brauer et al., 1999) in Lake Meerfelder Maar and to $12937 \pm 23$ cal BP in a multi-site Bayesian-based radiocarbon age model by Bronk Ramsey et al., (2015). HÄM_T1558 shows a predominant correlation to the upper phase of the LST, which is previously thought to have been dispersed in a southerly direction rather than northwards. Upper phase LST shards are also present in Wegliny, southwest Poland (Housley et al., 2013) further contradicting the previously thought dispersal axis of the upper phase LST. Some shards also show affinity to the mid and lower phase of the LST, as indicated by the $\mathrm{FeO}, \mathrm{TiO}_{2}$ and $\mathrm{MgO}$ values (Figure 4.8), suggesting that the dispersal of the phases may have been more widespread than previously thought.

\subsubsection{Vedde Ash (HÄM_T1494)}

Tephra deposit HÄM_T1494 is correlated to the Vedde Ash, which erupted from the Katla volcano in Iceland. The Vedde Ash has been dated to 12,121 $\pm 114 \mathrm{~b} 2 \mathrm{k}$ in the Greenland ice cores (Mortensen et al., 2005; Rasmussen et al., 2006), to 12,140 \pm 43 varve yr BP in Meerfelder Maar (Lane et al., 2015) and to $12,023 \pm 43$ cal BP by Bronk Ramsey et al., (2015). This tephra has been identified in several sites across NW Europe and marine cores from the North Atlantic providing several isochronous links. Furthermore, it is also present in the Greenland ice-core record (Mortensen et al., 2005), allowing palaeoclimatic comparisons to be made with the widely used INTIMATE event stratigraphy (Rasmussen et al., 2014).

The Vedde Ash was not found at Llyn Llech Owain or Cors Carmel, even though it is considered as one of the most widely distributed tephra deposit during the Lateglacial in NW Europe. Colourless glass shards with platy morphologies were identified in Llyn Llech Owain during the Loch Lomond 
Stadial part of the record, however, a single distinct peak is not observed and shards are in very low concentrations which prevented shard extraction for geochemical analysis. The absence of the Vedde Ash may partly reflect the ash plume limit.

\subsubsection{Ulmener Maar Tephra (HÄM_T1451)}

Whilst geochemical analyses were not possible to measure the glass shard composition of tephra deposit HÄM_T1451, based upon the morphological similarity, a distinct peak in TSC and corresponding stratigraphic position at the onset of the Holocene, HÄM_T1451 is tentatively correlated to the UMT. This discovery is thought to be the first cryptotephra deposit found for the Ulmener Maar tephra. However, the UMT has only been found in proximal to medial sites including Meerfelder Maar and other sites in western Germany only as a thin layer (Zolitschka et al., 1995; Brauer et al., 1999; Lane et al., 2015). Due to the lack geochemical data and the restricted dispersal of the UMT reported in the literature, HÄM_T1451 is only tentatively correlated to the UMT and remain speculative that the crystalised particels are a product of the UMT eruption. If a secure correlation is made between HÄM_T1451 and the UMT, its discovery in Lake Hämelsee would extended its dispersal extent and highlight the possibility of tracing the UMT at other sites along the same dispersal axis.

\subsubsection{Askja-S (HÄM_T1445-1444 and PLL_500)}

Tephra deposits HÄM_T1445-1444 and PLL_500 have been correlated to the Askja-S Tephra, which is considered to be a key isochronous marker for the early Holocene. The geochemical signature for the Askja-S Tephra is very distinct and can be easily discriminated to other similarly aged Icelandic 


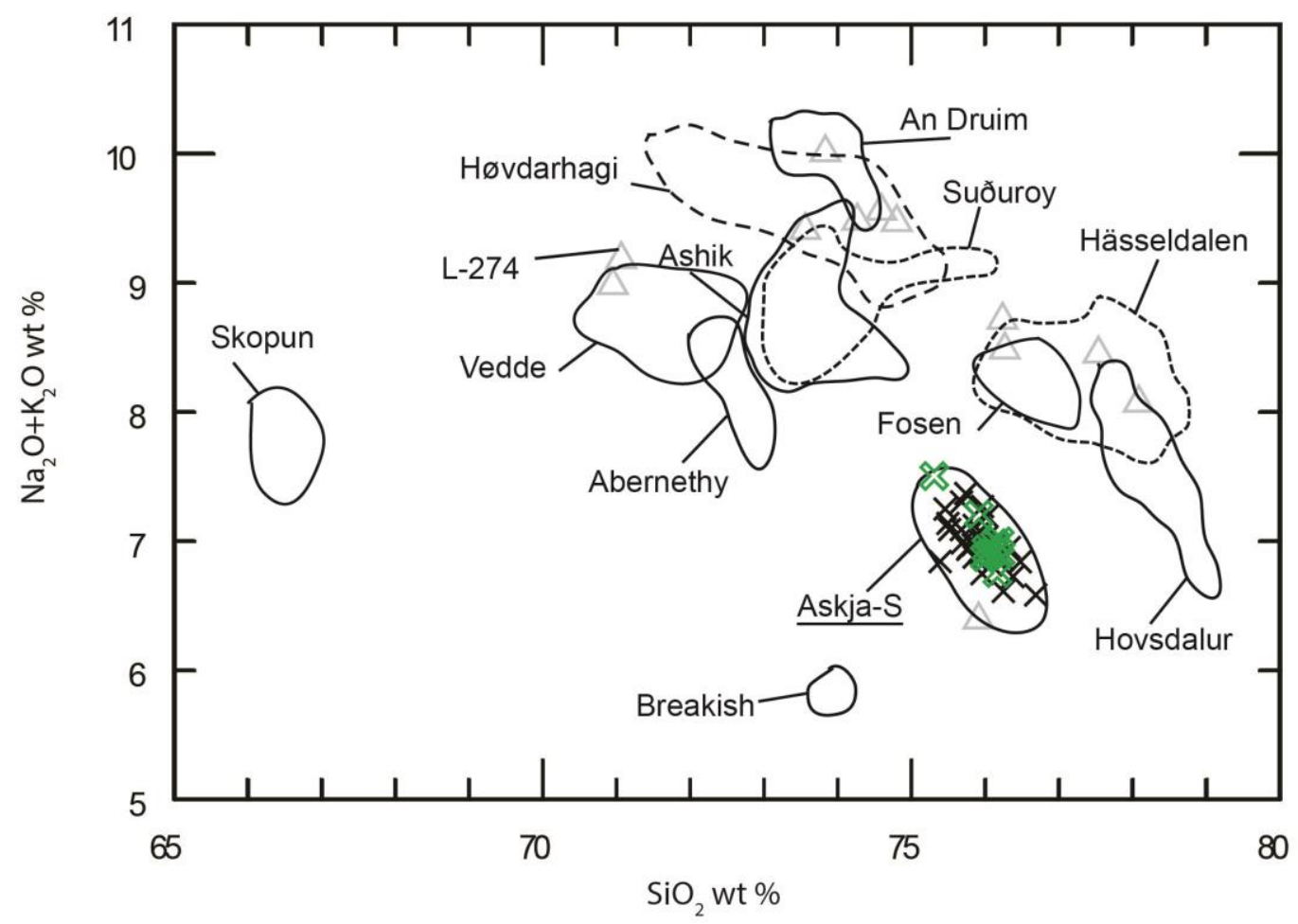

Key to symbols

\ HÄM_T1445-1444

$\times$ PLL_500

Figure $8.6-\mathrm{SiO}_{2} \vee \mathrm{Na}_{2} \mathrm{O}+\mathrm{K}_{2} \mathrm{O}$ bivariate plot showing tephra glass shard major element compositions for HÄM_T1445-1444 and PLL_500 and envelopes for similarly aged Icelandic Tephras. (Reference envelopes are based on data from Wastegård, 2002; Ranner et al., 2005;

Pyne-O'Donnell, 2007; Lind and Wastegård, 2011; Matthews et al., 2011; Lane et al., 2011, 2012; Lind et al., 2013; Lilja et al., 2013; Wulf et al., 2016; Timms et al., 2016; Jones et al., 2017). 
tephras on a TAS plot (Figure 8.6). This tephra has an extensive distribution from Arctic Norway (Pilcher et al., 2005) to Switzerland (Lane et al., 2011) and from northern Ireland (Turney et al., 2006) to north Poland (Wulf et al., 2016). One age estimate for the Askja-S Tephra is $10,830 \pm 57$ cal BP, which was derived by age-modelling a range of radiocarbon dates (Bronk Ramsey et al., 2015), however, Ott et al., (2016) provide an older age of 11,228 \pm 26 cal BP based on a varve-interval from the Hässeldalen tephra in Lake Czechowskie, Poland. Based on the relative stratigraphic positions of tephras in the Lake Hämelsee record, this study and Jones et al., (2017) suggests that the Ott et al., (2016) age estimate is marginally too old than the age estimate outlined by Bronk Ramsey et al., (2015). Its discovery in the Lake Hämelsee record provides an important and precise age constraint for the Hämelsee age model, where terrestrial plant macrofossils are sparse in this part of the record for radiocarbon dating.

New findings in this study now allow Pant-y-Llyn and Hämelsee to be precisely integrated within a broad palaeorecord network (Figure 8.7). Its discovery at Pant-y-Llyn extends the geographical area of the Askja-S Tephra deposition further south. Based on dispersal maps shown in recent papers (e.g. Wulf et al., 2016) the single ash cloud covers most of north-west Europe. However, we propose potential dispersal maps based on reported Askja-S findings and negative findings (Table 8.1 and Figure 8.8), and speculate that dispersal may have been characterised by more than one plume trajectory. This approach to investigating ash cloud dispersal based on negative findings can also be applied to other tephra deposits but is only undertaken for the Askja-S Tephra for this study. Proximal deposits in Iceland, however, suggest the main axis of Askja-S dispersal was mainly to the NNE (Sigvaldason et al., 2002). We acknowledge that several other factors may also account for the absence of the Askja-S Tephra in some records (e.g. uneven ash distribution within sites, failure to pinpoint cryptotephra deposits in low-resolution searches; Pyne O'Donnell, 2011; Timms et al., 2016), however, we use our maps to highlight geographical areas that are most likely to result in fruitful recovery of the Askja-S deposit. In particular, the relatively high shard concentrations (72 shards per $0.5 \mathrm{~g} \mathrm{dw}$ ) 


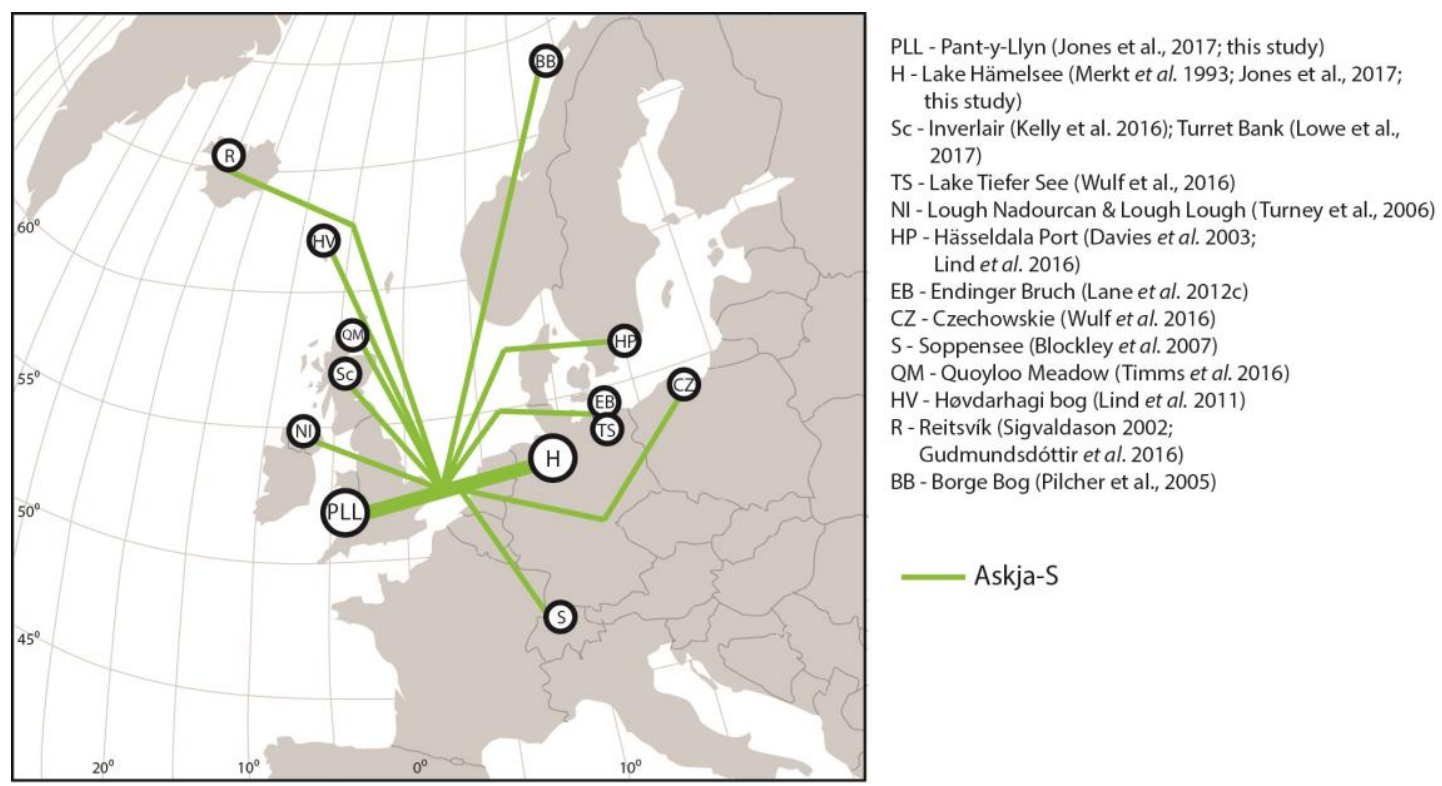

Figure 8.7 - Location map showing some of the key European sites to which Lake Hämelsee and Pant-y-Llyn can be correlated through the Askja-S Tephra. 

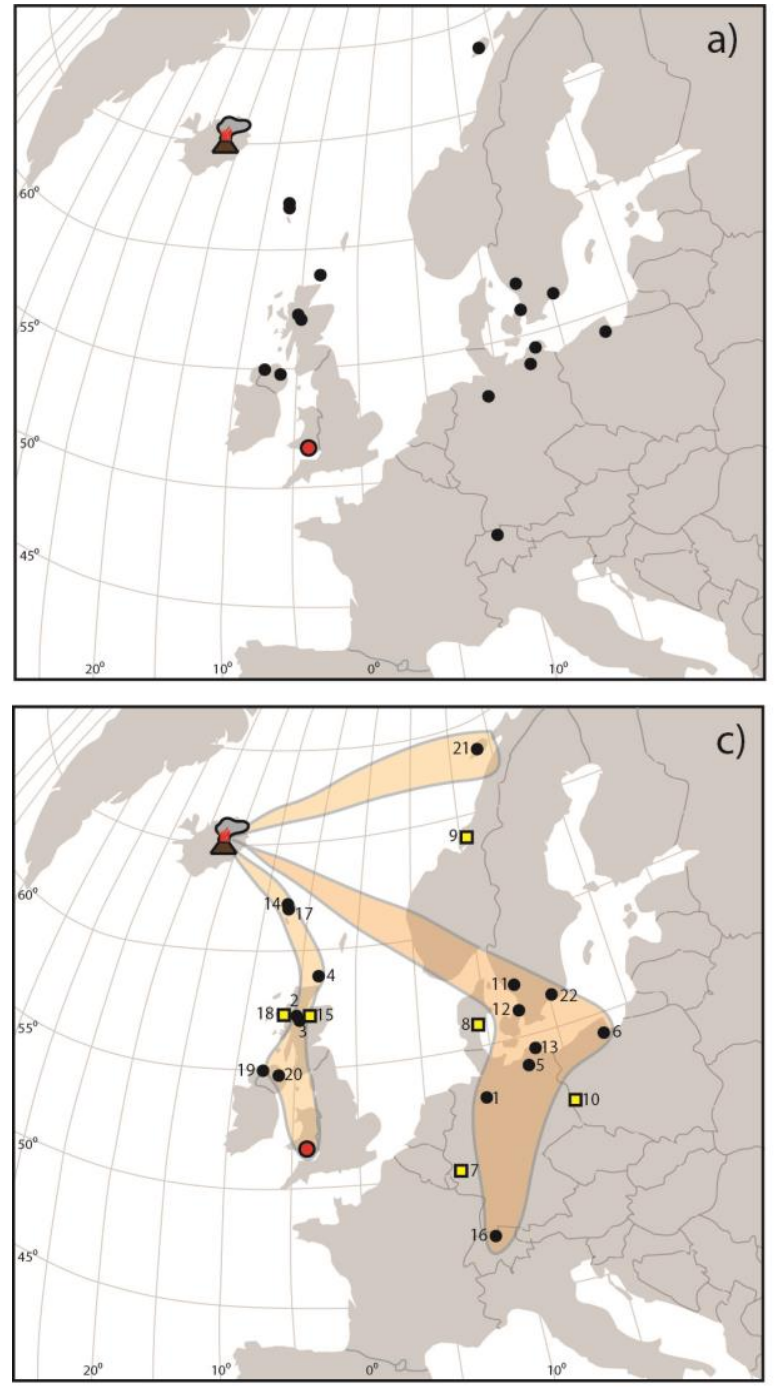

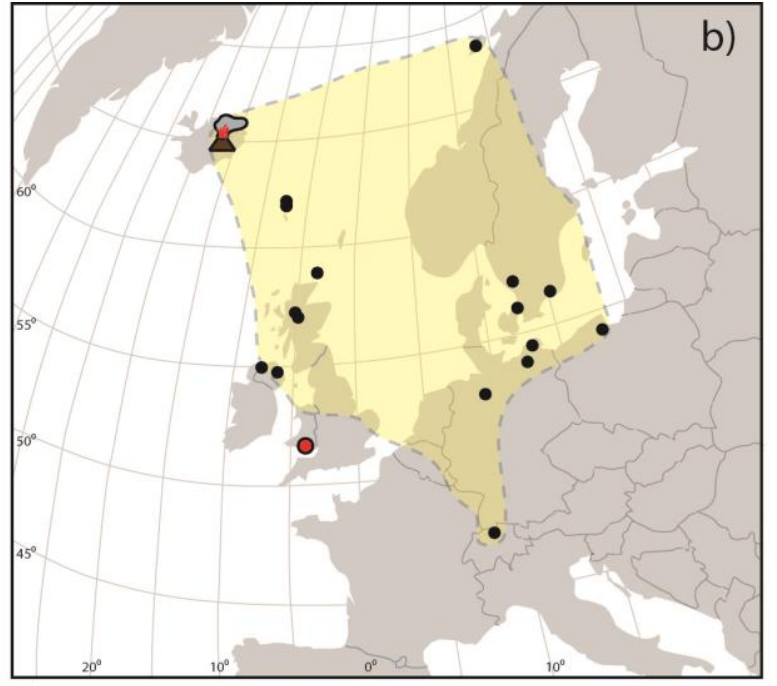

Pant-y-Llyn

Sites where the Askja-S present

Sites where the Askja-S is absent

Dyngjufjöll volcanic center (Askja volcanic system)

Askja-S spatial distribution (modified from Wulf et al., 2016)

Alternative Askja-S spatial distribution (this study)

Figure 8.8 - Spatial distribution maps for the Askja-S Tephra. a) Sites where the Askja-S Tephra is present. b) Current spatial distribution envelope for the Askja-S Tephra (modified from Wulf et al., 2016). c) Suggested plume trajectory, given the location of sites where the Askja-S is present and absent. Site numbers and details are provided in full in Table 8.1. 
Table 8.1- A compilation of positive and negative findings of the Askja-S Tephra (ordered by publication date). Absences are noted according to the sampling interval, age models and the stratigraphic position of other tephras in the original studies.

\begin{tabular}{|c|c|c|c|c|}
\hline Site & $\begin{array}{l}\text { Latitude } \\
\text { and } \\
\text { Longitude }\end{array}$ & \begin{tabular}{|l|} 
Number \\
in Figure \\
8.8
\end{tabular} & Reference & $\begin{array}{l}\text { Askja-S } \\
\text { Tephra } \\
\text { present }\end{array}$ \\
\hline $\begin{array}{l}\text { Lake Hämelsee, } \\
\text { Germany }\end{array}$ & $\begin{array}{l}52^{\circ} 45^{\prime} \mathrm{N}, \\
9^{\circ} 18^{\prime} \mathrm{E}\end{array}$ & 1 & Jones et al., 2017 & Yes \\
\hline $\begin{array}{l}\text { Turret Bank, } \\
\text { Scotland }\end{array}$ & $\begin{array}{l}57^{\circ} 00^{\prime} \mathrm{N}, \\
4^{\circ} 44^{\prime} \mathrm{E}\end{array}$ & 2 & Lowe et al., 2017 & Yes \\
\hline $\begin{array}{l}\text { Inverlair, } \\
\text { Scotland }\end{array}$ & $\begin{array}{l}56^{\circ} 52^{\prime} \mathrm{N} \\
4^{\circ} 43^{\prime} \mathrm{W}\end{array}$ & 3 & Kelly et al., 2016 & Yes \\
\hline $\begin{array}{l}\text { Quoyloo } \\
\text { Meadow, } \\
\text { Scotland }\end{array}$ & $\begin{array}{l}59^{\circ} 03^{\prime} \mathrm{N} \\
3^{\circ} 18^{\prime} \mathrm{W}\end{array}$ & 4 & Timms et al., 2016 & Yes \\
\hline $\begin{array}{l}\text { Lake Tiefer } \\
\text { See, Germany }\end{array}$ & $\begin{array}{l}53^{\circ} 35^{\prime} \mathrm{N} \\
12^{\circ} 31^{\prime} \mathrm{E}\end{array}$ & 5 & Wulf et al., 2016 & Yes \\
\hline $\begin{array}{l}\text { Lake } \\
\text { Czechowskie, } \\
\text { Poland }\end{array}$ & $\begin{array}{l}53^{\circ} 52^{\prime} \mathrm{N} \\
18^{\circ} 14^{\prime} \mathrm{E}\end{array}$ & 6 & Wulf et al., 2016 & Yes \\
\hline $\begin{array}{l}\text { Meerfelder } \\
\text { Maar, Germany }\end{array}$ & $\begin{array}{l}50^{\circ} 06^{\prime} \mathrm{N} \\
6^{\circ} 45^{\prime} \mathrm{E}\end{array}$ & 7 & Lane et al., 2015 & No \\
\hline $\begin{array}{l}\text { Store Slotseng } \\
\text { basin, SW } \\
\text { Denmark }\end{array}$ & $\begin{array}{l}55^{\circ} 19^{\prime} \mathrm{N} \\
9^{\circ} 16^{\prime} \mathrm{E}\end{array}$ & 8 & $\begin{array}{l}\text { Larsen \& Noe- } \\
\text { Nygaard, } 2014\end{array}$ & No \\
\hline $\begin{array}{l}\text { Grønlia fen, } \\
\text { Norway }\end{array}$ & $\begin{array}{l}63^{\circ} 47^{\prime} \mathrm{N} \\
10^{\circ} 28^{\prime} \mathrm{E}\end{array}$ & 9 & Lind et al., 2013 & No \\
\hline Wegliny, Poland & $\begin{array}{l}51^{\circ} 49^{\prime} \mathrm{N} \\
14^{\circ} 43^{\prime} \mathrm{E}\end{array}$ & 10 & $\begin{array}{l}\text { Housley et al., } \\
2013\end{array}$ & No \\
\hline $\begin{array}{l}\text { Mulakullegöl, } \\
\text { Sweden }\end{array}$ & $\begin{array}{l}57^{\circ} 12^{\prime} \mathrm{N} \\
13^{\circ} 25^{\prime} \mathrm{E}\end{array}$ & 11 & Lilja et al., 2013 & Yes \\
\hline $\begin{array}{l}\text { Tøvelde, } \\
\text { Denmark }\end{array}$ & $\begin{array}{l}54^{\circ} 57^{\prime} \mathrm{N} \\
12^{\circ} 17^{\prime} \mathrm{E}\end{array}$ & 12 & Larsen, 2013 & Yes \\
\hline $\begin{array}{l}\text { Endinger Bruch, } \\
\text { Germany }\end{array}$ & $\begin{array}{l}54^{\circ} 14^{\prime} \mathrm{N} \\
12^{\circ} 53^{\prime} \mathrm{E}\end{array}$ & 13 & Lane et al., 2012 & Yes \\
\hline $\begin{array}{l}\text { Havnardalsmyr } \\
\text { en, Faroe }\end{array}$ & $\begin{array}{l}62^{\circ} 01^{\prime} \mathrm{N}, \\
6^{\circ} 84^{\prime} \mathrm{W}\end{array}$ & 14 & $\begin{array}{l}\text { Kylander et al., } \\
\text { 2012; Wastegărd }\end{array}$ & Yes \\
\hline
\end{tabular}




\begin{tabular}{|c|c|c|c|c|}
\hline Islands & & & pers comm & \\
\hline $\begin{array}{l}\text { Abernethy } \\
\text { Forest, } \\
\text { Scotland }\end{array}$ & $\begin{array}{l}57^{\circ} 14^{\prime} \mathrm{N} \\
3^{\circ} 42^{\prime} \mathrm{W}\end{array}$ & 15 & $\begin{array}{l}\text { Matthews et al., } \\
2011\end{array}$ & No \\
\hline $\begin{array}{l}\text { Soppensee, } \\
\text { Switzerland }\end{array}$ & $\begin{array}{l}47^{\circ} 05^{\prime} \mathrm{N} \\
8^{\circ} 05^{\prime} \mathrm{E}\end{array}$ & 16 & Lane et al., 2011 & Yes \\
\hline $\begin{array}{l}\text { Høvdarhagi } \\
\text { bog, Faroe } \\
\text { Islands }\end{array}$ & $\begin{array}{l}61^{\circ} 54^{\prime} \mathrm{N} \\
6^{\circ} 55^{\prime} \mathrm{W}\end{array}$ & 17 & $\begin{array}{l}\text { Lind \& Wastegård, } \\
2011\end{array}$ & Yes \\
\hline $\begin{array}{l}\text { Loch Achik, } \\
\text { Scotland }\end{array}$ & $\begin{array}{l}57^{\circ} 15^{\prime} \mathrm{N} \\
5^{\circ} 50^{\prime} \mathrm{W}\end{array}$ & 18 & $\begin{array}{l}\text { Pyne O'Donnell, } \\
2007\end{array}$ & No \\
\hline $\begin{array}{l}\text { Lough } \\
\text { Nadourcan, } \\
\text { northwest } \\
\text { Ireland }\end{array}$ & $\begin{array}{l}55^{\circ} 03^{\prime} \mathrm{N} \\
7^{\circ} 54^{\prime} \mathrm{W}\end{array}$ & 19 & Turney et al., 2006 & Yes \\
\hline $\begin{array}{l}\text { Long Lough, } \\
\text { Northern Ireland }\end{array}$ & $\begin{array}{l}54^{\circ} 26^{\prime} \mathrm{N} \\
5^{\circ} 55^{\prime} \mathrm{W}\end{array}$ & 20 & Turney et al., 2006 & Yes \\
\hline $\begin{array}{l}\text { Borge Bog, } \\
\text { Arctic Norway }\end{array}$ & $\begin{array}{l}68^{\circ} 14^{\prime} \mathrm{N} \\
13^{\circ} 44^{\prime} \mathrm{E}\end{array}$ & 21 & Pilcher et al., 2005 & Yes \\
\hline $\begin{array}{l}\text { Hässeldala port, } \\
\text { Sweden }\end{array}$ & $\begin{array}{l}56^{\circ} 16^{\prime} \mathrm{N} \\
15^{\circ} 03^{\prime} \mathrm{E}\end{array}$ & 22 & Davies et al., 2003 & Yes \\
\hline
\end{tabular}


highlight the tantalising possibilities of tracing the Askja-S Tephra, as well as other Icelandic tephras, further south in the British Isles and perhaps France. However, the Askja-S Tephra was not found at Llyn Llech Owain or Cors Carmel. Twenty-two clear shards were identified in sample $670-665 \mathrm{~cm}$ in the early Holocene part of the Llyn Llech Owain record which may be correlated to the Askja-S Tephra based on stratigraphic position (Figure 5.13). However, no shards were identified after high resolution searching to isolate a peak and no shards were extracted to enable geochemical analysis to confirm a correlation. The stratigraphical position may also be too close to the Holocene onset which may suggest the Hässeldalen Tephra a more likely candidate.

In the Pant-y-Llyn sequence, the radiocarbon date at $510 \mathrm{~cm}(10 \mathrm{~cm}$ below the Askja-S Tephra) has revealed an age range of 12,958-12,713 cal BP, almost 2000 years older than the Askja-S Tephra. A further date of 12589$12105 \mathrm{cal} \mathrm{BP}$ is obtained from the sample dated at $395 \mathrm{~cm}$ (Table 6.1 and Figure 6.3). Given the hard-water error that affects sediments in limestone terrain (Walker, 2005), we suggest that these ages cannot be used to obtain a reliable age-model, especially the sample obtained from $395 \mathrm{~cm}$ where $\mathrm{CaCO}_{3}$ content is $68 \%$. The discrete Askja-S peak, however, provides a well-constrained age marker for the lowermost part of the sequence and constrains the brown gyttja to the early Holocene interval. Although bedrock was not reached during coring, the Askja-S Tephra provides a minimum age estimate for the sediment sequence and indicates that the underlying siltyclay unit is likely to represent the Loch Lomond Stadial. Further work will need to ascertain whether a full Lateglacial sequence is preserved at the site; such records are limited in number in south Wales (e.g. Walker et al., 2003, 2009).

8.1.7 Saksunarvatn Ash (HÄM_T1401.5) 
Tephra deposit HÄM_T1401.5 has been correlated to the Saksunarvatn Ash which has been found in several terrestrial sites in Europe (Timms et al., 2016), and in several marine cores, including LINK 14:185 in the North Atlantic (Rasmussen et al., 2011; Davies et al., 2012). A tephra deposit of the same major element composition has also been identified in the GRIP ice core (Grönvold et al., 1995; Davies et al., 2012) with an age of 10,297 \pm 45 b2k (Rasmussen et al., 2006). However, Davies et al., (2012) demonstrate a compositional difference between the tephra in GRIP and LINK 14:185 based on trace element data which may suggest two separate eruptions occurred closely spaced in time, with two ash plumes directed in opposite directions to one another. Bramham-Law et al., (2013) also supports the two axis of dispersal with trace element data from Potremser Moor, Germany, correlating with the LINK 14:185 south-east deposit. Consequently, HÄM_T1401.5 is correlated to the eruption that dispersed ash in a south easterly direction, as initially recognised by Mangerud et al., (1984). The Saksunarvatn Ash has been dated at Kråkenes to 10,210 \pm 35 cal BP (Lohne et al., 2014). The addition of the Saksunarvatn Ash to the already well established tephrostratigraphy record at Lake Hämelsee, makes it a key tie point site and an important addition to the overall European tephrostratigraphic framework for the Lateglacial (Lowe et al., 2015) (Figure 8.9). Lake Hämelsee will play a key role in providing links between central and northern European sites and also with the Greenland ice core records, which form the basis for the widely used INTIMATE event stratigraphy (Rasmussen et al., 2014).

\subsubsection{Fondi di Baia (LLO_580)}

Tephra deposit LLO_580 has been tentatively correlated to the Fondi di Baia Tephra, sourced from Italy. The Fondi di Baia Tephra is stratigraphically positioned in the early Holocene and dated to 9695-9525 cal BP (Smith et al., 2011). This eruption was not thought to have been a widely distributed tephra deposit because it has only been identified in two sites relatively close to the source volcano. These sites are the PRAD core in the central Adriatic Sea 


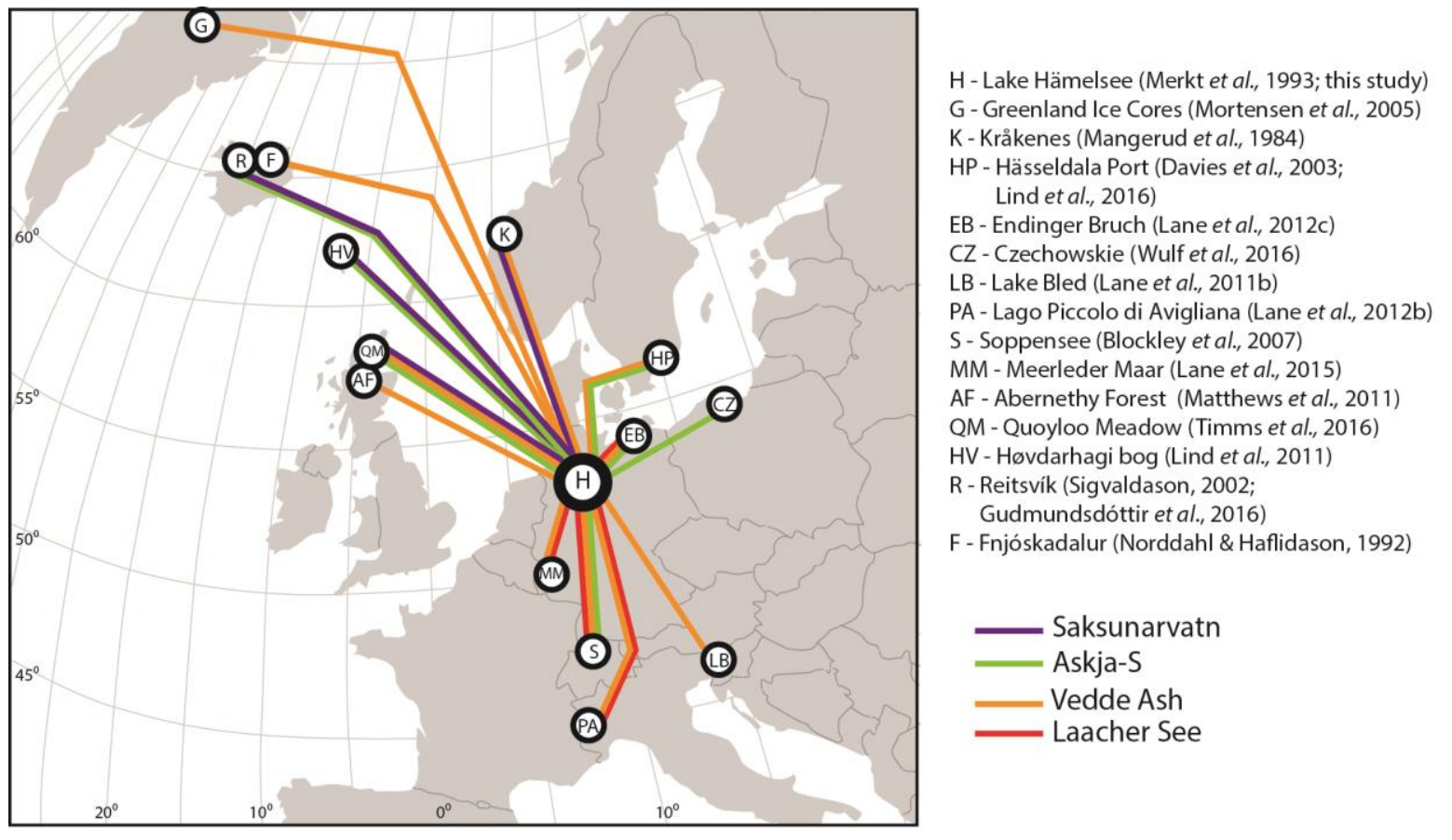

Figure 8.9 - Location map showing some of the key European sites to which Lake Hämelsee can be correlated through one or more tephra deposits. 
(Bourne et al., 2010) and Lago Grande di Monticchio (Wulf et al., 2008). However, geochemical data from Smith et al., (2011) has demonstrated that the proposed correlation of TM-6-1 tephra deposit in the Monticchio record (Wulf et al., 2008) and the PRAD-120 tephra deposit (Bourne et al., 2010) to the Fondi di Baia eruption could not be confirmed (Sabine Wulf, pers comm). This indicates that synchronisation of proxy data between these Italian sites and Llyn Llech owain is not currently possible. Further work is required to explore this correlation. The discovery of the Fondi di Baia Tephra at Llyn Llech Owain, however, has increased its spatial distribution by a significant distance and suggests the ash plume may have been transported in a north westerly direction. This discovery is the first Italian tephra deposit found within a British site, with the exception of one tephra deposit, identified at Exmoor (Fyfe et al., 2014), that has been tentatively correlated to an unnamed early Holocene Italian eruption of Campi Flegrei. This proposed correlation is tentative due to it only being present in two relatively local sites, as noted above, and not found in any other more northerly sites. It is also questionable whether the ash plume could have travelled in a north westerly direction against the prevailing westerly winds. However, one could argue that the wind may have been blowing in a direction towards Wales at the time of eruption, as may have been the case with the Icelandic tephra deposits found in the NGRIP and NEEM ice cores (Abbott and Davies, 2012; Bourne et al., 2015), located north-west of Iceland. As noted in section 5.6, the geochemical composition does not correlate perfectly with slight differences seen in the $\mathrm{Na}_{2} \mathrm{O}$ and $\mathrm{K}_{2} \mathrm{O}$ values. More geochemical analyses may confirm a more robust correlation.

The addition of this tentatively correlated Italian tephra, along with North American and Icelandic tephra deposits, makes Llyn Llech Owain a key site enabling connections to be made across vast areas (Figure 8.10).

8.1.9 Lairg A (LLO09_516) 


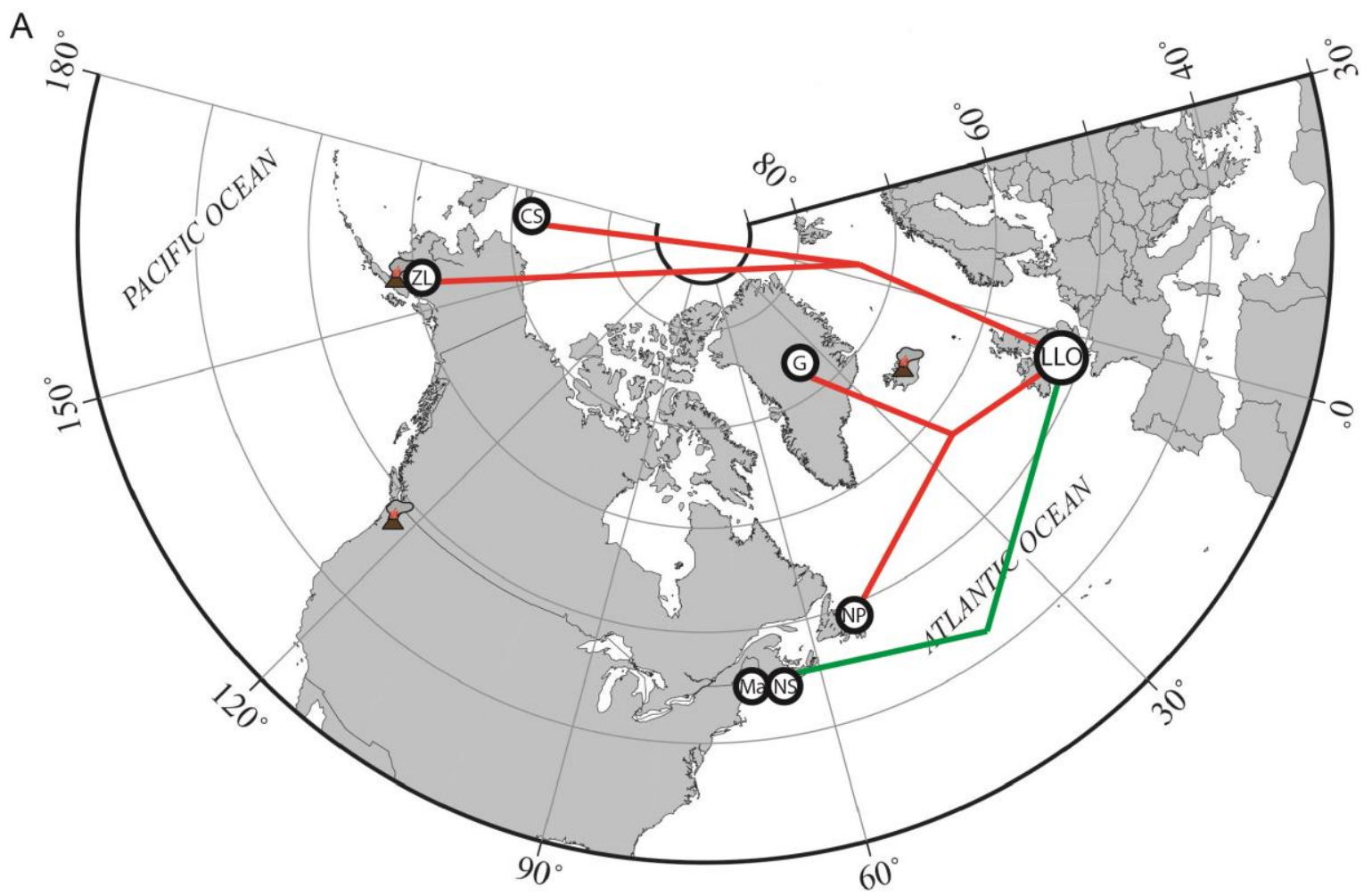

B

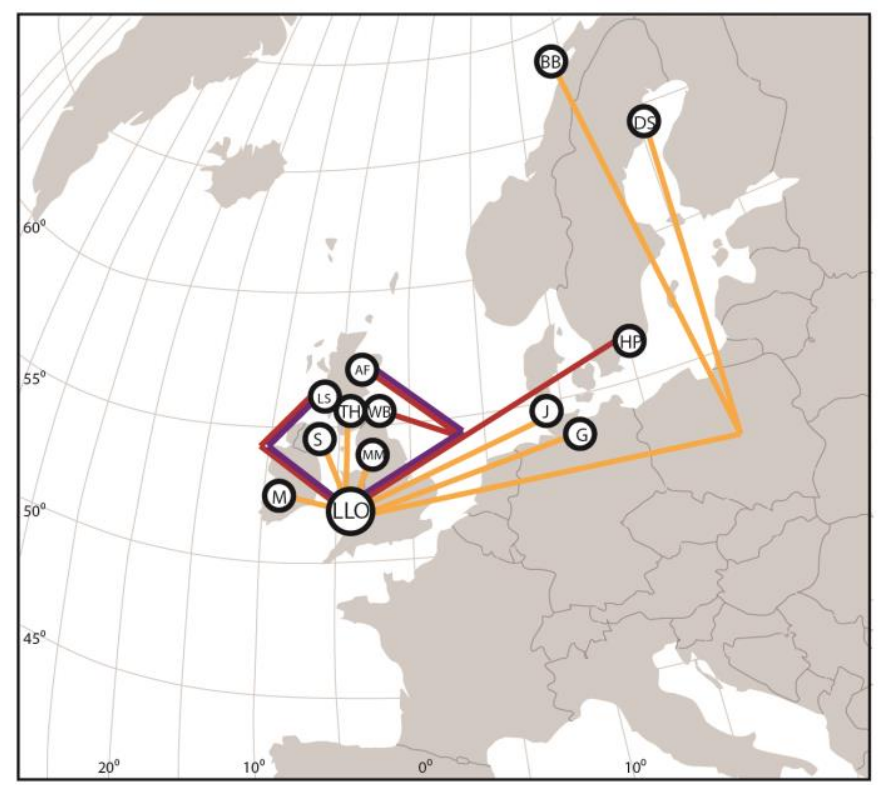

LLO - Llyn Llech Owain (this study)

Map A:

G - GRIP (Pearce et al., 2004)

CS - Chukchi Sea (Pearce et al., 2017)

ZL - Zagoskin Lake (Kaufman et al., 2012)

NP - Nordan's Pond Bog (Pyne O'Donnell et al. 2012)

Ma - Crocker Pond (Pyne O'Donnell et al., 2016) NS - Veihnot Lake and Tin-Ice Pond (Pyne O'Donnell et al., 2016)

Map B:

HP - Hässeldala Port (Davies et al. 2003; Lind et al. 2016)

BB - Borge Bog (Pilcher et al., 2005)

DS - Degerö Stormyr (Watson et al., 2016) MM - Malham Moss (Watson et al., 2016) $\mathrm{J}$ - Jardelunde (van den Bogaard and Schminckle, 2002)

G - Grambow (van den Bogaard and Schminckle, 2002)

TH - Temple Hill Moss (Langdon et al., 2003)

S - Sluggan (Hall et al., 1994)

M - Moyreen (Plunkett, 2006)

WB - Whitrig Bog (Turney et al., 1997)

AF - Abernethy Forrest (Matthews et al., 2011)

LS - Loch an t'Suidhe (Pyne O'Donnell, 2007)

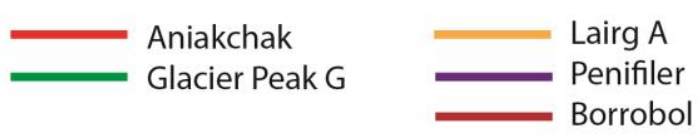

Figure 8.10 - Location maps showing some of the key sites to which Llyn Llech Owain can be correlated. Map A - through the Glacier Peak G and Aniakchak Tephras. Map B - through the Lairg A, Penifiler and Borrobol Tephras. 


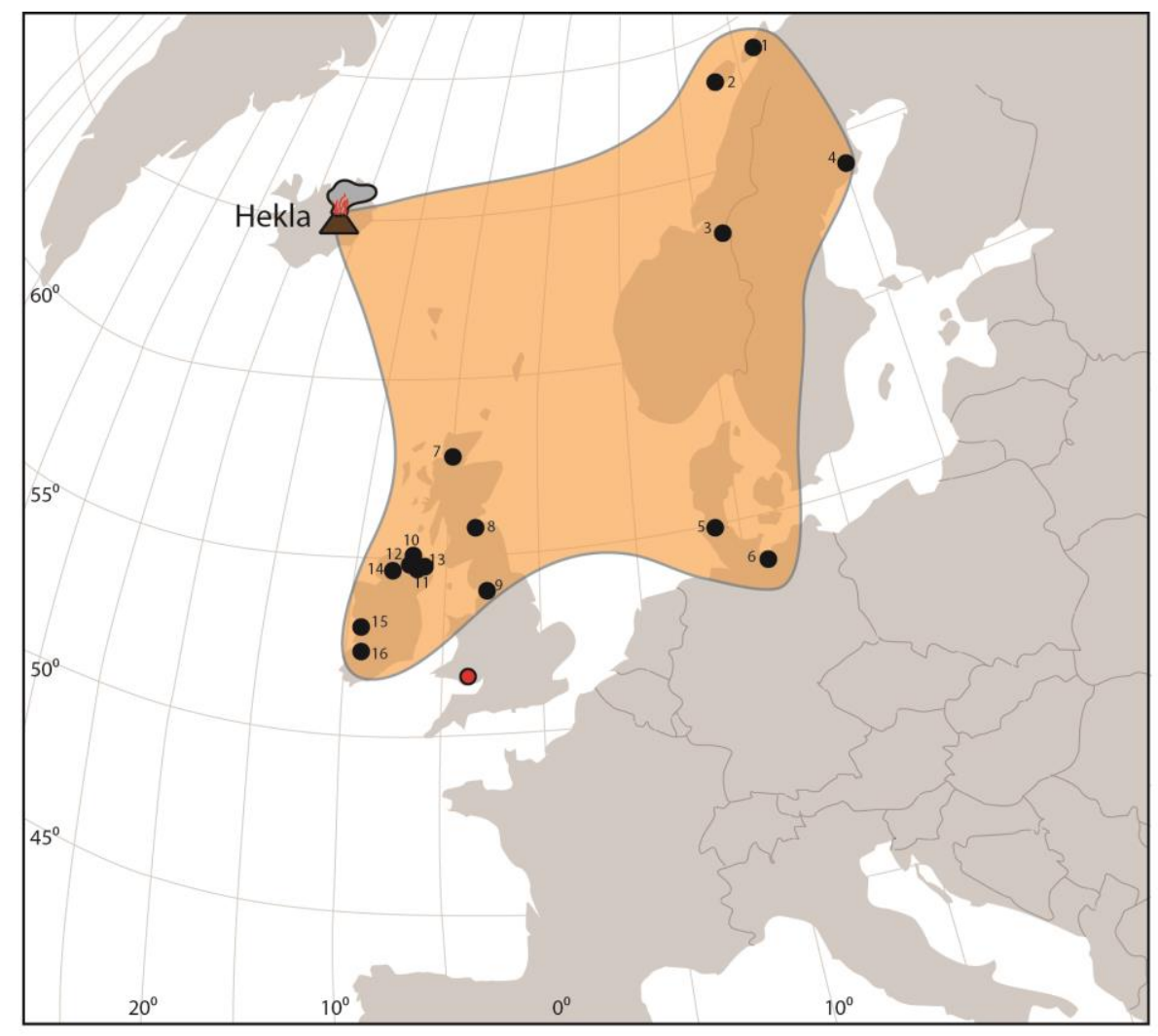

Figure 8.11 - Spatial distribution map of sites including the Lairg A tephra. (Modified from Lawson et al., 2012 and Watson et al., 2016). 1 - Sellevoll (Vorren et al., 2007), 2 - Borge (Pilcher et al., 2005), 3 Klocka Bog (Bergman et al., 2004), 4 - Degerö Stormyr (Watson et al., 2016), 5 - Jardelunde (van den Bogaard and Schminckle, 2002), 6 - Grambow (van den Bogaard and Schminckle, 2002), 7 - Lairg (Dugmore et al., 1995), 8 - Temple Hill Moss (Langdon et al., 2003), 9 - Malham Moss (Watson et al., 2016), 10 - Garry Bog (Hall et al., 1994), 11 - Fallahogy (Barber et al., 2000), 12 - Ballynahone (Pilcher et al., 1996), 13 - Sluggan (Hall et al., 1994), 14 - Claraghmore (Watson et al., 2016), 15 - An Loch Mór (Chambers et al., 2004),16 - Moyreen (Plunkett, 1999, 2006). Red dot represents the Llyn Llech Owain location. 
Tephra deposit LLO09_516 has been correlated to the Lairg A eruption which is stratigraphically located in the early-mid Holocene. More geochemical analyses than what was achieved for this study (4 analyses) would confirm a more robust correlation. The Lairg A Tephra has an age estimate of 69476852 cal yr BP (Pilcher et al., 1996). This discovery extends the spatial distribution further south (Figure 8.11) and enables correlations with other Lairg A bearing sites including Claraghmore bog and lake, Malham Moss and Degerö Stormyr (Watson et al., 2016) (Figure 8.10).

\subsubsection{Aniakchak (LLO09_297)}

Tephra deposit LLO09_297 has been tentatively correlated to the Aniakchak Tephra sourced from the caldera-forming eruption of Aniakchak from the Aleutian Range, southwest Alaska. A distinct TSC peak is observed at 297 $\mathrm{cm}$ and the geochemical composition firmly correlates with the Aniakchak Tephra, however, only two analyses were achieved. Further analyses would make the correlation more robust. This eruption is thought to have had a very widely dispersed tephra layer associated with the Aniakchak volcano with an estimated eruptive volume of $>50 \mathrm{~km}^{3}$ (Miller and Smith, 1987). Prior to this study, this tephra was already recognised for its wide spatial distribution with findings from the Prospector-Russell Col ice core, St Elias Mountains (Zdanowicz et al., 2014), sediment record from Newfoundland, eastern North America (Pyne-O'Donnell et al., 2012), a marine core on the SE Greenland shelf (Jennings et al., 2014), the Arctic ocean (Pearce et al., 2017) and from the GRIP ice core in Greenland (Pearce et al., 2004; Coulter et al., 2012) (Figure 8.10). However, no findings have been reported as far as Wales.

The age estimate for the Aniakchak Tephra is subject to debate. The age estimate based on all available radiocarbon dates, is in disagreement with the Greenland ice core age (Davies et al., 2016). However, Pearce et al., (2017) conclude that after taking account of the offsets between the IntCal13 radiocarbon timescale and the GICC05 ice-core timescale (Adolphi and 
Muscheler, 2016), a better agreement is seen and provides an age estimate of $3572 \pm 4$ cal BP for the Aniakchak Tephra. Although core 2009 has no chronological constraints to support this correlation, LLO09_297 is stratigraphically located approximately in the mid Holocene part of the sequence making the correlation to the Aniakchak tephra plausible. Along with providing a precise age estimate for this part of the Llyn Llech Owain record, this tephra provides a direct isochronous link with the Greenland icecore record, which is considered as a stratotype for the North Atlantic, where comparisons can be made between climate information during this period.

\subsubsection{Unknown tephra deposits - new eruptions?}

Out of the 21 geochemically analysed tephra deposits found within this study, eight deposits have not been correlated, or tentatively correlated, to any known eruptions and may represent new or previously undocumented eruptions. The uncorrelated deposits include LLO_767, LLO_483, LLO_467, LLO_580 pop 2 and 3, LLO09_505, LLO09_345 (pop 1, 2 and 3), LLO09_297 (2 outliers), and HÄM_T1470 and HÄM_T1456-1455 pop 2. These non-correlated tephra deposits suggests that our current understanding of widespread tephra deposits is incomplete, even for the time period as vastly studied as the Lateglacial and Holocene and demonstrates the insight gained from investigating distal locations.

All uncorrelated tephra deposits have rhyolitic compositions which are typically produced during very explosive eruptions (sub-plinian to plinian) and typified by platy and bubble-wall morphological features (Lane et al., 2015). Therefore, the shards produced during such eruptions, along with the small shard sizes that are observed for these deposits, can be transported very long distances, as illustrated by the Glacier Peak $G$ and Aniakchak Tephras found in the Llyn Llech Owain record. Reference geochemical tephra datasets and regional tephrostratigraphy review papers for Europe are reasonably well-established for enabling correlations (e.g. RESET - Bronk 
Ramsey et al., 2015; Davies et al., 2012: Lawson et al., 2012; Blockley et al., 2014), however reference datasets and tephrostratigraphy papers for volcanic regions from further afield, where some of these non-correlated deposits may have originated from, may not be as complete limiting the possibility of tephra correlations.

Tephra layer LLO_767 is positioned $1 \mathrm{~cm}$ below the Glacier Peak G tephra in the early Lateglacial Interstadial sediments which has an age estimate of 13.74-13.45 cal ka BP (Pyne O’Donnell et al., 2016). A distinct but small peak of nine shards is observed at $767 \mathrm{~cm}$ indicating that it may not be as significant as the larger TSC seen in other unknown tephra deposits found in this study (e.g. LLO09_505). With the exception of one Glacier Peak G shard in the same sample, it has a homogenous rhyolitic composition based on the analysis of 13 shards. The main population distinctly differs to the geochemical signature of the BT, based on higher FeO values, and also differs to other known Lateglacial Interstadial aged tephras including Roddans Port A and B, Dimna Ash, Laacher See Tephra and Neopolitan Yellow Ash (Figure 5.17). The geochemical data for this deposit lies within the Icelandic geochemical envelope (Figure 5.24 and 8.12) and could potentially represent an additional key tephra for the early Lateglacial Interstadial.

Population 2 (two analysed shards) and population 3 (three analysed shards) of tephra deposit LLO_580 are also not correlated to any known eruptions. The TAS plot and $\mathrm{FeO}$ vs $\mathrm{TiO}_{2}$ plot (Figure 5.19) shows a degree of similarity between population 2 and the Hovsdalur and Hässeldalen, whereas population 3 shows affinity to the Hässeldalen tephra. The $\mathrm{CaO}$ values, however, are offset with both correlatives. Both populations are positioned within the Icelandic geochemical envelope (Figure 8.12) and the geochemical similarity to the Hovsdalur and Hässeldalen Tephras supports the suggested Icelandic source for these deposits. These populations may represent new eruptions and offer additional tephras for the already highly populated tephrostratigraphy for the early Holocene. These non-correlated shards are 


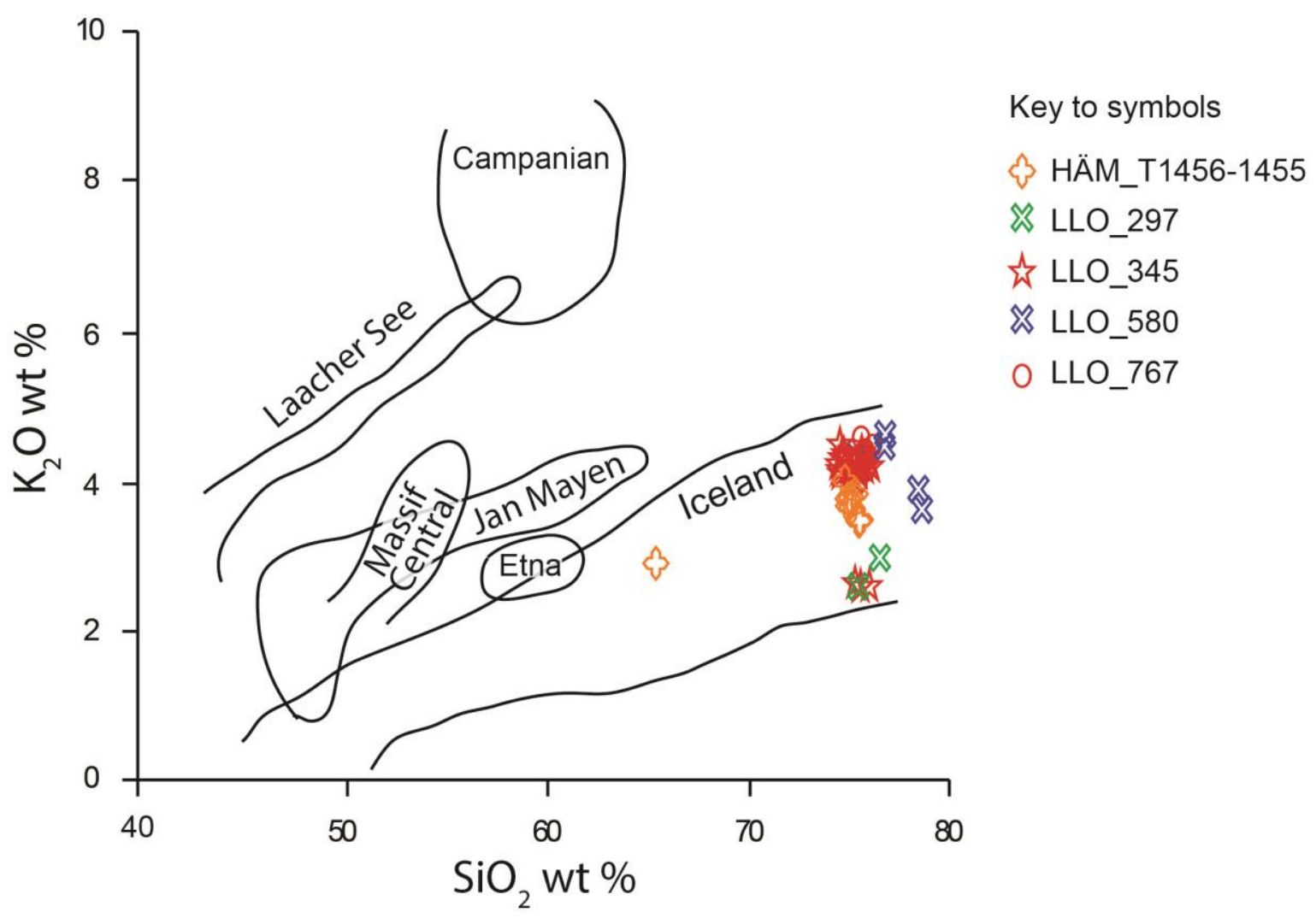

Figure 8.12 - Bivariate plot of $\mathrm{SiO}_{2} \vee \mathrm{K}_{2} \mathrm{O}$ concentrations in tephras derived from the main European ash provinces. Adapted from Davies et al., (2002) and Mortensen et al., (2005). 
part of the same deposit as the tentatively correlated Fondi di Baia tephra deposit, giving an age estimate of 9695-9525 cal BP (Smith et al., 2011).

Tephra deposit LLO09_345 consists of three chemical populations (Figure 5.22), all of which are located within the Icelandic geochemical envelope (Figure 5.24 and Figure 8.12). A reasonably large and distinct peak of 104 shards is observed at $345 \mathrm{~cm}$ in core 2009 which suggests a significant tephra deposit which, potentially may be deposited in other sites in Britain and possibly Europe. Population 1 and 3 are chemically distinct from other Icelandic tephras of similar approximate ages, including the Lairg $A$ and $B$, Hoy, Microlite, Hekla 3,4,5, BMR-190 and Kebister tephras. This suggests both populations may represent two unknown but closely timed eruptions.

Population 2 of LLO09_345 and an outlier shard from LLO09_297 shows affinity to the early Holocene Askja-S tephra. However, LLO09_345 is stratigraphically located in the mid Holocene part of the Llyn Llech Owain sequence which rejects a correlation with the Askja-S Tephra. Until recently, there have been no reported findings of other younger Askja-S type tephras found, however Guơmundsdóttir et al., (2016) have reported a younger tephra - the Askja L- dated to approximately 9400 cal BP (Striberger et al., 2012).The Askja-L tephra has an identical chemical composition to Askja-S, however the age estimate differs to the approximate stratigraphic position of LLO09_345 which lies more towards the mid Holocene ( 5,000 years BP). This discovery may indicate the Askja volcano to be more active during this period and that population 2 of tephra layer LLO09_345 may represent a new or previously unknown Askja eruption.

Tephra layers LLO_483, LLO_468 and LLO09_505 show affinity to the Icelandic 1362 Öræfajökull eruption based on chemical composition alone, however they are stratigraphically positioned in the early-mid Holocene. A distinct peak and reasonably high TSC is observed for all three deposits (44, 46 and 63 shards per $0.5 \mathrm{~g}$ ) (Figure 5.13) suggesting significant tephra deposits which may be found at other sites. As yet, there is no evidence for older Öræfajökull eruptions of early-mid Holocene age recorded in the literature, which indicates LLO_483, LLO_468 and LLO09_505 to be newly 
identified eruptions. Tephra deposit LLO09_505 was identified in core sequence 2009 and potentially correlates to either LLO_483 or LLO_468 found in the 2013 core sequence. LLO09_505 may correlate to either deposit from the 2013 core. These findings have provided new insights to the eruptive history of the Öræfajökull volcano which indicates the volcano was more active than previously thought.

Tephra glass shards analysed from HÄM_T1470 are chemically indistinguishable from HÄM_T1494 (Vedde Ash) (Figure 4.9), $23 \mathrm{~cm}$ below, and glass shards are found in all samples between these deposits. HÄM_T1470 has a relatively diffuse peak and a TSC of 12 at $1470 \mathrm{~cm}$. The deposit occurs above the onset of the Holocene in the Hämelsee sequence and thus careful consideration is required to ensure that this does not represent any reworking into the basin.

Two stratigraphically separate tephra horizons with Vedde Ash-like chemistry are present in the Abernethy Forest record (Matthews et al., 2011). AF591 (early Younger Dryas) has been attributed to the widely distributed Vedde Ash, and AF555 (late Younger Dryas) is considered to represent a separate eruption (Abernethy Tephra). Two separate tephra horizons with compositions matching the rhyolitic phase of the Vedde Ash are also present at Muir Park Reservoir, Loch Etteridge, and Lochan an Druim in Scotland (MacLeod et al., 2015), however the stratigraphic position of the younger tephra deposit correlated to AF555 is inconsistent, as it is seen both just above and just below the Younger Dryas to Holocene boundary. In assessing whether HÄM_T1470 could represent an occurrence of another, separate, Vedde Ash-like tephra deposit ( AF555), we need to consider the profile of tephra distribution in the core and the possible origin of the tephra shards found above HÄM_T1494 (correlated to the Vedde Ash) before the next sample where no shards were found. In Hämelsee, a reduction in TSC is seen between HÄM_T1470 and HÄM_T1494 which could indicate that the small peak at $1470 \mathrm{~cm}$ was generated by the primary deposition of a second, compositionally indistinct, tephra deposit. If so, HÄM_T1470 could well be 
correlated to the Abernethy Tephra (11,462 \pm 122 cal BP; Bronk Ramsey et al., 2015). However, as described above, all small tephra peaks analysed between 1475 -1449 cm contain shards of Vedde Ash composition, originating from the Katla volcanic system. This either indicates that the Katla volcano was very active during this period with several eruptions occurring or, a more plausible reason, it indicates evidence of re-working by bioturbation, turbidity and/or delayed in-washing of material from the catchment. Kleinmann et al., (2001) report that Hämelsee underwent rapid lake level variations during the early Holocene, which could easily have led to sediment reworking.

The reoccurrence of Vedde Ash chemistry shards throughout the early Holocene is also reported from Orkney, Scotland (Timms et al., 2016), where a high TSC peak for the Vedde Ash is also present. This may be due to secondary deposition of the Vedde Ash where shards were isolated or trapped in the surrounding catchment. Two glass shards that are indistinguishable to HÄM_T1445-1444 have also been found in HÄM_T1451 further suggesting these depths is subject to re-working. The combination of the low TSC of HÄM_T1470, its indistinct composition, its position in an interval that is characterised by relatively abundant shards of reworked Vedde Ash material (HÄM_T1494) and the many eruptions of Vedde Ash-like tephra from Katla reported in the literature (Lane et al., 2012; MacLeod et al., 2015), means that we are unable to prove a firm correlation of HÄM_T1470 to a specific eruption event and believe, most likely, that it represents reworking of Vedde Ash material.

Population 2 from tephra deposit HÄM_T1456-1455 is also considered a non-correlated tephra, of Icelandic origin (Figure 8.12), after comparisons with similarly aged tephras including Hässeldalen, Hovsdalur, Fosen, L-274, Suðuroy, An Druim, Breakish, Høvdarhagi, Abernethy, Skopun and Ashik. This deposit is stratigraphically positioned in the early Holocene in the Hämelsee sequence and $5 \mathrm{~cm}$ below the tentatively correlated $\sim 11 \mathrm{ka} \mathrm{BP}$ Ulmener Maar Tephra (HÄM_T1451). This population could be an additional isochronous marker for the early Holocene. 
Caution must be taken when interpreting some of these tephra deposits, especially LLO_580, population 2 and 3 of LLO09_345 and the outliers in LLO_297. One could argue that they are not robust enough to be valuable because of insufficient amount of chemical analyses due to the low concentration of shards that were extracted for analysis (e.g. LLO09_297 outliers). Heterogeneous chemical compositions also indicate tephra layers that are not robust (e.g. LLO09_345), however these could be reflecting several phases of an eruption or several closely spaced eruptions being deposited in close succession.

The most significant and perhaps has the biggest potential to be valuable for future work out of the unknown deposits found with-in this study may be LLO_483, LLO_468 and LLO09_505. Distinct peaks and reasonably high TSC (44, 46 and 63 shards per $0.5 \mathrm{~g}$ ) are observed for the three deposits in addition to homogenous geochemical composition, showing affinity to the Icelandic 1362 Öræfajökull eruption. Nine-teen geochemical analyses was achieved for LLO_483 making it a robust and homogenous data set for future comparisons.

8.1.12 Within site and inter-site differences: tephra deposition and taphonomic processes

There are significant inter and intra-site differences observed in the tephra findings within this study. These include:

- Marked differences in tephra deposit preservation between sites in close proximity to each other

- Variations in shard concentrations between cores sampled from the same site.

- Lateral variations in shard concentrations for the same deposit found within the same core. 
The absence of specific tephras between the Welsh sites, of close proximity $(<4 \mathrm{~km})$, are striking with a number of deposits found in the Llyn Llech Owain record, none found in Cors Carmel and only one found in Pant-y-Llyn, albeit only the early Holocene part was searched at Pant-y-Llyn. One would potentially expect to find a similar amount of tephra deposit in each sequence, perhaps with slightly differing TSCs, however this was not the case. Tephra shard presence was recorded in the Cors Carmel sequence, but TSC were too low ( 2 shards per $0.5 \mathrm{~g}$ ) to allow shard extraction for geochemical analysis. Not even the relatively high TSC of tephra layer LLO_804 from the Llyn Llech Owain sequence was present in the Cors Carmel record. Another observation made between the Welsh sites is the presence of the Askja-S tephra in the Pant-y-Llyn sequence but not in the Llyn Llech Owain or Cors Carmel sequence. PLL_500 also has a relatively high shard concentration (72 shards per $0.5 \mathrm{~g}$ ) suggesting the possibility of it being preserved in the Llyn Llech Owain or Cors Carmel sequence. A peak of 24 clear shards was initially found in the early Holocene part of the Llyn Llech Owain sequence at 670-665 cm (low resolution sample) which potentially could have been the Askja-S Tephra based on stratigraphic position. High resolution $(1 \mathrm{~cm})$ sampling, however, revealed no peak with $<3$ shards present. Three unsuccessful high resolution sampling attempts were made to try and isolate a peak. Another striking observation made from the Llyn Llech Owain and Cors Carmel records is the absence of the most widely dispersed tephra deposit found across north-west Europe; the Vedde Ash (Lane et al., 2012).

Differences are also seen between the TSC of the tephra deposits observed in core $\mathrm{H} 1$ and $\mathrm{H} 2$ in Lake Hämelsee. Comparing both the low and high resolution samples shown in Figure 4.5, TSC are consistently higher in $\mathrm{H} 2$ than in $\mathrm{H} 1$. Both cores were retrieved from the middle of the lake and within $10 \mathrm{~m}$ of each other. These results show that TSC are not constant over the profile of the lake. Even within 10 horizontal meters, a significant difference can be seen. This is exemplified by a difference of $\sim 300 \mu \mathrm{m}$ in thickness of the LST tephra in these latest cores, to those studied by Merkt and Müller (1999). 
There are a number of possible explanations for the differences noted above. These include taphonomic processes such as deposition onto an uneven lake bed at the time of tephra deposition and patchy distribution on the lake bed due to within-basin focussing and redistribution of tephra shards. Such variation in tephra distribution and thickness has been observed before. For example, differences of $>20 \mathrm{~cm}$ in the thickness of a visible tephra have been observed within cores taken from different areas of Lake Kråkenes (Mangerud et al., 1984). Such differences are also seen at Loch Ashik where the visible Vedde Ash layer found at one core may not be visible at a neighbouring core retrieved $\sim 10 \mathrm{~m}$ away (Davies et al., 2001). Many factors, such as the depth and size of the lake and its susceptibility to wind, sedimentation rates and catchment inlets (e.g. Boygle, 1999; Pyne O'Donnell et al., 2011) may cause patchy or uneven tephra deposition within lake systems. The cause of remobilised tephra shards (or any small particles) may have been triggered by wind-driven currents at the sediment water interface (Mackay et al., 2012), although there are many influences for this process including depth and size of the lake, scale of inputs, sedimentation rate and its susceptibility to high winds. Additionally, small topographic variations such as hummocks and intervening hollows on the catchment bed may have caused patchy distribution of tephra layers (Downing \& Rath, 1988). Watson et al., (2016) discuss a comparison of tephra presence and TSC between bogs and lakes of close proximity. Evidence of patchy distribution and internal re-working is demonstrated as they detected two specific tephras in the peat bog sequence that had equal TSCs suggesting two eruptions of a similar magnitude. However, in the nearby lake, the same two tephras were detected but one had TSCs 30 times higher suggesting one tephra had been focussed laterally to the coring location. Evidence of withinsite variations is also seen in peatlands where suggested causes include uneven deposition from the atmosphere and lateral movement of tephra over the surface of the peatland prior to its incorporation in the peat (Watson et al., 2015).

Chance may be a decisive factor, with regards to the coring position, for finding tephra layers in sequences from lakes or peat bogs (especially 
cryptotephras with low shard concentrations). The core could have been extracted from a location where several tephra layers had been preserved due to within basin focussing, however, a core containing no preserved tephra layers, such as the Cors Carmel sequence in this study, could easily have been extracted only a few lateral meters away. When TSC's are low, within-lake processes can favour tephra detection, by focussing shards and thus improving the detection limit for tephra layers (Watson et al., 2016), providing luck is on your side and the coring location lies on the spot where the tephras had been focussed.

Preferential deposition of some tephra horizons close to catchment inlets is seen in Scottish lakes (Pyne O'Donnell et al., 2011). No inlets are present at Llyn Llech Owain, however, the core location is close to the outflowing stream (Figure 5.1), which possibly could favour or decrease the chances of preserving tephra layers. Early Holocene tephra layers are also known to have been preserved in greater shard concentrations in the deepest central part of lakes, which is hypothesised to be due to a more intensified central focussing associated with early Holocene basin infilling (Pyne O'Donnell et al., 2011). The core at Llyn Llech Owain was extracted from the south west rim of the lake rather than the central area (Figure 5.1). Based on the findings of Pyne O'Donnell, (2011), a higher number of early Holocene tephra layers, and in greater shard concentrations, could possibly have been found if the Llyn Llech Owain core was extracted from the centre of the lake.

The proximity of the two cores collected from Hämelsee would suggest that within-basin particle redistribution was in some way responsible for the difference in TSC. The implications for cryptotephra studies are important where no single core may be perfectly representative of the full sediment record at a site, therefore careful consideration of coring location is important. The lake Hämelsee study, where two parallel sequences can be investigated, increase the chances of recording a complete sequence and provide detailed valuable insights into the variability of sedimentation within a lake basin. 


\subsubsection{Conclusion}

Welsh sites were previously thought to be a barren of tephra deposits of any origin, and perhaps assumed to be out of reach of ash dispersal. Until recently, very few Icelandic tephras have been found south of $53^{\circ}$ latitude and east of $6^{\circ}$ longitude (Figure 2.4) and our new findings in this study indicate that this is not a reflection of the dominance of more northerly dispersal trajectories (see also recent findings outlined in Watson et al., 2017). In the Llyn Llech Owain record, twelve tephra deposits have been found with six of those tentatively correlated, or tentatively correlated, to known eruptions: Borrobol, Penifiler, Glacier Peak G, Fondi di Baia, Lairg A and Aniakchak. These findings mark Llyn Llech Owain as a key site with tephra deposits originating from three different volcanic regions (North America, Italy and Iceland)(Figure 8.13) allowing site correlations over a vast area (Figure 8.10). The Pant-y-Llyn record contains the Icelandic Askja-S Tephra allowing correlations with other Askja-S Tephra bearing sites (Figure 8.7). No tephra deposits were found in the Cors Carmel record.

In the Lake Hämelsee record, 8 tephra deposits have been found, with four correlated to known eruptions: Laacher See Tephra, Vedde Ash, Askja-S, Saksunarvatn Ash. The new tephrostratigraphical record, within a partially varved Lateglacial sediment record, highlights the importance of Lake Hämelsee as a key site within the European tephra lattice (Figure 8.9). 


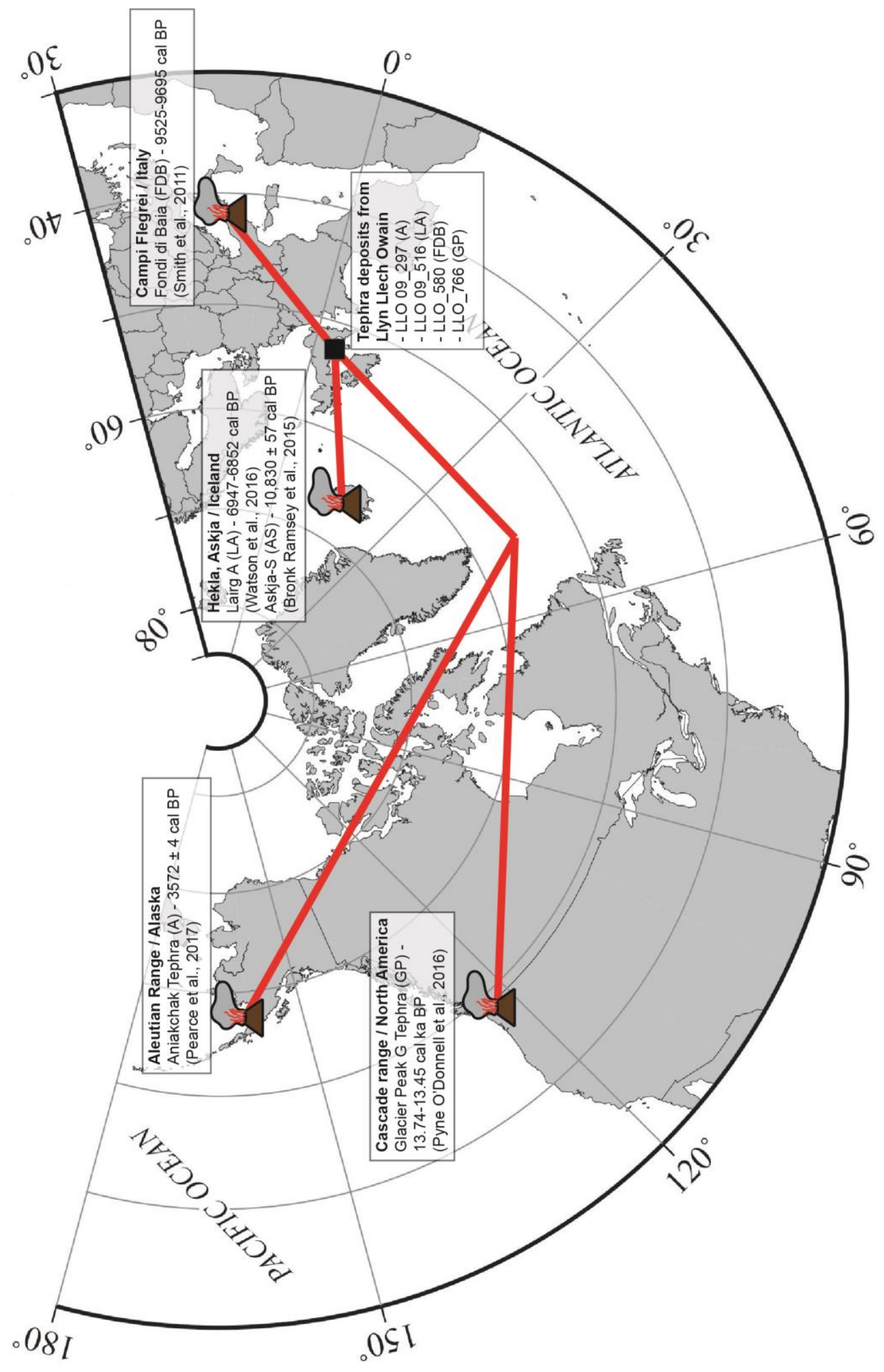

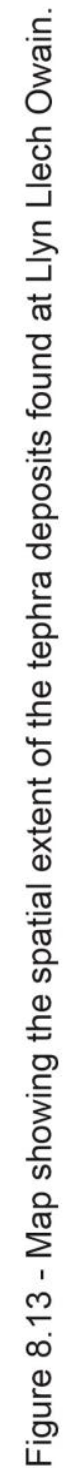




\subsection{Using correlated tephra deposits to constrain past environmental changes}

When tephra deposits can be correlated between sites, the proxy records can be independently synchronised allowing an investigation into the timing and environmental responses to climatic changes in widely separated localities. The tephra discoveries in this study demonstrate the potential of correlating sites across Europe and also North America by utilising the fartravelled Aniakchak and Glacier Peak tephra deposits as well as key European deposits such as the Borrobol, Laacher See Tephra, Vedde Ash, Askja-S, Saksunarvatn, Fondi di Baia and Lairg A. Although quantitative proxy reconstructions are not available for all records, the examples presented here outline the future potential of employing these isochrons. Robust age-models are not available for the sites investigated in this study so comparisons are made against depth for the Llyn Llech Owain, Pant-y-Llyn and Hämelsee records.

\subsubsection{Borrobol and Penifiler Tephras (LLO_782 and LLO_778)}

Before comparing sites using the Borrobol and Penifiler tephras, it must be emphasised that deposits LLO_782 and LLO_778 in the Llyn Llech Owain record are only tentatively correlated to these tephras (see discussion in section 5.6.2 and 8.1.1). If a confident correlation can be made to either the Borrobol and/or Penifler, the deposits could be valuable age markers to constrain the interstadial onset. Both tephras, however, are plagued by complexities and uncertainties. The Borrobol Tephra is found in a number of sites in Scotland and two in Sweden but only a few sequences are accompanied by quantitative proxy records. These include the chironomidderived air temperature records from Whitrig Bog (Brooks \& Birks, 2000) and 
Abernethy Forest (Matthews et al., 2011), both of which are shown in Figure 8.14. The Lateglacial Interstadial onset is only clearly defined in the Whitrig Bog record by the sharp rise in the chironomid-inferred temperature record. This increase in temperature is not captured in the Abernethy Forest record. The remaining records that preserve the BT or PT are largely limited to LOI data only and assigning the interstadial onset based on these records may by plagued by site-specific lags in the start of organic sedimentation and climatic warming.

Nevertheless, a selection of proxy records including pollen results from Hässeldala port (Davies et al., 2004), LOI curves from Skallahult (Davies et al., 2003), Loch Etteridge (Albert, 2007) and Loch an t'Suidhe (Pyne O'Donnell, 2007) are shown in Figure 8.14 as an illustrative example of the potential of employing BT and PT to constrain the interstadial.

At Whitrig Bog the BT is stratigraphically located $18 \mathrm{~cm}$ above the chironomid-derived interstadial onset but prior to the short-lived decrease in temperature which is interpreted by Brooks \& Birks, (2000) to be linked with Gl-1d cold phase seen in the Greenland ice-core record. The BT in this record is positioned within the warmest phase of the interstadial. In Abernethy Forest, however, it falls just below the warmest reconstructed temperatures, and there is no clearly defined interstadial onset which may be due to coring difficulties or the interstadial onset is absent at the site. Abernethy Forest also preserves, what is believed to be the PT and this tephra falls within a short-lived cold period which is interpreted by Matthews et al., (2011) to relate to the Older Dryas and the Gl-1d in Greenland. This is consistent with pollen stratigraphic data from Hässeldala port and the tephra in both Swedish sites are correlated to the PT (Davies et al., 2004) (Figure 8.14).

At Llyn Llech Owain, the proposed Borrobol Tephra (LLO_782) is positioned $4 \mathrm{~cm}$ below the significant rise in \%C values at $778 \mathrm{~cm}$. Diatoms are absent within this interval and first appear at $4 \mathrm{~cm}$ above the LLO_782 tephra deposit indicating the beginning of more favourable conditions for diatom productivity. The position of BT, prior to the initial rise in LOI values, in the 


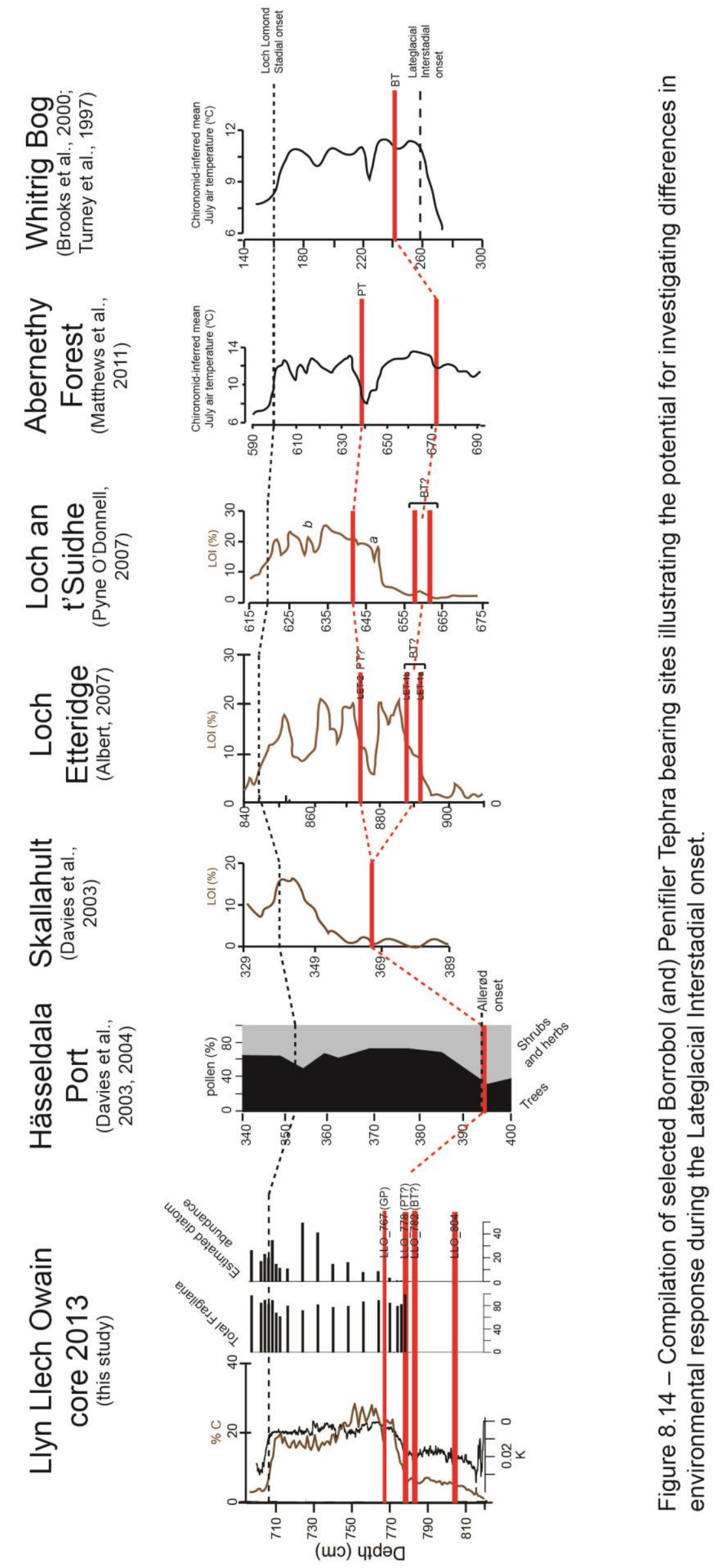


Loch an t'Suidhe record is consistent with that observed at LLO. At Loch Etteridge however, the BT is comprised of two supposedly separate tephra deposits $4 \mathrm{~cm}$ apart, both of which are positioned directly on the transition from low to higher LOI values. Due to the uncertainties surrounding the BT, it is difficult to unpick the significance of the differing stratigraphic positions observed between the records presented in Figure 8.14. The suggested climatic lag between the Scottish sites (i.e. peak warmth at Whitrig Bog versus pre-interstadial warming at Loch an t'Suidhe) is an unlikely scenario. Defining the start of the interstadial onset at LLO is difficult with just \%C data as there may be a lag between climatic amelioration and the beginning of organic sedimentation. It is also uncertain whether the suggested tephra correlations are correct and whether the BT at Loch an t'Suidhe and Loch Etteridge are truly separate events or a product of post-depositional working.

The PT adds complexity to this time-period. For the published sites, however, the position of the PT is consistent and seems to fall within the Older Dryas or Gl-1d event (see Hässeldala port, Loch Etteridge, Abernethy Forest). Given the \%C record for Llyn Llech Owain, the tentative correlation of LLO_778 to PT may well be incorrect.

Further work to develop chironomid-inferred temperature records (or another form of temperature record) for more BT and PT bearing sites is required to provide a more valuable insight into the regional development of the interstadial onset. The stratigraphic complexities associated with the BT and PT also needs to be resolved to establish correlations during this timeinterval. If these uncertainties can be resolved then the potential of employing the BT and PT as tie-points to constrain the warming at the start of the interstadial and the short-lived Older Dryas event is illustrated in Figure 8.14.

\subsubsection{Glacier Peak G Tephra (LLO_766)}

The Glacier Peak Tephra is a trans-continental deposit, and as a result of this study can be employed as a tie-point to other sites, including Thin-Ice Pond 
and Veinot Lake in Nova Scotia and Crocker Pond in Maine, east North America (Pyne O'Donnell et al., 2016) (Figure 8.15). Very few quantitative proxy records are available for these sites but for illustrative purposes the LOI records are compared with the $\% \mathrm{C}$ record from Llyn Llech Owain. Given the interstadial onset, as defined by the LOI curves (Pyne O'Donnell et al., 2016), differences are observed in the stratigraphic positions of the tephra. In Thin-Ice Pond and Veinot Lake, the tephra is positioned towards the latter part of the interstadial, whereas in Crocker Pond and Llyn Llech Owain the tephra is positioned more towards the early interstadial, closer to the first rise in LOI and \%C. The stratigraphic position of Glacier Peak in Llyn Llech Owain is positioned $10 \mathrm{~cm}$ above the initial rise in \%C values. In Crocker Pond this tephra is observed after a short-lived increase in LOI, however, this fluctuation is not observed in other sites and may reflect a site specific feature. It is possible that the differences in stratigraphic position of the Glacier Peak relative to organic content tephra reflects contrasting sedimentation rates and site specific processes. Further insight may be gained by developing quantitative proxy estimates of changes during the interstadial at these sites. Chironomid based temperature records, to test such inter-continental climatic differences would be particularly valuable. Here though, the discovery of the tentatively correlated Borrobol Tephra in Llyn Llech Owain, in addition to the Glacier Peak, illustrates the potential of employing tephra deposits to explore the duration and timing of the interstadial onset at Llyn Llech Owain as well as in North America.

\subsubsection{Laacher See Tephra (LST) (HÄM_T1558)}

The Laacher See Tephra is stratigraphically positioned in the Allerød and dated to $12,880 \pm 40$ varve years (Brauer et al., 1999) in Lake Meerfelder Maar and to $12937 \pm 23$ cal BP in a multi-site Bayesian-based radiocarbon age model by Bronk Ramsey et al., (2015). It has been found in several sites in continental Europe, especially in Germany, Switzerland and some sites in Poland. The LST is considered as a key tephra isochron during the period 

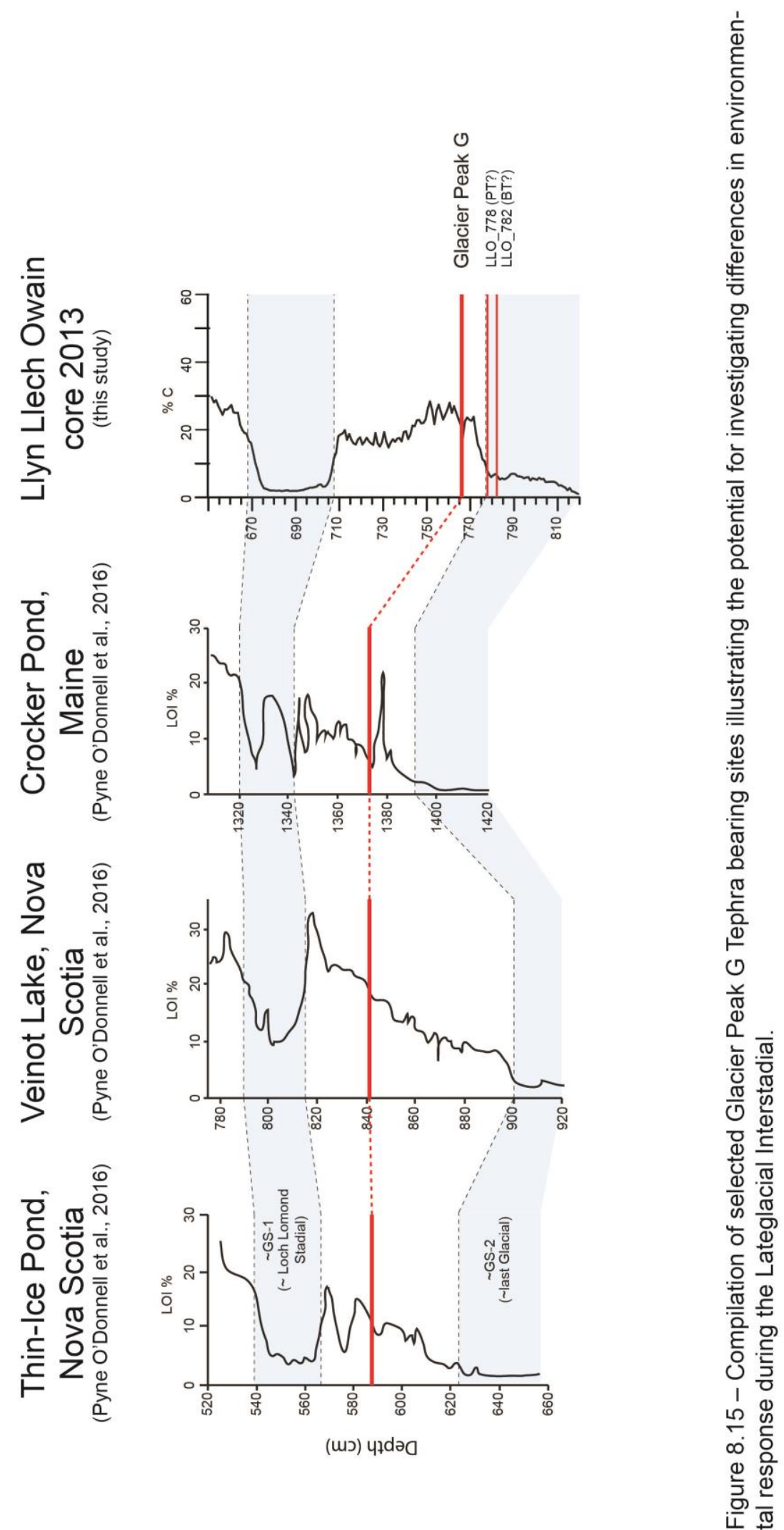

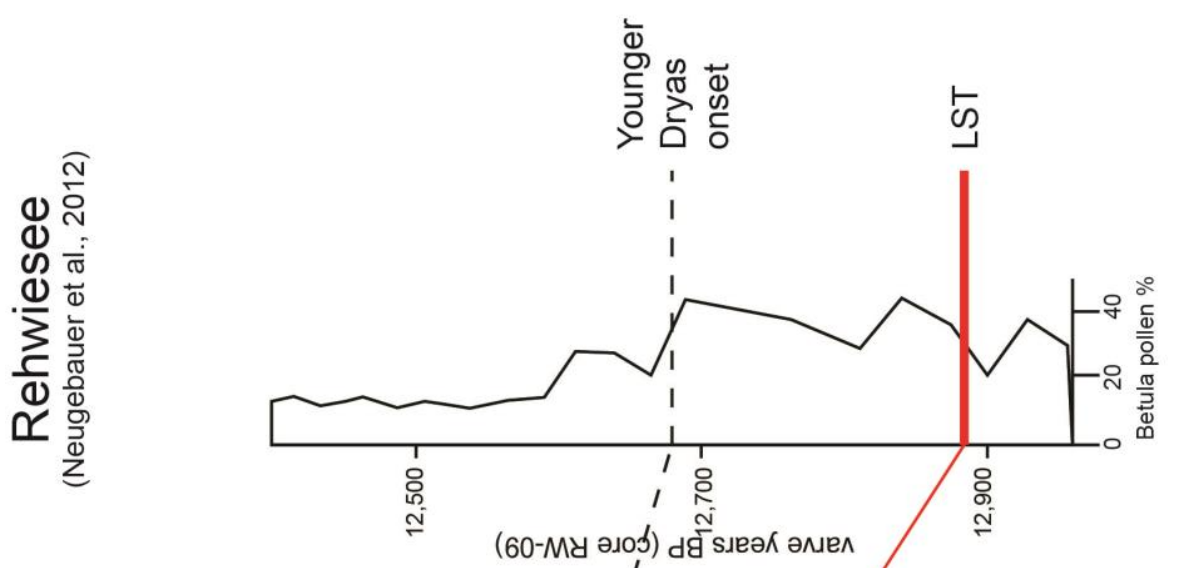

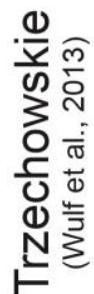

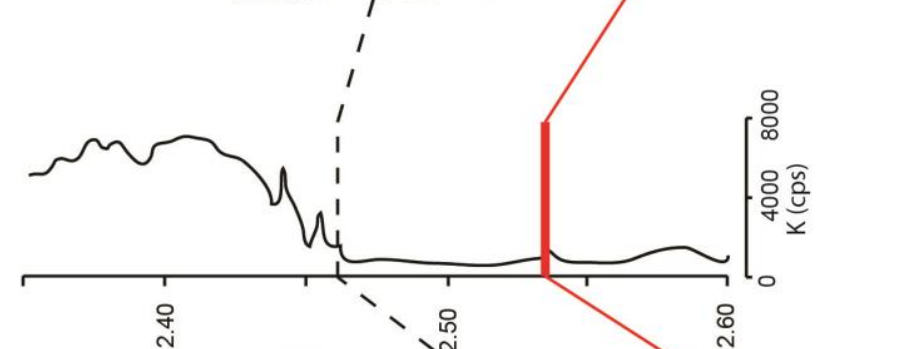

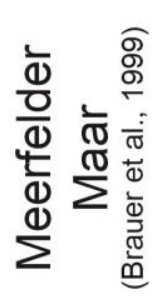

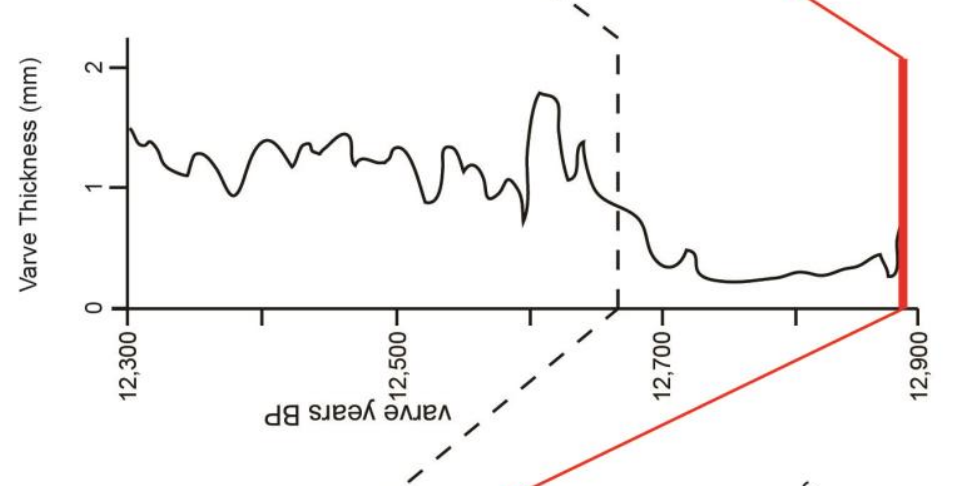

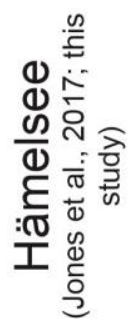

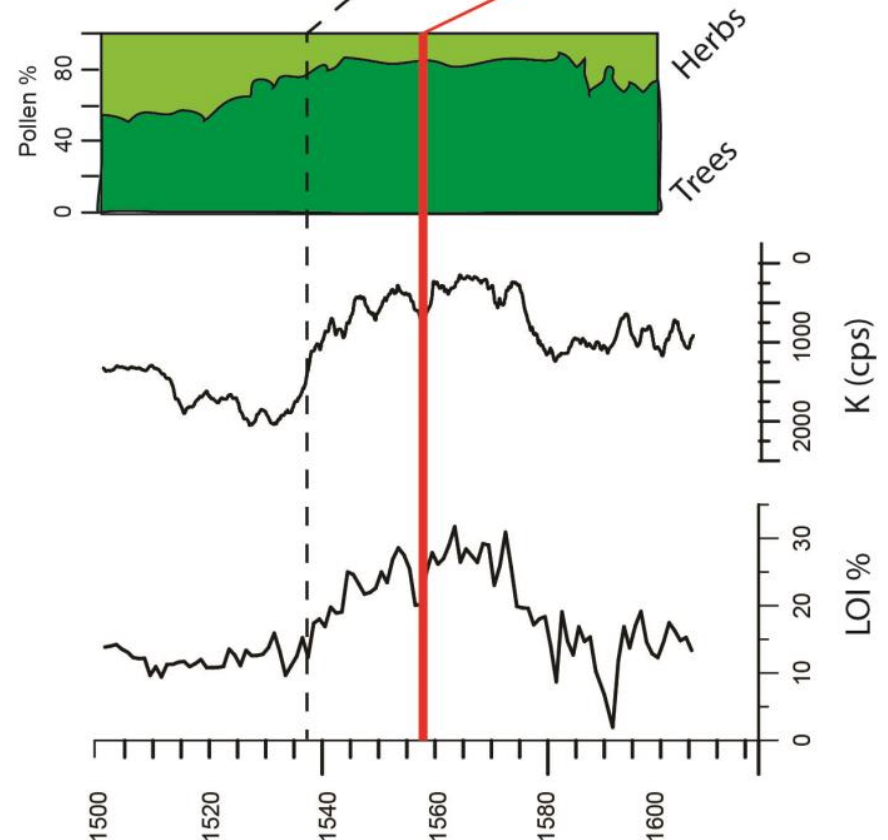

(u૭) पłdəव

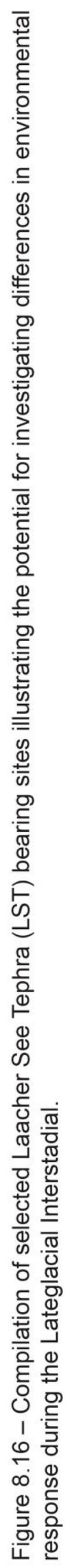


spanning late Allerød to the Younger Dryas onset. Figure 8.16 shows proxy records for selected LST bearing sites including Meerfelder Maar (Brauer et al., 1999), Trzechowskie (Wulf et al., 2013) and Rehwiesee (Neugebauer et al., 2012) as well as the Hämelsee record investigated in this study. In the Hämelsee record, the LST is positioned at $1558 \mathrm{~cm}$ depth and $21 \mathrm{~cm}$ prior to the Younger Dryas onset at $1537 \mathrm{~cm}$ where slightly decreased LOI values are observed suggesting less organic matter accumulating into the lake. Increasing K (XRF) values are also observed at $1537 \mathrm{~cm}$ indicating an increase in minerogenic in-wash into the lake. A change is also observed in the pollen record where herbaceous species replace trees. In the Meerfelder Maar record the LST is dated to $12,880 \pm 40$ varve years (Brauer et al., 1999) and positioned 200 years prior to the increase in varve thickness and the interpreted Younger Dryas onset. At Trzechowskie, the LST is positioned at $12.538 \mathrm{~m}$ during low $\mathrm{K}$ (XRF) values indicating low minerogenic in-wash and interpreted as the Allerød period and $0.08 \mathrm{~m}$, which corresponds also to ca. 200 years, prior to the increase in $\mathrm{K}$ (XRF) values which is interpreted as the Younger Dryas onset (Wulf et al., 2013). In the Rehwiesee record the LST is positioned ca. 200 years prior to the decrease in Betula pollen abundance which is interpreted at the Younger Dryas onset (Neugebauer et al., 2012). Of particular interest with regards to the sites shown in Figure 8.16, including Lake Hämelsee, is that the sediment where the LST has been identified is varved. The LST and these annually-resolved sediment records allow a floating chronology to be constructed giving insight into the relative age of the tephra and a major climatic transition (e.g. Wulf et al.,2013).

\subsubsection{Vedde Ash (HÄM_T1494)}

The Vedde Ash is one of the most widespread Icelandic tephra deposit with discoveries as far as west Russia and Slovenia (Lane et al., 2012). It is dated to $12,121 \pm 114$ b2k in the Greenland ice cores (Mortensen et al., 2005; Rasmussen et al., 2006), to 12,140 \pm 43 varve yr BP in Meerfelder Maar (Lane et al., 2015) and to 12,023 \pm 43 cal BP by Bronk Ramsey et al., (2015) 
and associated with the Younger Dryas Stadial or GS-1 in Greenland. Figure 8.17 shows proxy records for selected Vedde Ash bearing sites including Meerfelder Maar (Lane et al., 2013), Kråkenes (Mangerud et al., 1984; Bakke et al., 2009), Abernethy Forest (Matthews et al., 2011) and the GRIP ice-core which represents the event stratotype for the North Atlantic (Mortensen et al., 2005; Rasmussen et al., 2014).

In the Hämelsee record the Vedde Ash position is at $1494 \mathrm{~cm}$ depth and is located during the latter part of the low LOI values, interpreted as the Younger Dryas Stadial. It is positioned $19 \mathrm{~cm}$ prior to the rise in LOI values which is interpreted as the Holocene onset. The $\mathrm{K}(\mathrm{XRF})$ record suggests a two-part Younger Dryas with high values ( 1300-2000 cps) between 1513$1537 \mathrm{~cm}$ and lower values ( 1100-1300 cps) during the latter part between $1513-1485 \mathrm{~cm}$. The first phase suggests higher amounts of minerogenic inwash and could be interpreted as colder climatic conditions and the latter part with less minerogenic in-wash may be suggesting warmer conditions. The Vedde Ash is deposited during the middle part of the latter phase of the Younger Dryas in the Hämelsee record. Variability during the Younger Dryas Stadial has also been observed in other sites including Meerfelder Maar (Lane et al., 2013) and Kråkenes (Bakke et al., 2009) as shown in Figure 8.17. Both records show two parts which is observed by the $\mathrm{Ti}$ (XRF) values with higher values seen from 12,250 years BP and below the Vedde Ash position at Meerfelder Maar but from 12,070 years BP and above the Vedde Ash position at Kråkenes. By utilising the Vedde Ash, Lane et al., (2013) suggests that the changes observed in both sites are time-transgressive. In the Abernethy Forest record, the chironomid-based temperature record clearly shows the Loch Lomond Stadial ( Younger Dryas) with lower inferred temperatures between 600 and $550 \mathrm{~cm}$. The position of the Vedde Ash however, seems to be located during the early part of the Stadial, approximately $10 \mathrm{~cm}$ above the Stadial onset. In the GRIP ice-core record the Vedde Ash is positioned more towards the latter part of GS-1 ( Younger Dryas). 

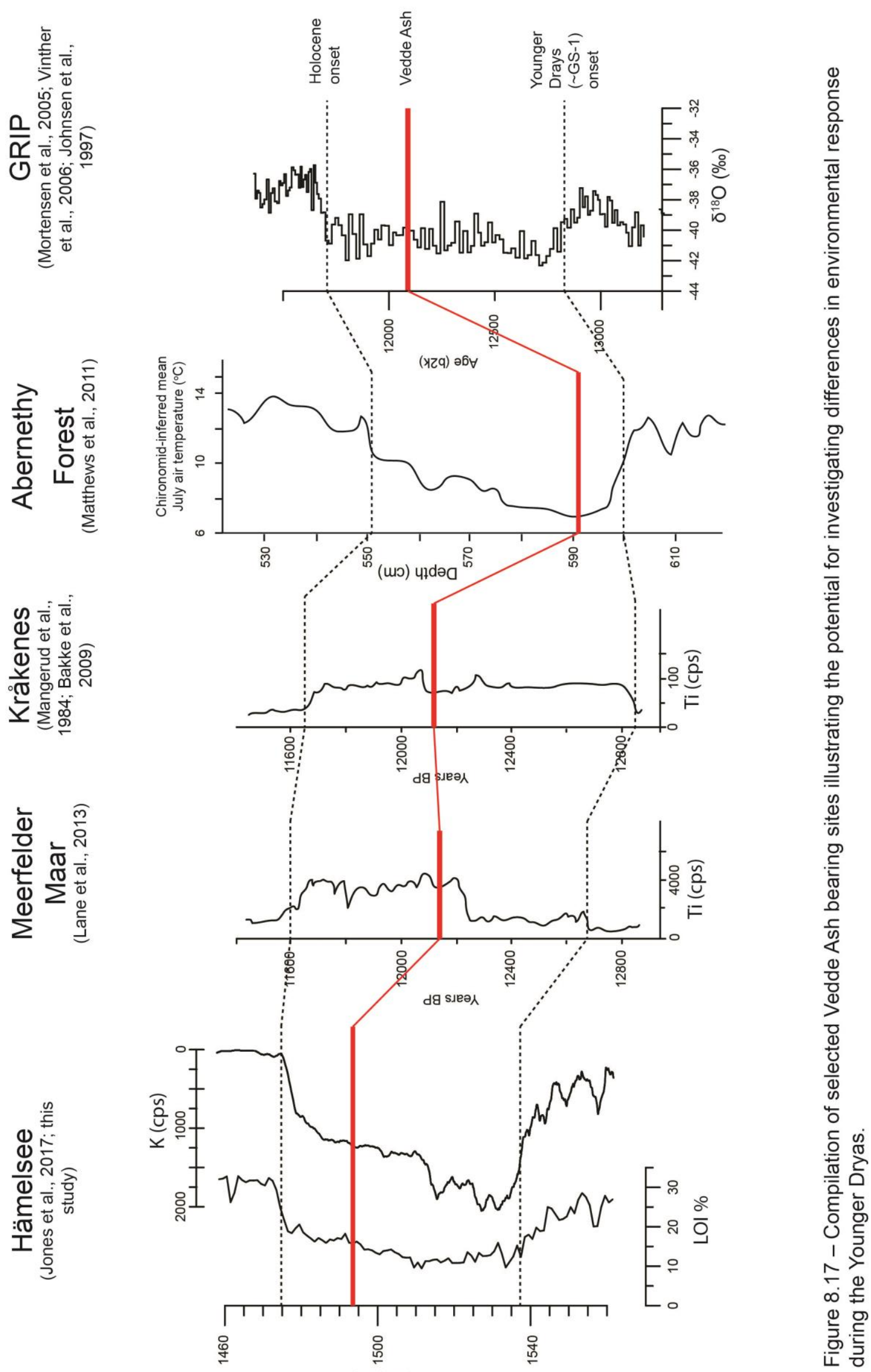

(แว) पวdә0 
The discovery of the Vedde Ash in the Hämelsee record allows it to be compared with other Vedde Ash bearing sites, such as those shown in Figure 8.17 , to investigate the variability seen within the proxy records during Younger Dryas and the transitions bracketing the isochron.

\subsubsection{Ulmener Maar Tephra ? (HÄM_T1451)}

The Ulmener Maar Tephra has only been discovered in a limited amount of sites in western Germany. It is present as a visible deposit in the Meerfelder Maar record and as a result of this study, it is also discovered as a tentatively correlated cryptotephra in the Hämelsee record. The UMT has been dated to 11,000 varve years BP (Brauer et al., 1999) and is associated with the early Holocene. In the Hämelsee record the UMT is positioned at $1451 \mathrm{~cm}$ and 24 $\mathrm{cm}$ above the rise in LOI values and sudden decrease in $\mathrm{K}(\mathrm{XRF})$ values which is interpreted as the Holocene onset (Figure 8.18). The pollen record at Hämelsee shows a period of decreased tree pollen during the deposition of the UMT which may be interpreted as the Pre-Boreal oscillation. In the Meerfelder Maar record the UMT is positioned approximately 700 varve years above the Holocene onset (Figure 8.18). The presence of the UMT in both records allows investigations to be made between the environmental response seen during the early Holocene across a north-south transect between the south western German site Meerfelder Maar and the north Germany site Lake Hämelsee.

In addition to the UMT, the Askja-S (see section 8.2.6) and Saksunarvatn Ash (see section 8.2.7) is also present in the Hämelsee record which provides potential for the early Holocene part of the record to be very precisely constrained in chronological terms. This would allow the early Holocene part of the Hämelsee record to be compared with other precisely dated and tephra bearing sites to investigate the environmental response to early Holocene climatic changes. 


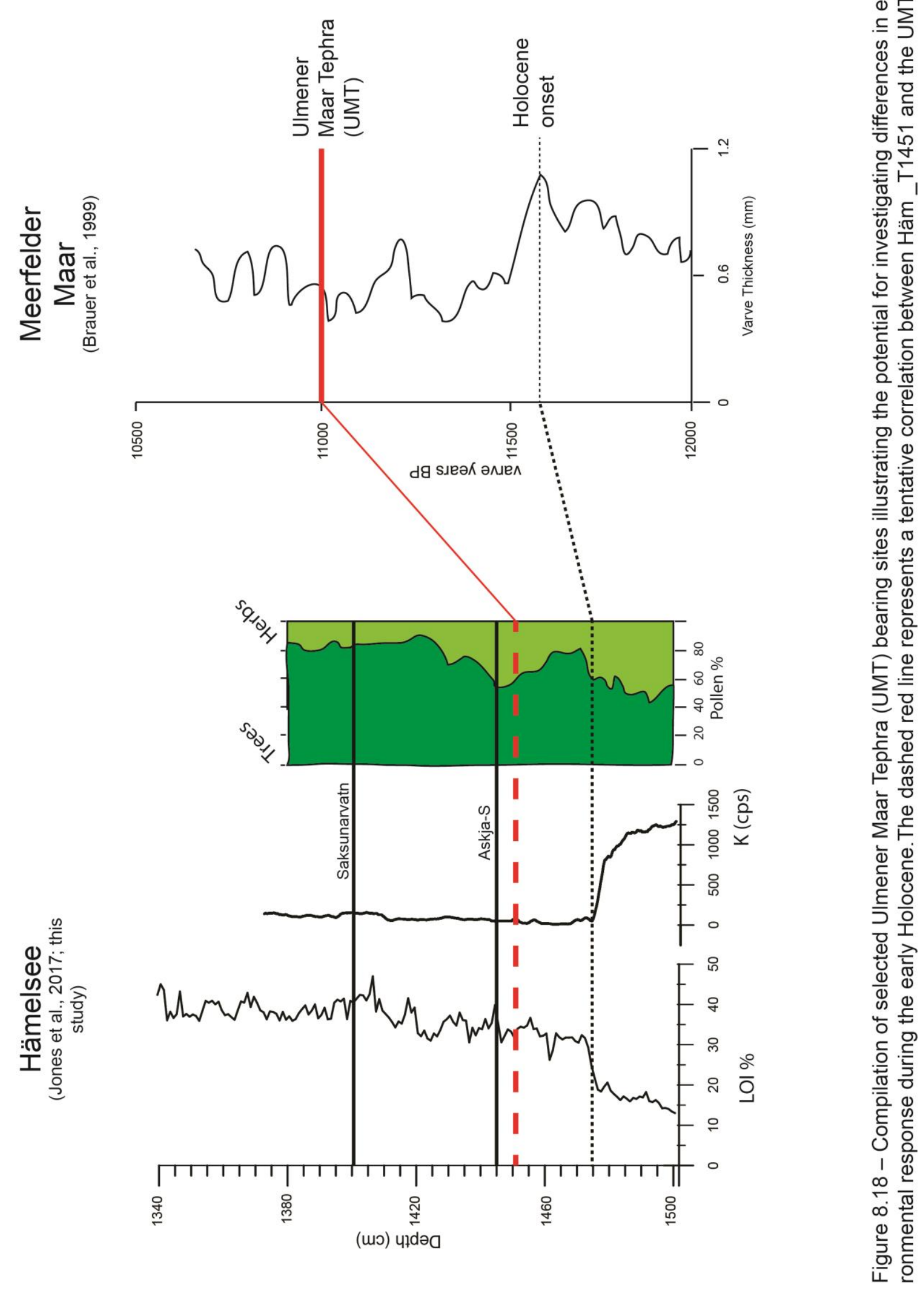




\subsubsection{Askja-S (HÄM_T1445-1444 and PLL_500)}

The Askja-S Tephra has been found in Pant-y-Llyn and Lake Hämelsee as part of this study, which has enabled direct comparison with other Askja-S bearing sites. The LOI records for Pant-y-Llyn and Lake Hämelsee are shown in Figure 8.19 along with four other LOI records from other Askja-S bearing sites, including Inverlair (Kelly et al., 2016), Endinger Bruch (Lane et al., 2012), Hässeldala port (Davies et al., 2003) and Long Lough (Turney et al., 2006). The Askja-S Tephra is a key tephra isochron for the early Holocene where potential investigations can be made to determine differences in the environmental response during the Younger Dryas termination and the early Holocene Pre-boreal oscillation. In the Pant-y-Llyn record, the Askja-S is positioned $11 \mathrm{~cm}$ above the abrupt rise in the LOI record at $511 \mathrm{~cm}$ and below a further increase in values at $495 \mathrm{~cm}$. In the Hämelsee record, the deposit is positioned $30 \mathrm{~cm}$ above the abrupt rise in LOI. The Askja-S deposit is positioned $15 \mathrm{~cm}$ above a short-lived increase in LOI values, from 30 to $45 \%$, in the Endinger Bruch record and $122 \mathrm{~cm}$ above the Holocene onset as interpreted by the LOI and pollen evidence which is dated to 12-138-11631 cal BP at the site (Lane et al., 2012). At Long Lough the Askja-S Tephra is deposited $22 \mathrm{~cm}$ above the rise in LOI values which is interpreted as the Holocene onset (Turney et al., 2006). In the Inverlair record the Askja-S is positioned on a period of decreased LOI values which occurs $\sim 5 \mathrm{~cm}$ after the initial early Holocene rise in LOI values. It is difficult to interpret if these fluctuations are linked because local differences in LOI records are known to occur between sites. Further work to develop a quantifiable temperature record for more Askja-S bearing sites is required to provide a more valuable insight into the potential differences during the transition from the Loch Lomond Stadial ( Younger Dryas) to early Holocene.

For the sites under investigation here, the Askja-S discovery at Pant-y-Llyn and Hämelsee provide valuable fix-points for age models. For the former calcareous-rich record this isochron is particularly valuable for overcoming 


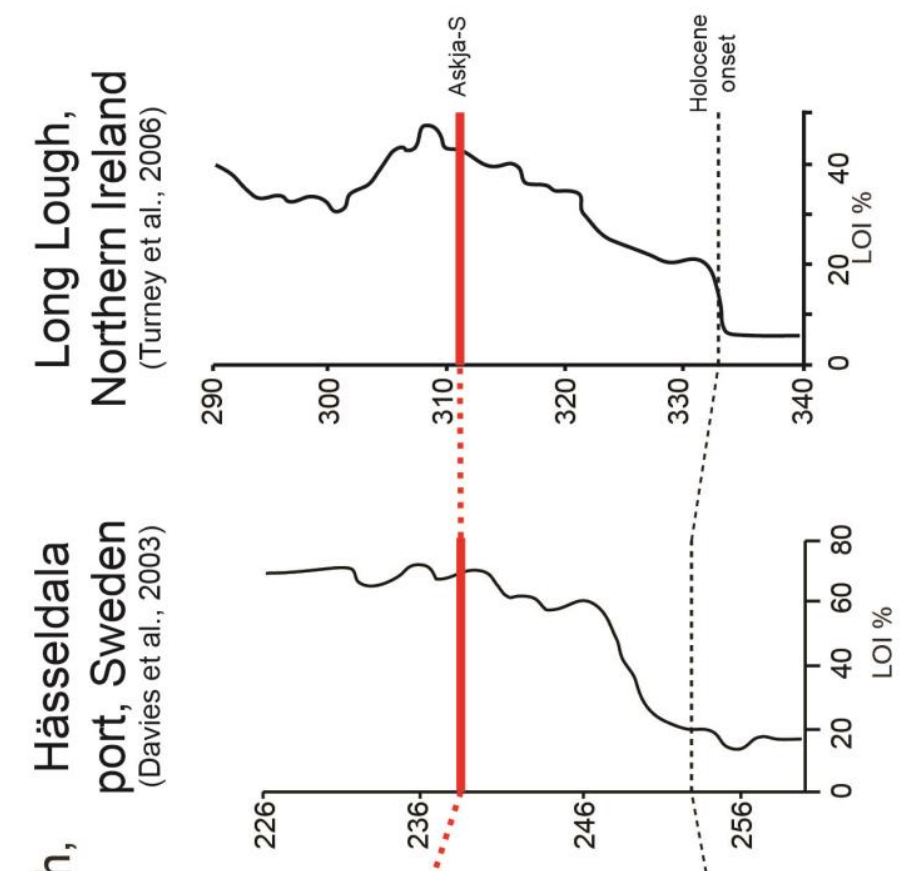

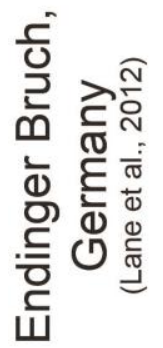

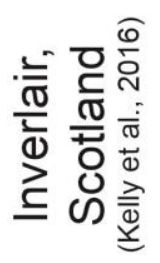
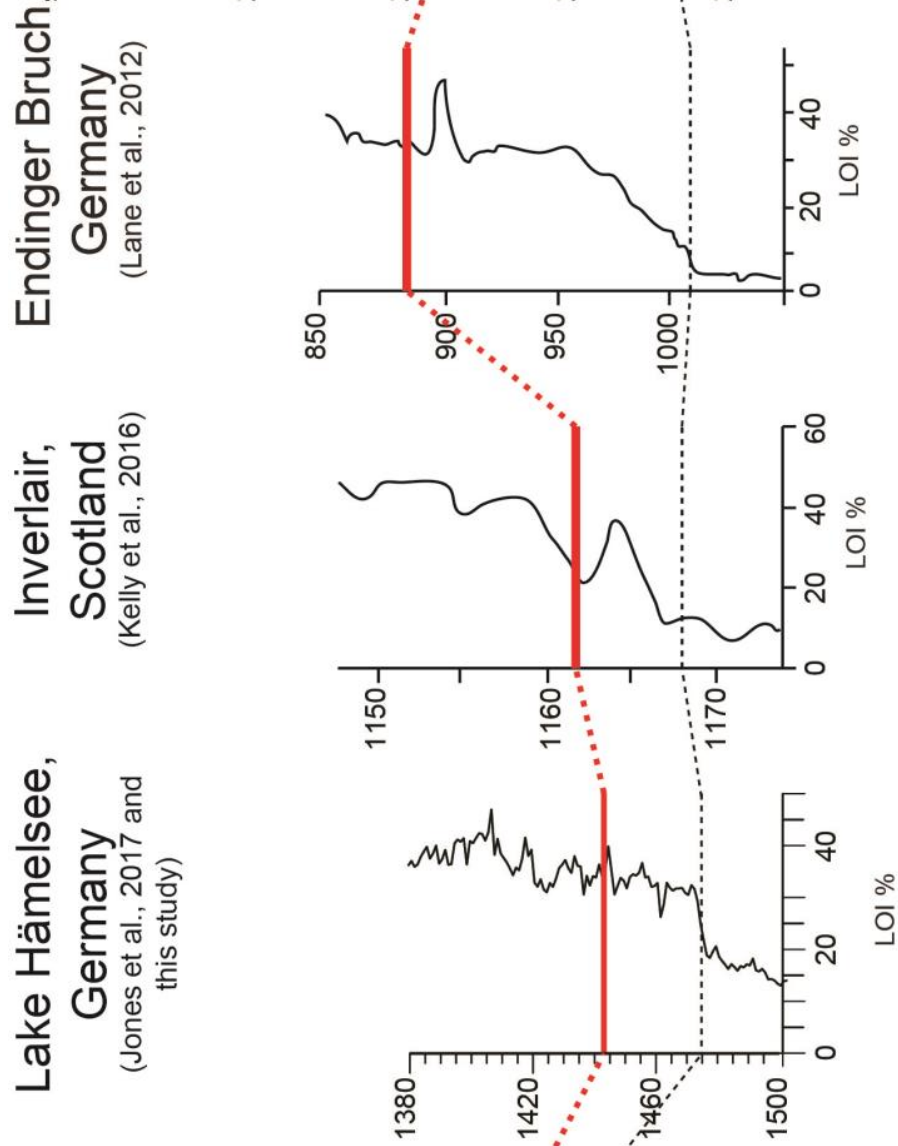

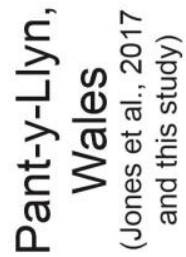

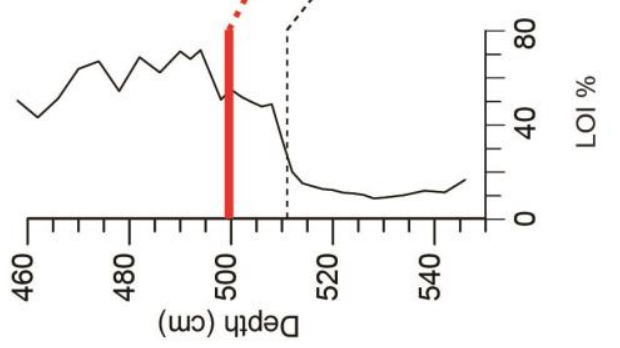

Ð

등

की

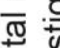

ब

E.

은

¿

$\subseteq \stackrel{\Phi}{0}$

음

它

可 인

o

垔

त

क्ञ

¿

흐 든

중

号

들

里

잉

莣

כ ๘

象 등

क ब

궁

힌

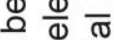

주 की

능 능

ब원

क त़

它

रह

这完

잉

ษ

番

का

는흐웡

은 우

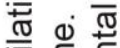

흥 히

ํํ응

오은

은 즌

$\infty$ 迥.

잉 क

言产 ⿺ 
the problems associated with radiocarbon dating such sediments. For the former, the early Holocene period is devoid of varves and terrestrial macrofossils for radiocarbon dating, this isochron provides a constraint for the chronology. Other proxy records may well benefit from using this isochron as a fix-point in age models.

\subsubsection{Saksunarvatn Ash (HÄM_T1401.5)}

The Saksunarvatn Ash is dated to 10,210 \pm 35 cal BP (Lohne et al., 2014) and is associated with the early Holocene. It has been discovered in several terrestrial and marine sites across north-west Europe including Kråkenes (Figure 8.20). The Saksunarvatn Ash was also previously thought to be present in the Greenland ice-cores however, based on trace element data, the deposit represents a different eruption to the deposit that dispersed towards Europe (see section 8.1.7). In the Hämelsee record, the Saksunarvatn is positioned at $1401 \mathrm{~cm}$ depth and $74 \mathrm{~cm}$ above the sudden rise in LOI values and sudden decrease in $\mathrm{K}(\mathrm{XRF})$ values at $1475 \mathrm{~cm}$ which is interpreted as the Holocene onset. The summary pollen record shows that the Saksunarvatn is positioned during a high abundance of tree pollen and low values of around 20 \% shrub and herb taxa. In the Kråkenes record it is positioned 1,300 years above the rise in LOI values and the increase in pollen-inferred temperature reconstruction which is interpreted as the Holocene onset.

The precise age estimate from Lohne et al., (2014) provides a robust age constraint for this part of the Hämelsee record and its discovery allows the potential for the record to be compared with other Saksunarvatn bearing sites such as Kråkenes (Mangerud et al., 1986), Potremser Moor (Bramham-Law et al., 2013) and Høvdarhagi bog (Lind and Wastegård, 2011) to investigate the environmental response during the early Holocene. 


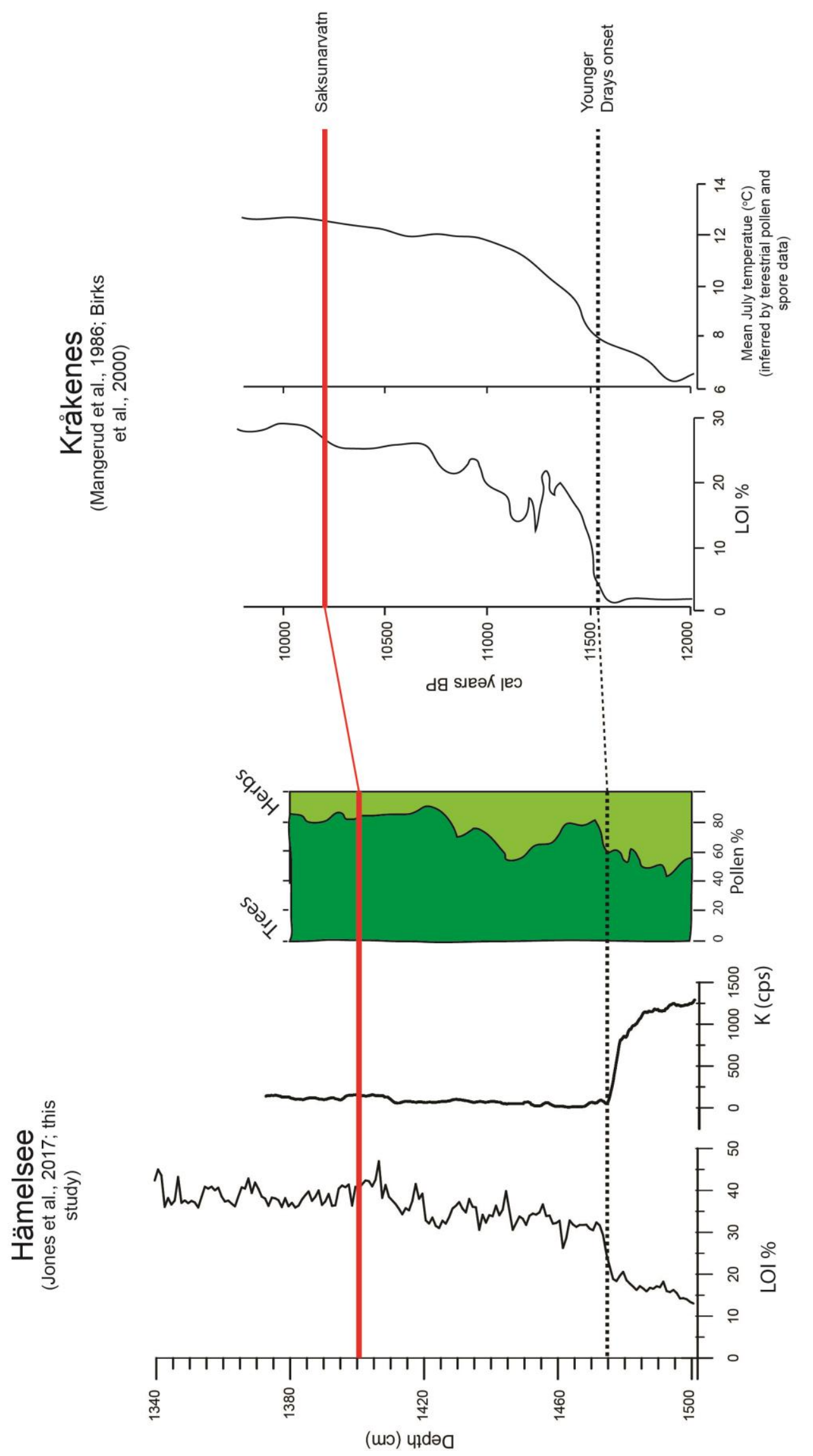

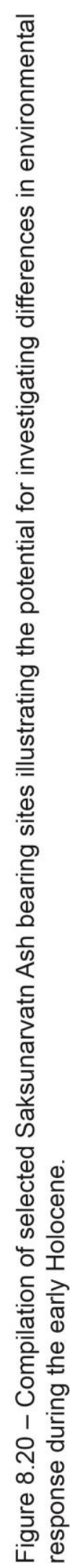




\subsubsection{Fondi di Baia}

The Fondi di Baia discovery, albeit only tentatively correlated (see section 5.62), in the Llyn Llech Owain record (LLO_580) is significant because it allows a direct comparison with the other two Fondi di Baia bearing sites in south Europe; PRAD (Bourne et al., 2010) and Lago Grande di Monticchio (Wulf et al., 2008). However, geochemical data from Smith et al., (2011) has demonstrated that the proposed correlation of TM-6-1 tephra deposit in the Monticchio record (Wulf et al., 2008) and the PRAD-120 tephra deposit (Bourne et al., 2010) to the Fondi di Baia eruption could not be confirmed (Sabine Wulf, pers comm). This indicates that synchronisation of proxy data between these Italian sites and Llyn Llech owain is not currently possible. Further work is required to explore this correlation.

The tentative discovery of the Fondi di Baia Tephra at Llyn Llech Owain has also provided an age constraint for the Llyn Llech Owain age model (see section 5.7).

\subsubsection{Lairg A (LLO09_516)}

The Lairg A Tephra deposit has an age of 6947-6852 cal yr BP (Pilcher et al., 1996) and has a wide spatial distribution across north western Europe with findings in Ireland, Scotland, northern Germany, Norway and north Sweden. Its discovery in the Llyn Llech Owain record allows direct comparisons with other Lairg A bearing sites including Temple Hill Moss (Langdon et al., 2003), Lake Claraghmore and Lake Svartkälsjärn (Watson et 

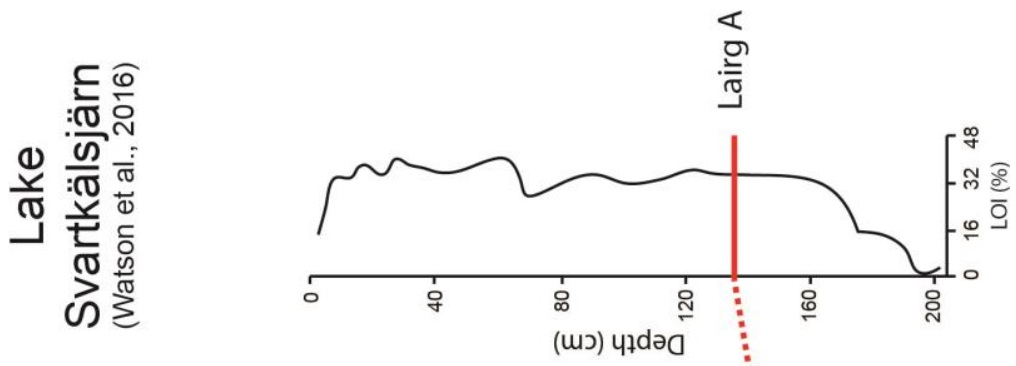

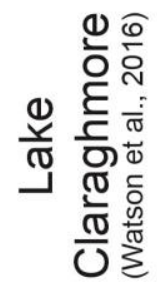
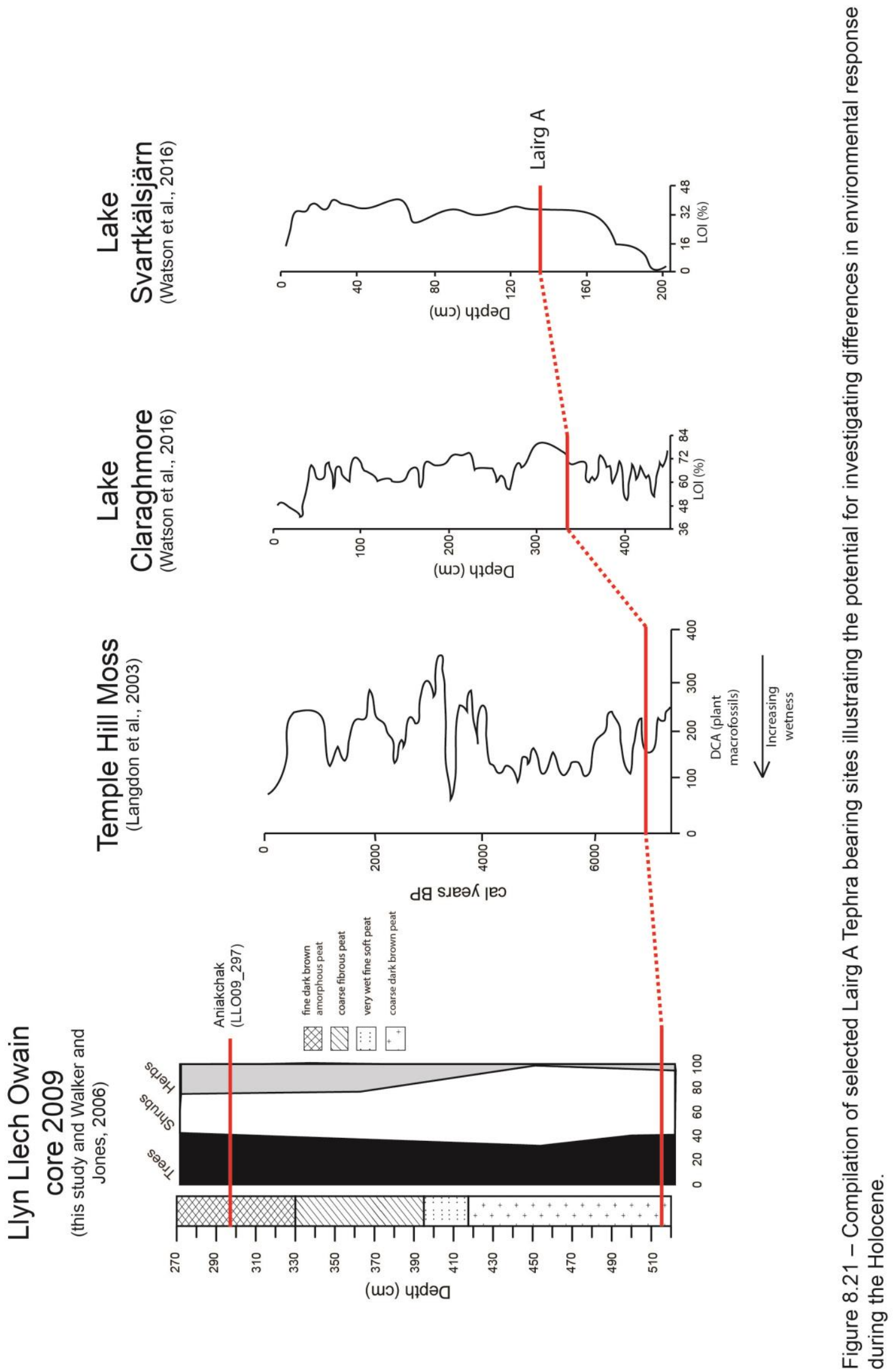

(u०) प1dəa 
al., 2016) (Figure 8.21). At Temple Hill Moss, the Lairg A deposit is stratigraphically positioned during a short-lived wet phase, as interpreted by DCA (plant macrofossil) values. The deposit is positioned below a period of high LOI values at Lake Claraghmore at $336 \mathrm{~cm}$ which can be interpreted as a period of increased organic matter. However, at Lake Svartkälsjärn the Lairg A deposit is positioned during a period of stable LOI values at around $30 \%$. The low resolution pollen record for Llyn Llech Owain (Walker \& Jones, 2006), shows $40 \%$ tree pollen (mostly Pinus and Quercus) and $55 \%$ shrub pollen (mostly Corylus) at the Lairg A position. The low abundances of herbaceous pollen during this time at Llyn Llech Owain are interpreted by Walker and Jones, (2006) as a reasonably complete woodland cover. Further work on developing a more robust proxy record for Llyn Llech Owain and other records would allow insight into the significance and spatial extent of the wet phase observed at Temple Hill Moss.

The Lairg A Tephra discovery at Llyn Llech Owain also has value as an age marker in addition to the Aniakchak Tephra, to build an age model for the Holocene part of this record.

\subsubsection{Aniakchak Tephra (LLO09_297)}

The Aniakchak Tephra is a very widely distributed tephra deposit with findings from sites in North America, the GRIP ice-core and from Llyn Llech Owain. Due to its large spatial distribution, the Aniakchak Tephra may be considered as a key tephra deposit that can be utilised to directly compare proxy evidence spanning the mid-late Holocene from other Aniakchak tephra bearing-sites on an inter-continental scale. This potential is highlighted in Figure 8.22 where comparisons are made between the $\delta^{18} \mathrm{O}$ record at Nordans Pond Bog, Newfoundland (Daley et al., 2009; Pyne O'Donnell et al., 2016), GRIP (Pearce et al., 2004) and the Llyn Llech Owain record. The Nordans Pond Bog $\delta^{18} \mathrm{O}$ precipitation record from Daley et al., (2009) shows fluctuating patterns throughout the Holocene, with a pronounced decrease in 

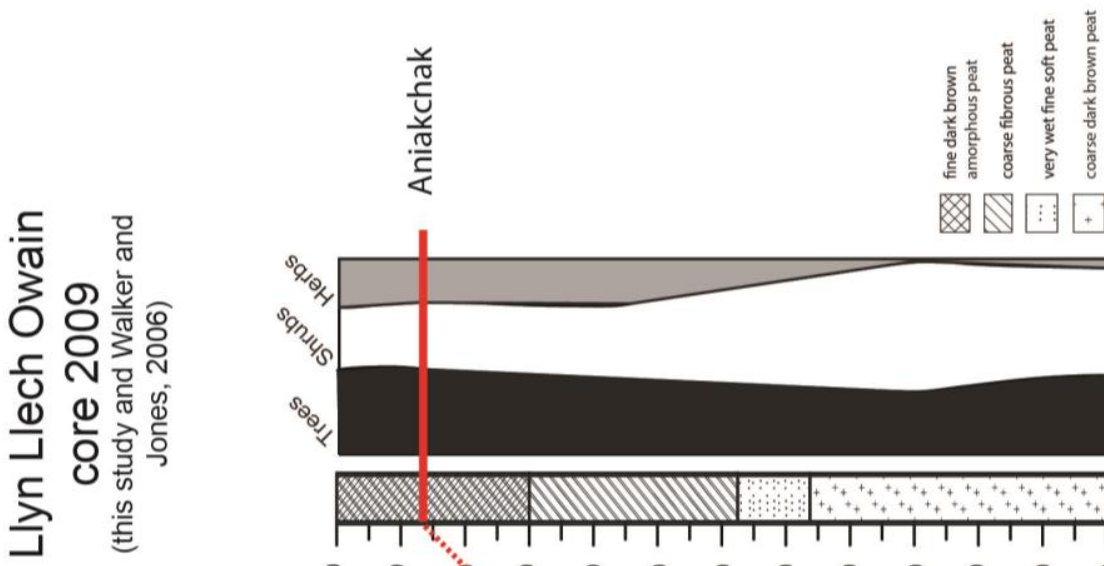

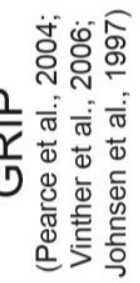

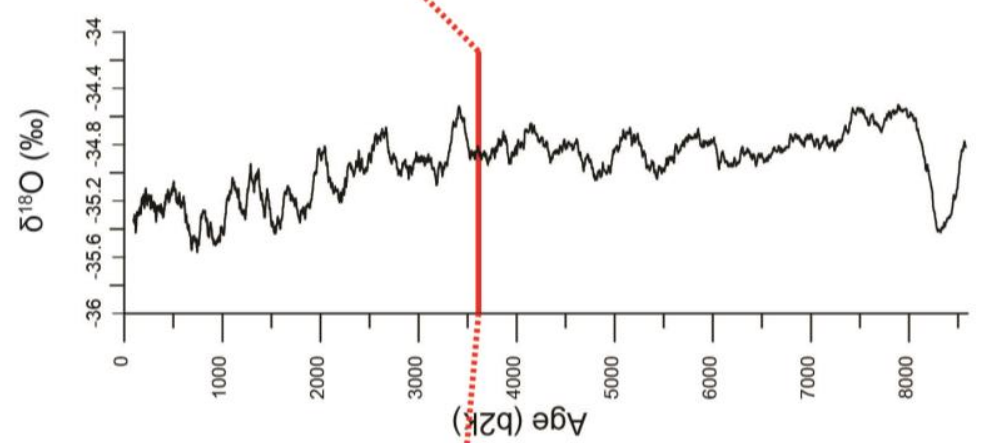

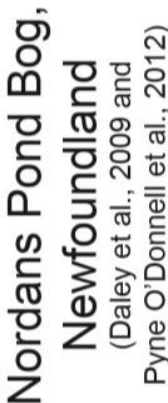

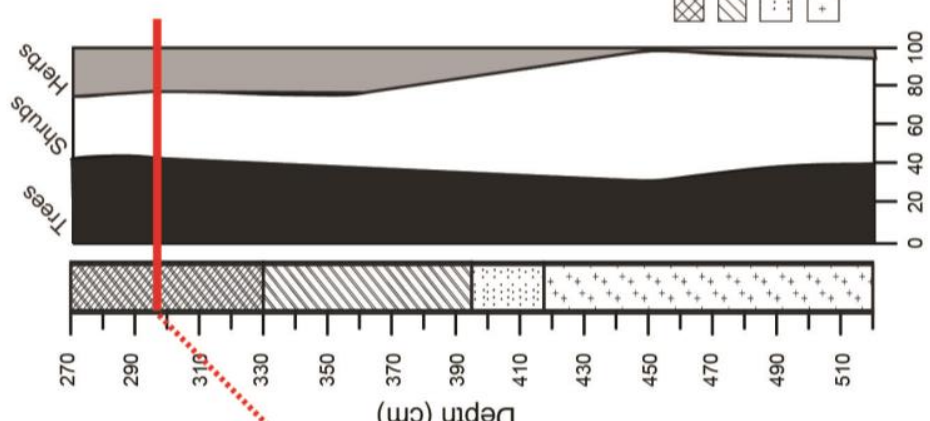

(யง) प1 dəa

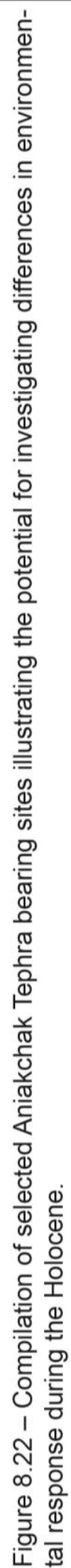


values between $~ 8400-8200$ cal yr BP which may be associated with the 8.2 cooling event. The 8.2 event is also observed in the GRIP record where a marked decrease in $\delta^{18} \mathrm{O}$ to $-35.45 \%$ is observed. Another shift of decreasing $\delta^{18} \mathrm{O}$ values is observed in the Nordans Pond Bog record at approximately 3800 cal years BP with the Aniakchak Tephra deposition 200 years above this shift. According to Daley et al., (2009) this indicates a change in the thermal gradient between the moisture source and the site of precipitation and/or a change in the prevailing origin of that moisture. The GRIP $\delta^{18} \mathrm{O}$ record also exhibits numerous fluctuations throughout the Holocene period. In GRIP, the Aniakchak Tephra is found in association with a short-lived and sudden increase in $\delta^{18} \mathrm{O}$ values. This short-lived fluctuation may indicate a period of increased air temperatures over Greenland. Only low-resolution pollen results are available for this part of the Llyn Llech Owain record and show a diversified woodland composition with pollen counts of Ulmus, Quercus, Tilia and an appearance of Alnus. Shrubs also contribute to the assemblage, mainly Corylus in addition to a sudden rise in Calluna (see Figure 5.2). The Aniakchak Tephra provides an important constraint to assess whether these observed changes in the proxy evidence are linked which may help in understanding their underlying mechanisms. Further work on developing more quantitative proxies, such as a chironomid-based temperature record, for the Holocene Llyn Llech Owain record would enable the site to be included in such investigations but on an inter-continental scale. Not only does the Aniakchak tephra deposit allow such independent comparisons to be investigated, it also can be used as a fix-point in agemodels for other tephra bearing sites. The age-model for Nordans Pond Bog record is based on $23 \mathrm{AMS}{ }^{14} \mathrm{C}$ ages, where the Aniakchak tephra discovery can now be added to the age-model acting as an added age constraint. Two radiocarbon dates are present for the Holocene part of the 2009 Llyn Llech Owain core (Figure 5.2). The identification of the Aniakchak can now be used to construct a preliminary age-model for the Holocene Llyn Llech Owain record, although, more age constraints may be needed to construct a robust age-model. 


\section{Conclusions}

\subsection{Summary of main findings}

As a result of this work, tephra deposits of Lateglacial and Holocene age have been discovered across a network of sites (Table 9.1). In most cases, these discoveries extend the geographical distribution of ash dispersal with respect to each volcanic event identified. Icelandic tephras of Lateglacial age have been discovered in Welsh sites for the first time highlighting the potential of employing tephrochronology more widely in areas such as Wales, south England and perhaps France. Furthermore, the work in northern Germany demonstrates the importance of sites such as Lake Hämelsee as a central hub and repository of ash from Icelandic and Eifel source regions. The tephra deposits preserved within the Lake Hämelsee highlights the important role of the site as it provides linkages to several other proxy records across Europe such as Meerfelder Maar and Soppensee (Lane et al., $2011,2015)$. Yet, traces of far-travelled ash clouds are also preserved at Llyn Llech Owain in the form of Glacier Peak G (Cascade), Aniakchak tephra (Alaska) and Fondi di Baia (Italy). Although further work is required to firmly establish some of these correlations, their presence in Llyn Llech Owain sediments considerably extends their dispersal extent and has the potential for precise correlation of records on a trans-continental scale. For a number of years, very little evidence has been presented of tephra preservation in Welsh sites, and yet now these new findings demonstrate that these sites may well facilitate linkages far beyond NW Europe.

Many of the ash deposits discovered in this study are correlated to known events such as the Askja-S Tephra identified in Pant-y-Llyn and Hämelsee, and the Vedde Ash Hämelsee. However, correlating some tephras to other published deposits and events has proven difficult. For instance nine tephra deposits from both Llyn Llech Owain and Hämelsee are thought to represent new, previously undocumented eruptions. These unknown deposits provide 
Table 9.1 - Summary of the tephra deposits found in Llyn Llech Owain, Pant$y$-Llyn and Lake Hämelsee, their homogeneity status and proposed correlations.

\begin{tabular}{|c|c|c|}
\hline Tephra deposit & Homogenous? & Proposed correlation \\
\hline \multicolumn{3}{|c|}{ Llyn Llech Owain } \\
\hline LLO_804 & yes & Borrobol type \\
\hline LLO_782 & yes & Borrobol Tephra \\
\hline LLO_778 & yes ( 1 outlier) & Penifiler Tephra \\
\hline LLO_767 & yes ( 1 outlier) & unknown \\
\hline LLO_766 & yes & Glacier Peak G Tephra \\
\hline LLO_580 & 3 populations & $\begin{array}{l}\text { Fondi di Baia Tephra (population } \\
\text { 1) }\end{array}$ \\
\hline LLO_483 & yes & unknown \\
\hline LLO_468 & yes & unknown \\
\hline LLO09_516 & yes & Lairg A Tephra \\
\hline LLO09_505 & yes & unknown \\
\hline LLO09_345 & 3 populations & unknown \\
\hline LLO09_297 & $\begin{array}{l}1 \text { population ( } 2 \\
\text { outliers) }\end{array}$ & $\begin{array}{l}\text { Aniakchak Tephra (main } \\
\text { population) }\end{array}$ \\
\hline \multicolumn{3}{|l|}{ Pant-y-Llyn } \\
\hline PLL_500 & yes & Askja-S Tephra \\
\hline \multicolumn{3}{|l|}{ Lake Hämelsee } \\
\hline HÄM_T1616 & yes & Borrobol type \\
\hline HÄM_T1558 & yes & Laacher See Tephra \\
\hline HÄM_T1494 & yes & Vedde Ash \\
\hline HÄM_T1470 & yes & unknown \\
\hline $\begin{array}{l}\text { HÄM_T1456- } \\
1455\end{array}$ & $\begin{array}{l}2 \text { populations (1 } \\
\text { outlier) }\end{array}$ & unknown \\
\hline HÄM_T1451 & 3 populations & Ulmener Maar? (population 3) \\
\hline $\begin{array}{l}\text { HÄM_T1445- } \\
1444\end{array}$ & yes & Askja-S Tephra \\
\hline HÄM_T1401.5 & yes & Saksunarvatn Ash \\
\hline
\end{tabular}


insights into the volcanic history of some volcanic centres, especially the Öræfajökull system where three deposits, of Öræfajökull 1362 signature, have been discovered during the early-mid Holocene. Further work is required to find these unknown tephras at other sites despite extensive searches have already been made in the literature.

Despite the positive tephra findings in these sequences, the complexity of tephra studies is noticeable in relation to Borrobol-type Tephra deposits. These BT-type deposits are chemically indistinguishable and may only be differentiated based upon secure stratigraphic correlation. Four tephra deposits with a BT-type chemical signature are identified. Three have been discovered in the Llyn Llech Owain record: LLO_804, LLO_782, LLO_778 and one in the Hämelsee record: HÄM_T1616. Deposits LLO_782 and LLO_778 have been tentatively correlated to the BT and PT however, deposit LLO_804 may represent a new event. Deposit HÄM_T1616 has not been correlated due to uncertain stratigraphical constraints.

A further finding of this study is the significant inter and intra-site differences are observed in the tephra findings within this study. These include marked differences in tephra deposit preservation between sites in close proximity to each other and variations in shard concentrations between cores sampled from the same site. These observations have provided insights to tephra deposition and taphonomic processes such as within-basin focussing and redistribution of tephra shards.

The identified tephra deposits found at Llyn Llech Owain, Pant-y-Llyn and Lake Hämelsee allow their respective proxy records to be synchronized with other tephra-bearing sites. Preliminary comparisons have been made using the discovered tephra deposits, such as the Glacier Peak G deposit to compare the interstadial onset at Llyn Llech Owain and east North American sites from Pyne O'Donnell et al., (2016). This provides great potential for the records to be investigated to constrain environmental responses to climate change. 


\subsection{Recommendations for future work}

This study has given rise to a new potential of employing tephrochronology in Wales and central Europe. Further work is required to develop and strengthen key elements. These include:

- Certain depths in the Llyn Llech Owain record, tephra shards were identified during low resolution searching however peaks were not isolated after high resolution sampling. Re-visiting these depths using a continuous sampling approach in a new core may lead to the discovery of these tephra deposits. Especially during the late interstadial, Loch Lomond Stadial and early Holocene where key tephra deposits like the Laacher See Tephra, Vedde Ash and Askja-S Tephra have the potential to be discovered.

- For some deposits further geo-chemical characterisation is required, especially the BT-type deposits. Trace element analysis may be useful to try and distinguish between the BT-type deposits. Trace element analysis would also provide added characterisation for the far-travelled tephra deposits.

- Further work is required for improving the age-model for Llyn Llech Owain. Several other radiocarbon dates may provide added constraints however, there is a lack of terrestrial macrofossils in the Lateglacial sediments, and aquatic macrofossils or bulk sediment samples tend to be un-reliable. Further tephra deposits, such as the Vedde Ash and Askja-S would provide valuable age constraints for the record which would improve the precision of the present age-model. With a reliable age-model in place, age estimates can then be given to some of the unknown tephra deposits identified such as LLO_483 and LLO_467. 
- The proxy records for the study sites have provided a wealth of information on the environmental response to Lateglacial climate change, however, they are largely based on qualitative data from the paleaoecological and sediment geochemistry data. Developing the record using quantifiable proxies such as chironomids which would provide an inferred temperature record would be more valuable. The quantitative record could then be used to compare other quantified records through utilising the tephra deposits discovered to investigate possible time-transgressive climate change. A temperature-based proxy would also aid in distinguishing the interstadial onset which in turn would help with the stratigraphic positions of the BT.

- The tephra discoveries in Llyn Llech Owain and Pant-y-Llyn indicates towards new geographical areas to investigate tephra presence and highlights the potential of employing tephrochronology more widely in areas south of $53^{\circ}$ latitude in Wales, south England and perhaps France. 


\section{References}

Abbott, P. M., Austin, W. E., Davies, S. M., Pearce, N. J. G. \& Hibbert, F. D. 2013. Cryptotephrochronology of the Eemian and the last interglacialglacial transition in the North East Atlantic. Journal of Quaternary Science, 28, 501-514.

Abbott, P. M. \& Davies, S. M. 2012. Volcanism and the Greenland ice-cores: the tephra record. Earth-Science Reviews, 115, 173-191.

Adolphi, F. \& Muscheler, R. 2016. Synchronizing the Greenland ice core and radiocarbon timescales over the Holocene-Bayesian wiggle-matching of cosmogenic radionuclide records. Climate of the Past, 12, 15-30.

Albert, P. 2007. A Lateglacial Tephrostratigraphy of Loch Etteridge, Central Grampian Highlands, Scotland: Highlighting Stratigraphic Complexities (MSc thesis). University of London.

Allen, J. R. M., Watts, W. A., Mcgee, E. \& Huntley, B. 2002. Holocene environmental variability-the record from Lago Grande di Monticchio, Italy. Quaternary International, 88, 69-80.

Bakke, J., Lie, Ø., Heegaard, E., Dokken, T., Haug, G. H., Birks, H. H., Dulski, P. \& Nilsen, T. 2009. Rapid oceanic and atmospheric changes during the Younger Dryas cold period. Nature Geoscience, 2, 202205.

Balascio, N. L., Zhang, Z., Bradley, R. S., Perren, B., Dahl, S. O. \& Bakke, J. 2011. A multi-proxy approach to assessing isolation basin stratigraphy from the Lofoten Islands, Norway. Quaternary Research, 75, 288-300.

Barber, K. E., Maddy, D., Rose, N., Stevenson, A. C., Stoneman, R. \& Thompson, R. 2000. Replicated proxy-climate signals over the last 2000 yr from two distant UK peat bogs: new evidence for regional palaeoclimate teleconnections. Quaternary Science Reviews, 19, 481487.

Barker, D. S. 1983. Igneous Rocks, Englewood Cliffs, NJ: Prentic-Hall.

Barker, S., Chen, J., Gong, X., Jonkers, L., Knorr, G. \& Thornalley, D. 2015. Icebergs not the trigger for North Atlantic cold events. Nature, 520, 333.

Battarbee, E. 1986. Diatom analysis. Handbook of Holocene palaeoecology and palaeohydrology.

Begét, J., Mason, O. \& Anderson, P. 1992. Age, extent and climatic significance of the c. 3400 BP Aniakchak tephra, western Alaska, USA. The Holocene, 2, 51-56.

Bergman, J., Wastegård, S., Hammarlund, D., Wohlfarth, B. \& Roberts, S. J. 2004. Holocene tephra horizons at Klocka Bog, west-central Sweden: aspects of reproducibility in subarctic peat deposits. Journal of Quaternary Science, 19, 241-249. 
Bigazzi, G., Hadler, J. C., lunes, P. J. \& Araya, A. M. O. 2005. Fission-track dating of South American natural glasses: an overview. Radiation Measurements, 39, 585-594.

Birks, H., Line, J., Juggins, S., Stevenson, A. \& Ter Braak, C. 1990. Diatoms and $\mathrm{pH}$ reconstruction. Philosophical Transactions of the Royal Society of London. Series B, Biological Sciences, 327, 263-278.

Birks, H. H., Battarbee, R. W. \& Birks, H. J. B. 2000. The development of the aquatic ecosystem at Kråkenes Lake, western Norway, during the late glacial and early Holocene-a synthesis. Journal of Paleolimnology, 23, 91-114.

Birks, H. H., Gulliksen, S., Haflidason, H., Mangerud, J. \& Possnert, G. 1996. New radiocarbon dates for the Vedde ash and the Saksunarvatn ash from western Norway. Quaternary Research, 45, 119-127.

Björck, S., Walker, M. J. C., Cwynar, L. C., Johnsen, S., Knudsen, K. L., Lowe, J. J., Wohlfarth, B. \& INTIMATE members. 1998. An event stratigraphy for the Last Termination in the north Atlantic region based on the Greenland ice-core record: a proposal by the INTIMATE group. Journal of Quaternary Science, 13, 283-292.

Björck, S. \& Wohlfarth, B. 2002. ${ }^{14} \mathrm{C}$ chronostratigraphic techniques in paleolimnology. Tracking environmental change using lake sediments. Springer.

Blockley, S. P. E., Lane, C. S., Lotter, A. F. \& Pollard, A. M. 2007. Evidence for the presence of the Vedde Ash in Central Europe. Quaternary Science Reviews, 26, 3030-3036.

Blockley, S. P. E., Bourne, A. J., Brauer, A., Davies, S. M., Hardiman, M., Harding, P. R., Lane, C. S., Macleod, A., Matthews, I. P., PyneO'Donnell, S. D., Rasmussen, S. O., Wulf, S. \& Zanchetta, G. 2014. Tephrochronology and the extended intimate (integration of ice-core, marine and terrestrial records) event stratigraphy 8-128 ka b2k. Quaternary Science Reviews, 106, 88-100.

Blockley, S. P. E., Lane, C. S., Hardiman, M., Rasmussen, S. O., Seierstad, I. K., Steffensen, J. P., Svensson, A., Lotter, A. F., Turney, C. S. M., Bronk Ramsey, B. \& INTIMATE members. 2012. Synchronisation of palaeoenvironmental records over the last 60,000 years, and an extended INTIMATE event stratigraphy to 48,000 b2k. Quaternary Science Reviews, 36, 2-10.

Blockley, S. P. E., Lowe, J. J., Walker, M. J. C., Asioli, A., Trincardi, F., Coope, G. R., Donahue, R. E. \& Pollard, A. M. 2004. Bayesian analysis of radiocarbon chronologies: examples from the European Late-glacial. Journal of Quaternary Science, 19, 159-175.

Blockley, S. P. E., Pyne-O'Donnell, S. D. F., Lowe, J. J., Matthews, I. P., Stone, A., Pollard, A. M., Turney, C. S. M. \& Molyneux, E. G. 2005. A new and less destructive laboratory procedure for the physical separation of distal glass tephra shards from sediments. Quaternary Science Reviews, 24, 1952-1960. 
Blunier, T., Chappellaz, J., Schwander, J., Dällenbach, A., Stauffer, B., Stocker, T. F., Raynaud, D., Jouzel, J., Clausen, H. B., Hammer, C. U. \& Johnsen, S. J. 1998. Asynchrony of Antarctic and Greenland climate change during the last glacial period. Nature, 394, 739-743.

Bohncke, S. J. P. \& Hoek, W. Z. 2007. Multiple oscillations during the Preboreal as recorded in a calcareous gyttja, Kingbeekdal, The Netherlands. Quaternary Science Reviews, 26, 1965-1974.

Borchardt, G. A., Aruscavage, P. J. \& Millard Jr, H. T. 1972. Correlation of the Bishop Ash, a Pleistocene marker bed, using instrumental neutron activation analysis. Journal of Sedimentary Research, 42.

Bourne, A. J., Abbott, P. M., Albert, P. G., Cook, E., Pearce, N. J. G., Ponomareva, V., Svensson, A. \& Davies, S. M. 2016. Underestimated risks of recurrent long-range ash dispersal from northern Pacific Arc volcanoes. Scientific Reports, 6, 1-8.

Bourne, A. J., Lowe, J. J., Trincardi, F., Asioli, A., Blockley, S. P. E., Wulf, S., Matthews, I. P., Piva, A. \& Vigliotti, L. 2010. Distal tephra record for the last ca 105,000 years from core PRAD 1-2 in the central Adriatic Sea: implications for marine tephrostratigraphy. Quaternary Science Reviews, 29, 3079-3094.

Bourne, A. J., Cook, E., Abbott, P. M., Seierstad, I. K., Steffensen, J. P., Svensson, A., Fischer, H., Schüpbach, S. \& Davies, S. M. 2015. A tephra lattice for Greenland and a reconstruction of volcanic events spanning 25-45 ka b2k. Quaternary Science Reviews, 118, 122-141.

Boygle, J. 1999. Variability of tephra in lake and catchment sediments, Svínavatn, Iceland. Global and Planetary Change, 21, 129-149.

Boyle, J. F., Chiverrell, R., Plater, A., Thrasher, I., Bradshaw, E., Birks, H. \& Birks, J. 2013. Soil mineral depletion drives early Holocene lake acidification. Geology, 41, 415-418.

Boyle, J. F. 2007. Loss of apatite caused irreversible early-Holocene lake acidification. The Holocene, 17, 543-547.

Bramham-Law, C. W. F., Theuerkauf, M., Lane, C. S. \& Mangerud, J. 2013. New findings regarding the Saksunarvatn Ash in Germany. Journal of Quaternary Science, 28, 248-257.

Brauer, A., Endres, C. \& Negendank, J. F. W. 1999. Lateglacial calendar year chronology based on annually laminated sediments from Lake Meerfelder Maar, Germany. Quaternary International, 61, 17-25.

Brendryen, J., Haflidason, H. \& Sejrup, H. P. 2010. Norwegian Sea tephrostratigraphy of marine isotope stages 4 and 5: prospects and problems for tephrochronology in the North Atlantic region. Quaternary Science Reviews, 29, 847-864.

Broecker, W. S. 2003. Does the trigger for abrupt climate change reside in the ocean or in the atmosphere? Science, 300, 1519-1522.

Broecker, W. S., Andree, M., Wolfli, W., Oeschger, H., Bonani, G., Kennett, J. \& Peteet, D. 1988. The chronology of the last deglactiation: 
implications to the cause of the Yonger Dryas event.

Paleoceanography, 3, 1-19.

Broecker, W. S., Kennett, J. P., Flower, B. P., Teller, J. T., Trumbore, S., Bonani, G. \& Wolfli, W. 1989. Routing of meltwater from the Laurentide Ice Sheet during the Younger Dryas cold episode. Nature, 341, 318-321.

Bronk Ramsey, C. 2017. OxCal Project, Version 4.3. https://c14.arch.ox.ac.uk/oxcal/OxCal.html.

Bronk Ramsey, B. 2008. Deposition models for chronological records. Quaternary Science Reviews, 27, 42-60.

Bronk Ramsey, B. 2009. Bayesian analysis of radiocarbon dates. Radiocarbon, 51, 337-360.

Bronk Ramsey, B., Albert, P. G., Blockley, S. P. E., Hardiman, M., Housley, R. A., Lane, C. S., Lee, S., Matthews, I. P., Smith, V. C. \& Lowe, J. J. 2015a. Improved age estimates for key Late Quaternary European tephra horizons in the RESET lattice. Quaternary Science Reviews, 118, 18-32.

Bronk Ramsey, B., Dee, M., Lee, S., Nakagawa, T. \& Staff, R. A. 2010. Developments in the calibration and modeling of radiocarbon dates. Radiocarbon, 52, 953-961.

Bronk Ramsey, B., Housley, R. A., Lane, C. S., Smith, V. C. \& Pollard, A. M. 2015b. The RESET tephra database and associated analytical tools. Quaternary Science Reviews, 118, 33-47.

Bronk Ramsey, B. \& Lee, S. 2013. Recent and planned developments of the program OxCal. Radiocarbon, 55, 720-730.

Brooks, S. J. \& Birks, H. J. B. 2000. Chironomid-inferred Late-glacial air temperatures at Whitrig Bog, Southeast Scotland. Journal of Quaternary Science, 15, 759-764.

Brooks, S. J., Lowe, J. J. \& Mayle, F. E. 1997. The Late Devensian Lateglacial palaeoenvironmental record from Whitrig Bog, SE Scotland. 2. Chironomidae (Insecta: Diptera). Boreas, 26, 297-308.

Brooks, S. J., Matthews, I. P., Birks, H. H. \& Birks, H. J. B. 2012. High resolution Lateglacial and early-Holocene summer air temperature records from Scotland inferred from chironomid assemblages. Quaternary Science Reviews, 41, 67-82.

Buckley, S. L. \& Walker, M. J. C. 2002. A mid-Flandrian tephra horizon, Cambrian Mountains, west Wales. Quaternary Newsletter 96, 5-11.

Burnett, A. P., Soreghan, M. J., Scholz, C. A. \& Brown, E. T. 2011. Tropical East African climate change and its relation to global climate: a record from Lake Tanganyika, Tropical East Africa, over the past 90+ kyr. Palaeogeography, Palaeoclimatology, Palaeoecology, 303, 155-167.

Campbell, S., Gunn, J. \& Hardwick, P. 1992. Pant-y-llyn-the first Welsh turlough. Earth Science Conservation, 31, 3-7. 
Chambers, F. M., Daniell, J. R. G, Hunt, J. B., Molloy, K. \& O'Connell, M. 2004. Tephrostratigraphy of An Loch Mor, Inis Oirr, western Ireland: implications for Holocene tephrochronology in the northeastern Atlantic region. The Holocene, 14, 703-720.

Clement, A. C. \& Peterson, L. C. 2008. Mechanisms of abrupt climate change of the last glacial period. Reviews of Geophysics, 46.

Cook, E. 2015. Tracing and constraining cryptotephra deposits in the Greenland ice-core records between GS-5.1 and the early Holocene. PhD Thesis, Swansea University.

Coope, G. R. \& Brophy, J. A. 1972. Late glacial environmental changes indicated by a coleopteran succession from North Wales. Boreas (Oslo), 1, 97-142.

Coulter, S. E., Pilcher, J. R., Plunkett, G., Baillie, M., Hall, V. A., Steffensen, J. P., Vinther, B. M., Clausen, H. B. \& Johnsen, S. J. 2012. Holocene tephras highlight complexity of volcanic signals in Greenland ice cores. Journal of Geophysical Research: Atmospheres, 117.

Coxon, C.E. \& Coxon, P. 1994. Carbonate deposition in Turloughs (seasonal lakes) on the Western limestone lowlands of Ireland: II: The sedimentary record. Irish Geography 27, 28-35.

Crabtree, K. 1969. Post-glacial diatom zonation of limnic deposits in North Wales. Verhandlungen der internationalen Vereinigungfiir theoretische und angewandte Limnologie, 17, 165-171.

Croudace, I. W., Rindby, A. \& Rothwell, R. G. 2006. ITRAX: description and evaluation of a new multi-function X-ray core scanner. Geological Society, London, Special Publications, 267, 51-63.

Daley, T. J., Street-Perrott, F. A., Loader, N. J., Barber, K. E., Hughes, P. D. M., Fisher, E. H. \& Marshall, J. D. 2009. Terrestrial climate signal of the "8200 yr BP cold event" in the Labrador Sea region. Geology, 37, 831-834.

Davies, L. J., Jensen, B. J., Froese, D. G. \& Wallace, K. L. 2016. Late Pleistocene and Holocene tephrostratigraphy of interior Alaska and Yukon: Key beds and chronologies over the past 30,000 years. Quaternary Science Reviews, 146, 28-53.

Davies, S. J., Lamb, H. F. \& Roberts, S. J. 2015. Micro-XRF core scanning in palaeolimnology: recent developments. Micro-XRF studies of sediment cores. Springer.

Davies, S. M. 2015. Cryptotephras: the revolution in correlation and precision dating. Journal of Quaternary Science, 30, 114-130.

Davies, S. M., Abbott, P. M., Pearce, N. J. G., Wastegård, S. \& Blockley, S. P. E. 2012. Integrating the INTIMATE records using tephrochronology: rising to the challenge. Quaternary Science Reviews, 36, 11-27.

Davies, S. M., Branch, N. P., Lowe, J. \& Turney, C. S. M. 2002. Towards a European tephrochronological framework for termination 1 and the 
early holocene. Philosophical Transactions of the Royal Society aMathematical Physical and Engineering Sciences, 360, 767-802.

Davies, S. M., Elmquist, M., Bergman, J., Wohlfarth, B. \& Hammarlund, D. 2007. Cryptotephra sedimentation processes within two lacustrine sequences from west central Sweden. Holocene, 17, 319-330.

Davies, S. M., Larsen, G., Wastegård, S., Turney, C. S. M., Hall, V. A., Coyle, L. \& Thordarson, T. 2010. Widespread dispersal of Icelandic tephra: how does the Eyjafjoll eruption of 2010 compare to past Icelandic events? Journal of Quaternary Science, 25, 605-611.

Davies, S. M., Turney, C. S. M. \& Lowe, J. J. 2001. Identification and significance of a visible, basalt-rich Vedde Ash layer in a Late-glacial sequence on the Isle of Skye, Inner Hebrides, Scotland. Journal of Quaternary Science, 16, 99-104.

Davies, S. M., Wastegård, S. \& Wohlfarth, B. 2003. Extending the limits of the Borrobol Tephra to Scandinavia and detection of new early Holocene tephras. Quaternary Research, 59, 345-352.

Davies, S. M., Wohlfarth, B., Wastegård, S., Andersson, M., Blockley, S. \& Possnert, G. 2004. Were there two Borrobol Tephras during the early Lateglacial period: implications for tephrochronology? Quaternary Science Reviews, 23, 581-589.

Dee, M. \& Ramsey, C. B. 2000. Refinement of graphite target production at ORAU. Nuclear Instruments and Methods in Physics Research Section B: Beam Interactions with Materials and Atoms, 172, 449-453.

Downing, J. A. \& Rath, L. C. 1988. Spatial patchiness in the lacustrine sedimentary environment. Limnology and Oceanography, 33, 447458.

Dugmore, A. J. 1989. Icelandic volcanic ash in Scotland. The Scottish Geographical Magazine, 105, 168-172.

Dugmore, A. J. \& Newton, A. J. 1992. Thin tephra layers in peat revealed by X-radiography. Journal of Archaeological Science, 19, 163-170.

Dugmore, A. J., Larsen, G. \& Newton, A. J. 1995. Seven tephra isochrones in Scotland. The Holocene, 5, 257-266.

Eiríksson, J., Knudsen, K. L., Haflidason, H. \& Henriksen, P. 2000. Lateglacial and Holocene palaeoceanography of the North Icelandic shelf. Journal of Quaternary Science, 15, 23-42.

Evans, G. H. 1970. Pollen and diatom analyses of late-Quaternary deposits in Blelham-basin, north Lancashire. New Phytologist, 69, 821-874.

Evans, G. H. \& Walker, R. 1977. Late quaternary history of diatom flora of Llyn-Clyd and Lynn-Glas, 2 small oligotrophic high mountain tarns in Snowdonia (Wales). New Phytologist, 78, 221-236.

Firestone, R. B., West, A., Kennett, J. P., Becker, L., Bunch, T. E., Revay, Z. S., Schultz, P. H., Belgya, T., Kennett, D. J., Erlandson, J. M., Dickenson, O. J., Goodyear, A. C., Harris, R. S., Howard, G. A., Kloosterman, J. B., Lechler, P., Mayewski, P. A., Montgomery, J., 
Poreda, R., Darrah, T., Hee, S. S. Q., Smitha, A. R., Stich, A., Topping, W., Wittke, J. H. \& Wolbach, W. S. 2007. Evidence for an extraterrestrial impact 12,900 years ago that contributed to the megafaunal extinctions and the Younger Dryas cooling. Proceedings of the National Academy of Sciences of the United States of America, 104, 16016-16021.

Francus, P., Lamb, H., Nakagawa, T., Marshall, M., Brown, E. \& Members, S. P. 2009. The potential of high-resolution X-ray fluorescence core scanning: Applications in paleolimnology. PAGES News, 17, 93-95.

Fyfe, R., Anderson, P., Barnett, R., Blake, W., Daley, T., Head, K., Macleod, A., Matthews, I. \& Smith, D. 2014. Vegetation and climate change on Exmoor over the last millennium: detailed analysis of Ricksy Ball. Plymouth University, Plymouth.

www.southwestwater.co.uk/media/pdf/5/5/Vegetation_and_climate_ch ange_on_Exmoor_Fyfe_et_al_2014.pdf.

Griggs, A. J., Davies, S. M., Abbott, P. M., Rasmussen, T. L. \& Palmer, A. P. 2014. Optimising the use of marine tephrochronology in the North Atlantic: a detailed investigation of the Faroe Marine Ash Zones II, III and IV. Quaternary Science Reviews, 106, 122-139.

Griggs, A. J. 2016. Constraining Rapid Climatic Transitions in the North Atlantic using Tephrochronology. PhD Thesis, Swansea University.

Grönvold, K., Óskarsson, N., Johnsen, S. J., Clausen, H. B., Hammer, C. U., Bond, G. \& Bard, E. 1995. Ash Layers from Iceland in the Greenland GRIP ice core correlated with oceanic and land sediments. Earth and Planetary Science Letters, 135, 149-155.

Guð̃mundsdóttir, E. R., Larsen, G., Björck, S., Ingólfsson, Ó. \& Striberger, J. 2016. A new high-resolution Holocene tephra stratigraphy in eastern Iceland: Improving the Icelandic and North Atlantic tephrochronology. Quaternary Science Reviews, 150, 234-249.

Hall, M. \& Hayward, C. 2014. Preparation of micro-and crypto-tephras for quantitative microbeam analysis. Geological Society, London, Special Publications, 398, 21-28.

Hall, V. A., Pilcher, J. R. \& McCormac, F. G. 1994. Icelandic volcanic ash and the mid-Holocene Scots pine (Pinus sylvestris) decline in the north of Ireland: no correlation. The Holocene, 4, 79-83.

Hardwick, P., Gunn, J., 1995. Landform-groundwater interactions in the Gwenlais karst, South Wales. A.G. Brown (Ed.), Geomorphology and Groundwater, John Wiley, New York (1995), 75-91.

Haworth, E. Y. 1969. The diatoms of a sediment core from Blea Tarn, Langdale. The Journal of Ecology, 429-439.

Haworth, E. Y. 1976. Two late-glacial (Late Devensian) diatom assemblage profiles from northern Scotland. New Phytologist, 227-256.

Hayward, C. 2012. High spatial resolution electron probe microanalysis of tephras and melt inclusions without beam-induced chemical modification. Holocene, 22, 119-125. 
Heiri, O., Lotter, A. F. \& Lemcke, G. 2001. Loss on ignition as a method for estimating organic and carbonate content in sediments: reproducibility and comparability of results. Journal of Paleolimnology, 25, 101-110.

Hoek, W. Z. 2008. The last glacial-interglacial transition. Episodes, 31, 226229.

Housley, R. A., Macleod, A., Nalepka, D., Jurochnik, A., Masojć, M., Davies, L., Lincoln, P. C., Bronk Ramsey, B., Gamble, C. S. \& Lowe, J. J. 2013. Tephrostratigraphy of a Lateglacial lake sediment sequence at Wegliny, southwest Poland. Quaternary Science Reviews, 77, 4-18.

Hunt, J. B., Fannin, N. G. T., Hill, P. G. \& Peacock, J. D. 1995. The tephrochronology and radiocarbon dating of North Atlantic, LateQuaternary sediments: an example from the St. Kilda Basin. Geological Society, London, Special Publications, 90, 227-248.

Hunt, J. B. \& Hill, P. G. 1993. Tephra geochemistry: a discussion of some persistent analytical problems. The Holocene, 3, 271-278.

Hunt, J. B. \& Hill, P. G. 2001. Tephrological implications of beam sizesample-size effects in electron microprobe analysis of glass shards. Journal of Quaternary Science, 16, 105-117.

Iversen, J. 1942. En pollenanalytisk tidsfæstelse af ferskvandslagene ved Nørre Lyngby. Meddelelser fra Dansk Geologisk Forening, 10, 130-51.

Jenkins, R. 2000. X-Ray Techniques: Overview. Encyclopedia of analytical chemistry.

Jennings, A., Thordarson, T., Zalzal, K., Stoner, J., Hayward, C., Geirsdóttir, Á. \& Miller, G. 2014. Holocene tephra from Iceland and Alaska in SE Greenland shelf sediments. Geological Society, London, Special Publications, 398, 157-193.

Jensen, B. J. L., Pyne-O'Donnell, S., Plunkett, G., Froese, D. G., Hughes, P. D. M., Sigl, M., Mcconnell, J. R., Amesbury, M. J., Blackwell, P. G., van den Bogaard, C., Buck, C. E., Charman, D. J., Clague, J. J., Hall, V. A., Koch, J., Mackay, H., Mallon, G., Mccoll, L. \& Pilcher, J. R. 2014. Transatlantic distribution of the Alaskan White River Ash. Geology, 42, 875-878.

Jessen, K. \& Jonassen, H. 1935. The composition of the forests in Northern Europe in epipalaeolithic time. Kunglige Danske Videnskabernes Selskab, Biologiske Meddelelser, XII (1), 64.

Jóhannsdóttir, G. E. 2007. Mid Holocene to late glacial tephrochronology in West Iceland as revealed in three lacustrine environments. M.S. thesis, University of Iceland, Reykjavik.

Johnsen, S. J., Clausen, H. B., Dansgaard, W., Gundestrup, N. S., Hammer, C. U., Andersen, U., Andersen, K. K., Hvidberg, C. S., Dahl-Jensen, D., Steffensen, J. P., Shoji, H., Sveinbjörnsdóttir, Á. E., White, J., Jouzel, J. \& Fisher, D. 1997. The $\delta^{18} \mathrm{O}$ record along the Greenland Ice Core Project deep ice core and the problem of possible Eemian climatic instability. Journal of Geophysical Research: Oceans, 102, 26397-26410. 
Jones, G., Davies, S. M., Farr, G. J. \& Bevan, J. 2017a. Identification of the Askja-S Tephra in a rare turlough record from Pant-y-Llyn, south Wales. Proceedings of the Geologists' Association, 128, 523-530.

Jones, G., Lane, C. S., Brauer, A., Davies, S. M., Bruijn, R., Engels, S., Haliuc, A., Hoek, W. Z., Merkt, J. \& Sachse, D. 2017b. The Lateglacial to early Holocene tephrochronological record from Lake Hämelsee, Germany: a key site within the European tephra framework. Boreas. doi:http://dx.doi.org/10.1111/bor.12250.

Kaufman, D. S., Jensen, B. J. L., Reyes, A. V., Schiff, C. J., Froese, D. G. \& Pearce, N. J. 2012. Late Quaternary tephrostratigraphy, Ahklun Mountains, SW Alaska. Journal of Quaternary Science, 27, 344-359.

Kelly, T. J., Hardiman, M., Lovelady, M., Lowe, J. J., Matthews, I. P. \& Blockley, S. P. E. 2016. Scottish early Holocene vegetation dynamics based on pollen and tephra records from Inverlair and Loch Etteridge, Inverness-shire. Proceedings of the Geologists' Association, 128, 125135.

Kindler, P., Guillevic, M., Baumgartner, M., Schwander, J., Landais, A. \& Leuenberger, M. 2014. Temperature reconstruction from 10 to $120 \mathrm{kyr}$ b2k from the NGRIP ice core. Climate of the Past, 10, 887-902.

Kleinmann, A., Merkt, J. \& Müller, H. 2001. Rapid short term variations and response of proxies during the older Holocene. Terra Nostra 3, 112114.

Koren, J. H., Svendsen, J. I., Mangerud, J. \& Furnes, H. 2008. The dimna ash - A 12.8 C-14 ka-old volcanic ash in Western Norway. Quaternary Science Reviews, 27, 85-94.

Krammer, K., Lange-Bertalot, H. 1986. Süßwasserflora von Mitteleuropa 2/1: Bacillariophyceae 1. Teil: Naviculaceae. VEB Gustav Fischer Verlag, Jena.

Krammer, K., Lange-Bertalot, H. 1988. Süßwasserflora von Mitteleuropa 2/2: Bacillariophyceae 2. Teil: Bacillariaceae, Epitlemiaceae, Surirellaceae. VEB Gustav Fischer Verlag, Jena.

Krammer, K., Lange-Bertalot, H. 1991a. Süßwasserflora von Mitteleuropa 2/3: Bacillariophyceae 3. Teil: Centrales, Fragilariaceae, Eunotiaceae. Gustav Fischer Verlag, Stuttgart.

Krammer, K., Lange-Bertalot, H. 1991b. Süßwasserflora von Mitteleuropa 2/4: Bacillariophyceae 4. Teil: Achnanthaceae, kritische Ergänzung zu Navicula (Lineolatae) und Gomphonema. Gustav Fischer Verlag, Stuttgart.

Kudrass, H. R., Erlenkeuser, H., Vollbrecht, R. \& Weiss, W. 1991. Global nature of the Younger Dryas cooling event inferred from oxygen isotope data from Sulu sea cores. Nature, 349, 406-409.

Kuehn, S. C., Froese, D. G., Shane, P. A. R. \& INTAV Intercomparison Participants. 2011. The INTAV intercomparison of electron-beam microanalysis of glass by tephrochronology laboratories: results and recommendations. Quaternary International, 246, 19-47. 
Kylander, M. E., Ampel, L., Wohlfarth, B. \& Veres, D. 2011. High-resolution $X$-ray fluorescence core scanning analysis of Les Echets (France) sedimentary sequence: new insights from chemical proxies. Journal of Quaternary Science, 26, 109-117.

Kylander, M. E., Lind, E. M., Wastegård, S. \& Löwemark, L. 2012. Recommendations for using XRF core scanning as a tool in tephrochronology. Holocene, 22, 371-375.

Lane, C. S., Blockley, S. P. E., Bronk Ramsey, B. \& Lotter, A. F. 2011 a. Tephrochronology and absolute centennial scale synchronisation of European and Greenland records for the last glacial to interglacial transition: a case study of Soppensee and NGRIP. Quaternary International, 246, 145-156.

Lane, C. S., Lowe, D. J., Blockley, S. P. E., Suzuki, T. \& Smith, V. C. 2017. Advancing tephrochronology as a global dating tool: Applications in volcanology, archaeology, and palaeoclimatic research. Elsevier, 40, 1-7.

Lane, C. S., Andrič, M., Cullen, V. L. \& Blockley, S. P. E. 2011b. The occurrence of distal Icelandic and Italian tephra in the Lateglacial of Lake Bled, Slovenia. Quaternary Science Reviews, 30, 1013-1018.

Lane, C. S., Blockley, S. P. E., Mangerud, J., Smith, V. C., Lohne, Ø. S., Tomlinson, E., Matthews, I. P. \& Lotter, A. F. 2012a. Was the $12.1 \mathrm{ka}$ Icelandic Vedde Ash one of a kind? Quaternary Science Reviews, 33, 87-99.

Lane, C. S., Blockley, S. P. E., Lotter, A. F., Finsinger, W., Filippi, M. L. \& Matthews, I. P. 2012b. A regional tephrostratigraphic framework for central and southern European climate archives during the Last Glacial to Interglacial transition: comparisons north and south of the Alps. Quaternary Science Reviews, 36, 50-58.

Lane, C. S., Brauer, A., Blockley, S. P. E. \& Dulski, P. 2013. Volcanic ash reveals time-transgressive abrupt climate change during the Younger Dryas. Geology, 41, 1251-1254.

Lane, C. S., Brauer, A., Martín-Puertas, C., Blockley, S. P. E., Smith, V. C. \& Tomlinson, E. L. 2015. The Late Quaternary tephrostratigraphy of annually laminated sediments from Meerfelder Maar, Germany. Quaternary Science Reviews, 122, 192-206.

Lane, C. S., Cullen, V. L., White, D., Bramham-Law, C. W. F. \& Smith, V. C. 2014. Cryptotephra as a dating and correlation tool in archaeology. Journal of Archaeological Science, 42, 42-50.

Lane, C. S., De Klerk, P. \& Cullen, V. L. 2012c. A tephrochronology for the Lateglacial palynological record of the Endinger Bruch (Vorpommern, north-east Germany). Journal of Quaternary Science, 27, 141-149.

Langdon, P. G., Barber, K. E. \& Hughes, P. D. M. 2003. A 7500-year peatbased palaeoclimatic reconstruction and evidence for an 1100-year cyclicity in bog surface wetness from Temple Hill Moss, Pentland Hills, southeast Scotland. Quaternary Science Reviews, 22, 259-274. 
Larsen, J. J. \& Noe-Nygaard, N. 2014. Lateglacial and early Holocene tephrostratigraphy and sedimentology of the Store Slotseng basin, SW Denmark: a multi-proxy study. Boreas, 43, 349-361.

Larsen, J.J., 2013. Lateglacial and Holocene tephrostratigraphy in Denmark Volcanic Ash in a Palaeoenvironmental Context. PhD Thesis. University of Copenhagen.

Lawson, I. T., Gathorne-Hardy, F. J., Church, M. J., Newton, A. J., Edwards, K. J., Dugmore, A. J. \& Einarsson, A. 2007. Environmental impacts of the Norse settlement: palaeoenvironmental data from Myvatnssveit, northern Iceland. Boreas, 36, 1-19.

Lawson, I. T., Swindles, G. T., Plunkett, G. \& Greenberg, D. 2012. The spatial distribution of Holocene cryptotephras in north-west Europe since $7 \mathrm{ka}$ : implications for understanding ash fall events from Icelandic eruptions. Quaternary Science Reviews, 41, 57-66.

Le Bas, M. J., Le Maitre, R., Streckeisen, A. \& Zanettin, B. 1986. A chemical classification of volcanic rocks based on the total alkali-silica diagram. Journal of petrology, 27, 745-750.

Lilja, C., Lind, E. M., Morén, B. \& Wastegård, S. 2013. A Lateglacial-early Holocene tephrochronology for SW Sweden. Boreas, 42, 544-554.

Lind, E. M., Lilja, C., Wastegård, S. \& Pearce, N. J. G. 2016. Revisiting the Borrobol Tephra. Boreas, 45, 629-643.

Lind, E. M. \& Wastegård, S. 2011. Tephra horizons contemporary with short early Holocene climate fluctuations: New results from the Faroe Islands. Quaternary International, 246, 157-167.

Lind, E. M., Wastegård, S. \& Larsen, J. J. 2013. A Late Younger Dryas-Early Holocene tephrostratigraphy for Fosen, Central Norway. Journal of Quaternary Science, 28, 803-811.

Litt, T., Brauer, A., Goslar, T., Merkt, J., Bałaga, K., Müller, H., RalskaJasiewiczowa, M., Stebich, M. \& Negendank, J. F. W. 2001. Correlation and synchronisation of Lateglacial continental sequences in northern central Europe based on annually laminated lacustrine sediments. Quaternary Science Reviews, 20, 1233-1249.

Litt, T. \& Stebich, M. 1999. Bio-and chronostratigraphy of the lateglacial in the Eifel region, Germany. Quaternary International, 61, 5-16.

Lohne, Ø. S., Mangerud, J. \& Birks, H. H. 2014. IntCal13 calibrated ages of the Vedde and Saksunarvatn ashes and the Younger Dryas boundaries from Krakenes, western Norway. Journal of Quaternary Science, 29, 506-507.

Lotter, A. F., Heiri, O., Brooks, S., van Leeuwen, J. F. N., Eicher, U. \& Ammann, B. 2012. Rapid summer temperature changes during Termination 1a: high-resolution multi-proxy climate reconstructions from Gerzensee (Switzerland). Quaternary Science Reviews, 36, 103113. 
Lowe, D. J. 2011. Tephrochronology and its application: A review. Quaternary Geochronology, 6, 107-153.

Lowe, D. J., Pearce, N. J. G., Jorgensen, M. A., Kuehn, S. C., Tryon, C. A. \& Hayward, C. L. 2017. Correlating tephras and cryptotephras using glass compositional analyses and statistical methods: a Review and evaluation. Quaternary Science Reviews, 175 1-44.

Lowe, J. J., Albert, P., Hardiman, M. J., Macleod, A., Blockley, S. P. E. \& Pyne-O'Donnell, S. D. F. 2008a. Tephrostratigraphical investigations of the basal sediment sequence at Loch Etteridge. The Quaternary of Glen Roy and vicinity. Quaternary Research Association, London, 6065.

Lowe, J. J., Birks, H. H., Brooks, S. J., Coope, G. R., Harkness, D. D., Mayle, F. E., Sheldrick, C., Turney, C. M. S. \& Walker, M. J. C. 1999. The chronology of palaeoenvironmental changes during the Last GlacialHolocene transition: towards an event stratigraphy for the British Isles. Journal of the Geological Society, 156, 397-410.

Lowe, J. J., Palmer, A. P., Carter-Champion, A., Macleod, A., Ramirez-Rojas, I. \& Timms, R. G. O. 2017. Stratigraphy of a Lateglacial lake basin sediment sequence at Turret Bank, upper Glen Roy, Lochaber: implications for the age of the Turret Fan. Proceedings of the Geologists' Association, 128, 110-124.

Lowe, J. J. \& Gray, J. M. 1980. The stratigraphic subdivisionof the Lateglacial in North-west Europe. In: Studies in theLateglacial of .North-west Europe (Ed. J. J. Lowe, J. M. Gray \& J. E. Robinson), pp. 157-175. Pergamon Press, Oxford.

Lowe, J. J., Hoek, W. Z. \& INTIMATE group. 2001. Inter-regional correlation of palaeoclimatic records for the Last Glacial-Interglacial Transition: a protocol for improved precision recommended by the INTIMATE project group. Quaternary Science Reviews, 20, 1175-1187.

Lowe, J. J. \& Lowe, S. 1989. Interpretation of the pollen stratigraphy of the late Devensian Late-Glacial and early Flandrian sediments at LlynGwernan, near Cader Idris, north Wales. New Phytologist, 113, 391 408.

Lowe, J. J., Lowe, S., Fowler, A. J., Hedges, R. E. M. \& Austin, T. J. F. 1988. Comparison of accelerator and radiometric radiocarbon measurments obtained from late Devensian Late-Glacial lake-sediments from LlynGwernan, north Wales, UK. Boreas, 17, 355-369.

Lowe, J. J., Bronk Ramsey, B., Housley, R. A., Lane, C. S., Tomlinson, E. L., RESET Team. \& RESET Associates. 2015. The RESET project: constructing a European tephra lattice for refined synchronisation of environmental and archaeological events during the last c. $100 \mathrm{ka}$. Quaternary Science Reviews, 118, 1-17.

Lowe, J. J., Rasmussen, S. O., Björck, S., Hoek, W. Z., Steffensen, J. P., Walker, M. J. C., Yu, Z. C. \& INTIMATE group. 2008b. Synchronisation of palaeoenvironmental events in the North Atlantic 
region during the Last Termination: a revised protocol recommended by the INTIMATE group. Quaternary Science Reviews, 27, 6-17.

Lowe, S. 1981. Radiocarbon dating and stratigraphic resolution in welsh Lateglacial chronology. Nature, 293, 210-212.

Lowell, T. V., Heusser, C. J., Andersen, B. G., Moreno, P. I., Hauser, A., Heusser, L. E., Schlüchter, C., Marchant, D. R. \& Denton, G. H. 1995. Interhemispheric correlation of Late Pleistocene glacial events. Science, 269, 1541-1549.

Mackay, E. B., Jones, I. D., Folkard, A. M. \& Barker, P. 2012. Contribution of sediment focussing to heterogeneity of organic carbon and phosphorus burial in small lakes. Freshwater Biology, 57, 290-304.

Mackie, E. A. V., Davies, S. M., Turney, C. S. M, Dobbyn, K., Lowe, J. J. \& Hill, P. G. 2002. The use of magnetic separation techniques to detect basaltic microtephra in last glacial-interglacial transition (LGIT; 15-10 ka cal. BP) sediment sequences in Scotland. Scottish Journal of Geology, 38, 21-30.

Macleod, A., Brunnberg, L., Wastegård, S., Hang, T. \& Matthews, I. 2014. Lateglacial cryptotephra detected within clay varves in Östergötland, south-east Sweden. Journal of Quaternary Science, 29, 605-609.

Macleod, A., Matthews, I. P., Lowe, J. J., Palmer, A. P. \& Albert, P. G. 2015. A second tephra isochron for the Younger Dryas period in northern Europe: The Abernethy Tephra. Quaternary Geochronology, 28, 1-11.

Mangerud, J., Andersen, S. T., Berglund, B. E. \& Donner, J. J. 1974. Quaternary stratigraphy of Norden a proposal for terminology and classification. Boreas (Oslo), 3, 109-126.

Mangerud, J., Lie, S. E., Furnes, H., Krisiansen, I. L. \& Lømo, L. 1984. A Younger Dryas ash bed in western Norway, and its possible correlations with tephra in cores from the Norweigian Sea and the North Atlantic. Quaternary Research, 21, 85-104.

Martin-Puertas, C., Brauer, A., Dulski, P. \& Brademann, B. 2012. Testing climate-proxy stationarity throughout the Holocene: an example from the varved sediments of Lake Meerfelder Maar (Germany). Quaternary Science Reviews, 58, 56-65.

Marty, J. \& Myrbo, A. 2014. Radiocarbon dating suitability of aquatic plant macrofossils. Journal of Paleolimnology, 52, 435-443.

Mathewes, R. W. 1993. Evidence for Younger Dryas-age cooling on the north Pacific coast of America. Quaternary Science Reviews, 12, 321-331.

Matthews I. P. 2008. Roman Lode, Exmoor, Devon: Tephrochronology Scientific Dating Report, Research Department Report Series English Heritage.

Matthews, I. P., Birks, H. H., Bourne, A. J., Brooks, S. J., Lowe, J. J., Macleod, A. \& Pyne-O'Donnell, S. D. F. 2011. New age estimates and climatostratigraphic correlations for the Borrobol and Penifiler 
Tephras: evidence from Abernethy Forest, Scotland. Journal of Quaternary Science, 26, 247-252.

Mazzocchi, M., Hansstein, F. \& Ragona, M. 2010. The 2010 volcanic ash cloud and its financial impact on the European airline industry. CESifo Forum, 11, 92-100.

Mcleod, C., Yeo, M., Brown, A., Burn, A., Hopkins, J. \& Way, S. 2005. The Habitats Directive: selection of special areas of conservation in the UK. Peterborough, Joint Nature Conservation Committee. JNCC official website (www. jncc. gov. uk/SACselection, 23/09/09).

Meara, R. 2013. Pwysigrwydd llofnod cemegol lludw folcanig o Wlad yr lâ: Teffra "Grákolla" o losgfynydd Torfajökull. Gwerddon, 13, 66-77.

Merkt, J. \& Müller, H. 1999. Varve chronology and palynology of the Lateglacial in Northwest Germany from lacustrine sediments of Hämelsee in Lower Saxony. Quaternary International, 61, 41-59.

Merkt, J., Müller, H., Knabe, W., Müller, P. \& Weiser, T. 1993. The early Holocene Saksunarvatn tephra found in lake sediments in NW Germany. Boreas, 22, 93-100.

Meyers, P. A. 1994. Preservation of elemental and isotopic source identification of sedimentary organic matter. Chemical Geology, 114, 289-302.

Meyers, P. A. \& Lallier-Vergès, E. 1999. Lacustrine sedimentary organic matter records of Late Quaternary paleoclimates. Journal of Paleolimnology, 21, 345-372.

Miller, T. P. \& Smith, R. L. 1987. Late Quaternary caldera-forming eruptions in the eastern Aleutian arc, Alaska. Geology, 15, 434-438.

Moreno, P. I., Jacobson, G. L., Lowell, T. V. \& Denton, G. H. 2001. Interhemispheric climate links revealed by a late-glacial cooling episode in southern Chile. Nature, 409, 804-808.

Mortensen, A. K., Bigler, M., Grönvold, K., Steffensen, J. P. \& Johnsen, S. J. 2005. Volcanic ash layers from the Last Glacial Termination in the NGRIP ice core. Journal of Quaternary Science, 20, 209-219.

Muscheler, R., Kromer, B., Björck, S., Svensson, A., Friedrich, M., Kaiser, K. F. \& Southon, J. 2008. Tree rings and ice cores reveal $14 \mathrm{C}$ calibration uncertainties during the Younger Dryas. Nature Geoscience, 1, 263267.

Naughton, O., Johnston, P. \& Gill, L. 2012. Groundwater flooding in Irish karst: The hydrological characterisation of ephemeral lakes (turloughs). Journal of Hydrology, 470, 82-97.

Nesje, A., Dahl, S. O. \& Bakke, J. 2004. Were abrupt Lateglacial and earlyHolocene climatic changes in northwest Europe linked to freshwater outbursts to the North Atlantic and Arctic Oceans? The Holocene, 14, 299-310.

Neugebauer, I., Brauer, A., Dräger, N., Dulski, P., Wulf, S., Plessen, B., Mingram, J., Herzschuh, U. \& Brande, A. 2012. A Younger Dryas 
varve chronology from the Rehwiese palaeolake record in NEGermany. Quaternary Science Reviews, 36, 91-102.

Newton, A. J., Dugmore, A. J. \& Gittings, B. M. 2007. Tephrabase: tephrochronology and the development of a centralised European database. Journal of Quaternary Science, 22, 737-743.

Norddahl, H. \& Haflidason, H. 1992. The Skogar tephra, a Younger Dryas marker in north Iceland. Boreas, 21, 23-41.

Olsson, I. U. 2009. Radiocarbon dating history: early days, questions, and problems met. Radiocarbon, 51, 1-43.

Ott, F., Wulf, S., Serb, J., Słowiński, M., Obremska, M., Tjallingii, R., Błaszkiewicz, M. \& Brauer, A. 2016. Constraining the time span between the Early Holocene Hasseldalen and Askja-S Tephras through varve counting in the Lake Czechowskie sediment record, Poland. Journal of Quaternary Science, 31, 103-113.

Pearce, C., Varhelyi, A., Wastegård, S., Muschitiello, F., Barrientos, N., O'Regan, M., Cronin, T. M., Gemery, L., Semiletov, I. \& Backman, J. 2017. The 3.6 ka Aniakchak tephra in the Arctic Ocean: a constraint on the Holocene radiocarbon reservoir age in the Chukchi Sea. Climate of the Past, 13, 303-316.

Pearce, N. J. G, Alloway, B. V. \& Westgate, J. A. 2008. Mid-Pleistocene silicic tephra beds in the Auckland region, New Zealand: their correlation and origins based on the trace element analyses of single glass shards. Quaternary International, 178, 16-43.

Pearce, N. J. G, Denton, J. S., Perkins, W. T., Westgate, J. A. \& Alloway, B. V. 2007. Correlation and characterisation of individual glass shards from tephra deposits using trace element laser ablation ICP-MS analyses: current status and future potential. Journal of Quaternary Science, 22, 721-736.

Pearce, N. J. G, Westgate, J. A., Preece, S. J., Eastwood, W. J. \& Perkins, W. T. 2004. Identification of Aniakchak (Alaska) tephra in Greenland ice core challenges the 1645 BC date for Minoan eruption of Santorini. Geochemistry, Geophysics, Geosystems, 5, 1-10.

Pennington, W. 1943. Lake sediments: the bottom deposits of the north basin of Windermere, with special reference to the diatom succession. New Phytologist, 42, 1-27.

Persson C. 1966. Försök till tefrokronologisk datering av några svenska torvmossar. Geologiska Foereningan i Stockholm Foerhandlingar 88, 361-395.

Persson C. 1971. Tephrochronological investigation of peat deposits in Scandinavia and on the Faroe Islands. Geological Survey of Sweden C 656 .

Pilcher, J., Bradley, R. S., Francus, P. \& Anderson, L. 2005. A Holocene tephra record from the Lofoten Islands, arctic Norway. Boreas, 34, 136-156. 
Pilcher, J. R., Hall, V. A. \& McCormac, F. G. 1996. An outline tephrochronology for the Holocene of the north of Ireland. Journal of Quaternary Science, 11, 485-494.

Piva, A., Asioli, A., Schneider, R. R., Trincardi, F., Andersen, N., ColmeneroHidalgo, E., Dennielou, B., Flores, J. A. \& Vigliotti, L. 2008. Climatic cycles as expressed in sediments of the PROMESS1 borehole PRAD1-2, central Adriatic, for the last 370 ka: 1. Integrated stratigraphy. Geochemistry, Geophysics, Geosystems, 9, 1-21.

Placzek, C., Quade, J., Rech, J. A., Patchett, P. \& De Arce, C. P. 2009. Geochemistry, chronology and stratigraphy of Neogene tuffs of the Central Andean region. Quaternary Geochronology, 4, 22-36.

Plunkett, G. M. 2006. Tephra-linked peat humification records from Irish ombrotrophic bogs question nature of solar forcing at $850 \mathrm{cal}$. yr BC. Journal of Quaternary Science, 21, 9-16.

Plunkett, G. M., Pilcher, J. R., McCormac, F. G. \& Hall, V. A. 2004. New dates for first millennium BC tephra isochrones in Ireland. The Holocene, 14, 780-786.

Pollard, A. M. , Blockley, S. P. E. \& Lane, C. S. 2006. Some numerical considerations in the geochemical analysis of distal microtephra. Applied Geochemistry, 21, 1692-1714.

Pyne-O'Donnell, S. D. F. 2011. The taphonomy of Last Glacial-Interglacial Transition (LGIT) distal volcanic ash in small Scottish lakes. Boreas, 40, 131-145.

Pyne-O'Donnell, S. D. F., Cwynar, L. C., Jensen, B. J. L, Vincent, J. H., Kuehn, S. C., Spear, R. \& Froese, D. G. 2016. West Coast volcanic ashes provide a new continental-scale Lateglacial isochron. Quaternary Science Reviews, 142, 16-25.

Pyne-O'Donnell, S. D. F., Hughes, P. D., Froese, D. G., Jensen, B. J., Kuehn, S. C., Mallon, G., Amesbury, M. J., Charman, D. J., Daley, T. J. \& Loader, N. J. 2012. High-precision ultra-distal Holocene tephrochronology in North America. Quaternary Science Reviews, 52, 6-11.

Pyne-O'Donnell, S. D. F. 2007. Three new distal tephras in sediments spanning the Last Glacial-Interglacial Transition in Scotland. Journal of Quaternary Science, 22, 559-570.

Pyne-O'Donnell, S. D. F., Blockley, S. P. E., Turney, C. S. M. \& Lowe, J. J. 2008. Distal volcanic ash layers in the Lateglacial Interstadial (GI-1): problems of stratigraphic discrimination. Quaternary Science Reviews, $27,72-84$.

Ranner, P. H., Allen, J. R. \& Huntley, B. 2005. A new early Holocene cryptotephra from northwest Scotland. Journal of Quaternary Science, 20, 201-208.

Rasmussen, S. O., Andersen, K. K., Svensson, A. M., Steffensen, J. P., Vinther, B. M., Clausen, H. B., Siggaard-Andersen, M. L., Johnsen, S. J., Larsen, L. B., Dahl-Jensen, D., Bigler, M., Röthlisberger, R., 
Fischer, H., Goto-Azuma, K., Hansson, M. E. \& Ruth, U. 2006. A new Greenland ice core chronology for the last glacial termination. Journal of Geophysical Research-Atmospheres, 111.

Rasmussen, S. O., Bigler, M., Blockley, S. P. E., Blunier, T., Buchardt, S. L., Clausen, H. B., Cvijanovic, I., Dahl-Jensen, D., Johnsen, S. J., Fischer, H., Gkinis, V., Guillevic, M., Hoek, W. Z., Lowe, J. J., Pedro, J. B., Popp, T., Seierstad, I. K., Steffensen, J. P., Svensson, A. M., Vallelonga, P., Vinther, B. M., Walker, M. J. C., Wheatley, J. J. \& Winstrup, M. 2014. A stratigraphic framework for abrupt climatic changes during the Last Glacial period based on three synchronized Greenland ice-core records: refining and extending the INTIMATE event stratigraphy. Quaternary Science Reviews 106, 14-28.

Rasmussen, T. L., Thomsen, E., Nielsen, T. \& Wastegård, S. 2011. Atlantic surface water inflow to the Nordic seas during the PleistoceneHolocene transition (mid-late Younger Dryas and Pre-Boreal periods, 12 450-10 000 a BP). Journal of Quaternary Science, 26, 723-733.

Reimer, P. J., Bard, E., Bayliss, A., Beck, J. W., Blackwell, P. G., Bronk Ramsey, C., Buck, C. E., Cheng, H., Edwards, R. L., Friedrich, M., Grootes, P. M., Guilderson, T. P., Haflidason, H., Hajdas, I., Hatté, C., Heaton, T. J., Hoffmann, D. L., Hogg, A. G., Hughen, K. A., Kaiser, K. F., Kromer, B., Manning, S. W., Niu, M., Reimer, R. W., Richards, D. A., Scott, E. M., Southon, J. R., Staff, R. A., Turney, C. S. M., van der Plicht, J. 2013. IntCal13 and Marine13 radiocarbon age calibration curves 0-50,000 years cal BP. Radiocarbon, 55, 1869-1887.

Renssen, H., Goosse, H. \& Fichefet, T. 2007. Simulation of Holocene cooling events in a coupled climate model. Quaternary Science Reviews, 26, 2019-2029.

Riede, F., Bazely, O., Newton, A. J. \& Lane, C. S. 2011. A Laacher Seeeruption supplement to Tephrabase: investigating distal tephra fallout dynamics. Quaternary International, 246, 134-144.

Roberts, N., Allcock, S. L., Arnaud, F., Dean, J. R., Eastwood, W. J., Jones, M. D., Leng, M. J., Metcalfe, S. E., Malet, E., Woodbridge, J. \& Yiğitbaşıoğlu, H. 2016. A tale of two lakes: a multi-proxy comparison of Lateglacial and Holocene environmental change in Cappadocia, Turkey. Journal of Quaternary Science, 31, 348-362.

Roberts, S. J., Turney, C. C. \& Lowe, J. 1998. Icelandic Tephra in Lateglacial Sediments of Scotland $\left(14-9,000{ }^{14} \mathrm{C}\right.$ BP). Fródskaparrit, 46, 335-339.

Robinson, M. 2004. A Late glacial and Holocene diatom record from Clettnadal, Shetland Islands, northern Scotland. Journal of Paleolimnology, 31, 295-319.

Roche, D. M., Paillard, D., Caley, T. \& Waelbroeck, C. 2014. LGM hosing approach to Heinrich Event 1: results and perspectives from datamodel integration using water isotopes. Quaternary Science Reviews, 106, 247-261. 
Roland, T. P., Caseldine, C. J., Charman, D. J., Turney, C. S. M. \& Amesbury, M. J. 2014. Was there a ' 4.2 ka event'in Great Britain and Ireland? Evidence from the peatland record. Quaternary Science Reviews, 83, 11-27.

Rossignol-Strick, M. 1995. Sea-land correlation of pollen records in the Eastern Mediterranean for the glacial-interglacial transition: biostratigraphy versus radiometric time-scale. Quaternary Science Reviews, 14, 893-915.

Rothacker, L., Dreves, A., Sirocko, F., Grootes, P. M. \& Nadeau, M. 2013. Dating bulk sediments from limnic deposits using a grain-size approach. Radiocarbon, 55, 943-950.

Round, F. 1957. The Late-Glacial and Post-Glacial diatom succession in the Kentmere valley deposit. New Phytologist, 56, 98-126.

Round, F. 1961. The diatoms of a core from Esthwaite Water. New Phytologist, 60, 43-59.

Sigvaldason, G. E. 2002. Volcanic and tectonic processes coinciding with glaciation and crustal rebound: an early Holocene rhyolitic eruption in the Dyngjufjöll volcanic centre and the formation of the Askja caldera, north Iceland. Bulletin of Volcanology, 64, 192-205.

Simpkins, K. 1974. Late-Glacial deposits at Glanllynnau, Caernarfon. New Phytologist, 73, 605-618.

Skeffington, M. S., Moran, J., Connor, Á. O., Regan, E., Coxon, C., Scott, N. \& Gormally, M. 2006. Turloughs-Ireland's unique wetland habitat. Biological Conservation, 133, 265-290.

Smith, V. C., Isaia, R. \& Pearce, N. J. G. 2011. Tephrostratigraphy and glass compositions of post-15 kyr Campi Flegrei eruptions: implications for eruption history and chronostratigraphic markers. Quaternary Science Reviews, 30, 3638-3660.

Sparks, R.S.J. 1990. - written communication to University of Edinburgh.

Steffensen, J. P., Andersen, K. K., Bigler, M., Clausen, H. B., Dahl-Jensen, D., Fischer, H., Goto-Azuma, K., Hansson, M., Johnsen, S. J., Jouzel, J., Masson-Delmotte, V., Popp, T., Rasmussen, S. O., Roethlisberger, R., Ruth, U., Stauffer, B., Siggaard-Andersen, M.-L., Sveinbjornsdottir, A. E., Svensson, A. \& White, J. W. C. 2008. High-resolution Greenland Ice Core data show abrupt climate change happens in few years. Science, 321, 680-684.

Striberger, J., Björck, S., Holmgren, S. \& Hamerlík, L. 2012. The sediments of Lake Lögurinn-A unique proxy record of Holocene glacial meltwater variability in eastern Iceland. Quaternary Science Reviews, 38, 76-88.

Swindles, G. T., Lawson, I. T., Savov, I. P., Connor, C. B. \& Plunkett, G. 2011. A 7000 yr perspective on volcanic ash clouds affecting northern Europe. Geology, 39, 887-890.

Taylor, K., Hammer, C., Alley, R., Clausen, H., Dahl-Jensen, D., Gow, A., Gundestrup, N., Kipfstuh, J., Moore, J. \& Waddington, E. 1993. 
Electrical conductivity measurements from the GISP2 and GRIP Greenlandice cores. Nature, 366, 549-552.

Thorarinsson, S. 1944. Tefrokronologiska studier på Island: Pjórsárdalur och dess förödelse. Geografiska annaler, 26, 1-217.

Thorarinsson, S. 1981. Greetings from Iceland. Ash-falls and volcanic aerosols in Scandinavia. Geografiska Annaler. Series A. Physical Geography, 109-118.

Timms, R. G. O., Matthews, I. P., Palmer, A. P., Candy, I. \& Abel, L. 2016. A high-resolution tephrostratigraphy from Quoyloo Meadow, Orkney, Scotland: Implications for the tephrostratigraphy of NW Europe during the Last Glacial-Interglacial Transition. Quaternary Geochronology, 40, 67-81.

Tryon, C. A., Logan, M. A. V., Mouralis, D., Kuhn, S., Slimak, L. \& BalkanAtlı, N. 2009. Building a tephrostratigraphic framework for the Paleolithic of Central Anatolia, Turkey. Journal of Archaeological Science, 36, 637-652.

Turney, C. S. M. 1998. Extraction of rhyolitic component of Vedde microtephra from minerogenic lake sediments. Journal of Paleolimnology, 19, 199-206.

Turney, C. S. M., Harkness, D. D. \& Lowe, J. J. 1997. The use of microtephra horizons to correlate Late-glacial lake sediment successions in Scotland. Journal of Quaternary Science, 12, 525-531.

Turney, C. S. M., Lowe, J. J., Davies, S. M., Hall, V., Lowe, D. J., Wastegård, S., Hoek, W. Z., Alloway, B., SCOTAV members. \& INTIMATE members. 2004. Tephrochronology of Last Termination Sequences in Europe: a protocol for improved analytical precision and robust correlation procedures (a joint SCOTAV-INTIMATE proposal). Journal of Quaternary Science, 19, 111-120.

Turney, C. S. M., van den Burg, K., Wastegård, S., Davies, S. M., Whitehouse, N. J., Pilcher, J. R. \& Callaghan, C. 2006. North European last glacial-interglacial transition (LGIT; 15-9 ka) tephrochronology: extended limits and new events. Journal of Quaternary Science, 21, 335-345.

Tynan, S., Gill, M., Johnston, P. M. 2007. Development of a Methodology for the Characterisation of a Karstic Groundwater Body with Particular Emphasis on the Linkage with Associated Ecosystems such as Turlough Ecosystems. Final Research Report to the Environmental Protection Agency (Project No. 2002-W-DS-08-M1). EPA, Johnstown Castle Estate, Wexford, Ireland.

van Asch, N., Lutz, A. F., Duijkers, M. C. H., Heiri, O., Brooks, S. J. \& Hoek, W. Z. 2012. Rapid climate change during the Weichselian Lateglacial in Ireland: Chironomid-inferred summer temperatures from Fiddaun, Co. Galway. Palaeogeography Palaeoclimatology Palaeoecology, 315, 1-11. 
van den Bogaard, P. \& Schmincke, H. U. 1985. Laacher See Tephra: A widespread isochronous late Quaternary tephra layer in central and northern Europe. Geological Society of America Bulletin, 96, 15541571

van den Bogaard, P. \& Schmincke, H. U. 2002. Linking the North Atlantic to central Europe: a high-resolution Holocene tephrochronological record from northern Germany. Journal of Quaternary Science, 17, 3-20.

van den Bogaard, P. 1995. AR-40/AR-39 ages of sanidine phenocrysts from Laacher See Tephra (12,900 yr BP) - chronostratigraphic and petrological significance. Earth and Planetary Science Letters, 133, 163-174.

van der Bilt, W. G., Lane, C. S. \& Bakke, J. 2017. Ultra-distal Kamchatkan ash on Arctic Svalbard: Towards hemispheric cryptotephra correlation. Quaternary Science Reviews, 164, 230-235.

van Geel, B., Bohncke, S. J. P. \& Dee, H. 1980. A palaeoecological study of an upper Late Glacial and Holocene sequence from "De Borchert", The Netherlands. Review of Palaeobotany and Palynology, 31, 367448.

Vinther, B. M., Clausen, H. B., Johnsen, S. J., Rasmussen, S. O., Andersen, K. K., Buchardt, S. L., Dahl-Jensen, D., Seierstad, I. K., SiggaardAndersen, M. L., Steffensen, J. P., Svensson, A., Olsen, J. \& Heinemeier, J. 2006. A synchronized dating of three Greenland ice cores throughout the Holocene. Journal of Geophysical Research: Atmospheres, 111.

Vorren, K. D., Blaauw, M., Wastegård, S., van der Plicht, J. \& Jensen, C. 2007. High-resolution stratigraphy of the northernmost concentric raised bog in Europe: Sellevollmyra, Andøya, northern Norway. Boreas, 36, 253-277.

Walker, M. J. C. 1995. Climatic changes in Europe during the last glacial/interglacial transition. Quaternary International, 28, 63-76.

Walker, M. J. C. 2005. Quaternary Dating Methods, Chichester, John Wiley and Sons.

Walker, M. J. C., Coope, G. R., Sheldrick, C., Turney, C. S. M., Lowe, J. J., Blockley, S. P. E. \& Harkness, D. D. 2003. Devensian lateglacial environmental changes in Britain: a multi-proxy environmental record from Llanilid, South Wales, UK. Quaternary Science Reviews, 22, 475520.

Walker, M. J. C., Davies, S., Hall, J. \& Sambrook, P. 2009. A Preliminary Palaeoecological record from Llyn Llech Owain, near Gorslas, Carmarthenshire. Archeology in Wales 49, 53-58.

Walker, M.J.C \& James, J.H. 1992. The Flandrian (Holocene) pollen record from Cors Carmel, near Llandybie, Dyfed. Report for Cyngor Cefn Gwlad Cymru, University of Wales, Lampeter. 
Walker, M.J.C \& Jones, S. 2006. Llyn Llech Owain: a Pollen Analytical Assessment. Report for Carmarthenshire County Council, University of Wales, Lampeter.

Walker, M.J.C \& Lowe, J. J. in press. Lateglacial environmental change in Scotland. Earth and Environmental Science Transactions of the Royal Society of Edinburgh.

Walker, M. J. C., Lowe, J. J., Blockley, S. P. E., Bryant, C., Coombes, P., Davies, S., Hardiman, M., Turney, C. S. M. \& Watson, J. 2012. Lateglacial and early Holocene palaeoenvironmental 'events' in Sluggan Bog, Northern Ireland: comparisons with the Greenland NGRIP GICC05 event stratigraphy. Quaternary Science Reviews, 36, 124-138.

Walker, R. 1978. Diatom and pollen studies of a sediment profile from Melynllyn, a mountain tarn in Snowdonia, North Wales. New Phytologist, 81, 791-804.

Wastegård, S. 2002. Early to middle Holocene silicic tephra horizons from the Katla volcanic system, Iceland: new results from the Faroe Islands. Journal of Quaternary Science, 17, 723-730.

Wastegård, S., Veres, D., Kliem, P., Hahn, A., Ohlendorf, C., Zolitschka, B. \& The PASADO Science Team. 2013. Towards a late Quaternary tephrochronological framework for the southernmost part of South America-the Laguna Potrok Aike tephra record. Quaternary Science Reviews, 71, 81-90.

Wastegård, S., Wohlfarth, B., Subetto, D. A. \& Sapelko, T. V. 2000.

Extending the known distribution of the Younger Dryas Vedde Ash into northwestern Russia. Journal of Quaternary Science, 15, 581-586.

Watson, E. J., Kołaczek, P., Słowiński, M., Swindles, G., Marcisz, K., Gałka, M. \& Lamentowicz, M. 2017a. First discovery of Holocene Alaskan and Icelandic tephra in Polish peatlands. Journal of Quaternary Science, 32, 457-462.

Watson, E. J., Swindles, G. T., Lawson, I. T, Savov, I. P. \& Wastegård, S. 2017b. The presence of Holocene cryptotephra in Wales and southern England. Journal of Quaternary Science, 32, 493-500.

Watson, E. J., Swindles, G. T., Lawson, I. T. \& Savov, I. P. 2015. Spatial variability of tephra and carbon accumulation in a Holocene peatland. Quaternary Science Reviews, 124, 248-264.

Watson, E. J., Swindles, G. T., Lawson, I. T. \& Savov, I. P. 2016. Do peatlands or lakes provide the most comprehensive distal tephra records? Quaternary Science Reviews, 139, 110-128.

Williams, A.N. 2001. The Lateglacial record at Traeth Mawr, South Wales: palaeoenvironmental reconstruction using pollen analysis and tephrochronology. Unpublished MSc Thesis, Royal Holloway, University of London.

Williams, A.N., Lowe, J.J., Turney, C.S.M., Woodcock, P. 2007. Preliminary tephrostratigraphical investigations at Traeth Mawr. In. Quaternary of 
the Brecon Beacons Field Guide. ed. by Carr, S.J., Coleman, C.G., Humpage, A.J \& Shakesby, R. Quaternary Research Association.

Wilson, S.A. 1997. The collection, preparation, and testing of USGS reference material BCR-2, Columbia River, Basalt: U.S. Geological Survey Open-File Report.

Wulf, S., Dräger, N., Ott, F., Serb, J., Appelt, O., Guðmundsdóttir, E., van den Bogaard, C., Słowiński, M., Błaszkiewicz, M. \& Brauer, A. 2016. Holocene tephrostratigraphy of varved sediment records from Lakes Tiefer See (NE Germany) and Czechowskie (N Poland). Quaternary Science Reviews, 132, 1-14.

Wulf, S., Kraml, M. \& Keller, J. 2008. Towards a detailed distal tephrostratigraphy in the Central Mediterranean: the last 20,000 yrs record of Lago Grande di Monticchio. Journal of Volcanology and Geothermal Research, 177, 118-132.

Wulf, S., Ott, F., Słowiński, M., Noryśkiewicz, A. M., Dräger, N., MartinPuertas, C., Czymzik, M., Neugebauer, I., Dulski, P., Bourne, A. J., Błaszkiewicz, M. \& Brauer, A. 2013. Tracing the Laacher See Tephra in the varved sediment record of the Trzechowskie palaeolake in central Northern Poland. Quaternary Science Reviews, 76, 129-139.

Zdanowicz, C., Fisher, D., Bourgeois, J., Demuth, M., Zheng, J., Mayewski, P., Kreutz, K., Osterberg, E., Yalcin, K. \& Wake, C. 2014. Ice cores from the St. Elias Mountains, Yukon, Canada: their significance for climate, atmospheric composition and volcanism in the North Pacific region. Arctic, 35-57.

Zillén, L. M., Wastegård, S. \& Snowball, I. F. 2002. Calendar year ages of three mid-Holocene tephra layers identified in varved lake sediments in west central Sweden. Quaternary Science Reviews, 21, 1583-1591.

Zolitschka, B., Negendank, J. F. W. \& Lottermoser, B. G. 1995.

Sedimentological proof and dating of the early Holocene volcaniceruption of Ulmener Maar (Vulkaneifel, Germany). Geologische Rundschau, 84, 213-219. 
